Doctorado en Geografía

Facultad de Humanidades y Cs. de la Educación

Universidad Nacional de La Plata

TESIS DE DOCTORADO

\title{
EL LUGAR DE LA VIVIENDA SOCIAL EN LA CIUDAD
}

Un análisis de la política habitacional desde el mercado de localizaciones intra-urbanas y las trayectorias residenciales de los habitantes

Autor: Juan Pablo del Río

Directora: María Cristina Cravino 


\section{Agradecimientos}

Después del sinuoso e intrincado recorrido de esta tesis, quiero agradecer a riesgo de olvido, a quienes de uno u otro modo me brindaron su colaboración y apoyo, sin lo cual esta tesis no podría haber sido posible.

Quiero agradecer a María Cristina Cravino por su compromiso, generosidad y dedicación como directora de este trabajo de investigación. También, por animarme a desafiar mis propias capacidades. Mi mirada actual acerca de la ciudad, los procesos urbanos y sus actores, sin su acompañamiento sería distinta, seguramente más limitada.

Por otra parte, quiero destacar que la elaboración de este estudio no podría haberse llevado a cabo sin los recursos otorgados por la Agencia Nacional de Promoción Científica y Tecnológica y el Consejo Nacional de Investigaciones Científicas y Técnicas, para afrontar los años de formación y trabajos necesarios que implicó el mismo.

Merece una nota aparte el Instituto del Conurbano de la Universidad Nacional de General Sarmiento, que no sólo fue la sede de trabajo donde se llevó a cabo este trabajo, sino un lugar que me abrió las puertas e influyó en mi formación e inquietudes, y a través de la cual amplíe del territorio, las políticas públicas y las problemáticas urbanas que afectan a diario a nuestras ciudades.

En este sentido, el Equipo INFOHABITAT cumplió un rol singular como puente a esta institución mayor, destacándose por espíritu de trabajo colectivo y a generosidad de cada uno de sus miembros. Por lo cual quiero hacer ext-ensivo el reconocimiento a todos y cada una de los compañeros/as del equipo.

De manera especial, quiero agradecer a Andrea Catenazzi y a Patricia Pintos por sus sugerencias y orientaciones, por demás pertinentes e inteligentes. Quienes junto a Mariana Relli, Raúl Fernádez Wagner y Omar David Varela, me sumaron fructíferas comentarios, a partir de la lectura de artículos preliminares, borradores y/o partes de manuscritos que luego se integraron en el texto de esta tesis. Desde ya los errores que aún persisten corren por cuenta de quien escribe.

También, quiero extender mi agradecimiento a Juan Duarte, con quien recorrimos esta etapa de formación y compartimos distintas reflexiones e instancias de investigación, algunas de las cuales se reflejan en estas páginas.

Además, quiero dar las gracias a cada una de las familias de los nuevos barrios del Conurbano Bonaerense, por su predisposición a compartir sus historias de vida y el tiempo que nos brindaron en la realización de nuestro trabajo de campo. También a todo el resto de los entrevistados por compartir sus puntos de vista y la información brindada, en especial a Mirian Rodulfo y Eduardo Resse. 
No quiero dejar de expresar mi gratitud hacia los profesores del Instituto de Estudios Urbanos de la Facultad de Derecho, Cs. Políticas y Sociales de la Universidad Nacional de Colombia y del Lincoln Institue of Land Policy, quienes me brindaron una oportunidad increíble de conocer herramientas y compartir los debates que, en el marco de las ciudades latinoamericana, se desarrollan alrededor de los mercados de suelo y las políticas urbanas. Desde ya quiero hacer extensiva las gracias a mis los compañeros de estudios, de quienes me enriquecí de sus experiencias, y a Carlos Morales, por acompañarnos, contenernos y alegrarnos en esa estadía de estudio.

Vale, también, retribuir los diversos encuentros y discusiones que mantuvimos con los compañeros del Departamento de Geografía de la Universidad Nacional de La Plata, en nuestros talleres de lectura geográfica. También, a los compañeros del grupo de Derecho a la Ciudad del Proyecto de Extensión "El Derecho a Tener Derecho" de la misma universidad, con quienes compartimos distintos esfuerzos y espacios de trabajo que me ayudaron a pensar la ciudad.

Igualmente, quiero dejar agradecerle a Fede y Mari, por su amistad y compartir las angustias de estos trayectos; a Malala y Bruno, por su apoyo y lectura atenta para combatir la rusticidad irremediable de mis escritos; a Susy, por sus correciones divertidas y desinteresadas; a Estani, por su asistencia técnica en la recta final.

Y, por último, no por ello menos importante, a la Negra y a Rabioli, por su apoyo incesante en el cotidiano, sin quienes esto tampoco hubiese sido posible.

La Plata, Diciembre de 2011 


\section{INDICE}

Introducción

Capítulo 1. Ciudad, hábitat y política

El lugar de la vivienda social en la división social del espacio urbano

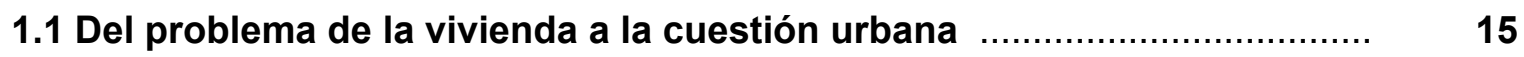

1.1.1 Más allá de la fábrica, lo urbano como cuestión ......................................... 17

1.1.2 Enfoques acerca de la ciudad latinoamericana y el hábitat popular ............ 19

1.1.3 Críticas a las visiones sectoriales viviendistas ....................................... 30

1.1.4 Algunas precisiones sobre el concepto de localización ................................ 33

1.1.5 El espacio urbano y la política habitacional ............................................. 34

1.2 El lugar asignado a la vivienda social en el mercado de localización ....... 36

1.2.1 El problema del acceso al suelo urbano ................................................ 38

1.2.2 Antecedentes sobre la teoría de la renta ................................................ 42

1.2.3 Notas sobre el proceso de formación de la renta urbana .............................. 44

1.2.4 Peculiaridades del mercado de suelo urbano ........................................ 47

1.2.5 Vivienda y economía urbana, más allá de la segregación ........................... 52

1.3 La reconstrucción del lugar a partir de los sujetos de la política ............. $\quad 60$

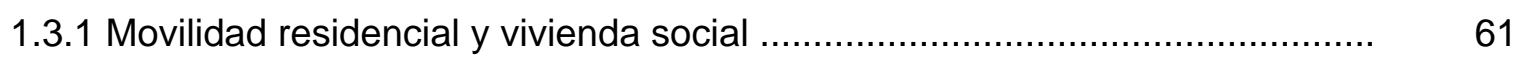

1.3.2 La construcción del espacio social, de la vivienda a la ciudad ...................... 62

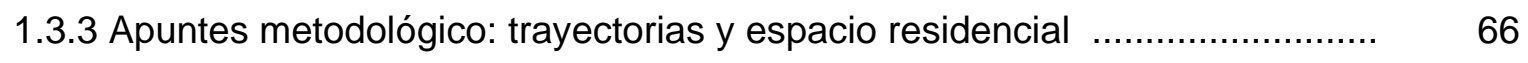

1.3.4 Los efectos de lugar: sujeto, hábitat y capital locacional .............................. 69

Capítulo 2. Estado y política habitacional $\quad 74$

Antecedentes y características del Plan Federal de Viviendas 
2.1 Antecedentes de la política habitacional ....................................... 76

2.1.1 El pasaje de las casas baratas a las viviendas masivas ........................... 76

2.1.2 La institucionalización del sistema de vivienda en los setenta .................... 84

2.1.3 Los meandros de la política habitacional de los noventa .......................... 90

2.1.4 La provincia de Buenos Aires frente a la descentralización ....................... $\quad 97$

2.2 La política federal de viviendas (2003-2010) ....................................... 107

2.2.1 La reaparición de la cuestión de la vivienda en la agenda pública .............. 108

2.2.2 Etapas, programas y objetivos de la política actual ............................... 112

2.2.2.1 El peso de los programas federales a nivel nacional .................... 118

2.2.3 Modalidad de ejecución, la política por convenio...................................... 122

2.2.3.1 El impacto de los convenios del PFCV en nuestra área de estudio 124

2.2.4 La implementación del PCFV en el Conurbano Bonaerense...................... 128

2.2.4.1 La relación entre nación, provincia y municipio............................. 129

2.2.4.2 La intensidad de la obra y el después......................................... 135

2.2.4.3 Asignación, uso y recupero ................................................... 139

2.2.4.4 El sector de la industria de la construcción................................... 144

2.2.4.5 Suelo, localización y ciudad...................................................... 147

2.3 Crisis y ladrillo o la continuidad de la genética sectorial ....................... 153

Capítulo 3. Suelo y vivienda social $\quad 159$

Una relación compleja en el mercado de localización intra-urbana

3.1 Las tierras y los proyectos urbanos frente al problema del suelo............ $\quad 160$

3.1.1 La distribución de los programas federales en el Conurbano Bonaerense 162

3.1.2 Diseño e implementación de modalidad Tierra y Proyecto Urbano (TPU) 165

3.1.3 Antecedentes de adquisición de suelo para vivienda a través del mercado 172

3.2 La vivienda social en el mercado de localización intra-urbana................. 178

3.2.1 La ubicación de las tierras ofertadas en la estructura urbana....................... 179

3.2.2 La incidencia del precio del suelo y su relación con la localización............... 182 
3.2.3 Los efectos del mercado en la distribución de la ciudad............................... 188

3.2.4 Algunas consideraciones al interior de las fronteras municipales ............... 193

3.3 Techo sí, ciudad no. La inserción urbana de la vivienda social ................ 196

Capítulo 4. El habitar y los efectos de lugar 199

Entre las trayectorias residenciales y las percepciones de los habitantes

4.1 Las trayectorias residenciales de los habitantes ............................... 200

4.1.1 Historias de "adjudicatarios" de vivienda social ........................................... 203

4.1.2 Política de relocalización pasiva, de dónde vienen y a dónde van ............... 229

4.1.3 Vivienda "puertas afuera", los efectos de la zona ...................................... 233

4.2 Viviendas nuevas, barrios en construcción …..................................... 235

4.2.1 Quiénes son los habitantes de los nuevos barrios ................................... 237

4.2.2 Interpretaciones acerca de la "satisfacción" habitacional ............................. 242

4.2.3 El día después, espacio barrial y sociabilidad "en obra" ............................. 250

4.2.3.1 Desconfianza, integración e intercambios ................................... 251

4.2.3.2 Organización en torno a nuevas demandas ................................. 253

4.2.3.3 Los problemas del barrio ........................................................ 255

4.2.3.4 El estatus del barrio .................................................... 258

4.2.3.5 Las relaciones de vecindad.................................................... 259

4.2.3.6 El futuro del barrio.................................................................. 261

4.2.4 La cartografía de la vivienda, el barrio y el entorno .................................... 264

4.3 Quisiera tener esta casa en el barrio donde vivía antes .......................... 266

$\begin{array}{ll}\text { Conclusiones } & 271\end{array}$

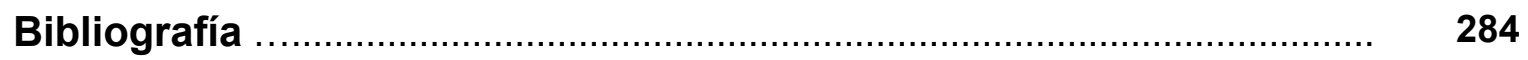


Índice de abreviaturas

Índice de figuras.

ANEXO 


\section{Introducción}


En el año 2003, la cuestión de la vivienda reaparece en la agenda pública a través de la "política federal de vivienda". Luego de décadas marcadas por la escasa intervención habitacional en el Área Metropolitana de Buenos Aires (AMBA) $)^{1}$ o con presencia de políticas focalizadas y sin escala frente al déficit (donde la resolución del hábitat había sido regulado por la restitución del principio de responsabilidad individual en el acceso al suelo y a la vivienda), se instala la construcción de vivienda como un eje central en la agenda. En AMBA la intervención en materia habitacional proyectada para la década de los 2000 equivale a la magnitud del crecimiento demográfico del último período intercensal. Es decir, que tras un período de exigua presencia estatal, en la actualidad el Estado adquiere un rol central a través de la inversión de recursos públicos significativos en materia habitacional.

La nueva política de vivienda promete escribir un nuevo capítulo en la historia habitacional, planteándose metas cuantitativas que se vinculen con la necesidad de reconstituir el tejido productivo y generar empleo en el escenario post crisis 2001. Esta política basada en una estrategia de reactivación económica impulsadas por el gobierno nacional. La magnitud de los anuncios se muestra capaz de incidir en el proceso de estructuración del espacio residencial metropolitano -siendo el Programa Federal de Construcción de Viviendas (PFCV) el emblema de la política de vivienda actual- y contraponiéndose a la tendencia de la década anterior e intensificando la construcción de viviendas nuevas en relación al déficit histórico (al menos en el AMBA).

En este escenario, la implementación de la política de vivienda, requiere para su materialización de un recurso particularmente escaso como es el suelo urbano. Pero la escasa disponibilidad de tierra pública "factible" de destinarse a la construcción de la vivienda social, dificulta la ejecución de esta política. El problema del acceso al suelo se transformó así en un verdadero desafío para la provincia de Buenos Aires y los municipios del Conurbano Bonaerense. Razón por la cual el Instituto de la Vivienda de la provincia de Buenos Aires (IVBA) asimiló un esquema de licitación de obra pública donde la provisión de suelo queda a cargo de la empresa constructora. Este deslizamiento de la responsabilidad del Estado, o la "terciarización" de la adquisición de suelo a través de un mecanismo de mercado nos despertó un interés especial.

\footnotetext{
1 El AMBA ó Gran Buenos Aires está constituido por la Ciudad de Buenos Aires y 24 municipios que la rodean. Ellos son: Almirante Brown, Avellaneda, Berazategui, Esteban Echeverría, Ezeiza, Florencio Varela, General San Martín, Hurlingham, Ituzaingó, José C. Paz, La Matanza, Lanús, Lomas de Zamora, Malvinas Argentinas, Merlo, Moreno, Morón, Quilmes, San Fernando, San Isidro, San Miguel, Vicente López, Tigre y Tres de Febrero. En este trabajo nos centraremos en los 24 municipios de la primera y segunda corona metropolitana, a los que haremos referencia como "Conurbano Bonaerense" ó simplemente como 24PGBA.
} 
Frente a esto, se nos plantearon dos interrogantes básicos. El primero, qué variación introduciría en las condiciones de localización de la vivienda social, una estrategia pública de adquisición de suelo destinado a la construcción de vivienda social a través de mecanismos de mercado. $Y$ en segundo lugar, si las mismas acarrearían algún tipo de efectos en la condiciones de vida de los destinatarios de la vivienda social y de qué tipo.

Considerando que la problemática habitacional constituye una de las manifestaciones clásicas de los debates en torno a la cuestión urbana y que ha sido abordada desde múltiples enfoques, encontramos en la relación entre localización y lugar una clave de lectura en la que anclamos nuestro abordaje teórico-metodológico. La vivienda como producto asume un papel crucial en la satisfacción de las necesidades de reproducción social y, al mismo tiempo, es un objeto que adquiere un notable contenido simbólico fuertemente mediado por un conjunto de relaciones sociales. Por esta razón, cuando la vivienda asume la categoría de "social", remite inmediatamente a una posición en el espacio urbano que hace referencia a ciertas condiciones materiales que las distinguen del resto del parque habitacional y le confieren un estatus diferenciado en la jerarquía urbana.

De allí que el estudio del lugar de la vivienda social en la ciudad, permita acercarse a una región más extensa del espacio social. En la cual se permean, por un lado, aspectos vinculados a las condiciones sociales y económicas generales y, por otro lado, aquellos asociados a los modos de vinculación de los actores sociales en y con la ciudad, la dinámica del hábitat popular o los procesos de gestión urbana, entre otros. En este sentido, partimos del supuesto que la mirada del lugar de la vivienda social en la ciudad nos permite observar, a través de la mediación que la política habitacional la relación entre el mercado de localizaciones residenciales intra-urbanas y las trayectorias residenciales de los sujetos destinatarios de la vivienda social.

En este sentido, el objetivo general de este trabajo es analizar el lugar de la vivienda social en el marco del proceso de producción de espacio urbano. Partimos del recorte que propone la mediación de la "política federal de viviendas" (2003-2010), prestando especial atención al Programa Federal de Construcción de Viviendas en su modalidad "Tierra y Proyecto Urbano" en el AMBA. Tres ejes fundamentales organizan el análisis de nuestro abordaje: el primero, es la identificación de la posición relativa de la vivienda social en el mercado residencial de localizaciones intra-urbanas; el segundo, es la lectura de los efectos de la política en las trayectorias habitacionales de los habitantes y en la experiencia del habitar. $\mathrm{Y}$ el tercero, que interactúa entre los dos anteriores, refiere a as características que asume la política habitacional. 
En este marco nuestros objetivos específicos son:

- Analizar los rasgos que asume la "política federal de viviendas" a partir del proceso de implementación del PFCV, en general, y la modalidad "Tierra y Proyecto Urbano" diseñada por el IVBA, en particular.

- Evaluar la localización de la vivienda social en la estructura de externalidades urbanas a nivel del AMBA y en base a la composición social de los entornos urbanos de los barrios.

- Identificar los efectos de la política en la trayectoria residenciales a partir del registro de la nueva experiencia del habitar (en la vivienda, el barrio y la zona) y las formas que adquiere el capital locacional de los habitantes en los nuevos barrios.

- Caracterizar la idea de ciudad que se pone en juego detrás de la política habitacional analizada y en este sentido indagar los alcance de los proyectos urbanos en los cuales se emplazan las viviendas.

Las hipótesis de partida son dos: por un lado, frente a una política de adquisición de suelo para la vivienda social que prioriza instrumentos de mercado frente a otros instrumentos públicos (esto significa que la provisión del suelo se encuentra a cargo de las empresas constructoras) es esperable una devaluación de las condiciones de localización de la vivienda social en la estructura de externalidades urbanas.

Por otro lado, el lugar asignado a la vivienda social en la ciudad por una política habitacional que asume el orden establecido por el mercado de localización residencial intra-urbana, trae aparejado una serie de efectos de lugar que en parte se revelan a través de las trayectorias residenciales de los adjudicatarios y en sus propias experiencias de habitar.

Estos registros se inscriben por fuera de los núcleos decisionales tradicionales de la política vivienda sectorial. No obstante, consideramos que esta mirada descentrada de las preocupaciones tradicionales de la política sectorial puede ayudar a pensar el modo en el cual las políticas públicas de hábitat conciben la relación con el espacio urbano y, al mismo tiempo, discutir nuevos arreglos en las formas de producción del hábitat.

Para dar cuenta de ello, se propone una estrategia metodológica cuali-cuantitativa que articula tres niveles analíticos. i) A nivel macro, se realiza un análisis de la estructura que adquiere el mercado de localizaciones residenciales intra-urbanas a nivel regional (24PGBA) y municipal. ii) A nivel micro, se analizan las trayectorias residenciales y las representaciones entorno al hábitat de los habitantes de tres barrios de vivienda social. Y por último, iii) a nivel meso, se identifica el desarrollo del proceso de implementación de la política federal de viviendas, en el marco del entramado de actores municipales, provinciales y nacionales, haciendo hincapié en los procesos de adquisición del suelo y su localización. 
Desde este abordaje se busca reconstruir la política del espacio "puertas afuera" de la vivienda social, es decir, dar cuenta opera la distribución de (la ciudad) recursos localizados producidos colectivamente. Para ello se exploran los vínculos entre estructura urbana, localización y renta del suelo, como así también, cómo la posición residencial de la vivienda social genera efectos de lugar (que influyen en la constitución en disposiciones subjetivas). Por otro lado, se intenta identificar cómo estos efectos son percibidos e internalizados de modos diferentes según las trayectorias habitacionales previas de los habitantes de los nuevos barrios. Por último, procuramos vincular la lectura de la experiencia urbana con la configuración de determinadas geografías barrial que da lugar a procesos de organización social en torno a nuevas demandas de ciudad.

Para esto se desarrolla un abordaje que combina el análisis de información secundaria a nivel documental y bibliográfico con múltiples registros de campo. i) Para realizar la clasificación de la estructura del mercado de localizaciones residenciales intra-urbanas, se recurrió a una serie de fuentes de información secundaria (cartográfica y estadística), a partir de la cual se realizó un procesamiento estadístico georreferenciado de más de 7 mil radios censales urbanos, a efectos de caracterizar la localización de más de 110 barrios de vivienda social construidos en los 24PGBA a través de "la política federal de viviendas". ii) El estudio de las trayectorias residenciales y las percepción que los habitantes de los nuevos barrios construyen alrededor del hábitat, requirió de la articulación de tres instrumentos: se realizaron entrevistas en profundidad para trabajar a efectos de reconstruir la trayectoria residencial y laboral de los adjudicatarios, además, se hicieron encuestas semi-estructuradas para reconstruir la perspectiva de los receptores de las viviendas $y$, complementariamente, se elaboraron entrevistas grupales ${ }^{2}$. Por último iii) la caracterización de la formulación y la implementación de la política habitacional, requirió de la sistematización y en análisis de de un conjunto de documentos oficiales (normativa, informes técnicos, resoluciones administrativas y expedientes) y estudios precedentes $\mathrm{y}$, al mismo tiempo, la realización entrevistas a funcionarios públicos de los tres niveles de gobierno.

La lectura cruzada de los registros fue clave, particularmente, a la hora de realizar un análisis de la localización o los efectos de lugar combinando la mirada subjetiva con un análisis más objetivo. Se realiza esta misma lectura en el estudio de las trayectorias y la percepción del hábitat, en términos de la intersección entre los datos cuantitativos de las encuestas y los testimonios orales. También en el cruce de las miradas de los propios habitantes y los funcionarios públicos en relación a los problemas emergentes a nivel barrial y el surgimiento de nuevas demandas.

La estructura de la tesis se organiza en cuatro capítulos, cada uno de los cuales se divide en tres o dos secciones dependiendo del capítulo.

2 En el caso a encuestas semi-estrcuturadas y la entrevistas grupales el trabajo de campo se realizó de manera colectiva (ver Cravino; del Río; Graham; Varela, 2011) en el marco de un proyecto de un proyecto de investigación solidarios, algo semejante sucedió con las entrevistas a los funcionarios públicos en algunos trayectos del trabajo de campo y la georreferenciación de los barrios de vivienda social (ver del Río y Duarte, 2011). 
En el primer capítulo, de naturaleza teórico-metodológica, se busca introducir la discusión del problema habitacional en la división social del espacio urbano. Con tal fin, se revisan una serie de debates teóricos que configuran el estado de la cuestión del problema de la vivienda en el contexto europeo de fines del siglo XIX, como en el contexto latinoamericano de mediados de siglo $X X$ a la actualidad. Luego, se revisa la crítica al enfoque viviendista que tradicionalmente ha dominado la definición de las políticas habitacionales. A partir de lo cual realizamos algunas aclaraciones respecto del uso que le daremos al concepto de localización. En este sentido, se considera la atención en la localización de la vivienda social un elemento clave para abordar la dimensión urbana de la política habitacional y pensar la relación entre espacio urbano, políticas habitacionales y los habitantes de la ciudad. En secciones siguientes, se explora el vínculo entre vivienda y economía urbana con el propósito de nutrirnos de elementos para analizar el lugar asignado a la vivienda social en el mercado de localización residencial intra-urbana. Por último, se vincula la noción de la movilidad y espacio residencial, los vínculos de la vivienda con la ciudad y los condicionamientos que acarrea una determinada posición residencial para las unidades domésticas, a partir de los cuales es posible reconocer determinados efectos de lugar.

En el segundo capítulo, se reconstruyen sintéticamente los principales mojones de la historia de la política de vivienda en la Argentina (desde principios del siglo XX hasta la década de los noventa), los rasgos predominantes de cada etapa y sus limitaciones. El objetivo es tener una lectura más amplia del contexto en el que emerge la "política federal de viviendas", de modo de no restringir la mirada al escenario post crisis 2001. De hecho, la mirada histórica observar una serie de cambios y continuidades. De allí que la política actual adquiera una lógica con rasgos específicos y, al mismo tiempo, revele características persistentes. La ausencia de la atención del problema del suelo y la localización es un aspecto que parece marcar una clara continuidad. En la segunda sección de este capítulo, se realizan una serie de consideraciones respecto de la reaparición en el año 2003, de la cuestión de la vivienda en la agenda pública. Se identifican las principales características que asume la "política federal de vivienda", sus etapas, programas y objetivos. También se consideran aspectos referidos a la distribución jurisdiccional del financiamiento, para destacar el protagonismo que adquiere el PFCV en el Conurbano Bonaerense. Finalmente y antes de las conclusiones de cierre del capítulo, realizamos un análisis de los emergentes en el contexto de implementación de dicho programa a partir del registro de núcleos problemáticos identificados en las entrevistas a funcionarios de los tres niveles de gobierno.

En el tercer capítulo como su título indica nos interesa trabajar la relación entre suelo, localización y vivienda. De todos los programas de la "política federal de viviendas" se selecciona y analiza el PFCV a través de la modalidad "Tierra y Proyecto Urbano" (TPU). La selección de este programa se debe a que el mismo se inserta en una estrategia provincial (de adquisición de suelo a cargo de las empresas constructoras), creada para dar respuesta al problema del acceso al suelo para la construcción de vivienda social. Nos focalizamos en el PFCV-TPU, ya que es el programa de mayor envergadura en el marco de la política actual en 
el Conurbano Bonaerense. Al análisis del diseño de este programa y los obstáculos en su implementación, le sigue (en una segunda sección) la lectura de la localización de los barrios en la estructura de externalidades urbana, a partir de los cual buscamos identificar los efectos de localización de los mecanismos de adquisición de suelo y las condiciones de inserción urbana de dichos barrios.

El cuarto capítulo tiene por objetivo introducir la lectura de la política habitacional desde las voces de los habitantes y sus trayectorias residenciales. Al mismo tiempo, propone llevar la escala de análisis al nivel barrial pero sin perder de vista la referencia a la escala metropolitana. En este punto, nos interesa reconstruir, por un lado, cómo el acontecimiento de la política habitacional es leído desde las trayectorias de los sujetos con la finalidad de comprender la complejidad del proceso de movilidad residencial, más allá de la "satisfacción" (o no) producida por la nueva vivienda. Por otra parte, buscamos identificar qué efectos de lugar trae aparejada la residencia en los nuevos barrios de vivienda social. Además, se identifica el lugar de residencia previo de los adjudicatarios en la estructura urbana, con el objetivo de contrastar la localización percibida y objetivada. En la segunda sección del capítulo, se indagan las razones por las cuales los adjudicatarios realizan una valorización diferencial de la vivienda respecto al barrio y la zona, a partir de la identificación de los problemas emergentes en los nuevos barrios y su vínculo con la forma que adquiere la acción pública. 
Capítulo 1 


\section{Capitulo 1. Ciudad, hábitat y política}

\section{El lugar de la vivienda social en la división social del espacio urbano}

La relación entre el hábitat popular y la ciudad asume múltiples formas de articulación. En el ámbito estatal, la política habitacional es el nexo por excelencia entre ambos campos. Vale aclarar que en este trabajo interesa prestar atención a dicha política por sus características diferenciadas en la forma de producción del espacio urbano. La localización de la vivienda social en la ciudad y la generación de condiciones de habitabilidad específicas, que inciden en la condiciones de vida de los adjudicatarios, son dos rasgos en los cuales detendremos nuestra atención. Para ello, en este primer capítulo, consideramos necesario revisar una serie de aportes teóricos con el objetivo de encuadrar nuestro punto de vista acerca de la relación entre la ciudad y el problema de la vivienda. Debido a que nos nutrimos de diversas lecturas en estas líneas introductorias intentamos explicitar la complementariedad entre las mismas.

Un primer movimiento que hemos propuesto, es identificar el contexto de surgimiento del problema de la vivienda y la configuración de "lo urbano" como cuestión en la agenda pública asociada a la política social. En este punto es importante subrayar que aún cuando el problema de la vivienda se configura en la tensión entre capital y trabajo, su extensión excede este dominio, y el surgimiento de la cuestión urbana supone otras formas de oposición social más allá de la tensión directa entre los términos antes mencionados. Emerge así un problema social por fuera del ámbito clásico de la producción. Pero como veremos luego, la atención pública del problema de la vivienda será hegemonizada desde una perspectiva sectorial, que asumirá una racionalidad marcadamente productivista ocultando la dimensión urbana e histórica de la vivienda.

Los movimientos posteriores (cada uno de los cuales están asociados a la segunda y tercera sección del capítulo) implican identificar un conjunto de aspectos teórico-metodológicos para afianzar el abordaje empírico que realizaremos en los capítulos subsiguientes. En primer lugar, la necesidad de analizar el lugar asignado a la vivienda social en la estructura urbana, nos lleva a indagar la relación entre la vivienda y la economía urbana. $\mathrm{Y}$, aunque la adquisición de suelo para vivienda social se encuentra mediada por la acción del Estado, esta operación no escapa en el marco de la política actual de vivienda, a las reglas de funcionamiento del mercado de localización urbana. El orden del mercado de suelo es asimilado en gran medida por la propia acción pública en materia habitacional, de allí que nuestra referencia al rol que desempeña el Estado sea más bien tangencial (aunque recuperaremos la preocupación por el rol del Estado en la política habitacional en el capítulo 2).

En segundo término, recuperamos el lugar reconstruido por los habitantes de los barrios de vivienda social, esto nos obliga a observar la relación entre sujeto, hábitat y capital locacional a partir del desarrollo de su experiencia urbana. Y, con el propósito de analizar cómo es leída la 
localización de la vivienda social desde la perspectiva de los habitantes, rastreamos algunos elementos que nos permitan comparar la transformación de la percepción urbana en la trayectoria residencial de los sujetos y sus vínculos con el cambio de posición en el espacio residencial producido por el acceso a la vivienda social.

Este conjunto de decisiones metodológicas responden a la intención de realizar un análisis de la política habitacional, desplazándonos de su núcleo decisional tradicional. Por un lado, esto nos lleva a pararnos en el plano del suelo y la localización, no sólo para atender una de la dimensiones críticas en términos de la implementación y el desempeño de este tipo de política pública, sino también para recordar que la absolutización de la propiedad privada del suelo es el principal obstáculo para que vastos sectores de la población tengan acceso a las condiciones de habitabilidad urbana extrínsecas a la vivienda. Al mismo tiempo, la lectura del par suelo-localización permite identificar hasta qué punto la acción del Estado alterna este orden urbano preestablecido. Dicho de otro modo, partimos del supuesto que una política habitacional que no internaliza el papel que juega el suelo y la localización -como elementos primarios de la inserción de la vivienda en el espacio urbano- está condenada a ser considerada una "política de obra de viviendas" y no una política "habitacional".

Por otro lado, al posicionarnos en la mirada de los sujetos de la política, sus trayectorias residenciales y sus formas de habitar, concebimos poder aprehender parte de la dinámica del hábitat popular como una región mayor de la realidad social que trasciende el recorte de la política de vivienda. En este sentido, el dispositivo institucional en materia habitacional basado en el producto vivienda, tiende a invisibilizar lo que sucede antes y después con los sujetos de la política ${ }^{3}$. En otras palabras, la constitución de la categoría beneficiario-adjudicatario es una operación desterritorializada (que enajena el vínculo del sujeto con el lugar). El carácter trasversal de la trayectoria residencial no solo nos brinda un vínculo con contextos de determinación más amplios, sino también nos proporciona un punto de vista descentrado para entender el cambio en la posición residencial de los sujetos y evaluar desde la experiencia del habitar los efectos de lugar que la política de vivienda produce. La hipótesis que ordena el desarrollo posterior de este eje es que el acceso a la vivienda social puede implicar un proceso de movilidad residencial ascendente, determinado en gran medida por el efecto de patrimonialización del "techo" y, en simultáneo, una descapitalización del acceso a las condiciones urbanas extrínsecas a la vivienda.

\subsection{Del problema de la vivienda a la cuestión urbana}

En esta sección nos proponemos situar el problema de la vivienda en el marco de la cuestión urbana. Esto supone un doble reconocimiento, el primero, como lo señala Castells (1974), consiste en identificar el surgimiento de formas de contradicción social sin reducirlas a la

\footnotetext{
${ }^{3}$ Se utiliza el término "sujetos de la política" como sinónimo del término de sujetos de la administración trabajado por Topalov (2004), concepto al cual posteriormente haremos referencia en nuestro texto.
} 
oposición directa entre capital y trabajo. Esto obliga a pensar las mediaciones particulares que introduce el espacio urbano en el marco de las sociedades capitalistas, adquiriendo sus efectos una autonomía relativa. Siguiendo a este autor las contradicciones sociales urbanas son secundarias estructuralmente, es decir, se sitúan en el ámbito de la reproducción y son contradicciones pluriclasistas, que responden a alianzas variables según la coyuntura. Por otro lado, considerando el proceso de urbanización avanzado del siglo XX, Lefebvre (1976) introduce la idea de la sociedad urbana como una tendencia hacia la sociedad post-industrial, entiende que la realidad urbana modifica las relaciones de producción sin llegar a transformarlas y afirma que "el espacio y la política del espacio 'expresan' las relaciones sociales, al tiempo que inciden sobre ellas" (1976: 21). Más allá de las críticas de Castells a Lefebvre $^{4}$, existe un campo fecundo de análisis en relación a lo urbano, en el que se inscribe el problema de la vivienda, o dicho de otra manera, la lectura de la dimensión espacial tiene algo que aportar a la lectura del proceso social.

En segundo lugar, es necesario proyectar una crítica al enfoque viviendista tradicional que naturaliza una visión mercantil-individualista de la vivienda en el plano de la política pública, a la vez que enajena a la vivienda de su dimensión social e histórica, negando todo tipo de contradicciones (Yuvnosky, 1984)., Siguiendo esta línea, la perspectiva de la arquitecturaciudad demanda una arquitectura transproyectual, que abandone la tradición que supone un análisis de los lugares en los cuales el movimiento es nulo y que asimile la circulación del producto en función de la relación con las actividades. El pasaje de la arquitectura-objeto a la arquitectura-ciudad implica desterrar la reflexión de la ciudad como una sumatoria de objetos arquitectónicos pensados como unidades cerradas. El problema de la ciudad es pensar el problema de la sociabilidad en el espacio, es decir, pensar el modo de vida de todos (Winograd, 1988).

Teniendo en cuenta lo dicho anteriormente, respecto de la inscripción del problema de la vivienda en el marco de la cuestión urbana, la estructura de esta sección parte de la presentación de una breve reseña del debate europeo de fines del siglo XIX, para luego revisar las perspectivas teóricas vinculadas al campo temático del hábitat popular y la ciudad latinoamericana. Esto nos habilita a introducir la problematización del hábitat popular en nuestro contexto y, también, nos permite plantear el tratamiento relativamente marginal que ha tenido en esta discusión el papel del mercado de suelo en la diferenciación intra-urbana de nuestras ciudades. A partir de allí, buscamos introducir en el marco de un enfoque habitacional integral, el uso que le daremos al concepto de localización en un doble registro: como posición estructural y como lugar de la vida cotidiana. En este sentido, nuestra lectura de la relación entre política habitacional y espacio urbano estará mediada por la categoría de localización, a partir de la cual nos proponemos aproximarnos a la idea de ciudad que subyace detrás de la política habitacional actual.

\footnotetext{
${ }^{4}$ Ver Capítulo 6 "De la sociedad urbana a la revolución urbana" en Castells (1974) La Cuestión Urbana.
} 


\subsubsection{Más allá de la fábrica, lo urbano como cuestión}

A fines del XIX las condiciones de explotación de la clase trabajadora, dado los niveles de avance de la revolución industrial, dan lugar a reformas sociales que buscan morigerar la precariedad de la vida urbana. La ciudad reunía y potenciaba aquello que en el campo se encontraba disperso, volvía a los pobres conscientes de su pobreza. Esto generó un movimiento reactivo en los sectores burgueses preocupados por frenar la formación de revueltas populares e incluso la propia burguesía veía en la insalubridad de los barrios, un problema al interior de su propia clase, esto es el traslado de las condiciones materiales a la preocupación de la salud obrera. Hasta el momento y desde los comienzos del capitalismo, la fábrica como espacio de la producción era el ámbito por excelencia donde se dirimía la "cuestión social", mientras la ciudad era considerada un ámbito extra laboral.

Sin embargo, la ciudad se transforma en un problema en sí misma y dadas las pésimas condiciones de los barrios obreros de las ciudades británicas que describe la publicación de Mearns (citado por Hall, 1996: 26-27), la vivienda y el planeamiento urbano surgía como objeto de política social. "Pocos de los que lean estas páginas tienen idea de lo que son estas pestilentes guaridas, donde miles de personas viven hacinadas en medio de horrores que nos recuerdan lo que hemos oído sobre los barcos de esclavos. Para entrar en ellas hay que adentrarse por patios nauseabundos a causa de los gases venenosos y mal olientes que resultan de la acumulación de las aguas residuales y de todo tipo de basura que yace esparcida y a menudo flota bajo nuestros pies; patios en los que casi nunca entra el sol, ni el aire fresco, y que muy pocas veces ha recibido el efecto benéfico del agua [...] Las paredes y el techo están negras por la suciedad que se ha ido acumulando a lo largo de años de dejadez. Resuman a través de las grietas de las placas del techo; baja por las paredes; está en todos sitios. Lo que recibe el nombre de ventanas está embutido de trapos o cubierto de maderas para evitar que entre el agua y el viento [...] Cada habitación de estas putrefactas y pestilentes viviendas alberga a una familia, a veces dos. Un inspector de sanidad anotó que en una de ellas encontró al padre, la madre, tres niños, iy cuatro cerdos!".

Hasta fines del siglo XIX la burguesía urbana se mantuvo al margen del terrible destino de sus vecinos proletarios, luego el temor y la amenaza no dejaron lugar a dudas, la ciudad se había transformado en un problema (Hall, 1996). En otras palabras, surge como uno de los nuevos "problemas sociales" que se inscribe en el proceso de fragmentación de la "cuestión social", el cual será acompañado por la especialización de la representación científica. Así, "lo urbano" surge como cuestión pública u objeto de política y el urbanismo como la disciplina de intervención.

En dicho contexto, se generó un consenso a favor de la intervención del Estado, dado que el lassez-faire urbano no tiene solución, desde esta mirada las construcciones responden a las exigencias del mercado y lo que el inquilino puede pagar viene determinado por el sueldo que cobra. La institucionalización de los sistemas públicos de vivienda, la habilitación de poder comprar terrenos con finalidad de construir viviendas para los trabajadores, la regulación de 
pautas constructivas acorde al higienismo urbano y el zonning entre otros dispositivos públicos, tuvieron origen frente a la lectura de este nuevo problema social.

En el análisis de Topalov (2004) acerca de la trayectoria de la "cuestión social", la construcción del "problema urbano" se inscribe dentro de la descomposición científica y administrativa de la cuestión social. El paradigma positivista de conocimiento se permea en la constitución del movimiento racionalista (el CIAM y la Carta de Atenas de 1933) y las propuestas del zonning. La mención de Le Corbusier a "la máquina de habitar" para referir a la vivienda da cuenta de esto. A cada problema social le corresponde un ámbito del saber, una especialidad profesional y unas técnicas específicas de intervención. El problema de la vivienda y el urbanismo surgen de algún modo de este proceso de autonomización. La ciencia delimita y mensura elementos de la realidad social, o de las prácticas populares, a los de efectos de establecer secuencias causales y transformarlas en objeto de intervención, por ejemplo: la condición de la vivienda, la insalubridad y la mortalidad.

Esta especialización da lugar a la "cuestión urbana", en tanto separación entre los ámbitos laborales y no laborales. La división pasa a ser tan marcada que, como señala Topalov, en el análisis de la tuberculosis y su estudio se ignoran los daños referentes al ámbito del trabajo y sólo se presta atención a las condiciones de higiene y promiscuidad en las viviendas. Paradójicamente esta división implica, a la vez, un conocimiento y un enmascaramiento de las realidades de la vida popular, se desarticulan así prácticas que tienen una coherencia en el mundo popular y se les asignan un sentido externo. Sentido que debe ser "verdadero" y objetivo dado que la intervención propuesta persigue efectos. El conocimiento se encuentra en gran medida al servicio de estrategias represivas o de disciplinamiento social, aunque con el tiempo asumen la forma de "norma objetivada". En este contexto, la máxima de racionalidad se impone sobre las voluntades individuales, el trabajo es sólo un factor de la producción y los consumidores pasan a ser racionales. Por ello, la norma urbana debe organizar un sistema eficiente que tienda a la optimización, cada espacio urbano debe cumplir una única función. La ciudad es dividida en zonas, el lugar del trabajo está por definición separado de la vivienda. La planificación regula el desarrollo del suburbio de modo de garantizar el "nuevo orden social".

El giro de la "norma objetivada" supone una abstracción que no ha sido formulada para un grupo o clase particular, sino que adquiere carácter universal. La norma formaliza una necesidad objetiva del individuo o la sociedad y, simultáneamente, el medio racional que garantiza su satisfacción. De este modo, los aparatos públicos crean sus propias categorías de intervención, cada individuo ocupa una serie de posiciones independientes unas de otras en los sistemas de clasificación práctica de la política social. Mientras las leyes científicas ignoran al individuo concreto, las normas elaboradas por las ciencias reconstruyen a un individuo diferente, que se convierte en "sujeto de la administración" (Topalov, 2004).

A pesar de la progresiva autonomización del problema urbano y su burocratización creciente, en Contribuciones al problema de la vivienda, Engel (1873) nos recuerda que el problema de la vivienda está medido por la relación estructural capital-trabajo y desde allí discute con Proudon 
y Sax los límites de las reformas sociales propuestas en la época. La reforma proudoniana enunciaba un repertorio de acciones que apuntaban a la supresión de las viviendas de alquiler, rescatar las viviendas mediante el pago a sus propietarios, crear un sistema en el cual el pago del alquiler anual les permitiera a los trabajadores convertirse en propietarios, expropiar un conjunto de vivienda de alquiler para paliar el déficit e implementar leyes contra la usura. Frente a estas propuestas, Engels cuestiona que el problema de la vivienda deba ser resuelto transformando a los obreros en propietarios, no alcanza con que éstos sean poseedores, ya que media una transferencia de los costos de reproducción al propio trabajador.

Este debate se encuentra atravesado por un sinnúmero de interrogantes, algunos de los cuales tienen plena vigencia en la actualidad. Se acepta que el desarrollo de la industria y la ciudad implican ciertas contradicciones sin que éstas alteren el orden social de fondo. Se pone en cuestión, por ejemplo, si los cambios de la forma de tenencias de la vivienda, -el pasaje de arrendatario a propietario- altera la condición social de la clase trabajadora. También se pregunta si el ahorro del alquiler se traslada o no en menores costos en términos salariales. La renta del suelo se introduce al debate de la planificación de la ciudad y, al mismo tiempo, aparece como un producto social. Se cuestionan determinadas tipologías residenciales propuestas en el contexto de la reforma -como las colonias rurales- en función de quién se beneficia con la extracción de renta de las viviendas para obreros en áreas periféricas. La solución haussmaniana como método higienista propuesto por la burguesía para resolver el problema es criticada porque sólo desplaza el problema. La discusión por la igualdad de derechos, la idea de justicia y la voluntad inscriptas en paradigmas de intervención estatal o de mutualidad obrera son presentadas como opuestas al conflicto. Se debate si la reformas urbanas alteran o no las relaciones capitalistas de producción o si lo que se busca es armonizar la relación capital trabajo, en esencia, contradictoria.

Veamos ahora como algunos de estos ejes o trazas discursivas son retomadas, al menos parcialmente, en los debates que a continuación nos interesa recuperar, acerca de la cuestión del hábitat popular en el marco de la ciudad latinoamericana.

\subsubsection{Enfoques acerca de la ciudad latinoamericana y el hábitat popular}

Si bien, parece difícil hablar de una teoría acerca de la urbanización latinoamericana, algunos de los enfoques o debates dan cuenta de una serie de elementos que, por los menos en las últimas seis décadas, se pusieron en juego en el campo del hábitat popular y la ciudad latinoamericana. En los años 50-60, la discusión del desarrollo/subdesarrollo asociadas en el ámbito urbano a las "teorías de la marginalidad" se desplazó al problema del desarrollo frente a la dependencia, a partir de lo cual surge el enfoque de la "urbanización dependiente". Otra parte de la discusión del hábitat gira en torno al "debate de la autoconstrucción" y la autogestión del hábitat atravesado, en los años 70-80, por la perspectiva turneriana y el enfoque estructuralista-histórico. En los años 90, una segunda etapa del debate conocido como 
"debate de la mercantilización", pone la atención desde la perspectiva liberal individualista en la informalidad y la regularización de la tenencia del suelo.

Veamos a continuación las principales características de estos enfoques teóricos que delimitan el campo de la urbanización popular latinoamericana, a efectos de considerar sus implicancias en la lectura de la ciudad, en general, y en la política habitacional en particular. Para realizar este recorrido, nos nutrimos de la clasificación realizada por Duhau (1998) en cuya revisión distingue al menos seis enfoques distintos ${ }^{5}$ : las teorías de la marginalidad, la perspectiva histórico-estructural, la teoría de la urbanización dependiente, la perspectiva turneriana, el enfoque democrática-autonomista y la perspectiva liberal individualista.

Como veremos luego, un denominador común a todos los enfoques que marcan el debate del hábitat popular y la política urbana, ha sido el énfasis puesto en la vivienda como proceso y como producto, en tanto cristalización de las condiciones particulares de reproducción de la fuerza de trabajo. Es decir, se prioriza en el mejor de los casos una mirada de la ciudad centrada en la mediación que se produce al interior del mercado de trabajo, siendo a nuestro juicio la dinámica del mercado de suelo, un punto de vista relegado en el análisis de la conformación de nuestra ciudades.

A mediados del siglo XX, el proceso de desarrollo industrial relativo y la concentración urbana, con diferentes matices entre los países latinoamericanos, dieron lugar a importantes transformaciones urbanas. Desde la mirada económica, el ritmo de la urbanización no se condijo con el ritmo ni el nivel de desarrollo industrial, dando lugar a un "desajuste" entre urbanización e industrialización que se visualiza como problema en términos de la pobreza urbana. Esta problemática consiste de un conjunto de población que no logra integrarse plenamente a la vida y la economía urbanas. La teoría de la marginalidad ensaya una primera explicación desde un enfoque ecológico-cultural, planteando un dualismo entre la ciudad moderna y la atrasada (reducto de ruralidad, dada la inercia de pautas culturales), y la asociación entre formas sociales y modos de ocupación de espacio. El concepto de la marginalidad no sólo remite a la ecología urbana, sino que también adquiere una variante antropológica, la idea de la "cultura de la pobreza" (Lewis, 1996) se inscribe en este contexto. Siguiendo a Mesa (1985) la hipótesis central de esta teoría de la marginalidad es que existen barreras culturales que impiden que el tránsito de lo rural a lo urbano se dé en la forma esperada, desde la óptica de la modernización. Las relaciones sociales que se presentan en este proceso bloquean el desarrollo de las grandes ciudades. Asimismo, la ruralización de la ciudad presenta una inercia que implica que una parte importante de estos grupos no puedan articularse a la sociedad moderna.

Según el posicionamiento político que asumió esta teorización, pueden reconocerse algunos matices. Por un lado, si se parte del supuesto que lo "marginal" es producto de la falta de oportunidades, de educación, de ausencia de opciones, etc., y que el Estado y la clase

\footnotetext{
${ }^{5}$ Nos referimos, a la revisión planteada por Duhau (1998) en Hábitat popular y política urbana.
} 
dominante no están eximidos de la creación de estos obstáculos, entonces éstos últimos deben ofrecer apoyo para superar dichas barreras. De este modo, la política urbana debe orientarse a la integración de estos sectores, especialmente mediante incentivos a la participación, y brindando capacitación, asistencia técnica y apoyo financiero a los procesos de autoconstrucción. Por otro lado, bajo el supuesto de que la transformación en el espacio (ecológico) introduce cambios en el comportamiento social, la política urbana esperable es la erradicación de los reductos de ruralidad y la integración de dichos sectores a través de la vivienda moderna (Jaramillo, 1990).

En reacción a la escuela de la marginalidad, a fines de los años '60, surge la teoría de la urbanización dependiente, que planea que el problema no es el retraso de la modernización, sino que la urbanización es un elemento determinado por una estructura social y económica que asume características diferentes, dada la relación dependiente y subordinada de nuestros países en el proceso de acumulación del capital a escala mundial ${ }^{6}$. Mesa (1985) formaliza el planteo de la teoría de la urbanización dependiente de la siguiente manera: dadas las diferencias que derivan del papel de América Latina en la red internacional capitalista, siendo ésta resultante del carácter imperialista del capitalismo, la historia de la urbanización es la historia de la dependencia. La ciudad es un instrumento de despojo y una manifestación de esta relación internacional y las relaciones de asimetrías tienden a reproducirse a nivel interno.

A partir de la crítica singeriana ${ }^{7}$, esta teoría busca dar cuenta de las modalidades y de la articulación de las relaciones capitalistas al interior de cada una de las formaciones sociales, de modo de dar cuenta de las diferencias entre los procesos de urbanización y ajustar en peso de la dinámica supranacional como la única variable explicativa. De allí que se introduzcan las articulaciones de intereses del capitalismo nacional y el papel del Estado en el proceso del desarrollo económico. Una referencia importante de cómo esta discusión se traduce al interior del ámbito urbano se constituye en torno a la noción de "expoliación urbana" (Kowarik, 1979). Desde esta perspectiva se pone el énfasis en la dimensión política de la urbanización, en la cual los sectores populares sufren un doble proceso de expoliación: a través de la venta la fuerza de trabajo en una lógica sometida al capital; y como habitantes de una ciudad sumergida en un proceso de expansión que les niega el acceso a los servicios de consumo colectivo (Valladares y Coelho, 1995). Como sostienen estas autoras, el papel del Estado cobra relevancia en el análisis, ya que debía crear la infraestructura necesaria para el desarrollo del capital, era el encargado de generar los bienes de consumo colectivos ligados a la reproducción de la fuerza de trabajo y, al mismo tiempo, debía garantizar el orden social

\footnotetext{
${ }^{6}$ Ambas teorías han recibidas diversas críticas, Carrión (1991) sostiene que tanto la teoría de la modernización como las teoría de la dependencia quedan subsumidas en la perspectivas metodológica de la "teoría del espejo" que se presenta como una propuesta reduccionista y general que niega la complejidad del proceso urbano. Por ejemplo, frente al fenómeno de la macrocefalia urbana, la primera teoría entiende la tendencia hacia la concentración territorial de la sociedad producto del desarrollo de la industria. La modernización de la sociedad equivale a su industrialización y la urbanización es resultado de la asimilación del proceso. La segunda, explica el fenómeno en el marco de la tendencia general del desarrollo capitalista hacia la concentración y la centralización del capital proceso que se reproduce en el espacio y mediado por las relaciones de dependencia supone una desarticulación de la red urbana.

${ }^{7}$ En referencia al trabajo de Singer (1971) "Urbanización dependencia y marginalidad” En: Castells y Vellz Imperialismo y Urbanización en América Latina.
} 
necesario para el desarrollo del modelo de acumulación. Sin embargo, la lógica del capitalismo en su fase oligopólica lleva a la reducción de los fondos públicos contenidos en los salarios indirectos y con ello la constitución de una acción pública desprovista del alcance propio del Estado de Bienestar de los países desarrollados.

Los aportes de la Sociología Urbana Francesa son solidarios con esta perspectiva y renovaron la reflexión sobre los problemas urbanos: rechazando la idea de la autonomía del espacio urbano e introduciendo el concepto de espacio como producto social. Estos aportes incorporaron la dimensión política y la lectura de las contradicciones urbanas a partir del énfasis puesto en la relación entre Estado y clases sociales. También introdujeron nuevos actores (como los movimientos sociales) a la escena urbana. Posteriormente, algunos de los postulados de esta escuela son criticados y revisados ya que el modelo propuesto era demasiado "mecánico" y no permitía considerar rasgos específicos de la distintas sociedades latinoamericanas. La teoría del Estado al cual recurría esta perspectiva suponía un Estado indiferenciado, omnipresente y monolítico; esto a su vez, implicaba una lectura parcial de la relación entre el Estado y los distintos actores sociales (Valladares y Coelho, 1995).

En este contexto, los estudios fueron mediados por la indagación del problema de la pobreza urbana, vía las particularidades del modelo de desarrollo y sus implicaciones en las condiciones de reproducción de la fuerza de trabajo. En un registro paralelo a esta lectura de urbanización latinoamericana se plantea el "debate de la autoconstrucción" o autogestión del hábitat. También conocido como el "debate de la mercantilización" de la vivienda autoconstruida, cuyo punto central de discusión es, básicamente, si la autogestión del hábitat constituye una forma más de la explotación capitalista de la fuerza de trabajo o, si por el contrario, es un proceso en cuyo reconocimiento y potenciación -leído de manera "optimista"residiría la solución al problema de la vivienda.

Frente a las lecturas de la inevitabilidad de la pobreza, que sostienen que las mismas condiciones de la pobreza contribuyen a reforzar un ambiente donde ésta se reproduzca, la perspectiva turnerina realizará su aporte. Fernández Wagner (2008) plantea que John Turner demostró que los pobres no estaban quietos y "sin esperanza", por el contrario trabajaban sin descanso para mejorar su condición de vida. A pesar de la precariedad de sus medios, los pobres producen, ahorran, invierten en su propio desarrollo, construyen su vivienda, mejoran su barrio y hacen ciudad. Desde esta mirada, la vivienda no es sólo un sustantivo sino también un verbo, además de ser un objeto o producto, pasa ser vista como proceso social. El planteamiento de Housing as a verb en Freedom to build tuvo gran influencia tanto en el modo de pensar el problema como en la prescripción de política. Las recomendaciones internacionales de la Conferencia de Vancouver de UN-HABITAT (1976) son un ejemplo de ello.

El principal aporte de la perspectiva turneriana fue postular que la autoconstrucción ofrece a los habitantes de los asentamientos irregulares una libertad personal en cuanto al proceso de producción de la vivienda frente a la respuesta oficial, dado el alto grado de flexibilidad y la 
adecuación a las condiciones cambiantes de los ciclos económicos y arreglos familiares. En este contexto, la vivienda es vista como proceso de carácter permanente e intermitente que se ajusta a la disponibilidad de ingresos, tiempos, materiales, etc. Asimismo, es una fuente alternativa de ingresos tanto por el abaratamiento de la mano de obra individual en reemplazo de la mano de obra asalariada, como por las posibilidades de generar recursos mediante el arrendamiento.

Esta perspectiva sitúa la mirada en el poblador como usuario de la vivienda, en tanto constructor-gestor de la misma, y atiende la dimensión de la autonomía de los usuarios en las decisiones de la resolución del hábitat. La escala del proceso de producción al cual refiere este enfoque se delimita a nivel doméstico, no contempla la regulación urbana ni una lectura macroeconómica de dicho proceso. En este sentido, Turner (1976) introduce la preocupación por el control de los usuarios en las decisiones de diseño, construcción y administración de su vivienda. La libertad de este proceso de apropiación de la vivienda tiene un vínculo estrecho con la satisfacción, el bienestar y la realización personal de sus propios usuarios. Esta perspectiva se opone a la producción industrial y estandarizada de viviendas provistas por los sistemas estatales que no se ajustan a las necesidades de los habitantes. También plantea que las soluciones promovidas por los propios usuarios suelen ser mejores que la soluciones heterónomas provistas desde los sistemas de planificación centralizada.

La visión turneriana recibió numerosas críticas, entre ellas el hecho de centrarse en una suerte de empirismo individual y realizar un planteo por fuera de la problemática de la vivienda como cuestión social e histórica, esto es, crear una teoría de la producción espontánea de la vivienda que pierde de vista la perspectiva del conflicto y las contradicciones. En oposición, la perspectiva histórico-estructural resalta que la vivienda es un atributo no incorporado al salario, en tanto costos de reproducción de la fuerza de trabajo, y plantea la explotación de los trabajadores en los procesos de autoconstrucción como aspecto central del debate del hábitat popular y la ciudad latinoamericana.

Como señala Fernández Wagner (2008), el principal representante de la posición neo-marxista, Emilio Pradilla, realiza duras críticas a las implicancias que tiene destacar a la autoconstrucción como la solución del problema de la vivienda en América Latina. Desde esta perspectiva, no se debe perder de vista que la autoconstrucción está determinada por (y refuerza) el proceso de pauperización de los sectores populares, quienes se ven imposibilitados de acceder a una "vivienda adecuada" por la restricción de ingresos. Esta imposibilidad de acceder se da por no constituirse como sujetos de crédito y por el elevado precio de la vivienda en un mercado de oferta limitada en el marco de una economía capitalista dependiente. Por tanto, la propuesta de la autoconstrucción constituye una alternativa reaccionaria que contribuye a aumentar la explotación de la fuerza de trabajo, debido a que la vivienda deja de considerarse parte del salario e incrementa la plusvalía relativa.

Repasemos, los tópicos que introduce Pradilla (1982) al debate. Si bien, el proceso de autoconstrucción es una tarea laboriosa que dura años -supone acumulación de horas de 
trabajo y pequeñas inversiones del fondo de subsistencia-, al concluirse la misma no hay garantías de movilidad social. El trabajador puede estar igual, mejor o peor, pero su situación no dependerá del cambio ocurrido en su vivienda. Por el contrario, ésta depende de su ubicación en la estructura del mercado de trabajo. En el proceso de autoconstrucción lo que está en juego es la prolongación del proceso de trabajo (alargamiento de la jornada) y la coexistencia de la producción y el consumo del hábitat. Dada la necesidad de usar edificación aún en obra con el fin de evitar el pago de renta se prolongan situaciones de hacinamiento. Además la vivienda autoconstruida está muy lejos de satisfacer las necesidades de una familia en el contexto histórico-social actual del desarrollo del capital. Todo esto prolonga las paupérrimas condiciones de vida de los trabajadores, implica un incremento de la extracción de la plusvalía relativa y presiona a la baja del salario real. Otro elemento central aportado por Pradilla a la discusión, es la relación entre valor y precio en proceso de la circulación o de mercantilización de este tipo de vivienda ${ }^{8}$. La baja productividad del trabajo invertido en la producción de la vivienda autoconstruida, tiene como correlato que ésta condensa mayor valor que una vivienda parecida construida bajo las condiciones sociales medias. Esto significa que el proceso de la autoconstrucción se consume una cantidad de trabajo humano vivo mayor a la media social, es decir, al trabajo socialmente necesario para la construcción de una vivienda similar. Siendo esto un desperdicio social de trabajo cargado en las espaldas de los propios trabajadores. $\mathrm{Y}$, cuando la vivienda autoconstruida es transada en el mercado y se convierte en objeto mercancía ${ }^{9}$, el precio tiene una desventaja es menor que el correspondiente a su valor real. En otras palabras el vendedor pierde una parte del tiempo de trabajo invertido en su construcción. Por otra parte, para este autor las condiciones de acceso a la tierra sobre la que se desarrolla normalmente la autoconstrucción, tiende a exacerbar la prioridad de los pobladores por obtener la propiedad privada del suelo. Ésto -no sólo tiene efectos sobre la dependencia de los sectores populares en relación a los intermediarios o actores políticos que manejan los resortes estatales, sino que además, fomentaría la ideología pequeño burguesa.

El planteamiento de Pradilla tiene importantes puntos de contacto o puede inscribirse en la teoría de la urbanización dependiente, que planea una agenda de investigación en torno al papel de la periferia en la cadena mundial y el análisis de la fase avanzada del capitalismo. En este análisis, la tendencia a la concentración se explica recuperando el estudio del "cambo técnico de la producción y la homogeneización espacial" (de Castells citada por Mesa, 1985). Desde allí se observa que en América Latina el cambio técnico y la transformación de las lógicas espaciales (mediadas las relaciones de subordinación o dependencia) no se producen

\footnotetext{
8 En este punto, se suma al debate el geógrafo inglés Rod Burgess $(1978,1979)$ para profundizar las críticas al planteo de Turner, dada la confusión que éste presenta sobre la naturaleza del "producto" y la "utilidad" y el "valor de mercado". Para Burgess, el error de Turner se produce en dos planos, por un lado, en la incomprensión de la relación entre el valor de uso y el valor de cambio y, por otro, en la negación del estatus de mercancía a la autoconstrucción (Fernández Wagner, 2008).

${ }^{9}$ Situación que normalmente se explica por una lógica de la necesidad y no se encuentran orientadas a iniciar un nuevo proceso productivo orientado a la obtención de un beneficio.
} 
del mismo modo que en los países de capitalismo avanzado ${ }^{10}$. En este sentido, se subraya que la característica contradictoria de la urbanización latinoamericana deriva del límite de la capacidad social y política del Estado de encontrar recursos apropiados para generar condiciones de urbanización distintas y, al mismo tiempo, de la capacidad real de los capitales de alimentar estos fondos (que puede ser expresado como la restricción del grado de acumulación). La minimización de recursos del Estado lleva a una pugna entre distintos sectores por su apropiación. Por otra parte, las condiciones de proletarización deben ser ajustadas a las modalidades de acumulación propias de nuestros países, donde la reproducción de la fuerza de trabajo no está sólo remunerada a nivel del salario, es decir por el valor de los medios de vida necesarios para la subsistencia del trabajador y su familia. Por el contrario, los obreros y su familia, están en la obligación de ejercer otras actividades no capitalistas con el fin de tener acceso a las condiciones mínimas de reproducción o supervivencia. Esto significa que se requiere trabajo adicional al trabajo necesario para garantizarse su reproducción, con el consecuente agravamiento de las condiciones de explotación (Mesa, 1985).

A pesar de la enérgica crítica del enfoque marxista a la perspectiva turneriana y su introducción al debate de un elemento clave del problema de la vivienda, nos referimos a las características particulares de la inserción laboral de los sectores populares en el mercado de trabajo. Un nuevo enfoque recupera parte del planteamiento de la perspectiva turneriana, aunque con un desplazamiento del abordaje de autoconstrucción de un proceso espontáneo, obligado e involuntariamente autónomo, hacia otro que lo considera como acciones colectivamente organizadas bajo la denominación de "producción social del hábitat"11. Según Duhau (1998), el enfoque democrático-autonomista plantea que la urbanización popular es el componente principal de las ciudades contemporáneas del "tercer mundo". Sin embargo, la reglamentación urbana, el régimen legal imperante y la zonificación operan de modo excluyente, negando esta realidad. Por otra parte, la ciudad informal tiene una alta interdependencia funcional con la ciudad formal, a la cual le aporta trabajo, servicios y bienes baratos. Por tanto, se plantea la necesidad de acercar e incorporar los asentamientos irregulares a las normas de regulación del desarrollo urbano y propiedad del suelo. El mundo de la instituciones formales está distanciado del mundo real, vastas realidades urbanas no están contempladas en la planificación de la ciudad. Desde este enfoque, se considera necesario incorporar los saberes y la dimensión colectiva del hábitat popular en el campo de la política habitacional y, al mismo tiempo, como

\footnotetext{
${ }^{10}$ La menor capacidad del Estado para homogeneizar las condiciones generales de producción determinan mayor especialización en determinadas áreas, de allí la importancia de las ciudades para la acumulación capitalista en nuestros países. En otras palabras, al no gozar de las ventajas de la homogenización espacial, el capital tiende a reforzar la concentración. La debilidad del Estado en el control de las condiciones generales de la producción deriva en situaciones negativas para el conjunto social (capital y fuerza de trabajo), una expresión de ello podría visualizarse en el plano habitacional.

${ }^{11}$ El concepto de producción social del hábitat abarca diversas "formas de producción de la vivienda y el hábitat que tienen en común haber sido concebida de manera planificada y que son dirigidas y controladas por sus productores/originadores (el sujeto es un actor social, distinto de una unidad doméstica centrada en objetivos de su propia reproducción), pudiendo existir diversos tipos de destinatarios individuales o colectivos" (Rodriguez et al, 2007: 27)
} 
plantean Hardoy y Satterthwaite (1987), es imprescindible replantear y flexibilizar los marcos jurídicos y regulatorios.

En esta línea, para Romero (1996: 85-86): “... las propuestas de ciudad vigentes se basan en la ciudad ideal, ordenada y hermosa, sin clases sociales, con una concepción y simple de lo que es la vida social. Lo grave es que tal concepto está plasmado en leyes, reglamentos y se ha permeado a la opinión pública, con su simplicidad y sin visión crítica, en tal sentido que sólo un pequeño porcentaje de nuestra sociedad puede llegar a tener el nivel establecido [...] Necesitamos adecuar las leyes, reglamentos, normas urbanas y de construcción como así también las reglas de operación de los instrumentos e instituciones de vivienda, de forma tal que no sea una débil concesión, de la concepción formal de la ciudad «moderna» [...] Esto implica una apertura y una desregulación, que rompa con el concepto de lo que esta «bien» y lo que esta «mal» e irlo sustituyendo por los criterios discutidos, concertados, concertados que vayan logrando la discusión social democráticamente".

En esta perspectiva opera una suerte de política de reconocimiento que se articula con un proyecto de acción, cuyo alcance no es necesariamente la transformación radical de la sociedad, pero si la recuperación de valores sociales y culturales puestos en juego en la construcción de la urbanización popular. Esta revalorización está, a su vez, acompañada por la potenciación del proceso de organización colectiva y autogestión. Como sostiene Romero (1996), en el proceso de construcción de la ciudad no participan sólo los gobiernos y empresarios, sino también los sectores populares que resuelven soluciones habitacionales mientras el Estado no resuelve la cuestión.

Desde las perspectivas democráticas se dirige la atención a los movimientos urbanos emergentes. Se busca comprender sus relaciones intrínsecas y reflexionar sobre el proceso de autoconstrucción, se indaga en sus razones y lógicas, y se cuestiona la forma de planeación de las ciudades. Pero, al mismo tiempo, también se proponen posibles mediaciones de política pública, se plantea una matriz opuesta a las formas de dominación política y de la mercantilización de la informalidad urbana, se pone en cuestión el funcionamiento actual del mercado de vivienda, se propone articular la política de vivienda con formas de economía social y se introducen nuevas reflexiones, mediadas por la educación popular y la acción comunitaria. Estas propuestas tienen lugar tanto en el plano territorial, desde el punto de vista normativo y de la discusión del diseño urbano, como en el plano productivo (vinculado al financiamiento, las soluciones tecnológicas, el diseño arquitectónico o la producción de materiales) y en la dimensión los procesos de organización (vinculada a la organización social, la participación y la autogestión) (ver Romero, 1996).

Desde una mirada de la autoconstrucción como autogestión integralmente asistida y equitativamente concertada, Pelli (1996) entiende que es posible replantear los criterios de la acción habitacional mediante la articulación de los recursos financieros y técnicos utilizados dentro del proceso de resolución de la necesidad, con la cesión de espacios de poder a los propios habitantes para que puedan hacerse cargo de los procesos. En este modelo, los 
"beneficiarios" de las acciones institucionales de vivienda (esto es, los habitantes) tienen protagonismo en las decisiones de diagnóstico, solución y resolución, así como en el control y administración de los procesos. El aporte "externo" (financiero, técnico, normativo, político) se diseña e implementa de manera de alimentar la acción de grupos de decisión, control y gestión. La apuesta es integrar grupos de habitantes, técnicos y múltiple actores en los procesos de resolución y cogestión de hábitat.

Esta idea implica un cambio importante frente a la forma convencional en que se desarrolla la acción habitacional. La dimensión física y la simbólica de vivienda; la concepción de sus formas de uso y de sus formas de producción; y, especialmente, las relaciones de poder presentes entre los actores que participan del proceso de resolución se ven modificados. Pelli (1996: 19), dice: "para quienes, a través de nuestras experiencias de abordar en la práctica el problema, a través del estudio y la reflexión, o a través de la construcción de un amplio consenso en torno a un conjunto de ideas, hemos ido arribando a la convicción de que la inclusión de la gente en la gestación y en la conducción de los procesos de resolución de sus propias necesidades habitacionales es una condición insoslayable para que el desarrollo de los procesos alcance su plenitud como acto de producción y como acto social".

Desde el enfoque democrático-autonomista, en el cual convergen múltiples lecturas y formas de acción frente a la cuestión habitacional, se observa entonces un giro por parte de los investigadores, las organizaciones sociales y las ONGs. Éstos alejan su atención (casi excluyente) del Estado y de su relación con el capital, devolviendo protagonismo a la participación popular en el desarrollo de prácticas y en la reflexión sobre el proceso de inclusión de los habitantes en la producción de su propia solución habitacional ${ }^{12}$. Por último, desde esta perspectiva se reconoce que la apuesta es compleja, se aceptan múltiples caminos por recorrer, pero no se niegan las limitaciones ni las contradicciones.

Finalmente, consideremos la perspectiva liberal individualista, que en los años noventa ganó amplia difusión de la mano de postulados neoliberales y recetas de los organismos multilaterales de crédito. Su principal representante, De Soto (2000), identifica que los elevados costos de la formalidad impuestos en los marcos jurídicos implican limitaciones a las actividades legales y al desarrollo económico, viendo la informalidad como un germen de la economía de mercado reglada por la libre competencia. Fernandes apunta: “...De Soto está en lo correcto cuando cuestiona la legitimidad de los sistemas jurídicos de exclusión. El problema es que él da por sentado que el reconocimiento de la propiedad individual es garantía de la legitimidad..." (2002: 5). La hipótesis central de De Soto es que los marcos legales imponen costos de entrada y una permanencia onerosa a escala de economía familiar, restringiendo así la utilización productiva y eficiente de recursos e inhibiendo la iniciativa individual. Se sostiene que es posible reducir la pobreza mediante la integración económica de los más pobres, a

\footnotetext{
${ }^{12}$ Estos aspectos fueron negados en gran medida por los enfoques anteriores, tanto desde las teorías liberales como estructuralistas.
} 
través del acceso al título de propiedad del suelo. Es decir, la regularización de los asentamientos informales permitiría una solución a la pobreza.

Veamos los supuestos que intervienen aquí. Se parte de considerar que la economía informal urbana (viviendas autoconstruida y pequeños negocios) constituye un conjunto de activos muertos que, al ser integrados al sistema financiero, podrían transformarse en recursos líquidos. Mediante la utilización de los títulos de propiedad como garantía crediticia, por ejemplo, la gente podría realizar inversiones en sus viviendas y negocios. Además, la seguridad de la tenencia legal de la propiedad sería una condición necesaria para que desinhibir al emprendedor de invertir en la mejora de sus activos. Al mismo tiempo, el título legal garantizaría el acceso al crédito. De este modo, la legalización de los asentamientos informales y el suministro de títulos individuales de dominio absoluto permitirían avanzar hacia la erradicación de la pobreza.

Las críticas a esta propuesta fueron múltiples. La sistematización realizada por Edesio Fernandes (2002) nos muestra el variado repertorio de comentarios ${ }^{13}$ : tiene dificultades acerca de comprensión del proceso histórico de la construcción social del derecho de propiedad; existe una simplificación excesiva sobre la compleja dinámica de los mercados de suelo urbano informales y formales; se da por supuesto un sistema financiero y bancario receptivo a los sectores de escasos recursos cuando la experiencia demuestra lo contrario; la evidencia muestra que pocas personas han obtenido créditos oficiales luego de los programas masivos de regularización; se da por sentado que los pobres estarían interesado en obtener crédito formal cuando hay estudios que, dadas las implicaciones socioeconómicas y fiscales, empíricamente observan lo contrario; varios trabajos cuestionan la sostenibilidad urbana y socioeconómica de los asentamientos que fueron objeto de titulización masiva.

El propio Fernandes agrega cuatro elementos relevantes al debate. Primero, no se puede perder de vista el papel que tiene la posesión del suelo en los países latinoamericanos, donde la combinación histórica de mercados de capital débiles, economías de alta inflación y sistemas de seguridad social deficientes, convirtieron el valor del suelo en un mecanismo de capitalización fundamental. Esto está fuertemente emparentado con una cultura de especulación de larga data (asociada a una herencia de patrimonialismo y clientelismo político), que ha influido profundamente en las condiciones de acceso a la vivienda y a los suelos urbanos, y en la distribución espacial de equipos y servicios públicos.

Segundo, De Soto no cuestiona la naturaleza del sistema jurídico, el cual opera como el primer generador de ilegalidad urbana. El tratamiento jurídico de los derechos de propiedad debe trascender la ley civil anacrónica (e interpretarse bajo un criterio de orientación social de la ley urbana pública redefinida), pero De Soto otorga un tratamiento conservador del derecho de propiedad, el cual parece suponer una definición universal y natural.

${ }^{13}$ Fernandes (2002) pasa revistas de las crítica al planteo de Soto que realizaron Payne (2001), Bourbeau (2001), Riofrío (1998), Calderón (2001), Gilbert (2001), Duhau (2001), Kagawa (2001), Zeledon (2001), Fernandes (2001). 
Tercero, otra falla es considerar que los asentamientos informales no tienen acceso al crédito. Por el contrario, bajo ciertas condiciones sociales, políticas e institucionales, se ha mostrado que los habitantes tienen acceso al crédito y a servicios públicos informales y, en ocasiones formales.

Cuarto, a pesar de que los programas de regularización dominial promueven la seguridad individual de la tenencia legal, este tipo de acciones de manera asilada no garantiza la integración socioespacial. Por el contrario, los riesgos de agravar el proceso de exclusión y segregación aumentan, excepto que el otorgamiento del título se realice en el marco de programas integrales de mejoramiento barrial que contemplen condiciones urbanas, políticoinstitucionales y socioeconómicas (Fernandes, 2002).

En suma, los enfoques y perspectivas que han marcado la agenda del debate de la urbanización latinoamericana y el hábitat popular han aportado indudables y variadas contribuciones. A pesar de ello, los esfuerzos y las trayectorias del debate ponen de manifiesto cierta desatención del papel que juega el suelo en la producción y la distribución del espacio urbano, más allá del proceso constructivo a escala doméstica o de las consideraciones de la ciudad como realidad macroeconómica. Nos referimos a cómo se articula el suelo esencialmente como un mercado de localización. En buena medida los debates sobre el tema no consideran (o lo hacen muy parcialmente) la organización del mercado del suelo en torno a la composición de rentas de localización, que es la que define los procesos especulativos y la expulsión -ya naturalizada a estas alturas- de sectores pauperizados a ámbitos marginales de la ciudad. Creemos que la relación que existe entre el suelo y el hábitat en un sentido amplio, no ha sido interpelada en clave distributiva en los enfoques anteriores ${ }^{14}$. Esta dimensión, más bien, ha sido reservada a una lectura al interior del proceso productivo general y de su mediación a través del mercado de trabajo, que dada las condiciones particulares de dependencia estructural y pobreza urbana, se reflejan a posteriori en el problema de la vivienda y del hábitat.

Desde esta visión, la ciudad opera como un "espacio cerrado" (Massey, 2005) ${ }^{15}$. Es un punto en el espacio que tuvo un crecimiento mayor (o desfasado) a la capacidad de la industrialización periférica de asimilarlo, dando así lugar a una masa de población que encuentra límites para insertarse plenamente en el mercado laboral urbano o que cuenta con empleos de baja productividad y régimen de salarios bajos. Aún adscribiendo a esta preocupación por las condiciones de apropiación y distribución en el marco del proceso social, interesa discutir cómo la dimensión de la localización intra-urbana participa en el proceso de

\footnotetext{
${ }^{14}$ El giro de la perspectiva liberal individualista ha reintroducido el tema del suelo en agenda de debate aunque no necesariamente preocupado por el papel estructural que juega el suelo en el arreglo distribucional de la ciudad.

${ }^{15}$ En Filosofía y política de la espacialidad, se propone imaginar el espacio de modo abierto como producto de interrelaciones, como esfera de la posibilidad de la existencia de la multiplicidad y como proceso un proceso del devenir. El espacio como producto de las interrelaciones, se constituye a través de interacciones desde lo inmenso de lo global hasta lo ínfimo de la intimidad; como esfera de la posibilidad de a existencia de la multiplicidad, implica coexistencia de distintas trayectorias, hace posible la existencia de más de una voz; y como producto de las relaciones implícitas en las prácticas materiales que deben realizarse, siempre está en proceso de formación, nunca acabado (Massey, 2005).
} 
apropiación y distribución de la renta urbana. Y no sólo entre los propietarios que capturan renta a partir de la demanda derivada de los desarrolladores capitalistas, sino también en términos de ventajas y desventajas para los usuarios-productores que consumen, producen, disfrutan y sufren el espacio urbano.

Esta dimensión central para la planificación y la gestión de las ciudades, supone algún nivel de autonomía relativa que da sentido a la existencia del campo de la política urbana. En este entramado entran en tensión un conjunto de intereses y mediaciones que, aunque interdependientes del proceso que están más allá de su control, supone una serie de variables al alcance que definen un umbral de acción. Veamos a continuación como a partir de la crítica de a la perspectiva sectorial o viviendista, es posible reconocer algunas articulaciones entre la política de vivienda y la dimensión urbana, en el marco de un enfoque habitacional integral. Más adelante veremos otros aportes que presentan las lecturas de la división social del espacio, los estudios que toman nota de la experiencia de habitar, los enfoques de la justicia espacial, entre otros.

\subsubsection{Críticas a las visiones sectoriales viviendistas}

En el marco del orden tecnocrático el "problema de la vivienda" suele ubicarse en las coordenadas definidas por la escasez económica de recursos, los costos por unidad, el déficit cuantitativo, la producción de vivienda nueva y las soluciones en manos de las empresas constructoras. Desde esta mirada, la política de vivienda se divorcia de la dimensión urbana y, también, se disocia de las penurias habitacionales de quienes las padecen. El problema se aborda a partir de una matriz productivista, donde prima la racionalidad de la obra pública, cuya naturaleza es fuertemente sectorial, es decir se encuentra determinada por la lógica de la industria de la construcción.

Repasemos las críticas centrales que Yujnovsky (1984) plantea al modelo de resolución dominante de la acción pública en materia habitacional. Uno de los principales rasgos del enfoque viviendista es desligar la vivienda de la estructura urbana, una vez realizado este movimiento, la vivienda es concebida como una unidad individual edificación-lote aislada de su inserción en la ciudad. De este modo, la vivienda es divorciada de los aspectos sociales y territoriales que la constituyen como producto histórico y la relaciona funcionalmente con el resto de los objetos y servicios urbanos. Su vínculo con la renta del suelo se oculta, para asumirse una concepción de propiedad plena basada en los intereses individuales de los propietarios. Se asume que los agentes resuelven el acceso a la vivienda a partir de decisiones de libre de consumo, este proceso se enmarca en el plano de elecciones que pertenecen al ámbito privado del individuo o a la familia. De esta forma, la condición primaría de la vivienda como satisfacción de necesidad de uso pasa a ocupar un segundo plano.

No caben dudas que el acceso a la vivienda y al suelo urbano no se resuelve a través de elecciones individuales de consumo libre al interior de las unidades domésticas. Las decisiones 
en materia residencial dependen, como señala Bourdieu (2001), tanto de las "disposiciones económicas" socialmente constituidas de los agentes como del "estado de la oferta", los cuales se encuentran fuertemente condicionados entre sí y dependen directa o indirectamente de un conjunto de condiciones económicas y sociales que estructuran y son producidas por la "política de vivienda", en el sentido amplio del término. Esto significa que las preferencias residenciales se encuentran, por un lado, determinadas por la satisfacción de necesidades de uso, la capacidad de pago, los gustos, y por otro lado, se encuentran definidas por la regulación urbanística, los programas habitacionales, el sistemas de crédito y la regulación de la industria de la construcción y los mercados de suelo.

Sin embargo, la traducción de la visión naturalizada mercantil-individualista de la vivienda al plano de la política pública, supone restringir el problema en mayor o menor medida a una ecuación de productividad dada por la optimización de los recursos para alcanzar la mayor producción posible. Esto se expresa en la construcción de la mayor cantidad de soluciones habitacionales en el menor tiempo posible (y con la mayor capitalización política). En el plano económico, la eficiencia de las metas aritméticas orienta el modelo de implementación hacia la industria de la construcción casi como la única alternativa posible.

El problema para la industria de la construcción es simple: es financiero. Primero, se trata de redireccionar fondos públicos y del mercado de capitales a la implementación de un sistema de créditos hipotecarios (con productos libres y regulados), de este modo garantizar la máximo ampliación del mercado. Segundo, el crédito debe combinarse con fondos públicos destinados al subsidio (parcial o total) de vivienda social para asegurar la cobertura de los "excluidos" del mercado. Para este sector, la articulación de un conjunto de instrumentos de financiamiento en un mercado segmentados, según la capacidad de ahorro previo de la demanda, constituye la respuesta al "problema habitacional".

En el plano de la vivienda social, el corolario de estas las respuestas, rara vez ha superado el crecimiento urbano expansivo, el principio funcionalista de ciudad dormitorio, o las viviendas estereotipadas producidas en serie. En términos generales, las soluciones aportadas (desde esta visión sectorial tradicional) no contemplan la dimensión urbana, no se ajustan a las necesidades de los destinatarios y han contribuido a generar procesos de segregación residencial.

Un enfoque más integral puede contraponerse a este enfoque tradicional que prioriza la mirada del déficit de la unidad-vivienda, la escasez de recursos económicos, la cuestión financiera, las metas cuantitativas y la segmentación de costo-capacidad de pago por unidad. En este plano, Yujnovsky (1984: 17) define la vivienda como “...una configuración de servicios -los servicios habitacionales- que deben dar satisfacción a necesidades humanas primordiales: albergue, refugio, protección ambiental, espacio, vida de relación, seguridad, privacidad, identidad, accesibilidad física, entre otras". Si se consideran los debates actuales deberíamos incluir además las necesidades productivas, de conectividad, la centralidad urbana, etc. Ya que como 
bien señala este autor, las necesidades no son fijas ni homogéneas, varían según cada sociedad, grupo social, región y momento histórico.

Por ello para él, el análisis de la producción de servicios habitacionales debe realizarse en función de una lectura de la estructura social, la relación sociedad-Estado y el juego de relaciones de poder. Por otra parte, es clave considerar los servicios habitacionales en una "configuración espacial urbana determinada", esto es en relación a una ciudad como espacio concreto y colectivo. Nos interesa rescatar particularmente este aspecto, ya que integra una de las dimensiones de análisis centrales a considerar en nuestro estudio. En este sentido, para Yujnovsky (1984) la vivienda no puede ser analizada por fuera de su contexto urbano o a partir de su ubicación en la estructura urbana, ya que buena parte de la calidad de los servicios habitacionales que brinda la vivienda depende de su relación con el entorno residencial y el conjunto de actividades urbanas de la aglomeración. Los mapas de accesibilidad relativa son estratégicos en función de los mercados de trabajo, los centros de consumo, la recreación, la salud y demás equipamientos, siendo también importante el servicio de transporte que vincula el sistema urbano.

Por otra parte, al momento de cuantificar el déficit habitacional deben considerarse no sólo las cantidades sino las calidades de los servicios consumidos, tradicionalmente el inventario se define en función de las características materiales de la vivienda sin considerase los servicios urbanos ni las calidades medioambientales. Otra de las dimensiones clave, aparte de la construcción de nuevas unidades, es considerar la renovación del parque existente, las posibilidades de reutilización de áreas centrales, la asignación de la sobreoferta existente mediante políticas de alquiler social y la integración de la vivienda social en áreas de nuevas operaciones urbanas. Una de las características de las políticas viviendista tradicionales ha sido cercenar el vinculo entre la vivienda y el espacio urbano, asunto que se refleja en su disociación histórica con lo que, en un sentido genérico, podemos denominar la política urbana.

La lectura clásica del déficit habitacional, divide el problema en el déficit cuantitativo y cualitativo $^{16}$, cristaliza una concepción institucional que niega la dimensión urbana del problema. Puede notarse que nos encontramos nuevamente frente una conceptualización cerrada y homogénea del espacio. La construcción del concepto del déficit habitacional evidencia una unidad de análisis, donde lo que sucede al interior de la ciudad opera de manera indiferenciada. De algún modo, la racionalidad tecnocrática obtura la lectura de la dimensión espacial, el locus del déficit es sólo una categoría nominal a la cual asociar una determinada magnitud de un problema cuya genealogía se encuentra fuera del campo urbano. La contingencia y la variabilidad del problema hay que buscarla en otro contexto explicativo que está más allá de la ciudad. El dónde no es una dimensión del déficit, sólo informa, en el mejor de los casos, la jurisdicción donde intervenir. Es interesante observar que no estamos frente a un problema en la construcción de un indicador, en el cual "lo urbano" como dimensión

${ }^{16}$ El déficit cualitativo se calcula en función de las viviendas ocupadas que tienen factibilidad de ser mejoradas, es decir, que presentan carencias de los componentes constructivos que son recuperables. Mientras que el déficit cuantitativo está asociado a las viviendas que son irrecuperables y requieren ser reemplazadas por viviendas nuevas. 
analítica del déficit habitacional haya sido anulada. Por el contrario esto evidencia, una vez más, la traza genética de cómo el problema sigue siendo concebido desde la racionalidad instrumental. $Y$ esto tiene consecuencias no menores en la formulación y el alcance de la política habitacional.

Recientemente, López y Cowes (2008) han propuesto una importante redefinición de la lectura del déficit habitacional que no sólo replantea el modo de construcción de las dimensiones clásicas del déficit cuantitativo y cualitativo, sino que además incorpora la dimensión de entorno habitacional y la disponibilidad de servicios urbanos. Por otra parte, la propuesta de la noción de déficit urbano se contrapone a la visión sectorial que hemos criticado. Catenazzi y Di Virgilio (2005) sostienen que el ejercicio del derecho a la ciudad tiene un vínculo estrecho con el acceso al consumo de bienes relacionados con las condiciones de habitabilidad. Estas condiciones, son definidas (las autoras recupera aquí el planteo de Coraggio, 1999) en función de la calidad de las relaciones sociales y las condiciones materiales del hábitat, ambas dimensiones se presentan como bienes complejos e indivisibles que no pueden adquirirse como mercancías (no son transables) pero se reflejan en el precio de los inmuebles urbanos. Para estas autoras, una lectura de la criticidad del déficit urbano centrada en las condiciones de habitabilidad, debería considerar a la ciudad como sistema urbano y a la vivienda como parte del mismo, el modo en que se realiza el proceso de construcción de la ciudad, las relaciones entre condiciones urbanas y la productividad y la ciudad como representaciones. Además, de identificar la situación de los hogares en el mercado de trabajo, la disparidad de los niveles de educación y las características de la organizaciones social en momentos de crisis (ver Catenazzi y Di Virgilio, 2005).

Una parte de nuestra preocupación introduce el desplazamiento del problema del hábitat "puertas afuera" de la vivienda, de aquí que la localización residencial en la estructura urbana cobre para nosotros relieve y sea necesario introducir algunas precisiones respecto de cómo utilizaremos esta noción.

\subsubsection{Algunas precisiones sobre el concepto de localización}

La tradición de la geografía neopositivista realizó un trabajo importante para situar el análisis locacional en el plano del espacio euclidiano, donde la variabilidad es dependiente de la distancia y el espacio se transforma en abstracto y ahistórico. Sin embargo, la idea de localización excede al espacio geométrico, en el cuál la localización refiere al par de coordenadas dónde se encuentra físicamente un objeto determinado. Vale aclarar que el tratamiento de la localización, no se ciñe sólo al proyecto regulado por el imperativo de la minimización de costes de agentes económicos individuales guiados por criterios de elección racional.

El término localización adquiere usos múltiples. Diversos enfoques relacionan la ubicación con oportunidades o constreñimientos sociales y, más allá del supuesto de isotropía, el espacio 
opera como productor. Por una lado, como afirma Bergmsman et al (1971, citado por Santos, 1990) las localizaciones antiguas condicionan las nuevas localizaciones. En este sentido, toda posición es relativa al conjunto de posiciones presentes, a su vez, es interdependiente con su trayectoria pasada. Desde un enfoque estructural, la noción de localización supone reconocer cuál es el orden y cómo se encuentra dispuesto un lugar en la estructura socio-espacial. Por otro lado, Ricoeur (2004) advierte que el espacio es sucesivamente vivido, construido, recorrido y habitado. Desde la fenomenología del los lugares hasta la geografía que describe el espacio habitado, el discurso de la espacialidad ha trazado un recorrido en el cual el espacio vivido es abolido por el espacio geométrico y reconstruido en el plano del espacio habitado. La dialéctica entre estos espacios, se vincula con la noción de la inscripción que en este ámbito discursivo es traducida como localización.

El espacio corporal está vinculado de modo inmediato al espacio del entorno. El movimiento va de la mano del reposo y la contracara del residir es desplazarse. "Los desplazamientos del cuerpo e incluso sus permanencia en el lugar no se dejan de expresar, ni pensar, ni siquiera, en última instancia, experimentar, sin alguna referencia, al menos alusiva, a los puntos, las líneas, las superficies, los volúmenes, las distancias, inscriptos en el espacio separado de la referencia al aquí y al allí inherente al cuerpo propio. Entre el espacio vivido del cuerpo propio y del entorno y el espacio público se intercala el espacio geométrico, donde no existe un lugar privilegiado sino una localidad cualquiera. El acto de habitar, de "vivir en", se sitúa en los confines del espacio vivido y del espacio geométrico. Pero el acto de habitar sólo se establece mediante el de construir [...] la correlación entre el habitar y construir se produce en un tercer espacio" (Ricoeur; 2004: 193). Para este autor, el espacio construido -sea de fijación donde habitar, sea de circulación para recorrer- consiste en un sistema de emplazamientos para las principales interacciones de la vida y el espacio urbano puede verse como medio de intertextualidad y como medio de inscripción.

En síntesis, el concepto de localización se utiliza en este trabajo en un sentido relacional, supone una acción mediante la cual la ubicación deja de ser considerada un sitio para convertirse en una posición determinada (lugar-situación) por un conjunto de lugares de existencia real y concreta que definen un totalidad $u$ orden. El movimiento de cualquier emplazamiento es capaz de alterar -mediante los vínculos que los conectan- la posición de los otros lugares. En tanto verbo localizar implica una operación metodológica de demarcación de límites en el orden del espacio, aún cuando estas líneas imaginarias sean difusas y reconozcan realidades multiescalares. En tanto sustantivo, la localización es un producto social construido en el marco del proceso de producción del espacio urbano y un hecho social -en sentido durkheiniano- como medio de acción que ejerce una coacción externa a las clases, grupos o individuos. $Y$, en ambos casos son claves las referencias de carácter contextual.

\subsubsection{El espacio urbano y la política habitacional}


En la introducción de este trabajo, hemos dicho que nuestro objeto de estudio se compone de una serie de interrogantes articulados entre sí, el más general, es: ¿Qué idea de ciudad se configura en torno a la política habitacional actual? Este interrogante se sitúa en el núcleo problemático de la relación vivienda-ciudad. Se podría cuestionar hasta qué punto la indagación sobre la vivienda permite dar cuenta de una problemática urbana más amplia. O por qué indagar la política de vivienda a partir de su inserción urbana, cuando la perspectiva sectorial ha tendido a negar este tipo de abordaje. Cierto discurso ha llegado a cuestionar hasta qué punto exigir a la política habitacional atributos propios de política urbana.

Más adelante intentaremos dar cuenta de los motivos y la líneas de argumentación que nos llevan a realizar un análisis de la política habitacional que "suspende" conceptualmente la escala de la vivienda-lote como unidad de análisis central, para desplazar la atención a los atributos habitacionales "puertas afuera" de la vivienda. Este se vuelve un dato crítico, particularmente cuando la acción pública tiene escaso interés en incorporar a la problematización del hábitat el papel que juega el mercado de suelo urbano. Por otra parte, dicha estrategia analítica vincula -aunque más no sea de modo tangencial- los resultados de localización de la política de vivienda con la cuestión de la renta del suelo, que a nuestro entender es la variable clave en el mecanismo de exclusión urbana que la propia política habitacional se propone atender.

El espacio urbano y la política habitacional pueden ser definidos de múltiples formas o amalgamarse de modo diverso. Se parte de la idea de que el espacio urbano (se retoman aquí algunas nociones de Lefebvre, 1976) es, por un lado, localización en función de la referencia a un centro (éste entendido no sólo como atractor de flujos sino como orden que distribuye, agrupa y reúne lo diferente); por otro lado, es un medio de producción y reproducción en términos de espacio construido que brinda soporte a todas las actividades humanas. Asimismo, es fuerza productiva asociada a los efectos de aglomeración; como así también, mercancía u objeto de consumo en tanto ámbito parcelado susceptible de ser apropiado. El espacio urbano configura una norma y un orden (dadas determinadas jerarquías espaciales y reglas implícitas o explicitas que regulan los intercambios en el espacio público y los usos posibles del espacio privado). Igualmente permite identificar prácticas o disposiciones subjetivas de formas de habitar e imaginar la ciudad. Por último, el espacio urbano, es también, objeto de disputa, lucha política, conflicto por la apropiación diferencial del espacio y las formas legítimas de representarlo.

A su vez, la política habitacional es entendida como un conjunto de tomas de posición acciones u omisiones- que, como sostienen Ozlak y O'Donell (1976) no son ni unívocas, ni homogéneas ni permanentes. Más bien son un conjunto de decisiones formales e informales resultantes de las mediaciones y la correlación de fuerzas en el entramado político, en las cuales el Estado interviene directa o indirectamente en la cuestión. Siguiendo a Yujnovsky (1984) forman parte de la política habitacional las regulaciones u acciones en la materia: los usos suelo (indicadores urbanísticos, subdivisión, reservas públicas, expropiación); los sectores 
productivos (créditos, impuestos, fomento a materiales o sistemas constructivos); el sector externo (aranceles de importación de materiales, importación de tecnologías); el financiamiento de la vivienda (sistema bancario oficial) y las políticas de precios (control de alquileres). Así como también, las inversiones directas o la provisión de servicios habitaciones por parte del Estado (construcción de viviendas, infraestructura, etc.).

A partir de aquí se abre un abanico de posibilidades para pensar la relación entre vivienda y ciudad o, mejor dicho, entre espacio urbano y política habitacional. Sin embargo, ni la realidad fáctica de la política habitacional actual permite trabajar las dimensiones arriba definidas, ni la complejidad de la relaciones en juego en el espacio urbano puede ser captada por nuestro esfuerzo. Por este motivo, en las siguientes secciones (sección 1.2 y 1.3) se realiza una aproximación a dos preguntas en las que se destacan las cuestiones a priorizar en nuestro análisis.

\subsection{El lugar asignado a la vivienda social en el mercado de localización}

Una forma de traducir la relación entre espacio urbano y política habitacional, es partir de la siguiente pregunta: ¿Cuál es el lugar asignado a la vivienda social en el mercado de localizaciones intra-urbanas? Este interrogante introduce la idea de lugar asignado para contraponerla a la noción clásica de lugar, vinculada a la dimensión de la identidad, los sentidos de pertenencia o las significaciones subjetivas derivadas de la experiencia situacional (perspectiva que se recupera en la sección 1.3). La intención de utilizar esta categoría deviene de la referencia de lugar como ubicación afectada por los procesos económicos y políticos a escala macro y como relación estructural dentro del proceso de desarrollo desigual más amplio.

Se califica al lugar como "asignado", ya que en la producción de la ciudad -donde se entrecruzan la lógica de la política, la lógica de mercado y la lógica de la necesidad- el proceso de adquisición de suelo para la construcción de vivienda social y "diseño urbano" de la política habitacional, en términos generales no está mediado por las necesidades ni la participación de los futuros habitantes (destinatarios-usuarios). Por el contrario, este proceso depende de un conjunto de decisiones de actores estatales, en las que antes y/o después participan los empresarios de la industria de la construcción y los propietarios del suelo.

La idea de lugar "asignado" en la división social del espacio, recupera la dimensión de la ubicación de Agnew $^{17}$ o posición estructural más arraigada en la tradición de la geografía radical, mientras que las otras dimensiones del lugar se encuentran más asociadas a la

\footnotetext{
${ }^{17}$ El concepto de lugar, reconoce desde la perspectiva de Oslender (2002) tanto propiedades objetivas como subjetivas las cuales son producidas y creadas. Los tres elementos constitutivos del lugar que describe este autor retomando el concepto Agnew, son el de localidad como marcos dentro de cuales están constituidas las interacciones sociales cotidianas, es decir, los contextos utilizados rutinariamente por los actores sociales; la ubicación como el espacio geográfico concreto que incluye la localidad afectada por los proceso económicos y políticos o la situación en el orden marco del proceso de desarrollo desigual; y el sentido del lugar como las significaciones subjetiva derivadas del vivir en un lugar, el sentido de pertenencia a lugares particulares.
} 
geografía humanista y de la percepción que se retomará luego. Por ello, el concepto de mercado de localizaciones residenciales intra-urbanas, supone una espacialidad relacional donde cada posición residencial se define en relación a otras posiciones, en función del conjunto de las ubicaciones posibles y de la dinámica de las mismas. Según Escolar (1998), en el espacio, los objetos reales se encuentran diferenciados y su posición singular es constitutiva de la idea de lugar. La singularidad de la posición puede variar por la modificación de los atributos específicos o locales. Pero también por los movimientos de la totalidad, que no es más que la referencia hacia otros lugares y procesos con los cuales está relacionado (interna o externamente) cada lugar. En este sentido, se consigna la categoría de localización en términos relacionales e históricos.

La noción de mercado de localizaciones residenciales intra-urbanas permite resaltar que la posición de la vivienda en la estructura socio-espacial no es neutra, por el contrario es producida a partir de un arreglo institucional y mercantil desde el cual se distribuyen de un modo asimétrico las condiciones de habitabilidad de la ciudad. En otras palabras, la ciudad como "valor de uso complejo" ${ }^{\text {"18 }}$ reconoce un orden donde el principal mecanismo de asignación de bienes y servicios deriva de la capacidad de pago de la demanda. El mercado de localizaciones residenciales intra-urbanas tiende a reflejar, entonces, la distribución de las condiciones generales de calidad urbana y la diferenciación socio-económica de la población residente.

Dicho de otro modo, existe una ecuación entre mercado de localización residencial, calidad urbana "puertas afuera" del lote y nivel socio-económico. Aún cuando sea posible identificar arreglos particulares, a nivel operativo entendemos al mercado de localizaciones intra-urbanas como un espacio relacional en el que se articulan las condiciones de calidad (como centralidad, consolidación urbana, accesibilidad-conectividad, calidad habitacional, etc.) con el perfil socioeconómico de las distintas áreas de la ciudad. Este concepto se sitúa en los debates acerca de cómo se distribuyen determinadas condiciones de vida en la ciudad, el papel que juega la renta del suelo en la política urbana y los procesos de división social del espacio residencial (Harvey, 1973; Topalov, 1979; Preteceille, 2002; Marcuse, 2002, Ribeiro, 2002; Lago, 2002; Rodríguez y Sugranyes, 2005; Abramo, 2006; Hidalgo, 2007; Morales, 2008; Duhau y Giglia, 2008; Rolnik et al, 2009; Soja, 2010).

A continuación se desarrollan una serie de ejes en torno al problema del acceso al espacio urbano en una economía capitalista periférica, su vínculo con la cuestión de la renta y la mediación interpuesta por los mercados de suelo urbano. Esperamos que al final de la próxima sección, estos ejes permitan dar cuenta con mayor precisión del alcance que tiene en el análisis de la política habitacional el mercado de localizaciones.

\footnotetext{
${ }^{18}$ Topalov (1979) utiliza este concepto para pensar la relación entre el proceso de apropiación y los efectos de aglomeración a nivel de conjunto social. Sin embargo, aquí se propone trasladar esta preocupación a nivel intra-urbano para pensar cómo se distribuye determinadas oportunidades/externalidades urbana de acuerdo a la localización residencial de los individuos, grupos o clases.
} 


\subsubsection{El problema del acceso al suelo urbano}

En el siglo XX las ciudades latinoamericanas sufrieron un fuerte proceso de urbanización. El acelerado crecimiento poblacional acompañado por una importante expansión física de la ciudad y los significativos obstáculos en la matriz del desarrollo económico, hicieron del escenario urbano un espacio donde chocaron imperiosas necesidades habitacionales de amplios sectores de la población con importantes restricciones del Estado para afrontar y conducir dicho proceso. El resultado fue entonces un esquema de producción de ciudad inverso al de la planificación "formal". El modelo de urbanización predominante se basó en la ocupación de hecho de la tierra -o la legalización de loteos de bajo estándar urbanístico-, la autoconstrucción de la vivienda, la lucha por la regularización de la tierra y/o la consolidación de los servicios urbanos básicos, que antes o después será acompañada por la densificación del barrio y la diversificación de actividades urbanas.

La autourbanización progresiva por generaciones con distintos niveles de organización social en la estructuración de la demanda y diversos tipos respuestas estatales, se convirtió -como ya hemos visto- en el rasgo fundamental de la urbanización popular latinoamericana. Aún hoy, persiste una elevada precariedad en la calidad urbanística y espacios fuertemente segmentados en este sentido. Sin embargo, este proceso está lejos de explicarse por el repentino crecimiento poblacional o migratorio que genera una demanda agregada $y$ desacoplada de la oferta habitacional.

Existen otros factores para explicar el desarrollo que asume el mercado de suelo y vivienda en las ciudades latinoamericanas, aquí nos interesa detenernos al menos en dos de ellos. El primero comprende a las características propias que asume la urbanización latinoamericana dado el carácter dependiente en el desarrollo desigual y combinado; el otro, la persistencia de un entramado público-privado que tiende a cristalizar un proyecto-ciudad excluyente, producto de la debilidad y dificultad del Estado en controlar y regular el mercado de suelo urbano.

El primer punto ya ha sido tratado en la primera sección pero lo repasamos aquí sintéticamente. Los rasgos distintivos de la urbanización latinoamericana en gran medida dependiente de una acumulación tardía y subordinada a nivel internacional son, siguiendo a Jaramillo (2008) un contarse entre una acumulación limitada (de lenta expansión y poco demandante de fuerza de trabajo dado el cambio técnico) y el crecimiento poblacional que genera un desequilibrio estructural en el mercado de trabajo. Esto tiende a consolidar un régimen de salarios bajos. A su vez, la baja remuneración de la mano de obra se traduce en la persistencia y la difusión de actividades mercantiles simples (ligadas a la subsistencia de muy baja productividad y escaso ingreso), las cuales son subsumidas al circuito capitalista. De allí una estructura del mercado de trabajo que consolida una "masa marginal" no absorbida por la economía capitalista, en coexistencia con un sector de los asalariados que no logra reproducirse completamente a través del salario. Y, por último, los bajos ingresos de la mayoría de la población que se combinan con una aguda desigualdad en la distribución del ingreso. 
En segundo lugar, cabe preguntarse qué sucede cuando una parte importante de la población queda excluida de la demanda solvente de una gama de bienes y servicios (entre los que podemos encontrar el suelo urbano, la vivienda y los servicios urbanos en un sentido amplio). Por otra parte, qué mediaciones ofrece una lectura a escala intra-urbana del papel que juega el mercado de suelo en dicho proceso de exclusión y qué rol que asume la acción pública en este escenario.

El acceso al suelo urbanizado, bien localizado y a precio accesible para los sectores de bajos ingresos constituye un verdadero problema en nuestras ciudades. En relación a los niveles de desarrollo e ingreso per cápita, las ciudades latinoamericanas poseen a nivel mundial una importante proporción de suelo "urbano" sin cobertura o con una cobertura precaria de servicios, equipamientos e infraestructura, como así también elevados precios de suelo en términos relativos (Smolka, 2003). Se paga caro por suelo de mala calidad, a ello se suma una tendencia preocupante: altas tasas de urbanización en términos demográficos y geográficos con parámetros excepcionalmente bajos en términos de la expansión anual de infraestructura y servicios. Este acuerdo urbanístico público-privado tácito en la historia de la urbanización latinoamericana (con base en la insuficiencia de oferta de suelo urbano de calidad) opera junto con la distribución asimétrica de recursos públicos y políticas socio-espacialmente regresivas (Kleiman, 2002). Induciendo, de esta manera, el alza de los precios del suelo producto de la generación de escasez relativa. Este circuito dificulta el acceso a la ciudad y condiciona la producción de la informalidad en la ocupación del suelo y la vivienda (y/o la proporción de población enajenada de condiciones de calidad urbana en sentido amplio).

Veamos ahora cómo la existencia de amplias zonas "urbanas" con escasez de suelo servido y la segmentación de la calidad del espacio público urbano contribuye a retroalimentar el círculo de la especulación, la debilidad del financiamiento público y la informalidad urbana. En la figura 1, Morales Schechinger (2008) muestra que estos procesos son interdependientes. La existencia de zonas de la ciudad desprovistas de infraestructura y servicios urbanos y las fuertes asimetrías de la inversión en el espacio público, incide en el pago de un sobreprecio producto de la escasez física relativa del suelo servido, equipado y bien localizado. Se forma así, una renta diferencial producto de la concentración de la demanda en ciertas áreas de la ciudad, dotada de una "fertilidad" distinta introducida por la propia acción pública.

La intensidad de la demanda en dichas áreas aumenta las expectativas a futuro, lo que conlleva mayor especulación. La retención del suelo es una estrategia frecuente de los propietarios, que mediante el control de la oferta, generan una escasez de tipo económica aumentando aún más el sobreprecio del suelo servido, equipado y bien ubicado. La inversión especulativa en el mercado de suelo prácticamente no tiene riesgo y su carga impositiva es mínima. Por esta vía, el Estado participa del proceso de exclusión de parte de la demanda de aquellas zonas que reúnen un umbral de cualificación urbana medianamente "aceptable".

La lógica de la especulación se acelera cuando la acción pública asume los costos de la urbanización y privatiza los beneficios. Desprovisto de recursos, el Estado, no logra invertir lo 
necesario para reducir las asimetrías de la calidad del espacio urbano. La magra base fiscal y la reducida presión impositiva sobre el suelo, contribuye al desajuste entre los recursos financieros y las necesidades de inversión crecientes en el espacio público de la ciudad. Este esquema profundiza el déficit urbano-habitacional y la escasez de suelo servido retroalimenta el sobreprecio que se paga por el suelo urbano de calidad. Frente a la agudización de este escenario, medidas como la desgravación impositiva o la reducción de costos de transacción como también la ampliación del perímetro urbano que intentan ampliar la oferta profundizan el círculo de especulación.

Por otra parte, la demanda excluida del área urbana cualificada ${ }^{19}$ como tal, se canaliza a través de múltiples circuitos. El segmento del mercado de suelo de baja calidad o las áreas en expansión sin servicios urbanos, son consideradas parte del circuito de la precariedad urbana. Esto se debe a que existen también loteos formales de muy bajo estándar urbanístico, es decir que no asumen la condición de suelo servido, equipado y con condiciones de localización relativamente homogéneas. Otra respuesta frecuente de la demanda excluida, además de la estrategia "vivienda adentro" de cohabitación o hacinamiento familiar, es la densificación intralote. Esto es, el aumento de la intensidad constructiva más allá del reglamento o la norma urbana. Por último, la ocupación de hecho o la irregularidad en el dominio del suelo es la forma clásica de informalidad urbana, sea a través de la participación en proceso de tomas de tierra o mediante la intermediación mercantil. En cualquiera de los casos, estas formas de acceso a la ciudad suponen el pago de un sobreprecio por lugares de baja calidad, lo cual se expresa de diversos modos.

En algunos casos, la situación habitacional acuciante de los sectores populares se traduce en canales de especulación al interior del mismo mercado inmobiliario informal. Esto se manifiesta en los precios del suelo que pueden llegar a ser iguales, y en algunos casos superiores, a áreas con mayor estatus urbano. Aún disponiendo de cierta capacidad de pago, parte de la población es excluida del mercado inmobiliario formal por las condiciones que rigen dicho mercado (garantía, avales, adelanto, etc.) y por la dificultad de afrontar compromisos a largo plazo dada la inestabilidad de los ingresos. Otros costos indirectos de la urbanización (que exceden las desventajas de los términos de la transacción) se desprenden de las condiciones de localización del terreno. Este factor incide en la calidad de vida tanto en términos de las características ambientales, como de la complejidad de las funciones urbanas que brinda el sitio de vida, las externalidades sociales y los costos de desplazamientos, entre otros. A ello se suma el pago diferido de los servicios, la infraestructura y en ocasiones la regularización.

\footnotetext{
${ }^{19}$ Aunque también debemos tener en cuenta que en regiones metropolitanas como la nuestra en los últimos años se da la paradoja de la pugna por el mismo suelo por parte de los extremos de la escala social, lo cual presiona hacia arriba los precios en áreas otrora consideradas marginales.
} 
Fig. 1 Esquema de retroalimentación entre especulación inmobiliaria, gestión e informalidad

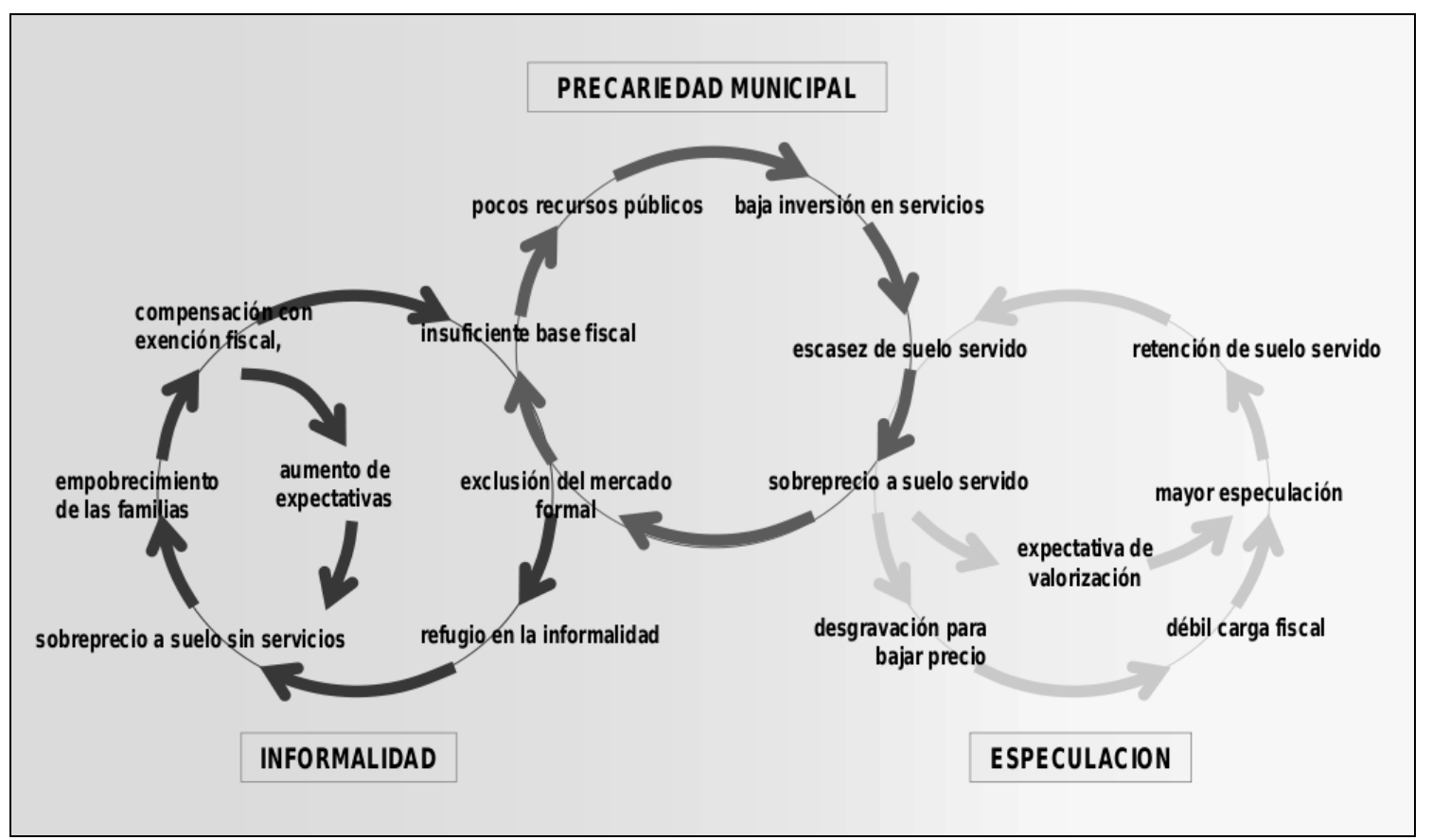

Fuente: Morales Schechinger (2008) en base a Smolka, Curso de Especialización en Mercados y Políticas de Suelo en América Latina. Bogotá. UNC-LILP.

El esfuerzo que los sectores populares realizan para vivir en este tipo de urbanización implica también esfuerzos para el Estado, especialmente en términos del financiamiento de los costos indirectos originados por el hecho de que una parte del parque habitacional se encuentra fuera de la ciudad formal. Y, por otro lado, por la compensación con exenciones impositivas que reducen los recursos públicos y realimentan la especulación y la desinversión de la ciudad.

Si bien, la relación entre la especulación, la informalidad urbana y la debilidad de los recursos financiaros o la capacidad de regulación estatal, es esquemática y supone un-modelo de espacio urbano donde el funcionamiento del mercado de suelo urbano se vuelve tautológico, sirve para identificar la interacción entre la política pública y los procesos de especulación urbana. Esta relación deja al descubierto una erosión importante de los recursos públicos por medio de la transferencia de recursos a los propietarios del suelo. También, pone de relieve que los submercados o segmentos de mercado inmobiliario tienen una interdependencia entre sí. Y, al mismo tiempo, permite observar que los mercados de suelo condicionan y agravan situaciones de pobreza urbana.

En este contexto, encontrar un lugar para vivir se transforma para los sectores populares en una verdadera peregrinación y la ciudad un "lugar sagrado" al cual venerar. Riofrio (1981) señala que la ciudad precaria paga a largo plazo la espera de la inversión pública y supone mayores dificultades en el proceso de readecuación urbana, las cuales son asumidas por el Estado y los pobladores. Por último, como afirma Trivelli (1982: 27) "no cabe ninguna duda de 
que es más caro ser pobre, tanto en cuanto al asentamiento en el medio urbano como en lo referente a los costos de operación de la vida cotidiana".

A continuación se consideran algunos antecedentes de la teoría de la renta agrícola, de la cual se derivan los principales elementos teóricos sobre la formación de la renta en la ciudad. Esto nos ayudará a comprender algunas de las relaciones descriptas en este apartado.

\subsubsection{Antecedentes sobre la teoría de la renta}

Los mercados de suelo urbano tienen ciertas peculiaridades que es necesario destacar. Aunque el suelo adquiere un precio, éste no depende del costo de producción ${ }^{20}$. Por otra parte, si se considera la relación singular que existe entre cada lote y su ubicación con respecto al conjunto de las actividades urbanas, el suelo urbano se vuelve irreproducible. En otras palabras, dado el esfuerzo que implica crear ubicaciones similares, la oferta de suelo urbano es a corto y mediano plazo inelástica. La irreproductibilidad del suelo urbano hace que su oferta sea por definición monopolizada. Si a esto sumamos la tendencia de las preferencias locacionales a concentrarse en determinadas regiones del espacio urbano. Se entiende que la literatura registre que exista en el mercado de suelo urbano un desacople estructural entre la oferta y la demanda.

Antes de introducirnos de lleno en las particularidades del funcionamiento del mercado de suelo urbano, que como luego veremos puede analizarse básicamente como un mercado de localizaciones, consideremos brevemente los antecedentes de la formulación de la teoría de la renta rural y las consecuencias de este debate en el plano distributivo, ya que algunos de los conceptos claves que utilizaremos derivan de allí.

La teoría económica clásica considera una paradoja el hecho de que la tierra tenga un precio, o se transe en el mercado como cualquier otra mercancía, debido a que la tierra y sus atributos no se producen. En otras palabras, la tierra no es resultado del trabajo social y es un elemento irreproducible por la voluntad del capital. Sin embargo, quien detenta su dominio jurídico y ejerce el control de excluir a los demás de su uso, puede bajo ciertas circunstancias, absorber una parte del excedente social en forma de renta ${ }^{21}$. En este sentido la tierra no tiene valor, pero adquiere un precio como resultado de la existencia de la renta. El precio se forma mediante el mecanismo de capitalización de la renta que se desprende de equiparar la posesión del terrateniente, un lote, a la posesión de un capital que en el sistema financiero brinda una tasa de interés similar a la percibida por el arrendamiento de la tierra.

\footnotetext{
${ }^{20}$ El precio expresa una valorización/representación social -mediada por la capacidad de pago- atribuida de manera explícita o implícita a tal o cual lugar dentro de la ciudad, a partir de las elecciones locacionales, productivas o residenciales de las empresas o las familias.

${ }^{21}$ En relación al tema de la tierra y su vínculo con el problema de la distribución no es menor la distinción entre los abordajes de Escuela Clásica o de la Economía Política de los enfoques de la Escuela Marginalista (o Neoclásica) que descartan la teoría del valor-trabajo por la teoría de la utilidad marginal.
} 
Antes del siglo $X X$, la discusión de la renta se vinculaba esencialmente al mundo agrícola buscando explicar la existencia de una clase terrateniente que percibía un ingreso sin participar de modo directo en el proceso productivo. En este contexto, las circunstancias por las cuales el propietario de la tierra logra obtener un ingreso deducido de la ganancias capitalista derivan: primero, de la existencia de la ganancia extraordinaria sobre la base de condiciones irreproducibles en el marco de la agricultura (por ejemplo, fertilidad); segundo, de la presión o competencia entre productores agrícolas por desarrollar su producción en aquellos terrenos donde se encuentran la características irreproducibles que dan origen a un rendimiento diferencial.

Consideremos como opera la relación entre ganancia extraordinaria, escasez y propiedad privada. Según Jaramillo (2009), en la estructura jurídica existe la posibilidad de un dominio sobre las características irreproducibles que están en la base de la ganancia extraordinaria. Quien posea el dominio jurídico sobre dichas circunstancias no reproducibles, puede ceder a un agente productor el acceso a ellas. Este agente económico deberá entregar a cambio una parte de la ganancia extraordinaria, aunque la competencia puja a que sea la totalidad. De este modo, para que la propiedad jurídica genere la posibilidad de percibir renta, es necesario que exista ganancia extraordinaria. Ésta tiene lugar sólo si las condiciones irreproducibles de producción obstaculizan efectivamente la ampliación de las cantidades producidas de los bienes, es decir, si son escasas. Cuando las condiciones irreproducibles pueden ser objeto de transacciones: "...lo que se transa es en realidad el derecho a percibir renta que está asociado a esta propiedad" (2009: 89).

La teoría ricardiana fue pionera al introducir la idea que la renta es una porción del producto de la tierra que se paga al propietario por el uso de las "fuerzas originales e indestructibles del suelo". Bajo el supuesto de la necesidad de ampliar la producción de alimentos y en condiciones de intensidad constante de capital, las fuerzas vinculadas a la calidad (o fertilidad) y la ubicación, conjuntamente con la escasez de su irreproductibilidad y la presión de la demanda, dan origen a la Renta Diferencial (Tipo I). En la formulación de Ricardo la variación de la intensidad de capital introducido a los terrenos da origen a otro tipo de renta diferencial (Tipo II).

Otro aporte clave de esta formulación es ordenar la relación de los términos tierra-precio, ya que no sería la existencia de la renta de la tierra la que determinaría el precio del producto. Si la "renta es una parte del producto de la tierra", es el precio del producto el que determina la renta.

Por otro lado, la distribución de las actividades agrícolas captada en el clásico modelo de Von Thünen, puso de manifiesto que la estructura de las localizaciones tiene estrecha relación con la renta del suelo. En este modelo, la localización depende de un principio de accesibilidad simple, expresado como el costo de transporte al mercado central. La renta tiene relación con el ahorro de transporte que verifican los productores en los terrenos más cercanos al mercado, dependiendo el acceso a los terrenos de la competencia entre los productores (o las 
producciones) con mayor capacidad de pago. Según Camagni (2005) la renta aparece aquí como un residuo que el productor puede pagar al propietario del suelo, una vez descontados de su ingreso total, los costos de producción, el beneficio normal y los costos de transporte. Las localizaciones más centrales serán atribuidas a aquella actividad que obtenga el mayor producto neto por unidad de superficie. La localización de actividades pasará a depender, entonces, de la intensidad y eficiencia con que cada actividad productiva utilice el suelo.

La derivación teórica de la formulación ricardiana -asimilada también en el modelo von thüniano- lleva a plantear que la tierra marginal soporta renta nula, es decir, que el propietario estaría dispuesto ceder el acceso al productor a título gratuito. Esto no sólo era incongruente frente a la institución de la propiedad, sino que además contradecía la evidencia empírica de la época (Jaramillo, 2009). Por ello, la perspectiva marxista aporta al planteamiento original de las rentas diferenciales la noción de Renta Absoluta, cuya base se apoya en la propiedad privada y el poder de retención que otorga su dominio jurídico. Se denota así la existencia de una fuente adicional de la renta, presente aún en las tierras "marginales" que no gozan de ventajas productivas relativas.

Desde esta perspectiva otra fuente de renta deriva de la escasez de cierto tipo de tierras, las cuales pueden ser monopolizadas de modo de obstaculizar la ampliación de determinada producción. El ejemplo de la producción de vino, utilizado también por A. Smith, es emblemático. Una determinada región cuenta con tierras con condiciones agroecológicas excepcionales que permite producir una variedad única de vino. Si el interés de los consumidores en adquirir dicho producto aumenta por encima de la cantidad ofrecida y la demanda está dispuesta a pagar un precio mayor, el precio que se forma será de monopolio. Pero, por el mecanismo que antes hemos visto, esta ganancia extraordinaria será apropiada por el terrateniente en forma de renta (Renta de Monopolio). Jaramillo (2009) destaca que esta renta surge en ciertas áreas, lugares o regiones con circunstancias excepcionales de diverso tipo y, a la vez, escasas. Pero, además, la escasez puede tener en ciertas circunstancias una expresión generalizada que afecte al conjunto de las tierras. Se distingue, así, la Renta de Monopolio Focalizada de la Renta de Monopolio Generalizada.

\subsubsection{Notas sobre el proceso de formación de la renta urbana}

La traducción de este esquema de rentas al ámbito urbano no es sencilla y supone algunos recaudos. En principio, para el desarrollo del conjunto de actividades humanas se requiere utilizar al suelo como soporte, y es indudable el protagonismo de éste en las ciudades (las cuales se han convertido en la forma de asentamiento por excelencia). Los efectos de la economía de aglomeración parecen estar detrás de este proceso, junto con la brutal transformación de las relaciones técnicas de producción en el mundo rural. Por otro lado, al interior del espacio urbano se desarrollan un conjunto de actividades heterogéneas y articuladas espacialmente entre sí. Dicha articulación opera como una fuerza productiva, tanto 
a nivel de conjunto urbano como de manera situada, y supone algunas distinciones analíticas entre el espacio público y el espacio privado.

Son varias las consideraciones a tener en cuenta al reflexionar acerca de cómo intervienen las rentas antes vistas al interior de la ciudad. El traslado del debate de la renta rural al ámbito urbano ha llevado a diversos autores a plantear que el suelo urbano no se produce y, por tanto, carece de costo de producción. La condición "urbana" del suelo difiere de la tierra rural en varios aspectos, uno de ellos es el hecho de que el suelo urbano se produce y por tanto tiene un costo de producción. Este no es un dato menor, ya que si algunos atributos o acciones dotan al suelo de su cualidad "urbana", y estos atributos suponen un esfuerzo colectivo, a nuestro juicio es significativo saber quién asume dicho costo, porque éste altera la estructura de relaciones y actores vista en el ámbito rural.

Esto supone que estamos en presencia de un nuevo arreglo distribucional. En tanto, la denominación "urbana" implica algún atributo mínimo mediado por la inyección de trabajo social. Proceso que no se da al interior de los lotes individuales que componen la ciudad, sino por el contrario en el espacio público que habilita su existencia. Si bien, la delimitación de lo "urbano" y, en términos urbanísticos, del "suelo urbanizado" entraña una discusión en sí misma, no parece existir duda bajo las condiciones de urbanidad contemporáneas que esta categoría más allá de toda convención- se encuentra mediada por un proceso de trabajo que debería revisarse a la luz de su conexión de la Renta Urbana Absoluta y se encuentra en la genética del resto de las rentas urbanas.

Por tanto, aún cuando el precio de mercado del suelo urbano sea mayor al precio de su producción ${ }^{22}$, puede observarse que la intensidad de capital-trabajo inyectada en el espacio público, no controlada por los agentes privados "formales" ${ }^{23}$, se manifiesta como un proceso que habilita la oferta original de suelo "urbano". La inversión "inyectada" en el espacio público ${ }^{24}$ varía con el tiempo, esto significa que esta acción no sólo "da a luz" u origina una "localización urbana", sino que además puede alterar su trayectoria posterior. Bajo condiciones de una demanda que valoriza dicha inversión, esto significa que muestra disponibilidad de pago según la intensidad de la inversión en el espacio público urbano, estamos en presencia de una renta cuya fuente genética deriva de la intensidad de uso de capital extra-lote ${ }^{25}$ aunque su apropiación la realice quien controla el domino del lote.

En este sentido, surge una distinción importante: en la formulación original de la teoría de la renta en el medio rural la dimensión del espacio público parece no tener relevancia, sin

\footnotetext{
${ }^{22}$ No se inhibe aquí la aparición de renta, ni se pretende vincular su magnitud con la teoría del valor-trabajo.

${ }^{23}$ Se considera aquí que el proceso acondicionamiento material que realiza un loteador pirata (agente privado informal), por mínimo, rudimentario y precario que sea, implica alguna intensidad de capital-trabajo, además del control de ciertas redes de relación.

${ }^{24}$ Nos referimos aquí al espacio público en términos de un espacio abstracto (y a la vez concreto) que liga, regula y ordena lo que acontece en la ciudad.

${ }^{25}$ Resulta complejo pensar una designación específica para esta fuente de renta. Pero en tanto se verifican asimetrías importantes en la densidad de inversión en el espacio público urbano y emergen configuraciones espaciales altamente segmentadas en términos de la calidad del espacio público o la cualidad de lo "urbano" no parece comportarse de modo uniforme, es necesario repensar este proceso a la luz de las consecuencias que hemos visto en el apartado 1.2.1
} 
embargo en la ciudad ésta es una dimensión constitutiva de la existencia de dicho espacio. Darle al espacio público un tratamiento indiferenciado puede constituir un descuido teórico importante, ya que de sus cualidades se desprende buena parte de las rentas diferenciales o de la "fertilidad urbana" (Trivelli, 1981; citado por Baer, 2011). En el medio rural, la calidad del suelo y sus atributos son intrínsecos a la tierra, pero utilizando esta analogía para el suelo urbano, las cualidades del mismo pasan a ser en esencia extrínsecas al lote. Siguiendo este planteo, en el ámbito urbano la fertilidad es derivada de: la disponibilidad de servicios, infraestructura y equipamientos urbanos, las posibilidades constructivas normativas y económicas, el potencial comercial de tal o cual área, la composición del nivel socioeconómico del lugar, la distribución del sistema de centros y subcentros urbanos y la accesibilidad en términos de costo/tiempo de transporte. ${ }^{26}$

Véase que dentro de esta idea de "fertilidad urbana" se reúnen factores cuyo origen es diverso. Primero, se distingue el proceso de trabajo e inversión en el espacio público que es constituyente del espacio urbano, aunque luego continúe produciéndose, dimensión que en los párrafos precedentes hemos puesto de relieve. Segundo, otro factor complementario aunque no excluyente, es el componente normativo que habilita cambios en las cualidades de la oferta del suelo urbano ${ }^{27}$. Ésta puede ser otra de las formas en la cuales se presenta la acción pública en el ámbito urbano, que no parece ser tan evidente o potente en la modulación de la calidad de la oferta de la tierra rural. Tercero, incide también la interacción de actividades, tanto por relaciones de complementariedad o agregación como en términos de externalidades negativas ${ }^{28}$. Y por último, otro factor a tener en cuenta, son las pautas de interacción social, éstas tampoco son estables ni están exentas de contradicciones.

En relación a este último punto, es importante notar que la interacción entre clases, grupos o individuos puede priorizar mayor o menor heterogeneidad social. A su vez, lo que para un grupo puede constituir una forma de interacción positiva para otro grupo puede ser exactamente lo contrario. Lo que para la lectura de la política urbana puede ser una situación contradictoria, para la economía urbana es simplemente un problema a nivel de la capacidad de pago. La necesidad de un grupo de excluir a otro, por ejemplo para denotar prestigio, genera condiciones para el surgimiento de renta de segregación. De este modo, resulta

\footnotetext{
${ }^{26}$ Resta aquí considerar la fertilidad en un sentido estricto e intrínseco al lote urbano, en función de las características diferentes de los terrenos, a saber: las condiciones geomorfológicas o topográficas que afectan el proceso constructivo y supone diferencias de constructividad. Siguiendo a Jaramillo (2009), esta fuente de renta, junto con la localización en gran medida dependiente de la dotación de valores de uso infraestructurales son las fuentes de la Renta Diferencial Tipo I. Mientras que la Renta Diferencial Tipo II es dependiente de la intensidad de capital aplicado al terreno (normalmente asociado a la construcción en altura) vinculada a la edificabilidad. Estas rentas junto con la Renta Absoluta constituyen para este autor la familia de "rentas urbana primaria", asociada al proceso productivo de la construcción, que se diferencia en su naturaleza y dinámica del proceso de consumo del espacio construido, para el cual reserva una familia de "rentas urbanas secundarias".

${ }^{27}$ Está claro que es condición necesaria para la formación de la renta, no sólo un estructura de la oferta de tendencia inelástica sino también un demanda con disponibilidad a pagar un precio mayor al costo de producción (Camagni, 2005). Por ello, no necesariamente un cambio de la normativa urbana necesariamente implica un aumento de los precios del suelo. Sin embargo, esto no obtura la verificación por el lado de la oferta la existencia o la aparición de una "fertilidad" de tipo normativa.

${ }^{28}$ La relación varía según las actividades y las regiones del espacio urbano, en algunos caso supone mayor productividad, en otros casos puede implicar relaciones contradictorias donde el beneficio para una actividad supone un perjuicio para la otra actividad (os problemas ambientales son un ejemplo de ello).
} 
paradigmático como el traslado de la renta rural a la renta urbana llega a esconder detrás de la máscara neoclásica de la eficiencia y el equilibrio óptimo sustentado en el supuesto de máxima de "productividad", formas de legitimación de la diferenciación socioeconómica y estrategias de control de la estructura urbana por parte de determinados grupos. Por esta razón, es necesario ser precavido con la analogía de la fertilidad urbana.

Otro aspecto constitutivo del proceso de formación de rentas se vincula con el principio de la aglomeración. En la literatura este principio no es visto como un factor de diferenciación intraurbana, más bien es un elemento macroterritorial que caracteriza al conjunto de la ciudad, por ello se lo trata emparentado a la noción de Renta Absoluta. Camagni (2005) recupera este concepto marxista y sostiene que atribuir la explicación de la localización urbana y de la renta del suelo, sólo al principio de accesibilidad y al principio de la interacción espacial que están en la base de la renta diferencia, deja fuera el dato de la aglomeración. Un principio fundamental "...que nos indica la existencia de algunas fuerzas genéticas ineludibles del fenómeno urbano que tienen como contrapartida la valorización del suelo" (2005: 188). Esta renta absoluta de aglomeración se desprende de un aumento de la "demanda de ciudad", es decir, cuando el conjunto del suelo urbano es objeto de una demanda que busca refugio o disfrute en la economía de aglomeración. Mientras que la renta absoluta de escasez se vincula con situaciones que limitan la oferta, en el corto o largo plazo, del conjunto del suelo urbano.

A partir de los antecedentes del estudio de la renta agrícola y las peculiaridades del proceso de formación de la renta en el ámbito urbano, en el apartado siguiente entenderemos mejor cuáles son las peculiaridades que distinguen al mercado de suelo urbano.

\subsubsection{Peculiaridades del mercado de suelo urbano}

Hemos visto que aunque el suelo urbano adquiere un precio y tiene un costo de producción, su precio no depende de dicho costo. En cierto sentido, el suelo urbano es irreproducible dado que la posición de cada lote en el espacio urbano es única e irrepetible. A diferencia de otros bienes cuya producción puede ser industrializada, se replican de manera homogénea y no guardan un vínculo fijo con el espacio entre su producción y consumo (es decir, no son inmuebles), el suelo urbano es un bien heterogéneo dada su singularidad de ubicación. Esto explica por qué el suelo urbano se encuentra monopolizado por su propietario. A su vez, la relativa irreproductibilidad hace que la oferta del suelo urbano sea inelástica en el corto y mediano plazo. Por estos motivos la literatura marca que en el mercado de suelo urbano existe un desencuentro estructural entre la oferta y la demanda.

Los diversos demandantes del espacio concentran sus preferencias en pocas ubicaciones pero la creación de ubicaciones similares depende de un gran esfuerzo colectivo, lento y costoso. Esto hace que la oferta del suelo resulte inelástica, es decir estructuralmente escasa. Por este motivo, la relativa irreproductibilidad del suelo urbano deriva de la dificultad de repetir 
su ubicación respecto a las actividades generales de la sociedad, más que de la dificultad de crearlo como soporte físico (Morales Schechinger, 2005).

En este sentido, como señala Trivelli (1981:13) “...no hay dos lotes iguales”, de allí la relativa insustitubilidad locacional, es decir que la demanda efectiva por un terreno no logre ser sustituida plenamente por la oferta de otro terreno. Pocos oferentes por el lado de la oferta en un mercado que opera localmente y una demanda con preferencias o requisitos disímiles, con poca concurrencia y baja complementariedad con la oferta. La rigidez del suelo urbano y la estructura del espacio construido contribuyen a su inelasticidad, que junto con las asimetrías de información características del mercado inmobiliario y la dificultad de entrada de nuevos oferentes y consumidores (dada la magnitud de los recursos en juego), convergen en un régimen de competencia imperfecto. La norma en el mercado de suelo urbano es entonces una situación de competencia monopólica, dada por el efecto de la localización.

El hecho de que el precio del suelo esté atado a la disponibilidad de pago de la demanda, así como a la posibilidad del propietario de agotar el excedente del consumidor, se explica en gran medida por esta situación monopólica. Según Smolka (1981), el precio del suelo urbano es determinado por el poder de su propietario de administrar su escasez, así como por la disposición y capacidad del demandante. Por un lado, la estructura de la oferta obedece a la capacidad de retención y el control de la relación institucional de propiedad que tiende a saturar la capacidad del consumidor. Por el otro, la estructura de la demanda del suelo se ajusta a las ventajas localizadas de uso o ganancia de las cuales pueden apropiarse los agentes. En otras palabras, la demanda deriva de la actividad que en el suelo se localice (del uso que pueda adquirir) o de su uso potencial ${ }^{29}$. Por este motivo, el propietario busca anticipar en el precio las expectativas de valorización futuras.

Consideremos, con mayor detenimiento, por qué el precio del suelo depende básicamente de su uso potencial o de la demanda derivada. En el apartado anterior, vimos que el uso potencial tiene relación directa con la "fertilidad urbana" dada por un conjunto de factores que por definición son extrínsecos a dicha parcela. Esto tiene implicancias tanto para los propietarios del suelo, los promotores o constructores como para el usuario final del espacio construido. Sin embargo, en el proceso productivo de la construcción mediado por relaciones capitalistas es donde se observa con más claridad la lógica del uso potencial.

El promotor o constructor privado, a partir de la disponibilidad de un capital, desarrolla una actividad productiva al final de la cual busca maximizar su ganancia. Este agente realiza una lectura compleja del espacio urbano combinando, por un lado, las tendencias de consumo o la formación de expectativas y, por otro, las restricciones normativas, las ventajas de aglomeración, accesibilidad, interacción de actividades, etc. En función de esta lectura, proyecta sobre un terreno específico una edificación destinada a un tipo de uso con

\footnotetext{
${ }^{29}$ Los demandantes no requieren suelo para consumirlo en sí mismo, sino por las actividades que pueden realizar en él; es decir, que estarán dispuestos a competir en función de los beneficios que represente dicha actividad. Por ello la demanda del suelo no es directa sino derivada del uso que se le pueda dar (Morales Schenchinger; 2005).
} 
determinada intensidad de aprovechamiento. A partir de entonces el promotor demanda dicho terreno. Frente a la competencia, estima cuanto puede pagar por el suelo luego de realizar el "cálculo hacia atrás" ${ }^{30}$. De allí se desprende su máxima capacidad de pago.

En este sentido, como señala Baer (2011) la demanda compite por la actividad que allí se puede desarrollar y en función de expectativa de tipo e intensidad que el suelo tolera en términos económicos y normativos. El problema de la asignación de uso en mercados altamente cambiantes donde se ponen en juego la anticipación de expectativas no es solo si finalmente se verificará una respuesta de consumo favorable a los intereses del promotor y acorde con los tiempos de rotación del capital en juego; sino, como bien apunta este autor, destacar que en ocasiones la lógica del "mayor y mejor uso potencial" puede oponerse a la optimización de uso del espacio en términos colectivos, ya que el promotor o el propietario original pueden decidir esperar a que se generen las condiciones de demanda y el terreno permanecer vacante.

En las líneas anteriores, se puso de manifiesto que tanto la oferta, el acondicionamiento (o la edificación) y el consumo final de un terreno particular, son interdependientes de lo que suceda en el conjunto de los terrenos de la ciudad. Por esta razón, lo que se oferta y demanda en el mercado de suelo no es el suelo como bien particular, sino una serie de externalidades condensadas en él. Si consideramos que el capital fijo asume una depreciación prolongada y los efectos de localización son de largo plazo, es decir, que la estructura urbana -aunque dinámica temporalmente- tiene un peso inercial que es fuertemente reproductivo. El juego de las anticipaciones se vuelve crucial, ya que a pesar de que su resultado es incierto, tendrá consecuencias de largo plazo. Por otra parte, no podemos dejar de considerar que en él participan agentes heterogéneos, cuya racionalidad no necesariamente es la maximización de los rendimientos. Por todo esto, no parece adecuado equiparar, mediante categorías presuntamente universales, la lógica de la especulación inmobiliaria (o las estrategias de desarrolladores o constructores), con los intereses de quienes persiguen mejoras en sus condiciones de habitabilidad en el espacio urbano.

Esto nos lleva a discutir la articulación de las actividades urbanas o la articulación de los sectores demandantes del espacio construido. Para el abordaje neoclásico, los principios de interacción y competencia entre los demandantes de suelo configuran un gradiente de precios que refleja la especialización de espacio construido. La tesis central que de allí se deriva es: la organización "óptima"31 del espacio construido se ajusta a la capacidad de pago de la demanda. En esta línea, la generalización de la localización eficiente a nivel urbano es aquella en la cual los terrenos mejor ubicados -en función de una serie de factores que hemos visto anteriormente- se asignan a las actividades que en dicho lugar de la ciudad generan el mayor rendimiento económico y son más sensibles a los costos de interacción espacial en relación a

\footnotetext{
${ }^{30}$ Esto equivale a realizar el cálculo residual del suelo, significa descontar al precio esperado por la venta del inmueble edificado, la tasa normal de ganancia, los costos de producción, los costos financieros y los costos de transacción.

${ }^{31}$ El criterio de lo "óptimo" se asemeja aquí a la idea de eficiencia una vez generalizados los rendimientos económicos y los costos de interacción espacial de los demandantes de suelo urbano.
} 
determinadas centralidades del espacio urbano. Según Poléses (2005), el costo de interacción espacial es una noción más compleja que el costo de transporte y busca traducir a términos económicos otras dimensiones como: las comunicaciones interpersonales, los costos de desplazamientos diarios, los costos de oportunidad de desplazamiento, los costos de transacción, entre otros.

Una proposición derivada de los supuestos que sostienen la arquitectura conceptual neoclásica permitiría afirmar que: el hecho que los pobres se ubiquen en lugares de la ciudad que son apetecidos o valorizados socialmente por sectores con mayor capacidad de pago constituye una deseconomía, debido a que se inhiben la aparición de mayores rendimientos en los sectores capitalizados de la industria de la construcción y se minimiza la generación de la renta global obtenida por los propietarios. Continuando este tipo de razonamientos, no sería óptimo que los pobres residan en localizaciones urbanas si otros sectores sociales son más sensibles a dicha localización en términos de los "costos de interacción espacial". Esto significa, por ejemplo, que estaríamos ante un escenario de "ineficiencia urbana" si otro sector está dispuesto a pagar más por dicho suelo a cambio de viajar menos o, en su versión más sofisticada, para encontrar/producir un clima de comunicación interpersonal propicio para la innovación o los generación de negocios.

Nótese el traslado de la lógica de los rendimientos diferenciales, de las producciones agrícolas a las actividades urbanas. Esta estrategia no sólo alcanza a las actividades urbanas productivas o de circulación, sino que también se extiende a las actividades reproductivas que no necesariamente persiguen la obtención de una ganancia. En este sentido, el uso residencial (que representa una cuarta quinta parte del espacio urbano) pasa a estar gobernado por una racionalidad única que pareciera tener como función garantizar o avanzar en la progresiva mercantilización del espacio urbano. Por otra parte, no podemos perder de vista que, en las ciudades latinoamericanas, la producción del espacio residencial no se resuelve en forma plenamente capitalista (esto significa mediante la intermediación de desarrolladores privados que controlan el mercado de la vivienda y persiguen la lógica del "mayor y mejor uso"). Por tanto, deberíamos repensar hasta que punto asimilar la lógica de los rendimientos diferenciales, como criterio de regulación de las políticas públicas urbanas.

Asumir esta línea teórica, equivale a enajenar al espacio residencial de todo significado que lo vincule con la reproducción de la vida o la satisfacción de necesidades. Las preferencias de localización no son producto de una relación unívoca y excluyente, dicho en otras palabras, patrimonio exclusivo de la capacidad de pago. Por el contrario, adquieren múltiples variaciones e implican al mismo tiempo la distribución de oportunidades sociales que trascienden la miopía de la utilidad económica marginal. El reverso de este pensamiento es claro, la “...operatoria del mercado de suelo genera efectos regresivos sobre la distribución de la riqueza a través de la valorización del suelo y sus formas de apropiación y también como consecuencia de la segregación socioeconómica residencial" (Trivelli: 1981: 15). 
Frente a la mirada ortodoxa ${ }^{32}$ de la articulación de las actividades urbanas en el espacio construido, surge una lectura alternativa, basada en la convención de la coordinación espacial. Abramo (2006) sustituye la objetividad de la teoría de las probabilidades y el naturalismo de la teoría de la renta por el juego cognitivo subjetivo para dar cuenta de un ambiente de anticipaciones ${ }^{33}$, en el cual emergen creencias acerca de la configuración futura de externalidades de vecindad. Estas creencias, al ser compartidas por el conjunto de los participantes del mercado, operan como un factor de coordinación espacial. Para esta lectura heterodoxa del mercado de localización, el orden residencial es obtenido por convención. La dinámica de la innovación urbana y de la destrucción creativa introducida por los emprendedores shumpeterianos genera cambios en ciclos de vida o en el perfil de las localizaciones. Se difunde, entonces, un proceso permanente de homogeneización y diferenciación del espacio residencial. Desde esta mirada, desaparece cualquier pretensión de equilibrio óptimo, eficiencia o equidad. Abramo (2006: 187-188) concluye: “...la configuración residencial que emerge del mercado capitalista de la localización es una configuración caleidoscópica. El umbral que en ella separa el orden del desorden urbano es tan exiguo que la política urbana (regulación y procedimientos institucionales) se evidencian como uno de los únicos medios que permiten devolver la visibilidad al futuro de la estructura residencial y reducir el furor de la espectacularidad urbana mercantil".

Desde un abordaje diferente, Jaramillo (2009) también recupera el carácter convencional que asume la imbricación de las actividades en el espacio construido, sin descartar las determinantes funcionales. Encuentra en la semiología del espacio una forma más apropiada de leer las prácticas espaciales y la interacción social. Para él este enfoque recupera el componente convencional sin excluir los determinantes técnicos de la conducta sobre el espacio. Al mismo tiempo, la perspectiva de este autor, subraya el casuismo desestructurado, articula el carácter colectivo de los esquemas de asignación de usos con las prácticas individuales e introduce la dimensión de las representaciones en la imbricación de los usos del espacio construido.

Desde esta mirada, el lenguaje (ciudad) es utilizado por muchos individuos que tienen algunas características similares y otras diferentes, y que realizan prácticas que también tienen similitudes y diferencias. Dichas prácticas de uso del lenguaje (o la ciudad) implican un proceso de interacción que es, por definición, social e independiente de cada individuo. El espacio

\footnotetext{
32 Algunas de las limitaciones del enfoque neoclásico, observadas por Jaramillo (2009, a partir de la revisión de Abramo, 1997) son: aborda la asignación de usos del espacio construido como derivadas de decisiones individuales separadas e independientes de los agentes en el marco urbano; privilegia en estas elecciones o "preferencias" la dimensión técnica de los proceso de interacción espacial; supone una comportamiento paramétrico de los agentes individuales cuyas acciones responden a una racionalidad general; parte del supuesto de igualdad entre los agentes, información perfecta, conocimiento pleno de futuro, etc.; llega a conclusiones discutibles: los usos del suelo y los precios tenderían a un orden y equilibrio que tienen la virtualidad de ser estables y eficientes; y, a partir de allí, desprende conclusiones normativas como: la operación espontánea del mercado es lo más conveniente en términos sociales y técnicos, este mecanismo asegura equidad y eficiencia a nivel generalizado.

${ }^{33}$ Como afirma Abramo (2006:184) “...la elección residencial se apoya en una representación que transforma el espacio en un mosaico de externalidades de vecindad que sólo será revelado después de que los actores del mercado hayan tomado su decisión. Es esta característica auto-referencial del mercado de la localización la que intensifica su aspecto de especularidad. Ya que todos procuran anticipar las elecciones ajenas, cada uno se pregunta sobre lo que los otros piensa que él piensa".
} 
construido es el significante y las actividades urbanas son el significado. La ligazón entre dichos términos es puramente convencional.

El lenguaje es una actividad entre sus participantes $y$, a la vez, un conjunto de reglas externas a cada uno de sus usuarios. La legua se presenta como el repertorio de signos y leyes de asociación entre ellos, mientras que el habla es la forma de articular o combinar palabras siguiendo reglas que permitan expresar algo. Los procesos de cambio dependen del juego de lengua y habla, en él un articulador puede intentar modificar dos aspectos: el texto o el código. Si el cambio no es compartido por el resto de los participantes el mensaje no será entendido y la lengua no se modificará. Si la novedad no es tan brusca y es entendida se transformará en lenguaje. A partir de pensar la convención urbana como analogía del lenguaje, Jaramillo (2009) complejiza la lectura de la articulación de las actividades urbanas y los cambios que en ella acontecen.

Desterrada cualquier pretensión de equilibrio, eficiencia o equidad por la vía del mercado de suelo urbano como mecanismo de asignación de bienes y servicios urbanos, nos encontramos frente a un orden urbano regulado por convención y sujeto a un nuevo arreglo distribucional, donde el poder público no es un simple mediador del interés privado sino que se erige como productor primario de la ciudad. En este contexto, la política urbana esta llamada a cumplir un papel fundamental en distribución del espacio urbano, como un producto colectivo que modela la condiciones de vida de vastos sectores de la población.

\subsubsection{Vivienda y economía urbana, más allá de la segregación}

En la década pasada cobraron amplia difusión el uso de los términos "fragmentación" y "segregación socioespacial”34, en gran medida asociados al proceso de fuerte polarización social resultante de la nuevas mediaciones entre economía y sociedad en el marco del proyecto neoliberal. La conclusión inevitablemente de la reestructuración económica global en la década de los noventa, fue la de un aumento de la segregación urbana, aunque dichas conclusiones no necesariamente tuvieran un correlato empírico en la medición de la evolución de la segregación (en términos de la concentración espacial y la homogeneidad social de las áreas de residencia) ${ }^{35}$, hasta llegar a mostrar en algunos casos una tendencia contraria.

Por otra parte, suelen realizarse distinciones acerca del fenómeno de la segregación en función de cómo se manifieste la valorización subjetiva de las "dimensiones objetivas" o si existe restricción en términos de interacción social de los distintos sectores sociales. Suele considerase que la segregación residencial es "excluyente" cuando se niega el espacio público

\footnotetext{
${ }^{34}$ Mientras el primer término resalta la pérdida de la unidad urbana, donde el vínculo entre las partes se disuelve o pierde la referencia común en relación a un todo. El segundo término prestan atención al distanciamiento o separación de los grupos de población en el espacio urbano.

${ }^{35}$ Las consideraciones acerca de las formas de medición de la segregación residencial son variadas puede (ver al respecto Sabatini, Cáceres y Cerda, 2001)
} 
como interfase de encuentro de grupos diferentes. Se identifica, además, entre los procesos de segregación voluntaria y los procesos de segregación involuntaria. En determinados estudios, se considera que no toda diferencia en el espacio produce situaciones segregativas, ya que sólo en presencia de acción coercitiva o de intencionalidad de discriminación éstas tendrían lugar.

Por ejemplo, Marcuse (2004) utiliza el concepto de segregación para denotar el proceso por el cual un grupo de población es forzado involuntariamente a aglomerarse en un área espacial definida. Este autor sostiene que la política pública debe atender la segregación involuntaria o indeseable cuando opera de modo jerárquico o excluyente. Desde esta visión, la diferenciación por criterios de tipo socioeconómico o producto de la operación del mercado es una división tan sólo funcional. Preteceille (2004), en cambio, diferencia la tradición norteamericana -donde el enfoque de la segregación residencial tiene un origen étnico-racial asociado al guetto- de la tradición francesa -para la cual la matriz de diferenciación residencial es socioeconómica, mediada por las relaciones de clase y la mercantilización del espacio urbano-.

En este punto es importante resaltar, como señala Sousa (2008), que la segregación no es exclusivamente el reflejo de la desigualdad de renta ni de las redes de interacción sociales, sino que también es producto de la estructura urbana de la ciudad. Rodríguez (2001) también reconoce el vínculo entre el análisis de segregación y las distintas calidades del espacio urbano (de localización, dotación de infraestructura y servicios), así como sus respectivos vínculos con las preferencias residenciales de quienes poseen más prestigio y poder. De cualquier modo, en un contexto más general, asocia al concepto de segregación a la existencia de diferencias o desigualdades dentro de un colectivo y a la separación de los sujetos en categorías que tienen cierto grado de distinción jerárquica o valorativa.

Del mismo modo, Grafmayer (1994; citado por Carpón y González, 2006), es uno de los autores que, además de considerar la segregación como distribución residencial desigual de la población en el espacio y la espacialización del distanciamiento social entre grupos en términos de conflictos sociales, agrega a su abordaje el acceso desigual a los servicios y equipamiento urbanos. En un registro semejante, para Cravino (2007), la segregación puede ser abordada como descripción: asociada a la distribución desigual de estratos o grupos sociales en el espacio; entendida como distanciamiento simbólico microsocial, en términos de los procesos de interacción social en un espacio acotado; y vista como proceso, en tanto que factor explicativo de las condiciones de acceso a la ciudad.

En muchos de los trabajos agrupados debajo de la temática de la segregación es frecuente identificar algunos descuidos como, por ejemplo, el tratamiento de modo descriptivo y estático, la despreocupación de las causas del proceso, abordajes que recurren de modo implícito un concepto homogéneo del espacio, equiparar proximidad a interacción social u homogeneidad a aislamiento, desestimar la interpretación de los efectos de escala, asimilar el concepto de espacio urbano a un simple reflejo de la estructura social, restringir la lectura de lo urbano al espacio residencial, desestimar el debate de la renta del suelo, etc. Entre los aciertos, menos 
frecuentes, debemos destacar los estudios que procuran un abordaje histórico y multiescalar, la consideración de la percepción del espacio, el vínculo entre el espacio y las marcas de diferenciación o distanciamiento simbólico, la atención a las relaciones de vecindario, las dinámicas de la socialización barrial, el reconocimiento de efecto del espacio como disposición social, el esfuerzo por interpretar la relación entre transformaciones sociales y estructura urbana, entre otros aportes.

En este marco, nos interesa recuperar los puntos de contacto entre algunos elementos de la segregación residencial y el problema del acceso a la ciudad, utilizando para ello la mediación del mercado de suelo urbano visto desde el contexto de la ciudad latinoamericana (caracterizada por heterogeneidades importantes en la calidad del espacio público urbano, temas vistos en los apartados anteriores de esta sección). Queremos destacar cómo -más allá del análisis de las formas residenciales de urbanizaciones cerradas que han protagonizado los esfuerzos de muchas de las investigaciones- el mercado de suelo urbano es el elemento central que nos devuelve una escala total del proceso de diferenciación residencial en nuestras ciudades. Éste no sólo es un medio a través del cual se manifiestan formas de prestigio o estrategias de innovación inmobiliaria que apuestan a prácticas de aislamiento o diferenciación, sino que también se transforma en una variable explicativa de las restricciones en las condiciones de acceso a nuestras ciudades. Dado que el acceso desigual a los servicios y equipamiento urbanos continúa siendo una constante, la calidad del espacio urbano, así como sus posibilidades de uso y apropiación, merece ser leída en función de la estructura socioespacial de la ciudad.

Esto significa que priorizaremos una mirada de la economía urbana a partir de la cual las condiciones actuales de funcionamiento del mercado de suelo continúa siendo, para la mayoría de los hogares, la principal barrera en acceso a las condiciones generales de calidad urbana. Al mismo tiempo, rechazamos la hipótesis neoclásica, según la cual la segregación residencial es simplemente un reflejo de las desigualdades sociales, donde los mercados de suelo cumplen una función "neutra" en tanto "optimizan" la localización en función de la capacidad de la demanda. Por el contrario, sostenemos que asimilar la institución del mercado de localización como criterio de asignación de recursos y servicios urbanos conduce a una distribución socioeconómica regresiva de las condiciones generales de calidad urbana, siendo esta una dimensión particularmente estratégica en el diseño y la implementación de la política habitacional.

En este sentido, son varios los estudios que sostienen que la localización de la vivienda es una variable crítica al momento de evaluar la calidad de los programas habitacionales (Rodríguez y Sugranyes, 2005; Hidalgo Dattwyler, 2007; Bois Morales, 2008; Rolnik et al, 2009). Por ello, para recuperar la dimensión espacial en el análisis de la política habitacional, es clave entender el lugar donde se sitúan las operatorias habitacionales en la estructura urbana, así como la relación entre el perfil socio-económico de las distintas áreas y la distribución de las condiciones de calidad urbana en el conjunto de la ciudad. 
Diversos autores han tratado la relación entre estructura urbana y renta del suelo considerando como operan los procesos de distribución/apropiación a nivel macro y micro. La Escuela de Sociología Urbana Francesa ha aportado la noción de "valor de uso complejo"(Topalov, 1979) como constitutiva del fenómeno urbano, en tanto articulación en el espacio de valores de uso elementales caracterizados por ser bienes colectivos, no mercantiles y con períodos largos de rotación de capital. La ciudad como producto colectivo concentra las condiciones generales de la producción capitalista, generando "efectos útiles de aglomeración" que determinados sectores de la sociedad internalizan, sin controlarlos individualmente ni participar en su producción. Por otra parte, los "efectos exteriores urbanos" (Harvey, 1973) son subproductos, intencionados o no, de las actividades de agentes públicos o privados, donde los beneficios y costos que constituyen el sistema urbano son distribuidos en la ciudad mediante mecanismos ocultos en la dimensión espacial.

Al recuperar estos puntos de vista como aspectos constitutivos de la división social del espacio, encontramos un recurso para complejizar la lectura de la segregación residencial en la relación entre la apropiación diferencial de la renta del suelo y la distribución de externalidades urbana que se ponen en juego en el mercado inmobiliario. En esta línea, Ribero (2002) plantea que la segregación residencial y las desigualdades en las condiciones de vida entre los territorios resultan de la acción de los grupos sociales interesados en la apropiación de la "renta real", entendida como el acceso desigual al consumo de los bienes y servicios colectivos y las ganancias generadas por la valorización inmobiliaria. De este proceso deriva una determinada estructura socio-espacial, entendida en términos de Lago (2002) como el patrón de distribución de la población según su perfil socio-económico en las diferentes áreas que conforman el espacio metropolitano, integrándose el grado concentración de los diferentes grupos sociales y el grado de homogeneidad social de las áreas.

Desde esta orientación, la división social del espacio residencial refiere, según Duhau y Giglia (2008), a las formas espaciales que adopta la distribución residencial intraurbana o intrametropolitana de los distintos estratos socio-económicos que conforman la población de la aglomeración. A su vez, la estructura socio-espacial refiere a las formas espaciales discernibles que adopta la división social del espacio residencial, en tanto expresión espacial de las diferencias socio-económicas, que responde a procesos que de modo sistemático tienden a reproducir una cierta división social o, eventualmente, a transformarla.

Por otro lado, hemos visto que el orden urbano basado en la "coordinación" del mercado produce una segmentación del espacio urbano en base al nivel de ingreso y una fricción social diferencial a la movilidad residencial en el mercado de localizaciones intra-urbanas. A su vez, la gestión urbana implica un proceso constante de distribución y generación de rentas, dada la movilización de recursos producidos colectivamente. Por lo tanto, la acción pública participa legitimando el orden urbano existente, al tiempo que encierra en sí misma un margen de transformación. 
En este sentido, es interesante recuperar la idea de justicia espacial como una categoría con cierta autonomía de la idea de justicia social, en tanto el espacio tiene implicaciones distributivas que van más allá de las relaciones que se estructuran en el mercado de trabajo y requieren ser consideradas en el análisis de las políticas territoriales. Soja (2010), nos recuerda que la (in)justicia espacial refiere a la distribución justa y equitativa en el espacio de los recursos valorados socialmente y las oportunidades para utilizarlos. Es más, ésta debe ser entendida no sólo como resultado, sino también como proceso. En sintonía con esta idea, Santos (2007) sostiene que es necesaria una geografización de la ciudadanía, ya que el valor del individuo depende en gran medida del lugar donde vive.

En la metrópolis actual, la división social del espacio residencial resultará, en palabras de Duhau y Giglia (2008:155), "de las formas pasadas o actuales de producción del espacio residencial que determinan, a través del funcionamiento del mercado inmobiliario, el tipo de vivienda y las áreas en las que la misma estará localizada, de acuerdo con el nivel socioeconómico de los hogares". Frente a esta afirmación, cabe preguntarse: si el lugar de la vivienda social en la división del espacio residencial está determinado por la capacidad de pago de la demanda ¿qué resultados han de esperarse en términos de su localización en la estructura urbana? Además, al intentar alguna respuesta a esta pregunta debemos tener en cuenta que, por un lado, en diversas situaciones la acción pública produce transformaciones en la ciudad que alteran el comportamiento de los precios del suelo. Cuando el Estado demanda suelo, provee equipamientos o infraestructura y define la normativa urbanística, modifica el espacio urbano y, por ende, modifica con él la configuración de los precios del suelo. Por otro lado, en el mercado de localizaciones intra-urbanas, los precios experimentan normalmente cambios constantes en su magnitud ${ }^{36}$, que suelen ser aprovechados por los actores que desarrollan prácticas especulativas. En múltiples ocasiones, las políticas habitacionales han encontrado obstáculos derivados del funcionamiento de los mercados de suelo.

En este sentido, la relación entre mercado de suelo y política habitacional plantea una serie de paradojas producto de la disociación entre la política de vivienda y la gestión del suelo. Por un lado, la política de vivienda genera una demanda agregada, que dada su escala, aumenta las expectativas $y$, al estar sujeta a las estrategias de retención de los propietarios, dificulta el proceso de adquisición de suelo. Por otro lado, es la misma acción pública la que valoriza el suelo al dotar de equipamientos colectivos, servicios públicos y normativa urbana a las distintas áreas de expansión o crecimiento de las ciudades. Sin embargo, a pesar de generar esa valorización con su accionar, el propio Estado tiene dificultad para poder adquirir

\footnotetext{
${ }^{36}$ Jaramillo reconoce tres tipos de cambio distintos en la magnitud de los precios del suelo. Los movimientos estructurales se deben a un cambio tecnológico global, al crecimiento demográfico o al crecimiento económico. Los cambios de magnitud de los precios derivados de estos movimientos son de largo plazo, generalmente tienen tendencias ascendentes y se encuentran asociados al comportamiento global de la economía y de la estructura urbana. Los movimientos coyunturales obedecen a fenómenos transitorios de fluctuación de los precios. Se relacionan con aceleraciones y desaceleraciones en la demanda del mercado de la tierra, generalmente causados por cambios en las finanzas y movimientos de la actividad constructora. Los movimientos estructurales-particulares suelen ser cambios buscos y se encuentran asociados a la transformación de la estructura urbana producto de los cambios de uso del suelo y los potenciales de constructividad. Tienen una localización puntual y se producen constantemente en las ciudades en crecimiento (Jaramillo, 2003).
} 
posteriormente suelo equipado, o deberá desembolsar una masa mayor de dinero para pagar la valorización que generó ${ }^{37}$.

Llegada esta instancia y vistos los rasgos que asume el mercado de suelo urbano, surgen nuevos interrogantes: ¿cómo se comporta dicho mercado cuando la demanda deriva de la vivienda social?, ¿qué exigencias tiene la adquisición estatal de suelo para vivienda social?, ¿habrá complementariedad entre la demanda efectiva y la oferta de suelo?, ¿cómo es evaluada la heterogeneidad estructural de la oferta que caracteriza a este mercado desde la política pública?, ¿acaso la oferta frente a este tipo de uso determinado se volverá homogénea?, ¿qué implicancias tiene frente al monopolio de la oferta de suelo el hecho que la demanda de suelo para vivienda social también esté monopolizada (es decir, que no exista competencia entre los demandantes para este uso)?, ¿el precio del suelo será menor?, ¿cómo opera a lógica de uso potencial futuro?, ¿el constructor presionará para aumentar la intensidad de uso del suelo?, ¿el acceso a las condiciones generales de calidad urbana dependerá de la capacidad de pago del Estado o se tendrá en cuenta la necesidades de las reproducción de hogares demandantes de vivienda social?.

En el espacio urbano, el sistema de precio del suelo guía la asignación de las localizaciones posibles entre los distintos agentes económicos demandantes de suelo en el mercado inmobiliario. En dicho sistema se expresa, en principio, la valorización social que, en mayor o menor medida, también remiten a ciertas condiciones objetivas de la localización. Cuál es el posicionamiento de una política habitacional frente al sistema de precios del suelo urbano, es una incógnita.

Más allá del problema de la adquisición de suelo para la vivienda social, repasemos brevemente la teoría de la localización residencial para ver cómo el tema de las decisiones residenciales ha sido abordado. Esta teoría encuentra entre sus principales referentes a Wingo (1961), Alonso (1964), Muth $(1969)^{38}$, quienes plantearon una relación estrecha entre las elecciones residenciales de la población y el principio de la accesibilidad, basado en la incidencia del transporte. El modelo de Wingo se orientó a la relación entre transporte y uso del suelo urbano. Los costos generalizados de viaje ${ }^{39}$ (de los desplazamientos diarios residenciatrabajo) determinan las rentas, las densidades y los niveles de utilización del suelo del espacio urbano. Dichos costos emergen como la variable explicativa de la organización interna del espacio urbano.

El modelo de Alonso, conocido como bid rent model, agrega la incidencia de las preferencias de los agentes. Esto significa que los criterios de maximización de la renta y minimización de

\footnotetext{
${ }^{37}$ Aunque en experiencias concretas pueden observarse experiencias innovadoras que se desarrollan en un sentido contrario.

${ }^{38}$ Retomamos aquí a Rodríguez (2000), Polése (2005), Camagni (2005), Ramirez Franco (2008).

${ }^{39}$ Consideran la fricción social del tiempo de desplazamiento, esto es no sólo consideran el tiempo y el costo monetario del viaje, sino además se discrimina el valor asignado por los diferentes grupos sociales al tiempo. Además del costo subjetivo que las personas le asignan al viaje, incide la edad del usuario, la cantidad de miembros del hogar que se desplazan, la relación entre el costo de transporte y el ingreso familiar, el costo de oportunidad del tiempo de desplazamiento, etc.
} 
los costos difieren entre los consumidores de suelo, siendo el equilibrio y la estructura de precio de suelo el resultado de las pendientes de preferencias de los grupos demandantes (expresada en la función de renta ofertada). La pregunta de la decisión residencial clásica es: ¿cuántos metros cuadrados de suelo está dispuesta a sacrificar la demanda ${ }^{40}$ por reducir el costo de viaje a su lugar de trabajo? De allí, surge el trade-off (representado como una curva de indiferencia a igual nivel de utilidad o satisfacción) entre el gasto por metro cuadrado de suelo urbano y el costo generalizado de viaje.

Finalmente, como señala Ramirez Franco (2008), el modelo de Muth agrega una distinción posterior entre suelo urbano y espacio residencial, ya que incorpora un análisis el mercado de vivienda (funciones de producción y precio de la vivienda). Los resultados son semejantes. Dadas las condiciones de equilibrio de la localización, es esperable que si el cambio marginal en los costes de transporte es positivo, los precios de vivienda decrezcan con la distancia y aumente que el consumo en vivienda.

Los precios del mercado de suelo urbano son la objetivación de las preferencias, tamizadas por la disponibilidad de pagar, es decir, el valor que los hogares le asigna a cada "lugar" de la ciudad en el proceso de elección residencial. Como sostiene Polése (2005), al elegir un terreno para instalarse, lo que está "comprando" una familia es una localización, y el precio que paga corresponde en principio a las ventajas que entiende le procurará dicha localización. Si bien, los modelos neoclásicos antes mencionados tienen múltiples limitaciones -las cuales han sido marcadas en el apartado anterior ${ }^{41}$ y niegan un conjunto de relaciones complejas que se ponen en juego en las estrategias residenciales de los habitantes de la ciudad- es cierto, que han realizado un esfuerzo para incorporar las preferencias ${ }^{42}$ al espacio residencial para explicar por qué hogares con la misma capacidad de pago pueden hallarse en distintos lugares de la ciudad.

Una reflexión sobre el diseño de la política habitacional que tenga en cuenta el mercado de suelo no puede tomar por dada la capacidad de pago de la demanda. Más bien, debería ser requisito para dicha reflexión pensar las condiciones necesarias para alterar la capacidad y/o la forma de estructurar la demanda de suelo para la vivienda social. No obstante, es sugestivo incorporar una lectura "redefinida" de las preferencias de localización y discutir la articulación de las políticas de vivienda con las políticas de transporte, como lo sugiere la agenda neoclásica.

Por otra parte, es necesario reconocer que el espacio urbano no es homogéneo, y que su heterogeneidad no deriva sólo de la singularidad de la ubicación, sino también de la elevada segmentación de la calidad del espacio público urbano. Una política de hábitat entendida en

\footnotetext{
${ }^{40}$ Las condiciones de la demanda pueden variar según la sensibilidad a los desplazamientos diarios del hogar y la valoración del tamaño de la vivienda, dada principalmente por el tamaño de la familia (posición en el ciclo de vida) y el ingreso familiar.

${ }^{41}$ Vale recordar el uso de un concepto euclidiano del espacio, donde la variabilidad está dada principalmente por la distancia y los costes de desplazamiento.

${ }^{42}$ Preferencias que desde este enfoque adquieren interés sólo cuando son expresadas en términos de la disponibilidad de pago.
} 
sentido amplio requiere asegurar una relativa homogeneidad de las condiciones urbanas y reconocer la capacidad de producirlas. Las condiciones de bienestar (e, incluso, de ingresos directos e indirectos) no pueden ser variables externas al "modelo" de localización de la vivienda social, sino que deben ser internalizadas.

En resumen, debemos tener presente que la vivienda, en su carácter de inmueble, se encuentra fija al soporte suelo y, por ende, una parte de sus atributos son dependientes de las características del espacio construido y de la posición relativa en la matriz de distribución de externalidades urbanas. En este sentido, la relación entre vivienda y economía urbana es clave y contradictoria. Por un lado, la dinámica de la renta del suelo impone una serie de limitaciones a la adquisición pública de suelo para la vivienda social, en particular cuando los mercados de suelo no están regulados. Por otro lado, el lugar en la ciudad representa una suerte de ingreso indirecto no remunerado. Es decir, la política habitacional distribuye una "renta real" a cada una de las unidades domésticas que son objeto de la acción pública, la cual depende básicamente de la localización. Ello no sólo denota una condición asociada a la jerarquía urbana, sino que también determina un horizonte de posibilidad en el uso de la ciudad. 


\subsection{La reconstrucción del lugar a partir de los sujetos de la política}

En la sección anterior se problematizó la relación entre espacio urbano y política habitacional a partir de la idea del lugar asignado a la vivienda social en la jerarquía de dicho espacio, operación que fue mediada por la categoría del mercado de localizaciones residenciales intraurbanas. En esta sección en cambio, se busca introducir una segunda mediación en la lectura del espacio urbano y la política habitacional, básicamente nos preguntamos: ¿Cómo este lugar "asignado", es reconstruido a través de las propias trayectorias residenciales de los habitantes y desde una mirada barrial situada a partir de la mudanza a la vivienda social?

Esta pregunta incorpora un doble registro: el lugar reconstruido desde la perspectiva de los habitantes y una lectura de la política mediada por la movilidad residencial a partir de la cual los moradores viven nuevas experiencias urbanas. Es decir, el interrogante se plantea en la intersección entre el habitar y el residir. Siguiendo a Duhau y Giglia, habitar "es el proceso mediante el cual el sujeto se sitúa en el centro de unas coordenadas espacio-temporales, mediante su percepción y su relación con el entorno que lo rodea [...] Si el habitar define un conjunto amplio de fenómenos vinculados a la experiencia de la metrópoli, y a la relación con los espacios en cuanto lugares, es decir, geográficamente delimitados, materialmente reconocibles y provistos de significados compartidos, el residir alude a la vinculación con un espacio donde se desempeñan las funciones propias de la reproducción social" (Duhau y Giglia, 2008: 24).

La dimensión del lugar reconstruido apela al espacio vivido de las prácticas y representaciones que emergen en la experiencia de habitar la ciudad. Es el espacio cotidiano, usado, apropiado y percibido por las geografías personales a partir de las cuales se crean determinados mapas mentales e imaginarios. Como sostiene Lindón (2007) los lugares son construidos socialmente por el intercambio simbólico y recíproco entre la gente con los lugares, pero también, por la convergencia entre la subjetividad y la inter-subjetividad con la materialidad de los lugares o las características del entorno. Para el constructivismo geográfico el sujeto construye los lugares cotidianamente y, a la vez, éstos reconfiguran las identidades de los sujetos que los habitan. Las acciones del sujeto se configuran dentro de una lógica compartida y también reconstruida constantemente. Estos lugares así construidos modelan esas tramas de sentido y las acciones que en ellos se concretan (Lindón, 2007).

Por otra parte, la trayectoria habitacional se inscribe dentro de los procesos de movilidad residencial asociados a la permanencia y los cambios de residencia, siendo sus componentes la duración, la situación de tenencia, la localización, el tipo de vivienda y la autonomía residencial (ver Gilbert, 2001; Delaunay y Dureau, 2004). La trayectoria permite reconstruir por intermedio de los relatos, los modos de vida y las opciones habitacionales subjetivas que se presentan a través del tiempo mediadas por restricciones estructurales. Siguiendo a Di Virgilio 
(2007) la trayectoria y la estrategia se definen en la intersección entre las necesidades y expectativas habitacionales de los hogares y los factores institucionales y estructurales. Mientras que la trayectoria atiende la preocupación por la búsqueda de las determinaciones, la estrategia refleja la capacidad de los sujetos por influir en el recorrido de su vida.

A partir de aquí, el análisis busca reconstruir el lugar desde la perspectiva del espacio vivido, el modo en que determinadas geografías personales son atravesadas por itinerarios urbanos pasados y las prácticas actuales de uso de la ciudad, para desde allí registrar la percepción del espacio urbano a partir de una mirada situada en los barrios de vivienda social. Se considera que el lugar de los sectores populares en la ciudad mediado por la vivienda social ${ }^{43}$, no puede ser totalmente comprendido sin contemplar la mirada de los actores, sus lógicas de representación y de construcción del hábitat (innumerables autores han realizado aportes en esta línea a los estudios urbanos: Lomtinz, 1975; Lefebvre, 1978; Canclin, 1997; Grafmeyer y Danseau, 1998; Signiorelli, 1999; Bourdieu, 1999, 2001; Lindón, 2007; Cravino, 2007; Carman, 2006; Girola, 2007; Santos, 2007).

A continuación desarrollamos una serie de apartado que nos permitirán nutrirnos de los elementos teórico-metodológicos que habiliten nuestra entrada al campo en los capítulos subsiguientes.

\subsubsection{Movilidad residencial y vivienda social}

Pensar la relación entre movilidad residencial intra-urbana y vivienda social, implica reconocer en gran medida en este tipo residencial un "punto de llegada" de los sujetos de la política pública, más que un "punto partida" o tránsito en el proceso de movilidad residencial. Por otro lado, da cuenta de la relación entre un proceso de movilidad social más amplio y la composición interna de la estructura del espacio urbano, mediado por la acción de la política pública.

Siguiendo a Sautu, los procesos de movilidad social se inscriben en los cambios de diversos aspectos de la estructura social y las relaciones que le dan vida. Este tipo de cambio tiene origen en la transformación económica y social que da origen a la movilidad estructural inter e intra-generacional, es decir, no se tratan de procesos de cambio radical de las bases sociales y económicas de la propia estructura. Un análisis desde esta perspectiva requiere articular "los cambios macroestructurales que explican la dimensión y las características del proceso de

\footnotetext{
${ }^{43}$ En este trabajo se utiliza la denominación de sectores populares para ubicar una región del espacio relacional. Si bien, resulta imposible establecer límites se puede reconocer un punto del espacio social, donde convergen ciertas condiciones de existencia e identidades (imprecisas, heterogéneas y cambiantes). Al menos este punto tienden a distanciarse del mojón de convergencia de los sectores medios (a pesar de que ciertos atributos puedan yuxtaponerse) y se encuentra opuesto a las posibilidades materiales de consumo, la referencia identitaria y los iconos de las elites. Aún cuando "lo popular" puede asociarse con determinados niveles de ingresos o defina cierta región de sociabilidad o mundo simbólico. Nuestro énfasis está puesto en la dimensión de hábitat y en determinadas formas de resolución de acceso al espacio urbano, que en la tradición de estudio de la ciudad latinoamericana se dio en llamar "hábitat popular" para designar el fenómeno de: conventillo, inquilinatos, hoteles pensión, villas miserias, viviendas de interés social, loteos populares, asentamientos informales, etc. Del mismo, modo la categoría de "vivienda social" supone cierta codificación burocrática, pero a pesar de ello creemos sirve como puerta de entrada para observar la experiencia urbana de determinados grupos sociales.
} 
movilidad en su conjunto y sus impactos en el nivel de las personas y las familias, y grupos específicos. Sin duda, este análisis será necesario ubicarlo en el contexto de las transformaciones que tienen lugar en la economía y sus interconexiones con otros procesos sociales a los cuales afecta y por los que a su vez es afectado" (Sautu, 2011: 105).

En nuestro caso, dicho contexto refiere a la relación entre política habitacional, mercado de trabajo y mercado de suelo y vivienda. Cómo señala Di Virgilio (2007), un análisis de las trayectorias residenciales y las estrategias habitacionales se inscribe dentro de los estudios de la estratificación social y supone poder explicar: "las diferencias y las similitudes que se observan entre grupos sociales que ocupan posiciones diferenciales en la producción y en el consumo pero habitan en localizaciones próximas en la ciudad, y entre grupos sociales que ocupan posiciones similares en la producción y en el consumo, pero que residen en distintas áreas y/o localizaciones en la ciudad" (Di Virgilio, 2007: 39).

La localización no es un dato menor en la movilidad residencial. Investigaciones recientes revalorizan el papel de localización en las estrategias habitacionales. El rol de la misma no puede ceñirse a un simple dato o atributos de la vivienda. No alcanza con considerar las características físicas de la vivienda, las formas de tenencia o la proximidad de las redes sociales. El significado de la ubicación de la vivienda en la ciudad articula los recursos barriales, la historia de la familia y el proceso mismo de producción de la ciudad. Delaunay y Dureau (2004) entienden que los componentes de la movilidad residencial intra-urbana son: la localización, la duración, el tipo de vivienda, la forma de tenencia, la autonomía residencial y la estrategia de mudanza.

No dejamos de reconocer la importancia de estos seis componentes y la presencia transversal de la vivienda social en todos ellos (a los que haremos referencia de modo indirecto en el capítulo 4), son embargo, nuestro interés en el análisis de las trayectorias residenciales de los adjudicatarios de vivienda social se centrará en la cuestión de la localización.

\subsubsection{La construcción del espacio social, de la vivienda a la ciudad}

En oposición a la mecánica lineal que propone que el espacio es simplemente un reflejo de la estructura social o al paradigma racionalista que asimilaba implícitamente el supuesto que un orden físico acarrea o traer aparejado determinado orden social, en las ciencias sociales ha cobrado relevancia teórico-metodológica la perspectiva que recupera la construcción social del espacio.

Como sostiene Bourdieu (1999), al abordar fenómenos urbanos debemos recordar que el espacio social se traduce de manera "turbia" en el espacio físico. Para este autor, el hábitat contribuye a formar habitus y éste construye hábitat a través los usos sociales que induce a darle. Los procesos de apropiación del espacio urbano suponen modos individuales o colectivos donde las ganancias de espacio pueden asumir formas de ganancias de 
localización, posición u ocupación. En este sentido, las formas de habitar de los sectores populares tienen lógicas específicas no siempre reconocidas por políticas habitacionales.

En el primer apartado de este capítulo, hemos dicho que la vivienda es una configuración compleja de servicios habitacionales y que la misma cumple un papel fundamental en la satisfacción de necesidades humanas. A pesar de ello, en la práctica cotidiana el techo es incorporado y naturalizado por los actores, como una disposición del habitar no siempre problematizada. $Y$ esto se da aún en condiciones de relativa precariedad habitacional. Sin embargo, en torno a la vivienda se articulan un conjunto de relaciones sociales históricamente determinadas.

Para la industria de la construcción, la casa es un producto intercambiable en el mercado como cualquier otra mercancía, mientras que para la agenda pública la vivienda aparece como una demanda problematizada de modo variable por la tensión existente entre renta-capital-trabajo. Sin embargo, para las unidades domésticas el techo es un bien cargado de significaciones donde se entrecruzan afectos, proyectos familiares e inversiones no sólo monetarias, sino también de trabajo y tiempo. Aquí, se pone de manifiesto que el acceso al suelo y a la vivienda no es una decisión dependiente de un individuo aislado. Por el contrario, se trata de un problema colectivo en el proceso más amplio de producción de la ciudad y la reproducción social de condiciones de existencia. La vivienda es probablemente el "objeto" urbano en el cual esta tensión se evidencia más claramente.

Las decisiones habitacionales tales como compartir el techo o el lote con un familiar, alquilar una pieza, ocupar la tierra, autoconstruir la casa, registrar la demanda de una vivienda social, alquilar o comprar un inmueble residencial. Así también como realizar cualquiera de estas acciones en tal o cual barrio de la ciudad, se encuentran determinadas, por un lado, por el horizonte de posibilidades prácticas de los habitantes y, por otro, por la "política de vivienda" entendida en un sentido amplio. Según Bourdieu (2001), mientras que las primeras, dependen de las preferencias de los agentes y los recursos que éstos pueden movilizar o poner a su servicio, la segunda dimensión, fuertemente asociada al estado de la oferta es el resultado de un conjunto de condiciones económicas y sociales. Ejemplos de esto pueden ser la regulación en materia urbano-habitacional, los mecanismos crediticios, los subsidios a la oferta o demanda de vivienda, los incentivos a la industria de la construcción, la construcción directa de viviendas por parte del Estado, la regulación de los alquileres, entre otras.

El pasaje de la dimensión individual a la dimensión social de la vivienda se termina de evidenciar al considerar la inserción de la vivienda en el espacio urbano. La metáfora "puertas adentro" o "puertas afuera" permite recrear este punto. Por un lado, un ámbito doméstico fuertemente asociado al espacio íntimo, privado, el de la vida en familia y al proyecto de formar un hogar. Por otro lado, un ámbito colectivo vinculado al barrio, a la coexistencia con otros en un lugar compartido, al encuentro con los vecinos y los desconocidos, o también, a proyectos organizados entorno a demandas localizadas. 
Del mismo modo que la unidad "vivienda" permite trazar un límite que juega un papel fundamental en las representaciones sociales del hábitat y la ciudad, en relación al barrio, se configura otro límite imaginario clave para entender la estructura de sentido de estas representaciones. El lugar es fuente de identidad y en la frontera difusa entre vivienda, barrio y ciudad se construyen no sólo edificios, sino también nuevos sentidos de pertenencia. Las percepciones de los habitantes se configuran así en un contexto siempre "en obra" y, a su vez, dependen de la posición socio-económica de éstos, las trayectorias habitacionales previas, la "calidad" de la política habitacional y las miradas de los otros: los no destinatarios de la vivienda social. Todo ello se entrecruza desde la perspectiva de los actores en sus representaciones.

Las lecturas del espacio urbano desde las esferas de lo privado y lo público, atravesadas por la dimensión material y simbólica, generan un esquema de análisis desde el cual interpretar las percepciones. La casa tiene un vínculo simbólico indisociable con el hogar y la constitución de un proyecto familiar de largo plazo. El acceso a la vivienda no sólo implica la satisfacción parcial o total de una necesidad material. Alcanzar la condición de propietario puede interpretarse (Cravino, 2007) como posibilidad de transmitir un legado familiar, dejarle algo a los hijos -una herencia- $y$, al mismo tiempo, es un objeto de consumo que expresa los éxitos económicos o estatus en la estructura social.

En el producto-vivienda “...el componente simbólico cumple un papel especialmente fuerte. En cuanto bien material que se expone a la percepción de todos (como la ropa) y de manera duradera, esta propiedad expresa o delata, más decisivamente que otras, el ser social de su propietario, sus "medios", como suele decirse, pero también sus gustos, el sistema de clasificación que pone en juego en sus actos de apropiación y que, al objetivarse en bienes visibles, da pábulo a la apropiación simbólica efectuada por los otros, que son así capaces de situarlo en el espacio social al situarlo en el espacio de los gustos. Es además motivo de inversiones a la vez económicas y afectivas particularmente importantes: bien de consumo que, debido a su elevado costo, suscita una de la decisiones económicas más difíciles y llenas de consecuencias de todo un ciclo de vida doméstica, también es una "colocación", es decir, un ahorro financiero de un patrimonio del que se espera que perdure al menos tanto como su propietario e incluso que le sobreviva, en calidad de herencia transmisible" (Bourdieu, 2001: 35).

Vale introducir ahora la dimensión del espacio público. La vivienda, como espacio residencial doméstico, se define también en función del "espacio jurídicamente público" (Duhau y Giglia, 2008) que actúa como un elemento organizador de la ciudad y de la experiencia urbana. Según estos autores, en el último tiempo este espacio ha perdido protagonismo como tejido conectivo y omnipresente de la ciudad. Sin embargo, en términos de la producción de la ciudad como "valor de uso complejo" (Topalov, 1979) el papel del espacio público sigue siendo clave. Aún cuando los criterios de gestión pública en el montaje de los sistemas de ingeniería urbana de capital fijo desvalorizado asuman rasgos neo-empresariales o se legitimen formas de 
reproducción diferenciada del espacio urbano, el rol que juega el Estado continúa siendo central.

Al reorganizar el sistema de transporte, construir espacios verdes, proveer equipamientos colectivos o redes de infraestructura el Estado incide de modo directo en la dinámica urbana, genera ganancias extraordinarias localizadas que son apropiadas por los propietarios del suelo y oportunidades diferenciales de reproducción social para los residentes, de uno u otro lugar, de la ciudad. La vivienda en su calidad de inmueble se encuentra vinculada al suelo, una parte importante de sus atributos dependen de las características del espacio construido y la distribución de efectos de centralidad urbana. Hemos visto que dada la inercia del capital fijo y la topología de las actividades urbanas, las características de ubicación o posición relativa tienen duración de largo plazo y transformarlas requiere de un gran esfuerzo colectivo. En este punto, Vio (2008) introduce una pregunta que la hacemos nuestra: ¿Cómo los programas habitacionales inciden en el proceso de distribución/localización de la población en el territorio metropolitano y cómo incide esto en las condiciones de vida de los hogares?

Rosenbaum et al (2002), por ejemplo, aplica la noción de la "geografía de oportunidades" al análisis de la política habitacional. Esta mirada sostiene que determinadas condiciones de residencia pueden contribuir a reforzar situaciones de aislamiento social o pérdida de bienestar por medio de los problemas de accesibilidad, conectividad y desacople trabajo-residencia. La revisión de Suárez et al (2009) realizan de la literatura de la geografía de oportunidad (de Galser y Killen, 1995) los efectos de vecindario (de Wilson, 1996) y la estructura de oportunidades (de Moser 1998), dan cuenta de que la concentración espacial de la pobreza puede erosionar los activos de los hogares en tanto las redes sociales restringen la capitalización de recursos. La hipótesis implícita es que el aislamiento de circuitos sociales y económicos que representan a la sociedad más amplia, suponen una dinámica cultural endógena y de socialización restringida asociada a la probabilidad con otros semejantes. Pese a lo interesante del vínculo entre lugar y oportunidades aquí propuesto, este enfoque pierde de vista el análisis de las condiciones estructurales que producen tales efectos y plantea un punto de fuga hacia adelante.

En contraposición, el análisis de Santos (2007) en El Espacio del Ciudadano, nos resulta más adecuado para identificar los condicionamientos que determinan los "efectos de lugar" ${ }^{\text {"44 }}$. En este libro, se retoma la relación entre clase, renta y lugar para cuestionar las visiones neutras del espacio y sostiene que es imposible hablar de ciudadanía en sentido abstracto sin reconocer su componente territorial. Así: "Cada hombre vale por el lugar donde está: y su valor como productor, consumidor y ciudadano depende de su localización en el territorio. Su valor va cambiando, incesantemente, para mejor o para peor, en función de las diferentes accesibilidades (tiempo, frecuencia, precio), independientes de su propia condición. Personas con las mismas virtudes, la misma formación, incluso el mismo salario tienen valor diferente según el lugar en el que viven: las oportunidades no son las mismas. Por eso, las posibilidades

\footnotetext{
${ }^{44}$ Noción que luego recuperamos a partir del enfoque estructural-constructivista de Bourdieu (1999).
} 
de ser más, o menos, ciudadano depende, en gran medida, del punto del territorio donde se está. Mientras que un lugar ha de ser condición de su pobreza, otro lugar podría, en el mismo momento histórico, facilitar el acceso a aquellos bienes y servicios que les son teóricamente debidos, pero que, de hecho, le faltan" (Santos, 2007: 107; la traducción es nuestra).

En suma, las distintas nociones aquí presentadas permiten observar que los servicios habitacionales que brinda la vivienda "puertas afuera" determinan en parte las condiciones de reproducción social, dependiendo éstas de su ubicación en -lo que en el apartado anterior denominamos- el mercado de localizaciones residenciales intra-urbanas. Al mismo tiempo, antecedentes recientes sobre la lectura de la política habitacional y su dimensión espacial (Rodríguez y Sugranyes, 2005; Hidalgo Dattwyler, 2007; Girola, 2007; Bois Morales, 2008; Rolnik, Klintowitz, Reis y Bischof, 2009) destacan desde distintas ópticas, cómo se configuran entorno a los barrios de vivienda social determinados efectos, tanto simbólicos como materiales, que inciden notablemente en la calidad del hábitat y en la condiciones de vida de los habitantes.

\subsubsection{Apuntes metodológicos: trayectorias y espacio residencial}

El estudio de las trayectorias puede ser abordado desde distintas perspectivas de análisis. Las orientaciones interpretativas y etnográficas se distinguen de otras estrategias cuantitativas, como por ejemplo el estudio de los cursos de vida. En las investigaciones cualitativas sobre los relatos de vida, priman según Bertaux y Thompson (1997: citado por Sautu, 2004) dos orientaciones, una focalizada en los significados subjetivos que una persona en particular asigna a su pasado y presente y, otra, orientación que busca recoger información fáctica e interpretativa en la cual varios entrevistados actúan como informantes acerca de los contextos que modelan sus vidas y las reacciones frente a los sucesos, sentimientos, acciones, etc.

Las estrategias metodológicas de trabajo con trayectorias suponen arreglos particulares al objeto de estudio. A partir de un estudio comparado de las trayectorias ocupacionales y sociales de trabajadores en empleos precarios (trabajadores de la construcción y empleadas domésticas), Casassus (1998) recuerda la importancia del análisis conjunto de la movilidad geográfica, ocupacional y familiar. La autora sostiene que las trayectorias laborales se definen primero por las formas de inserción en un espacio urbano construido socialmente. Por ejemplo, el domicilio funciona como carta de presentación social y, a su vez, impone exigencias diferentes a hombres y mujeres.

En el contexto latinoamericano de los asentamientos auto-construidos, Gilbert (2001) pone en tensión la relación propiedad y movilidad residencial. Este geógrafo inglés muestra que en determinadas situaciones la informalidad urbana produce inmovilidad residencial, esto se da en un contexto urbano con una tendencia creciente hacia la movilidad. Más allá de las críticas a ciertos supuestos del autor, lo sugerente del trabajo es que el análisis de las trayectorias 
residenciales altera la lectura del sentido de la propiedad y de los propios barrios autoconstruidos.

En el libro "Los con techo" (Rodriguez y Sugranyes, 2005), se sostiene que los problemas de la vivienda no acaban con alcanzar el sueño de la casa propia y que la perspectiva de la movilidad residencial no ha sido analizada con detenimiento por la política de vivienda. Cuando se hace abstracción de la trayectoria recorrida por las familias al momento de producir las viviendas o problematizar las formas de producción del hábitat, la vivienda pierde toda propiedad histórica y simbólica.

En estos ejemplos pueden observarse algunos matices, el análisis de la trayectoria informa en un caso sobre el valor del domicilio y el emergente de normas o valores entorno al uso del espacio a partir de una mirada de género; en otro caso, se pone de relieve los sentidos construidos entornos a la vivienda y el barrio y, mediante una lectura de la propiedad situada en la trayectoria, se interpela un orden urbano más amplio. En el último ejemplo, se utiliza la trayectoria residencial como una categoría que reconstruye la unidad del sujeto y su hábitat evidenciando las limitaciones en la concepción de una política habitacional basada en metas cuantitativas de construcción.

La noción de trayectoria residencial permite, entonces, reconstruir por intermedio de los relatos subjetivos los modos de vida y las opciones habitacionales que se presentan a través del tiempo mediadas por restricciones estructurales, como el mercado inmobiliario, el mercado de trabajo y, en sentido amplio, la política habitacional. Sin embargo, frente a estas condiciones estructurales las familias despliegan un repertorio de respuestas, donde el margen de acción varía según la posición en la estructura social. En este sentido, las estrategias habitacionales son un conjunto de prácticas y decisiones de las unidades domésticas, que suponen capacidad de agencia en la estructura de opciones restringida por las condiciones materiales de vida.

En este sentido, las trayectorias y estrategias residenciales son dos categorías entrecruzas. Según Di Virgilio (2007), la trayectoria y la estrategia se define en la intersección entre las necesidades y expectativas habitacionales de los hogares y los factores institucionales y estructurales. La exploración que realiza esta autora (por los trabajos de Grafmeyer, 1998; Charbonneau, 1998; Núñez, 2000; Bourdieu, 2000) muestra que el término trayectoria surge de un encadenamiento no casual entre una serie de posiciones residenciales sucesivas, ella supone un orden inteligible. Mientras que la trayectoria sugiere la preocupación por la búsqueda de las determinaciones, la estrategia refleja la capacidad de los sujetos por influir en el recorrido de su vida. Es decir, estos conceptos se definen en el cruce entre la lógica de los actores y los determinantes estructurales. La trayectoria o itinerario hace referencia a las relaciones existentes entre la movilidad residencial y la movilidad social en la medida en que permiten analizar la relación entre la estructura social y el proceso de apropiación del espacio. La localización en la ciudad y los efectos de proximidad pueden facilitar u obstaculizar la acumulación de las diferentes formas de capital -en sentido bourdiano-, dependiendo esto de 
las características del entorno y de las características económicas y sociales de sus habitantes (Di Virgilio, 2007).

El concepto de estrategia habitacional deriva de las estrategias familiares de vida. En este plano, Cravino (2007) sostiene que es necesario considerar y discutir ciertas cuestiones. En primer lugar, los niveles de conciencia de la acción, las representaciones de los sujetos, la reconstrucción lógica "ex post" que realiza el investigador, como así también, la construcción de las necesidades sociales, los aspectos dinámicos de las unidades domésticas, las formas de organización y división del trabajo, el atravesamiento de la noción de clase, y por último, la influencia de los mercados de trabajo y de las políticas de Estado. Por otra parte, junto a estas advertencias metodológicas la autora resalta la envergadura de las estrategias habitacionales de los sectores populares en la historia familiar dado que la vivienda es la mayor inversión que realizan las unidades domésticas. El acceso a la vivienda y la mudanza definen gran parte de la identidad familiar, el dónde y cómo habitar es una decisión pensada con detenimiento, aunque cruzada muchas veces por la necesidad de tomar medidas urgentes ante situaciones que exigen resolverse rápidamente.

De manera complementaria, la localización no es un dato irrelevante en la movilidad residencial. Está lejos de ser sólo un dato físico y supone lugares construidos por las historias particulares, la dinámica del crecimiento urbano y la historia colectiva de la ciudad. Una de las dimensiones del concepto de lugar trabajado por Agnew (citado por Oslender 2002), habilita a interpretar el lugar como una posición residencial definida de modo relacional en un sistema clasificado socialmente y dinámico en el tiempo. En este sentido, el modelo conceptual del espacio residencial de Levy (1998) permite interpretar las relaciones entre la movilidad residencial y el proceso de apropiación del espacio urbano a partir del análisis de las trayectorias. Los conceptos básicos de esta propuesta son los tipos residenciales, el espacio residencial y las posiciones residenciales.

Siguiendo a este autor, los tipos residenciales son elementos que componen el contexto del hábitat. Éstos son definidos por los lazos entre las características del parque inmobiliario y las características socioeconómicas y sociodemográficas del individuo o el hogar. Mientras que las primeras características permiten localizar el tipo residencial en un espacio geográfico concreto, las segundas sitúan la posición social del tipo residencial en un contexto del hábitat localizado geográficamente. El espacio residencial es, por otro lado, el contexto del hábitat, y se inscribe en un espacio urbano concreto. El espacio residencial está constituido por los arreglos de los tipos residenciales en el espacio geográfico y en el espacio social, es decir, por la distribución de los hogares en el parque habitacional y sus características socioeconómicas y sociodemográficas. Finalmente, la posición residencial corresponde a la posición del grupo o el individuo en el espacio residencial, y está asociada por su pertenencia a un tipo residencial determinado. Esta última noción es la que interroga sobre las interacciones entre los circuitos residenciales de los hogares y los contextos sociales en los cuales están realizados (Levy, 1998). 
Al considerar la temporalidad y poner en movimiento este esquema, es posible visualizar cambios en las posiciones de los hogares, así como ver secuencias que se ajustan al ciclo de vida o a cambios en la jerarquía de tipos residenciales. Los recorridos forman itinerarios en el espacio residencial que pueden ser ascendentes, neutros o descendentes, que pueden estar sujetos a una movilidad activa del hogar o no. Es decir, también es posible que el hogar permanezca inmóvil (conserve su dirección postal) pero que su posición relacional se modifique. Esto puede ser el resultado de una nueva configuración o arreglos entre tipos residenciales, pero también puede responder a cambios en la composición del vecindario, al lanzamiento de una nueva operatoria inmobiliaria o a distintas decisiones de política pública que provocan cambios en la estructura del espacio residencial.

Por último, cada arreglo social tiene su correspondencia en la matriz de la renta urbana y, a su vez, los efectos de la renta del suelo inciden en la estructuración del espacio residencial. Este no es un dato menor, ya que como hemos visto en las ciudades latinoamericanas, la precariedad de las condiciones de calidad urbana y las asimetrías en la distribución de ciertas externalidades tiene una alta correspondencia con el perfil socioeconómico de la población. En este marco, la irrupción de la acción pública por medio de los programas habitacionales puede generar nuevas mediaciones en el acceso al espacio urbano que merecen ser consideradas.

El estudio de las trayectorias residenciales de los hogares "receptores" de vivienda social es una ventana que permite un acercamiento a nuevas dinámica del hábitat popular y, a su vez, propone una mirada trasversal a la acción pública. La mudanza a un barrio de vivienda social es un punto de inflexión en los itinerarios de los hogares y, por tanto, es un acontecimiento que activa sentidos del habitar registrados en los relatos de vida. Sin perder de vista las relaciones que regulan la estructura urbana, este enfoque recupera necesidades, representaciones y disposiciones que estos actores ponen en juego en torno al espacio urbano. Dimensiones que suelen estar ausentes en el diseño de las política habitacionales.

\subsubsection{Los efectos de lugar: sujeto, hábitat y capital locacional}

Hemos visto que el análisis de las trayectorias es un recurso metodológico basado en la formalización analítica de la experiencia, objetivaciones de las historias de vida o recorridos subjetivos, permitiendo comprender determinadas formas de acción en función de los condicionamientos que las anteceden. En el plano habitacional, las "elecciones" residenciales son el resultado de las transacciones entre los ajustes que operan a diversas escalas en el espacio urbano. En este sentido, un análisis de las trayectorias de los sujetos de la política habitacional permite integrar, desde la perspectiva de los habitantes, las articulaciones entre el mercado de tierra y vivienda, la dinámica del hábitat popular y la misma acción pública, sin perder de vista cómo los habitantes participan del armado de los itinerarios y de los sentidos o representaciones que en el proceso se generan. 
Para Levy los habitantes participan en la construcción del hábitat a través de su posición geográfica, así como por su posición social evaluada. Esto tiene lugar tanto a partir de la autopercepción, como por un definición objetiva, es decir, por la posición de los otros habitante en dicho contexto. Para este autor, el hábitat es un elemento físico localizado en un espacio geográfico concreto, que participa en la construcción de este espacio de contexto ejerciendo un mayor o menor nivel de constricción. De cualquier modo, en la medida en que no se concibe sin ocupación, el hábitat está sometido a una práctica social, ya que las prácticas de los grupos o individuos participan de la evolución del contexto. Es decir, el contexto habitacional está físicamente construido por los tipos de viviendas o de inmuebles que caracterizan morfológicamente el espacio en el cual está localizado, pero también está socialmente construido por la distribución de los arreglos entre las viviendas y por un orden en términos de estatus social (Levy, 1998).

El cruce de la trayectoria con el "efecto del lugar" (Bourdieu, 1999) cobra fuerza cuando éste es valorado en el sentido durkheniano, es decir, si se reconoce su valor explicativo. En esta línea, Remy nos recuerda que el lugar es una entidad productiva con propiedades emergentes, donde los juegos, interacciones y actividades definen una composición que influye a las unidades que lo componen. El lugar y la red son utilizados como recursos en las trayectorias o recorridos personales. Un barrio puede definirse como un lugar o sitio de convergencia no intencional entre una pluralidad de trayectorias, erigidas sobre la solidaridad de efectos que son constitutivos del ambiente del barrio e influyen sobre la atracción selectiva que el barrio ejerce funcionando como una suerte de economía o deseconomía externa (Remy, 1998).

En un trabajo reciente, Duhau y Giglia (2008) sostiene la siguiente hipótesis: existe un grado significativo de correspondencia entre cada una de las formas de producción del espacio urbano, su forma de organización y las prácticas de apropiación y el uso que se da a dicho espacio urbano. Esto sería así tanto en la experiencia local (ámbito donde la densidad de las redes de relaciones es mayor e implica un lazo de pertenencia fuerte) como en la metropolitana (dimensión en la cual el espacio es usado e imaginado según las estrategias de movilidad y cuya geografía responde a la lógica de relación con la metrópoli). Esto supone que la experiencia urbana es distinta según el tipo de hábitat urbano en el que se reside y a partir del cual se establecen relaciones con el resto del territorio metropolitano.

Un segunda consecuencia de la afirmación hecha, por estos autores, es que la experiencia urbana no cambia sólo a partir de las diferencias culturales, sociales o étnicas entre los sujetos, sino también a partir de su ubicación socio-espacial. Por último, se puede sostener que la posición residencial puede ser considerada efecto y resultado de la posición social y cultural de los sujetos en la metrópoli (Duhau y Giglia, 2008).

Por esta razón, los hogares valoran de modo diferente uno u otro lugar al momento de realizar "elecciones" residenciales. Abramo (2006) identifica tres factores que inciden en la decisión residencial: la preferencia por accesibilidad, la preferencia por vecindario y la preferencia por "estilo de vida". Cada una de estas preferencias da cuenta de una lectura del lugar. Si la 
primera da cuenta de posición relacional de un determinado lugar en la economía urbana, la segunda se preocupa por el papel de las redes sociales territorializadas, mientras que la tercera rescata el conjunto de sentidos condensados entorno a la relación entre cultura y lugar que se encuentran en juego en las distintas partes de la ciudad.

En las estrategias familiares de vida se pone en juego un capital locacional que se apreciadevalúa a lo largo del tiempo, según la localización relativa en la permanente reconfiguración del mapa de externalidades urbanas y la cualificación intrabarrial a largo plazo. Al momento de tomar decisiones, las familias realizan cálculos intertemporales que acompañan la posición relativa de su capital (inmueble-residencia) en la jerarquía intraurbana, evaluando beneficios o pérdidas de su movilidad residencial (eventual desplazamiento territorial de la unidad residencial familiar) en la estructura intraurbana. Por ejemplo, un desplazamiento hacia la periferia se traduce en ganancias monetarias a partir de una mayor superficie residencial, pero también tiene un impacto negativo en los costos de transporte y en el potencial desarraigo social. Así, los movimientos en el mapa de accesibilidad se relacionan con el consumo de espacio, los tiempos de desplazamiento, las externalidades del vecindario, la historia de consolidación barrial, entre otros factores (Abramo, 2006).

Esta especie de capital -entendido como un conjunto de interacciones entre posiciones urbanas interdependientes y en movimiento producto de la dinámica colectiva de crecimiento urbano, la transformación de los mapas de accesibilidad y el juego de los imaginarios sociales que valora de modo desigual una u otra región del espacio urbano- se pone en juego en los intercambios del mercado de localizaciones intra-urbanas. El mercado del cual aquí se habla es un espacio relacional que funciona con arreglos no sólo de accesibilidad, renta o estatus, sino que también es un recurso más amplio que brinda oportunidades económicas, sociales y culturales, según a las estrategias de reproducción social de la unidades domésticas. Las familias conocen cómo funciona el campo de los efectos exteriores urbanos y, por ello, al momento de tomar las decisiones residenciales es sufrido y/o puesto en consideración. Dimensiones como la pertenencia al lugar, la historia de los procesos de consolidación barrial, los vínculos de relación primaria (redes familiares y lazos de amistad), las economías de don y contra don, la posición en la accesibilidad urbana, la relación con el lugar de trabajo y las oportunidades de ingreso son de una u otra forma puestas en juego.

Queda claro, entonces, que la unicidad derivada de posición espacial acarrea costos económicos, atributos de estatus y oportunidades desiguales de reproducción social. En relación al efecto de lugar, Bourdieu (1999: 120) afirma "el espacio social reificado (vale decir, físicamente realizado u objetivado) se presenta, en consecuencia, como la distribución en el espacio físico de diferentes especies de bienes y servicios y también de agentes individuales y grupos localizados físicamente (en tanto cuerpos vinculados a un lugar permanente) y provistos de oportunidades más o menos importantes de apropiación de esos bienes y servicios (en función de su capital y también de la distancia física con respecto a esos bienes, que depende 
igualmente de aquel). En la relación entre la distribución de los agentes y la distribución de los bienes en espacio se define el valor de las diferentes regiones del espacio social reificado".

En resumen, hemos intentado poner en evidencia que la política habitacional y la modalidad de gestión de suelo, no sólo acarrean consecuencias en términos de la distribución de rentas del suelo entre los agentes urbanos, sino que también pueden erosionar fuentes de ingresos públicos y dejar al descubierto la concepción urbana implícita en la política de vivienda. Además, el suelo y su localización en la estructura urbana se vinculan de modo directo con las condiciones de vida de los destinatarios de la vivienda social. Esto significa que la mudanza al barrio tiene, en la trayectoria residencial de los habitantes, efectos sobre su capital locacional y sobre las geografías de oportunidad.

Al mismo tiempo, hemos intentado introducir la dimensión del habitar, recuperando la idea del espacio vivido en el cual se usa, se practican y se perciben la ciudad. El dislocamiento obliga a los habitantes a elaborar nuevos mapas mentales, redescubrir la ciudad, redefinir redes de vecindad. Por este motivo, a sabiendas de que los barrios de vivienda social que estudiaremos merecerían un plazo de tiempo mayor para lograr una lectura acabada de los "efectos de lugar", consideramos que el cambio de residencia (la mudanza) es una instancia fértil para analizar las transformaciones en la experiencia urbana y ver cómo los habitantes reconstruyen esos lugares, entre la memoria y el descubrimiento de la casa, el barrio, el entorno y la ciudad. En el nuevo barrio, las experiencias vividas quedaron atrás y la nueva residencia obliga a nuevas experiencias urbanas en las que, en palabras de Santos (2000) entran en tensión el tiempo de la acción y el tiempo de la memoria. 
Capítulo 2 


\section{Capitulo 2. Estado y política habitacional}

\section{Antecedentes y características de la política federal de viviendas}

Más allá de que en las páginas anteriores no nos hemos centrado en papel que juega el Estado en el proceso de urbanización, a nuestro juicio éste es un actor central de dicho proceso. No sólo se desempeña como un demandante y un constructor más del espacio urbano, sino que también es el actor que regula lo que allí acontece y a partir de cuyas decisiones de gestión urbana se determina la asignación de recursos y beneficios localizados. Asimismo, es el productor del espacio urbano por excelencia, en tanto administrador y proveedor de los valores de uso que hacen posible la existencia misma de la ciudad.

En este punto, la relación entre el Estado y el espacio urbano delimita lo que podríamos denominar en sentido amplio la política habitacional (concebida como la definición y producción de un conjunto de condiciones económicas y sociales que estructuran el hábitat). Con éste término nos referimos a actividades que incluyen la provisión de equipamiento público, la regulación urbanística, la orientación de sistemas de crédito, la regulación de la industria de la construcción y los mercados de suelo. También puede incluirse dentro de este término a los programas habitacionales o la acción directa en la construcción de vivienda. Este último tipo de acciones es el más comúnmente asociado al término política habitacional, aunque sería más adecuado hablar de política de vivienda. En este sentido, la política de vivienda parece no haber podido internalizar las cuestiones referidas al problema del suelo o la localización y la incorporación de la dimensión urbana. Probablemente estas tensiones se pongan en evidencia a lo largo del capítulo para recuperarlas en los capítulos posteriores.

Hechos estos comentarios, en este segundo capítulo nos proponemos rastrear una serie de antecedentes históricos que nos permitan tener una lectura más amplia del contexto en el que emerge la "política federal de viviendas", de modo de no restringir la mirada al escenario post crisis 2001. De hecho, el registro histórico hecha luz o pone en relación una serie de cambios y continuidades. De allí que la política actual adquiera una lógica con rasgos específicos, que dan cuenta de características persistentes en materia habitacional. .

Por otro lado, en la segunda sección se realizan una serie de consideraciones respecto de la reaparición, en el año 2003, de la cuestión de la vivienda en la agenda pública. Se identifican las principales características que asume la "política federal de vivienda", sus etapas, programas y objetivos. También se considera aspectos referidos a la distribución jurisdiccional del financiamiento, para destacar el protagonismo que adquiere el PFCV (Programa Federal de Construcción de Viviendas) en el Conurbano Bonaerense, dónde detendremos nuestra atención.

Finalmente, y antes de las conclusiones de cierre del capítulo, realizamos un análisis de los emergentes en el contexto de implementación de dicho programa mediante la identificación de 
núcleos problemáticos en las entrevistas hechas a funcionarios de los tres niveles de gobierno. Esto nos permite analizar cómo opera el entramado de actores, sus relaciones e intereses, en el desarrollo de la política de vivienda. 


\subsection{Antecedentes de la política habitacional}

En esta primera sección nos proponemos reconstruir, aunque más no sea de modo sintético, algunos de los principales recorridos de la política habitacional argentina en su historia. Esto nos será de utilidad para encuadrar el surgimiento de "la política federal de vivienda" en un contexto de referencia más amplio e identificar ciertos cambios y continuidades en los distintos períodos de la política habitacional. El recorrido aquí planteado también, nos introduce de modo indirecto a la forma que adquirió la problematización y la resolución de la cuestión habitacional al interior del aparato estatal. Dicho de otro modo, en el marco de una trayectoria errática y contradictoria que da cuenta de una trama de intereses y actores reunidos en torno de la cuestión, y que con el correr del tiempo terminó cristalizándose en un sistema centralizado de vivienda a nivel nacional. Sistema que tiempo más tarde sería objeto de sucesivas reformas, vaivenes y nuevas contradicciones.

El trabajo realizado en los primeros apartados surge principalmente del análisis de fuentes secundarias, de la literatura especializada y de investigaciones precedentes (las obras de Yuvnosky, 1984 y Ballent, 2005, entre otros, constituyen una referencia inevitable). En el tercer y cuarto apartado recurrimos al análisis de otras fuentes documentales (por ejemplo, la normativa y los documentos oficiales) y a entrevistas exploratorias, realizadas a efectos de reconstruir ciertos antecedentes.

Esta sección tiene por punto de partida el mojón del problema habitacional a principios de siglo $X X$, cuando las condiciones de vida en los inquilinatos de inmigrantes fueron severamente cuestionadas. Dichos cuestionamientos dieron lugar a la creación de la Comisión Nacional de Casas Baratas. Posteriormente se da cuenta de los rasgos que asume la política de vivienda en el período peronista, momento en el cual se instituye el "derecho a la vivienda" y la respuesta estatal adquiere masividad por primera vez. Después, se recupera el sinuoso camino recorrido desde la interrupción del orden democrático, en el medio del cual se creó la Secretaría de Vivienda en la década del sesenta. Hacia la década del setenta, esta secretaría dará lugar al surgimiento de un sistema centralizado de vivienda, organizado en torno al Fondo Nacional de Vivienda (FONAVI). Finalmente, se analizan los rumbos que adquiridos por la política habitacional en el contexto neoliberal de los años noventa y las condiciones particulares del proceso de descentralización de dicha política en la provincia de Buenos Aires.

\subsubsection{El pasaje de las casas baratas a las viviendas masivas}

Hasta principios de siglo XX, el problema de la habitación obrera se había ceñido al ámbito del conventillo o el inquilinato. El crecimiento demográfico, de la mano de las inmigraciones, se enfrentaron a un parque habitacional que no alcanzaba a dar una respuesta satisfactoria al 
incremento de demanda. Si bien el conventillo no era la única tipología de vivienda popular, los debates de la época se focalizaron en él.

Por entonces, la concepción urbanística liberal dominaba la escena. El Estado no ejercía ningún tipo de intervención en relación a la vivienda, delegando en el mercado la resolución del problema habitacional y asumiendo la provisión de infraestructuras de modo directo.

Progresivamente, el paradigma higienista (hegemónico en la época) fue dando lugar a un conjunto de políticas públicas vinculadas a la fijación de criterios constructivos, regulaciones tipológicas y cantidad de inquilinos por habitación. Dicho de otro modo, se apuntaba a vigilar condiciones higiénicas. Sin embargo, como señala Ana Cravino (2008), este enfoque reformista fue desplazando su preocupación desde las cuestiones sanitarias a las morales, con los consecuentes requerimientos de disciplinamiento y control social relacionados al supuesto de que los cambios en el ambiente físico incidirían en la conducta social (pueden retomarse aquí el surgimiento del problema urbano y del urbanismo como política social, visto en el apartado 1.1.1).

La Huelga de Inquilinos de 1907, organizada por anarquistas y socialistas frente al aumento de alquileres en Buenos Aires, puso en evidencia las condiciones de vida de los sectores populares, la relación de subordinación de los inquilinos a los propietarios y la incidencia del alquiler en el ingreso de los obreros. Hay coincidencia en las fuentes citadas por Cravino (Gibral de Blacha, 2000; Gutiérrez y Gutman, 1988; Yujnovsky, 1974) al momento de identificar las principales causas de este proceso: la tendencia alcista de la tierra urbana, producto de la habilitación de la construcción en altura en algunos barrios por parte del Código de Edificación; $y$, el aumento de los impuestos por parte del Estado con el fin de afrontar los costos de la infraestructura.

Años más tarde se sancionaría la Ley 9.677 (1915), que daría origen a la Comisión Nacional de Casas Baratas (CNCB). Pese a que la demanda de los inquilinos fue fuertemente reprimida y desactivada, es difícil desvincular el surgimiento de esta iniciativa de la presión social y los debates de la época ${ }^{45}$. Más allá del origen de la iniciativa ${ }^{46}$, la misma refleja la necesidad de una participación más activa del Estado frente al problema de la vivienda. La Comisión, cuya creación fue propuesta por el diputado Juan Cafferata, se nutriría de un fondo generado a partir de la asignación para tal fin de un porcentaje de lo recaudado en las carreras de caballos. A su vez, tendría las atribuciones de dirección, fomento y control de la construcción de casas higiénicas y baratas destinadas a trabajadores de escasos ingresos.

De esta forma, a partir de las discusiones de 1912 en el Congreso Nacional y del surgimiento de la CNCB se produce un desplazamiento de la iniciativa para la construcción de casas para

\footnotetext{
${ }^{45}$ Los debates entre militantes, católicos y socialistas, dan cuenta de las discusiones de ese momento. Los ejes giraron en torno a: vivienda individual o vivienda colectiva, los requerimientos de ingeniería sanitaria, tipologías arquitectónicas más o menos adecuadas para combatir la insalubridad habitacional, el resguardo de la intimidad y la privacidad de la familia, la discusiones en relación a la forma de tenencia de la vivienda en alquiler o en propiedad, la construcción pública no estatal por parte de cooperativas, la programación y ejecución descentralizada de los planes de financiamiento estatal, los congelamientos de alquileres, entre otros (Linenur, 2001; Ballent, 2005).

${ }^{46}$ Véase el contrapunto entre Rigotti (1991) y Yujnovsky (1974) en Nuñez (2010).
} 
las clases obreras, donde las actividades realizadas por las sociedades de beneficencia perderían peso y en relación al posicionamiento del Estado. Sin embargo, el objetivo nunca fue atender el conjunto de la necesidad habitacional. Por el contrario, se buscaba ejercer una acción "ejemplificadora" sobre los sectores populares.

El propósito de la Comisión era difundir, a través de la construcción de "casas experimentales", nuevos criterios habitacionales (ventilación, asolamiento, división de funciones, entre otras) y aplicar exenciones impositivas a los desarrollos que cumplieran con los nuevos estándares. De allí el limitado alcance de la acción desde el punto de vista cuantitativo ${ }^{47}$.

A mediados del siglo XX se produce en la Argentina un importante giro en el tratamiento dado por el Estado a la cuestión de la vivienda; el tiempo de "los hechos" había llegado. Según Ballent (2005), en el período peronista se configuraron un conjunto de acciones sistemáticas y sostenidas en el tiempo, tendientes a abordar la cuestión de la vivienda a gran escala. El problema entonces planteado era que la respuesta al problema de la vivienda por parte de la acción pública adquiriera masividad. Por ello, el Estado inicia planes de vivienda masivos, para lo cual emprende acciones directas e indirectas. Recuperando ideas previamente expuestas en el debate público sobre el tema, se produce un punto de quiebre en términos cuantitativos respecto de las acciones implementadas para paliar el déficit habitacional. En el período anterior la discusión del sector se hizo pública y muchas de las ideas fueron reabsorbidas, no sin contradicciones ${ }^{48}$. Como sostiene Liernur $(1984)^{49}$, el debate previo constituyó una de las condiciones de posibilidad de las políticas peronistas.

En 1943, la CNCB fue absorbida por la Secretaría de Trabajo y Previsión Social, dando origen a la Dirección de Vivienda, que más tarde se transformaría en el Consejo de la Vivienda y, en 1945, en la Administración Nacional de Vivienda. Finalmente, en 1947, este organismo pasaría a depender del Banco Hipotecario Nacional (BHN), el cual primero complementaría sus acciones con otros organismos del estado, pero que luego disputaría mayor espacio en este tipo de políticas. No interesa aquí detenerse en las particularidades de estos cambios, pero sí

\footnotetext{
${ }^{47}$ La memoria 1918-1919 de la CNCB (citada por Ana Cravino, 2008), resalta su visión: “...la Comisión no pretende proveer a la población de la cantidad de habitaciones higiénicas y baratas que se necesitarían para eliminar los peligros que para la moral y la salud pública representan las malas condiciones en que vive la población menos acomodada. Su plan de trabajos, pues, en materia de construcciones, tiende a crear una cantidad de casas baratas suficiente para demostrar la bondad del sistema y capaz de ejercer cierta influencia, por lo menos en las zonas donde se levanten los barrios típicos".

${ }^{48}$ Pueden observarse distintas tensiones entre sectores de interés, instituciones Estatales, modelos de ciudad, etc. En el trabajo de Aboy (2003) pueden identificarse algunas de estas contradicciones, que representan algo más que la diferencia entre la morfología del chalet californiano afín al modelo familiar católico y el siedlungen heredado de la racionalidad colectiva centroeuropea. Esta investigadora reconoce "la existencia de una compleja trama donde coexisten modelos sociales y urbanos diferentes y aún contradictorios, que fueron canalizados por el peronismo en relación con la vivienda. Esta ambigüedad se expresaría en la tensión entre potentes fuerzas sociales movilizadoras que atravesaron al peronismo: por un lado, la aspiración de ascenso social cuyo emblema sería "el sueño de la casa propia" y, por otro, los idearios de iqualación social y conciliación de clases. Uno y otro sueño fueron canalizados por el peronismo y ambos fueron asociados con sendas tipologías de vivienda. De este modo, la vivienda individual en lote propio fue apta para encarnar un horizonte de anhelos emparentado con el ascenso social y la conquista de la respetabilidad burguesa, mientras que la aspiración igualadora encontró su cristalización en el barrio obrero construido en base a pabellones exentos, materialización emblemática de una ciudad de iguales" (Aboy, 2003: 2).

${ }^{49}$ Ballent (2005) sigue la tesis de Liernur (1984), quien sostiene que el tiempo de las palabras y de las intervenciones de escaso peso cuantitativo que anteceden al peronismo revistió valores sustantivos e implicó la difusión de nuevos modos de habitar y la creación de nuevas tipologías de vivienda, que luego el Estado extendería a través de la construcción masiva.
} 
es importante destacar que tras un proceso sinuoso, se puede observar un desplazamiento del tratamiento de la cuestión. Un esquema simplificado del análisis propuesto por Ballent (2005) permite reconocer en la conformación de la Autoridad Nacional de Vivienda (más allá del desarrollo errático de su política) la condensación del estatus político-institucional dado por el peronismo a la vivienda en un primer momento, cuando el derecho a la vivienda pasaba a constituirse en un derecho del trabajador. Este organismo autárquico tenía las competencias de construir vivienda, asignar crédito, estimular la industria de la construcción, controlar el desarrollo urbano, expropiar y administrar un importante Fondo Nacional de Viviendas. Pero, poco más tarde, el Banco Hipotecario Nacional se transformaría en el organismo central en la ejecución de la política habitacional.

Distintos tipos de instrumentos caracterizarían la política de vivienda peronista, entre los cuales se destacan: los créditos hipotecarios, la construcción directa por parte del Estado, la liberalización de derecho de importación para los materiales de la construcción y la prórroga de los contratos de alquiler (Gaggero y Garro; 1996). La construcción directa adquirió mayor despliegue en el primer plan quinquenal; la vivienda como obra pública era considerada una poderosa herramienta de extensión del bienestar y un medio eficaz para cumplir con el compromiso asumido. "El gobierno debió servirse de modelos urbanos y cuerpos técnicos existentes, a modo de herramientas disponibles, como consecuencia de haber definido la prioridad de subsanar de inmediato una parte del déficit de viviendas, mediante la construcción directa por parte del Estado. El cumplimiento de un contrato, que recién aparece escrito en la Constitución de 1949, pero que es fundacional, entre Perón y los trabajadores, hizo que la prioridad recayera en la cristalización de ese compromiso en obras, por encima del diseño de una política de viviendas articulada en torno a un modelo de intervención" (Aboy, 2003: 11).

A partir de la nacionalización del Banco Central y la modificación de la carta orgánica del BHN, éste comenzó a dirigir su acción al fomento de la vivienda. Como señala Gaggero y Garro (1996), el crédito comenzó a tener una clara orientación social, se procuró otorgar la mayor ayuda y los máximos beneficios a las personas menos pudientes, con preferencia a los jefes de familia, obreros o trabajadores modestos. Los tiempos de pago eran prolongados, las tasas de interés muy bajas y el crédito cubría la totalidad del valor del inmueble. El destino no era solamente la adquisición o construcción de la vivienda unifamiliar, se conjugaban múltiples actores beneficiarios, destinos y tipologías. Incluso se promovió la construcción de viviendas colectivas para otorgar en alquiler a los precios que fijaba el Estado, aunque ésta fue una modalidad poco asimilada por el mercado.

En el segundo plan quinquenal, tras cierta decantación de la política habitacional, la obra pública comienza a replegarse y las líneas de crédito ganan protagonismo. El financiamiento consolida su perfil en la atención de los trabajadores, empleados, afiliados y obreros asociados a gremios, cooperativas, entidades intermedias, siendo este conjunto de entidades las que ocupan el lugar dejado por el Estado. El análisis realizado por Ballent (2005) al "Plan Eva Perón" del BHN, muestra que la masividad de la política se alcanzó a través de la 
simplificación de un modelo de gestión profundamente efectivo y sistemático, basado en el financiamiento de la vivienda individual. Esto fue acompañado por la estandarización de las tipologías y la ejecución individual o en mano de las entidades intermedias, las cuales producían agrupamientos de la tipología celular diseñada por BHN.

"Los aciertos del Plan señalaban también sus limitaciones, ya que la propuesta era funcional a la forma poco controlada en que habían crecido las ciudades argentinas y al uso del suelo que tal crecimiento impulsaba, basado en el fraccionamiento de la tierra en lotes individuales. Esta especie de "máquina" de gestión de la vivienda masiva, veloz y eficaz en muchos aspectos, que fue el Plan Eva Perón, carecía de instrumentos de control urbanístico y afianzaban las formas tradicionales de uso de la tierra y de la ciudad [...] sobre todo en el segundo período de gobierno, resulta innegable que la planificación sectorial funcionaba. No puede hacerse el mismo balance en el caso de las políticas de planificación urbana o territorial" (Ballent, 2005: 90-92).

Nos interesa rescatar esta última afirmación de la autora, ya que pone en evidencia las limitaciones de este proyecto de gestión de la ciudad, a pesar del importantísimo rol que jugó el peronismo en el avance de la planificación urbana. Asimismo, pese a su estado de desarrollo primario, ${ }^{50}$ en dicha época parece haberse vislumbrado un horizonte de acción profundamente innovador respecto el escenario actual. En este sentido, la tesis de Ballent resulta sugerente y, con recaudos de contexto, merecería ser revisada en la lectura de la política habitacional actual en términos de sus efectos materiales y simbólicos.

Para ella la tensión manifiesta en el primer momento del peronismo entre los dos polos de gestión urbana: i) la transformación radical de la estructura urbana; y, ii) la redistribución de los beneficios de la ciudad existente terminó desbalanceada hacia la segunda opción. Esto se traduce en que para el peronismo, la ciudad consolidada materialmente era una pesada herencia que se transformó en un obstáculo y el espacio conquistado simbólicamente un pacto difícil de desandar. De allí el surgimento de los denominados "polos peronistas", como manifestaciones de "intervenciones urbanas" puntuales, pragmáticas y flexibles en los espacios libres existentes. En este sentido, las intervenciones de vivienda fueron de carácter periférico, mientras que la apropiación metafórica del centro configura en el imaginario peronista un particular sentido del "derecho a la ciudad", entendido como disposición libre de lo existente antes que la creación de realidades nuevas (véase Ballent, 2005: 33-54).

La respuesta que el peronismo le dio al problema habitacional tuvo una importante continuidad hasta la etapa de institucionalización del sistema centralizado de vivienda. No obstante, la inestabilidad sociopolítica, el posicionamiento ideológico de los gobiernos subsiguientes y el

\footnotetext{
50 "Las políticas efectivamente realizadas, modestas con respecto a los planes radicales, pero considerables en cuanto a sus efectos sociales, y tan ambiciosas como veloces en relación con el período de poco más de diez años en que fueron realizadas, no siempre pueden ser consideradas políticas de desarrollo urbano en sentido estricto, ya que en gran medidas fueron el resultado de la aplicación de políticas sociales sobre la ciudad [...] Las gestiones del peronismo se dirigían certeramente hacia objetivos sociales en relación con el habitar, identificando cuestiones que implicaban la redistribución social de los beneficios de la modernización urbana, pero que carecían de la misma seguridad para definir qué ciudad estaba construyendo y qué instrumentos de control requería esta nueva construcción" (Ballent; 2005:36).
} 
contexto económico introdujeron matices importantes en la orientación de la política de vivienda. En base a la revisión de la política habitacional realizada por Yujnovsky (1984) entre 1955-1981, apuntamos una breve síntesis de las características más relevantes de la política habitacional previa creación del FONAVI.

A mediados de la década del 50 se produce un giro importante en la política de vivienda, mediado por el plan de estabilización económica y ajuste de la "Revolución Libertadora" (19551958). En este marco, se busca reducir la intervención del Estado en el sector y restituir el libre funcionamiento del mercado. Entre estas medidas, podemos citar: reducción drástica del crédito hipotecario (se pasa de la política de descuento o subsidio financiero al esquema de ahorro y las cédulas hipotecarias ${ }^{51}$, descongelamiento de alquileres, suba del impuesto inmobiliario, erradicación de villas, y promoción de cooperativismo (al menos en términos formales). Sin embargo, nuevas medidas en materia habitacional son gradualmente introducidas y combinadas con otros tipos de políticas asistenciales con el fin de amortiguar el costo político y social del golpe de Estado.

El dato más significativo de los gobiernos desarrollistas siguientes fue el desplazamiento del financiamiento hacia el sector privado o la integración de las entidades privadas al negocio del ahorro y préstamo para la vivienda. La organización intra-burocrática se adapta a la recepción y canalización de fondos crediticios externos, especialmente después de que la estrategia estadounidense de la "Alianza para el Progreso" comenzara a proveer el financiamiento externo para el apoyo de políticas reformistas. En esta línea, el Banco Interamericano de Desarrollo (BID) aporta un préstamo para cubrir el 50\% de los programas de vivienda.

En el año 1961 se creó el Fondo Federal de Vivienda, incorporando a las entidades privadas y a los aportes de organismos extranjeros. Reaparece la idea de que es necesario disponer un ente centralizado de planificación, por lo que en 1962 se crea la Administración Federal de Vivienda, con competencia en materia administrativa, técnica y de control del Fondo. Dicho organismo estaba a cargo del Plan Federal de Viviendas, pero rápidamente (y por presión del BID), el BHN se convirtió en la autoridad de aplicación a cargo del Fondo. Cabe recordar que el BHN tenía una estrecha relación con el sector de la construcción.

El mecanismo principal de esta política fue el refinanciamiento del crédito hipotecario y su implementación a través de entidades intermedias ${ }^{52}$. Dichas entidades realizan solicitudes de financiamiento a través de los planes de construcción, que son evaluados por el organismo competente y elevados posteriormente a contratación. La clave del sistema es una arquitectura financiera estable y de escala. La ejecución se descentraliza en las entidades y el Estado aporta garantía al sector privado, a la vez que regula y estimula el sistema mediante la inyección parcial de fondos. De este modo, la participación estatal se redujo notablemente y las

\footnotetext{
${ }^{51}$ La Carta Orgánica del BHN se modifica, pero esta vez el objetivo es apoyar la iniciativa privada en materia de vivienda y restituir el crédito corriente (no subsidiado).

52 Se incluyen aquí asociaciones de ahorro y préstamo, mutuales, sindicatos, cooperativas, consorcios, bancos con secciones hipotecarias, empresas y organismos públicos.
} 
operaciones financieras privadas ajustadas a la inflación se dirigieron al mercado de los sectores medios y altos.

En materia de tierras, comienzan a difundirse algunas medidas de control de desarrollo urbano. Por otra parte, el gobierno democrático se vuelve más receptivo a los "reclamos villeros".

En el gobierno de Illia (1963-1966) se introducen reformas democráticas con cierto consenso político. Además, se atienden algunas de las demandas de la Comisión Central de Asociaciones Privadas para la Reactivación de la Industria de la Construcción (CAPRICO) ${ }^{53}$, con el fin de afrontar la crisis económica. En este marco, se amplió el crédito (aunque no se logra llegar a sectores de menores ingresos) y se inicia un proceso de reactivación económica. También se retoman algunas de las recomendaciones del Consejo Nacional de Desarrollo (CONADE), como los planes de "acción directa" del Estado, mediante los cuales se inicia el proceso de construcción en tipología monoblock.

En 1964 entra en ejecución el Plan Federal de la Vivienda, con la misma modalidad de implementación del período anterior. También se asimilan los "contratos globales", destinados a financiar operaciones masivas o de conjuntos, y se reajustan los servicios financieros de los préstamos de acuerdo a la evolución del salario.

En 1965 se creó la Secretaria de Estado de la Vivienda (SEV), que responde a la necesidad de concentrar la atomización de reparticiones con competencia en materia habitacional. Por otra parte, se prorroga la ley de alquileres (a pesar de la presión para su derogación) y son reconocidas las demandas de las "organizaciones villeras", que ganan dinamismo en el contexto democrático. Al respecto se producen acciones de mejora, suspensión de desalojos, reconocimiento de las organizaciones vecinales y se intentan realizar planes de mayor alcance.

Con el golpe de Estado de Onganía (1966) se produce un retroceso importante a partir de la introducción de una lógica profundamente autoritaria y tecnocrática. Desde una visión económica desarrollista se promovió una modalidad de intervención estatal dirigida a favorecer la acumulación privada y a aumentar la productividad, supuestamente afectada por el excesivo proteccionismo estatal precedente. La política de vivienda se inscribió en este registro. En este marco, las acciones estatales debían dirigirse a dinamizar la economía, y la clave para lograrlo era alentar al máximo los esfuerzos del sector privado. Por esta razón, durante el gobierno de Onganía se atendieron plenamente las demandas empresarias (exención de impuestos equivalente al $50 \%$ de la inversión en construcción de viviendas, producción de grandes conjuntos, progresiva liberalización de alquileres, etc.). Del mismo modo, se favoreció al capital concentrado, con capacidad de responder a la industrialización de la producción masiva, y se relega a los sectores de las PyME.

\footnotetext{
${ }^{53}$ La CAPRICO estaba conformada por la Cámara Argentina de la Construcción, el Centro Argentino de Ingenieros, la Sociedad Central de Arquitectos, La Cámara Argentina de Ahorro y Préstamo para la Vivienda, La Cámara Argentina de a propiedad horizontal y la Unión Industrial Argentina. Entre sus demandas se encuentran la desgravación impositiva, aumentar el financiamiento en distintos segmentos de mercado, reajuste en el servicio de los créditos, respaldo estatal para adquirir crédito en el exterior, financiamiento destinado a operaciones masivas, derogación progresiva de la ley de alquileres, puesta al día de las deudas del estado con los contratistas de obra pública (ver Yujnovsky, 1984).
} 
En gran medida, la presión empresarial por ampliar su participación en el segmento de la vivienda económica responde a la saturación del mercado habitacional de altos ingresos. Esto se manifiesta, por ejemplo, en la influencia del sector privado para elevar los umbrales de los créditos del Plan de Viviendas Económicas Argentinas (PVEA), que apuntaba a sectores cuya capacidad de ahorro no clasificaba para el préstamo bancario tradicional. Siguiendo con el esquema de la CONADE, la SEV se constituye en el organismo centralizador y planificador $^{54}$. Desde este lugar, se busca que el BHN funcione como el agente financiero de la Secretaría, mientras que la ejecución se descentraliza a las provincias y municipios. Se continúa con los programas de "acción directa", a cargo de la SEV, que también representan una oportunidad para las empresas de participar en el negocio de la construcción de viviendas a través de los contratos directos, por fuera del régimen clásico de ahorro y préstamo. La política para las villas consiste en efectivizar de modo eficiente la erradicación de estos asentamientos, ejerciendo un fuerte control sobre la población que allí habita. Sin embargo, una mirada sobre los avances reales logrados por esta política muestra las limitaciones estructurales del esquema (surgen en esta época los Núcleos Habitacionales Transitorios, que nunca se convirtieron en definitivos).

Durante los tres años previos a la vuelta del peronismo, la política de vivienda adquirió rasgos más populistas, poniéndose al servicio de la "salida política" del gobierno militar. El Ministerio de Bienestar Social (MBS) asume protagonismo político en la distribución de recursos para captar el apoyo sindical. En vista de la restauración del proceso democrático, la política destinada a las villas se vuelve más clientelar, y se otorga legitimidad las organizaciones internas. Sin embargo, en el plano de los alquileres prima la inercia del período anterior: una lógica desalojista y la vuelta al régimen de mercado. En términos generales, tienen continuidad los programas de vivienda preexistentes.

Sin embargo, el dato más significativo de este período es la creación del Fondo Nacional de la Vivienda (FONAVI), a cargo del MBS, mientras que la SEV se transforma en Subsecretaría. El contexto económico recesivo, la asunción de compromisos estatales en obra de vivienda por encima de la disponibilidad financiera, la desaceleración de la actividad constructiva, la saturación del mercado inmobiliario (de los sectores con capacidad de pago y acceso al crédito), y la "crisis" del sector de la construcción rodean el consenso en el que emerge el FONAVI. El Fondo es manejado por el MBS, el cual es asistido por un consejo asesor, compuesto por la Subsecretaría de Vivienda, los representantes gremiales de la Confederación General de Trabajo (CGT) y la Cámara Argentina de la Construcción (CAC).

Desde su creación, el Fondo se transforma en un campo de disputa por el control y la asignación de recursos. Las mayores tensiones surgen de la puja entre las distintas opciones disponibles respecto de la distribución de los recursos. Uno de los principales dilemas radicó en definir si los fondos serían destinados a sostener el sistema de financiamiento privado

\footnotetext{
${ }^{54}$ Distintos organismos quedan bajo competencia de la SEV: el Banco Hipotecario Nacional, la Caja Federal de Ahorro y Préstamo para la Vivienda, la Superintendencia de Locaciones, la Dirección General de Préstamos Personales y Con Garantía Real.
} 
preexistente (subsidio a la demanda) o si se buscaría reforzar el esquema de acción directa (subsidio a la oferta). Otros puntos de discusión fueron: qué proporción se destina a cubrir compromisos hipotecarios previos y cuánto a reactivar o sostener el sistema. Finalmente, debía decidirse si el Fondo se orientaría a la población de menores ingresos o no y, en el plano constructivo, si se priorizaría o no a los sectores empresarios de capital concentrado ${ }^{55}$. Como corolario del período (1970-1973), continuaron los beneficios a las grandes empresas, las cuales lograron exenciones impositivas y ampliaron su participación en la construcción de viviendas económicas a través del FONAVI.

En síntesis, como planean Cravino, Fernández Wagner y Varela (2002), a principios del siglo $X X$ comenzaron a esbozares una serie de elementos que luego conformarían un sistema centralizado de vivienda, en torno a un esquema de seguridad social. A partir de 1915, la CNCB genera los primeros antecedentes de la construcción de viviendas sociales. A pesar del exiguo margen constructivo, la CNCB haría importante aportes al debate de la época. En 1923, la sanción de la primera Ley de Congelamiento de Alquileres representó un compromiso con los sectores de bajos ingresos, regulando en su favor una de las principales formas de acceso a la vivienda. En la década del '40, la Ley de Propiedad Horizontal facilitaría el acceso a las áreas centrales y llevaría a la densificación de la ciudad junto con la política de créditos blandos del BHN (que financió el acceso a la vivienda de modo extendido a los sectores asalariados). Además, el Estado tuvo distintas iniciativas de acción directa en la construcción de barrios para los trabajadores.

De este modo, la temática fue creciendo progresivamente en la agenda pública. En 1955, se crea la Comisión Nacional de la Vivienda y, en 1959, el Fondo Federal de la Vivienda. Finalmente, en 1965, se creó la Secretaría de Estado de Vivienda. En la década del '70, este conjunto de antecedentes converge para dar lugar a la conformación de un sistema centralizado de provisión de "vivienda social", cristalizado en el FONAVI, cuyas características veremos a continuación.

\subsubsection{La institucionalización del sistema de vivienda en los setenta}

Si bien en 1970 se sancionó la ley 19.929, que dio origen al FONAVI, la misma sería promulgada recién en 1972. La creación del Fondo responde al objetivo de contar con recursos genuinos para contrarrestar y disminuir el déficit habitacional, posibilitando el acceso a una vivienda digna a los sectores de menores ingresos de la población. Los recursos de esta primera versión del FONAVI provenían de los aportes hechos por los empleadores, equivalente al 2,5\% del total de las remuneraciones, de un gravamen del $1,5 \%$ a la venta del ganado, y de los fondos de la recuperación de los préstamos que financiaban la construcción de viviendas

\footnotetext{
55 El Fondo se destina mayormente al Plan de Erradicación de Villas de Emergencia (PEVE), a la construcción de conjuntos masivos a través del PVEA, a la construcción de viviendas individuales con terreno con infraestructura y, en menor medida, a reactivar y sostener el sistema de ahorro y préstamo, generando una mayor vinculación con Cámara de Propiedad Horizontal y con las PyMEs asociadas a la Confederación General Económica (CGE).
} 
económicas, además de un aporte excepcional proveniente de un impuesto inmobiliario transitorio.

La cristalización definitiva del FONAVI, se da un año después de la promulgación mediante la ley 21.581/77, que define un nuevo régimen de financiamiento del Fondo, determina las características generales de la política de financiamiento y las modalidades de implementación. Además, nombra a la Secretaría de Desarrollo Urbano y Vivienda (SDUV) como la autoridad competente para establecer las normas reglamentarias técnicas o administrativas, encargarse de la planificación general del sistema y hacerse cargo de la distribución de los recursos. A partir de esta nueva ley, el Fondo pasa a ser financiado por medio de contribuciones salariales equivalentes al $5 \%$, más el aporte del $20 \%$ proveniente de las obligaciones previsionales de los trabajadores autónomos.

En el plano sociopolítico, y en un contexto autoritario, el nuevo esquema apuntó a "ordenar" la dinámica que se venía produciendo con la primera generación del FONAVI desde el 72-73. En aquel entonces, la política de vivienda se había vuelto altamente dinámica como respuesta a la demanda también dinámica. Las líneas de acción o formatos de implementación adquirían una articulación variable. Sin embargo, también se produjo un incremento de la discrecionalidad en relación a la ejecución de los recursos. La política de vivienda se había convertido en un espacio más donde la pugna por el control político de los recursos del aparato del Estado podía expresarse, resultado de los intereses contrapuestos en el interior del propio peronismo.

Si retomamos la revisión de Yujnovsky (1984), la política habitacional previa al golpe de Estado de 1976 suponía la atención de los intereses de los sectores de capital local en la construcción de viviendas. La misma buscaba apuntalar a las PyME, impulsar el mercado interno y defender el empleo. La vivienda se orientaba a los sectores de menores recursos y era vista como una forma de distribución del ingreso. A partir de 1973, se produjo una expansión del crédito con participación del financiamiento público. Se abarató el crédito, se eliminaron los reajustes de intereses y se ampliaron los sectores de población con acceso a los diferentes planes.

En lo que respecta a los alquileres, los contratos no reajustan los precios a nivel de mercado, se suspenden los desalojos y no se avanza en la liberalización del mercado de locaciones (en contraposición a los intereses de los propietarios). Una parte de los recursos se destina a vivienda individual en lote propio (con prototipos de BHN), pero también se consolida la tendencia a la producción de grandes conjuntos, cuya construcción era generalmente dejada a cargo de empresas más concentradas. Se satisfacen las demandas empresariales de mayores costos, exención de impuestos, justificación de las demoras de obras, etc. Por otra parte, la CGE se transformó en el interlocutor de referencia de la política de vivienda, logrando desplazar a la CAC del Consejo Asesor Permanente del FONAVI en el MBS.

Al mismo tiempo, se acentuaron los vínculos entre gobierno, partido y CGT, como mecanismo a través del cual se canalizó el financiamiento. En síntesis, los programas habitacionales siguen los lineamientos del período anterior, se profundiza la orientación social y aumenta la escala de la acción pública. Sin embargo, las metas planteadas estuvieron lejos de alcanzarse. 
A partir de golpe de Estado encabezado por Videla, se produce un quiebre drástico en todos los ámbitos de la vida social argentina. La política habitacional no será una excepción, aunque también es posible rastrear elementos de continuidad que terminan de cristalizar en este nuevo contexto $^{56}$. La introducción del cambio brusco en el modelo macroeconómico, con una orientación aperturista y financiera, junto con la desarticulación de la industrialización sustitutiva de importaciones, generaron un debilitamiento del mercado interno, una caída del salario real y una pérdida de la capacidad de consumo. En materia de vivienda, se produce una disminución de la demanda, seguida por una reducción de la construcción, al tiempo que se liberalizan los alquileres y el sistema financiero asume rasgos cada vez más especulativos. De este modo, se restringen las posibilidades de acceso a la vivienda vía el mercado, se reduce el crédito y se impone una división al interior del entramado estatal. Por un lado, el BHN debe atender a los segmentos con capacidad de ahorro (que son cada vez menos) y, al mismo tiempo, transformarse en una entidad bancaria comercial. Por este motivo, el banco se elimina las tasas subsidiadas y se introducen estrictos reajustes frente a la inflación. Por otro lado, la SDUV que administra el FONAVI queda a cargo de los sectores con escasos recursos.

Identificamos aquí una contradicción fundacional: cuando comienza a erosionarse la matriz de distribución y se produce una caída de las remuneraciones de los sectores asalariados, la política de vivienda consolida precisamente un esquema de financiamiento con base en la remuneración del trabajo. Sin embargo, debemos tener en cuenta que el nuevo dispositivo institucional logra ajustar la distribución de recursos (en función del déficit habitacional) y redireccionar la acción pública hacia los sectores de bajos ingresos (sin alcanzar a los deciles más bajos). No obstante, en el mediano plazo, la tensión mencionada anteriormente, combinada con la presión que reciben las provincias para devolver el Fondo y garantizar la retroalimentación fiduciaria ${ }^{57}$, terminarán redirigiendo la oferta a sectores con cierta capacidad de pago.

Sólo a modo de ejemplo, la relación entre la cuota mensual de los préstamos modales de fomento y el salario mensual del obrero industrial muestra el pasaje de una incidencia del 20-30\% (para oficial y peón respectivamente), en 1941, a una del 40-60\%, en 1980. Entre 1945 y 1955, la incidencia cuota-salario para los préstamos de fomento del BHN se encontraba en el orden del 30-40\% (oficial y peón respectivamente), elevándose al 45-65\% para el FONAVI, entre 1977-1980.

Mientras que, si se considera la cuota mensual (en base al costo medio de la vivienda FONAVI) en relación a los ingresos familiares en el AMBA en 1978, el 47\% de los hogares no pueden

\footnotetext{
56 Por ejemplo, la necesidad de instituir un sistema de planificación centralizada con un tipo de ejecución descentralizada garantizando a una base normativa férrea. Prima la influencia de la filosofía de la CONADE y de los equipos técnicos del BID, por sobre el esquema anterior. La Subsecretaría de Vivienda se encontraba debilitada frente al entramado decisional mediado por la primacía del BHN, que aportaba la estructura territorial y financiera, junto con el MBS, que controlaba los recursos, y la intermediación de la CGT y la CGE (y, antes, la CAC).

${ }^{57}$ En el artículo 18 (Ley 21.581) se establece el mecanismo de reintegro. Las provincias son responsables de reintegrar los valores equivalentes a las cuotas de amortización de la vivienda financiadas por el Fondo, independientemente del cumplimiento de las obligaciones de pago de los adjudicatarios (pudiendo la Nación comprometer futuros fondos).
} 
acceder a una vivienda de $75 \mathrm{~m}^{2}$, dicha proporción asciende al $59 \%$ al considerar hogares con déficit de vivienda (ver Yujnovsky, 1984: 292-293, 303).

EI FONAVI responde, entonces, a la necesidad de inyectar fondos, generando inversión frente a la contracción de la economía y a la exigencia tecnocrática de organizar un sistema administrativo estable a nivel inter-jurisdiccional, con mecanismos de control, asignación de recursos y mecanismos de adjudicación. La normativa (Ley 21.581) no sólo determina el origen del financiamiento, sino también el destino del mismo. La "vivienda económica" es el objeto central de la política -definido por la capacidad de financiamiento-. De ella deriva un sujeto definido en función de la capacidad de pago en relación al costo de amortización de la vivienda (artículo 7), el equilibrio entre la orientación social y la sostenibilidad financiera del Fondo (artículo 12) y el sistema de puntaje de definición de prioridades (artículo 13).

Por otra parte, nos interesa resaltar de qué modo aparece tratada la cuestión del suelo en el marco de la política de vivienda. Los debates de la época muestran avances en relación a la reflexión de la planificación urbana, del crecimiento "desequilibrado" de las ciudades, de la necesidad de regular el desarrollo especulativo, y de los problemas de acceso al suelo que ya evidenciaban los programas de vivienda social. A modo de ejemplo, la SEV fue pionera en la discusión de un anteproyecto de ley nacional de planificación urbanística y regulación de uso del suelo, que encontró amplia oposición de los sectores empresarios de la industria de la construcción y de los propietarios ${ }^{58}$. Sin embargo, en el proceso de constitución de la matriz de la política de vivienda, la cuestión de la localización o el suelo se cristaliza por fuera de estas preocupaciones. El suelo será considerado un insumo que habilite el desembarco de la inversión. El problema es garantizar el dominio de la tierra, la aprobación formal de los proyectos en los organismos provinciales o municipales (con competencia en materia de uso del suelo) y la ecuación del costo de extensión de infraestructura y equipamiento, dada la ubicación naturalizada de los terrenos asociados a la vivienda económica.

De este modo, el dispositivo político, institucional y financiero por antonomasia de la política de vivienda traduce en un problema de finanzas al problema urbano que origina el "déficit habitacional". EI FONAVI se proyecta como un fondo continuo y circular (que se retroalimenta en el tiempo), un medio eficaz para combatir el déficit a través del financiamiento de la oferta. El principio técnico era el siguiente: la construcción directa por parte del Estado, basada en la

\footnotetext{
${ }^{58}$ Entre los mecanismos de implementación que proponía la SEV para desarrollar un sistema de desarrollo urbano nacional, en el anteproyecto de ley de 1972, se encuentra: regular la administración de tierras fiscales, agilizar procedimientos de expropiación a partir de la declaración genérica de utilidad pública, avanzar en las política impositiva inmobiliaria, recuperar la valorización que realiza el Estado producto del desarrollo de obra pública, programas de desarrollo urbano o cambios de zonificación. Ya desde 1956, la Comisión Nacional de Vivienda señalaba la importancia que tenía atender el problema de la tierra en los planes de vivienda social. Sugería, a su vez, desarrollar planes reguladores. cuyo financiamiento debía priorizares en función de la inclusión de un impuesto inmobiliario progresivo a los baldíos urbanos. También marcaba la necesidad de extender los servicios públicos urbano y los equipamientos a todas las urbanizaciones del país y discutir una norma urbanística a nivel nacional. En el Ministerio de Obras Públicas de la provincia de Buenos Aires se discutía la necesidad de regular la ocupación y la subdivisión del suelo. En la década del '60, la Comisión Federal de Vivienda y Planeamiento insistía en que la movilización de la tierra urbana debía efectuarse con un sentido social y acorde a reglas de planeamiento urbano. Para la CONADE la cuestión metropolitana empieza a ser foco de atención y existe una preocupación por el crecimiento "anormal" de la ciudad. La Dirección de Ordenamiento Urbano de la provincia intenta avanzar en el condicionamiento de la producción de "loteos" mediante la provisión de a infraestructura básica y estrategias de zonificación preventiva, entre tanto otros antecedentes que encontraron obstáculos en los intereses del desarrollo inmobiliario privado (ver Yujnovsky, 1984).
} 
remuneración del trabajo, no sólo incidiría en la demanda (como subsidio indirecto) o contribuiría al crecimiento del sector de la construcción, sino que además tendría la capacidad de incidir en el mercado inmobiliario. Al producir una oferta de magnitud tal que afrontara el déficit, es decir, que intervendría un tercio del parque habitacional, el resultado indirecto sería generar una regulación del mercado. Esto, como sabemos, estuvo lejos de cumplirse.

En la lectura de Rodríguez y Di Virgilio (2008), es posible reconocer alcances y limitaciones del FONAVI en términos del modelo de gestión, el financiamiento, el modelo de producción y la dificultades de implementación de la política. Con la creación de este dispositivo a cargo de la SDUyV, la Nación se encargaba de dictar reglamentaciones, establecer programas, determinar prioridades de inversión, cupos por región, normativas de gestión, controles técnicos, y criterios generales de selección de beneficiarios. Mientras tanto, los organismos provinciales quedaban a cargo de la ejecución de los programas. El sistema se configuraba como un esquema centralizado de decisión, con una ejecución descentralizada. El modelo característico fue la construcción de vivienda nueva en grandes conjuntos, en áreas de localización periférica y con escasos servicios urbanos previos. La industrialización de la producción buscó minimizar costos y, a su vez, acarreó dificultades de modificación y crecimiento posterior. El modelo "llave en mano", altamente funcional para las grandes empresas constructoras que ganan con la masividad seriada, tiene como contracara un destinatario final que no participa en ninguna fase del proceso de producción de la vivienda. Es concebido como beneficiario de la asistencia: luego de obtener el cupo, le toca esperar "el sorteo".

Ante la crisis social y el proceso de reestructuración económica, con las respectivas transformaciones del mercado de trabajo, el reverso del esquema -basado en las retribuciones salariales y en los fondos de recupero- será el desgaste de la sostenibilidad del sistema. Dicho de otro modo, el cambio estructural incide en las limitaciones del recobro y atenta contra la lógica de un fondo rotatorio ${ }^{59}$. Esto también se explica por limitaciones a nivel de la gestión y por cierta desapropiación del producto de la política. Un efecto secundario es la valorización del suelo privado en el marco del desarrollo de la obra pública tras la certificación de "reconocimiento de mayores costos", al igual que el desarrollo de nichos empresariales protegidos (Rodríguez y Di Virgilio, 2008).

En esta línea, Cuenya (1997) sostiene que, frente al aumento de la demanda de los servicios urbanos y a la ampliación de restricciones habitacionales, la producción masiva de viviendas no sólo buscaba atender el déficit habitacional. En este esquema de política habitacional centralizada, el Estado se hace cargo de las necesidades sociales desde el punto de vista presupuestario-financiero e interviene en la producción de vivienda a través de la contratación del sector privado. Para esta autora, las dificultades de instrumentación de la política y un modelo de gestión poco flexible terminaron por descuidar a los sectores de más bajos ingresos,

\footnotetext{
${ }^{59}$ En el año 2002, el nivel del recupero sobre el monto total de facturación llegó al 35\% (Presentación del Programa Federal del Fortalecimiento y Optimización del Recupero de Cuota de las Viviendas FONAVI, SSDUV, 2004).
} 
transfiriendo al mismo tiempo importantes recursos a la industria de la construcción. Queda así consolidada una modalidad de intervención prácticamente única.

Un balance del FONAVI puede observarse en el estudio de COHRE (2005), el cual recupera un proyecto de reforma (que jamás se implementó) al decreto 690/92, allí se "recogía los cuestionamientos de las organizaciones populares al desempeño de esa institución y proponía nuevos principios rectores, entre ellos, diversificar las soluciones según el tipo de déficit, instrumentar líneas de acción diferenciadas en función del nivel socioeconómico de los hogares y descentralizar la gestión. La descentralización se efectuó finalmente en el marco de una situación de emergencia del sistema previsional, que obligó al Estado a reasignar a las provincias los fondos coparticipables correspondientes al FONAVI" (COHRE, 2005: 44).

Podemos decir, entonces, que la lógica general de la política de vivienda de décadas anteriores se mantuvo a lo largo de los '80. Recién en la década siguiente se introduciría un proceso de descentralización de la política y un nuevo paradigma de financiamiento a la demanda. Sin embargo, con la vuelta a la democracia, se reavivarían los debates acerca de la política habitacional, por lo que el FONAVI sería objeto de diversas críticas. La dificultades persistentes respecto del desfasaje del déficit habitacional sería una de ellas, la necesidad de vincular la política de vivienda con una política de ordenamiento territorial que regule la expansión urbana, es otra. En paralelo, se le reclama al nuevo gobierno incentivar el desarrollo de la industria de la construcción como una forma de combatir la crisis económica ${ }^{60}$.

Para explicar parte de la dinámica que adquirió la disputa por estos fondos en la década de 1990, Rodulfo ${ }^{61}$ sostiene que hay que retrotraerse a fines de los '80. En el año 1988, la SDUV adquirió un "préstamo de ajuste" sectorial al Banco Mundial con el fin de realizar una revisión de la política a partir de la cual quedar habilitado para recibir financiamiento posteriormente. Al poco tiempo, los requisitos de pago del préstamo requirieron un excesivo esfuerzo fiscal, coincidente con el proceso de hiperinflación. El flujo de inversión anual que se destinó a la construcción de viviendas disminuyó bruscamente y condicionó la coparticipación provincial. Por ello, además de la crisis de producción de viviendas asociada a la salida de la dictadura, a partir del 1989 el sistema se paralizó nuevamente (como puede verse en la figura 2). En el año 1992, al tiempo que avanza la reforma del Estado y el FONAVI es afectado por el Pacto Fiscal entre la Nación y las provincias, los fondos dejan de ser específicos y pasan a ser coparticipables y afectados por el desempeño fiscal. La nueva administración de la SDUV recupera el control del sistema de vivienda tras la cancelación del crédito del Banco Mundial. A partir de entonces, la curva de construcción comienza nuevamente una tendencia creciente, hasta el estancamiento del 97-02.

\footnotetext{
${ }^{60}$ Varios de estos aspectos pueden verse en la Revistas del FUNDAVI (Fundación para el Desarrollo de los Asentamientos humanos y la Viviendas) n 2y 3 Buenos Aires, 1985.

${ }^{61}$ Entrevista realizada a principios del 2011.
} 


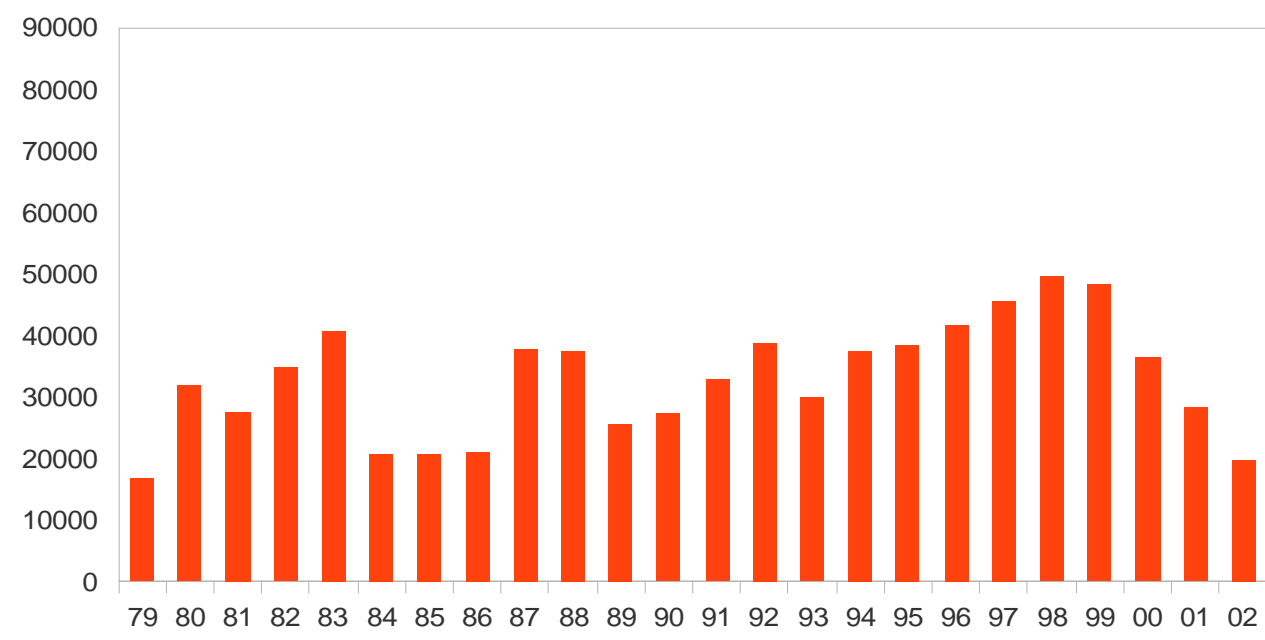

Fuente: elaboración propia en base a Revista de Comisión Nacional de Vivienda № 33 (2011) e Informe de Auditoría FONAVI-Programas Federales, SDUyV (2009).

Frente a estos episodios concurrentes, en el año 1995 las provincias comenzaron a posicionarse para presionar por la aprobación de la ley del Sistema Federal de Viviendas. Como se verá más adelante, el cuerpo de esta ley responde tanto a cambios estructurales de época, como a una demanda de federalismo y a la presión ejercida por las provincias para obtener mayor control sobre los fondos. Dicha pulseada tendrá consecuencias e implicaciones hasta la actualidad, especialmente en la forma de implementación del Plan Federal de Viviendas.

\subsubsection{Los meandros de la política habitacional de los noventa}

Si la etapa de institucionalización del sistema centralizado de vivienda social se desarrolló cuando el ciclo de acumulación del fordismo periférico mostraba su agotamiento y el trabajo perdía participación en el PBI, el período de reestructuración económica neoliberal y el ajuste estructural también introducirán algunas innovaciones en materia habitacional. Como señala Cuenya (2005), durante la década de los '90 la política de vivienda atraviesa una redefinición ideológica y política en torno al papel que deben asumir los distintos actores estatales, privados y comunitarios en la satisfacción de las necesidades de hábitat.

La idea rectora de esta redefinición fue la de generar un desplazamiento desde la "regulación" de la oferta (asociada a la producción estatal) hacia el financiamiento de la demanda individual y, a su vez, recurrir a la emisión de títulos para generar nuevos recursos. La tesis implícita en esta política es que la creación de activos en propiedad sería el "salvavidas" que permitiese resolver el problema de la vivienda. Conjuntamente, la facilitación constituía la estrategia 
central del Estado, bajo el supuesto de que la disponibilidad de crédito reduciría las limitaciones de la demanda y la desregulación del mercado anularía los obstáculos por el lado de la oferta. Una vez exploradas al máximo las posibilidades brindadas por el mercado como mecanismo de asignación de bienes y servicios, las agencias multilaterales de crédito aceptarían la atención de los pobres de forma explícita (esto es mediante subsidios estatales). Sin embargo, estas políticas paliativas son focalizadas, y se concentran únicamente en la "población objetivo".

La "financierización", la facilitación y la focalización, conceptos claves del período, se combinan con el proceso de descentralización de la política y con un redireccionamiento hacia el problema de la tierra. De allí surge la difusión de los programas de regularización dominial. Como se verá en los párrafos siguientes, al mismo tiempo que se desmantelaba la concepción de la vivienda social, se daba continuidad a las políticas de radicación ${ }^{62}$ y se ensayaban programas alternativos, en algunos casos con una vocación habitacional más integral que sectorial.

Realizados estos comentarios introductorios, el reposicionamiento de la acción pública fue el rasgo destacado del periodo. Siguiendo el planteo de Cravino, Fernández Wagner y Varela (2002), el proceso de reforma del Estado desarticuló un sistema centralizado de provisión de vivienda social basada (al menos en su concepción) en un carácter solidario o redistributivo y "universal". Esta propuesta fue reemplazada por una política errática, concebida desde una estrategia de focalización y descentralización, donde el Estado se retiró como vector del mercado inmobiliario para asumir un rol de facilitador y de asistencia particularizada a determinados sectores de la población.

En este sentido, tras una trayectoria conformada por diversos intentos fallidos de regulación, se produce un desplazamiento de la acción estatal y se abandona la concepción social de la vivienda. Puebla (2002) señala que entre las décadas de 1970 y de 1990 se produce un quiebre en la orientación habitacional en toda América Latina. La autora caracteriza este cambio como el pasaje "del intervencionismo estatal a la estrategia facilitadora", siendo las máximas del modelo: la modernización del sector por medio de la mayor participación de los promotores privados y el desarrollo del derecho de propiedad; la descentralización y la simplificación administrativa; la reducción de costos indirectos y de subsidios; la implementación de nuevos esquemas de recuperación; el abandono de la concepción de constituir reservas territoriales; y, la asimilación de un esquema de provisión de suelo (a cargo del promotor mediante la compra directa en el mercado) ${ }^{63 .}$ Para Cuenya (1997), la propuesta

62 En oposición a las políticas de "erradicación" que caracterizaron a la dictadura militar, las de este período fueron políticas basadas en la conservación de la localización de población mediante la regularización dominial de las tierras ocupadas, la re-urbanización de barrios y los ajustes en la configuración del loteamiento interno. Desde mediados de los setenta, comienzan a desarrollarse a nivel mundial estas políticas de "segunda generación", asociadas a la influencia de la Cumbre de Vancuver UN-Habitat.

63 Las estrategias facilitadoras y de descentralización también pueden verse claramente reflejadas en los lineamientos del Banco Mundial: i) aumentar la actividad del sector privado en el componente de la oferta la vivienda, ii) implementar instrumentos regulatorios y financieros por medio de los cuales el sector público asegure el funcionamiento del mercado de tierra y vivienda y su rentabilidad, iii) proponer la modalidad de lotes con servicios, evitando programas de mejoramiento de asentamientos dado el deficiente recupero, iv) mejorar los instrumentos institucionales vinculados a la demanda (registros, regularización, subsidios, financiamiento), la oferta (obstáculos de regulación urbanística, infraestructura) y la gestión (control institucional). El supuesto que se sitúa por debajo de este planteamiento es que la 
consiste en multiplicar los efectos de las actividades del sector privado. El supuesto que se sitúa por debajo de la orientación de esta política es que la desregulación de los mercados inmobiliarios puede contribuir a satisfacer las necesidades de vivienda, siempre que no haya limitaciones desde la oferta ni desde la demanda, siendo la mitigación de tales impedimentos el papel básico del Estado "facilitador".

La arquitectura normativa diseñada entre 1991-1995 irá configurando un modelo de política en el cual es posible reconocer algunos rasgos del nuevo paradigma. La sanción de la ley 23.966/91 del Régimen Nacional de Previsión Social desafectó el porcentaje de retenciones fijadas en los convenios gremiales destinados al FONAVI y derivó los saldos de transferencia pendiente al Régimen de Previsión Social. El origen financiero del Fondo pasó a depender del $42 \%$ del impuesto al combustible. De este modo, el FONAVI deja de estar atado a las contribuciones salariales (que se encontraban en franco retroceso). Conceptualmente, el recurso para satisfacer las necesidades habitacionales deja de estar mediado por la relación capital-trabajo.

La ley 24130/92, por la que se ratifica el Pacto Fiscal, autorizó al Estado nacional a realizar una retención no reintegrable del $15 \%$ de los fondos coparticipables para cubrir obligaciones previsionales, como señala Rodríguez y Di Virgilio (2008): a cambio de remitir a las provincias una suma fija mensual destinada a cubrir desequilibrios fiscales y recursos financieros provenientes de cuatro fondos, entre ellos el FONAVI.

Los primeros indicios de la descentralización se observan en la misma ley. En ella, el Estado nacional limitó sus funciones y transfirió a los Institutos de Vivienda Provinciales la potestad de definir los requerimientos técnicos y financieros de los proyectos de vivienda, junto con otras tantas competencias reglamentarias. En este plano de tensión entre la delegación de responsabilidades y la transferencia de recursos, tres años más tarde, las provincias presionaron en el marco de la conformación del Sistema Federal de Viviendas para fijar un piso mínimo de los recursos transferibles por el Estado nacional a los Estados provinciales. En caso que la recaudación del impuesto al combustible fuese menor al mínimo, la ley 24.464/95 determinó que el Tesoro Nacional debería cubrir el desfasaje, a cuenta de la futura recaudación del impuesto por encima del mínimo fijado en 900 millones de pesos al año.

Por dicha ley se creó el Sistema Federal de Vivienda, compuesto por el FONAVI, los organismos provinciales y la Municipalidad de la Ciudad de Buenos Aires, y el Consejo Nacional de Vivienda (CONAVI) ${ }^{64 .}$ Como se señala en el párrafo anterior, la ley garantizó un

desregulación de los mercados inmobiliarios puede contribuir a satisfacer las necesidades de vivienda, siempre que no haya limitaciones desde la oferta ni de la demanda. La mitigación de tales limitaciones es, en esta concepción, el papel básico del Estado "facilitador" (Cuenya, 1997).

64 El Consejo Nacional de la Vivienda está integrado por el Poder Ejecutivo, los estados provinciales y la Ciudad Autónoma de Buenos Aires, y su finalidad (artículo 12 , Ley 24.464) es: a) Coordinar la planificación del Sistema Federal de Vivienda; b) Proponer anteproyectos de normas legales, técnicas y administrativas para el mejor cumplimiento de los objetivos del Sistema Federal de la Vivienda; c) Promover convenios de colaboración técnica y financiera con otros países o con organismos internacionales; d) Evaluar el desarrollo de los objetivos del Sistema Federal de Vivienda y en particular el avance en la reducción del déficit habitacional y el estricto cumplimiento de lo establecido en la ley del Sistema Federal de Vivienda; e) Definir criterios indicativos de selección de adjudicatarios de 
piso mínimo de financiamiento de 900 millones de pesos/dólares al año y sumaría el recurso "producido de la negociación de títulos que se autorice a emitir para la construcción de viviendas económicas" (artículo 3), entre otros aportes posibles para el financiamiento del sistema La nueva normativa se dirigía a sostener el financiamiento individual de la demanda, con una meta de cobertura del $45 \%$ del Fondo en un plazo de 4 años. Asimismo, introduce una clara preocupación por marcar un giro en la regularización dominial de las obras realizadas por el propio FONAVI y la valuación de su parque habitacional; y, finalmente, expresa la necesidad de disponer de escrituras traslativas de dominio como garantía de las jurisdicciones para obtención de créditos nacionales o internacionales.

La ley fija los porcentuales de distribución del Fondo y ata la futura distribución de recursos a una "matriz de desempeño" determinada por "el uso que se haga de los fondos, el nivel de recuperos, el nivel de inversión realizado específicamente en obra, directamente o por medio del crédito y la variación del déficit habitacional" (artículo 5). Más allá de que dicha matriz no haya sido implementada, prorrogando los coeficientes de distribución fijados originalmente en la ley, se destaca la inquietud del momento por incorporar al sistema criterios de eficiencia y corregir importantes limitaciones operativas.

Respecto a la reforma del FONAVI y la creación de este nuevo marco institucional y financiero, Cuenya (2005) identifica tres grandes cambios: i) la descentralización de los recursos FONAVI y la asignación de facultades a los organismos jurisdiccionales; ii) la reorientación de los recursos, con un desplazamiento de la acción tradicional de construcción de conjuntos masivos de viviendas hacia el crédito individual a la demanda (para financiar la compra, construcción o mejoramiento de la vivienda); iii) el establecimiento de pautas para mejorar el esquema financiero y sanear deficiencias crónicas en el funcionamiento del FONAVI, cuestionado por problemas de ineficiencia y corrupción. Respecto del primer cambio mencionado, cabe destacar que se delegaron una enorme cantidad de funciones cruciales como, por ejemplo: la programación de obras e inversiones; la definición de las características de las obras; la aprobación de la ejecución; el seguimiento y control; la adjudicación y la administración de los recursos; y, finalmente, la posibilidad de descentralizar la ejecución de las acciones a municipios, comunas y entidades sin fines de lucro

Para la autora, estos cambios implicaron diversas cosas. En el primer caso, el resultado fue una quita del poder a la cartera nacional de vivienda ${ }^{65}$ El segundo cambio trajo aparejado la

viviendas construidas o créditos otorgados con fondos del FONAVI; f) Dictar su estatuto interno garantizando la representación de todas las jurisdicciones.

${ }^{65}$ Desde el punto de vista institucional, Rodulfo (2003) sostiene que se produjo una desjerarquización del organismo nacional de vivienda. "En 1994 la Secretaría de Vivienda y Calidad Ambiental se transforma en Subsecretaría de Vivienda de la Secretaría de Desarrollo Social prácticamente sin asignación presupuestaria propia. De los U\$S 1300 Millones que administraba hasta 1991, pasó a U\$S 900 Millones (transferencias automáticas a jurisdicciones provinciales) en el año 1992 quedándose sin recursos propios salvo los del endeudamiento externo BIRF BID y sus contrapartidas nacionales. Programa Municipios I y II ( U\$S 500 en 4 años para infraestructura urbana y fortalecimiento municipal).Dicha situación se modifica levemente hacia 1996 e incluye el Programa 17 de Mejoramiento habitacional e infraestructura básica U\$S 30 Millones/año y el Contrato de Préstamo BID PROMEBA y sus contrapartidas (por U\$S 170 Millones/4 años) aunque luego este fue transferido al área de la Secretaria de Desarrollo Social y posteriormente FOPAR Fondo Participativo de inversión Social; PROSOFA Programa Social en Áreas de Frontera Grupos Vulnerables entre otros" (Rodulfo, 2003: 4). 
posibilidad de una transformación de la política de vivienda "llave en mano". Esto suponía, en gran medida, afectar los intereses de los contratistas beneficiados por el Estado mediante el antiguo modelo. Por último, el tercer cambio creó condiciones favorables para mejorar los aspectos financieros del sistema y controlar la gestión de los organismos ejecutores (Cuenya, 2005).

Por otra parte, según Cravino, Fernández Wagner y Varela (2002) la reinstauración del principio liberal de la responsabilidad individual en el acceso a la vivienda, implicó el abandono de los principios de solidaridad social y la responsabilidad compartida que habían caracterizado el diseño del sistema de antaño. Ello se evidencia en cómo los cambios macroeconómicos impactaron en el sistema financiero. Se produjo la privatización del BHN, priorizando la fórmula del recupero y la transformación de los préstamos en "títulos valores", insertos en el mercado de capitales. La reforma laboral eximió al empleador de aportar la contribución al FONAVI y el esquema de financiamiento fue reemplazado por un gravamen a los combustibles (un impuesto de acceso masivo y regresivo).

El nuevo dispositivo legal apuntó a orientar los recursos FONAVI hacia el circuito financiero, mediante un sistema de créditos individuales y potencialmente "titulizables". Simultáneamente, la ley aportó "gobernabilidad" provincial y se orientó al beneficio del capital financiero. Es decir, su diseño se subordinó a la lógica hegemónica del período (Rodríguez y Di Virgilio, 2008). En consonancia con Rodulfo (2003), estas investigadoras apuntan a que (frente al nuevo esquema de descentralización y diversificación de las modalidades de gestión y producción) el sector concentrado de la gran empresa se resultó desplazado hacia otros rubros de infraestructura, de mayor rentabilidad relativa. Constructoras de menor escala atendieron al subsidio a la demanda, aunque con una estructura más débil y atomizada territorialmente. En este sentido, la descentralización parece haber incidido positivamente, ya que al promover una ejecución más "territorializada" de la política de vivienda cambiaron los actores económicos que se benefician.

En este marco, según Cuenya (2005), el nuevo sistema redefinió roles y protagonismos entre los actores públicos y privados vinculados al sistema político, económico e institucional de la vivienda. El balance oficial registra un mejora en la desempeño global del sistema: se incrementan la unidades año terminadas; se registra una mayor diversificación de operatorias; aumentan las tasas de recupero y escrituración; y, se incrementa el ingreso de otros recursos (aportes provinciales, municipales, entidades privadas y del sistema financiero) al FONAVI. Pero frente a ello, persiste el carácter de fondo específico del FONAVI, que continuará asegurando una masa considerable de recursos y un peso significativo en la construcción de viviendas nuevas (a través de las empresas constructoras, en contraposición a otro tipo de soluciones habitacionales) ${ }^{66}$.

${ }^{66}$ En el año 1998, la inversión en viviendas con infraestructura fue de $\$ 1.129$ millones, mientras que se destinaron $\$ 33$ millones a créditos individuales, \$38 millones a obras de equipamiento y \$37 millones a obras de infraestructura (Cuenya, 2005). 
Asimismo, se verifican importantes ineficiencias jurisdiccionales (Cuenya 2005). La literatura parece coincidir en que la continuidad de las operatorias tradicionales "llave en mano" en este período se presentó articulada con mecanismos de cofinanciamiento que acentuaron la desatención de los sectores de bajos ingresos, filtrando "hacia arriba" los recursos.

Estas tendencias en la política de vivienda fueron acompañadas por decisiones más amplias en materia habitacional. Diversos mecanismos afectaron el acceso a la ciudad: la privatización de las empresas de servicios públicos, la reconfiguración de las redes de transporte, la retracción del espacio público, la venta de bienes del Estado (entre ellos reservas de tierra fiscal), junto con el desmantelamiento de otras instituciones que en ciertos aspectos habían mostrado una vocación de seguridad social. Estos cambios contribuyeron al encarecimiento de la ciudad, siendo ineludible el deterioro del habitat de los sectores de bajos ingresos, que viendo restringidas sus posibilidad habitacionales, continuaron tomado tierra y ampliando el mercado inmobiliario informal.

En relación a esto último, la principal novedad en el cuadro sectorial fue la difusión de un conjunto de programas alternativos. Aunque fueron de pequeña escala y marginales, algunos aspectos de estos programas merecen ser rescatados. En este sentido, se difunde una serie de acciones vinculadas a: la regularización dominial de la tierra; el mejoramiento barrial integral y la urbanización de asentamientos informales; los lotes con servicios; los bancos de tierra; los micro-créditos para el mejoramiento de la vivienda; la vivienda progresiva; e intervenciones de pequeña escala con distinto tipo de articulaciones sectoriales. Converge aquí el reconocimiento de la agenda de las organizaciones sociales (que acumulan experiencias del retorno democrático), con los nuevos criterios técnicos que reconocen las limitaciones de la mirada sectorial tradicional y con los lineamientos de programas con endeudamiento externo de los organismos internacionales ${ }^{67}$.

En la figura 3, se puede ver una comparación genérica de los rasgos asumidos por los programas alternativos frente a la política tradicional de vivienda "llave en mano", donde se diferencia en el modelo de gestión, la lógica de producción y la relación con la demanda.

En algunos casos, la descentralización habilita un proceso de intermediación de los gobiernos locales, que ajustan mejor la respuesta a la estructura de la demanda. Al mismo tiempo, los programas alternativos suponen, en mayor o menor medida, un reconocimiento de las formas de producción existente de la ciudad y de los actores que participan de dicho proceso ${ }^{68}$. También implican una irrupción de modelos de gestión que se corren del formato preestablecido de la licitación de obra pública y una comprensión del problema superadora

\footnotetext{
${ }^{67}$ En el caso de la regularización de los asentamientos informales, es evidente la importancia que esta línea de acción adquiere de la mano de la agenda de "lucha contra la pobreza" de los organismos internacionales. La política, en gran medida del Banco Interamericano de Desarrollo y en menor medida del Banco de Reconstrucción y Fomento, aboga y financia en los últimos años la instrumentación de programas de mejoramiento de barrios en todos los países Latinoamericanos (Fernádez Wagner, 2010).

68 En el caso argentino, el Programa de Mejoramiento de Barrios (PROMEBA) es un ejemplo emblemático, en tanto introdujo una visión más integral de la problemática de los asentamientos informales y de los modos que puede asumir la política pública en materia habitacional.
} 
respecto de la mirada del déficit de vivienda y relativamente independiente del esquema del producto preestablecido (a medida del beneficio de la empresa contratista).

Fig. 3 Política de vivienda de primera generación vs. de segunda generación.

\begin{tabular}{|l|l|l|}
\hline & \multicolumn{1}{|c|}{$\begin{array}{c}\text { Políticas de vivienda } \\
\text { "llave en manos" }\end{array}$} & $\begin{array}{c}\text { Políticas de vivienda } \\
\text { "alternativas" }\end{array}$ \\
\hline Tipo de intervención & $\begin{array}{l}\text { Erradicación de los } \\
\text { asentamientos irregulares. }\end{array}$ & $\begin{array}{l}\text { Radicación de los asentamientos } \\
\text { irregulares. }\end{array}$ \\
\hline Tipo de producto & $\begin{array}{l}\text { Construcción de conjunto } \\
\text { habitacional sobre terreno libre. }\end{array}$ & $\begin{array}{l}\text { Construcción de baja y media } \\
\text { complejidad (de baja productividad). }\end{array}$ \\
\hline Financiamiento & $\begin{array}{l}\text { Fondos públicos, con muy bajo o o } \\
\text { ningún recupero. }\end{array}$ & $\begin{array}{l}\text { Fondos públicos u otras fuentes, con } \\
\text { recupero parcial o total de la inversión. }\end{array}$ \\
\hline Decisión y planificación & $\begin{array}{l}\text { La realiza el Estado en forma } \\
\text { centralizada. }\end{array}$ & $\begin{array}{l}\text { Centralizada, con distintos grados de } \\
\text { participación de la población. }\end{array}$ \\
\hline Construcción & $\begin{array}{l}\text { Grandes empresas por licitación } \\
\text { pública. }\end{array}$ & $\begin{array}{l}\text { Pequeñas empresas locales, } \\
\text { cooperativas, o los usuarios } \\
\text { organizados. }\end{array}$ \\
\hline Asignación social & $\begin{array}{l}\text { Listado de "handicapología" de la } \\
\text { población destinataria. }\end{array}$ & $\begin{array}{l}\text { Receptor pasivo, no participa en } \\
\text { la toma de decisiones. } \\
\text { respuesta a una demanda específica. }\end{array}$ \\
\hline Usuario & $\begin{array}{l}\text { Receptor activo, con diferentes grados } \\
\text { de implicación en el proceso. }\end{array}$ \\
\hline
\end{tabular}

Fuente: Raúl Fernández Wagner (s/f)

A pesar de las limitaciones conocidas de las políticas sociales compensatorias, según Rodulfo (2003), junto con la focalización en la atención de situaciones críticas (postergadas por más de tres décadas), estas acciones abrieron espacios a la participación de los diversos actores sociales involucrados; pusieron en el debate de las políticas habitacionales la situación del déficit cualitativo de los sectores populares y el aporte (real y potencial) de estos actores a la transformación de la realidad habitacional; tuvieron una valoración positiva del accionar público respecto de la exploración de campos de problemáticas desatendidas; mostraron la necesidad de asociación entre el sector público y comunitario en la gestión y ejecución de proyectos y programas habitacionales; y, dieron cuenta de la articulación en los procesos y acciones sociales emprendidas o a emprender.

En paralelo, las principales críticas o problemas apuntados son las restricciones asociadas a la marginalidad en la agenda, la escasez de recursos destinados, el alcance de experiencia piloto, la extrema pobreza de la población destinataria, las estructuras municipales con dificultad para asimilar la nueva dinámica de trabajo de los programas de vivienda popular, la necesidad de ampliar la capacidad operativa de los gobiernos locales (en los procesos de coordinación 
intersectorial, asistencia técnica, cooperación y participación con los habitantes) y, además, el reconocimiento de que este tipo de experiencias son muy vulnerables frente a los cambios políticos y administrativos (Cuenya, 2005). No obstante, es importante destacar que en algunos casos estas experiencias previas se entrelazan con las diferentes capacidades técnicas y políticas de los gobiernos municipales al momento de implementar el PCFV. En este punto, hay un encuentro y un lugar de tensión entre "experiencia piloto" y la masividad de la política que señalaba Ballent (2005).

En síntesis, en este período se verifica un proceso de abandono de concepto de vivienda social, ya que el origen del financiamiento pierde el vínculo con solidaridad social que originalmente tenía, se prioriza formas de cofinanciamiento y la capacidad de pago. Al mismo tiempo, se descentraliza la política habitacional y las jurisdicciones provinciales ganan mayor protagonismo. En paralelo, algunas de las falencias históricas del sistema de vivienda son cuestionadas y se difunden programas alternativos. Estos programas, sin embargo, resultan marginales frente a la continuidad de las operatorias de vivienda tradicionales "llave en mano" que, tamizadas por los mecanismos de co-financimiento, se filtran a sectores de mayores ingresos.

\subsubsection{La provincia de Buenos Aires frente a la descentralización}

Dado que no existen demasiados antecedentes de investigaciones que abarquen de modo sistemático el estudio de la descentralización de la política de vivienda en la provincia de Buenos Aires. A partir de la información oficial aquí sólo se describir los rasgos que asumió dicho proceso en los años noventa, sin profundizar en su análisis. No obstante, esto nos permitirá observar aún en el plano de la formalidad ciertas diferencias con la "política federal de viviendas".

A partir de 1992, la provincia de Buenos Aires continúa administrando el 14,5\% de los recursos de este fondo específico ${ }^{69}$, pero con la descentralización y la federalización del FONAVI adquiere autonomía en la definición de la política de vivienda y en el diseño de programas propios $^{70}$. La recuperación de la estabilidad económica y el fin del ciclo de hiperinflación del 1989-90, permitieron que simultáneamente se volviera a poner en ejecución la construcción de obras paralizadas, se devolviera la operatividad financiera al programa y se aumentara la cantidad soluciones habitacionales administradas por el Instituto de la Vivienda de la Provincia de Buenos Aires (IVBA).

\footnotetext{
${ }^{69}$ La Ley 24.130/92 recurre a los coeficientes de distribución de la resolución № 765/89 de la Secretaría de Vivienda de la Nación.

70 "Como consecuencia del mayor poder otorgado a las provincias (descentralización de los recursos financieros y poder político de aplicación de la nueva ley), la profundidad y el alcance de los cambios impulsados por la nueva normativa en dirección a un rol facilitador del Estado, pasaron a depender, en buena medida, de la voluntad política de sus gobiernos, de la fuerza de sus alianzas y compromisos con las empresas constructoras y clientelas políticas, de la vocación de trabajo con ONG y organizaciones de base" (Cuenya, 2005: 5).
} 
En el apartado anterior se vio cómo cambió el origen del Fondo a principio de la década. Al tiempo que se desvinculaba la vivienda de los aportes patronales y de los trabajadores, se buscaba garantizar un umbral mínimo de recursos. A fin de la década, esta supuesta contradicción se resuelve, ya que la política de ajuste del gasto público terminará por licuar los recursos destinados a financiar la política de vivienda. El Decreto 455/99 suspende la obligación del Tesoro Nacional de atender la garantía el FONAVI (en el caso que las percepciones del Fondo fueran inferiores a los 900 millones de pesos) y la ley 25.400/01 ratifica el Pacto Fiscal del año 2000 y el Compromiso Federal del año 1999, a los cuales la provincia de Buenos Aires adhirió. Allí se establecía que las jurisdicciones podrían destinar un 50\% de los fondos específicos a otros destinos ${ }^{71}$.

El crecimiento y la crisis de la curva de viviendas terminadas con financiación del IVBA se explica en este contexto más amplio, vinculado a las políticas de ajuste estructural (ver figura 4). Según el propio IVBA (2006), la orientación global de política provincial no escapa al proceso de descentralización y tercerización de los roles del Estado que operaban a nivel nacional. En este período, el Instituto adquirió el rol de facilitador de emprendimientos descentralizados, los cuales eran impulsados por municipios o entidades intermedias (cooperativas, gremios, sindicatos, etc.), quienes se encargaban de aportar los terrenos y los beneficiarios, mientras que el organismo provincial aporta los fondos y la supervisión de los trabajos.

Fig. 4 Cantidad de viviendas terminadas IVBA, total provincia 1978-2002

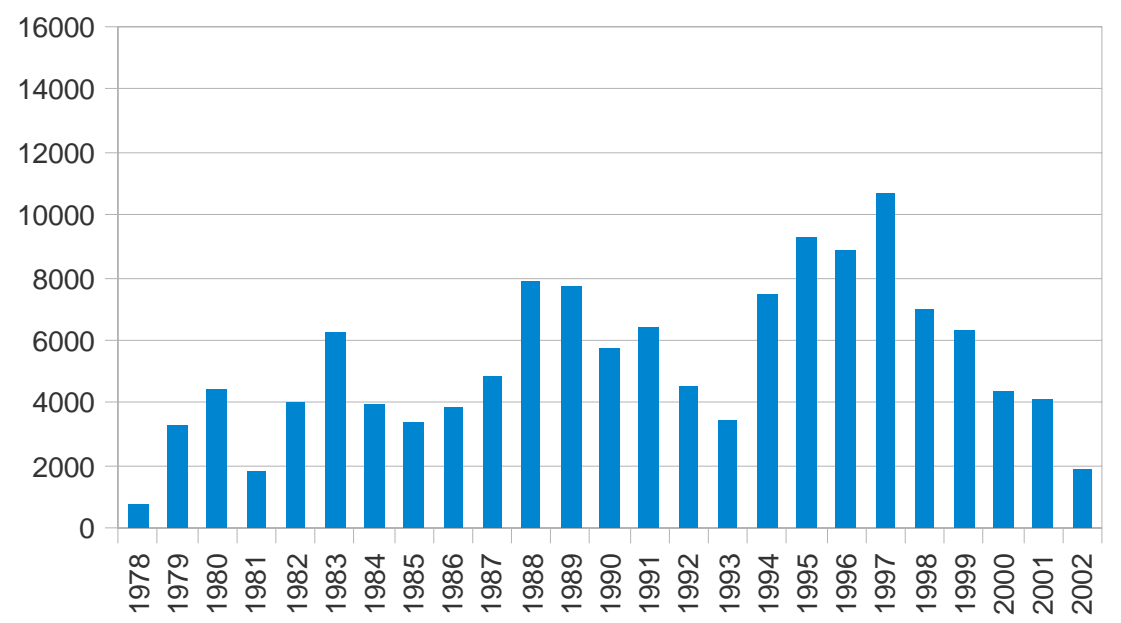

Fuente: elaboración propia en base IVBA (2006).

Salvo la decisión de continuar construyendo viviendas en el interior de la provincia en tipología individual y en planta baja e instrumentar la titularización de hipotecas con el Banco Hipotecario (al cual se encomienda la cobranza del recupero de una operatoria específica), el IVBA no asumió ninguna otra iniciativa de formulación de política y se transformó básicamente en un

\footnotetext{
${ }^{71}$ Esta normativa continúa vigente.
} 
órgano de control y financiación. La distribución y el financiamiento de las viviendas quedó sujeta a la disponibilidad de terrenos y solicitudes de terceros, municipios y/o entidades (IVBA, 2006).

Del conjunto de acciones emprendidas por el organismo de referencia en materia habitacional ${ }^{72}$ pueden observarse ciertos cambios y continuidades en relación a la etapa de institucionalización de un sistema centralizado vivienda social.

En la etapa previa a, cuyo inicio data de fines de los setenta, el rasgo central fue que el IVBA se convirtió en el organismo autárquico, encargado de aplicar la Ley FONAVI (21.581/77) ${ }^{73}$ e implementar las operatorias centralizadas diseñadas a nivel nacional. Esto último era hecho bajo un régimen de licitación de obra pública destinado a la construcción de viviendas nuevas en grandes conjuntos a través de empresas constructoras.

El principal cambio en la nueva etapa es la desaparición de las obras ejecutadas a cargo del IVBA, vía licitación pública y contrato de obra. Ninguna de las acciones emprendidas en la década del noventa asumió esta modalidad. Si bien en la primera mitad de la década terminó de ejecutarse la Operatoria FONAVI remanente (la cual tuvo un peso significativo en el balance global, representando la segunda operatoria en importancia y casi el $21 \%$ del total de viviendas construidas entre 1992-2003), no se iniciarían nuevos proyectos de vivienda bajo esta modalidad. Del mismo modo, la Operatoria FOPROVI ${ }^{74}$ dejó de ser ejecutada por la provincia, redirigiendo dicho fondo a operatorias descentralizadas a nivel municipal. Si bien los contratos de obra dejan de estar a cargo del IVBA, la construcción del producto cerrado y homogéneo, que tradicionalmente prioriza el sector empresarial, no desapareció como mecanismo hegemónico.

Por otra parte, tuvo continuidad la Operatoria Autogestión Constructiva, implementada desde mediados de los ochenta como un programa de coparticipación destinado a financiar un monto fijo por vivienda a través del POPROVI. Esta operatoria se orientó a incentivar procesos de ayuda mutua en articulación con municipios y entidades. El IVBA aportaba financiamiento para viviendas de $40 \mathrm{~m}^{2}$ de un dormitorio, así como el asesoramiento técnico y social, mientras que los municipios y las entidades intermedias aportan la tierra, la conducción de obra, la administración de fondos y la mano de obra. Hacia mediados y fines de los noventa, esta

72 El detalle de los programas que se describen a continuación se realizó a partir del documento "Instituto de Vivienda de la provincia de Buenos Aires. 50 años (1956-2006)" Dirección de Política Habitacional, Ministerio de Infraestructura, Vivienda y Servicios Públicos. Gobierno de la Provincia de Buenos Aires.

${ }^{73}$ Con una escala de financiamiento sin precedente para la historia de la política habitacional provincial, en el período 1977-1991 se alcanzó una producción promedio de 5016 viviendas/año (el 64\% de las cuales se realizaban bajo operatoria FONAVI), siete veces mayor que la producción media acumulada entre 1956-1976. Frente a este cambio, la provincia sancionó la provincia Ley Orgánica del Instituto de La Vivienda de Buenos Aires (Decreto-Ley 9.579/80) y amplió su capacidad operativa para dar mejor respuesta la creciente complejidad de la nueva política, que incluyó: la compra de terrenos; la realización del proyecto (barrios de viviendas con su infraestructura y equipamiento); la elaboración de pliegos de licitación conforme a la Ley 6.021 de Obra Pública Provincial; la licitación para su ejecución; la elección de la empresa ganadora en la contienda; la ejecución de la obra; la inspección durante su desarrollo; la recepción final; y, la entrega a los adjudicatarios (IVBA, 2006).

${ }^{74}$ La operatoria del FOPROVI (Fondo Provincial de la Vivienda), cuyo origen deviene de un porcentual del impuesto inmobiliario y otros recursos (véase Decreto-Ley 9573/80 y Ley 10.352/85), responde a un esquema de ejecución centralizado por la Provincia, muy semejante al FONAVI pero con variantes en el perfil de los destinatarios y los mecanismo de asignación de la vivienda. 
modalidad de gestión se recupera con otro sentido, en un esquema de relación interministerial donde se cruzan los planes de empleo con la construcción de vivienda.

Un punto aparte merece la irrupción de los Programas Pro-Casa y Pro-Tierra, en el año 1988. Según el IVBA (2006), se procuraba un acercamiento a la realidad local, la provincia recuperaba experiencias de ejecución descentraliza de antaño y se buscaba movilizar recursos locales. En este sentido, se consideraba importante intensificar la relación con los municipios y las organizaciones barriales. Estas acciones implicaron un cambio de escala. La producción de viviendas suponía un desplazamiento de los intereses empresarios tradicionales y se abordaría el problema del acceso a la tierra (mediante la venta de lotes con servicios en cuotas para sectores de bajos recursos), que desde principios de la década se agrava por el aumento de la pobreza.

Si bien estos programas sufrieron dificultades de implementación y no lograron sostenerse en el tiempo, fueron pioneros en la búsqueda de nuevas modalidades de gestión. Avanzados los noventa, la descentralización de la política habitacional cobraría otro significado. No obstante, la operatoria Pro-Casa representó el 8,1\% del total de viviendas construidas entre 1992-2003 y el cuarto lugar en las quince operatorias registradas en el período. Por otra parte, estos programas introducen una preocupación por leer la matriz suelo y atender las dificultades de los sectores populares en el acceso a la tierra urbanizada. Vale señalar que esta preocupación desaparecerá de los programas habitacionales, siendo redefinida en torno al problema de la regularización dominial.

Como señala Relli (2007: 18): "durante la gobernación de Antonio Cafiero se comenzaron a instalar nociones novedosas en relación a las funciones del Estado en materia de vivienda social, la necesidad de articular con otros actores (municipios y ONG) y de diversificar las soluciones de acuerdo con un diagnóstico que veía y consideraba los diferentes tipos de déficit que padecía la población (fundamentalmente, los habitantes del Conurbano Bonaerense). En ese marco conceptual -e ideológico- se diseñaron varias operatorias alternativas al modelo tradicional que, por un lado, atendieron las problemáticas de acceso a la tierra y la vivienda con una batería de propuestas distintas (lotes con servicios, vivienda evolutiva, apoyo a la autoconstrucción, etc.) y, por otro lado, introdujeron a los Municipios y entidades sin fines de lucro como actores copartícipes en la gestión de los programas, lo cual llevó a denominarlas "operatorias descentralizadas", como una manera de diferenciarlas de las políticas tradicionales".

En contraposición en la gobernación de Eduardo Duhalde, en el marco de las reformas mayores, gana autonomía en el control de los recursos del FONAVI y desarma los programas alternativos anteriores. Aunque algunos aspectos del modelo de gestión se extendieron a las nuevas operatorias que comenzarán a desarrollarse, como por ejemplo: el reparto de responsabilidades y tareas ejecutivas a gobiernos locales y entidades comunitarias. En el marco de la nueva gestión, el IVBA abandonó por varios años el sistema de licitación de las obras a empresas y se constituyó en ente financiador de emprendimientos sugeridos por 
empresas, municipios o entidades sin fines de lucro (mutuales, cooperativas, ONG, sindicatos, asociaciones civiles). A estas instituciones se les asignó el rol de gestoras y ejecutoras de los programas, teniendo a su cargo obligaciones específicas, según las distintas operatorias (Relli, 2007).

Fig. 5 Cantidad de soluciones habitacionales según programa, total provincia 1992-2003

\begin{tabular}{|c|c|c|c|}
\hline \multicolumn{2}{|r|}{ Programas IVBA } & $\begin{array}{c}\text { Soluciones } \\
\text { habitacionales }\end{array}$ & $\%$ \\
\hline \multicolumn{2}{|l|}{ FONAVI } & 13.593 & 20,7 \\
\hline \multicolumn{2}{|l|}{ FOPROVI } & 70 & 0,1 \\
\hline \multicolumn{2}{|c|}{ Autogestión constructiva } & 2.508 & 3,8 \\
\hline \multicolumn{2}{|c|}{ Viviendas rurales } & 460 & 0,7 \\
\hline \multicolumn{2}{|c|}{ Otras operatorias/ transf. } & 264 & 0,4 \\
\hline \multicolumn{2}{|l|}{ Pro-casa } & 5.206 & 7,9 \\
\hline \multicolumn{2}{|l|}{ Pro-techo } & 279 & 4,2 \\
\hline \multicolumn{2}{|c|}{ Reconstrucción de barrios } & 189 & 2,8 \\
\hline \multicolumn{2}{|c|}{ Banco Hipotecario Nacional $\left(^{*}\right)$} & 5.451 & 8,3 \\
\hline \multirow{5}{*}{$\begin{array}{l}\text { Plan } \\
\text { Bonaerense } \\
\text { Tierras y } \\
\text { Vivienda }\end{array}$} & Abuelos & 661 & 1,0 \\
\hline & Novios & 1.348 & 2,0 \\
\hline & Solidaridad & 33.193 & 50,7 \\
\hline & Financiamiento compartido & 1.523 & 2,3 \\
\hline & Emergencia habitacional & 719 & 1,0 \\
\hline \multicolumn{2}{|l|}{ TOTAL } & 65.437 & 100,0 \\
\hline
\end{tabular}

Fuente: elaboración propia en base a IVBA (2006).

En este sentido, la cristalización del nuevo modelo de la política habitacional se remonta al año 1992, cuando se produce el lanzamiento del Plan Bonaerense de Tierra y Vivienda. Dicho plan estuvo compuesto por una serie de programas que consolidarán la estrategia provincial de descentralización. En una primera etapa se distinguen cuatro programas:

El Programa Bonaerense I Abuelos, Novios, Chicos de la Calle y Violencia Familiar, cuyo objetivo es realizar una focalización social supervisada por el Instituto. En este programa, la ejecución está a cargo de municipios o entidades sin fines de lucro por medio del sistema de administración de obras. Estos no sólo ejecutan la obra sino que también proveen el terreno y la infraestructura. La provincia aporta la supervisión y el financiamiento a través del FONAVI y el FOPROVI, con un monto fijo por solución habitacional (se incluyen vivienda, ampliaciones y terminaciones). 
El Programa Bonaerense II Solidaridad apunta a construir vivienda nueva de dos dormitorios de $52 \mathrm{~m}^{2}$ en conjuntos habitaciones en planta baja, ampliaciones o terminaciones para población de bajos recursos. Al igual que el caso anterior, la provincia aporta el financiamiento fijo por unidad a través del FONAVI y el FOPROVI y la asistencia técnica a municipios y entidades. Estos ceden el suelo, se hacen cargo de la infraestructura, la ejecución de la obra y la selección de los beneficiarios. Este programa es el más importante del período. De los 15 programas que se implementan entre 1992-2003, representa el 50,7\% del total de las soluciones habitacionales construidas y el $85 \%$ del Plan Bonaerense Tierra y Vivienda.

El Programa Bonaerense III Financiamiento Compartido tiene por objetivo brindar asistencia financiera parcial (entre el $50-90 \%$ del precio de la vivienda) a entidades públicas y privadas que promuevan o ejecuten emprendimientos habitacionales. La tipología puede ser vivienda individual o colectiva, la infraestructura y el suelo corren por cuenta de las entidades. La ejecución está a cargo de empresas constructoras contratadas por las entidades, mientras que la provincia asume la supervisión e inspección de obra.

El Programa Bonaerense IV Emergencia Habitacional se propone dar soluciones habitacionales mediante viviendas industrializadas o asistencia financiera a municipios declarados en situación de emergencia habitacional por el gobierno provincial. La ejecución de la obra es delegada al municipio por sistema de administración o contrato de obra. El sistema de financiamiento es igual a los Programas Bonaerenses I y II, pero existe la variante de construir viviendas prefabricadas, a diferencia de los programas anteriores que utilizan un sistema constructivo tradicional.

Salvo el programa de financiamiento (Bonaerense III), en todos los casos los programas se rigen por el Decreto-Ley 9.104/78, por el cual la provincia está facultada a celebra los convenios con los municipios para financiar y realizar obras por fuera del Régimen de Obras Públicas provincial. La realización de la obras queda a cargo del municipio, tanto a través de ejecución directa como vía terceros. La provincia sólo define una serie de criterios operativos (basados en el Decreto-Ley 3.201/70, el Decreto 1.178/73 y en una serie de resoluciones administrativas) y delega el rol ejecutivo a los municipios, apostando a la iniciativa de nivel local. La función del IVBA pasa a ser entonces el financiamiento y la supervisión, junto con la optimización de la gestión y la organización de los recursos del sistema.

Una segunda etapa se inicia en el año 1995, en sintonía con la sanción de la Ley de Sistema Federal de Viviendas (ver apartado 2.1.3). En momento se creó el Bonaerense $V$ Prestamos Familiares, con el objetivo de brindar asistencia financiera a grupos familiares con ingresos escasos y limitada capacidad de ahorro para que pueda ser destinada a la construcción, terminación, refacción o ampliación de viviendas permanentes.

Otra línea que refleja la preocupación por optimizar la gestión es el diseño del Subprograma de Titulación de Hipotecas del Programa Bonaerenses II. Por convenio suscrito entre el IVBA y el BHN, este programa terciariza en el Banco la administración de la cobranza de recuperos del Programa Bonaerenses II Solidaridad, con el fin de mejorar la recaudación (con la meta de 
aumentar en un $300 \%$ el flujo de recupero) y asegurar el reciclaje de los fondos ${ }^{75}$. De este modo, se instrumenta la participación de la Provincia en el marco de la operatoria de titularización de hipotecas del BHN. El régimen propuesto busca ser compatible con sectores socioeconómicos con una capacidad pago equivalente a los precios promedios del mercado de alquileres. EI IVBA aporta un financiamiento complementario del $15 \%$ del precio de venta y registra, gestiona y supervisa los emprendimientos que se ajustan a esta operatoria.

Estos dos programas también son significativos en cuanto a su magnitud. El Subprograma de Titulización de Hipotecas es el tercero en importancia del período y alcanza 8,3\% del total de soluciones habitacionales ente 1992-2003. Si se considera sólo las soluciones habitacionales construidas en Plan Bonaerense Tierra y Vivienda, su peso relativo asciende a casi el 14\%, proporción semejante al Programa de Préstamos Familiares.

Una tercera etapa del Plan Bonaerense Tierra y Vivienda puede identificarse a partir del 19961997. Momento en cual se observa una nueva articulación intersectorial y la órbita de la vivienda recibe la influencia de otras políticas sociales.

A principio de los noventa, se creó en la Comisión de Tierras Fiscales Nacionales el "Programa Arraigo", con el objetivo de regularizar la situación dominial de las ocupaciones de los terrenos fiscales nacionales. Se sancionó también la denominada "Ley Pierri" (24.374/94), dirigida a atender la regularización dominial del conjunto de inmuebles urbanos. Estos dos acontecimientos introducen en la agenda pública el reconocimiento de una realidad urbana ampliamente extendida en la Provincia. En este contexto surge ${ }^{76}$ el Subprograma de Reintegración Urbano Social del Programa Bonaerenses II, en el año 1996, el cual adopta un esquema de coordinación y gestión asociada entre Nación, provincia y organizaciones. El IVBA brinda cooperación (financia materiales y mano de obra) y asistencia técnica en el proceso de regularización urbana, social y dominial de tierras fiscales a cargo del Programa Arraigo.

En el año 1997, el Subprograma de Autoconstrucción y Ayuda Mutua del Programa Bonaerenses // se inscribe dentro de un acuerdo marco con el Consejo Provincial de la Familia y el Desarrollo Humano. El objetivo, al igual que en el caso anterior, es prestar cooperación financiera para la compra de materiales y brindar asistencia técnica en emprendimientos habitacionales ejecutados por el Consejo Provincial de la Familia, destinados a población de alto riesgo en el Conurbano Bonaerense. Estos programas no obstante tuvieron más bien rasgos paliativos, no pasaron la fase experimental y tuvieron muy bajo impacto.

\footnotetext{
${ }^{75}$ En la ratificación del convenio "se encomienda al Banco Hipotecario Nacional, la gestión y administración de la cobranza de los recuperos provenientes de la adjudicación en venta de las viviendas construidas por dicho Organismo, a fin de acrecentar un flujo de fondos mediante el mejoramiento de los niveles de recaudación que garantiza su reciclaje, la reinversión permanente y sostenida de recursos genuinos destinados a obras..." (Decreto 109/97)

76 Desde ya, este subprograma no constituye la única línea de acción de la provincia en relación al proceso de regularización de asentamientos informales, competencia asumida por la Secretaría Social de Tierras. Sin embargo, muestra el alcance y el nivel de involucramiento e interacción de la política sectorial de vivienda en el problema de la tierra. Este subprograma representa el $0,7 \%$ de las unidades construidas en el marco del Plan Bonaerense de Tierra y Vivienda del IVBA entre 1991-2003.
} 
El mismo año surgió el Subprograma Trabajar del Programa Bonaerenses II Solidaridad, en articulación con el "Programa Trabajar" del Ministerio de Trabajo y Seguridad Social de la Nación. Este programa se propone construir viviendas económicas para sectores de bajos ingresos. La mano de obra se encuentra subvencionada por el programa de empleo. Mientras que el IVBA aporta el financiamiento a 25 años y la documentación técnica, el Instituto Provincial de Empleo gestiona la propuesta con los municipios y las entidades intermedias.

Dos años más tarde, en la misma línea de vinculación interministerial con el "Programa Trabajar", se diseñó el Subprograma Mejorar del Programa Bonaerenses $V$, con la finalidad de mejorar y completar viviendas permanentes. Los productos varían entre la construcción o terminación de un ambiente. El IVBA aporta asistencia financiera destinada a la compra de materiales. El Instituto Provincial de Empleo aporta recursos para la capacitación de los beneficiarios. Los municipios seleccionan los destinatarios, proveen herramientas y dirección técnica. Finalmente, el Ministerio de Trabajo financia la mano de obra.

En síntesis, el Plan Bonaerense Tierra y Vivienda muestra un gran número de programas y subprogramas. Si bien esto da cuenta de cierta diversificación de la acción pública en materia habitacional, al momento de mensurar la escala no todos los programas resultan significativos. Los tres o cuatro programas que tuvieron un impacto real y extendido se explican por las modalidades tradicionales construcción de vivienda "llave en mano", a través de empresa constructora, con ejecución descentralizada en los municipios y entidades sin fines de lucro y, en menor medida, marcada por la continuidad de operatorias FONAVI hasta mediados de la década. Por otro lado, se observa que el IVBA asumió un rol orientado hacia la asistencia financiera y técnica, como así también a la titularización de hipotecas a cambio de mejorar el desempeño de recuperos.

Otra de las características de la política habitacional de la década fueron la "lucha" contra la inercia de la macrocefalia urbana y una suerte de división territorial de recursos. Ambos proceso influyeron en el direccionamiento del financiamiento del fondo específico de vivienda hacia el interior de la provincia.

Dadas las dificultades del enfoque sectorial para resolver "equilibradamente" la relación entre la extensión de servicios, la disponibilidad de tierra y la localización en el Área Metropolitana de Buenos Aires, primó la postura de que la hiper-concentración concebida como fuente de diversos "males" debía ser combatida. Desde el punto de vista político, en los primeros años de la dictadura militar, en la etapa inicial del FONAVI esta decisión estuvo asociada a la conflictividad social y política del Conurbano, la fuerte presencia de las organizaciones villeras, curas del tercer mundo y organizaciones de base. Desde el punto de vista técnico, la magnitud del déficit de infraestructura implicaba mayores costos para las operatorias de vivienda en el principal aglomerado del país, y las intervenciones habitacionales en el interior de la provincia apuntalaban a la desconcentración urbana.

Esta visión de desactivar el "desorden" quedó reflejada en la nueva Constitución Provincial (artículo 36, inciso 7), del año 1994: "La Provincia promoverá el acceso a la vivienda única y la 
constitución del asiento del hogar como bien de familia; garantizará el acceso a la propiedad de un lote de terreno apto para erigir su vivienda familiar única y de ocupación permanente, a familias radicadas o que se radiquen en el interior de la Provincia, en municipios de hasta 50.000 habitantes, sus localidades o pueblos".

Paradójicamente, los distritos con mayor concentración de casos de déficit habitacional no tuvieron prioridad al momento de recibir recursos para atender el problema. Si consideramos, por ejemplo, el programa habitacional con mayor peso en la provincia de Buenos Aires en el período 1992-2003 (Programa Bonaerense II Solidadridad), el 82\% de las viviendas se construyeron en el interior de la provincia, mientras que, según el Censo Nacional de Población Hogares y Vivienda (2001), más del 80\% de las viviendas no aptas se encuentra en la Región Metropolitana de Bueno Aires.

En este marco a través del Programa Familia Propietaria (creado por Ley 11.423 y regulado por Decreto 2.510/94) la provincia de Buenos Aires se endeuda para comprar tierra (para facilitar el acceso al suelo y construir vivienda social). Operación que también se produciría en su mayoría en los partidos del interior de la provincia.

Paralelamente, el direccionamiento del FONAVI y el FOPROVI al interior de la provincia de Buenos Aires no pueden comprenderse sin registrar la creación del Fondo de Reparación Histórica del Conurbano Bonaerense (FRHCB). Dicho Fondo se inscribe en un complejo proceso negociación política, con diversos alineamientos y alianzas que trasciende el ámbito provincial para convertirse en una verdadera discusión federal (ver Danani, Chiara y Filc, 1997). En este contexto, el por entonces vicepresidente Eduardo Duhalde cedió su puesto y aceptó la candidatura a gobernador de la provincia de Buenos Aires ${ }^{77}$, condicionándola a la creación del FRHCB.

La Ley Nacional de Reforma Impositiva (ley 21.473/92) redefinió el régimen de coparticipación federal y asignó una masa considerable de recursos para el financiamiento de programas sociales en el Conurbano Bonaerense. La adhesión provincial (ley 11.247/92) y la creación del "Ente" encargado de administrar el FRHCB (decreto 1279/92) implicaron importantes inversiones de infraestructura socioeconómica en el marco del "Plan de Justicia Social para el Conurbano Bonaerense". En gran medida, la inversión fue destinada al saneamiento cloacal y de agua potable, junto con la consolidación de la red vial, y otras obras complementarias que apuntaron a consolidar la ciudad existente. Es decir, formaron parte de la política habitacional de sin que se hayan construido prácticamente viviendas, entre los rubros presupuestarios del Ente del Conurbano Bonaerense pueden verse cuál fue la diversidad del destino que tuvieron los fondos y los ínfimos recursos destinados a vivienda ${ }^{78}$.

\footnotetext{
77 Diario La Nación 01/06/97.

${ }^{78}$ El registro de erogaciones clasificadas por finalidad, función y programa de la Contaduría General de la Provincia de Buenos Aries (1994-1995) muestra que en el año 1994 el 1,17\% del total de las erogaciones de la cuenta especial del FRHCB se destinó a vivienda, mientas que en el año 1995 el proporción fue del 0,24\%. Según el Plan de Justicia Social (1993), durante este período el menú de obras se dirigió a la construcción de pavimentos (accesos a escuelas, repavimentación y rehabilitación de calles), a la ampliación de redes de agua potable y cloacales, a los desagües pluviales, al saneamiento de arroyos, al bacheo, a la ampliación de redes de luminarias, a los equipamientos
} 
Más allá del las controversias generadas en torno al $\mathrm{FRHCB}^{79}$ y a las prácticas políticas que se sirvieron de él, el surgimiento de este dispositivo financiero-institucional se asienta en un conjunto de realidades fácticas y debates previos que alimentaban la construcción de un problema territorial que requería ser nacionalizado. Distintos discursos registran la existencia de una suerte de entidad territorial, "el Conurbano", cuya dinámica es interdependiente de la escala nacional, pero sin embargo asume los costos del centralismo, al tiempo que la Avenida General Paz la despoja de los beneficios del mismo.

En el imaginario provincial, el nuevo dispositivo (la recepción de recursos específicos de la Nación para saldar la deuda histórica y consolidar la ciudad existente) opera delimitando esta entidad-problema y supone una convergencia con cierto discurso que entiende que es necesario "desactivar" aquello que da origen al problema. De allí que la política de vivienda busque emitir señales hacia otros distritos y, al mismo tiempo, se reconfigure cierta división territorial de los recursos transferiros por la Nación tras alterarse el mecanismo de coparticipación. Vale señalar, complementariamente, que el presupuesto del Ente del Conurbano Bonaerense cuadriplica las transferencias del FONAVI a la provincia en 1993 y las sextuplica en $1995^{80}$.

Por último, tras la desarticulación del sistema centralizado de vivienda social, Cravino, Fernández Wagner y Varela (2002) afirmen que en el AMBA la política habitacional estuvo caracterizada por el tratamiento marginal de la vivienda y una centralización en la cuestión de la tierra. En este plano, se da continuidad a las políticas de radicación de los años ochenta asociadas a la reinstauración de la democracia, siendo la principal intervención del Estado en materia habitacional las acciones de regularización ex post ${ }^{81}$. Razón por la cual, para estos investigadores, los sectores populares fueron los auténticos protagonistas de la política habitacional de los noventa, mediante el empleo de su tiempo, sus recursos y su trabajo en el proceso de auto urbanización y autoconstrucción de la ciudad.

\footnotetext{
comunitarios, a las escuelas primarias y técnicas, a hospitales y a jardines de infantes (ambas fuentes son citadas por Danani, Chiara y Filc, 1997).

79 EI FRHCB fue ampliamente criticado por su carácter de fondo partidario, por el alcance de las obras realizadas, por la discrecionalidad de la distribución de recursos, por la tensión entre la emergencia y la permanencia del fondo, así como por el nivel de autonomización al interior de la estructura estatal, por la participación del Consejo Provincial de la Mujer, etc. No nos detendremos en este punto, ya que los cuestionamientos del FRHCB no forman parte de objeto del análisis aquí propuesto.

80 Según Danani, Chiara y Filc (1997), en base a datos de la Contaduría General de la Provincia respecto de la ejecución presupuestaria económico-financiera de la Provincia de Buenos Aires, la recaudación anual del FRHCB en millones de pesos fue de \$ 427 en 1993, \$ 578 en 1994 y \$ 624 en 1995, mientras que las transferencias del Estado nacional a la provincias en concepto del FONAVI alcanzó los \$ 106 millones de pesos en 1993, los \$ 126 en 1994 y los \$ 103 en 1995 (datos extraídos del Consejo Nacional de Vivienda, Revista CONAVI № 26, año 2008).

${ }^{81}$ También denominadas curativas en oposición a la política activa y preventiva, como por ejemplo, la producción de suelo urbanizado o lote con servicios.
} 


\subsection{La política federal de viviendas (2003-2010)}

Una aproximación al contexto de surgimiento de la "política federal de viviendas", supone realizar un trabajo en dos planos. Por un lado, es necesario considerar el devenir de las articulaciones entre los distintos niveles del Estado y la nueva orientación sectorial en materia de vivienda desarrollada en la década de los noventa. Por otro lado, es imprescindible examinar las consecuencias de la crisis económica (que se produce hacia el final de dicho período) y, a partir de ello, la redefinición de la relación entre Estado, sociedad y mercado.

El agotamiento del régimen de la convertibilidad tiene múltiples facetas. Pero las señales se vuelven más contundentes desde la recesión de 1998. Momento en el cual la liquidez de activos del proceso de privatización ya se había evaporado, el ingreso de divisas se estanca, la balanza comercial muestra signo negativo y el financiamiento del déficit de la cuenta corriente vía el endeudamiento externo muestra sus límites. A pesar de ello, hacia el fin del régimen de convertibilidad, se apostó al refinanciamiento de la deuda y la profundización de las políticas de ajuste que no hicieron más que agudizar el ciclo recesivo. Proceso que se desencadena drásticamente en el 2001, cuando se genera una crisis económica, social y política de tal magnitud, que marcaría un cambio de época. Se introduce entonces un giro en relación al proyecto neoliberal que da lugar a un modelo de acumulación de características neodesarrollistas.

Los avatares de la crisis se trasladan a la política de vivienda transformando en un hecho el desfinanciamiento del FONAVI. La política de vivienda queda inscripta en un contexto de reducción del gasto social y, devaluación mediante, sus recursos pasan a estar pesificados. En el apartado 2.1.3, vimos que la descentralización del FONAVI se operativizó con un piso de recursos transferibles a las provincias asegurados en 900 millones de pesos/año. Pero, como señala el estudio de COHRE, en el año 1999 el decreto 455/99 quitó el piso mínimo de aportes, transfiriéndose sólo 600 millones de pesos. Luego, el flujo del FONAVI fue afectado por los pactos de coparticipación que autorizaron a las provincias a aplicar un $50 \%$ de esos recursos a gastos corrientes. En 2002, el margen de libre disponibilidad se amplió al 100\%. Los recortes presupuestarios y el cambio de partidas con destinos específicos implicaron el remate casi definitivo del sistema público de vivienda. La transferencia de recursos FONAVI muestra una tendencia decreciente a medida que avanza la década del noventa, hasta desaparecer en 2002 con la paralización total de los planes de vivienda (COHRE, 2005).

De este modo, al tiempo que la política de vivienda es desfinanciada, las necesidades aumentan dada la transformación del mercado laboral y la ampliación de los sectores con restricciones de recursos para afrontar el acceso al suelo y a la vivienda. Por otro lado, las consecuencias de la crisis configuran un escenario complejo. En el año 2002, la EPH muestra indicadores récord, la tasa de desocupación ascendía al 21,5\%, la línea de indigencia alcanzaba el $27,5 \%$ de la población y el $57,5 \%$ se encontraba por debajo de la línea de 
pobreza. La crisis de representación política dominaba la escena, las instituciones democráticas fueron totalmente desacreditadas, y el malestar social asumió distintas formas de protesta y organización popular.

Fig. 6 Cantidad de viviendas terminadas (FONAVI + P. Federales) total país 1979-2009.

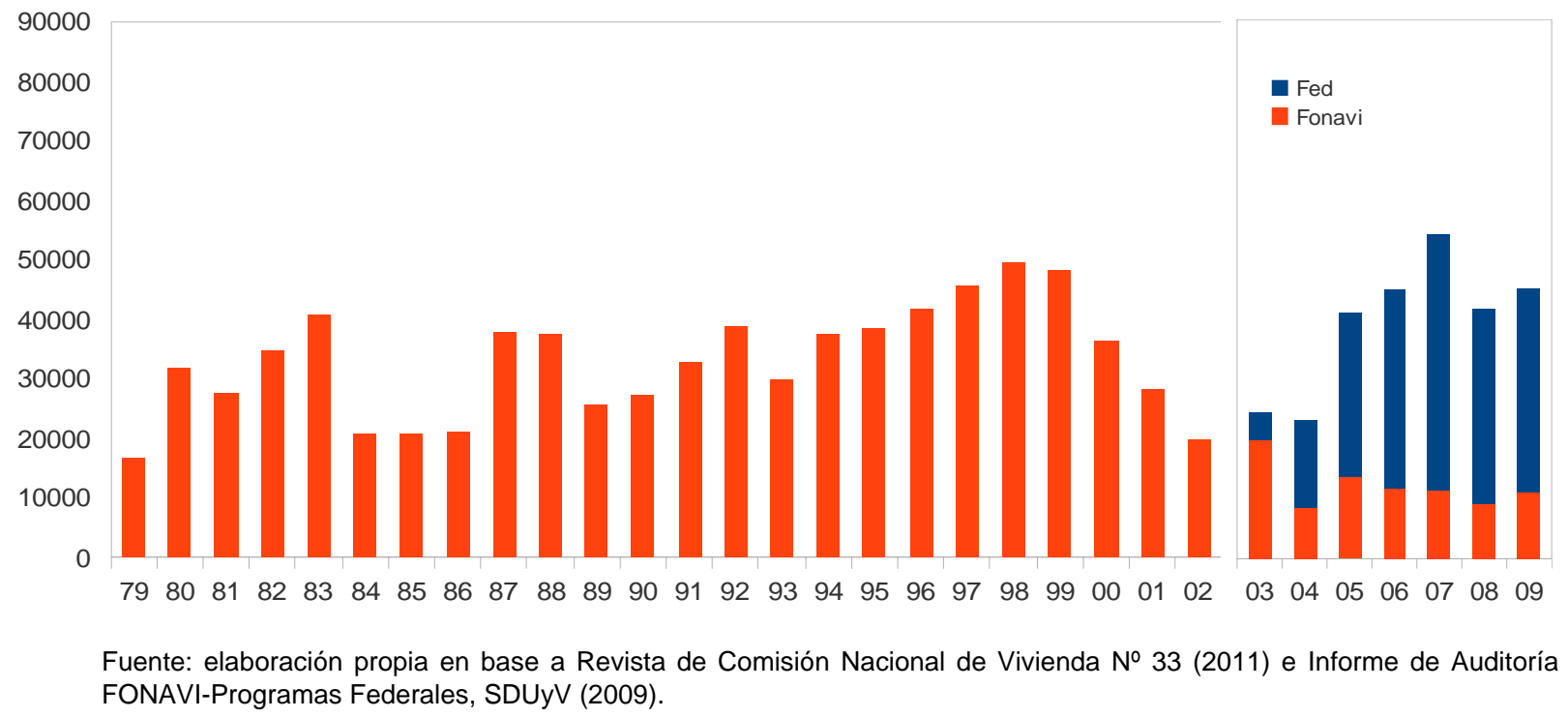

En este contexto, surgen diversos espacios intersectoriales en los que se buscará dar contención a la crisis. Emergen allí distintos acuerdos, como por ejemplo, el financiar el Plan Jefas y Jefes de Hogar Desocupados. Al poco tiempo, este plan se articula con las construcciones de viviendas en el marco del Programa de Emergencia Habitacional "Techo y Trabajo", que surge como la primera manifestación de acción pública en materia habitacional postcrisis. Finamente, en el 2003 la economía muestra señales positivas y la presidencia Kirchner redefine la orientación del gasto público, fijando la inversión en materia de vivienda como una prioridad. Esto abrirá un nuevo capítulo en la política habitacional cuyos principales rasgos veremos a continuación.

\subsubsection{La reaparición de la cuestión de la vivienda en la agenda pública}

En el año 2001, la crisis de la argentina atravesó por completo todos los ámbitos de la vida social. La política habitacional se encontraba jaqueada, el estado de situación reunía obras paralizadas y la libre disponibilidad de los recursos del FONAVI destinados a cubrir el déficit fiscal de las provincias. De allí que la forma en la que reaparece la cuestión de la vivienda en la agenda, se encuentre mediada, en primer lugar, por el contexto de la crisis donde se entrecruzan: la lógica de la asistencia a la emergencia, el reconocimiento de diversas 
organizaciones sociales que ganaron legitimidad política ${ }^{82}$ y la necesidad reemplazar los planes sociales por la generación de empleo genuino. En una segunda etapa, en cambio, la política de vivienda recibe una inversión significativa de recursos que se inscribe en una estrategia más amplia del gobierno nacional de apuntalamiento de la economía y reconstrucción del tejido productivo.

En distintas mesas de diálogo y espacios intersectoriales de concertación de intereses se generó un consenso que contribuyó a redefinir en cierta medida la orientación de la acción pública. Esto incidió en el sector habitacional, que en dicho contexto fue considerado un medio que permitía, simultáneamente, atender la emergencia habitacional, crear empleo, reactivar la economía y aplacar el conflicto social ${ }^{83}$. La ley de presupuestos de 2003 refleja esta visión, en ella se prioriza: la continuidad de los programas habitacionales existentes destinados a la población con NBI (necesidades básicas insatisfechas), la reactivación de las obras FONAVI y la atención de la emergencia habitacional vía la articulación interministerial (de las áreas de trabajo, desarrollo social y vivienda). Esta última línea de acción buscaba construir viviendas, a través de la capacitación productiva y la formación de cooperativas de trabajo integradas por los beneficiarios del Plan Jefas y Jefes de Hogar. Esta iniciativa del interregno del gobierno de Duhalde retoma antecedentes que ya se habían producido en otras jurisdicciones, entre ellas en algunos de los programas descentralizados de vivienda en provincia de Buenos Aires en los que tenía participación el Consejo de la Familia (como hemos visto en el apartado 2.1.4).

Como señala Ostuni, con la llegada a la presidencia de Kirchner, este esquema inicial sufre ciertas transformaciones. Por un lado, el superávit fiscal brindaba al sector público la posibilidad de desarrollar algunas líneas de intervención propias, sin tener que recurrir al financiamiento externo. A diferencia del gobierno de Duhalde (que mantenía una baja curva de inversión en vivienda y presentaba programas sociales protegidos en el marco de los acuerdos de las mesas de diálogo y con apoyo financiero externo), las nuevas autoridades impulsan programas de vivienda financiados con recursos públicos. Y además, retoman la idea de la transferencia intersectorial de recursos para desarrollar líneas de acción que tengan el propósito, en primer lugar, de generar empleo (Ostuni, 2008).

En el 2002, la salida de la convertibilidad, una balanza comercial positiva y la restitución de las retenciones a las exportaciones, permitieron redireccionar recursos provenientes de los

\footnotetext{
${ }^{82}$ Esta consideración es significativa a la hora de comprender la participación en el proceso constructivo de distintos actores no tradicionales sectorialmente como, organizaciones, ONGs y otras entidades.

${ }^{83}$ Según Rodulfo (2007), la crisis fue considerada por algunos sectores como un espacio de oportunidad y dio lugar a diversas manifestaciones y propuestas que consideraron a la vivienda como fin y medio en el proceso de recuperación nacional y del marco de gobernabilidad necesario al mismo. Existió, en este marco, una puesta en valor de algunas experiencias implementadas por gobiernos locales, las cuales articulaban las contraprestaciones del Plan Jefas y Jefes de Hogar con algunas modalidades de atención de necesidades críticas de hábitat y vivienda. La Cámara Argentina de la Construcción, la UOCRA, sectores gremiales y sociales coordinados por la CTA, ONGs concurrieron a precisar la importancia de la contribución del sector habitacional a la protección del hogar, a la solidaridad, a la creación de trabajo y reactivación económica. En el mismo sentido, la Mesa del Diálogo Argentino -integrada por el sector gubernamental, sectores representativos de la sociedad, la Iglesia Católica y el PNUD- junto con las otras iniciativas contribuyeron a priorizar el fortalecimiento de programas sociales dirigidos a la emergencia habitacional y la finalización de viviendas en ejecución avanzada del sistema FONAVI como medio de reactivación del empleo y trabajo en la construcción y como satisfactores sociales inmediatos en la crisis (Rodulfo, 2007).
} 
beneficiados con el nuevo tipo de cambio hacia otros sectores. En 2003, se consolida esta tendencia, se ordena la balanza de pago perdiendo participación la determinación del endeudamiento externo y luego de tres años las reservas vuelven a ser positivas. En este contexto, la decisión del gobierno nacional fue transferir una masa significativa de recursos no reembolsables a las provincias para activar el sistema de provisión pública de vivienda y compensar el deterioro de la base financiera del Sistema Federal de Viviendas. Por un lado, se destinaron recursos significativos a la construcción de la vivienda pero, por otro lado, ello se hizo por fuera circuito preestablecido a través de dicho Sistema. De este modo, el gobierno nacional se garantiza el control de la política de vivienda, retrotrayéndose a la etapa previa a la descentralización del FONAVI.

A partir de la creación del Ministerio de Planificación Federal, Inversión Pública y Servicios (MPFIPS), se reunieron bajo la órbita de la Subsecretaría de Desarrollo Urbano y Vivienda (SDUV) un conjunto de programas habitacionales que previamente estaban dispersos en distintas reparticiones nacionales. A su vez, la cartera de vivienda pasó a depender de la Secretaría de Obras Públicas demarcando en parte la inscripción que asumirá la política de vivienda. Por otra parte, la tendencia en la inversión en vivienda y urbanismo muestra un cambio importante. De los 702 millones de pesos asignados en el presupuesto de $2003^{84}$ pasa a 1.020 millones en 2004, y a 2.127 millones en 2005. A pesar del variado repertorio de acción pública en materia habitacional ${ }^{85}$, uno de los rasgos de la política actual es la prioridad dada a la construcción directa de vivienda nueva, a través de empresas constructoras, tendencia que resulta coherente con la estrategia de dinamizar la economía, incentivar la industria de la construcción y generar empleo.

En una de las entrevistas puede verse reflejada esta orientación como uno de los rasgos que caracterizan la etapa actual de la política habitacional. Si bien el concepto de obra pública se presenta trasversal a las distintas etapas de la política, este concepto es presentado como estructurante (de modo explícito) en la etapa actual:

“...la Secretaría de la Vivienda se crea en el Área Social y no en el área que había estado antes que era Economía y Obra Pública, como se ha visto ahora, también es la gran diferencia, que ahora se volvió a la etapa que sea pre de la cosa social, está vinculada a la promoción de la obra pública y a la economía, que en general es lo que cocina la decisión del Federal. La decisión del Federal viene de la crisis socioeconómica muy fuerte, que es tomada desde la órbita de la economía y la producción y forma parte del Plan de Obra Pública, esa es una diferencia sustancial respecto de lo que han abonado la parte institucional de las leyes que la metió en el Área de Desarrollo Social, primero, y luego la descentralizó hacia las provincias. Esa es

\footnotetext{
${ }^{84}$ Oficina Nacional de Presupuesto: www.mecon.gov.ar/onp (consulta marzo 2011)

${ }^{85}$ Suele distinguirse entre las líneas de acción en materia habitacional, las destinadas a la promoción del mercado, las acciones complementarias al mercado y la construcción directa por parte del Estado. A su vez, cada una de líneas supone diferencias importantes según los tipos de instrumentos y los modos de articulación de actores en el proceso de implementación de la política.
} 
una de las diferencias, o sea, se volvió al concepto de obra pública. Porque en los hechos, en realidad, el Fonavi tomó el concepto de obra pública pero en la campana institucional siempre estuvo vinculado a los objetivos de desarrollo social, por lo menos existía la contradicción (Entrevista Nº7 Ex-Funcionario Nacional, 2011).

Esta impronta también puede reconocerse en los documentos oficiales ${ }^{86}$ y en la formulación de los mismos programas. Se parte de la idea de que una inversión significativa en el sector, permite mejorar las condiciones habitacionales de la población y, simultáneamente, incentivar la reactivación del tejido productivo, dado el efecto multiplicador del sector de la construcción en la demanda directa e indirecta de otros bienes y servicios. La generación de trabajo es una pieza clave de la política, se apunta a "generar por unidad de inversión la mayor cantidad de empleos". Por otra parte, la política habitacional es encuadrada como una política distributiva en tanto el "otorgamiento en propiedad de la vivienda a familias pobres" implica una contribución a la distribución del ingreso y resuelve el acceso a la vivienda a hogares que de otro modo se ven imposibilitados de hacerlo.

En este marco, para Rodulfo la política se concibe desde una matriz productivista y es un dispositivo eficaz para atender la coyuntura postcrisis, aunque determinados rasgos adquieren continuidad en el tiempo. La producción de vivienda es un factor que contribuye a asegurar los niveles de actividad y empleo hasta tanto se generen condiciones de reactivación de otros sectores productivos. Además debe considerarse que a diferencia de otros rubros de la obra pública, la demanda del sector está territorialmente distribuida con la población y la oferta tiene capacidad de respuesta y retracción rápida, la generación de empleos directos e indirectos supone relativa elasticidad y el impacto social y económico es significativo. Por otro lado, los acotados plazos de obras permiten ampliar y regular la actividad en forma voluntaria y en determinados sitios, posibilitándole así la movilización de insumos disponibles en las diversas regiones y la captación de "valores de oportunidad" (Rodulfo, 2007).

Esta asimilación de la política de vivienda, como una herramienta macroeconómica estratégica, se vincula con un cambio de contexto sociopolítico que introduce un amplio contraste con la década precedente y el tema gana visibilidad en la agenda (incluso más allá de los números de producción real que hemos visto en la figura 6). No debemos perder de vista que esta política opera simultáneamente como una instrumento eficaz de acumulación política, en tanto el control (dado el origen del financiamiento) deja de estar en manos de las provincias y retorna a la Nación. Frente a la emergencia, la respuesta inmediata de la adjudicación de obras a un sector y la entrega del beneficio de la vivienda a otro, se transforma en una respuesta doblemente efectiva. De allí que en un contexto de reconstrucción del tejido productivo y de restablecimiento del poder o la legitimidad política del Estado nacional se verifique una tendencia hacia la recentralización de la política de vivienda.

${ }^{86}$ SDUV (2008) "La política federal de vivienda. Balance de 4 años de Gestión" Subsecretaría de Desarrollo Urbano y Vivienda. Ministerio de Planificación Federal, Inversión Pública y Servicios. 
Aquí otro fragmento de la entrevista introduce mayor complejidad de las manifestaciones que asume este proceso:

“¿Existe una recentralización? Sí, porque recentralizaste tres cosas, los fondos, tengo fondos propios y traccionó otros hasta acá, los contratos los centralizo yo. Antes incluso se hacían en las provincias, hace mucho aún con los Fonavi de los '80... ¿Pero el contrato no lo firma la Empresa con la Provincia? Si pero se hace acá [se refiere a la Capital Federal], incluso la adjudicación se recentralizó el trámite. El primer pago también se hacía acá con las provincias. Ahora como tienen miles de efectores no se nota tanto porque al municipio se lo da directo. O sea que hay recentralización de recursos, recentralización de a quién y cuánto. $Y$ bueno y los subejecutores a quien sí y a quien no [...] el protagonismo está dado por lo que pasaba, por la diferencia entre los '90 y los 2000... más que por otra cosas. Acá estamos en una época de federalización, donde la visibilidad de lo Nacional estaba opacada, era Federal, entonces vos ahora tenés una fuerte política Nacional, por más que se llama Federal es Nacional. Es centralizada, re-centralizada con ejecución descentralizada. Igual que en los '80 pero la ejecución no está normada, al principio trató de tener ciertas pautas de comportamiento, pero que después se fue deslizando a la cosa de la política" (Entrevista No7 Ex-Funcionario Nacional, 2011).

En síntesis, la reaparición de la cuestión de la vivienda en la agenda pública se vincula con el cambio de rol del Estado. El cual asume un nuevo protagonismo en el marco de un proceso de reconstitución de su legitimidad, recupera ciertas facultades de intervención en la economía y asimila la idea keynesiana para a cual la inversión pública opera como un mecanismo estratégico de movilización de factores productivos. La política del sector aparece, entonces, subordinada a una estrategia más amplia. La modalidad del financiamiento, la asignación de recursos, la rigidez del diseño y la forma de aprobación de los proyectos -entre otras características- dan cuenta de la recentralización de la política de vivienda. Y como observa, Fernández Wagner (2008), si bien la política se apoya parcialmente en IPVs nucleados en el Consejo Federal de la Vivienda, este plan de construcción masiva, diseñado y ejecutado desde el gobierno nacional, tiene mínimos márgenes de adecuación a los problemas locales. Esto se evidenciará luego en múltiples conflictos que surgen en el proceso de implementación a nivel local, donde será posible identificar más claramente las tensiones existentes con la masividad de la política.

\subsubsection{Etapas, programas y objetivos de la política actual}

En el año 2003, la SDUV se propone una serie de líneas de acción para "abordar integralmente el problema habitacional", de modo de "responder a múltiples demandas" y "atender distintas necesidades de la población". Las principales acciones oficiales propuestas son: i) propiciar el fortalecimiento del Organismo Nacional de Vivienda, a través de la concentración de programas cuyas acciones referidas al mejoramiento del hábitat (construcción y mejoramiento de vivienda, 
infraestructura, equipamiento social comunitario) en su estructura y mediante la dotación de los recursos necesarios para desarrollar su gestión; ii) desarrollar el trabajo de manera horizontal y en forma mancomunada con las diferentes áreas gubernamentales y no gubernamentales (del ámbito nacional, provincial y municipal) que tienen relación directa con el mejoramiento del hábitat, la generación de empleo y la reactivación productiva; iii) buscar el fortalecimiento del Sistema Federal de Vivienda canalizando, a través de los Organismos Provinciales de Vivienda, los nuevos programas e incorporando un importante volumen de recursos nacionales a los del Fondo Nacional de la Vivienda (SDUV, 2008).

Frente a estos lineamientos declarados se verifica efectivamente un fortalecimiento de la cartera nacional de viviendas y una concentración no sólo de los programas sino también de los recursos, el diseño de la política y la toma de decisión. Por otra parte, como ya mencionamos, no hay que perder de vista que si bien la inyección de financiamiento se instrumenta o ejecuta a través de los actores del Sistema Federal de Vivienda, buena parte de las decisiones dependen del nivel del gobierno nacional. En este sentido, es posible identificar cierta tensión entre la recentralización de "la política federal de vivienda" y el "sistema federal vivienda" derivado de la etapa anterior. Por ello, es inevitable dejar planteado al menos como interrogante: ¿A qué intereses responde la política federal de vivienda al generar un canal de financiamiento paralelo al FONAVI? ¿Y hasta qué punto nos encontramos, en términos de sus características, frente a una nueva política de vivienda post FONAVI?

Repasemos ahora las etapas de estructuración de los programas, sus características y objetivos de modo de ordenar el panorama que presenta la política de vivienda a nivel nacional. A partir del año 2003, surgieron una variada gama de programas federales de vivienda a cargo de la SDUV que se sumaron a los programas previos. Los cuales eran en su mayoría programas focalizados dependientes de financiamiento externo. Respecto a los nuevos programas, puede decirse que atienden demandas diversas y se diferencian por el tipo de acción, la modalidad de gestión, los niveles de articulación intersectorial, la población objetivo a la que atienden, etc. Sin embargo, no todos los programas adquieren magnitud, ni tienen inserción territorial en nuestra área de estudio, el AMBA (ver en la figura 7, detalle de cuál de los programas dependientes de la SDUV tienen inserción territorial en el AMBA).

Siguiendo a Rodulfo (2007), pueden reconocerse al menos tres etapas de la política federal de viviendas, a las cuales es posible a agregar una o dos etapas más a partir del análisis del desenvolvimiento reciente de dicha política pública.

Un primera etapa se inicia en el 2003, con los Programas Federales Reactivación Viviendas FONAVI I y II, el Programa de Emergencia Habitacional "Techo y Trabajo" y el Programa Federal de Solidaridad Habitacional. Como dijimos antes, se da continuidad un conjunto de programas focalizados que atendían a probación $\mathrm{NBI}^{87}$ y se los centraliza en la SDUV. En esta

\footnotetext{
${ }^{87}$ A saber: el Programa de Desarrollo Social en Áreas Fronterizas del NOA y NEA (PRSOFA), el Programa de Mejoramiento Habitacional e Infraestructura Básica (PROMHIB), el Programa de Provisión de Agua Potable Ayuda Social y Saneamiento Básico (PROPASA), el Programa de Mejoramiento de Barrios (PROMEBA) y el Programa de integral de Recuperación de Asentamiento Irregulares (Rosario Hábitat).
} 
etapa las acciones estuvieron orientadas a la reactivación de las obras paralizadas, apuntalar las regiones con mayor desocupación laboral y brindar capacitación productiva de organizaciones de desocupados, en el marco de una articulación interministerial, que redireccionó los Planes Jefas y Jefes de Hogar hacia el proceso productivo a través de la formación de cooperativas.

El Programa Federal Reactivación Viviendas FONAVI tiene por objetivo reactivar construcciones paralizadas o con muy bajo nivel de avance mediante el auxilio financiero de fondos nacionales y contribuir a la generación de empleo a través de la inserción de mano de obra desocupada. En la segunda etapa el programa incluyó como mano de obra a los beneficiarios del Programa Jefas y Jefes de Hogar.

El Programa Federal de Emergencia Habitacional surge a partir de una articulación entre el Ministerio de Planificación Federal, Inversión Pública y Servicios, el Ministerio de Desarrollo Social y el Ministerio de Trabajo, Empleo y Seguridad Social. Se propone originalmente atender la emergencia habitacional y laboral a través de la formación de cooperativas de trabajo y la participación de los beneficiarios del Plan Jefes y Jefas de Hogar y desocupados. El programa apuesta a la reinserción laboral en el proceso productivo a través de la construcción de viviendas nuevas. Los adjudicatarios de la vivienda son elevados por el municipio con la consideración de las áreas sociales del IPV, pero los propios cooperativistas tienen prioridad, siempre que no posean otras propiedades.

El Programa Federal de Solidaridad Habitacional es otro de los programas sociales, tiene por objetivo satisfacer las necesidades habitaciones de las personas con mayores niveles de pobreza y generar empleo. Aplica recursos a la construcción de viviendas e infraestructura en proyectos no mayores a 40 viviendas. Su ejecución se realiza mediante empresas locales que incorporen personal (en un 50\%) proveniente de los Plan Jefas y Jefes de Hogar en relación de dependencia.

Como señala Rodulfo (2007), en esta primera etapa aparece una innovación respecto a las modalidades de ejecución tradicionales, este escenario es habilitado en parte por la crisis social y el nivel de movilización de las organizaciones sociales. Se configuran de este modo múltiples prácticas, las cuales se extienden desde el reconocimiento de actores, el avance de algunas organizaciones en actividades productivas, hasta estrategias de amortiguación del conflicto social y reducción de la beligerancia de los movimientos sociales.

Una segunda etapa, se inicia en el año 2004 con los Programas Federales de Construcción de Viviendas y el Programa Federal de Mejoramiento Habitacional "Mejor Vivir", con la intención de fortalecer la reactivación económica e incorporar la mitigación del déficit cualitativo, respectivamente. Además, se firman convenios de fortalecimiento institucional con los organismos provinciales de vivienda para atender el recupero del FONAVI y con las áreas de Desarrollo Urbano de estos organismos, junto a otros convenios de capacitación con la UOCRA para la provisión de la mano de obra necesaria. 
El Programa Federal de Construcción de Viviendas busca atender a los hogares de bajos recursos que necesitan una vivienda. Está dirigido a fortalecer el proceso de reactivación económica de la industria de la construcción y reducir el desempleo, a través de la construcción de viviendas nuevas por medio de empresas constructoras. Se instrumenta, al igual que resto de los programas federales, mediante convenios firmados entre la Nación, las provincias y convenios específicos entre los organismos jurisdiccionales y la SDUV.

El Programa Federal de Mejoramiento Habitacional "Mejor Vivir" se destina a la terminación, ampliación o refacción de la vivienda de aquellos grupos familiares que requieren que su vivienda sea completada y/o mejorada. Se instrumenta mediante un sistema de módulo de inversión destinado a familias que habiendo iniciado la construcción de su vivienda única no disponen de acceso al crédito convencional. El lote debe tener dominio saneado y los criterios de déficit cualitativo contemplados son: carencia de baño instalado, carencia de provisión interna de agua por cañería, carencia de terminaciones adecuadas en pisos, paredes y techos o presencia de hacinamiento.

Este programa se destaca por la atención que presta al abordaje del déficit cualitativo y la recuperación del parque habitacional aunque, como destaca Rodulfo (2007), permanece atado al modelo del producto de la obra pública. Y, por otra parte, ha resultado de poco interés para las empresas constructoras dada la dificultad operativa de atender una demanda dispersa y con necesidades diferenciadas según la realidad de cada familia.

El Programa Federal de Fortalecimiento y Optimización del Recupero de Cuotas FONAVI tiene por objetivo mejorar la calidad de gestión del Sistema Federal de Vivienda, dando carácter prioritario al recupero de las inversiones FONAVI como fuente genuina de retroalimentación del Sistema Federal de Vivienda. En el año 2002, la tasa de recupero sobre la facturación del sistema alcanzaba el $35 \%^{88}$. La apuesta es duplicar en un año el desempeño de la tasa de cobro, por ello las actividades prioritarias son la regularización y puesta al cobro de la totalidad de las viviendas terminadas, conjuntamente con el aligeramiento de los mecanismos de adjudicación y cobro de los planes en ejecución.

Esta línea de acción, además de incidir en la cultura de pago como principio de solidaridad de la vivienda social (en términos de la retroalimentación del financiamiento), también refleja la preocupación por verificar a nivel jurisdiccional la existencia de demanda antes de decidir la localización de las intervenciones. Esto es particularmente interesante porque pone en evidencia la tensión entre la localización de la demanda y la localización de la oferta. $\mathrm{Y}$, al mismo tiempo, los riesgos de la captación de recursos a nivel jurisdiccional que permiten movilizar la economía local pero que se encuentran disociados de la necesidad habitacional real.

El Programa Federal de Fortalecimiento de las Áreas de Desarrollo Urbano de los Institutos de Vivienda Provinciales se propone fortalecer las áreas de Desarrollo Urbano de los IPV, o

${ }^{88}$ Presentación de la Programa Federal de Fortalecimiento y Optimización del Recupero de Cuotas FONAVI. http://www.vivienda.gov.ar consulta noviembre de 2010. 
crearlas en el caso de que no existieran, y brindar las condiciones para incorporar la dimensión del desarrollo urbano en la implementación de los programas de vivienda estatales, articulando esfuerzos entre el organismo provincial y los respectivos municipios. La apuesta del programa es implementar actividades como la identificación de las tierras vacantes dentro del tejido urbano aptas para las operatorias de construcción de viviendas, la programación de actividades según disponibilidad de tierras, el desarrollo de los proyectos a escala urbana con la adecuada inserción en la trama existente, conexiones viales, infraestructura, equipamiento comunitario, etc. Además, busca apuntalar el desarrollo del diseño urbano de los conjuntos habitacionales, respetando características ambientales, normas vigentes y planes urbanos.

Este programa marca una cuestión central para la instrumentación de la política. A pesar de constituir una acción marginal dentro de la SDUV, pone de manifiesto el grado de desarrollo o problematización de la dimensión urbana y el modo en que se introduce la cuestión del suelo en la política de vivienda desde el nivel nacional.

La tercera etapa lanzada en 2005, con el Programa Plurianual de Construcción de Viviendas da continuad a una segunda etapa del Programa Federal de Construcción de Viviendas. Producto de los retrasos y desajustes en la implementación de la primera etapa, la principal preocupación de este programa es dar señales claras al sector de la construcción, "mostrar previsibilidad a empresarios, proveedores y trabajadores" ${ }^{\text {89 }}$ y apalancar el crecimiento con generación intensiva de trabajo. Con este propósito se pasa de las 120.000 viviendas financiadas en la primera etapa a la financiación de 300.000 viviendas nuevas. Por otra parte, las viviendas son consideradas un medio para mejora las condiciones de vida y la distribución del ingreso.

Otro rasgo de esta etapa es la diversificación de subprogramas que introducen ajustes dada la atención de nuevas demandas, entre ellas la dificultad de acceder al suelo. El Subprograma Federal de Construcción de Viviendas con Municipios se dirige a consolidar la relación directa entre Nación y Municipios, en términos de financiamiento y ejecución de obras. El Subprograma de Urbanización de Villas y Asentamientos apunta a la consolidación de áreas urbanas ya ocupadas. Y el Subprograma Federal para el Mejoramiento del Hábitat Urbano, Obras de Infraestructura y Obras Complementarias se articula con otros programas para cubrir la demanda de obras de infraestructura complementarias o nexos indispensables para habilitar las viviendas.

Una cuarta etapa, puede reconocerse entre fines de 2007 y 2009. Tras la experiencia desarrollada, la nueva gestión busca reforzar la inversión en los denominados "programas sociales" de la cartera vivienda", elabora una nueva reglamentación, siendo el dato más importante el aporte de los fondos ANSES a la política federal de viviendas.

\footnotetext{
${ }^{89}$ Presentación del Programa Federal de Construcción de Viviendas II. http://www.vivienda.gov.ar consulta noviembre de 2010.

${ }^{90}$ En el 2010 , se llega a un coeficiente de inversión equivalente al $40 \%$ en los programas sociales de la cartera de vivienda, cuando en 2007 el presupuesto alcazaba el 35\% (Ver Rey, 2011).
} 
También surge el Programa Federal de Integración Sociocomunitaria (ex Programa Federal de Emergencia Habitacional), siendo el reto de la nueva etapa conformar empresas sociales a través de micro-emprendimientos, es decir, que las cooperativas comiencen a autogestionarse y a generar trabajo más allá de los planes estatales. Las experiencias son muy variables según los niveles de organización y consolidación de las cooperativas. Por otra parte, este programa se vincula de modo transversal y se encuentra en parte traccionado por el Programa Ingreso Social "Argentina Trabaja" del Ministerio de Desarrollo Social.

En el año 2009, surge el Programa Federal de Construcción de Viviendas "Techo Digno" que integra las líneas de acción de construcción de vivienda nueva y las obras de infraestructura complementarias. Mientras que la urbanización de villas y asentamientos se independiza como programa. En la reglamentación particular del programa ${ }^{91}$ queda en evidencia la necesidad de cubrir desfajases financieros y cubrir los compromisos de los convenios previos firmados entre la Nación y las provincias, particularmente los asociados al Programa Federal de Construcción de Viviendas (2004) y Programa Federal de Construcción de Viviendas Plurianual (2005).

En esta etapa, los fondos ANSES son administrados a través de un fideicomiso del Banco Nación y la SDUV. Las provincias y los municipios acceden al fideicomiso tras refrendar el convenio y firmar los contratos con las empresas constructoras. Existen variantes según las provincias respecto a la inversión y cantidad de metros cuadrados. Pero, en todos los casos, se condiciona el pago de la vivienda en un plazo de financiamiento menor y con una cuota mayor en comparación a las otras operatorias habitacionales. El origen de los fondos, condiciona aún más la obligación de optimizar el sistema de recupero de cuotas y de aquí se infiere cierto redireccionamiento hacia sectores medios.

Una quinta etapa podría identificarse a partir de la publicidad de la nueva línea de crédito para trabajadores sindicalizados. A principios de 2011, se anuncia el Plan Mi Casa Banco Nación CGT que consiste en proporcionar una línea de crédito subvencionada por la SDUV y financiada por el Banco Nación. El esquema de financiamiento reconoce un precio máximo por metro cuadrado, el cual es subsidiado en un 35\% por la SDUV, mientras que el Banco Nación financia el saldo restante al beneficiario $y$, también, financia a la empresa constructora encargada de la construcción del edificio en torre. Los trabajadores agremiados tienen que aportar la tierra, la cual forma parte de la garantía al fideicomiso. El destino del crédito es vivienda única y permanente, se requiere un aporte inicial del $10 \%$, y se cuenta con financiamiento a 20 años con una tasa de interés del 14\%. Para un departamento de $62 \mathrm{~m}^{2}$ se estima una cuota de 1600 pesos con una acreditación de ingresos de 5300 pesos $^{92}$.

\footnotetext{
${ }^{91}$ Secretaría de Obras Públicas de la Nación, Resolución 428/2009 de Creación de Programa Federal de Construcción Techo Digno.

${ }^{92}$ Diario La Nación 09/03/2011.
} 
Fig. 7 Programas habitacionales nacionales dependientes de la SDUV, 2010

\begin{tabular}{|c|c|c|c|c|}
\hline Programas SDUyV & $\begin{array}{l}\text { Año de } \\
\text { origen }\end{array}$ & Tipo de acción & $\begin{array}{c}\text { Nivel } \\
\text { Ingreso }\end{array}$ & AMBA \\
\hline $\begin{array}{l}\text { Desarrollo Social en Áreas de Frontera } \\
\text { NEA y NOA (PROSOFA) }\end{array}$ & 1994 & Híbrida / Infraestructura sanitaria & Bajo/NBI & No \\
\hline $\begin{array}{l}\text { Mejoramiento Habitacional e } \\
\text { Infraestructura Básica (PROMHIB) }\end{array}$ & 1996 & $\begin{array}{l}\text { Híbrida / Mejoramiento e } \\
\text { infraestructura comunitaria }\end{array}$ & Bajo/NBI & No \\
\hline Mejoramiento de Barrios (PROMEBA) & 1997 & Híbrida / Mejoramiento Barrial & Bajo/NBI & $\mathrm{Si}$ \\
\hline $\begin{array}{l}\text { Provisión de agua potable, ayuda social y } \\
\text { saneamiento básico (PROPASA) }\end{array}$ & 1999 & Híbrida / Infraestructura sanitaria & Bajo/NBI & No \\
\hline $\begin{array}{l}\text { Asentamientos Irregulares Rosario } \\
\text { Hábitat (ROSARIO) }\end{array}$ & 2001 & Híbrida / Mejoramiento Barrial & Bajo/NBI & No \\
\hline $\begin{array}{l}\text { Federal de Emergencia Habitacional } \\
\text { (PFEH) }\end{array}$ & 2003 & Vivienda nueva & Bajo & Si \\
\hline $\begin{array}{l}\text { Federal de Solidaridad Habitacional } \\
\text { (PFSH) }\end{array}$ & 2003 & Vivienda nueva & Bajo & No \\
\hline $\begin{array}{l}\text { Federales de Reactivación Fonavi I y II } \\
\text { (PFRF) }\end{array}$ & 2003 & Vivienda nueva & $\begin{array}{l}\text { Medio } \\
\text { Bajo }\end{array}$ & Si \\
\hline $\begin{array}{l}\text { Mejoramiento de Vivienda } \\
\text { MEJOR VIVIR (PFMV) }\end{array}$ & 2004 & Mejoramiento habitacional & Bajo & $\mathrm{Si}$ \\
\hline Cáritas (CARITAS) & 2004 & Vivienda nueva & Bajo & $\mathrm{Si}$ \\
\hline $\begin{array}{l}\text { Federal de Construcción de Vivienda } \\
\text { (PFCV) }\end{array}$ & 2004 & Vivienda nueva & $\begin{array}{l}\text { Medio } \\
\text { Bajo }\end{array}$ & $\mathrm{Si}$ \\
\hline $\begin{array}{l}\text { Subprog. de Urbanización de Villas y } \\
\text { Asentamientos Precarios (SUVyA) }\end{array}$ & 2005 & $\begin{array}{l}\text { Vivienda nueva / Solución } \\
\text { habitacional / Regularización }\end{array}$ & Bajo & $\mathrm{Si}$ \\
\hline $\begin{array}{l}\text { Subprog. de Mejoramiento del Hábitat } \\
\text { Urbano, Infraestructura y Obras } \\
\text { Complementarias (SMHU) }\end{array}$ & 2005 & Infraestructura & $\begin{array}{l}\text { Medio } \\
\text { Bajo }\end{array}$ & Si \\
\hline $\begin{array}{l}\text { Federal de Construcción de Viviendas } \\
\text { Plurianual (PFCV) }\end{array}$ & 2005 & Vivienda nueva & $\begin{array}{l}\text { Medio } \\
\text { Bajo }\end{array}$ & Si \\
\hline $\begin{array}{l}\text { Federal de Integración Sociocomunitaria } \\
\text { (ex-PFEH) }\end{array}$ & 2009 & - & Bajo & $\mathrm{Si}$ \\
\hline $\begin{array}{l}\text { Federal Construcción de Viviendas } \\
\text { "Techo Digno" + Reconvertido Anses } \\
\text { (PFCV) }\end{array}$ & 2009 & Vivienda nueva & $\begin{array}{l}\text { Medio } \\
\text { Bajo/ } \\
\text { Medio }\end{array}$ & $\mathrm{Si}$ \\
\hline
\end{tabular}

Fuente: elaboración propia en base a Convenios e Informes de Avance de la Subsecretaría de Urbanismo y Vivienda (http://www.vivienda.gov.ar consulta diciembre 2010) e información periodística.

\subsubsection{El peso de los programas federales a nivel nacional}

Una lectura de la cantidad de viviendas y mejoramientos terminados de los programas habitaciones nacionales en ejecución al 2010 (ver figura 8), pone de manifiesto el peso de la "política federal de viviendas" sobre el resto de los programas habitacionales $(70,7 \%$ vs el $29,3 \%$ de las soluciones habitacionales) ${ }^{93}$. Si se considera sólo las viviendas terminadas, la participación relativa de los programas federales asciende al 96,2\%. Por otra parte, si bien en este cuadro no se incluyen las operatorias del FONAVI (considerados fondos propios de las

${ }^{93}$ Dado que los datos publicados por la SSDUyV (en el Resumen de estado de programas habitacionales nacionales) incluyen en algunos casos viviendas y mejoramientos terminados con anterioridad al 2003, la proporción de los "otros programas" se encuentran sobre representada. 
provincias), su inclusión dejaría en evidencia la erosión que sufrió dicho fondo frente a los recursos de los programas federales.

Fig. 8 Cantidad de soluciones habitacionales terminadas 2003-2010 total país según programas federales y otros programas nacionales ${ }^{i}$ en ejecución al 2010.

\begin{tabular}{|c|c|c|c|c|c|}
\hline Programa & Viviendas & Mejoramiento & Total & $(\%)$ & $\begin{array}{l}\text { P. Federales } \\
\text { vs. Otros (\%) }\end{array}$ \\
\hline PFRFONAVI & 28630 & 42 & 28630 & 6,8 & \multirow{5}{*}{70,7} \\
\hline PFSH & 21921 & 10991 & 32912 & 7,7 & \\
\hline PFCV & 150598 & 3306 & 153904 & 36,2 & \\
\hline PFMV & & 68093 & 68093 & 16,0 & \\
\hline PFEH & 17087 & & 17087 & 4,0 & \\
\hline PROPASA & & 4107 & 4107 & 1,0 & \multirow{6}{*}{29,3} \\
\hline PROMHIB & 3690 & 4508 & 8198 & 1,9 & \\
\hline PROMEBA & 1232 & 61270 & 62502 & 14,7 & \\
\hline PROSOFA & & 43140 & 43140 & 10,2 & \\
\hline ROSARIO HAB ${ }^{\mathrm{ii}}$ & 1142 & 2541 & 3683 & 0,9 & \\
\hline CARITAS & 2403 & & 2403 & 0,6 & \\
\hline TOTAL & 226703 & 197998 & 424701 & 100,0 & 100,0 \\
\hline
\end{tabular}

Fuente: elaboración propia en base a Resumen de estado de programas habitacionales nacionales al 31/12/10 de la SDUyV-MFPIPyS (http://www.vivienda.gov.ar) Nota ${ }^{i}$ No se incluye FONAVI. " Datos informadas de 2003 a 2007.

Por otra parte, una mirada al interior de los programas federales a nivel nacional muestra la relevancia del PFCV, programa que representa casi el 56\% de las soluciones habitacionales del conjunto de la política federal, seguido por el PFMV con cerca del $24 \%$ del total de las viviendas y mejoramientos "terminados", "en ejecución" y "a iniciar" (ver figura 9). Ambos programas, a su vez, son los únicos que muestran una tendencia de mayor participación en la composición de viviendas o mejoramientos "en ejecución" y "a iniciar".

Esto indica, aunque parezca contradictorio, factores que pueden coexistir: el dinamismo de estos programas va de la mano -en algunos casos- de mayores dificultades de implementación y la asunción de compromisos a futuro que operan -en parte- como un mecanismo para asegurar la continuidad de las obras. Es decir, frente a las demoras administrativas, los cuellos de botella o la falta de materiales, los desfajases inflacionarios y la presión por la redeterminación de costos e, incluso la paralización de las obras producto los conflictos en el territorio, se observa que el nuevo financiamiento tiene como destino no sólo invertir en nuevas unidades funcionales, sino también cubrir los desajustes del financiamiento de las etapas previas. 
Fig. 9 Cantidad de vivienda y mejoramientos terminados, en ejecución y a iniciar según programas federales en ejecución 2003-2010, total país.

\begin{tabular}{|l|r|r|r|r|r|r|r|}
\hline Programa & \multicolumn{3}{|c|}{ Viviendas } & \multicolumn{2}{c|}{ Mejoramiento } & Total \\
\hline & Terminadas & En ejecución & A iniciar & Terminados & En ejecución & A iniciar & \\
\hline PFRFONAVI & 28630 & 3121 & 0 & 42 & 0 & 0 & 31793 \\
\hline PFSH & 21921 & 2942 & 2389 & 10991 & 4847 & 729 & 43819 \\
\hline PFCV & 150598 & 83792 & 35510 & 3306 & 0 & 1161 & 274367 \\
\hline PFMV & 0 & 0 & 0 & 68093 & 33689 & 14845 & 116627 \\
\hline PFEH & 17087 & 5831 & 1120 & 0 & 0 & 0 & 24038 \\
\hline Total & $\mathbf{2 1 8 2 3 6}$ & $\mathbf{9 5 6 8 6}$ & $\mathbf{3 9 0 1 9}$ & $\mathbf{8 2 4 3 2}$ & $\mathbf{3 8 5 3 6}$ & $\mathbf{1 6 7 3 5}$ & $\mathbf{4 2 4 7 0 1}$ \\
\hline PFRFONAVI & 13,1 & 3,3 & 0,0 & 0,1 & 0,0 & 0,0 & 6,5 \\
\hline PFSH & 10,0 & 3,1 & 6,1 & 13,3 & 12,6 & 4,4 & 8,9 \\
\hline PFCV & 69,0 & 87,6 & 91,0 & 4,0 & & 6,9 & 55,9 \\
\hline PFMV & 0,0 & 0,0 & 0,0 & 82,6 & 87,4 & 88,7 & 23,8 \\
\hline PFEH & 7,8 & 6,1 & 2,9 & 0,0 & 0,0 & 0,0 & 4,9 \\
\hline Total (\%) & $\mathbf{1 0 0 , 0}$ & $\mathbf{1 0 0 , 0}$ & $\mathbf{1 0 0 , 0}$ & $\mathbf{1 0 0 , 0}$ & $\mathbf{1 0 0 , 0}$ & $\mathbf{1 0 0 , 0}$ & $\mathbf{1 0 0 , 0}$ \\
\hline
\end{tabular}

Fuente: elaboración propia en base a Resumen de estado de programas habitacionales nacionales al 31/12/10 de la SDUyV-MFPIPyS (http://www.vivienda.gov.ar).

En el caso del PCFV, puede verse que las "viviendas terminadas" representan el 69\% del total, mientras que su participación asciende al $87,6 \%$ si se considera las "viviendas en ejecución" y al 91\% de las "viviendas a iniciar". Esto se debes no sólo a la consolidación del protagonismo del programa, sino también a los desfajases antes mencionados y a las condiciones propias en el contexto de formulación del programa (que hemos visto antes): la necesidad de dar señales claras al sector de la construcción respecto la sostenibilidad de la inversión.

Cabe notar también, la orientación hacia la construcción de las viviendas nuevas respecto a los mejoramientos habitacionales. En este punto, es conocida la preferencia de las empresas del sector por realizar productos seriados sobre soluciones particularizadas. Nótese en la figura 9 que en el marco de los programas federales la proporción de "viviendas nuevas terminadas" sobre los "mejoramientos terminados", se intensifica (en relación al conjunto de los programas habitacionales nacionales registrados en figura 8): por cada mejoramiento se construyen 2,6 viviendas nuevas.

A pesar de la clara tendencia de la "política federal de viviendas" a construir vivienda nueva, en contraposición a la atención del déficit cualitativo, se debe destacar que en el período actual se ha incrementado la proporción de soluciones habitacionales (vinculada a los mejoramientos, terminaciones o ampliaciones) que en gran medida se encuentran asociadas al PFMV ${ }^{94}$. En la figura 10 se grafica la producción habitacional a través de los recursos de los Programas Federales y del FONAVI a cargo de las provincias, de allí surgen dos aspectos a resaltar. Primero, se constata un aumento del financiamiento destinado a atender el déficit cualitativo.

${ }^{94}$ Este programa no tuvo prácticamente incidencia en el Conurbano Bonaerense. 
Segundo, es dicha inversión la que explica la mayor proporción en el aumento de la producción habitacional, es decir, en cantidad de viviendas la variación de la producción entre ambos períodos no es tan significativa.

Fig. 10 Producción habitacional según viviendas y soluciones habitacionales ${ }^{i}$ por ejercicio Fonavi ii y Programas Federales, total país 1993-2009.

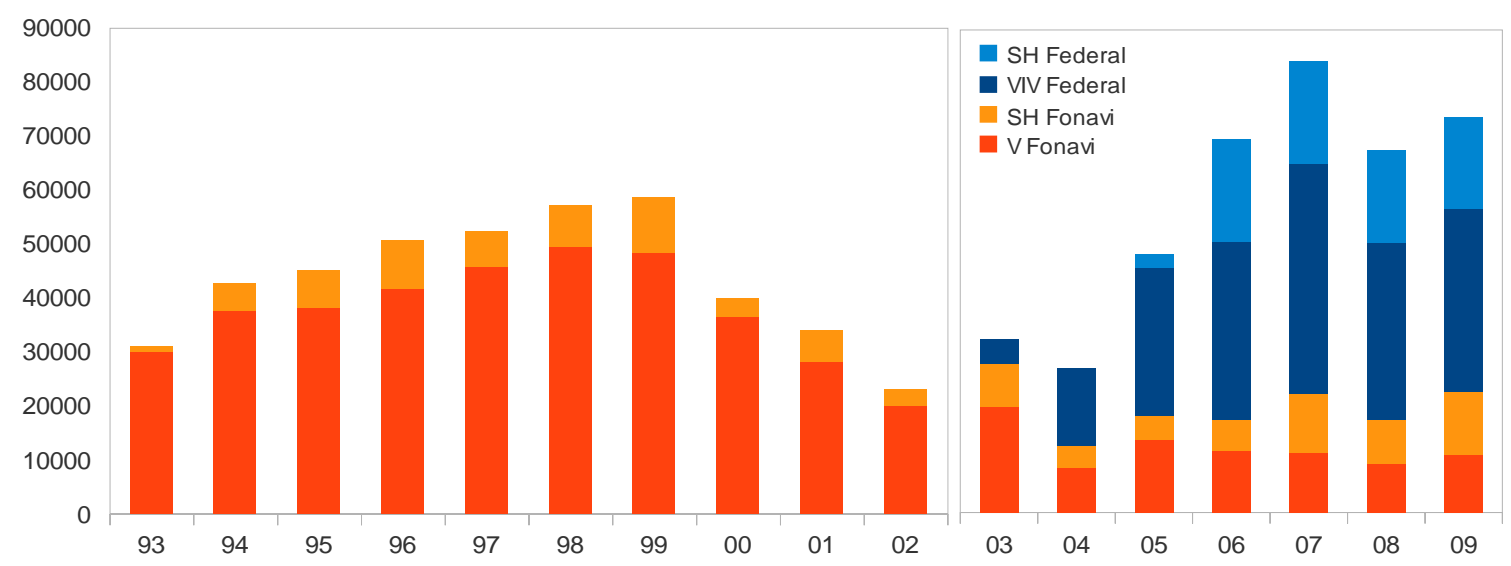

Fuente: elaboración propia en base a Informe de Auditoría Fonavi-Programas Federales Ejercicio 2009. Dirección de Control de Gestión, Dirección Nacional de Política Habitacional -SSDUyV. Nota: i En este caso, las soluciones habitacionales corresponden a lotes y servicios, núcleos húmedos, terminaciones y ampliaciones. ii No incluye los Programas Federales Reactivación FONAVI I y II.

Al hacer un balance de las etapas de política federal de vivienda se identifica un primer momento de crisis, donde la prioridad es reactivar obras, atender la pobreza y amortiguar el conflicto social. Resulta interesante la propuesta de articulación de planes sociales de empleo con la atención de la emergencia habitacional a través de las cooperativas de trabajo, a contramarcha de los esquemas constructivos tradicionales. Esta estrategia, sin embargo, no estuvo exenta de conflictos en el proceso de implementación, siendo sus resultados también variables según la organización que median en el proceso y el nivel de consolidación de las cooperativas de trabajo. En un segundo momento, el punto crítico de la crisis queda atrás, se produce un desplazamiento hacia una política de reactivación económica y empleo. Se introduce, a su vez, una preocupación por mejorar el parque habitacional existente, pero el mejoramiento habitacional continúa siendo visto como un producto de obra pública. En la etapa siguiente, se intensifica la lógica de apalancar el crecimiento económico, brindar previsibilidad al sector empresarial y apostar a la generación de trabajo. Luego, con el cambio de administración, se intenta equilibrar la participación de los "programas sociales" frente a los programas de naturaleza constructivista. Por otra parte, el cambio en la composición del financiamiento y la introducción de los fondos ANSES, parece exigir una inversión con carácter más productivo y el redireccionamiento socioeconómico de la población objetivo, de modo de asegurar un umbral de recupero. Si bien, sería apresurado desarrollar en la actualidad alguna 
consideración al respecto, el pasaje de los recursos "no reembolsables" a un financiamiento compuesto en parte por los fondos de previsión social, supone cierta tensión en términos de la orientación de los recursos. Por un lado, en el período actual vastos sectores de clase media encuentran restricciones para acceder a la vivienda sin poder acceder al crédito hipotecario. Por otro lado, producto de las debilidades del sistema de adjudicación de la vivienda social, ${ }^{95}$ quedan dudas de si ésta efectivamente llega a los sectores más postergados de la estructura social.

\subsubsection{Modalidad de ejecución, la política por convenio}

Hemos dicho que la "política federal de vivienda" responde a un esquema de decisión centralizado con la ejecución descentralizada a través las provincias y los municipios. Repasemos entonces los aspectos formales que hacen al proceso de la implementación de los programas federales, deteniéndonos particularmente en el Programa Federal de Construcción de Viviendas (PFCV) donde centramos nuestro interés.

El diseño de la política y el financiamiento está a cargo de la SDUV del MPFIPS, que también controla los mecanismos de auditoría de ejecución de recursos. En este modelo, la Nación tiene un rol predominante en la definición de los programas habitacionales, sus formatos, la distribución de recursos y la aprobación de proyectos susceptibles de recibir (o no) financiamiento. La Nación maneja un convenio "obra por obra" y los mismos están atados al financiamiento que se define año a año. Vale recordar aquí, la flexibilidad para reasignar partidas presupuestarias y alterar el resultado fiscal con la que cuenta el Jefe de Gabinete de Ministros (facultad especial que el Congreso cedió al poder ejecutivo bajo en el contexto de "emergencia pública" en el año 2001). Este esquema muestra un contrapunto importante en relación al control que las provincias asumieron del FONAVI desde principio de los noventa, refrendado por la Ley del Sistema Federal de Viviendas.

EI PFCV aparece, entonces, como un programa de gobierno. Como señala Ostuni (2008), a diferencia del FONAVI el PFCV no se trata de un fondo creado por ley que fija el mecanismo de financiamiento y el origen de los fondos. O que frente a un cambio de gobierno adquiere continuidad como política, dependiendo su modificación de la generación de un consenso legislativo amplio. En este sentido, el PFCV aparece como una política específica en un contexto particular, que se construye en función de objetivos que, a priori no se restringen a una respuesta diseñada en torno al problema habitacional. Frente al desfinanciamento del FONAVI, los fondos que originan el PFCV provienen del superávit fiscal y permiten crear un nuevo programa en el marco de una estrategia de salida a la crisis. Cuya potencialidad central es constituirse en una herramienta de reactivación económica. Preocupado por ello, el PFCV establece metas para el conjunto de las jurisdicciones y plantea un sistema de premios a

\footnotetext{
${ }^{95}$ Ver Informe Relatoría Especial de Naciones Unidas "Vivienda adecuada como elemento integrante del derecho a un nivel de vida adecuado y sobre el derecho a la no discriminación en este contexto" Visita oficial a la República Argentina. Abril, 2011.
} 
quienes las cumplan. Otra diferencia interesante respecto al FONAVI es que la asignación de cuotas de financiamiento a cada jurisdicción no sigue las pautas de la distribución de los fondos coparticipables, al ajustarse al déficit habitacional registrado en cada jurisdicción, la provincia de Buenos Aires y la Ciudad Autónoma ganan participación en la canalización de recursos (Ostuni, 2008).

Mientras que la definición de los programas y la decisión del financiamiento dependen de la Nación, la ejecución está a cargo de los IPV, los organismos municipales u otras entidades intermedias sin fines de lucro. Estos actores se encargan del diseño de proyecto, la gestión de la tierra, el llamado a licitación, la contratación, la supervisión de la calidad constructiva, la certificación del avance de obra, la selección de los adjudicatarios, la entrega de las viviendas, la atención de demandas posteriores, el cobro de la cuota de recupero y transferencia del dominio.

Debemos advertir que el PFCV se inicia con la firma de un Convenio Marco entre el MPFIPS y las provincias. En el convenio se especifican: cupo por provincia, cantidad de viviendas o mejoramientos habitacionales financiados, monto máximo por unidad y superficie mínima según región geográfica, requisitos que deben cumplir los proyectos y pasos a seguir por los organismos jurisdiccionales para acceder al financiamiento de los proyectos.

La solicitud de financiamiento de proyectos se realiza acompañada de una memoria descriptiva $^{96}$ que los IPV, los Municipios o las entidades intermedias presentan a la MPFIPS. Es decir, la presentación de proyectos es el mecanismo por el cual se evalúa y se acuerda el financiamiento $y$, posteriormente, se utiliza para verificar el cumplimiento del plan de trabajo y atender el cronograma de inversiones. Ante la solicitud del pedido de financiamiento, la SDUV extiende si corresponde la "no objeción para licitar" y los organismos provinciales o municipales realizan el llamado a licitación. Luego de la apertura de la licitación, se evalúa la "no objeción para contratar" en base a la memoria descriptiva remitida por los IPV o los Municipios. Finalmente, se procede a la firma del Convenio Particular ${ }^{97}$ entre la SDUV y los organismos jurisdiccionales y la firma del contrato entre estos organismos y la empresa adjudicataria.

Pero frente a la formalidad de los convenios, la dinámica cotidiana muestra escollos importantes en la ejecución de la política. Uno de los centrales es el problema de los recursos y su forma de administración, que muestra un contraste marcado con el régimen precedente del Sistema Federal de Vivienda. Por otra parte, en el contexto inflacionario los compromisos

\footnotetext{
${ }^{96}$ En dicha presentación se describen las características del proyecto, el cual debe dar cuenta de: presupuesto oficial del proyecto y costo por vivienda tipo; situación de dominio del terreno, localización, condiciones técnicas de no inundabilidad y capacidad portante; infraestructura a proveer por los programas federales e infraestructura a proveer por la provincia; equipamiento y accesibilidad existente en el entorno, disponibilidad de una trama vial que asegure el acceso permanente (incluido el transporte público necesario); integración del proyecto urbanístico en función de las principales arterias urbanas, existencia de continuidad de la comunicación física; y diseño y tecnología de la vivienda acorde a los estándares mínimos de calidad para viviendas de interés social.

${ }^{97}$ En el Convenio Particular se especifica: el plan de trabajo y el cronograma financiero de los proyectos que serán financiados, el monto de financiamiento para cada obra, la metodología utilizada para redeterminar los montos convenidos (Decreto 1295/02), mecanismos de pago, metodología de rendición de cuentas, cierre financiero con la recepción provisoria de la obra, adjudicación y escrituración de las viviendas por parte del organismo provincial o municipal, cobro de las cuotas de amortización por parte del organismo provincial o municipal (SDUV, 2008).
} 
asumidos por el gobierno nacional, en muchos casos, exceden la capacidad financiera real generando dificultades de diversa índole. En uno de los fragmentos de la entrevista a uno de los funcionarios lo señala:

“...en realidad lo que rige es el convenio obra por obra, pero ojo el contrato de obra está dentro de ese convenio, pero la licitación la hizo la provincia. Y la Nación en ese convenio fija hasta ahí, si hay un deslizamiento de costo, sino paga, y se demoró en el pago y tiene consecuencia, todo eso lo tiene que asumir la provincia [...] Porque es un régimen complejo de obra pública, porque en realidad la obra pública fue al presupuesto, pero en la Nación están imputadas por pago y no por obra. Vos te preguntas porque hay problemas en realidad no es que esta obra tenga el financiamiento nacional asegurado, tiene asegurado el financiamiento en el convenio, pero en el proyecto de presupuesto no, porque te imputan el certificado en el momento del pago" (Entrevista № 7 Ex-Funcionario Nacional, 2011).

Por otra parte, la lógica del tratamiento caso por caso supone una administración que no tiene una unidad claramente definida y genera cierto desorden. Saber cuánto cuesta una obra en el marco del PFCV es prácticamente imposible. La asistencia financiera de la Nación a la provincia en un convenio marco, se superpone con la asistencia financiera de otro convenio a efectos de cubrir el deslizamiento de costos. Además, en un barrio concreto puede converger el financiamiento de más de una operatoria de los programas federales, o la provincia puede realizar aportes complementarios para una misma obra. Todo esto genera una complejidad posterior al momento de instrumentar el recupero, que por otra parte, en algunos casos supone la combinación de fondos reembolsables y no reembolsables. Surge así otro aspecto problemático, la cuestión del recupero y la escasa sostenibilidad del sistema. Si bien esta es una dificultad previa, en la etapa actual se desdibuja la idea de la solidaridad social del recupero o la necesidad de un fondo rotativo permanente que figuraba en el espíritu de la ley FONAVI.

\subsubsection{El impacto de los convenios del PFCV en nuestra área de estudio}

En julio de 2004 y agosto de 2005, se firmaron el primer y el segundo convenio marco del PFCV. En dichos convenios se establece que el financiamiento de la Nación a las provincias es no reintegrable. El financiamiento corresponde a un monto por vivienda con infraestructura y debe asegurar una superficie cubierta mínima. La Nación financia el 100\% de la obra de vivienda más infraestructura, las jurisdicciones pueden aportar financiamiento complementario y deben resolver el aporte del suelo donde se emplazarán las viviendas.

En este contexto, la provincia de Buenos Aires recibe en el primer convenio del PFCV el 30,8\% de la inversión nacional (que alcanzaba los 3,8 mil millones de pesos) y en el segundo 
convenio su participación asciende al 33,2\% (de la inversión nacional total equivalente a 17,4 mil millones de pesos). Es importante notar que esta proporción duplica el 14,5\% que le corresponde a la provincia de Buenos Aires del FONAVI a través de la coparticipación. Y, al mismo tiempo, el aumento de los recursos destinados a la provincia de Bueno Aires, se explica en gran medida por la participación de la inversión en los 24 partidos del Gran Buenos Aires en la composición del déficit habitacional.

De este modo, el PFCV introduce una novedad importante en la provincia de Buenos Aires, altera la división territorial de los recursos (observada en el apartado 2.1.4) priorizando la inversión en el Conurbano Bonaerense. La visibilidad de la "política federal de viviendas" en esta región, se contrapone al direccionamiento de los años noventa en el cual la política de vivienda de la provincia de Buenos Aires se dirigió hacia el interior de la provincia, desafectado el FONAVI del Conurbano Bonaerense.

De estos cambios en la matriz de distribución de los recursos, puede observarse el cambio de marcha que se produce en los datos agregados a nivel provincial en figura 11, a partir del momento en que comienzan a terminarse algunos de los conjuntos iniciado en el marco de la "política federal de vivienda".

Fig. 11 Cantidad de viviendas terminadas IVBA, total provincia 1978-2010.

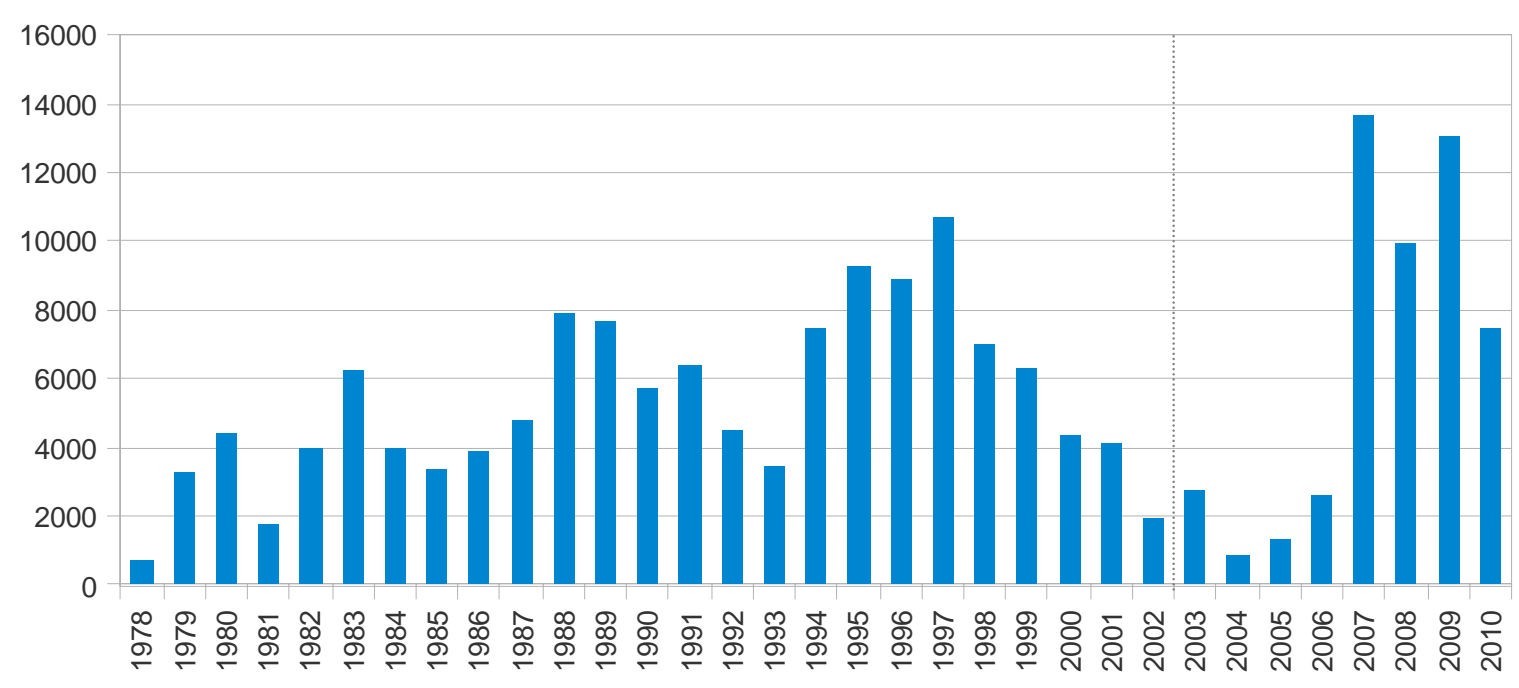

Fuente: elaboración propia en base IVBA (2006), e Informes de Gestión IVBA 2009 y 2010.

En cuanto a la distribución de los cupos entre las provincias surge del acuerdo entre las jurisdicciones y la Nación y es "carácter inicial". Pero susceptible de ser modificada cada 3 meses, en función de la eficiencia en el gasto, la característica del déficit habitacional, el nivel de desocupación y la optimización de los recupero FONAVI. Se imprime así una lógica de eficiencia, junto con la preocupación por reactivar el tejido productivo con la mayor celeridad 
posible, los plazos de ejecución de la obra no podían exceder los 12 meses $^{98}$ y la tecnología a utilizar debía ser mano de obra intensiva.

Como ya mencionamos la inversión acordada para el PFCV asciende, en la primera etapa (2004-2006), a 3.8 mil millones de pesos para la construcción de 120 mil viviendas y, en la segunda etapa (Convenio Plurianual), a 17.4 mil millones de pesos para la construcción de 300 mil viviendas en todo el país. Esto implica en los 24 partidos del Gran Buenos Aires, una inversión total acumulada (entre los dos convenios) de 5.5 mil millones y 102 mil viviendas. El costo por unidad vivienda con superficie mínima de $44 \mathrm{~m}^{2}$ financiada por la Nación era de 30 mil pesos, en la primera etapa. Y, en la segunda etapa, el costo estipulado asciende a 66,6 mil pesos por unidad de vivienda equivalente a una superficie mínima de $55 \mathrm{~m}^{2}$, siendo el monto actualizable según inflación ${ }^{99}$. Estos números pueden asociarse, en parte, a los problemas de ejecución que veremos posteriormente. La dificultad para sostener el ritmo de financiamiento dada la dinámica inflacionaria y la puja por las redeterminaciones de costos del sector empresario, es otro dato a tener en cuenta. En poco más de un año -entre la firma del primer convenio y el segundo- el costo por unidad de vivienda por metro cuadrado aumentó un $77,6 \%$ (pasando de $681 \$ / \mathrm{m}^{2}$ a $1210 \$ / \mathrm{m}^{2}$ ).

Por otra parte, es importante resaltar que la magnitud de los anuncios, aún cuando las metas planteadas están lejos de ser alcanzadas en los tiempos previstos, supone un cambio significativo en la tendencia de la curva de producción (como se observa en la figura 11). La apuesta cuantitativa es elocuente a nivel nacional y aún más considerable en los 24 partidos del Conurbano Bonaerense. El estudio realizado por Infohabitat $(2007)^{100}$ puso de manifiesto que el volumen de soluciones habitacionales anunciadas en el período 2004-2007 en dicho territorio, equivale a las soluciones habitacionales construidas entre 1976 y 2003 . Esto se explica en parte por el desplazamiento en el criterio de financiamiento a nivel nacional, el pasaje de la alícuota de coparticipación a un porcentaje ajustado al déficit habitacional y, en interior de la provincia de Buenos Aires, por el redireccionamiento de los recursos al Conurbano Bonaerense. No obstante, debemos ser prudentes ya que si observamos los datos "fríos" a nivel nacional, la cantidad de viviendas/año efectivamente terminadas entre 2003-2009 alcanzaron las 39.166 unidades, mientras que el período 1992-2002 las unidades/año llegaron a las 37.166 (ver figura 6, sección 2.2), es decir, la tasa de crecimiento entre dichos periodos fue del $4,2 \%$.

\footnotetext{
${ }^{98}$ Este inciso en el segundo convenio marco desaparece, ya que rápidamente se pusieron en evidencia la capacidad operativa real de la estructura administrativa. En algunos casos hubo que esperar 4 o 5 años para que se finalizaran las obras y aún hoy existen obras de la primera etapa sin concluir. Según el Informe de Gestión del IVBA (2008), cuatro años después de firmado el primer convenio del PFCV, al año 2008 el $80 \%$ de las vivienda con contrato de obra efectivizado a través del PFCV modalidad TPU estaban pendientes de la finalización de la obra y, en el caso del PFCV modalidad con Municipios, dicha proporción rondaba el $40 \%$.

${ }^{99}$ Según los registros de las entrevistas realizada en el 2010, el monto de la vivienda del PFCV rondaba los 102 mil pesos.

${ }^{100}$ Informe Final del estudio realizado por el Equipo Infohábitat (SDUV-UNGS, 2007) "Análisis Georrefernciado para el Seguimiento de Nuevas Intervenciones Públicas en Hábitat en el Área Metropolitana" Convenio Subsecretaría deDesarrollo Urbano y Vivienda de la Nación y Universidad Nacional de General Sarmiento.
} 
A pesar de ello, es importante resaltar que en la provincia y en el Conurbano Bonaerense la "política federal de viviendas" es la principal acción que desarrolla el Estado en materia habitacional. El Estado financia casi la totalidad de las intervenciones habitacionales del período actual (es decir, los fondos propios de la provincias Buenos Aires son ínfimos en relación a la inversión de los programas federales). En la figura 12, se observa que en el marco de los programas federales de vivienda 9 de cada 10 soluciones habitacionales que se realizan en el Conurbano Bonaerense corresponden al PFCV, contra 5,6 de cada 10 a nivel país. Esto muestra que el PFCV es una pieza clave en el análisis de la política habitacional en esta área de estudio.

Fig. 12 Distribución de los programas federales según porcentaje de soluciones habitacionales ${ }^{i}$ en ejecución 2003-2010," Conurbano Bonaerense vs. Total país.

\begin{tabular}{|l|r|r|r|}
\hline & Conurbano Bonaerense & Total país & Diferencia \\
\hline PFRFONAVI & $4,9 \%$ & $7,5 \%$ & $-2,6 \%$ \\
\hline PFSH & - & $7,2 \%$ & - \\
\hline PFCV & $87,1 \%$ & $55,9 \%$ & $31,2 \%$ \\
\hline PFMV & $0,1 \%$ & $23,9 \%$ & $-23,8 \%$ \\
\hline PFEH & $7,9 \%$ & $5,4 \%$ & $2,5 \%$ \\
\hline Total & $100,0 \%$ & $100,0 \%$ & - \\
\hline
\end{tabular}

Fuente: elaboración propia en base a Resumen de estado de programas habitacionales nacionales (agosto de 2010) de la SDUV-MFPIPyS (http://www.vivienda.gov.ar) y Base Gerencial (abril de 2009) del IVBA-SSUV de la Provincia de Buenos Aires.

Nota: ' Se incluye vivienda y mejoramientos terminados o en ejecución. li En el caso de los 24 partidos de la provincia de Buenos Aires el porcentaje se calculó en base a los datos del período 2003-2009 dada la disponibilidad de información, por ese motivo los datos no se muestran en números absolutos.

En suma, se verifica un cambio importante en la matriz de financiamiento de la política de vivienda y en su distribución geográfica. La "política por convenio" supone mayor flexibilidad hacia el interior del gobierno nacional, se "desengancha" de las reformas que se introdujeron al sistema en los noventa para situarse en una coyuntura determinada por la voluntad política de la nueva gestión, siendo el PFCV una herramienta decisiva para la reactivación económica con un impacto considerable en nuestra área de estudio. No obstante, la dimensión cuantitativa del financiamiento requerirá se contrastada en la siguiente sección con las problemáticas emergentes en otro plano, ya que como sugiere uno de los entrevistados mejor no preguntar por la calidad:

“...si sumás todo, creo que nosotros hicimos cerca de 40 y pico mil viviendas construidas en los últimos 4 años, es un número bastante importante en lo que es la historia de la provincia de Buenos Aires, no preguntes por la calidad, de eso podemos hablar después. Pero es un número importante, ahora eso tiene costos, costos de calidad, costos de mucho conflicto. $Y$ aún así es muy insuficiente en términos del déficit de la provincia de Buenos Aires..." (Entrevista No 9 Funcionario Provincial, 2011). 
Veamos a continuación qué sucede cuando los anuncios y la "letra chica" del convenio entran en fricción con el territorio y el entramado de intereses que se ponen en juego en el proceso de implementación de la "política federal de vivienda".

\subsubsection{La implementación del PCFV en el Conurbano Bonaerense.}

En este apartado, nos proponemos introducir algunos de los aspectos emergentes, matices y contrapuntos que configuran, en mayor o menor proporción, la forma en la cual la política de vivienda "baja al territorio" o finalmente acontece en la geografía municipal. Para ello, nos nutrimos mayormente del análisis de las entrevistas realizadas, entre el 2008 y 2011, a funcionarios de los distintos niveles de gobierno quienes son en gran medida los operadores de la política. En los capítulos 3 y 4 se trabajarán dimensiones de análisis complementarias que permitirán comparar o confrontar varios de los aspectos que aquí se planean.

Ya hemos dicho que nuestro análisis se centra en el PFCV, el cual tiene supremacía sobre cualquier otro programa habitacional en el Conurbano Bonaerense. No obstante, el PFCV tiene al menos tres variantes en su ejecución. En la primera variante, el IVBA está a cargo de la ejecución de la obra. En la segunda variante, el comitente es el municipio, la licitación y el contrato de obra es responsabilidad del nivel local y el IVBA solo realiza la supervisión de las obras. Esta modalidad es semejante a vista (en el apartado 2.1.4) para los programas descentralizados de los noventa, aunque al mismo tiempo entraña un nuevo vínculo entre la Nación y los municipios. Una tercera variante se asocia a las acciones en villas y asentamientos. El Subprograma de Urbanización de Villas y Asentamientos Precarios SPUVyA- más adelante se independizó del PFCV. Este subprograma supone la construcción de viviendas nuevas, combinada con mejoramientos, proceso de esponjamiento, provisión de infraestructura, regularización dominial, etc. Los arreglos jurisdiccionales y formas de intervención implican mayor complejidad que en la primera y la segunda variante del PFCV, las cuales están orientadas a la construcción de vivienda nueva y a la conformación de nuevos barrios. En este sentido consideramos que el SPUVyA constituye una realidad en sí misma, razón por la cual no lo incluimos en nuestro análisis, aún cuando varios de los rasgos asociados a las problemáticas de la implementación del PFCV podrían extenderse a dicho Subprograma ${ }^{101}$.

También debemos advertir que haremos referencia a cierta mirada que con el correr de los años, los distintos actores fueron construyendo en relación a la "política federal de vivienda". Si bien no se trata de "la visión general" es posible reconocer ciertos nudos problemáticos que en la implementación de la política se han ido cristalizando. En este sentido, la trama municipal puede, bajo determinadas circunstancias, adquirir cierto protagonismo en el devenir de la política de vivienda, lo cual nos permite introducir ciertos contrapuntos. No obstante, el nivel

\footnotetext{
${ }^{101}$ Otros aspectos de la diferenciación interna de las líneas de acción que componen el PCFV y su contexto de emergencia son abordados en el capítulo 3, donde le prestaremos especial atención al tratamiento de la cuestión del suelo, contexto en el cual la referencia al SPUVyA volverá a ser necesaria.
} 
municipal no fue contemplado en nuestro diseño metodológico como una unidad de análisis (a efectos comparativos), razón por la cual este nivel administrativo es para nosotros una escala de lectura más en la cual se analiza la política de vivienda. Por último, la ejecución en el territorio municipal de dos o más programas federales de viviendas, permite introducir ciertos contrastes entre el PFCV y los otros programas habitacionales.

\subsubsection{La relación entre nación, provincia y municipio}

Un aspecto que surge inmediatamente después del entrecruzamiento de las entrevistas a los funcionarios, es la tensión entre nación, provincia y municipio en el marco del proceso de recentralización de la política que hemos observado anteriormente. La dependencia del financiamiento del nivel nacional es un dato trasversal a todas las jurisdicciones. El moldeamiento de los programas y el núcleo decisional de la política aparece extrínseco a los municipios, incluso al nivel provincial. Además, se observa que según la modalidad de ejecución del PFCV, la negociación o relación entre la Nación y los municipios puede ser directa, dejando por fuera de ciertas decisiones a la provincia.

No obstante, frente a estos condicionantes también deben tenerse en cuenta la capacidad de gestión local o provincial y la inercia de la década previa. Como hemos visto en el apartado 2.1.4, el IVBA adquirió un "saber hacer" vinculado a la descentralización y el financiamiento, es decir, se basó en una política de administración de fondos, la supervisión del trabajo de los municipios y las entidades en el marco del rol "facilitador". El período actual supone un cambio de lógica, la vuelta a la construcción directa a cargo del Estado adquiere mayor relevancia, se abandona el concepto de asistencia financiera de los noventa y se vuelve a la licitación de obra pública. Pero frente al nuevo escenario el IVBA se encuentra "formateado" para otra cosa. Aquí, uno de los entrevistados da cuenta de ello indirectamente:

"Otro cuello de botella, fue la propia capacidad de producción de los institutos que venía con una producción muy baja de los noventa y tuvieron que hacer un salto de escala, en la cual era muy difícil saltar [...] como te digo, significó una cierta incapacidad para poder cubrir esa escala por los Institutos y por los municipios, acogotamiento de los sectores encadenamientos productivos en la construcción y un bajísimo nivel de control de obra, lo cual originó a su vez, demoras en la construcción de los conjuntos habitacionales y problemas constructivos posteriores [...] Pero bueno, había que construir, construir y construir y en ese proceso es muy difícil controlar y estamos pagando las consecuencias de eso" (Entrevista No 9 Funcionario Provincial, 2011).

Más allá de la inercia burocrática de una administración que en los noventa había externalizado numerosas responsabilidades. No menos real es el desfinanciamiento del FONAVI que en la actualidad atenta contra la posibilidad de definición de una política propia por parte de dicho organismo. Dado que los recursos y los "formatos" de la "política federal de viviendas" se que 
explican en gran medida por lo que acontece en términos de la política de vivienda en la provincia de Buenos Aires. El mismo funcionario nos decía:

“...en realidad para cualquier Instituto, no solamente para el nuestro, hoy tiene dos grandes entradas, el Fonavi y el Federal. Pero en realidad no son equiparables, el Federal de todo lo que construye el Instituto es más o menos el noventa y pico por ciento, y los fondos propios de libre disponibilidad para poder hace programas propios diferentes al Federal, es el 10\% para ponerlo en números gruesos. Respondiendo a tu pregunta, la capacidad que tiene el Instituto para tomar decisiones en términos de programas alternativos a los federales es muy baja" (Entrevista № 9 Funcionario Provincial, 2011).

También resulta interesante marcar cómo las relaciones de interdependencia (jerárquica y presupuestaria) se observa a nivel nacional, donde el Área de Vivienda depende de la Secretaría de Obras Públicas y el MPFSIP. Dicho en otras palabras, la Ley de Ministerios define una lógica de funcionamiento y la posición en el organigrama no es una variable intrascendente. De hecho, en la etapa actual la cartera de Vivienda ha perdido jerarquía quedando sumida a la órbita de Obra Pública. Una de las entrevistas permite ejemplificar los avatares de dicha situación:

"Desde el 92 a acá Vivienda es una cartera que no tiene firma, esa es una diferencia sustancial [...] del 99 sale de Desarrollo Social, Secretaría de Desarrollo Social, no hay que olvidarse que era una Secretaría de la Presidencia en los noventa, no dependía de ningún ministerio, ósea que incluso estaba más arriba que ahora, mucho más arriba que ahora. Ahora está inmersa en la Secretaría de Obras Publicas, el Plan es de Obras Públicas... y Vivienda. Pero el Plan es de Obra Pública, y es así la lógica es esa y el hombre que decide es ese. No hay otra, no, no todo lo demás es para el gil, la realidad institucional es quien tiene la firma, quien tiene la resolución, el Subsecretario tiene el presupuesto, eleva dentro del marco... pero la resolución la tiene el Secretario de Obras Públicas. Y eso tiene temas institucionales, que luego obstaculizan bastante la gestión..." (Entrevista № 7 Ex-Funcionario Nacional, 2011).

En el plano municipal, las realidades son heterogéneas en términos de recursos, capacidad institucional, densidad equipos técnicos, estilos de gestión y posicionamiento o alineación con el gobierno nacional y/o provincial. La forma en la cual se instrumenta el PFCV presenta matices según el nivel de problematización de política urbana y la capacidad de negociación de los referentes municipales, o el modo en cual el programa se procesa en el conjunto de las políticas públicas territoriales. Sin embargo, un denominador común es la gestión del conflicto en el territorio, en tanto los municipios son los mediadores de la relación con los "beneficiarios" pero, por otra parte, tienen mínimo control de los resortes de la política. Y, al mismo tiempo, la apertura del programa a la participación de los municipios en la formulación y el diseño es nula. Esto último puede verse reflejado, también en la mirada a nivel nacional, que evidencia el nivel de desarticulación de la política de vivienda entre los distintos niveles de gobierno: 
“¿Específicamente en relación a la articulación nación, provincia y municipios... [no termina de formularse la pregunta y se anticipa la respuesta] No hay... No te financia el costo, te da una plata para un cosa, te da un volumen de dinero, te lo mide por avance de obra, pero te da un volumen, si hay mayores costos, no es responsable, no sé como lo arreglan lo municipios y la provincia... Hay un modelo de gestión que es centralizado con ejecución descentralizada, múltiples efectores no relacionados entre sí. En el modelo con Provincia, la única cosa que une a todo el sistema es la decisión sobre los recuperos. Esa es la articulación, múltiples efectores, ejecución descentralizada, riesgos descentralizados, aunque claro cuando la papas quemas, les sacan unas compensaciones por mayores costos, aunque no te creas que mucha. [Aquí el entrevistado lee las preguntas del cuestionario y auto-responde] ¿Cuál es el margen de maniobra a nivel provincial y municipal? Poco ¿Que decisiones tomas? Las de ejecución ¿Qué posibilidades de readecuación? Baja" (Entrevista No 7 Ex-Funcionario Nacional, 2011).

Por otro lado, es interesante marcar la contradicción que se genera entre una política de vivienda de corte productivista (definida por fuera de la frontera municipal e incluso provincial) que está lejos de ser pensada como una política habitacional o urbana. En especial, cuando los recursos o elementos que los municipios disponen para señalizar el "aterrizaje" de los planes de vivienda en el territorio son limitados. Esto, sin duda, trasciende las lógicas endógenas del nivel municipal, ya que varios aspectos problemáticos del proceso de implementación de la política pueden verse reflejados, tanto en municipios con políticas urbanas activas $^{102}$, como en aquellos para los cuales "el Federal" tan sólo significa una oportunidad de "hacer obra" o canalizar recursos en el territorio municipal.

En este punto, una de las entrevistas remite a la preocupación de los funcionarios municipales de lo que acontece en su territorio y al mismo tiempo la distancia respecto de las decisiones:

"Estamos tratando de masticar nosotros a ver con qué bajamos... En realidad, la lógica $y$, en las reuniones previas a la entrega de las viviendas y de adjudicación, siempre se habló de que las casas se pagan, que no se pueden vender, que no se pueden ceder, que se van a pagar aproximadamente 600 cuotas (50 años), que el valor de la cuota no está estipulado. Hubo como un trabajo en la previa. Lo que pasa es que como no se pudo sostener... Nosotros como Municipio en los Planes Federales estamos cerca de todo y lejos, también, de un montón de decisiones. Porque nosotros no administramos las obras, ni tampoco somos los dueños de la tierra [refiere a barrios pertenecientes a la operatoria PFCV-TPU]. Entonces todas las decisiones son provinciales o tienen que ver con el Instituto. Por lo tanto, en algunas cosas se nos escapa la tortuga, porque no podemos tomar decisiones, con la empresa qué hacés, si les paga la Provincia, si administra la Provincia. Y lo mismo con el tema de la gente,

102 Nos referimos a los municipios en los cuales la reflexión sobre la ciudad se observa como un dato o una preocupación, que se traduce en propuesta de gestión urbana. 
cuando las viviendas se intrusaron, nosotros planteamos el desalojo, pero en realidad es la Provincia, la dueña de la tierra, la dueña de las casas" (Entrevista No 6 Funcionario Municipal, 2009).

Aquí otro recorte de la entrevista da cuenta de algunas de las manifestaciones de entramado interjurisdiccional y el modo en que opera el proceso de toma de decisiones:

“...estamos con las plateas [paradas] hace casi un año... ¿El problema es de financiamiento, es que Nación cortó los fondos? Es que Nación, es que Provincia, es que pido más las redeterminaciones, es que el precio con el que contrate ya no me sirve, es un montón de factores y variables que hacen que la empresa y el comitente, en este caso la Provincia, no se pongan de acuerdo y la obra está suspendida en principio, ahora hay algunos intentos de volver, pero bueno... ¿Y la obra está custodiada? Si está toda alambrada, con la custodia de la empresa... porque si se va del predio perdería todos los derechos contractuales... ellos siguen estando ahí y sistemáticamente reaviva la nota de 'me debés, no sé cuanto y no sé qué...' esa es una negociación donde interviene el Instituto de la Vivienda, nosotros como municipio miramos desde afuera, nada más, y se nos caen los lagrimones porque hay un montón de gente esperando vivienda" (Entrevista № 6 Funcionario Municipal, 2009).

La regla de oro al interior del entramado de la administración pública emerge no casualmente. Uno de los primeros elementos que los funcionarios municipales ponen sobre la mesa es dependencia material asociada al flujo de recursos. Puede verse reflejado aquí la relación subordinada de los municipios al financiamiento y cómo los principales actores productivos (las empresas) estrechan sus vínculos con la ventanilla que paga.

En este otro fragmento se refleja el circuito de los recursos y la relación directa entre la Nación y las empresas, a pesar de tratarse de obras cuya ejecución y contratación se encontraba a cargo de la provincia:

“...la Nación se tomó un año para saber cuánta plata debía en el Federal, imaginate el despelote que tenían... Entre que no tenía plata, ese discurso le sirvió como anillo al dedo. Realmente creo que no sabían la plata que estaban debiendo, de la cantidad de obras parada, las redeterminaciones que debían, los contratos que nunca pagaron. Eso sí les creo. Lo que no pueden haberse tomado es un año para resolverlo. $Y$ de hecho de todas las obras paradas, de las 40 en la provincia, se priorizaron 15-18 es el listado de obra que están a más del 80-90\% y tampoco se priorizaba por obras sino por empresa. Entonces cerraban paquetes con las empresas. Cerraban con las empresas por ahí una obra en un municipio, otra en otro. Resultaba que una obra al 50\% entraba en el paquete. Así son las decisiones que toma Nación" (Entrevista Nº 4 Funcionario Municipal, 2009).

Asimismo, vale la pena mencionar que el diseño del PFCV como un programa "enlatado" se configura alrededor de las necesidades de los actores empresarios, o mejor dicho, en función 
de la convocatoria que el gobierno nacional realiza en pro de la reactivación económica y productiva. En este marco, el margen de decisiones a nivel provincial y municipal prácticamente se restringe a garantizar la disponibilidad de un emplazamiento donde anclar el producto (o la unidad de inversión) y la selección de la población beneficiaria.

“¿Ustedes pueden opinar en estos proyectos? No, nos dan la factibilidad, como es $\mathrm{PH}$ nosotros tenemos que decir que sí. Y bueno hemos podido intervenir poco. Donde más hemos podido intervenir, fue acá [marca en el plano] ¿Y por qué en un lado si y en otro, no? Porque la empresa constructora es del municipio, es un constructor local, hubo más llegada" (Entrevista Nº 6 Funcionario Municipal, 2009).

En este otro testimonio también se introduce la idea de un proyecto urbano que se encuentra cerrado y el cual el municipio no puede modificar:

“¿El municipio pudo modificar algo? No, no te dejaban. Está armado así. Teníamos una vez por semana un inspector de La Plata y le decíamos 'mirá no sé puede modificar esto o aquello', y te decían que no. No se podía cambiar ni el tamaño de las viviendas, ni la distribución, ni hacer una parte comercial, nada...." (Entrevista № 5 Funcionario Municipal, 2009).

Sin embargo, aparecen registros contrapuestos que muestran que, en algunos casos, los municipios dispuestos a desafiar los moldes preestablecidos a nivel nacional pueden tensar (al menos hasta cierto punto) los márgenes de acción. Esto resulta más evidente en aquellos municipios que tienen experiencia de gestión urbana y un proyecto urbano propio a partir del cual negociar ciertas condiciones en la implementación, aunque la discontinuidad de estos financiamientos hace difícil sostener ciertas estratégicas de política urbana a mediano y largo plazo. Aquí se ilustra la posición de un funcionario municipal:

"Porque también la Nación te deja poco margen para tomar decisiones, yo diría que nada, pero... Nosotros aprendimos que ya no le hacemos caso, isi realmente! Porque te dicen que 'tenés que hacer blanco' $y$, después, vos ves que otros municipios dicen 'voy a hacer negro, porque yo necesito realmente hacer esto' $y$ se ponen firmes $y$ después no los matan, no los matan... entonces no podemos ser corderos del financiamiento. Pero bueno es lo que tenemos" (Entrevista No 4 Funcionario Municipal, 2009).

Otra cuestión que ya hemos mencionado, pero que fue puesta de relieve con frecuencia, refiere al desajuste entre los anuncios y la ejecución real. Situación mediada tanto por la sobre representación del propio presupuesto de la Nación al momento de asumir compromisos, como por la necesidad de proyectar expectativas "hacia adelante".

"Porque el problema con las leyes de emergencia [económica], es que vos haces ésto, programas ésto, pero luego tenés un discurso, pero luego vienen los bifes, y lo que es cierto es que los programas federales han excedido su nivel presupuestario asignado, porque sino no se estarían dando los desfajases de los pagos, ¿por 
qué no se visualiza? porque como yo tengo este compromiso pero imputando pago por pago, lo que me falta de compromiso no está imputado" (Entrevista № 7 ExFuncionario Nacional, 2011).

Concurrentemente, esta situación se encuentra afectada por capacidad de gestión real o por los retrasos que la misma demanda de acción pública genera. Es decir, los cuellos de botella en distintas segmentos de la cadena productiva y la inflación de los precios son factores igualmente convergentes.

“...vos decís con esta plata vamos a construir 2000 viviendas, pero en realidad no tenés tierras, se demoran las obras por problemas de cuello de botella en los procesos productivos $y$, además, una parte de la plata que estaba destinada a una nueva vivienda va a arreglar los desastres de anteriores. Obviamente hay un desfasaje ahí entre lo anunciado y lo efectivamente realizado" (Entrevista № 9 Funcionario Provincial, 2011).

Fig. 13 Temas emergentes en la relación entre niveles de gobierno, PFCV (2003-2010)

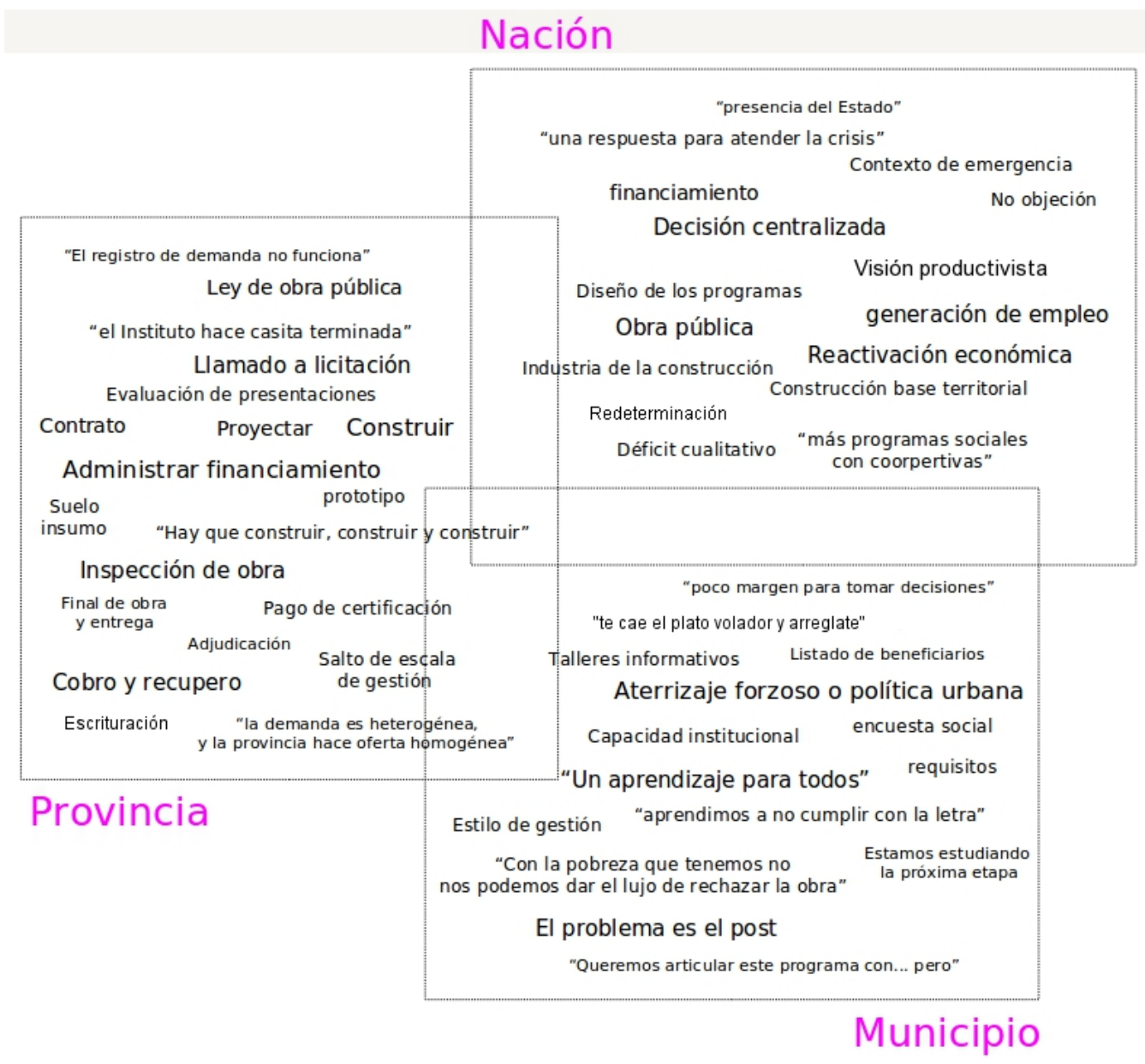

Fuente: elaboración propia en base registros de las entrevistas a funcionarios público de los distintos niveles. 
En la figura 13, puede observarse un esquema tentativo, elaborado a partir de los registros de las entrevistas, de la diferenciación entre los temas o cuestiones emergentes en cada uno de los niveles de gobierno en torno al PFCV. Si bien esto no pretende ser una síntesis pone al descubierto una serie preocupaciones que difieren según la escala y tensan la relación en el interior de una política pública en la que se yuxtaponen visiones de tipo macroeconómicas, sectoriales y territoriales.

\subsubsection{La intensidad de la obra y el después}

Otra secuencia a reconstruir, posterior a la lógica del financiamiento y formato predefinido del PFCV, es la tensión entre el momento de la obra y el después. En gran medida la genética de la "política federal de vivienda" se nuclea en base a unidades de inversión asociada a módulos de obra. Los problemas giran como planteaba uno de los funcionarios provinciales, alrededor de la acción de "licitar-adjudicar", "proyectar-construir" e "inspeccionar-pagar".

En este marco, una meta no menor, que frecuentemente se comporta como un "blanco móvil", es alcanzar el final de obra. Las peripecias e impericias que median en este recorrido son variadas y como describía otra funcionaria: "esta es una historia siempre con final abierto". Pero la presión es clara, la máxima es "hay que construir, construir y construir". El cómo, el para quién y el dónde, no importa o se encuentran en un segundo plano.

El criterio de eficiencia impuesto es "ejecutar el cupo" (a riesgo de perderlo) y ello se refleja en la matriz de desempeño vista en el apartado anterior. Esto acarrea secuelas aún en la arena estrictamente constructiva. A la paralización de las obras por la discontinuidad del financiamiento, es acompañada también por causas asociadas a los vicios constructivos y "la calidad es uno de los costos a pagar".

La comparación de las entrevistas presenta distintos registros que complejizan la lectura. Por ejemplo, otro de los sentidos que se pone juego en relación a "la obra" es la necesidad de materializar la presencia del Estado en el territorio. En algunos municipios la reaparición de "los Federales" significa volver a construir vivienda pública, "luego de 30 años en los cuales no paso nada". Esto sin duda se puede asociar a otra de las dimensiones puestas de manifiesto en la ejecución de la política. La movilización de recursos implica, al mismo tiempo, la generación de nuevos saberes y un aprendizaje para el conjunto de los actores que participan del proceso.

“Ley 6.022 estipula 70\% de la mano de obra tiene que ser local y el intendente también le exigió a la empresas que se cumpla. La experiencia de barrio donde la empresa recurrió a cooperativas es muy buena, porque en otros casos el capataz de obra cuando vos vas se te esconde. En cambio acá el tipo te buscaba para mostrarte como hacían las cosas, como habían hecho una platea o cortado un azulejo. Una actitud frente al trabajo espectacular" (Entrevista №4 Funcionario Municipal, 2009). 
La relación entre la ampliación de las fuentes de empleo y la producción de capacidades productivas, forma parte del relato y la realidad de la política actual. De igual modo, la sola presencia de la intervención habitacional anima expectativas que hasta entonces se encontraban obturadas, tanto por la realidad habitacional de las familias como por la ausencia del Estado en este terreno. Por otro lado, la "llegada" de la política a territorios abandonados no sólo anticipa la presencia de la acción pública, sino que también se convierte en una poderosa herramienta de acumulación política. A continuación uno de los funcionarios entrevistados ensaya una explicación de cómo opera la lógica de la política en este sentido:

"Además [la política] sirve de reproductor y de acumulador de poder porque es visible acumula lo que da y la expectativa del otro, que no tiene pero va a llegar, entonces me acumula, por lo que hago y lo que no hago [...] Porque el Estado tiene recursos simbólicos y poder material influye, le da un rayo de luminosidad que el otro percibe no sólo en el hecho, sino en el hecho que pre-anuncia, en la virtualidad del hecho. Lo mismo te pasa en el sector empresario..." (Entrevista №7 Ex-Funcionario Nacional, 2011).

En otro sentido, a pesar del proverbios "se equivoca el que hace" es importante recuperar algunas de los inconvenientes que se registran a posteriori. En este otro testimonio se entrecruzan la dimensión del aprendizaje y del aspecto problemático cuando "entra la gente":

"Fue un aprendizaje para todos, para la empresa, el Instituto, el municipio, para nosotros. Viste en la teoría es todo lindo, todo pintadito, pero entra la gente a vivir y ahí te quiero ver [...] Ninguna obra tenía contemplado el tema de los discapacitados, por ejemplo. En la segunda entrega vino un tipo y dijo: 'que lindo me van a entregar la casa...', estaba en silla de ruedas, pero no podía pasar. Era un dúplex aparte, cómo sube" (Entrevista Nº 5 Funcionario Municipal, 2009).

Varios de los diseños de los proyectos urbanos responden casi exclusivamente a maximización de la ecuación de rendimiento unidad de vivienda por superficie, comprometiendo en ocasiones hasta la posibilidad de ampliación o el crecimiento futuro de la vivienda. Determinados proyectos tienen la escala de una localidad urbana en si misma (más de 2 mil habitantes) y el equipamiento urbano ni siquiera está contemplado o llega con demora. Algo semejante sucede con las obras de infraestructura de nexo. Frente al problema del suelo y la dificultad de disponer de terrenos próximos a las área con cobertura de servicios urbanos, la mayoría de los barrios requirieron inversiones complementarias que en ocasiones arriban cuando las casas ya están terminadas. La categoría de "vivienda terminada sin infraestructura" sintetiza la situación de viviendas a la espera de ser habilitadas.

Otra realidad se asocia a déficit implícito que los mismos barrios de vivienda inducen, ya que a pesar de que las viviendas están pensadas como una vivienda mínima evolutiva, como señala otro de los entrevistados, no siempre los ingresos de los hogares permiten afrontar la ampliación. 
"Los prototipos son prototipos de 43 metros cuadrados no tienen nada que ver con la realidad de las familias, por lo menos de las nuestras, no sé en los otros distritos. Nosotros tenemos familia, madre sola con 11 chicos, en una vivienda de 43 metros cuadrados, o sea hay variables del NBI que nunca las vamos a modificar porque la gente sigue hacinada. En el de Villas [refiere al SPUVyA] vos podías armar viviendas según la cantidad del grupo familiar, pero en estos no [refiere al PFCV]. Tenés viviendas que son muy chicas. A ver... tiene la prerrogativa de que supuestamente puede crecer, este [se marca sobre el plano], este otro nunca crecerá [refiere a la tipología duplex]. $Y$ tampoco crecerá porque el universo económico de las familias les da para que puedan enfrentar la construcción de un dormitorio más" (Entrevista Funcionario $\mathrm{N}^{\circ} 6$ ).

En este otro ejemplo, se pude observar la rápida transformación del barrio que gran medida da cuenta de un conjunto de necesidades urbanas que trascienden la vivienda y no están "contempladas" :

“...hacía falta una unidad sanitaria, pero no dan abasto. Algunas familias tienen varios hijos. Imaginate, de golpe una explosión demográfica que no está contemplada. La parte comercial, la gente abre una puertita pone un kiosco. No se puede, pero la gente necesita vivir. Poner remises, vender comida. Si eso hubiese estado contemplado en el proyecto..." (Entrevista No 5 Funcionario Municipal, 2009).

El efecto del día después de finalizada la obra, con la intensidad que ello implica, lleva en muchos casos, a la necesidad de cerrar el ciclo y comenzar con otro proyecto u otra obra, sin embargo como veremos más adelante esto no será posible porque la demanda de los vecinos serán persistentes.

"Queríamos que cuando la gente entrara se olvidara. Entonces había que asegurarse de que todo anduviera. Que la puerta cierre, que el picaporte funcionara, que no hubiera filtraciones. Porque queríamos terminar y seguir con otra cosa. No tener que volver, el lote tal, la manzana tal. Un laburo de locos fue, había que ser arquitecto y psicólogo con la gente" (Entrevista № 5 Funcionario Municipal, 2009).

El "post obra" cuyo impacto generalmente lo recibe el municipio implica un conjunto de emergentes, muchos de los cuales pueden vincularse con la propia lógica de la política habitacional, una de las entrevistas lo refleja:

"En realidad demandas siempre surgen y para mi el PFCV no tiene simultaneidad con otros tantos programas lanzados... La llegada de la escuela, por ejemplo, en este barrio, que se están terminando de construir las viviendas, la escuela ya está avanzada. En aquel otro, todavía estamos esperando que se licite y ya tengo 3 años de entregado. Y los chicos y la matrícula... la que vivía acá ya no tiene más cupo en la escuela y la salita que está desbordada. Me parece que hay como todo un tema del equipamiento social que si bien está atendido por otros programas, no tuvo 
simultaneidad con los Federales que son estos platos voladores que te depositan 500 viviendas en el medio de nada y después, bueno... [...] ¿Por qué crees que se da esa descoordinación? Me parece que tiene que ver con un tema de desarticulación o falta de simultaneidad a la hora de lanzar los programas... A ver, nosotros somos un Municipio ávido de todo lo que nos mandan y agarramos todo en el momento en que nos mandan. El tema es que quizás otro municipio, con otro grado de necesidades, podría decir 'bueno no, no voy a querer 200 viviendas sino vienen acompañadas de una escuelas'. Son decisiones, que si bien son políticas, me parece que tienen que ir con una cuota técnicas y previendo un poco el post. Me parece que el Federal tiene como una veta muy cuantitativa, te hago 300 mil viviendas en todo el país y muevo el mercado y la mano de obra y que se yo... y te entrego la vivienda y nada. $Y$ eso después nos lo compramos nosotros, por eso es complicado" (Entrevista No 6 Funcionario Municipal, 2009).

Una política cuya temporalidad comienza y termina con la obra, implica a pesar de ella un proceso que continua en "el día después" y cuyas manifestaciones son diversas, extendiéndose desde un conjunto de demandas que se reflejan en la esfera municipal hasta en la erosión de la misma política pública. En la párrafo anterior, uno de los funcionarios municipales pone de manifiesto la imposibilidad "ética" (ante la escala de la necesidad) de rechazar los recursos que "bajan" de la Nación, a pesar de no acordar con la concepción y/o el modelo de ejecución de la política de vivienda.

Contradictoriamente el aprendizaje de la primera etapa del PFCV y los costos de implementación, generan dudas acerca de qué decisión tomar a futuro. Surge aquí un cuestionamiento interesante respecto a la sustentabilidad de esta forma de acción pública en el siguiente testimonio:

“¿Están con ganas de hacer algún Plurianual [refiere a segunda etapa del PFCV], no? Más o menos... El Plurianual tenía un precio de vivienda que se fue redeterminando. Te cuento la historia para que veas porque no se si queremos... era un precio que hasta el año pasado era 118 mil pesos por vivienda, estaban bastante ajustado. Y a fin del año pasado hubo una especie de talleres, y demás, donde se redeterminó es precio pero en menos. Está en 104 mil para el Conurbano con la tierra, con todo. Por lo que bueno, viste, estamos reflexionando seriamente si... ¿Cuánto sería el valor real? Hoy por hoy, estamos en unos 20-30 mil pesos por debajo, no sé a esta altura... Este es un valor que lo obtuvimos nosotros a septiembre-octubre del año pasado y con la proyección [de la inflación] por ahí se fue un poquito más... y en realidad lo redeterminaron por escrito en $\mathbf{8 0}$ mil pesos... esto es algo de palabra que con el Conurbano estaba en 104 pesos" (Entrevista Nº 6 Funcionario Municipal, 2009).

Aquí se pone en evidencia la ausencia de una norma clara, los niveles de incertidumbre con los cuales deben lidiar los municipios y el modo en el cual se desarrollan los procesos de 
negociación, donde los escritos difieren de lo acordado "de palabra". Vinculado a esto el mismo entrevistado decía:

"En todos los federales había obras de nexo que eran como un suplemento del $15 \%$ del valor de la contratación. Y en esta nueva redeterminación del año pasado, quedó como que esas obras las hace el Municipio [...] En estas obras nuevas del Plurianual, además de ser municipal, bajan el valor de la vivienda que era lo que estábamos tratando de negociar en más. $Y$ además ellos no acompañan con financiamiento las obras de nexo. Entonces digo, este que está acá [se marca en el plano] la piloteamos más o menos, pero el de allá que no me llega ni la canilla... Nosotros no podemos financiar, ni tampoco se lo podés poner al precio de la vivienda" (Ídem).

Por otra parte, al desfajase de los recursos en un contexto inflacionario se suma el desgaste del proceso de la gestión, que finalmente desencadena en la impaciencia de la población y a reiteradas situaciones de intrusión que sufren los barrios:

"Hemos perdido un poco de envión en estos últimos años. O sea arrancó con mucha obra y después tuvimos dos años que nos han costado muchísimo, algunas obras se han parado, terminar de negociar y cerrar estas nos está costando. Porque no baja financiamiento, porque la empresas están paradas desde otro lugar, porque la articulación entre la empresa, la nación, la provincia, la municipalidad. Esa triangulación siempre es complicada, te sentás con la empresa y te dice que no le dan planta, te sentás con el Instituto y te dicen que le sobre certificaron no se qué. Entonces siempre hay como discursos encontrados, en qué terminan, en que no me entregan las casas y acá tenemos viviendas en un estado de avance muy importante que sino empezamos a entregar, las van a ocupar, o se van a meter..." (Ídem).

La dilatación de "la entrega" entraña mayor riesgo de ocupación o toma de las viviendas. En este marco en el cual el apremio se generaliza, el Estado municipal entrega las viviendas a efectos de evitar un conflicto territorial y garantizar la llegada a los adjudicatarios. Las circunstancias alteran los circuitos administrativos previstos por la normativa, en algunos casos por ejemplo las viviendas se entregan sin el final de obra, a tal efecto se labra un acta de recepción provisoria. Como corolario de ello, podríamos decir que aún reduciendo el PFCV a una política de obra el desarrollo en este plano muestra múltiples restricciones.

\subsubsection{Asignación, uso y recupero}

Ahora veamos cómo se configura la idea del sujeto de la política de viviendas. En el contexto sectorial, el "beneficiario" o destinatarios de la vivienda se presenta difuso, aunque en algunos casos los municipios trabajan con registros de demanda que fijan claros criterios de prioridad. La implementación del PFCV supone la definición de un perfil de adjudicatario que se delimita entre la acreditación de la necesidad habitacional y una capacidad de pago mínima, de modo 
que permita el recupero posterior de la inversión por parte del Estado. En dicho recorte, cualquiera de los extremos supone un actor totalmente pasivo, receptor de un beneficio. Esto sin duda incide en la etapa posterior, en la cual a partir del uso afloran un repertorio de problemas, demandas e incluso dilemas en la gestión posterior de los conjuntos habitacionales. El universo del post obra presenta una serie de dificultades que por lo general son anuladas en el diseño de la política o invisibilizada por una racionalidad técnica para la cual hay que continuar produciendo. Esta tríada entre la forma de asignación, uso y recupero muestra, entonces, otras dinámicas y efectos de la política en la que a continuación ejemplificaremos.

La asignación de las viviendas se realizan a nivel municipal y la construcción del listado de adjudicación supone prácticas distintas, no se dispone de criterios uniformes controlados a nivel provincial. En este terreno, los municipios ganan autonomía pero su contracara, en algunos casos, es el aumento de la discrecionalidad. Pero también registramos experiencias en la cual a partir de la encuesta social se confecciona un puntaje con la finalidad de atender la necesidad como prioridad y, posteriormente, utilizan dicha información para conformar barrios heterogéneos desde el punto de vista social. También se ha implementado en uno de los municipios un registro único de demanda habitacional, respaldados por ordenanza que define prioridades, las cuales acompañadas por el trabajo técnico y social que busca instalar reglas de juego clara en la relación entre Estado y sociedad.

En el otro extremo, se observan casos en los cuales los propios funcionarios se han visto comprometidos en la "venta del cupo" o "un lugar en la lista de beneficiarios". Entremedio existe una gama variopinta de situaciones que no siempre garantizan que la vivienda llegue a quien realmente la necesita. Por otra parte, es relevante destacar que el proceso de adjudicación es normalmente una instancia posterior a la obra. Esto pone en evidencia que quién o quiénes serán los adjudicatarios de la vivienda, sus necesidades o formas de habitar no son datos relevantes en el diseño del barrio, mucho menos en la participación de dicho proceso.

Entre los requisitos para constituirse en adjudicatarios de la vivienda social, figuran tener residencia en el municipio y no disponer de otra propiedad. Se priorizan, además, grupos familiares jóvenes, también, madres solteras y cupos por discapacidad, entre otros. En la mayoría de los casos los municipios exponen demandar un mínimo nivel de ingreso a efectos de garantizar el recupero de los fondos. Esto contradice la idea de que en cierto punto surge un imaginario colectivo que vincula las "transferencias de fondos perdidos de la Nación" equivalen a que las viviendas son un "regalo". No obstante, esto no inhibe múltiples complejidades entre los criterios de asignación y recupero.

En el siguiente párrafo, uno de los funcionarios provinciales presenta una mirada que introduce otros matices referidos a la sostenibilidad del sistema:

“...más allá de esos esfuerzos para recuperar el costo de la casa... el recupero nuestro sigue siendo bajo, estamos aproximadamente en un $40 \%$ de la cartera, sigue siendo muy, muy bajo. Pero además, hay que recomponer, hay que hacer toda una reforma estructural en ese sentido del recupero y volver en realidad a hacerlo, porque nunca 
estuvo así, al viejo esquema del ahorro-financiamiento-subsidio [...] Acá la cultura es que te van a regalar la casa. No hay cultura de ahorro, no hay cultura de financiamiento y repago. Nadie está diciendo que no haya que tener subsidio. Estoy diciendo que es imposible sostener la cadena de financiamiento si no recomponés esas tres patas" (Entrevista № 9 Funcionario Provincial, 2011).

En relación a esto último, surgen dos aspectos interesantes a señalar, uno asociado a las posibilidades reales del alcance de una política habitacional que persiga la sostenibilidad financiera plena y la contradicción latente respecto la cobertura de qué "población objetivo". Aún cuando se acepte la necesidad de un subsidio total, resulta interesante problematizar los sentidos que se ponen en juego en términos del proceso o la mediación de la política pública. Ya que ésta anima o desalienta un conjunto de prácticas sociales que en determinadas circunstancias atentan contra la propia legitimidad de la acción pública.

Esto tiene consecuencias en los elementos que anteriormente apuntamos. La instancia en la cual los habitantes se mudan al nuevo barrio y la vivienda es puesta en uso, no forma parte del campo problemático de política de vivienda. Sin embargo, su lectura retrospectiva da cuenta de sus huellas, sólo a modo de ejemplo, mencionemos la generación de informalidad en el mercado que genera la misma política de vivienda. Ya sea porque la vivienda pública en su concepción se encuentra fuera del mercado o sea por la falta de escrituración, lo cierto es que en la dinámica urbana estas viviendas rápidamente pasan a formar parte del parque del mercado informal. En este otro fragmento este aspecto problemático es puesto de relieve:

"...el tema del recupero no es una cosa nueva, lo que pasa que en el Fonvi había incumplimiento y ahora hay desorden. La política explícita o implícita es la misma, no se le exige a los programas la solidaridad social que de alguna manera tienen las leyes que originan $y$, además, la idea que es una necesidad permanente que requiere un recurso permanente. Vos pensá respecto del mercado, en la última auditoría, 5\% de escrituración de lo terminado, o sea mercado informal del 95\% de lo producido..." (Entrevista N07 Ex-Funcionario Nacional, 2011).

En este otro ejemplo, se pueden indagar parte de las causas que hacen a las dificultades técnicas del recupero, los problemas de aplicar un sistema unificado (sin resolver caso por caso), los desajustes de criterios interjurisdiccionales y la contradicción entre la necesidad de cobrar y la exposición del Estado a nuevas demandas:

"Pero es complicado porque el tema del recobro no es bajar a dejarle las boletas a la gente... más en vivienda social, hay todo un trabajo de social que tiene que acompañar. Porque cuando fuiste con la boletita 'tomá tenés que pagar 200 pesos por mes' y te dicen 'se llueve la casa', 'y yo no voy a pagar por algo que se me llueve' y 'que me lo dieron'. Nos parece a nosotros como postura del Municipio, que debería haber un acompañamiento social y me parece que el Instituto no está pensando mucho en eso. A nosotros nos pone bastante intranquilos, porque después hay que lidiar con la gente, hay que ver los casos de irregularidad. Porque además hay que 
pensar que la vivienda no se puede ceder, ni prestar, ni alquilar, ni vender, ni nada, pero ya se detectaron muchos casos. Si nosotros desde el municipio, tenemos una preocupación por no regularizar situaciones clandestinas, hay que poner en común eso con el Instituto que dice 'yo le cobro al que esté, no me importa si se metió, si la vendió, si la compró...'. Antes de bajar una chequera y decir 'pagá', hay que ponerse de acuerdo en un par de cosas para unificar discurso. ¿Incluso en el monto? Si. Esta obra va a cumplir 3 años de entregada, hay que remontar eso... no pagaste 3 años y ahora 'empezá a pagar'. ¿Qué valor? Esta obra se contrato con 44 mil pesos por vivienda, estas con 52.600, las primeras casitas del Emergencia Habitacional un monto de 18 mil pesos. Son todas iguales, todas la misma superficie. ¿Qué haces? a uno le cobras menos a otros más. ¿Cómo empezar? Porque, además, aunque no parece todos se comunican... O sea se complejiza un montón, porque no podés unificar cuotas. Además sobre las viviendas hay redeterminaciones de precio, para que la empresa pueda sostenerse en este pasaje que hay de una vivienda contratada en 52 mil pesos y que hoy tiene un precio del doble, 104 mil. Todas esas redeterminaciones inciden en el valor de recobro. No, si, lo paga la gente, queda como parte del financiamiento perdido de la Nación a la provincia" (Entrevista $N^{0} 5$ Funcionario Municipal, 2009).

Por otra parte, la dinámica previa de las unidades domésticas que serán "beneficiarias" de la futura vivienda social no son contempladas por la racionalidad técnica, pero paradójicamente el técnico se guarda el poder de veto respecto a las modalidades de uso posterior de la vivienda. La búsqueda del contrapeso entre la atender todas las demandas del post obra y el reconocimiento de ciertas lógicas del hábitat popular se torna entonces compleja. Y constituye un desafío en sí mismo, como puede verse en estos ejemplos:

"Más allá de que uno trata de trabajar socialmente con la familia... cuando entregamos en verano, había chicos que se bañaban 5 veces. Por eso hay todo un tema que tiene que ver con: cómo entendés tu nueva vivienda, cómo la manejas. Y cómo nos bancamos y hasta dónde el reclamo. Porque una fisura en el techo, bueno puede ser, la arregla la empresa. Pero después había cosas que tenían que ver con el uso. Y que la empresa no te las va a reconocer nunca" (Entrevista No 6 Funcionario Municipal, 2009).

En este otro caso, se introduce una lectura de las prácticas de los nuevos habitantes:

"Un caso de una señora con la hija, una de las casas estaba en la etapa II ¿Qué hicieron? La casa de la hija la alquilaron y se juntaron los 8 en la casa de la etapa I. Porque ellos estaban acostumbrados a vivir así. 'No, no se puede vivir así, usted está generando hacinamiento. Y tampoco la puede alquilar a la casa'. Después iban a algunas casas y tenían todo impecable. En otras había humedad porque tenían todo cerrado y después te decían 'iehhh! acá las casas tienen humedad'. No, no es así. Todos los días se hacían cosas, se atendían reclamos. El inodoro está tapado te 
decían, metías la mano y sacabas un pañal [...] Algunos metían la garrafa adentro en vez de ponerla afuera. En vez de ponerla afuera que estaba el gabinete. Había un olor a gas que te querías morir. Una bomba de tiempo. '¿A no se puede? No, porque no tengo plata para el candado...' te decían." (Entrevista № 5 Funcionario Municipal, 2009).

Otro rasgo presente es la heterogeneidad en las formas de apropiación de la vivienda por parte de la población destinataria ${ }^{103}$. Sin duda, parte de las dificultades que se observan en este punto responden a factores que van más allá de la acción pública en materia habitacional. Sin embargo, otro tanto parece encontrar respuesta en el carácter mismo de la formulación y la implementación de este tipo de política pública. Vale aclarar que en algunos municipios se realizó un trabajo social asociado a la organización de talleres informativos y el seguimiento o acompañamiento alcanza mayor recorrido, mientras que en otros es algo totalmente subestimado.

Aquí uno de los entrevistados, da cuenta de la preocupación que en algunos casos existió por presentar a los vecinos o explicar las características de las viviendas y, en paralelo, las dudas respecto al alcance del seguimiento posterior:

"Se hicieron reuniones de vecinos, a la gente se le presentaba los vecinos y antes de la mudanza ya se conocían, se les explicaba cómo iba a ser la casa, cómo era el barrio... lo que pasa es que la cerradura, que el vidrio, que se rompió... y no entender hasta donde llega la responsabilidad de ellos [...] ¿Se hace seguimiento? ¿en qué consiste? Seguimiento... se sigue yendo, chequeando la titularidad, hubo casos, esos casos siempre hay, que te la venden por una bicicleta. También hay gente que viene y dice 'yo tengo un terreno, pero no puedo construirme la casa' y le dan de baja, porque no puede recibir el Federal" (Entrevista № 4 Funcionario Municipal, 2009).

En este registro, resulta interesante notar también la contradicción que vislumbra entre quienes teniendo un terreno no pueden acceder a ser adjudicatarios de una vivienda social, pero en paralelo, no pueden afrontar el costo de la construcción y se constituyen como sujetos excluidos de la política habitacional.

Una constante en casi todos los barrios es un porcentaje menor de adjudicatarios que rechazan la vivienda en la instancia de la entrega (o la venden posteriormente). La indagación de esto, raramente, es objeto de análisis, o mejor dicho, no se llega a interpelar a una política que concibe a un único tipo de respuesta y para siempre. Como hemos visto, en última instancia las situaciones de irregularidad que se generan no inhiben al Estado a avanzar o intentar recuperar la inversión, ni tampoco detener el proceso de entrega:

"Había gente que vos le entregabas la casa y no la quería [...] llegábamos ahí y decían 'esto no me gusta', 'no, no la quiero' decían. Y bueno 'ahí renuncie a la casa' y se

${ }^{103}$ Existe una lectura generalizada que parte del supuesto de "normalidad" en la administración, el uso o el mantenimiento de la vivienda "moderna". Esto frecuentemente hace chocar la mirada de los técnicos con los usuarios. En las entrevistas son numerosas las anécdotas al respecto, pero es un tema que excede nuestro análisis. 
llamaba a otro. Teníamos lista de espera, si no la querían teníamos gente a rolete" (Entrevista No 5 Funcionario Municipal, 2009).

Aquí otro de los funcionarios, busca una explicación al fenómeno de renunciar o transferir la vivienda, más allá de la mecánica de la entrega:

“...algunos era 'se la cedí a mi mamá', 'la dejo a mi hermana, porque yo en realidad me sigo quedando a donde estaba' [...] Entonces por ahí tenía gente que irse de acá era cortar con todas sus redes sociales, con su forma de vida, con su empleo, con un montón de cosas. También es difícil de sostener eso... pero ante tanta necesidad, la prioridad es te damos una vivienda nueva. Después se sigue el trabajo social en el barrio, tratando de ver quiénes son los referentes y tratando de crear comunidad nueva pero es difícil arrancar de cero con 1500 familias que vienen de realidades distintas" (Entrevista No 6 Funcionario Municipal, 2009).

Esta realidad muestra varios aspectos superpuestos, los barrios de vivienda pública nacen con una cuota de irregularidad, inducida no sólo por sus habitantes sino también generada por el propio Estado, que encuentra dificultades para formalizar un sistema que contemple la movilidad que a posteriori se desarrolla en los barrios. En otras palabras, esto encuentra una explicación en varios factores: el desajuste de la oferta pública a la necesidad habitacional, la desatención de la localización y el vínculo con las geografías personales, la dinámica de la rotación demográfica unidades domésticas o su necesidad de movilidad residencial y la incapacidad de gestión estatal de adelantarse al problema.

\subsubsection{El sector de la industria de la construcción}

Un actor que desempeña un papel fundamental en la matriz de la política de vivienda asociada al PFCV es la industria de la construcción. Si bien se trata de un sector que en los noventa no dejó de estar presente, en el período actual la finalidad que persigue la política le asigna una centralidad, tal vez, mayor. $\mathrm{Y}$, a pesar de las experiencias previas de programas habitacionales alternativos, parte de un concepto de intervención urbano-habitacional más complejo que requiere una articulación con otros actores productivos. En la etapa actual parece difícil pensar en formas de gestión e intervención en la cual las empresas constructoras no sean un actor protagónico.

Aquí uno de los funcionarios reconoce que la política actual es una política del sector de la construcción y evidencia al interior del procesamiento de la política habitacional, la tensión existente entre una lógica sectorial-productiva y una lógica territorial-urbana.

“...hay un problema en el enfoque de la política de vivienda, que no es una política de vivienda, es una política del sector de la construcción, más economicista y productivista que de política de vivienda. Hay un problema de homogeneidad en la respuesta que debiera ser mucha más heterogénea y obviamente que hay un problema urbano [...] en vez de hacer viviendas llave en mano del Federal, hagamos mejora de 
barrios integrales mucho más abarcativas, en áreas mucho más masivas y con intervención de la misma lógica, es decir, una lógica territorial no con una lógica constructivista" (Entrevista No 9 Funcionario Provincial, 2011).

Por otra parte, en algunos de los pasajes anteriores hemos visto que las empresas tienen más peso que los propios gobiernos locales. El énfasis puesto en las metas cuantitativas y la salida de la crisis encuentran en la industria un aliado a la hora de pensar una estrategia macroeconómica de respuesta rápida a la generación de empleo. $\mathrm{Y}$, en gran medida, la preocupación del Estado por sostener el compromiso de inversión hacia futuro se asocia a la emisión de brindar señales al sector. Como veremos esta prioridad parece no ser compatible con estrategias de abordaje territorial más complejas, ya que los márgenes de utilidad de estas empresas no son solidarios con la heterogeneidad de las realidades habitacionales de las familias.

En este fragmento puede observarse indirectamente la tensión entre el interés de la empresa y los problemas que generan sus productos:

"Acá la empresa sacó más rédito, porque sacó el doble de vivienda y la ecuación económica es por unidad, el tema de esto [refiere a tipología de duplex] es que no sé ni cómo va a crecer esas viviendas. El tema de que sea vivienda evolutiva que es una de las premisas, está ahí medio cercenado. Y esto crea complejidades en el post. Si acá que eran terrenos enormes hubo problemas de conflicto, imaginate este" (Entrevista No 6 Funcionario Municipal, 2009).

Otro aspecto a considerar, es que en el escenario posterior a la crisis del 2001, la posición de la industria no es la misma que una vez avanzado el proceso de recuperación económica. El boom del mercado inmobiliario y la ampliación de la inversión en otros segmentos de obra pública resulta para algunas empresas más atractivo que la construcción de vivienda social. Además, debemos considerar que la demanda agregada de la industria en conjunto supone (como ya hemos mencionado) algunos cuellos de botella en la cadena productiva. La dinámica inflacionaria y la redeterminación de costos vinculado a estadísticas oficiales (actualmente cuestionadas), complica en muchos casos la relación entre el sector público y el sector privado.

“¿Y la relación con la empresa cómo era? Buena, venía el inspector y veía que la empresa no era que lo iba a hacer... lo hacía. Cuando se le pedía cosas, cuando había que hacer alguna modificación, iban y lo corregían. El cortocircuito fue cuando la Secretaría [refiere a la Subsecretaría de Desarrollo Urbano y Vivienda de la Nación] empezó a cortar los pagos, empezó a demorarlos, de 30 a 60, de 60 a 90..." (Entrevista No 5 Funcionario Municipal, 2009).

El mismo funcionario en referencia a otra obra comentaba:

"Esa no terminó y la obra está demorada [...] En ese caso la empresa al no cobrar desde 2008, no pasa nada, pero está al 92\% [refiere al avance físico de obra] y entraron a tomarlo hará un mes" (Ídem). 
Por otra parte, no podemos dejar de mencionar el vínculo o la familiaridad entre los actores públicos y privados. Y, apoyado en esto, como bajos ciertas circunstancias las empresas trazan estrategias de especulación (haciendo uso y abuso de la Ley de Obra Pública) a partir de conocer los mecanismos que operan en el interior de administración. En última instancia, los riesgos para el sector empresarial son menores y los costos (de una obra parada) quedan en el territorio y se van a cargo de la cuenta del Estado.

En el fragmento que veremos a continuación, se introduce otro aspecto vinculado al papel de las empresas en el proceso de licitación, que remite a la dependencia del Estado de una oferta privada que no siempre cumple las expectativas, razón por la cual en muchos casos no logran ejecutarse los cupos asignados:

"Se cayeron dos proyectos, uno tenía una cuestión de inundabilidad que había que rellenar y las empresas tampoco insistieron en avanzar. $Y$ el otro, porque las presentaciones que hicieron las empresas fueron muy débiles y a la hora de firmar contrato no cumplían con los requisitos, no llegaban" (Entrevista № 4 Funcionario Municipal, 2009).

El papel que juega el sector empresario no es homogéneo, más bien supone desempeños variados. En algunos casos rescindir el contrato es inevitable y, en otros, las empresas trabajan respetando la norma, a tal punto, que hasta los funcionarios se sorprenden.

"El problema fue más que nada la puesta en marcha. Cuando entro la gente a vivir. La empresa se manejó muy bien, diez puntos, mire 'pasa tal cosa, tal otra' y lo solucionaban enseguida" (Entrevista № 5 Funcionario Municipal, 2009).

A diferencia de otros programas federales que recurren a cooperativas de trabajo, el PFCV se ejecuta exclusivamente a través de empresas constructoras. No obstante, en la implementación de la política en algunos municipios surgieron algunas experiencias interesantes de articulación entre cooperativas y empresas constructoras, con el objetivo de fortalecer la inserción de las cooperativas del PFEH en el tejido productivo, lograr su continuidad laboral y cubrir los desajustes entre obra y obra.

"En la primeras 400 viviendas del Emergencia Habitacional se crearon las cooperativas con gente del Plan Jefas y Jefes de Hogar. Las cooperativas de trabajo después fueron subcontratadas por la empresa y las reparten entre 20-30 cooperativas. Y era una especie de competencia para bien. Obviamente siempre hay un puntero que sabe $y$ arrastra. Vos no podés juntar a gente que viene de pintar cordones a levantar una casa" (Entrevista № 4 Funcionario Municipal, 2009).

Sin embargo, no podemos dejar de mencionar que las condiciones de subcontratación o la diferencia que el propio Estado realiza entre empresas y cooperativas de trabajo al momento de financiar la vivienda, dejan al descubierto la precariedad e inestabilidad de esta estrategia. En el marco del PFCV las empresas cobran aproximadamente un $45 \%$ más por vivienda (equivalente) que lo que cobra una cooperativa del PFEH. 
En este otro ejemplo, se introducen algunos matices en la contraposición del vínculo del municipio con las empresas y su relación con las cooperativas:

"Cuando trabajamos con las cooperativas la garantía de obra era mucho más manejable. Porque nosotros somos más cercanos a la cooperativa, en eso de construir juntos el vínculo, acompañarlos. Entonces 'anda a cambiarme el cuerito', 'andá y cambialo'. Pero la empresa que está en otra, hasta que nos hacían el reclamo nosotros, hasta que nosotros hacíamos el reclamo por orden de servicio y hasta que eso se hace efectivo, la canilla seguía perdiendo un mes más y hay un montón de cosas que no se atendieron... ya son casos perdidos" (Entrevista No 6 Funcionario Municipal, 2009).

El vínculo con las cooperativas, por supuesto, no está exento de contradicciones:

"También, tenemos ahí [refiere a la experiencia del PFEH] una cuota grande de inversión en cuanto a capacitación, cooperativas, trabajo como empresa social y demás, que nos costó muchísimo construir. $Y$ a veces cuando merma los planes, algunas de las cooperativas quedan muy enganchadas a la demanda de trabajo del Estado. Como los formamos desde el Estado a algunos les cuesta entender que nosotros somos un cliente más y que ellos pueden tener mucho otros" (Ídem.)

Si bien el análisis de los programas federales que se articulan con cooperativas requiere una lectura en profundidad y excede los límites de este trabajo, nos interesa realizar tres comentarios. En primer lugar, el desarrollo de algunas cooperativas puso en evidencia las posibilidades de organización social y productiva de sectores hasta entonces relegados del mapa de los actores de la política de vivienda. Asimismo, las cooperativas dejaron al descubierto el margen de ganancia del sector empresarial y, en algunos casos, con calidad de productos (y procesos) superiores. En segundo término, como veremos a continuación, las experiencias cooperativas muestran la potencialidad de constituir tejidos productivos flexibles con capacidad de dar respuestas a la mayor parte de las necesidades habitacionales (es decir, no sólo construir vivienda nueva sino también atacar el déficit cualitativo) que, por otra parte, no resultan atractivas al sector empresarial. Probablemente el fortalecimiento de estos actores productivos, articulados con un sistema de asistencia técnica, financiera, políticas de suelo y mejoramiento urbano podrían ser una alternativa de diferenciación de la política actual.

\subsubsection{Suelo, localización y ciudad}

En este punto nos interesa introducir uno de los aspectos, que a nuestro juicio, es crítico en el marco de la "política federal de vivienda" en el AMBA, nos referimos al modo en el cual se manifiesta la relación entre suelo, localización y política urbana. Si bien esta cuestión la abordaremos con mayor detalle en el siguiente capítulo, es útil introducir algunas de las visiones que se generan en torno a ella. En el Capítulo 1, vimos que el problema del suelo y la localización tiene múltiples facetas. Algunas de ellas se ponen de manifiesto en la etapa previa 
a la intervención habitacional (por ejemplo: el problema de la disponibilidad de suelo para construir vivienda social se transformó en un verdadero obstáculo), otras en cambio, comprometen la dinámica urbana que se produce el día después de entregada la obra, instancia en la cual múltiples demandas y problemas se ponen en juego.

En el discurso de todos los entrevistados se observan puntos en común: el antagonismo que por definición existe entre centralidad urbana y la vivienda social; la mención a la localización como un mero insumo para realizar una obra; y la asimilación del desarrollo de una política de vivienda como algo constitutivamente desarticulado de la política urbana. Una vez más, vale aclarar que es posible encontrar alguna jurisdicción como excepción a la regla. Sin embargo, constituyen casos verdaderamente aislados. Son escasos los municipios que cuentan con equipos técnicos y funcionarios que desarrollan una lectura urbana Más allá de la lógica de la obra, reflexionan sobre la problemática de la tierra, el crecimiento urbano, la relación entre viviendas y el plan urbano (cuando existe). En general, la no disponibilidad de suelo se toma como una variable dada, raramente es problematizada y la palabra clave, más bien, es: "ejecutar".

Algunos de estos rasgos pueden observarse en los siguientes testimonios:

"Ninguno de los Federales está pensado como proyecto urbano, se salió a buscar suelo donde se pudo" (Entrevista No8 Funcionario Provincial, 2010).

Otro funcionario decía:

"La obra está ahí y no la contemplaron. Vino ahí y iblop!, la plantaron como un ovni, podría haber estado ahí como en cualquier otro lado. El entorno no está en ningún momento estudiado" (Entrevista No 5 Funcionario Municipal, 2009).

Por evidente que parezca, las decisiones residenciales y cualquier estrategia de gestión urbana, parten de considerar el dónde como una variable central que orienta la acción. Llama la atención que las operatorias urbanas asociadas a la vivienda social se desvinculen de esta variable tan básica. En este punto, surge un interrogante inevitable, referido a cuáles son las razones que hacen que el Estado tenga tanta dificultad para desarrollar políticas activas de suelo y regulación de los mercados articuladas a una política de vivienda social. O dicho de otro modo, qué dificultad encuentra para pensar un proyecto de ciudad que incluya la vivienda social como un elemento constitutivo de la misma.

En este sentido, excepto que "proyecto urbano y vivienda social" sean términos auto excluyentes, debemos considerar la relación de los "proyectos urbanos de vivienda social" con: la estructura urbana, su diseño en función de la supuestas "población objetivo", la escala del proyecto y la relación con la centralidad urbana o la capacidad de crearla, el vínculo con la red de transporte público (y la conectividad metropolitana). También hay que considerar su ubicación en función de las tendencias de crecimiento de la ciudad, la disponibilidad de equipamiento urbano (o la producción integrada del mismo al proyecto habitacional), la relación 
entre dicha pieza urbana y el contexto territorial, la mixtura social y de usos, la evolución (no sólo de la vivienda sino) de la operatoria urbana en conjunto, etc.

Advertiremos luego que la adquisición de suelo, en el marco del PFCV, implicó una política predominantemente asociada a la compra de suelo o la adquisición a través de las empresas ${ }^{104}$ $y$, muchos de los aspectos arriba mencionados, se vuelven especialmente críticos. En contraposición a esto, cuando indagamos acerca de cuáles eran los mecanismos de adquisición de tierra, en otros períodos de la política de vivienda, uno de los funcionarios nos respondía lo siguiente, dando cuenta nuevamente de la "tensión" que genera la disponibilidad de tierra al momento de implementar la política:

"No es muy diferente ahora. Es decir, la tierra de dónde sale, sale de lo que ponen los municipios, de lo que pone una entidad privada, llámese cooperativa, gremio, lo que sea. O lo que pone el Fisco de la provincia que cada vez es menos, en este momento es prácticamente cero. No hay una lógica unitaria en ese sentido [...] ... con lo cual vos no podés programar la tensión, es decir, la política de vivienda no se puede programar en términos del déficit municipal sino en términos de la disponibilidad de tierras" (Entrevista No 9 Funcionario Provincial, 2011).

Por otra parte, resulta inevitable mencionar que ante una configuración de la necesidad atomizada y dispersa espacialmente (en gran medida asociada al déficit cualitativo intra-lote y al déficit de consolidación urbana), la respuesta dominante de la política pública habitacional es construir aglomeraciones de vivienda nueva asociada a un proceso de expansión urbana, constituyendo de esta forma una respuesta homogénea y espacialmente concentrada. Frente a esto es evidente que el efecto del mercado de suelo y el poder de lobby del sector de la construcción son variables completamente internalizadas al diseño de la política de vivienda y raramente discutidas.

En contraposición a la lógica dominante del PFCV, observemos una experiencia marcadamente contrapuesta, donde el PFEH se articula con estrategias previas de gestión urbana a nivel municipal, generando impactos sociales y urbanos sustantivamente diferentes:

"Este programa estuvo buenísimo mientras estuvo bien financiado. Esta operatoria, nosotros la hicimos en lote vacante, no era una parcela grande sino que eran pequeños lotes que iban quedando remanentes [...] Entonces el tema fue que estuvo más bueno socialmente porque nosotros hacíamos completamiento de tejido, terminábamos de consolidar las áreas parceladas con la vivienda y la familia no estaba tan estigmatizado como ellos son 'los que se vinieron a vivir acá', 'los nuevos', 'los ladrones'. Sino que al ir metiéndose entre los barrios ya instalados, era mucho mejor [...] Como nosotros ya teníamos un plan de lotes dando vuelta, la familia ya vivía en el lote. Entonces esto que nos cuesta tanto que es poder aprender el proceso

\footnotetext{
${ }^{104}$ Aunque es importante mencionar que recientemente el IVBA ha diseñado un nuevo Programa de Lotes con Servicio que se encuentra en proceso de instrumentación. Dicho programa se financia con fondos propios y surge como una política de diferenciación a la "política federal de viviendas" .
} 
constructivo y ver como avanza la obra y ver como avanza la pared. $Y$ no eso de 'hola, mira, te regalo la casa' o 'la vas a pagar pero...'. Vivir el proceso constructivo, vivir el día a día de la obra, el frío, el mate a los muchachos, se pelean, se auditan, eso va creando como un sentido de pertenencia de la vivienda distinto, a cuando cargaste todo en el flete y te bajaste en una casa nueva... A la hora apropiarse de la casa dio resultado posteriores distintos" (Entrevista № 6 Funcionario Municipal, 2009).

En oposición a este tipos de experiencias, la implantación de la política de vivienda a través del PFCV, supone un proceso de relocalización mediante el cual la población destinataria de la inversión asociada a la vivienda social, es traslada de un lugar a otro de la ciudad. Dicho proceso, implica siempre un balance entre lo que se pierde y se gana, llegando en casos extremos (como ya hemos visto) a que incluso los adjudicatarios rechacen la vivienda.

Este otro fragmento da cuenta de estos desplazamientos urbanos:

"La mayoría vivía en la casa de la madre o del padre o alquilaba un cuartito de alquiler... Muy pocos eran los que alquilaban un departamento o una casa, a lo sumo alquilaban un cuartito. Pero la mayoría, vivían dos o tres hijos con sus familias en la casa de los padres. Yo vivió acá a 15 cuadras y no sabés, quedaron los padres, no hay chicos..." (Entrevista No 4 Funcionario Municipal, 2009).

Las áreas donde se emplazan los conjuntos de vivienda social no siempre reúnen los atributos urbanos mínimos, aunque parezca un contrasentido, el final de obra de la vivienda, en muchos casos significa, el inicio de la "obra" de construcción de la ciudad. En determinados barrios del municipio el transado de la población de un lugar a otro, significa una migración de 2000, 5000 y hasta 10000 habitantes (por barrio). Este proceso acarrea diversos impactos (que serán visto en los próximos capítulos).

Respecto de las condiciones de localización de los barrios en la ciudad, las respuestas y las percepciones de los funcionarios son disímiles y contrapuestas, aunque como se puede ver, en ambos casos se prioriza una lectura formal desde la perspectiva de la zonificación urbana:

"La premisa es encuadrar todo dentro de área urbana que no quede nada que no tuviera un acceso medianamente pensado desde la planificación del territorio. Ehhh... No quiero traer ejemplos que no corresponden. Pero siempre ha pasado que no tienen tierra, entonces ponen en la parte complementaria o rural, dicen 'vamos por eso $y$ después vemos cómo...' En general son enclave bastante cercanos a terminar de completar los espacios de la trama urbana preexistentes" (Entrevista No 6 Funcionario Municipal, 2009).

En este otro caso, en cambio, nos decían:

"Es zonificaciones especial, porque no encuadraba la normativa. Porque eran parcelas rurales. Ahora estamos a la espera de que se convalide en provincia. Para aprobar el plano de mensura y subdivisión y poder hacer la recepción final de obra. 
Eran todas parcelas rurales menos este que era industrial mixta" (Entrevista № 4 Funcionario Municipal, 2009).

En este contexto el refuerzo de la redes de infraestructura existente, la construcción de las obras de nexo, de equipamientos, resolver la accesibilidad al barrios, la conectividad del transporte público, son algunos de los problemas emergentes en dicho proceso. Las respuestas rondan en torno a las acciones de "conectar" el barrio, "se mejoró el pavimento previendo el circuito del colectivo", "se licitó la escuela el jardín y la escuela primaria", "se adaptó una salita en una de las casas", "se va a ampliar la planta de tratamiento", "se está trabajando para mejorar a presión de agua", etc. Aquí se observan algunos ejemplos con mayor detalle:

"Por gestión del municipio ante la empresa entra [al barrio] la línea municipal, dos ramales. Antes tenían que caminar 15 cuadras y ya habían comenzado a entrar colectivos truchos. Para evitar que prospere eso, se gestionó hacer entrar a la línea municipal y se hicieron reuniones en el barrio con los vecinos por el tema" (Entrevista № 4 Funcionario Municipal, 2009).

El mismo entrevistado nos decía:

"Lo más complicado en ese barrio por la escala, fue el tema del equipamiento. Porque muchos se mudaron al barrio y perdieron el año de escuela. No había ni escuelas, ni jardín. Se implementó un sistema que el micro los iba a buscar al barrio gratis y los llevaba a las escuelas donde estaban, pero muchos igualmente perdieron el año" (Ídem.).

Frente al desenlace de este tipo de políticas de obra de escaso anclaje territorial, es evidente que los municipios quedan atrapados por la lógica de la necesidad en un entramado de alta dependencia de los recursos y son los que reciben principalmente el "rebote" de los efectos de la política. Este otro testimonio refleja esta situación:

“¿Cómo tomó el Municipio los planes de vivienda en relación a la política urbana que venía teniendo? No, fue con los brazos abiertos. $Y$ a veces en esto de ignorar las consecuencias de... muy inocente. Por eso te digo... ahora al Plurianual lo miramos con otra distancia. Estamos como el que ve la vaca y llora, porque con el problema que hay hoy con el financiamiento de la vivienda social, hasta dónde asumir compromisos como comitente, dependiendo económicamente del Estado Nacional y demás [...] nosotros tenemos de 7 a 15 mil familias en emergencia habitacional o con problemas grandes... Por lo tanto, no podemos ser demasiado exquisitos" (Entrevista Funcionario No6).

Finalmente, aunque la cuestión del suelo es un problema de competencia provincial y municipal, es importante señalar que el diseño de la "política federal de vivienda" a nivel nacional (aún cuando esté exenta formalmente por la distribución de las competencias) no contribuye a su resolución. Por el contrario, la producción masiva de vivienda nueva a través 
del modelo "llave en mano" tiende a agravar (al menos en los grandes núcleos urbanos) el problema del acceso al suelo para la vivienda social. En la provincia de Buenos Aires, ante la escasez de suelo urbano disponible en el AMBA al momento de implementar el PFCV. EI IVBA buscó resolver el problema convocando a las empresas constructoras a presentar en el pliego licitatorio los terrenos para la construcción de vivienda social. Se terminó desarrollando una estrategia, en la cual el suelo es considerado un insumo más del proceso de producción y la localización un "efecto colateral". En el próximo capítulo, nos dedicaremos al análisis de estos dispositivos administrativos de adquisición de suelo que confirman que el suelo y la localización nos son asumidas como una dimensión constitutiva del hábitat. 


\subsection{Crisis y ladrillos o la continuidad de la genética sectorial}

En la líneas anteriores, vimos que el surgimiento de la "política federal de viviendas" irrumpe en el escenario post crisis 2001 y, luego de un proceso de desfinanciamiento del FONAVI, reintroduce la cuestión de la vivienda en la agenda pública. En este contexto, la política fue concebida desde el ámbito de la economía y la producción. Esto significó que a pesar de la relativa diversificación de los programas, las líneas de acción estuvieron dirigidas principalmente a asistir una estrategia de reactivación económica, a través del incentivo de la industria de la construcción con una prioridad asociada a la generación de empleo y a la reconstrucción del tejido productivo. De allí la centralidad que adquirió el PFCV (Programa Federal de Construcción de Viviendas). Siendo el principio regulador de la política, la capacidad del sector de empujar el crecimiento del PBI, dado el "poder de los ladrillos" en el arrastre de la economía.

Una vez restablecidas las retenciones a las exportaciones al sector económico beneficiado en el escenario post-convertibilidad y ordenada la balanza de pagos, se priorizó la inversión en materia habitacional en la matriz del gasto público. Se orientó así un volumen significativo de recurso a la construcción masiva de la vivienda nueva a través de las empresas constructora y, en menor medida, vía cooperativas de trabajo (buscándose de este modo apuntalar la inserción de desocupados en el mercado de trabajo y amortiguar el conflicto social).

Ahora bien, el esquema de financiamiento difirió del establecido por la Ley del Sistema Federal de Vivienda, el gobierno nacional optó por transferir recursos no reembolsables a las provincias por fuera del sistema. De este modo, garantizó quedar a cargo del control de la política de vivienda, retrotrayéndose de esta manera a la etapa previa a la descentralización del FONAVI. Pero sin la necesidad de atarse al marco normativo del mismo y con un amplio margen de maniobra conferido por la Ley de Emergencia Económica. La definición de los programas habitacionales y el dominio de los recurso volvió así a la órbita nacional, donde se estableció un modalidad de ejecución por convenios (marco y particular), en la cual se asume un convenio "obra por obra" sujeto a la aprobación de la Nación. El cuánto, el cómo y el a quién pasan a ser decisiones nacionales. De allí que coincidamos con varios autores (Rodulfo, 2007; Rodríguez y Di Virgilio, 2008; Fernández Wagner, 2008) en observar un proceso de recentralización de la política de vivienda en el período actual.

En relación a los años noventa no sólo se observa un relativo desandamiaje del proceso de descentralización -aún cuando en la actualidad la ejecución continué 
siendo descentralizadas, al igual que en los noventa y en la etapa de institucionalización del FONAVI- sino que también se verifica una retrotracción del concepto de asistencia financiera y el restablecimiento de un esquema de licitación de obra pública en el cual el Estado asume mayores riesgos.

Respecto a los denominados "programas alternativos", que paradójicamente surgieron en los noventa y significaron una innovación en el marco de los paradigmas tradicionales de la política habitacional (el Programa de Mejoramiento de Barrios es probablemente el mejor ejemplo), en el período analizado (2003-2010) estos programas continuaron teniendo una escala reducida sin haber ganado protagonismo. Por el contrario la "política federal de vivienda" mostró una prioridad en el sentido contrario a los mismos. $Y$ algunas de las principales continuidades que se registraron entre ambas décadas, fueron: el esquema de incentivación de la oferta, asociada una respuesta única o producto homogéneo; la desatención de la dimensión urbana o territorial en diseño de la política; el descuido del déficit cualitativo en la composición de la inversión; la concepción de un sujeto todavía difuso y pasivo; y, entre otras continuidades, la debilidad de la sostenibilidad financiera.

En relación a este último punto, no nos referimos tan sólo a la persistencia de un bajo nivel de recupero -aún cuando en el caso de la provincia de Buenos Aires que miramos más de cerca se registraron en los últimos años tasas de recupero ascendentes- sino, más bien, a la tensión existente entre el giro de recursos a fondo perdido de la Nación a los distintos subejecutores de la política, el contexto de la salida de la crisis socioeconómica que contribuyó a dilatar la instrumentación de los recuperos y el desorden y/o la heterogeneidad de criterio que se observó en este plano. Esta tensión entraña una contradicción con el criterios de solidaridad social del recupero de la inversión a efectos de retroalimentar un fondo circular y permanente que atienda la problemática habitacional.

Simultáneamente la definición de la "política federal de vivienda", como un programa de gobierno aferrado a una fuerte decisión política, no ha dejado de ser un fondo presupuestario circunstancial cuya previsibilidad se define año a año. Esto pone en evidencia una cuestión nodal, a pesar de la magnitud de los anuncios los desfajases en la ejecución real se explican, más que por los cuellos de botella en los encadenamientos productivo (que fueron importantes inicialmente), por la ampliación de los compromisos públicos dirigido a incentivar la demanda que en el contexto inflacionario erosiona o excede la capacidad de pago tensada por los deslizamientos de costo. Opera así una sobre representación de nivel presupuestario, en la cual la 
ampliación del nuevo financiamiento se destina no sólo a proyectar expectativas sectoriales "hacia adelante" sino también a cubrir compromisos "hacia atrás".

Por otro lado, el análisis de las etapas de la "política federal de viviendas" mostró que en un primer momento de crisis, la prioridad fue reactivar obras, atender la pobreza y amortiguar el conflicto social. En un segundo momento, este punto de inflexión quedó atrás y se produjo un apuntalamiento de una estrategia macroeconómica de producción y trabajo, que con el correr del tiempo tendió a consolidarse como basamento central de la política, introduciendo algunas variaciones menores, como por ejemplo: ampliar levemente la participación de los recursos destinados a denominados programas sociales. Luego, los fondos ANSES pasaron a formar parte de la composición del financiamiento, introduciendo de este modo una tensión entre el origen de los fondos y la necesidad de garantizar el recupero, razón por es esperable un desplazamiento del PFCV (financiado con dicho fondos) hacia sectores socioeconómico de mayores ingresos. Más allá de la periodización planteada en el apartado 2.2.2, hasta la actualidad no se ha producido una reflexión sobre el camino recorrido. $\mathrm{Y}$, una vez pasado el período de la crisis o asentado el proceso de crecimiento económico, la política a nivel nacional ha sido confirmar la tendencia productivista que apuntala al sector de la construcción sin introducir grandes innovación al respecto.

De allí que en el proceso de implementación de la política hayamos registrado una serie de conflicto que en parte pueden asociarse a la racionalidad asume la política de vivienda a nivel nacional. Si bien, no todos las limitaciones corren por cuenta del nivel nacional y, a nivel provincial o local pueden, también observarse obstáculos diversas que complejizan el modo en el cual la acción pública se realiza en el territorio municipal, no menos cierto es que la formulación de la política actual desestima el abordaje territorial como una variable clave en dicho proceso. La desarticulación entre los distintos niveles de gobierno, a pesar de algunas excepciones, se observó como una constante; siendo la agenda de temas profundamente dispar y relativamente homogénea la dependencia del las decisiones del financiamiento y el producto a nivel nacional.

Pero, pese a la dependencia que comparten respecto del financiamiento central y de un conjunto de decisiones que se toman a otras escalas jurisdiccionales, los municipios analizados muestran significativas diferencias en cuanto a la reflexión que producen sobre las problemáticas emergentes en el transcurso de la implementación de la política, el modo de encausarlas y la introducción de variantes en la realización de la acción pública. Esto se explica, en gran medida, por: las trayectorias o 
experiencias de gestión urbana; la existencia, en algunos casos, de un proyecto de urbano municipal explícito que piense desde otro lugar la relación con la vivienda social o el hábitat popular; el impacto previo generado en algunos municipios por los programas habitacionales "alternativos", incidiendo en el reprocesamiento de la cuestión en gestión a nivel local; y, las variaciones que introducen las condiciones sociales, técnica y políticas a nivel distrital.

De allí que, en período analizado, el contraste entre los municipios sean significativos. Mientras que, en algunos casos, observamos que los municipios problematizan, negocian o evalúan la localización de las viviendas, su integración urbana y la forma en las que se constituye el vinculo con los "adjudicatarios"; en otros, se evidencia una posición más pasiva frente al acontecimiento urbano de la localización de la vivienda social, como da cuenta la metáfora del "plato volador" (aún cuando el municipio haya extendido un certificados de aptitud urbanística). En otros casos, los destinatarios son incluso considerados clientes (nos referimos a los episodios de la comercialización de las viviendas por los propios funcionarios públicos). Junto a las interesantes experiencias de articulación en la forma en la cual algunos municipios sintetizan o digieren estos programas estandarizados, coexiste una racionalidad (a nuestro juicio, dominante) que instituye una lógica sectorial. Priman allí los conceptos del producto de obra pública, unidad de inversión y "polígono" de intervención.

Desde el punto de vista temporal la instancia posterior a la intensidad de la obra pasa a formar parte de los "efectos colaterales", los cuales normalmente corren por cuenta del nivel muncipal. Por esta razón, encontramos severas dificultades en términos de la integración urbana de los barrios de vivienda social, utilizando las palabras de dos de los entrevistados, podríamos sintetizar los siguiente: "la racionalidad sectorial simple y la lógica de la integralidad o la complejidad del territorio, son dos visiones contrapuestas que en la política de vivienda no han encontrado articulación posible, dominando claramente una sobre otra". De allí que una lectura de la gestión del hábitat que introduzca la cuestión de la localización y los sujetos o del "sitio de vida", como señalaba otro de los funcionarios, sean vista como una complicación que "retarda" la respuesta efectiva del "aquí y ahora" frente a una demanda "que es grande y no puede esperar".

Finalmente, advirtamos (antes de pasar al siguiente capítulo) que la redefinición de los criterios de distribución de los cupos de vivienda hallaron en el Conurbano Bonaerense un territorio prioritario, fijando metas cuantitativa históricas y siendo PFCV el programa que protagonizó el desarrollo de la "política federal de viviendas" en dicho espacio. En este contexto, la escasa disponibilidad de suelo emerge como un aspecto 
problemático que pone en entredicho las posibilidades de ejecutar los cupos de vivienda dejando al descubierto el nivel de "maduración" de la política "habitacional". 
Capítulo 3 


\section{Capitulo 3. Suelo y vivienda social Una relación compleja en el marco del mercado de localización intra-urbana}

En este capítulo nos proponemos abordar la relación entre suelo, localización y vivienda social, ya que la construcción de vivienda requiere para su materialización de suelo y este un recurso escaso, que como hemos visto en el capítulo 1 circula en un mercado con características particulares. También vimos que la "política federal de viviendas" realizó una apuesta fuerte a la inversión en viviendas en el Conurbano Bonaerense a través de Programa Federal de Construcción de Viviendas (PFCV), en un momento en el cual, a su vez, se verificaba una tendencia hacia el agotamiento del stock de suelo urbano disponible.

En este escenario, la disponibilidad de tierra pública, "factible" de destinarse a la construcción de la vivienda social, dificultó la ejecución de la política. El problema del acceso al suelo se transformó así en un verdadero desafío para la provincia de Buenos Aires y los municipios del Conurbano Bonaerense. Razón por la cual el Instituto de la Vivienda de la provincia de Buenos Aires (IVBA) asimiló un esquema de licitación de obra pública donde la provisión de suelo queda a cargo de la empresa constructora. De allí que este capítulo nos dediquemos a su estudio.

La estructura de capítulo será la siguiente: en primer lugar, realizamos una breve consideración del contexto en el cual surgió la modalidad "Tierra y Proyecto Urbano" (TPU) como una variante del PFCV en la provincia de Buenos Aires; en segundo término, destacamos la relevancia cuantitativa de esta operatoria en el Conurbano Bonaerense; luego, caracterizamos el circuito administrativo de esta operatoria a efecto de entender cómo la política es sintetizada por la instancia provincia y, a continuación, advertimos acerca de las limitaciones que otros estudios han encontrado respecto de la adquisición de suelo para vivienda social a través de mecanismo de mercado. En la segunda sección del capítulo, introducimos una lectura de la localización de los barrios en la estructura de externalidades urbana, a partir de los cual buscamos identificar los efectos producidos por el mecanismo de adquisición de suelo estudiado y las condiciones de inserción urbana de dichos barrios. 


\subsection{Las tierras y los proyectos urbanos frente al problema del suelo}

La implementación de prácticamente toda política urbana y, especialmente, la política de vivienda requiere para su materialización de un recurso particularmente escaso como es el suelo urbano. La exigua disponibilidad de tierra pública "factible" de destinarse a la construcción de la vivienda social, dificulta la ejecución de las políticas habitacionales impulsadas por el propio Estado. En este marco, la "política federal de vivienda" impulsada a nivel nacional ha puesto a la provincia y a los municipios frente al desafío de adquirir con suelo disponible para tal fin.

En el capítulo anterior, hemos observado que una de las limitaciones históricas de la política de viviendas refiere al tratamiento que recibe el suelo como un mero insumo de un proceso constructivo. Esto condiciona la falta de previsión y de disponibilidad pública de suelo como también, la carencia de estrategias más complejas en el proceso de adquisición (o producción) de suelo urbano en el marco de la política habitacional actual. Esta dificultad se advirtió como una de las principales limitaciones en el proceso de implementación del PFCV (algunos rasgos ya han sido observados en apartado 2.2.1).

En el fragmento de las entrevistas que se trascribe a continuación, uno de los funcionarios da cuenta de los problemas del acceso a la tierra cuando indagamos acerca del desfasaje entre los anuncios y la capacidad de ejecución real de los cupos asignados:

"...gran parte de las viviendas que la provincia de Buenos Aires tenía que construir no pudo construirlas porque no había tierras y para acceder a la tierra había que comprarla y el Instituto no compraba tierras. Nosotros ahora estamos comprando tierras en varios lugares. No es la mejor manera comprar tierras por la inflación a los precios, pero en la salida de la coyuntura tampoco tenemos mucha salida. Ahora para nosotros es una sangría comprar tierras [...] Pero la primera explicación de los desfasajes tiene que ver claramente con esto, no había tierra para hacer eso" (Entrevista № 9, Funcionario Provincial, 2011).

Y complementariamente desestima que haya tierra fiscal disponible:

"No era cierto tampoco la expectativa de que no importa porque hay mucha tierra fiscal ociosa, yo te puedo asegurar que no es así. Estamos haciendo un estudio con el ARBA, un trabajo concreto con el ARBA muy, muy fuerte de rastrillaje hasta el último centímetro de terrenos fiscales. En la primera tanda de análisis que hicimos, en unos 18 municipios sacamos 2 terrenitos, de los cuales, los dos tienen problemas además. Primero no es cierto de que la tierra este desocupada, en general está ocupada, y no estoy diciendo ocupada por ocupaciones ilegales, figura desocupada pero se hizo una escuela, un jardín de infantes. Y la que está desocupada está asignada a una futura escuela, una cárcel o a una comisaría pero que tampoco es tanta, pero está asignada. $Y$ en algunos casos de predios relativamente grandes más bien ruru-urbanos, o son 
reservas ambientales, o están declaradas... En realidad no hay disponibilidad" (Entrevista No 9, Funcionario Provincial, 2011).

Este problema se vio particularmente agravado en los distritos del Conurbano Bonaerense, producto de la convergencia de una tendencia hacia el agotamiento del stock de suelo disponible, la prioridad de la región en la asignación de un cupo considerable de financiamiento habitacional (vivienda nueva y módulos de mejoramiento) y los efectos de la demanda agregada generada por la propia política de vivienda. La escasez de suelo fiscal o público libre de destino asignado y, especialmente, la baja proporción de municipios con políticas activas de suelo urbano ${ }^{105}$, transformaron la adquisición de suelo en un verdadero problema para la política de vivienda y para la ejecución en el tiempo previsto de los cupos asignados por distrito. Todo esto se produce en un escenario de déficit de reservas de suelo urbano.

En relación a esto último, Pugliese (2004) observa una desestructuración del mercado formal de loteros populares que explicó en gran medida la expansión del área metropolitana entre los años '50 y '70. En la provincia de Buenos Aires existe en la actualidad un crecimiento despreciable de nuevo suelo urbanizado (el incremento de la cantidad de parcelas entre 19762004, ha sido menor al 1\%). Las estimaciones realizadas en este estudio ${ }^{106}$ muestran que el $22 \%$ de las partidas urbanas de la provincia de Buenos Aires se encuentran baldías. Sin embargo, en relación a la demanda potencial proyectada al 2011, el AMBA (junto con el conglomerado de Zarate y Campana) muestra, a diferencia del resto de la provincia, un agotamiento del stock disponible. "Se observa con claridad que en términos absolutos, el área metropolitana de Buenos Aires concentra muy fuertemente el déficit de suelo para el 2011, aun considerando dentro de ella a la llamada tercera corona" (Pugliese, 2004: 35).

En este punto resulta de gran importancia que frente al proceso de subdivisión de antaño, las dos tipologías que marcaron la expansión urbana de la década del noventa (y continúan en la actualidad) en el AMBA fueron en gran medida las urbanizaciones cerradas y las villas y asentamientos informales. Frente a este escenario, la política de vivienda supone la configuración en la década de los 2000 de un nuevo capítulo del crecimiento del parque habitacional del AMBA con metas cuantitativas históricas. En este sentido, el impacto de la demanda de suelo a nivel metropolitano no es un dato menor.

En la división federal de competencias, la gestión del suelo es responsabilidad de la provincia y de los municipios. De este modo, la Estado Nacional podría quedar formalmente excluida de la atención de dicho problema, aunque, como hemos visto (en el capítulo 2) las razones por las cuales el tema del suelo es una variable velada en la política habitacional encuentran respuesta en otros factores. Desde un punto de vista estructural, en la gestión de nuestras ciudades parece existir una dificultad histórica para afectar los intereses de los sectores vinculados a la

\footnotetext{
${ }^{105}$ Por ejemplo nos referimos, a: la producción de suelo servido, la negociación de deuda para movilizar el suelo ocioso, la penalización del suelo baldío, la implementación de impuestos inmobiliarios progresivos, la creación de bancos de tierra, la recuperación de plusvalías, la provisión prioritaria de servicios, entre otro tipo de instrumentos.

${ }^{106}$ Pugliese (2004) "Programa de gestión del suelo urbano" UGEIF Ministerio de Economía de la Provincia de Buenos Aires.
} 
propiedad del suelo. La lectura de Yujnovsky (1984) muestra, por ejemplo, cómo en distintos pasajes de la crónica de planificación urbana, los intereses de los propietarios encontraron en el sector de la construcción un fuerte aliado. En la coyuntura actual, la política de vivienda profundiza el carácter "productivista" que paradójicamente contribuye a soterrar la cuestión del suelo.

En términos formales, el Convenio Marco del Programa Federal de Construcción de Viviendas firmado entre la Nación y las jurisdicciones, especifica que el Estado Nacional otorga financiamiento para la vivienda, quedando la provisión de tierra a cargo de la provincia o el municipio. El desafío de adquirir suelo, en el escenario de escasez antes mencionado, dio lugar a un variado repertorio de estrategias de gestión por parte de los municipios y la provincia (véase Duarte, 2010). Pero nosotros nos detendremos en una modalidad particular diseñada por la provincia de Buenos Aires para dar respuesta a este problema: el aporte de tierra a cargo de las empresas constructoras. Nos interesa, tanto por la dimensión que adquiere esta modalidad de adquisición de suelo a nivel metropolitano, como por la mediación del sector privado en la creación de nuevas localizaciones urbanas vinculadas a la vivienda social.

En el proceso de implementación del PFCV, la mayor parte de la construcción de las viviendas estuvo a cargo de la provincia mediante el régimen de ejecución de obra pública. Frente a las dificultades de adquirir suelo en los tiempos previstos para la ejecución de las obras, el IVBA crea la modalidad "Tierra y Proyecto Urbano" (TPU) para viabilizar la implementación del PFCV. En el año 2005, se realiza un llamado a licitación por concurso público para la construcción de 27 mil viviendas con provisión de tierras y proyecto de urbanización por parte de las empresas oferentes. Es decir, las empresas constructoras se encargan del diseño urbano y de resolver la adquisición del suelo, éste puede ser de propiedad de la misma empresa o estar sujeto a un acuerdo de compra en el mercado mediante la asociación de la constructora con el propietario del suelo.

\subsubsection{La distribución de los programas federales en el Conurbano Bonaerense}

Dentro de la diversidad de las líneas programáticas de la "política federal de viviendas" que se distinguieron en el apartado 2.2.2, muchas de ellas no tuvieron desarrollo en el Conurbano Bonaerense, alcanzando notable participación la modalidad de actuación destinada a la construcción de vivienda nueva "llave en mano" a través de empresas constructoras. En la figura 12 (del apartado 2.2.3.1), se observó que en el área el PFCV representó el 87\% de las soluciones habitacionales en ejecución en el período 2003-2009, en el marco de los programas federales de vivienda.

Entre los programas que no alcanzaron escala en el Conurbano Bonaerense podemos mencionar tres. En primer lugar, el PFMV "Mejor Vivir", éste no tuvo prácticamente cobertura, el peso ínfimo se debió a las dificultades de implementación. Los municipios tuvieron dificultades al momento de estructurar la demanda y para muchos funcionarios la decisión de 
instrumentarlo por medio de empresas constructoras fue un error. Ya que a las empresas no les resultó operativo ni rentable atender una demanda espacialmente dispersa y satisfacer requerimientos particularizados de mejoramiento habitacional. En segundo lugar, el PFRF destinado a la reactivación de las obras FONAVI, tuvo correspondencia con la baja presencia del FONAVI en el período previo en el área de estudio. Por último, el PFEH "Techo y Trabajo" adquirió cierto peso inicialmente, con énfasis en la inserción productiva de las organizaciones de desocupados en cooperativas de trabajo. Sin embargo, la mejora del mercado de trabajo, la redefinición interna de las propias organizaciones y la readecuación del propio programa -hoy mixturado con el Programa "Argentina Trabaja" del Ministro de Desarrollo Social- parecen incidir en su cobertura.

En relación al PFCV -línea de acción en la que centramos nuestra atención- hemos visto que a pesar del planeo de instrumentación inicial en el proceso de implementación, el mismo sufrió diversos cambios, muchos de los cuales estuvieron asociados al problema de disponibilidad pública de tierra. EI PFCV puede dividirse en cuatro tipos de operatorias o subprogramas: i) el PFCV-TF ejecutado por el IVBA a partir de la licitación para la construcción de viviendas en tierra fiscal; ii) el PFCV-TPU ejecutado por el IVBA por licitación pública para la provisión de tierras y proyecto de urbanización por parte de las empresas oferentes; iii) el PFCV con Municipios, cuya ejecución de obra queda a cargo de los distritos locales, mientras que el IVBA realiza la supervisión; iv) el SPUVyA (Subprograma de Urbanización de Villas y Asentamientos) que apunta a la consolidación urbana y la regularización dominial, e implica un tejido de actores más complejo (además del municipio y IVBA).

El limitado alcance de la modalidad PFCV-TF es un indicador de la escasez de suelo de disponibilidad pública. Del mismo modo, los dos emergentes más significativos de la política de vivienda en el Conurbano Bonaerense -la operatoria TPU y el SPUVyA- también tienen un vínculo estrecho con el problema del acceso al suelo. Según Biglia, Marsili y Vallina (2008), cuando se asignaron los cupos del PFCV, varios municipios del área metropolitana pronto detectaron que la escasez de suelo fiscal disponible sería un problema para la ejecución de las viviendas asignadas. Para enfrentar este problema surgieron tres estrategias distintas: la Nación creó un fondo para que los municipios compren tierras; por otra parte, la Subsecretaría de Urbanismo y Vivienda de la Provincia de Buenos Aires adecuó el PFCV de modo de incorporar la oferta de tierras por parte de las empresas; por último, se redirigió el programa a la intervención de las tierras de las villas y los asentamientos.

Vale mencionar que el diseño de la "política federal de vivienda" no contempló como línea de acción la urbanización de asentamientos precarios, la regularización dominial o el mejoramiento barrial. El direccionamiento de la acción pública a la consolidación del tejido intersticial existente y la atención de la informalidad urbana es una innovación interesante propuesta por la provincia de Buenos Aires, a partir de la incorporación a la agenda, de una problemática histórica centrada en el AMBA. En relación al SPUVyA, cabe señalar que adquiere una escala de intervención significativa en relación a los registros históricos 
precedentes. El giro propuesto garantiza la atención de los sectores más postergados y, al mismo tiempo, supone mayor complejidad y niveles de articulación con la comunidad y al interior del propio Estado. Sin embargo, al momento de evaluar ciertas dificultades no se debe perder de vista que el financiamiento se dirige originalmente a la construcción de vivienda nueva.

En la figura 14, puede verse que por cada 100 nuevas viviendas 40 se construyen por la modalidad TPU y 32 se realizan en el marco del SSUVyA. En relación a la distribución en los partidos del AMBA, se observa que mientras que el SPUVYA se radica principalmente en los municipios de la primera corona metropolitana, la modalidad TPU se desarrolla en los distritos de la segunda corona. Si se realiza una lectura agregada de los 24 partidos, se observa que por cada mejoramiento habitacional se construyen 6,5 viviendas nuevas. Dato que reafirma, una vez más, la proyección de acciones de modo inverso a la manifestación de la relación entre el déficit cualitativo y cuantitativo.

Por otra parte, si se considera el subuniverso de la construcción de viviendas nuevas en términos de "nuevas localizaciones", el protagonismo de la operatoria TPU aumenta. Utilizamos la denominación de viviendas nuevas en nuevas localizaciones para referirnos, en primer lugar, a los procesos de extensión, completamiento o crecimiento del tejido urbano y recordar que esos emplazamientos son producidos por la acción del Estado. Y, en segundo lugar, para diferenciarlas de los lugares previamente auto-urbanizados por los pobladores o los habitantes donde posteriormente llega la acción pública.

La modalidad TPU representa el 39,9 \% de la construcción de nuevas viviendas en los 24 partidos del AMBA, mientras que si se considera la construcción de vivienda en "nuevas localizaciones", el peso del la modalidad TPU es del $50,2 \%$. Si se amplía el área de estudio a la RMBA, es decir, se suman los emplazamientos en la tercer corona metropolitana esta proporción asciende al $75 \%{ }^{107}$.

Por último, en la figura 14 también puede observarse que el PFCV tiene una distribución heterogénea. Mientras que el SPUVyA se distribuye de norte a sur en los partidos de la primer corona. EI PFCV con Municipios tiende a concentrarse en los distritos de zona norte y en los partidos de la segunda corona, mientras que la modalidad TPU tiene mayor presencia en la zona sur y en la segunda corona. Si comparamos este dato con los precios promedios del suelo urbano por distrito resulta sugerente que la oferta de las empresas se haya concertado en los partidos de zona sur donde el precio del suelo es más barato ${ }^{108}$.

\footnotetext{
${ }^{107}$ Este último dato se consigna en base a la consulta realizada a octubre de 2007 a la Base Gerencial de programas habitacionales del IVBA-SSUyV de la provincia de Buenos Aires, mientras que el resto de los datos se desprenden de la figura 14, consulta a abril de 2009.

${ }^{108}$ El informe de "Distribución Territorial del Precio de Oferta de Terrenos en la Región Metropolitana" de la Dirección General de Sistemas de Información Geográfica del CABA, registra para junio de 2005, precios promedio de 98 $\mathrm{U} \$ \mathrm{~S} / \mathrm{m}^{2}$ para los partidos de zona sur, $115 \mathrm{U} \$ \mathrm{~S} / \mathrm{m}^{2}$ para zona oeste y $222 \mathrm{U} \$ \mathrm{~S} / \mathrm{m}^{2}$ para zona norte.
} 
Fig. 14 Viviendas nuevas y mejoramientos en ejecución o terminados según programas federales en Conurbano Bonaerense, 2003-2009.

\begin{tabular}{|c|c|c|c|c|c|c|c|c|c|c|c|}
\hline \multirow{4}{*}{ PARTIDOS } & \multirow{3}{*}{\multicolumn{2}{|c|}{$\begin{array}{c}\text { TOTAL } \\
\text { 2003-2009 }\end{array}$}} & \multicolumn{9}{|c|}{ PROGRAMAS FEDERALES DE VIVIENDA } \\
\hline & & & \multicolumn{5}{|c|}{ PFCV } & \multirow{3}{*}{$\begin{array}{l}\text { PFMV } \\
\text { Mejor } \\
\text { Vivir } \\
\text { Mej. }\end{array}$} & \multirow{2}{*}{\multicolumn{2}{|c|}{$\begin{array}{c}\text { PFRF } \\
\text { Reactivación } \\
\text { FONAVI }\end{array}$}} & \multirow{3}{*}{$\begin{array}{c}\text { PFEH } \\
\text { Techo y } \\
\text { Trabajo } \\
\text { Viv. }\end{array}$} \\
\hline & & & \multirow{2}{*}{$\begin{array}{l}\text { TPU } \\
\text { Viv. } \\
\end{array}$} & \multirow{2}{*}{$\begin{array}{c}\text { TF } \\
\text { Viv. }\end{array}$} & \multicolumn{2}{|c|}{ SPUVyA } & \multirow{2}{*}{$\begin{array}{c}\begin{array}{c}\text { Con } \\
\text { Municipio }\end{array} \\
\text { Viv. } \\
\end{array}$} & & & & \\
\hline & Viv. & Mej. & & & Viv. & Mej. & & & Viv. & Mej. & \\
\hline Alte Brown & 600 & 302 & 600 & & & & & & & 302 & \\
\hline Avellaneda & 1372 & 871 & & & 1.372 & 571 & & & & 246 & \\
\hline Berazategui & 748 & - & 748 & & & & & & & & \\
\hline E. Echeverría & 2252 & - & 2.252 & & & & & & & & \\
\hline Ezeiza & 720 & 120 & & & & & 300 & & & 120 & \\
\hline F. Varela & 3636 & 130 & 3.354 & & & & & & & 130 & 282 \\
\hline San Martín & - & - & & & & & & & & & \\
\hline Hurlingham & 372 & 154 & & 78 & & & 294 & & & 154 & \\
\hline Ituzaingó & - & - & & & & & & & & & \\
\hline José C. Paz & 4339 & - & & & & & 2635 & & & & 1704 \\
\hline La Matanza & 3383 & 376 & 3015 & & & & & & & 376 & 368 \\
\hline Lanús & 45 & - & & & & & & & 45 & & \\
\hline L. de Zamora & 1380 & - & & & 1380 & & & & & & \\
\hline Malvinas Arg. & 638 & - & & & & & 638 & & & & \\
\hline Merlo & 258 & - & & & & & 258 & & & & \\
\hline Moreno & 3354 & - & 2.854 & & & & & & & & 500 \\
\hline Morón & 758 & - & & & 708 & & 50 & & & & \\
\hline Quilmes & 1637 & 142 & & & 1637 & & & & & 142 & \\
\hline San Fernando & 842 & 138 & & & 290 & & 408 & 42 & 144 & 96 & \\
\hline San Isidro & 2943 & 2672 & & & 2893 & 2676 & & & 50 & & \\
\hline San Miguel & 160 & - & & & & & 160 & & & & \\
\hline Tigre & 31 & - & & & & & 31 & & & & \\
\hline Tres de Feb. & 2248 & - & & & 1548 & & 648 & & & & 52 \\
\hline Vicente López & 432 & - & & & 432 & & & & & & \\
\hline TOTAL & 32148 & 4905 & 12823 & 78 & 10260 & 3247 & 5584 & 42 & 234 & 1566 & 2906 \\
\hline
\end{tabular}

Fuente: Elaboración propia en función de datos de la Base Gerencial (a abril de 2009) de Instituto de la Vivienda, Subsecretaría de Urbanismo y Vivienda (IVBA-SSUV) de la Provincia de Buenos Aires.

\subsubsection{Diseño e implementación de la modalidad Tierra y Proyecto Urbano (TPU)}

Un análisis de la arquitectura institucional de la ejecución de PFCV a cargo del IVBA (que como hemos visto en el Conurbano Bonaerense se desarrolla principalmente a través de la modalidad TPU), brinda algunos elementos para reconstruir la implementación de la política de vivienda y muestra el modo en que algunos aspectos son atendidos o problematizados. En este punto es importante un análisis conjunto de la documentación oficial, con el registro de los propios funcionarios y técnicos que gestionan desde interior del IVBA el programa y una serie de instrumentos asociados a él. 
La SDUV de la Nación otorga el financiamiento de los fondos no reembolsables frente a la prestación de los proyectos de los Organismos Provinciales de Vivienda. En este contexto, el IVBA realiza el llamado a licitación pública para la construcción de viviendas bajo el régimen de la Ley General de Obras Públicas № 6.021. El dispositivo del TPU integra en una única oferta la construcción de viviendas con la infraestructura básica asociada -mediante un sistema de precio fijo por unidad de vivienda-, acompañada por la tierra ofertada y el diseño del proyecto urbano realizado por la empresa.

El IVBA, mediante el Departamento de Estudios y Proyectos de la Dirección General de Obras (DGO), diseña los prototipos de vivienda y elabora las especificaciones técnicas de los pliegos a través del Área de Licitación de la Dirección General de Administración (DGA). La empresa que se presenta a la licitación debe contar con el terreno -de su propiedad o mediante compromiso de venta o cesión del propietario con el cual se asocia la empresa-, con la respectiva certificación de factibilidad hidráulica, la certificación urbanística del Municipio ${ }^{109}$ y la factibilidad de provisión de servicio (de agua potable, desagües cloacales y/o pluviales, gas natural, red de electricidad e iluminación) otorgada por los respectivos Entes Prestatarios. Además la empresa debe presentar el proyecto urbano de acuerdo a las pautas de diseño y seleccionar uno o más, de los prototipos de vivienda diseñados por la DGO.

En relación a la tierra ofertada por las empresas es importante introducir una aclaración. La vivienda y la infraestructura básica (asociada a la vivienda) tienen un costo fijo, determinado por el financiamiento de la Nación. De acuerdo al Convenio Marco del PFCV, a las jurisdicciones les corresponde aportar el suelo, para ello la provincia Buenos Aires aporta recursos complementarios a los fondos nacionales y, en arreglo con las empresas, fijó como tope una financiación equivalente al 10\% del monto asignado a la construcción de viviendas. De esta forma, la Provincia busca anticipar la previsión de recursos e intenta regular el precio del suelo, aunque ésta no fue una regla escrita y como veremos luego, se produjeron algunas excepciones.

Una vez realizada la presentación de la oferta a la Dirección de Estudios y Proyectos de la DGO, se evalúa en conjunto con el Municipio el proyecto presentado. A tal efecto, se creó una Comisión de Preadjudicación y otra Comisión de Revisión y Reajuste de Documentación. Las mismas hacen observaciones de naturaleza legal o técnica. En algunos casos, se introducen variaciones o modificaciones al proyecto las cuales quedan supeditadas a la aceptación de la empresa.

En este punto es importante señalar que en algunas de las presentaciones el proyecto urbano no se ajusta plenamente al marco de la Ley de Ordenamiento Territorial y Uso del Suelo (Decreto-Ley 8.912/77). Esta cuestión contribuyó a que los equipos técnicos del IVBA participen en el diseño de la propuesta urbana de los barrios. La consecuencia en algunos casos fue aumentar la calidad del proyecto urbano, en otros casos, el ajuste a norma significó

\footnotetext{
${ }^{109}$ El municipio otorga el certificado urbanístico o habilita el cambio de zonificación de uso del suelo.
} 
la baja del proyecto. Resulta interesante marcar aquí el umbral entre las posibilidades de intervención del equipo técnico en la modificación del proyecto urbano y la ecuación económica de la empresa. Ya que la incorporación del suelo a la propuesta técnica y financiera de la empresa, implica el control directo de una variable más en su cálculo de utilidad. La negociación deja de ser "tantas viviendas por cuánto" y pasa a ser "ahí no menos de tantas viviendas a tanto".

Desde el punto de vista formal, la localización o el tratamiento de la evaluación del terreno en el Pliego de Licitación se dirige a acreditar la calidad del dominio, cumplimentar con una serie de normas legales, asegurar estándares urbanos o ambientales y garantizar la operatividad de la obras. Por otro lado, los criterios urbanísticos considerados para ponderar las propuestas ofertadas por las empresas, incluyen algunos otros atributos que valoran la integración urbana del terreno a la ciudad existente.

Una vez saldados los aspectos formales, la Comisión Técnica Evaluadora realiza la evaluación y selección de las propuestas presentadas siguiendo un sistema de puntaje ajustado a una serie de criterios de evaluación del terreno ofertado y el proyecto urbano. Se consideran las cualidades del terreno en términos de la aptitud hidráulica, la posibilidad de conexión a la infraestructura de servicios existentes, el nivel de consolidación del tejido del entorno, la accesibilidad, la conectividad, entre otros. ${ }^{110}$ Por otro lado, se consideran las pautas de diseño urbano (como un ítem específico dentro de la calificación) ${ }^{111}$.

Una vez evaluadas las presentaciones, el IVBA emite un informe del proyecto en condiciones de preadjudicar, al cual se adjunta una memoria descriptiva de los aspectos técnicos, económicos y legales. Este informe es presentado ante la SDUV de la Nación. Esta última, tiene la potestad de dictaminar finalmente la "no objeción para contratar". A partir de allí, se firma el Convenio Particular entre la Nación y la provincia, la empresa a la cual se le adjudica la obra transfiere la propiedad del terreno al IVBA, se realiza el anticipo financiero y se procede a

\footnotetext{
${ }^{110}$ La planillas de puntaje de evaluación del terreno (Pliego de Licitación PFCV-TPU, 2005), consideran distintos niveles o rangos en los que se presentan cada una de las siguientes variables: 1) Aptitud hidráulica y escurrimiento de aguas pluviales, 2) Medios de transporte próximos al terreno, 3) Distancia entre la vivienda más alejada y calle pavimentada vinculada a vía principal, 4) Provisión de agua potable, 5) Desagües cloacales, 6) Provisión de gas natural o envasado, 7) Terreno rodeado por manzanas de uso residencial consolidado en más de un 25\%, 8) Equipamiento urbano, 9) Pautas de diseño.

${ }^{111}$ En el Anexo I del Pliego de Licitación PFCV-TPU (2005), se considera: 1) La disposición en el conjunto de las calles principales, los espacios verdes y las parcelas para equipamiento público favorecen su utilización por los habitantes del entorno inmediato, integrándose de esta forma el conjunto con el barrio que lo rodea. 2) Existe continuidad entre las calles principales del entorno inmediato y el sistema vial del conjunto. 3) El sistema de calles está jerarquizado y compuesto de calles principales para el acceso al conjunto (ancho $>20 \mathrm{~m}$ ) y secundarias (ancho $>15 \mathrm{~m}$ ) para la distribución interna. 4) Los espacios verdes se encuentran ubicados en relación con las calles principales, tienen un lado mínimo de $32 \mathrm{~m}$ y se encuentran rodeados de calles. 5) Las parcelas para equipamiento público están ubicadas sobre las calles principales y/o los espacios verdes, no lindan con viviendas, tienen una superficie mayor a $2500 \mathrm{~m} 2$, una proporción entre sus lados menor a 1:2 y al menos dos lados lindan con una calle. 6) El diseño de la manzana tipo incluye un diseño (tratamiento) diferenciado para los prototipos de esquina y/o los lados menores de las manzanas. 7) Se ha dado un tratamiento diferenciado para mejorar las condiciones de las viviendas más desfavorecidas por estar ubicadas en bordes con tránsito intenso o usos poco compatibles con la residencia. 8) Se ha dado un diseño diferenciado a la geometría del trazado y a la composición de los volúmenes de vivienda con el objeto de otorgar identidad al conjunto. 9) Se ha optimizado el diseño del parcelamiento, la elección de los prototipos y su disposición en las parcelas con el objeto de maximizar el asoleamiento de las viviendas reduciendo al mínimo los ambientes orientados hacia el cuadrante Sur. 10). Se ha considerado la eliminación de las barreras arquitectónicas.
} 
la firma del contrato que da inicio a la obra. Un porcentaje de las primeras cuatro transferencias que el Estado realiza a la empresas, se destinada a cubrir el costo del suelo.

Al municipio le corresponde la inspección de la obra y al Departamento de Obras de la DGO del IVBA la supervisión y seguimiento de la inspección. Éste es el encargado, a su vez, de realizar las actas de medición. El Departamento de Estudios Técnicos se encarga de la certificación de obra que se realiza mensualmente a partir de la cual se emite la transferencia o pago. Al igual que la ampliación de los plazos de obra, todo el procedimiento se realiza de acuerdo a la Ley Provincial № 6.021, mientras que la redeterminación de precios por variación de costos se guía por el Decreto Nacional No 1.292/02. El Departamento Contable de la DGA es el encargado de recibir la liquidación y realizar el pago de las certificaciones.

Las obras de nexo o infraestructura complementaria (vinculadas normalmente a la extensión de la red de agua corriente o red cloacal, captación, reserva y presurización de agua potable, estación de bombeo de líquidos cloacales, planta depuradora y desagües pluviales) se desarrollaron, en la mayoría de los casos, en una etapa posterior. Esto supone una nueva intermediación entre los actores. La provincia realiza, para la construcción de las obras de nexo, la ampliación de contrato con la misma empresa encargada de la construcción de las viviendas. El Área de Infraestructura del la DGO participa en la evaluación de la documentación presentada por la empresa. Y la Nación asigna los fondos a través del Subprograma de Infraestructura de Nexo y Obras Complementarias. Por otra parte, las Empresas Prestatarias de servicios participan en la aprobación de los proyectos de infraestructura. En este punto, es importante señalar que en algunos casos, los desajustes entre las obras (de vivienda e infraestructura de nexo) llegaron a demorar la entrega de las viviendas, ya que sin la terminación e inspección de la infraestructura no es posible emitir el final de obra. A pesar de ello, en el apartado 2.2.4 hemos visto que la presión social y los conflictos en el territorio han desafiado las reglas establecidas.

En relación a la canalización de la demanda habitacional, la articulación entre provincia y municipios encuentra ciertos obstáculos y variaciones según el tipo de operatoria. La confección del registro de la demanda habitacional se realiza, en todos los casos, a nivel municipal y la provincia realiza sólo un control de los requisitos formales que deben cumplir los adjudicatarios de los planes de vivienda. En este sentido, en el marco del PFCV-TPU la provincia tiene mayor participación en el proceso. Mientras que en la operatoria PFCV con Municipio, el IVBA queda en algunos casos relegado, llegando incluso a realizar la supervisión del cumplimiento de los requisitos de los adjudicatarios a posteriori de la entrega efectiva con los problemas que ello conlleva.

Desde el punto de vista de los interesados, (aparte de los circuitos de intermediación clásicos) una buena parte de ellos concurre a los municipios para registrar la demanda en el listado oficial, a efectos de participar en el proceso posterior de selección de los "beneficiarios" de vivienda. Instancia que en la mayoría de los casos se encuentra mediada por entrevistas del área de trabajo social de los municipios. La brecha entre la demanda y la cantidad de 
soluciones habitacionales construidas por el Estado, implica que una parte de los interesados reciban la noticia de ser preadjudicatarios y la mayoría continúen en la "lista de espera".

En la rutina administrativa, la Dirección General de Inmobiliario Social (DGIS) del IVBA entra en escena al producirse el output del sistema. El Departamento de Selección de Aspirantes es el encargado de corroborar que la persona considerada preadjudicataria cumpla con los requisitos formales mínimos ${ }^{112}$. Finalmente, el IVBA mediante la Dirección de Ejecución realiza la recepción provisoria de la obra, supeditada a la supervisión de la DGO y a la inspección final del Municipio.

Luego las viviendas son entregadas a los adjudicatarios, con participación de Área Social del municipio y del IVBA. La DGIS realiza la adjudicación con la documentación correspondiente (acta de adjudicación, boleto, plano, etc.) y, con participación de la Escribanía General de Gobierno, comienza la tramitación de la escrituración hipotecaria a favor del IVBA. Mientras que el Departamento Financiero de la DGA se encarga de determinar el precio, la cuota y el plazo de pago de cada una de las viviendas y, también, las quitas de acuerdo al Decreto 2258/06. La composición del recupero se realiza en base al costo promedio de la construcción de cada conjunto y sólo se incluye la cuota de recupero del terreno, según el artículo 2 de dicho decreto: "cuando correspondiere".

Si bien en las entrevistas realizadas a los distintos funcionarios, la interpretación de dicho artículo es variable: para algunos el costo de la tierra "se recupera siempre" (Entrevista Funcionario No9), para otros "el terreno no se recupera nunca" (Entrevista Funcionario No10) y, para algunos, "sólo cuando el suelo lo pone la empresa" (Entrevista Funcionario No8). Nos parece importante resaltar que esto constituye un indicador del modo en que la cuestión del suelo es digerida y sintetizada por el dispositivo burocrático.

Si bien, el acceso a la información de la totalidad de resoluciones que determina el precio de la cuota de los conjuntos habitacionales del PFCV no nos ha sido posible, a partir de la consulta de algunas resoluciones aisladas pertenecientes a las distintas operatorias del PFCV, el criterio que hemos identificado es el siguiente: el IVBA sólo recupera el costo del suelo cuando el mismo ha sido provisto por las empresas constructoras (a través de la modalidad TPU), lo que significa una erogación complementaria para la provincia de Buenos Aires. Si la tierra es de dominio municipal o provincial previamente a la ejecución de la obra, la misma no se incorpora en el cálculo de la cuota de recupero ${ }^{113}$.

Por otro lado, el mapa de actores identificados por Bettiol y Baccaro (2008), pone en evidencia dónde gravitan los núcleos decisionales de la política y el papel que juegan el destinatario de

\footnotetext{
${ }^{112}$ Los requisitos formales para constituirse en adjudicatarios de un plan de vivienda son: 1) constituir un grupo familiar, 2) poseer DNI argentino, 3) ser mayor de 18 años, 4) no ser beneficiario de ninguna vivienda o terreno otorgado por el Estado Argentino, ni poseer bienes inmuebles (restricción que alcanza a todos los integrantes del grupo familiar).

${ }^{113}$ En algunos casos, los municipios realizan un cobro de la tierra por separado. Recientemente, algunos municipios que han firmado convenio con el IVBA para el cobro descentralizado, han presionado por incorporar el terreno aportado por el municipio al cálculo del cuota de recupero. Sin embargo cuando la tierra es provincial no hay garantía de recupero. Paradójicamente, este es un tema que en la entrevista se presenta difuso y la contradicción de criterios entre los propios funcionarios.
} 
acción pública en relación a la decisión, el diseño y la construcción de la vivienda. Incluso su vinculación respecto al proyecto urbano y la localización del barrio. El futuro usuario no tiene ninguna participación en el proceso, a tal punto, que el listado definitivo de adjudicatarios es confeccionado a posteriori de la finalización de la obra. La lectura complementaria de Biglia, Marsili y Vallina (2008) dan cuenta de rol asignado a la dimensión social. Cuando los programas están basados sólo en lo constructivo, el ciclo de la acción pública termina con el final de obra y los usuarios deben ajustarse a una oferta unívoca. Entre los problemas se destacan la inexistencia de un análisis del déficit habitacional y el estudio de los perfiles de demanda. Se plantea la necesidad de que el diseño-construcción de la vivienda y el barrio, sean etapas posteriores a la adquisición de la tierra y la adjudicación de las viviendas. De este modo se involucraría a los postulantes en las decisiones y sería posible pensar un repertorio flexible de opciones que reconozcan diferentes necesidades (en términos de localizaciones, tipo de solución habitacional, articulación de programas, plan de financiamiento, régimen de tenencia, etc.). 
Fig. 15 Identificación de actores involucrados en la operatoria PFCV-TPU

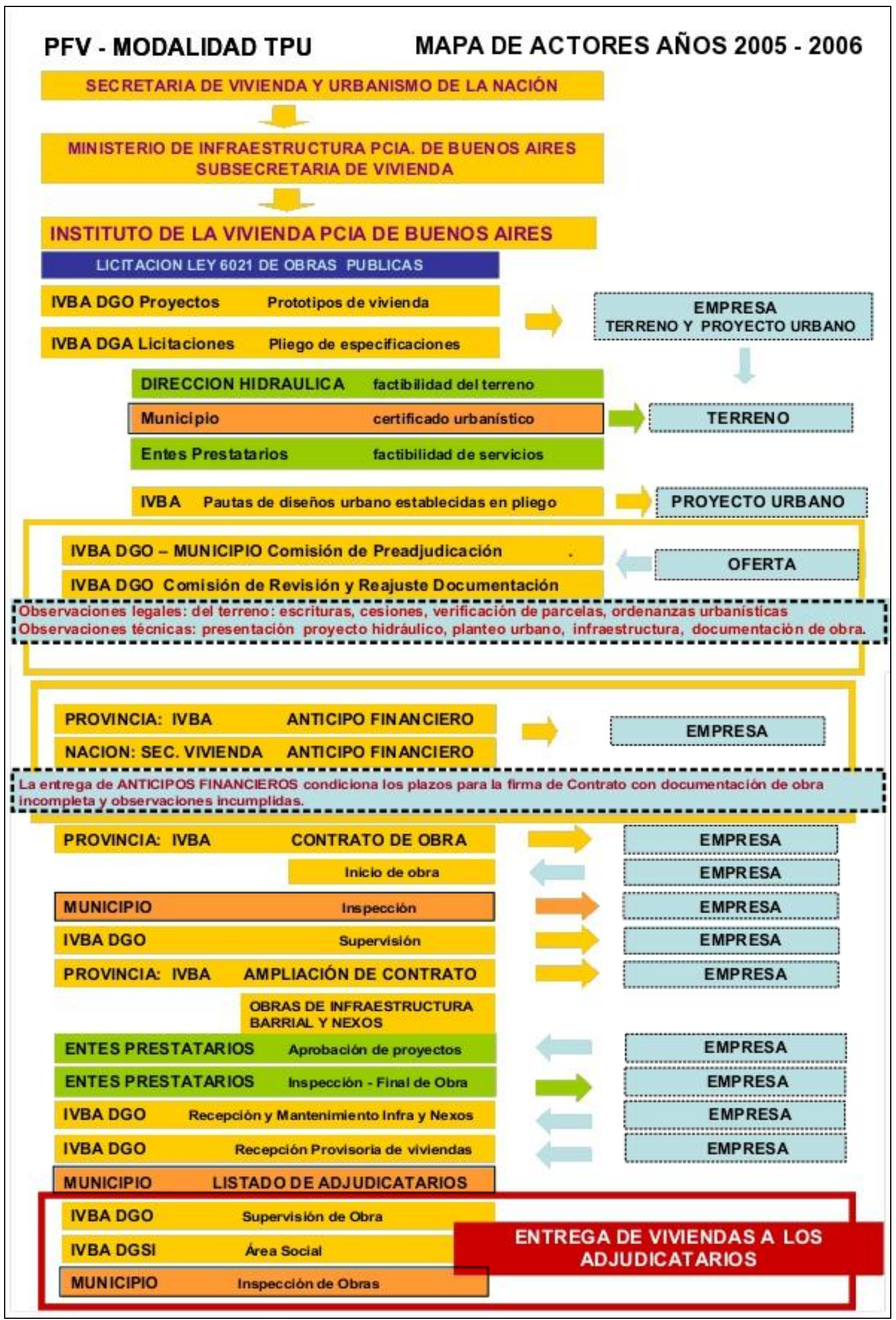

Fuente: Bettiol y Baccaro (2008). 
Finalmente, si retomamos la dimensión de la adquisición de suelo vale destacar que en el marco de la modalidad TPU, para cada terreno hay una única oferta, es decir, no hay "competencia" entre las empresas oferentes en términos del proyecto urbano para un mismo terreno. En este sentido, se partía del supuesto de que la abundancia de ofertas permitiría priorizar alternativas de localización. Para ello la operatoria estuvo sujeta a la evaluación de una serie de condiciones urbanas. No obstante, el apremio por ejecutar los cupos ante el riesgo de perderlos y la escasa oferta, hizo que prácticamente todas las presentaciones -salvo algunas rechazadas por no cumplimentar con los requisitos básicos- fueran aceptadas.

En este escenario, el margen del IVBA para elegir entre "las tierras y los proyectos urbanos" fue mínimo. Por ello resulta de interés analizar los resultados en términos de la localización de la vivienda social en la estructura urbana. Antes, introduciremos algunos aspectos que son relevantes al proceso de adquisición de suelo para la vivienda social a través de "mecanismos de mercado".

\subsubsection{Antecedentes de adquisición de suelo para vivienda a través del mercado}

Hemos visto que el acceso al suelo se transformó en una verdadera dificultad en el proceso de implementación del PFCV y que la resolución del Estado provincial fue priorizar la adquisición de suelo por intermedio de las propias empresas constructoras. En este sentido, cabe revisar algunos aspectos de la relación entre mercado de suelo y política habitacional. En el capítulo 1, mostramos que el vínculo entre hábitat popular y mercado de suelo es doblemente conflictivo. Por una parte, es la pieza que estructuralmente excluye o dificulta el acceso de los sectores populares a determinadas condiciones materiales mínimas vinculadas al hábitat, en tanto relación mercantilizada. Y, por otra parte, el mercado de suelo es la institución que regula las condiciones de distribución de la ciudad, a través del reparto de localizaciones.

Esto tiene múltiples implicancias al momento de pensar la política habitacional y se pone de manifiesto, tanto en el proceso de adquisición de suelo, como en la instancia posterior a finalizadas las obras, en la esfera del habitar: en el uso y la apropiación del espacio urbano. En este punto, múltiples antecedentes balizan en el camino. Rolnik, Cymbalista e Nakano (2008), nos recuerdan que hay un consenso en la literatura académica y en los operadores de la política de vivienda, respecto a que el suelo urbano debe ser un componente esencial de la política y que su disponibilidad en cantidad y condiciones adecuadas para la promoción de programas y proyectos la vivienda es fundamental para su éxito. Sin embargo, en la historia de políticas de vivienda brasilera el suelo rara vez se escapó del binomio de la expropiación o ubicación periférica (a través de las operaciones de conversión de la tierra rural urbano). En este punto, la compra de suelo por parte del Estado opera la mayor de las veces como una transferencia de recursos del sector público al sector privado por la obtención de terrenos de 
mala ubicación. Y las consecuencias de esto se extienden desde efectos en la calidad de vida de los habitantes hasta los costos indirectos de una modalidad extensiva de crecimiento urbano. El riesgo de una política de vivienda que no esté entrelazada con la aplicación de una serie de instrumentos de la política de suelo, es caer en una política de carácter sectorial que esté lejos de poder ser considerada una política urbana.

El caso chileno es paradigmático respecto al impacto de la liberalización del mercado de suelo, la ampliación de la mancha urbana y los subsidios habitacionales a la demanda en la conformación del espacio metropolitano de Santiago de Chile. La eliminación de los límites urbanos bajo el supuesto de que el aumento de la oferta reduciría los precios del suelo estuvo lejos de cumplirse. La liquidación de las reservas territoriales y la asimilación de un esquema de provisión de suelo a cargo del promotor, muestra que buena parte de los subsidios habitacionales fueron absorbidos por el alza de los precios del suelo. Ésto tuvo importantes efectos en la calidad y la localización de la vivienda social, tanto en términos sociales como de segregación residencial y en la acceso a la centralidad urbana (ver Montes, 2000; Rodríguez y Sugranyes, 2005; Brain y Sabatini, 2006; Hidalgo Dattwyler, 2007).

En relación a la experiencia mexicana, Iracheta (2005) señala que el mecanismo principal de adquisición de suelo también es la compra-venta. Frente a ello manifiesta que la incorporación planificada de suelo para vivienda popular constituye el núcleo estratégico de una política habitacional, requiriendo de una acción (de los distintos niveles de gobiernos) firme y concurrente en términos de planeación del desarrollo urbano e intervención activa del mercado del suelo. En esta línea, Duhau y Rodríguez (2006) sostienen que el elemento clave para la política de vivienda popular es el suelo.

Asimismo, estos autores, marcan las dificultades de gestión pública en la "organización de la fila" de las demandas y necesidades populares en materia de vivienda y servicios públicos. En este punto, sostienen que un modelo de oferta organizada y regulada de suelo para vivienda social implica una política de anticipación, que requiere organizar conjuntamente el financiamiento de los programas, la incorporación de suelo a través de instrumentos de planificación urbana, la provisión de infraestructura y los servicios públicos y la demanda. Todo esto requiere de una administración pública capaz de ejercer un control efectivo sobre el desarrollo urbano, la planificación y programación de la acción pública en una perspectiva de mediano y largo plazo y la definición de mecanismos y reglas claras de atención y priorización de la demanda. La incorporación planificada de suelo para vivienda social necesita, entonces: una intervención enérgica orientada a una planeación estratégica de los usos del suelo (que abandone la acción formal y pasiva) y la regulación activa de mercado de suelo que permita bloquear la urbanización informal; el desarrollo de infraestructura y servicios públicos con tiempo de inversión y planificación que trascienden los ciclos electorales; la definición de reglas de juego transparentes que permitan revertir los proceso de informalidad urbana requieren compromiso y altos niveles de legitimidad de la autoridades locales (Duhau y Rodríguez, 2006). 
Una vez recuperadas estas advertencias respecto a la importancia que juega el suelo en política habitacional, comparemos -aunque más no sea de modo esquemático- la diferencia entre tres lógicas distintas que se desenvuelven en la decisión de adquirir suelo en el mercado de localización intra-urbana y analicemos, particularmente, cómo se comporta la demanda derivada de la vivienda social. Una mirada de la figura 15, muestra el contraste existente entre las decisiones de: el promotor inmobiliario que demanda suelo para el desarrollo de un proyecto residencial, las unidades domésticas que requieren de una parcela para construir sus viviendas, y el Estado en la compra de suelo para vivienda social.

En relación a la estrategia del desarrollador inmobiliario, en la sección 1.2 hemos descripto con mayor detalle la lógica que lo gobierna. En la figura 16, puede observarse cómo son atendidas por este actor las variables que hacen a la relación entre la localización y la intervención urbana propuesta. También, consideremos, el modo en el cual las "señales" del perfil de la demanda y de la estructura urbana son convertidas en mercancía o se relacionan con el producto urbano que él oferta. La finalidad que persigue este actor es maximizar sus beneficios, vendiendo la máxima satisfacción (vivienda "puertas adentro" y "puertas afuera") en arreglo a las preferencias segmentadas por la capacidad de pago.

En oposición a este actor, la lógica del Estado minimiza y homogeniza las necesidades de la demanda habitacional y desatiende los efectos de la estructura urbana al momento de diseñar y proyectar el "producto urbano". La finalidad parece ser maximizar la cantidad de metros cuadrados construidos (por la industria) y el número de hogares "beneficiados" (por la política) minimizando la "satisfacción", dada una respuesta única pensada a partir de múltiples restricciones. De allí que la adquisición de suelo se vuelva relativamente unívoca, conciba una demanda agregada y homogénea, priorice grandes predios donde construir muchas viviendas y que el entorno urbano o el conjunto de variables que hacen a la valoración de los usuarios de la ciudad sean "efectos colaterales" sin importancia.

Al observar este panorama, es posible afirmar que existe una imposibilidad de pensar instrumentos que permitan maximizar la "satisfacción" o las "preferencias" residenciales de los habitantes a partir de incorporar el perfil de la demanda (o el reconocimiento de las estrategias residenciales previas) y su relación con la estructura urbana. Y esto sigue siendo válido, aún reconociendo múltiples y variadas limitaciones en cuanto la capacidad de pago de la población destinataria, máxima que se impone al contexto de definición de toda política habitacional. 
Fig. 16 Lógicas en la adquisición de suelo en el mercado de localización residencial

\begin{tabular}{|c|c|c|c|}
\hline & \multicolumn{3}{|c|}{ Decisión de adquisición de suelo urbano para... } \\
\hline & desarrollo inmobiliario & $\begin{array}{c}\text { construcción de vivienda } \\
\text { particular }\end{array}$ & $\begin{array}{l}\text { plan de vivienda } \\
\text { social }\end{array}$ \\
\hline Actor que decide & Desarrollador & Unidad doméstica & Estado \\
\hline $\begin{array}{l}\text { Relación con } \\
\text { proyecto constructivo }\end{array}$ & $\begin{array}{l}\text { Variable según el proyecto y } \\
\text { el tipo de demanda apuntada }\end{array}$ & $\begin{array}{l}\text { Acorde a las necesidades y } \\
\text { posibilidades de la familia }\end{array}$ & Normalmente uniforme \\
\hline Demanda & Atomizada & Atomizada y heterogénea & $\begin{array}{c}\text { Agregada y relativamente } \\
\text { homogénea }\end{array}$ \\
\hline Mecanismo & A través del mercado formal & $\begin{array}{l}\text { Mercado formal e informal u } \\
\text { ocupación de hecho }\end{array}$ & Modalidades diferentes \\
\hline $\begin{array}{l}\text { Distribución de la } \\
\text { oferta de suelo }\end{array}$ & $\begin{array}{l}\text { Según la tipo de demanda, } \\
\text { atomizada pequeños lotes o } \\
\text { en grandes macizos }\end{array}$ & $\begin{array}{l}\text { En general atomizada en } \\
\text { pequeños lotes. }\end{array}$ & $\begin{array}{l}\text { Normalmente, grandes } \\
\text { macizo urbanos o rurales }\end{array}$ \\
\hline Financiamiento & $\begin{array}{l}\text { Heterogéneo, transferido en el } \\
\text { costo final a la demanda }\end{array}$ & Heterogéneo, atado a ingreso & $\begin{array}{l}\text { Atado a presupuesto, } \\
\text { desestima instrumentos } \\
\text { urbanísticos }\end{array}$ \\
\hline $\begin{array}{l}\text { Decisión del } \\
\text { destinatario final en } \\
\text { la localización }\end{array}$ & $\begin{array}{c}\text { Indirecta, vía la interpretación } \\
\text { de la preferencias de la } \\
\text { demanda }\end{array}$ & $\begin{array}{c}\text { Total, mediada por la capacidad } \\
\text { económica y el poder }\end{array}$ & Nula \\
\hline Efecto de vecindad & Determinante & Atendido & Desatendido \\
\hline Zonificación & $\begin{array}{c}\text { En base a usos del suelo } \\
\text { permitidos y la intensidad uso } \\
\text { permitida }\end{array}$ & $\begin{array}{c}\text { Dentro del área urbana, zona } \\
\text { de uso del suelo variable (en } \\
\text { general residencial) }\end{array}$ & $\begin{array}{l}\text { La zonificación no es } \\
\text { determinante, adecuación } \\
\text { posterior por excepción }\end{array}$ \\
\hline $\begin{array}{l}\text { Servicios, } \\
\text { equipamiento y } \\
\text { amenidades }\end{array}$ & $\begin{array}{l}\text { Analiza tipo y calidad de } \\
\text { equipamientos y servicios } \\
\text { disponibles y futuros } \\
\text { potenciales }\end{array}$ & $\begin{array}{l}\text { Considera tipo y calidad de } \\
\text { servicios disponibles los } \\
\text { equipamientos disponibles y } \\
\text { futuros potenciales }\end{array}$ & $\begin{array}{l}\text { No considerados o } \\
\text { analizados en términos de } \\
\text { factibilidad de extensión y } \\
\text { costos operativos de obra }\end{array}$ \\
\hline Centralidad & $\begin{array}{l}\text { Considera centralidades } \\
\text { generales y en algunos casos } \\
\text { específicas según proyecto }\end{array}$ & $\begin{array}{c}\text { Generales y particulares según } \\
\text { composición hogar, redes } \\
\text { sociales y estrategias de } \\
\text { ingresos }\end{array}$ & No consideradas \\
\hline Escenario futuro & $\begin{array}{c}\text { Se consideran expectativas y } \\
\text { tendencias de la dinámica } \\
\text { urbana a futuro }\end{array}$ & $\begin{array}{l}\text { Prima tiempo presente, deseo } \\
\text { de estabilidad: "que no empeore } \\
\text { o que mejore" }\end{array}$ & $\begin{array}{l}\text { "con el tiempo llega la } \\
\text { ciudad, el barrio se } \\
\text { mimetiza" (lentamente) }\end{array}$ \\
\hline
\end{tabular}

Fuente: elaboración propia.

La adquisición de suelo urbano que realiza una unidad doméstica, para construir una "vivienda particular" orientada a la satisfacción de una necesidad habitacional, brinda algunas pistas de los atributos que definen en el acceso a la ciudad y el punto de encuentro entre la geografía doméstica y la geografía de la ciudad. Normalmente, una familia que busca un terreno para 
vivir, busca un lugar en la ciudad acorde a sus necesidades y posibilidades. La decisión de localización es una clave importante en el proceso de movilidad residencial y se presenta como una variable relativamente autónoma a nivel familiar. La forma en la cual se constituye esta demanda, aún mediada por las restricciones de ingreso, es altamente heterogénea, atomizada en el espacio y progresiva en el tiempo siendo la oferta de pequeño lotes predominantemente individualizada, diferenciada y dispersa. Como vimos en el apartado 1.3.4 el capital locacional que las unidades domésticas ponen en juego en el espacio residencial, supone decisiones en tiempo presente y la valoración de efectos de vecindad, de accesibilidad, de centralidad urbana y, también, de centralidades anudadas a las aglomeraciones de las redes sociales y las estrategias de obtención de ingreso.

Este esquema altamente flexible y dinámico se presenta, entonces, como la antítesis de del modelo de adquisición de suelo para los planes de vivienda social tradicionales. Si bien, puede parecer que estas racionalidades de producción de la ciudad se comportan de modo autónomo, es justamente en la lógica del desarrollo inmobiliario y en las expectativas de los propietarios del suelo donde podemos hallar un campo importante de acción al momento de pensar proyectos urbanos más inclusivos y formas de producción, adquisición o financiamiento del suelo para la vivienda social.

Por último, el esquema que presentamos en la figura 16 es sólo una identificación de algunos tipos ideales que podemos encontrar en la adquisición de suelo en el mercado de localización residencial intra-urbana. Esta identificación exploratoria está lejos de ser acabada o agotar las posibilidades existentes. La diferenciación entre el mercado inmobiliario formal e informal agrega aún mayor dificultad al análisis, aunque muchas de las observaciones de la adquisición de suelo para la "vivienda particular" podrían extenderse con ciertos recaudos a las asentamientos informales. Las variantes de los circuitos de compra-venta de vivienda usada, de rehabilitación o refuncionalización, el déficit cualitativo, la combinación de usos híbridos, el mercado de arriendo, la construcción de viviendas intra-lote (como parte del proceso de formación o allegamiento de nuevos hogares o miembros), entre muchas otras variantes, podrían complejizar aún más el modelo presentado.

Hecha esta última observación, a continuación indagamos cuál fue la posición resultante en el mercado de localización intra-urbana de la vivienda social ejecutada vía PFCV-TPU. Es decir, cuando la adquisición de suelo dependió de la tierra ofertada por las empresas constructoras o se desarrolló de manera "terciarizada" a través del mercado. 


\subsection{La vivienda social en el mercado de localización intra-urbana}

En esta sección, analizamos algunos aspectos vinculados a la posición residencial de la viviendas social en la estructura urbana, para ello necesitamos recuperar el concepto de mercado de localización residencial intra-urbana y aclarar el alcance operativo que aquí le daremos al mismo. En el capítulo 1, definimos al mercado de localizaciones residenciales intraurbanas como un arreglo institucional y mercantil desde el cual se distribuyen de modo asimétrico las condiciones de habitabilidad de la ciudad, una suerte de configuración espacial en permanente movimiento fuertemente asociada a las condiciones generales de calidad urbana y al perfil socioeconómico de la población residente de distintas áreas de la ciudad (ver sección 1.2).

Mediante esta noción se remarca, por un lado, que en el mercado de suelo urbano lo que se comercializa es un conjunto de localizaciones y externalidades, las cuales dependen (más allá de las posibilidades de apropiación individual) de la dinámica de interacción y uso colectivo de la ciudad, del régimen de regulación del espacio urbano y la intensidad de trabajo inyectado en el espacio público. Por otro lado, se procura comprender la ciudad de modo la indivisible ${ }^{114}$, ello implica recuperar aspectos como la interacción social, la competencia entre usos, la intensidad de utilización de factor suelo, los juegos de expectativas; sin por ello perder de vista que las localizaciones urbanas se constituyen en un hecho social, son producidas colectivamente y dependen en gran medida de la dinámica del espacio público de la ciudad.

A nivel operativo entendemos al mercado de localizaciones residenciales intra-urbanas, como un espacio relacional que articula las condiciones de calidad urbana con el perfil socioeconómico de las distintas áreas de la ciudad. Siendo las condiciones generales de calidad de urbana producto del proceso de acondicionamiento y cualificación del espacio urbano, que se manifiesta en torno a la distribución (e interrelación) de la centralidad urbana, la accesibilidad y la conectividad de las distintas áreas de la ciudad, los niveles de consolidación urbana y los atributos de habitabilidad del parque edificado.

Si bien, es posible reconocer otras dimensiones que inciden en la calidad del espacio urbano, muchas de las cuales pueden estar influidas por las preferencias o las valoraciones subjetivas. El abordaje que aquí priorizaremos remite una calificación del espacio urbano a partir de la "base material" de las externalidades urbanas. Ya que las dimensiones mencionadas en el párrafo anterior operan transversalmente a los criterios elección residencial. De este modo, hasta el capítulo 4 dejaremos en suspenso el análisis de los efectos de vecindad vinculados a las percepciones subjetivas o los criterios de clasificación-distinción variables según los actores.

\footnotetext{
${ }^{114}$ El fenómeno urbano reconocen una totalidad y tiene una lógica de producción compleja que es en esencia de carácter colectivo y sustentada en la dimensión pública del espacio urbano, tanto en términos simbólicos como físicos. Por ello, parece contradictorio que gran parte del conocimiento y la intervención estatal se dirija a resguardar las expectativas individuales de los agentes privados, en vez de identificar en el espacio público el significado al que refiere la propiedad privada como significante.
} 
En los apartados subsiguientes presentamos una serie de resultados a partir del análisis de la localización de la vivienda social en función de su posición relativa en la estructura urbana, en base al costo del suelo en la inversión total de los planes de vivienda y resultados asociados a la comparación entre la modalidad TPU y otras modalidades de gestión de suelo. Para todos ellos, se construyó una matriz donde se integraron un conjunto de dimensiones de análisis (proximidad a la centralidad urbana, accesibilidad-conectividad, consolidación urbana, conexión a servicios sanitarios básicos, calidad de ocupación de la vivienda, calidad constructiva, nivel socioeconómico y cercanía al borde rural) con el objetivo de clasificar las distintas áreas de la ciudad y, a partir de allí, poder caracterizar los entornos de los barrios de vivienda social.

A nivel técnico, cada una de estas dimensiones de análisis está compuesta por una serie de variables clasificadas y agregadas por deciles. Esto significó el procesamiento de los datos del Censo Nacional de Población Hogares y Vivienda (INDEC, 2001) y de otras fuentes secundarias (ver detalle de variables en la figura 17$)^{115}$, con la finalidad de dar cuenta de la estructura urbana de los 24PGBA ${ }^{116}$. La unidad de análisis espacial seleccionada a efectos de realizar la sistematización y regionalización de la información a escala metropolitana, fue el radio censal. De los 7982 radios censales se seleccionaron los 7924 radios censales urbanos. De esta forma se definió un universo estadístico de referencia con el cual se correlacionan posteriormente una serie de operatorias habitacionales o barrios.

A partir de la construcción de la matriz de la estructura urbana clasificadas por deciles, es posible evaluar la localización de los barrios mediante una caracterización de los entornos urbanos contiguos a los mismos. De algún modo, esta matriz se presenta como un resultado del funcionamiento del mercado de localización residencial intra-urbana, o como una aproximación al mismo. Por otra parte, en algunos casos desarrollaremos una lectura desagregada de todas las dimensiones que componen dicha matriz y, en otros, sólo trabajaremos con un índice sintético de la estructura urbana (IEU) producto de la sumatoria de todas las dimensiones (ver detalles de la metodología en el anexo A2).

\footnotetext{
${ }^{115}$ Si bien las fuentes de información corresponden a distintos años, la estabilidad del fenómeno urbano y la escala de análisis propuesta hace que la variabilidad temporal entre los distintos registros sea ínfima.

${ }^{116}$ El procesamiento de los datos se realizó para los 24 partidos del Gran Buenos Aires (que componen el Conurbano Bonaerense). No consideramos el aglomerado estadístico del GBA (equivalente al AMBA), ya que buscamos excluir de nuestro análisis a la CABA. La identificación de la localización de los barrios de vivienda social, en función de una estratificación por deciles de la estructura urbana, hubiese significado al considerar la CABA un reforzamiento de su ubicación periférica. $Y$, en nuestro caso, la intensión no era homogeneizar la lectura del Conurbano Bonaerense, sino por el contrario reconocer su variabilidad.
} 
Fig. 17 Dimensiones de análisis y variables para la clasificación de la estructura urbana

\begin{tabular}{|c|c|c|}
\hline Dimensiones & & Variables \\
\hline $\begin{array}{l}\text { IC - Centralidad } \\
\text { urbana }\end{array}$ & $\begin{array}{l}- \\
- \\
-\end{array}$ & $\begin{array}{l}\text { Centralidades comerciales, } \\
\text { Centralidades según número de empleados y compacidad bancaria, } \\
\text { Centralidades normativas primarias y secundarias definida por la } \\
\text { zonificación de usos del suelo y áreas habilitadas para uso residencial de } \\
\text { alta densidad según zonificación, } \\
\text { Casco histórico según mancha urbana Censo } 1947\end{array}$ \\
\hline $\begin{array}{l}\text { AC - Accesibilidad- } \\
\text { conectividad }\end{array}$ & $\begin{array}{l}- \\
-\end{array}$ & $\begin{array}{l}\text { Red de transporte público automotor, } \\
\text { Área de influencia de las estaciones de ferrocarril, corredores con más de } \\
\text { tres líneas de transporte y corredores según códigos de zonificación, } \\
\text { Existencia de transporte público a menos de } 300 \text { metros a nivel de } \\
\text { segmento censal } \\
\text { Existencia de al menos una cuadra pavimento a nivel de segmento } \\
\text { censal. }\end{array}$ \\
\hline $\begin{array}{l}\text { CSU - Consolidación } \\
\text { urbana }\end{array}$ & - & $\begin{array}{l}\text { Servicios en la vía pública según segmento censal: Servicios en la vía } \\
\text { pública según segmento censal: existencia de al menos una cuadra } \\
\text { pavimentada, existencia de alumbrado público, existencia de teléfono } \\
\text { público a menos de } 300 \text { metros, existencia de transporte público a menos } \\
\text { de } 300 \text { metros y servicio regular de recolección de residuos al menos } 2 \\
\text { veces por semana. }\end{array}$ \\
\hline $\begin{array}{l}\text { CSS - Conexión a } \\
\text { servicios sanitarios } \\
\text { básicos }\end{array}$ & - & $\begin{array}{l}\text { Procedencia de agua en la vivienda por red pública (agua corriente) } \\
\text { Servicio sanitario (hogares con inodoro con descarga y desagüe a red } \\
\text { pública). (López y Cowes, 2008) }\end{array}$ \\
\hline $\begin{array}{l}\text { COV - Calidad de } \\
\text { ocupación de la } \\
\text { vivienda }\end{array}$ & $\begin{array}{l}- \\
-\end{array}$ & $\begin{array}{l}\text { Hogares con hacinamiento crítico (más de } 3 \text { personas por cuarto), } \\
\text { Baño de usos exclusivo y servicio sanitario. (López y Cowes, 2008) }\end{array}$ \\
\hline $\begin{array}{l}\text { CCV - Calidad } \\
\text { constructiva }\end{array}$ & $\begin{array}{l}- \\
- \\
-\end{array}$ & $\begin{array}{l}\text { Calidad material de los materiales de la vivienda (Calmat I o no } \\
\text { deficitario) } \\
\text { Cañería de distribución de agua dentro de la vivienda } \\
\text { Baño con inodoro con descarga de agua } \\
\text { Cocina con pileta con instalación de agua (López y Cowes, 2008) }\end{array}$ \\
\hline $\begin{array}{l}\text { NSE - Nivel socio- } \\
\text { económico }\end{array}$ & - & $\begin{array}{l}\text { Nivel de equipamiento del hogar: tenencia de computadora y conexión a } \\
\text { Internet, tenencia de heladera o freezer, tenencia de horno microondas, } \\
\text { tenencia de lavarropas, tenencia de teléfono, tenencia de televisión por } \\
\text { cable y tenencia de videocasetera-reproductor. }\end{array}$ \\
\hline $\begin{array}{l}R R \text { - Distancia borde } \\
\text { urbano }\end{array}$ & $\begin{array}{l}- \\
- \\
-\end{array}$ & $\begin{array}{l}\text { Radios censales según proporción de población urbana, rural agrupada y } \\
\text { rural dispersa, } \\
\text { Radios urbanos ajustados a tejido urbano real, } \\
\text { Área del código de zonificación de usos rural intensivo o extensivo } \\
\text { Áreas de uso real del suelo asociado a usos periurbanos y rurales. }\end{array}$ \\
\hline
\end{tabular}

Fuente: elaboración propia en base a: i) Abba, A. (2005) Centralidades Metropolitanas En: "Diagnóstico para la Formulación de Lineamientos Estratégicos para el Territorio Metropolitano de Buenos Aires" DPOUT-SSUyV ; ii) Atlas Metropolitano de Buenos Aires (2002-2004) "Atlas Metropolitano. Patrones territoriales y códigos de ordenamiento territorial y usos del suelo, Región Metropolitana de Buenos Aires". UNLP-CONICET-CIC; iii) Sistema de Ordenamiento Urbano y Territorial. Secretaría de Asuntos Municipales de la provincia de Buenos Aires. Año: consulta al 2006; iv) Sistema de transporte público de pasajeros (2003) Convenio DGCyE-UNLP; v) Sistema de Información Territorial de la Dirección Provincial de Ordenamiento Urbano y Territorial. Año: consulta al 2007; vi) INDEC (2001) Censo Nacional de Población Hogares y Vivienda.

\subsubsection{La ubicación de las tierras ofertadas en la estructura urbana}

En este apartado se presentan los resultados de análisis de la localización de las operatorias del PFCV-TPU en la matriz de la estructura urbana. En otras palabras, se indaga sobre la ubicación de la tierra ofertada por las empresas constructoras, en función del acceso a un conjunto amplio de condiciones de calidad urbana externas a los barrios de vivienda social y su posición relativa en la estructura socio-espacial de la ciudad. 
En base a la metodología antes mencionadas (ver detalle Anexo A2), en la figura 18 se muestran los resultados de la posición media de las operatorias (o los contratos de obra) TPU en la matriz de la estructura urbana. En las columnas, se observan las distintas dimensiones de análisis evaluadas y, en las filas, la estratificación resultante de la clasificación de las variables expresadas en deciles. A partir de la localización de las 57 operatorias TPU y la caracterización de los entornos urbanos lindantes a las mismas, se identificó en qué decil de la estructura urbana se ubica la posición media del conjunto de las intervenciones habitacionales realizadas por el Estado y los valores máximos y mínimos alcanzados.

Los resultados obtenidos indican que estas operatorias habitacionales se ubican, en promedio, en los tres deciles con perores condiciones de calidad urbana, gravitando en una lectura agregada de todas las dimensiones de análisis en el decil 2. La proximidad de las operatorias a las áreas de centralidades urbanas (IC = decil 1$)$ y a las redes de accesibilidad-conectividad ( $A C=$ decil 1$)$ muestra el peor desempeño en relación al resto de las dimensiones de análisis. Si se considera el entorno de los barrios en términos de niveles de consolidación urbana (CSU = decil 3), conexión a los servicios sanitarios básicos (CSS = decil 3) y la calidad de ocupación de la vivienda (COV = decil 3), la zona urbana muestra una leve mejora. En cambio, si se considera la calidad constructiva de la vivienda $(\mathrm{CCV}=$ decil 2$)$ de los entornos urbanos, el desempeño disminuye.

Al analizar el nivel socioeconómico, se registra un orden sin diferenciación entre la "estructura socio-espacial" y las condiciones de calidad urbana. Si bien la lectura que realizamos es de carácter regional y se trata de una medida situada en el entorno de los barrios de vivienda social, parece coherente que no se observen diferencias ya que (como se dijo anteriormente) estas dimensiones están intrínsecamente unidas. En la figura 18 es posible observar que la posición promedio de las operatorias no varía respecto a las condiciones generales de calidad urbana (decil 2), ni en relación al nivel socioeconómico (decil 2).

Una mención particular merece la distancia al borde urbano o al ámbito rural $(\mathrm{RR}=$ decil 2). Si bien, las operatorias habitacionales se encuentran en promedio en el segundo decil, los valores mínimos negativos demuestran que $26 \%$ de las operatorias se localizan en ámbitos rurales o periurbanos, por fuera de la trama urbana.

El rango entre las operatorias que alcanzan las mejores y las perores posiciones (máximos y mínimos en la figura 18) da cuenta de la heterogeneidad de situaciones en la inserción urbana de los barrios. Por un lado, se puede notar que la distribución de los mínimos y los máximos refuerzan la posición marginal de los barrios en la matriz de accesibilidad y conectividad urbana. No obstante, es importante observar que los problemas de accesibilidad y conectividad son, en algunos casos, parcialmente revertidos por la propia acción pública (a partir de la infraestructura de nexo, la construcción de acceso pavimentado a los barrios y/o la posterior redefinición de los recorridos de transporte público gestionada por los municipios). Por otra parte, cabe señalar que la ubicación en el borde urbano y el acceso a la centralidad 
acompañan en menor medida esta tendencia y, al mismo tiempo, su transformación ofrece mayor resistencia.

Fig. 18 Posición de la operatoria TPU según distribución de condiciones de calidad urbana, nivel socioeconómico y distancia al borde urbano en los 24PGBA.

\begin{tabular}{|c|c|c|c|c|c|c|c|c|c|c|c|}
\hline & \multicolumn{7}{|c|}{ Condiciones de calidad urbana } & \multicolumn{2}{|c|}{$\begin{array}{l}\text { Nivel socio- } \\
\text { económico }\end{array}$} & \multicolumn{2}{|c|}{$\begin{array}{c}\text { Distancia a } \\
\text { borde urbano }\end{array}$} \\
\hline Decil & & IC & $A C$ & CSU & css & cov & CCV & & NSE & & $\mathbf{R R}$ \\
\hline 10 & + & & & & & & Máx. & + & & + & \\
\hline 9 & & & & Máx. & Máx. & Máx. & & & & & \\
\hline 8 & & & & & & & & & Máx. & & \\
\hline 7 & & & & & & & & & & & \\
\hline 6 & & Máx. & & & & & & & & & \\
\hline 5 & & & & & & & & & & & \\
\hline 4 & & & & & & & & & & & Máx. \\
\hline 3 & & & Máx. & TUP & TUP & TUP & & & & & \\
\hline 2 & • & & & & & & TUP & • & TUP & • & TUP \\
\hline 1 & - & TUP & TUP & Mín. & Mín. & Mín. & Mín. & - & Mín. & - & $\left({ }^{*}\right)$ \\
\hline
\end{tabular}

Fuente: Elaboración propia. En base a 57 operatorias TPU. Instituto de la Vivienda - Subsecretaría de Urbanismo y Viviendas - Provincia de Buenos Aires. Nota $\left(^{*}\right)$ : En el caso de la proximidad a los territorios de borde se observan los valores mínimos negativos, en tanto que en 15 operatorias se encuentran por fuera de la "mancha urbana" de los 24PGBA y dentro de ámbitos rurales o periurbanos. Es decir, se encuentran en áreas de uso rural para la normativa de zonificación de usos del suelo de los respectivos municipios.

Más allá de las limitaciones estructurales de la localización de los barrios de vivienda, a continuación veremos algunos ejemplos de la heterogeneidad de situaciones: el barrio Thevenet (300 viviendas), construido por la CONSTRUCTORA CALCHAQUI-TECMA SRL-UTE en un intersticio urbano de la localidad de Zevallos (partido de Florencio Varela), tiene una de las mejores localizaciones en la matriz de la estructura urbana. Se ubica sobre una avenida y en un área relativamente consolidada del tejido urbano (en términos de cobertura de servicios e infraestructura). El barrio se encuentra cerca del denominado "Cruce Varela" (RPN36 y RPN14), equidistante de la estación de ferrocarril de F. Varela y G. Monteverde, a unas 10 cuadras del centro urbano del municipio y alrededor de 4 cuadras del transporte público. Un caso similar constituye el barrio conocido como Malvinas (1990 viviendas), construidos por la empresa IECSA SA CALCATERRA SACIFI YC, en el borde urbano de la localidad de 9 de Abril (Esteban Echeverría), lindante a un pequeño centro barrial, a unas 20 cuadras del centro de Monte Grande y a 15 minutos de transporte de la estación de ferrocarril con conexión a Constitución (Buenos Aires). 
En contraposición, el barrio Santa Rosa (1432 viviendas), construido por la empresa MARTINEZ Y DE LA FUENTE S.A en un área de borde, se anexa al tejido de expansión residencial reciente de la localidad de San Rosa (Florencio Varela), con escaso nivel de consolidación urbana y marcada precariedad habitacional. Se encuentra a poco más de $2 \mathrm{~km}$ del centro local, pero con mayor tiempo de viaje que en el caso anterior (cerca de 45 minutos). Otro ejemplo con clara inserción en el ámbito rural o periurbano es el barrio de calle Remedios (343 viviendas), construido por la empresa REGAM S.A en la localidad de Virrey del Pino (La Matanza), con un ingreso distante (15 cuadras de la RNN3, km 45), a más de $7 \mathrm{~km}$ del centro de la localidad y a $15 \mathrm{~km}$ de la centralidad de González Catán.

Al observar estos matices en relación a los terrenos ofertados por las empresas, y dada la forma en la cual el Estado resolvió la adquisición del suelo urbano, cabe preguntarse si las diferencias observadas en la localización de los terrenos corresponden con algún tipo de variación en el precio de suelo. Hemos visto que la provincia de Buenos Aires buscó regular el precio de compra, y que también la tierra ofertada asume diferencias que no dependen sólo de condiciones de localización extrínsecas (la aptitud hidráulica, el requerimiento de relleno, la subdivisión realizada con anterioridad, podrían ser atributos intrínsecos al lote que se ponen en juego en la negociación). No obstante, el precio de la tierra ofertada no parece haber estado regulado por estos atributos, ni por su posición en el mercado de localización intra-urbana. Veamos a continuación cómo se comporta la incidencia del costo del suelo en relación a la localización urbana.

\subsubsection{La incidencia del precio del suelo y su relación con la localización}

Para resolver el interrogante arriba formulado, se realizó un cálculo del precio pagado por $\mathrm{m}^{2}$ de suelo y se lo comparó con el orden resultante de las localizaciones en la matriz de estructura urbana (de manera agregada y desagregada por indicadores). Por otra parte, se consideró la incidencia del suelo en la inversión total de las obras y en relación a la composición de la estructura de costo. Además, se analizó si la infraestructura complementaria o de nexo tiene alguna relación con el precio del suelo y si la inversión en infraestructura complementaria tiene algún tipo de correlato con la localización de barrio. ${ }^{117}$

A partir del análisis de 17 barrios en PFCV-TPU en seis municipios, se observa que el precio promedio pagado fue de $14,6 \$ / \mathrm{m}^{2}\left(5,03 \mathrm{U} \$ \mathrm{~S} / \mathrm{m}^{2}\right)$, con valores que varían entre los 5,4 y los $24,1 \$ / \mathrm{m}^{2}$. Aunque el precio debería expresarse en hectáreas, ya que corresponde a macizos sin subdividir y, en la mayoría de los casos, sin indicadores urbanísticos dado que se trata de tierra de carácter rural.

Para un análisis con mayor profundidad del precio por metro cuadrado, debería considerarse el área neta urbanizable, no la superficie bruta del terreno. Es decir, sería necesario considerar el porcentaje de cesiones al cual cada uno de los terrenos fue sometido según sus características

\footnotetext{
${ }^{117}$ Este análisis se realizó para 17 barrios del PFCV-TPU, para los cuales se logró obtener la información.
} 
y las del proyecto. No obstante, considerando la superficie bruta de los terrenos y sus características extrínsecas, es posible sacar algunas conclusiones preliminares.

La incidencia del costo del suelo en relación a la inversión en la obra de viviendas fue en promedio del 9,1\%. Vale recordar que la provincia acordó con las empresas un tope del 10\%.

En términos globales parece que los intentos del Estado por fijar un techo máximo de inversión en el suelo dieron resultado, aunque con asimetrías internas ${ }^{118}$.

\section{Fig. 19 Inversión total por barriosi del PFCV-TPU}

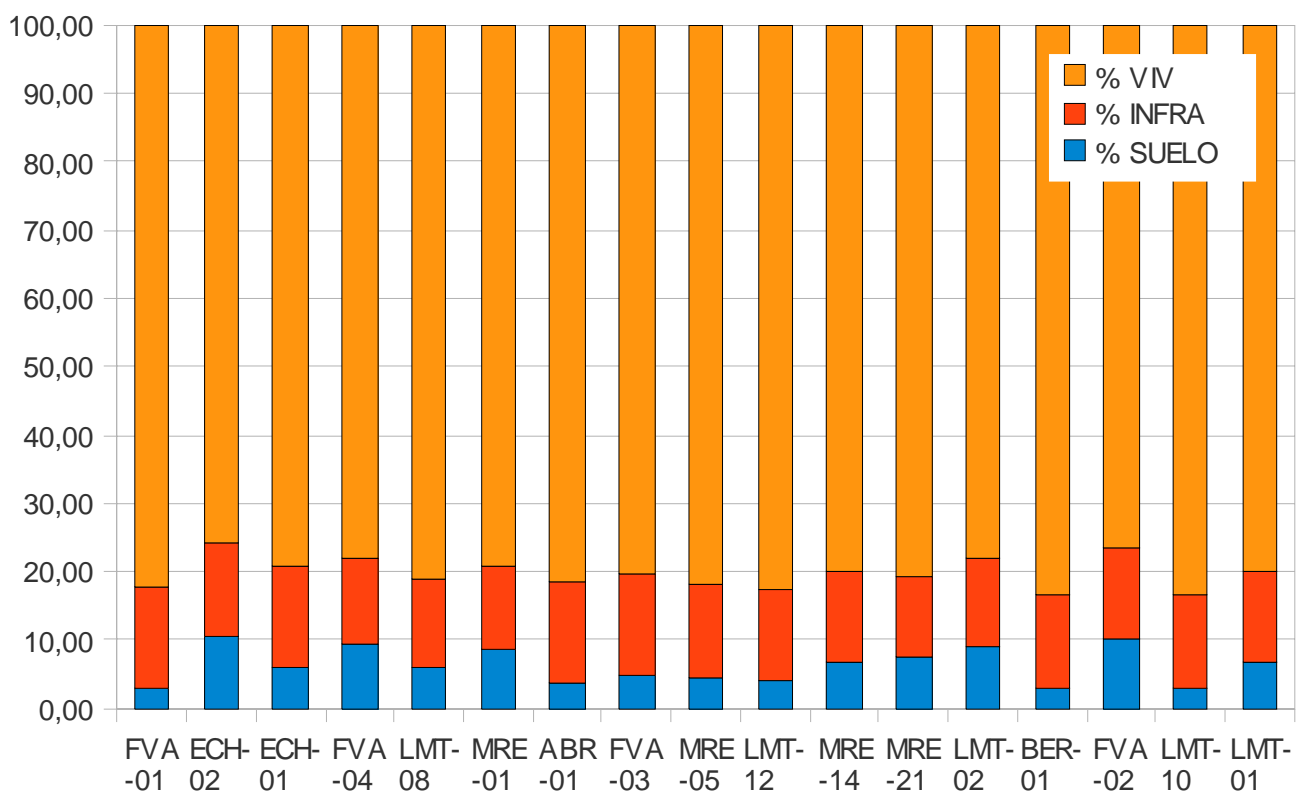

Fuente: elaboración propia en base a motos originales de contrato de obra PFCV-TPU, IVBA.

Nota i: la inversión total por barrio es el resultado de la suma del precio del suelo, la inversión en infraestructura de nexo y la inversión en viviendas (que incluye el costo de la infraestructura básica a pie de vivienda).

En la figura 19, se considera la inversión total por barrio (viviendas e infraestructura básica asociada, infraestructura de nexo y suelo) ${ }^{119}$. Al considerar la infraestructura complementaria o de nexo, el porcentaje de incidencia del suelo es del 7,2\%, mientras que la infraestructura complementaria representa el $13,5 \%$ y la vivienda con la infraestructura básica asociada el $79,3 \%$. No obstante, la infraestructura de nexo no siempre atiende exclusivamente al barrio de vivienda social, por tanto dicha lectura merece cierto cuidado.

\footnotetext{
${ }^{118}$ En el AMBA, los valores más bajos se encuentran en Florencio Varela y Berazategui, con porcentajes que varían entre el 3 y 4\%. Los precios más altos se observan en Esteban Echeverría y, también, Florencio Varela con incidencias del 13 y 14\%. Si se considera el conjunto de la RMBA, en La Plata y Berisso la incidencia máxima del suelo asciende al 17 y $22 \%$ respectivamente.

${ }^{119}$ Los contratos de construcción de viviendas del PFCV incluyen, tanto el precio de la vivienda como la infraestructura básica asociada a la vivienda (red de agua, red cloaca, red eléctrica, alumbrado, veredas, desagües pluviales, apertura de calles, enarenado y compactado, etc.), no así la infraestructura complementaria o de nexo entre el barrio y el resto de la ciudad (por ejemplo, vialidad pavimentada, tramos de conexión a anillos de red de agua y cloaca o planta de tratamiento cloacal, bombas impulsoras de líquidos, tanque cisterna y potabilización de agua, perforaciones de captación de agua, etc.) que fueron financiados por otra línea de financiamiento.
} 
Dado que el monto por vivienda es fijo, y que la infraestructura básica asociada a la vivienda tampoco muestra variabilidad, buscamos determinar si los costos de la infraestructura de nexo y del suelo tuvieron un comportamiento diferencial según su localización en la matriz de estructura urbana arriba presentada. Para ello, en la figura 20 representamos el porcentaje de incidencia de la infraestructura de nexo sobre la inversión total en cada barrio (ordenada de izquierda a derecha de la mejor a la peor localización en la estructura urbana). Como se puede ver, en términos generales, la proporción de inversión en infraestructura de nexo no muestra grandes contrastes, variando entre el $13 \%$ y el $15 \%$, y no está afectada por la calidad de la localización, ni por la proximidad de los servicios básicos (agua y cloaca).

En este sentido, se podría suponer que la inversión de infraestructura complementaria debería ajustarse parcialmente a la consolidación urbana de los sitios donde se emplazan los nuevos barrios. Estos resultados confirman los registros de las entrevistas: el financiamiento de la infraestructura de nexo funcionó como un fondo complementario de inversión en infraestructura, más asociado a la magnitud de la inversión original que a los niveles de consolidación urbana de los emplazamientos.

Fig. 20 infraestructura de nexo (en \%) sobre inversión total, barrios del PFCV-TPU ordenados (de izquierda a derecha) según calidad de localización

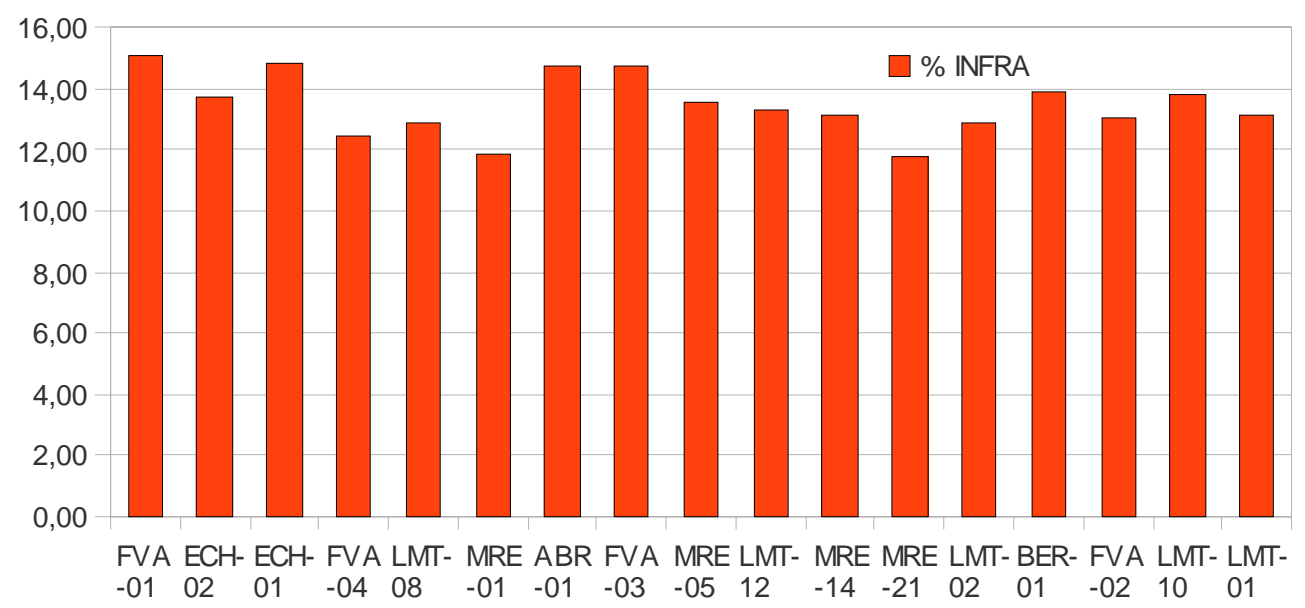

Fuente: elaboración propia en base a motos originales de contrato de obra PFCV-TPU, IVBA.

Por otra parte, si consideramos la posición marginal de los barrios del PFCV-TPU que observamos previamente en la figura 20 y la carencia de servicios básicos de agua y cloaca en dichas áreas, podría darse también una segunda interpretación. Ésta se basa en la posibilidad de que la relativa homogeneidad de la inversión se deba a que la conexión con las redes de agua y cloaca constituya una variable dura que afecte por igual a localización de todos los barrios. Según esta interpretación, la conexión con este tipo de redes se encontraría por debajo de la sensibilidad del índice de localización aquí utilizado (IEU) y la magnitud de inversión 
necesaria en la infraestructura de nexo es constante según la escala del barrio. Sin embargo, todos los indicios parecen confirmar la primera interpretación.

En contraposición a la infraestructura de nexo, la incidencia del costo del suelo sobre la inversión en la obra de vivienda (ver figura 21) muestra mayor variabilidad entre los barrios analizados (entre el $3 \%$ y el $14 \%$ ). Pero, al igual que en el caso anterior, la variación entre los registros parece comportarse de modo independiente de la calidad de la localización.

Si bien, como ya vimos, la iniciativa del Estado por fijar un techo a la relación de costos entre el suelo y la vivienda tuvo cierto efecto en términos generales, lo anterior muestra que los procesos de negociación y las condiciones en las cuales los propietarios aceptaron destinar la tierra a los proyectos de vivienda social fueron muy heterogéneos y no respondieron necesariamente a expectativas vinculada con la localización de los terrenos ofertados. De hecho, en los 17 casos analizados en la figura 21, el barrio que cuenta con mejor calidad de localización (FVA-01, barrio de 300 viviendas en la localidad de Zeballos, partido de Florencio Varela) tiene la menor incidencia del costo del suelo $(3,4 \%)$, mientras que en el barrio peor localizado (LMT-01, barrio de 600 viviendas en la localidad de González Catán, partido de La Matanza) la incidencia del costo del suelo es casi dos veces y media mayor $(8,6 \%)$.

Fig. 21 Incidencia suelo (en \%) sobre inversión de obra de vivienda, barrios del PFCVTPU ordenados (de izquierda a derecha) según calidad de localización

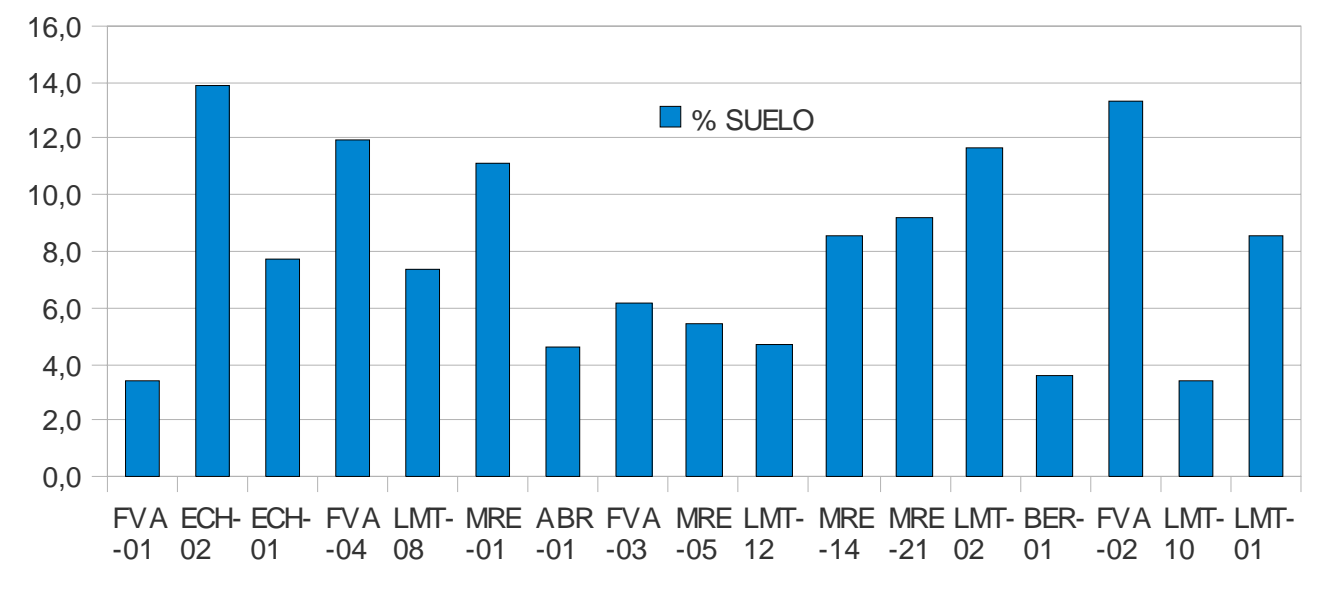

Fuente: elaboración propia en base a motos originales de contrato de obra PFCV-TPU, IVBA.

En la figura 22, se contrastan el índice sintético referido a la calidad de la localización en la estructura urbana (IEU) con el precio del suelo a los cuales se adquirió la tierra ofertada por las empresas. La gráfica propone una lectura del nivel de asociación de las variables, la distribución de la nube de punto muestra el bajo nivel de correlación que hay entre las variables. Es decir, el precio del suelo y las condiciones de localización (salvo alguna excepción) no se encuentran asociados entre sí. 
Un caso aparte constituye, nuevamente, el barrio Thevenet de la localidad de Zeballos (el registro FVA-01) con la mejor ubicación en la estructura urbana y uno de los precios del suelo más bajos. A partir de las entrevistas realizadas en el municipio, ${ }^{120}$ se obtuvo información complementaria acerca de las condiciones de negociación en las cuales el propietario decidió incorporar el terreno en la operatoria. De allí surge que el dueño se habría visto amenazado por una intrusión en el terreno incentivada por actores interesados en la realización de la obra.

Dadas estas particularidades, vale la pena realizar una lectura aislando este registro. No obstante los precios del suelo continúan teniendo alta independencia de las condiciones de localización en la estructura urbana, aunque es posible observar un leve nivel de asociación entre las variables ${ }^{121}$.

Fig. 22 Precio del suelo $\left(\$ / \mathrm{m}^{2}\right)$ de los barrios del PFCV-TPU vs índice de calidad de la localización (IEU)

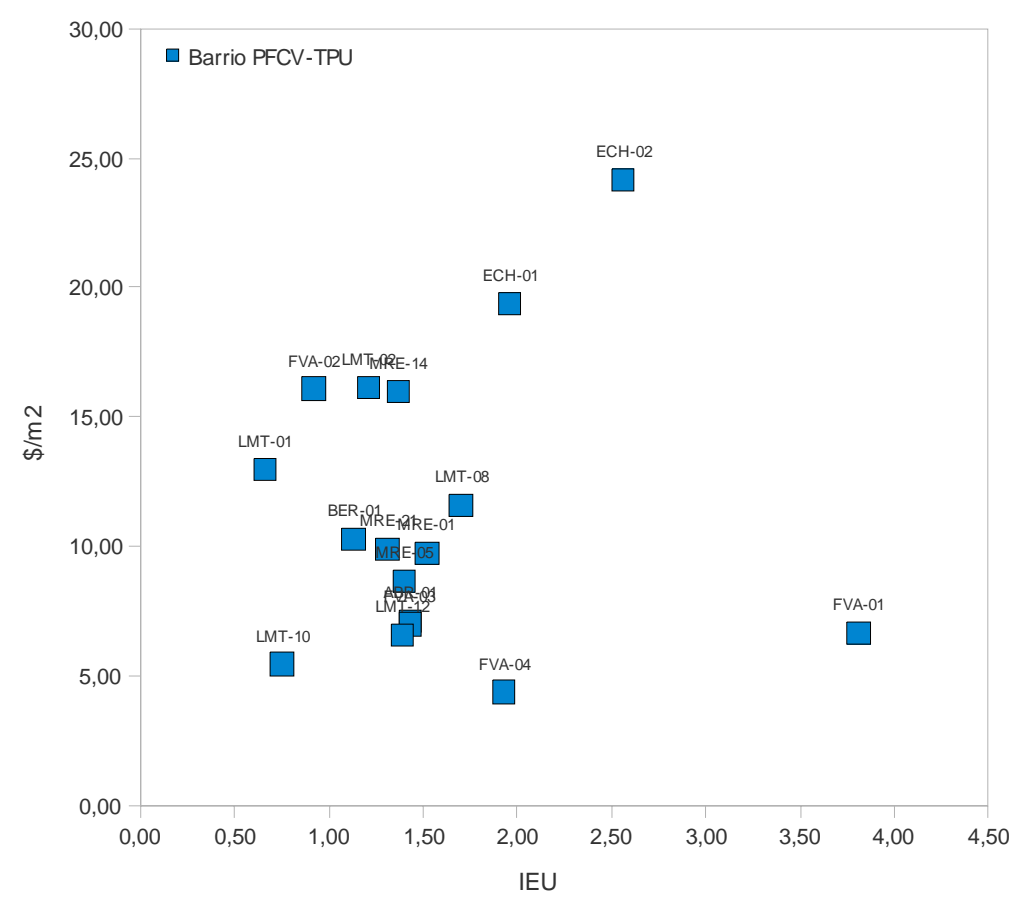

Fuente: elaboración propia en base a motos originales de contrato de obra PFCV-TPU, IVBA.

Otro de los ejercicios posibles a efecto de chequear la relación entre costo de suelo y la valoración de localización, es intentar realizar una comparación con precios de mercado. Sin embargo, la inexistencia de datos con la cobertura necesaria para realizar dicha

\footnotetext{
${ }^{120}$ Entrevista Funcionario № 6 (11/03/2009).

${ }^{121} \mathrm{Al}$ excluir el registro FVA-01, el coeficiente de correlación pasa de una asociación nula (coeficiente de Pearson $0,059)$ a mostrar una relación parcial entre precio y localización (coeficiente de Pearson 0,384 ).
} 
comparación ${ }^{122}$ nos llevó utilizar los datos de valuación fiscal ${ }^{123}$ con la intención de realizar algún chequeo complementario a la metodología propuesta por nosotros.

Fig. 23 Precio del suelo $\left(\$ / \mathrm{m}^{2}\right)$ de los barrios del PFCV-TPU vs valuación fiscal $\left(\$ / \mathrm{m}^{2}\right)$ ARBA

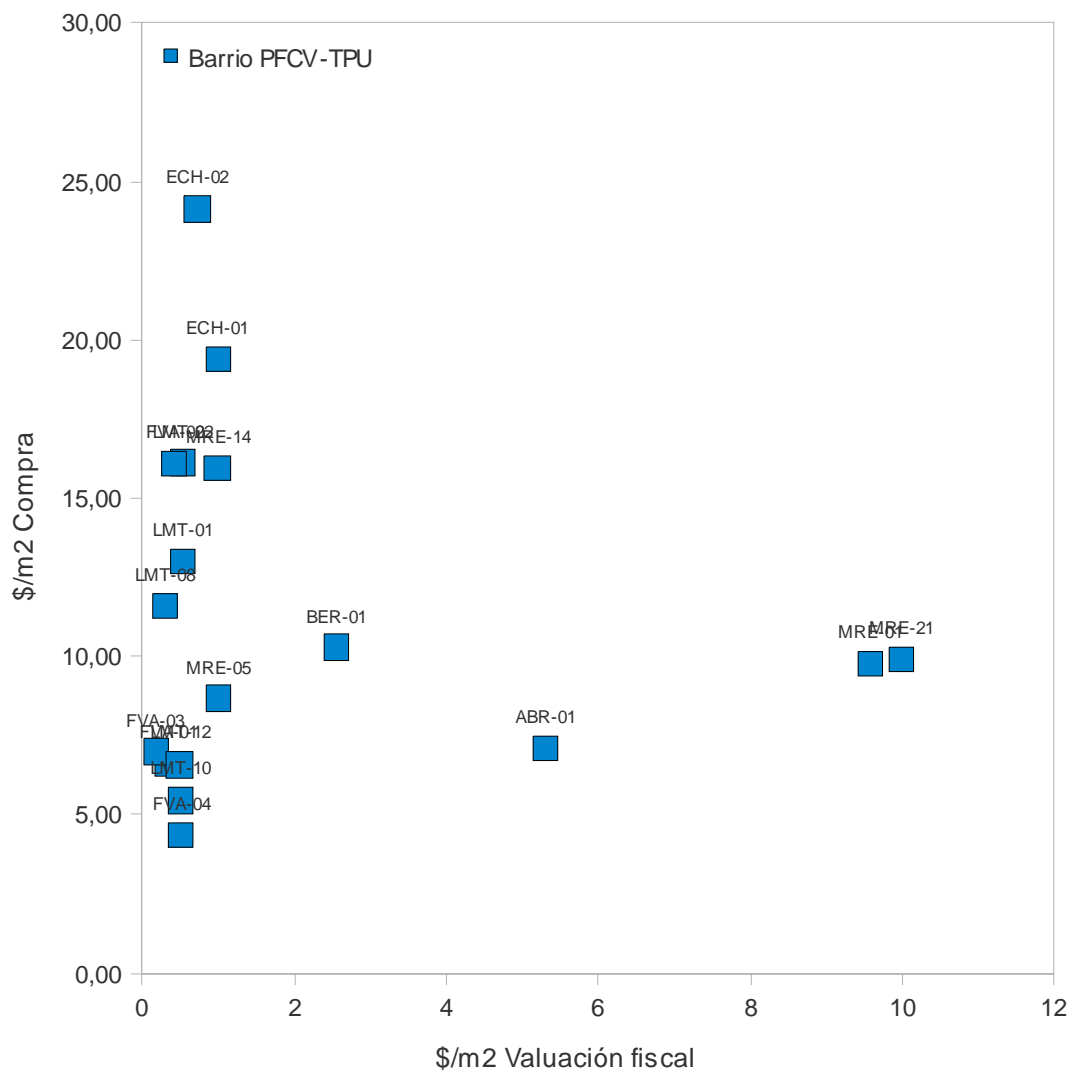

Fuente: elaboración propia en base a motos originales de contrato de obra PFCV-TPU, IVBA y Dirección Provincial de Catastro Territorial de la Agencia de Recaudación de la Provincia de Buenos Aires (ARBA).

Nota: la consulta de la valuación fiscal de la ARBA se realizó en el años 2011 y contratos del PFCV son en su mayoría del año 2005, no obstante la actualización de la valuación fiscal a partir del trabajo de las Comisiones Asesoras (integradas por miembros de la provincia, los municipios, la banca pública, los colegios profesionales, etc.) se realizó a mediados de década.

En la figura 23, se puede observar que los precios pagados por la tierra ofertada por parte de las empresas constructoras tampoco responden a la lectura del mercado de suelo que tienen las Comisiones Asesoras que realizan la valuación fiscal. No obstante, la gráfica presenta un indicio importante, la aglomeración de registros sobre el eje de las ordenadas da cuenta de la representación devaluada que dichas localizaciones tienen en el esquema de la valuación fiscal.

\footnotetext{
${ }^{122}$ Sólo para 3 barrios de los 17 pudimos obtener precios de suelo del entorno lindante del barrio, razón por la cual no es posible sacar ninguna conclusión al respecto, más allá del bajo nivel de oferta.

${ }^{123} \mathrm{Si}$ bien la valuación fiscal se encuentra por debajo del valor de mercado, a efectos de observar la variabilidad entre registros es una fuente válida dado el trabajo de las Comisiones Asesoras de Valuación.
} 
En síntesis, la adquisición de suelo para la construcción de vivienda social a cargo de las empresas constructoras (modalidad TPU-PFCV) fue definida como un mecanismo de mercado en el marco de la gestión de suelo. Si bien, en el apartado anterior se observó que esta modalidad se asocia a una posición devaluada en la estructura urbana y, al mismo tiempo, presenta ciertas heterogeneidades en la localización de los barrios, en las aproximaciones realizadas en este apartado las diferencias observadas en los precios del suelo no parecen explicarse por factores de localización.

En este sentido, el Estado parece estar dispuesto a comprar la disponibilidad pública de la tierra (con la que no cuenta) o cuya adquisición por otra vía resulta un problema al momento de ejecutar las obras de vivienda. Y, aún cuando la incidencia del suelo en el costo de la obra de viviendas parece razonable ( $y$ acorde los márgenes fijados por la provincia), la compra de la tierra no necesariamente se realiza en función de la localización diferenciada en la ciudad. Más bien se compra un "insumo" que en la urgencia garantice donde emplazar las obras. Vale aclarar que no se espera una generalización del ajuste entre las condiciones de la oferta y la demanda. Por el contrario, se puso en evidencia una vez más que la localización no representa una preocupación para política de vivienda.

Finalmente, aunque parecen quedar dudas sobre si la adquisición de suelo a cargo de las empresas constructoras puede ser considerada un mecanismo de mercado, ya que la relación entre precio y mercado de localizaciones intra-urbanas parece desvanecerse 0 , dicho de otro modo, la localización sólo es parcialmente mediada por relaciones mercantiles. En el apartado siguiente, compararemos la modalidad TPU con otras formas de gestión de suelo para vivienda social, y advertiremos que se refuerza nuevamente el vínculo con el papel que juega el mercado de localización intra-urbana.

\subsubsection{Los efectos del mercado en la distribución de la ciudad}

Para indagar sobre la existencia de algún vínculo entre la forma de adquisición de suelo utilizada por la operatoria TPU y su desempeño en función de la calidad de localización, nos propusimos comparar la localización de dicha operatoria con el resto de las modalidades de gestión de suelo (utilizadas para disponibilizar tierra destinada a la construcción de vivienda social). Dicho de otra forma, nos preocupa averiguar si la particular mediación entre el sector público y privado que se desarrolló en la operatoria PFCV-TPU repercute diferencialmente en el lugar asignado en la ciudad a la vivienda social.

El estudio realizado por Duarte (2010) identifica un conjunto de instrumentos utilizados para adquirir tierra en el marco de los programas federales de vivienda en el Conurbano Bonarense. En total se identifican 11 modalidades de adquisición de suelo, que luego se son agrupados en 6 tipologías, a saber: mecanismo de mercado (integra la modalidad de "compra directa del Estado" y el "aporte de la tierra por empresas constructoras" o TPU), Estado terrateniente 
(incluye "tierra fiscal vacante" y "tierra fiscal ocupada"), instrumentos urbanísticos (equivale a "cesiones urbanísticas"), instrumentos tributarios (abarca "donación de tierra de privados", "dación en pago" y "juicios por deuda de tasas e impuestos"), instrumentos jurídicos (incluye "expropiaciones" y "prescripción administrativa") y tierra privada (equivale al "aporte de tierra de privados"). Cada uno de estos instrumento tiene su especificidad y complejidad (ver Duarte, 2010).

Esta comparación entre la operatoria TUP y el resto de las modalidades de adquisición de suelo significó introducir a la matriz de la estructura urbana (aparte de los 20 barrios del PFCVTPU) 90 barrios más, pertenecientes a las operatorias del PFCV con Municipios, el SPUVyA y el PFEH. El resultado de dicho procedimiento se representa en la figura 24, donde se muestra la ubicación de modalidades de adquisición de suelo, las tipologías de adquisición de suelo y los programas habitacionales según su posición media en la estructura urbana. La sistematización de la información dio como resultado una tabla cruzada ordenada en deciles, donde el decil 10 representa el mayor nivel de calidad urbana mientras que el decil 1 representa el menor nivel de calidad urbana. A partir de la localización de los barrios objeto de análisis y la descripción estadística de sus entornos urbanos contiguos, se identificó en qué decil se ubica la posición media de los subgrupos de barrios agregados por tipología y modalidad de adquisición de suelo y por programa habitacional.

Al considera la totalidad de los barrios sin discriminar la modalidad, la tipología de adquisición de suelo, ni el programa habitacional (lectura no graficada en la figura 24), se observa que la posición media de los 110 barrios de vivienda social se encuentra en el tercer decil con peores condiciones de calidad urbana. Si bien, la media se encuentra en el decil 3, existen barrios peor y mejor ubicados (mínimo decil 1 y máximo decil 8), pero la distribución que se inclina siempre hacia la región con menores ventajas urbanas. Esto coincide con lo visto en el apartado 3.2.1, donde corroboramos que al considerar los barrios de la operatoria TPU, los mismos se ubicaban en un escalón inferior en la jerarquía urbana (media decil 2).

Otro aspecto a tener en cuenta, si se incorpora la lectura de las tipologías de adquisición construidas por Duarte (2010), es que los instrumentos urbanísticos o el aporte de la tierra pública estatal (categoría estado terrateniente) arrojan resultados sensiblemente mejores que los mecanismos de mercado o los instrumentos tributarios. Mientras que los primeros se ubican en el decil 6 y 5 en estructura de externalidades urbanas, los segundos se ubican decil 2.

Aún cuando el número de registros en algunas de las tipologías es muy bajo para realizar generalizaciones, es esperable que las cesiones urbanísticas o las cargas a los loteadores de un proceso de subdivisión de antaño obtengan mejores resultados que la donación de tierra de privados, el aporte de tierra por empresas constructoras o la donación en pago. Esto se debe, en parte, a la naturaleza de los mismos programas habitacionales, que requieren resolver la disponibilidad de suelo de maneras diferentes (ya hemos visto algunas diferencias entre el PFCV y el PFEH). Pero, por otro lado, también se explica por las restricciones que impone la renta de suelo en la obtención de mejores posiciones en la jerarquía urbana. De hecho, la 
posición relativa que asume la adquisición del suelo vía los mecanismos de mercado expresa claramente los obstáculos impuestos por el mercado de localizaciones intra-urbanas.

La tipología instrumentos tributarios -compuesta por las modalidades de adquisición de suelo donación de tierras de privados, juicios por deuda de tasas e impuestos, dación en pagotambién podría ser interpretada a partir de los efectos de la renta del suelo: los propietarios sólo descuidan o se desprenden de suelo de bajo precio. De cualquier modo, esta afirmación debe complejizarse, ya que los instrumentos tributarios fueron utilizados exclusivamente por dos municipios de la segunda corona metropolitana, los cuales desarrollaron previamente políticas activas de suelo con el objetivo de recuperar y movilizar el pasivo dominial de los denominados "loteos populares".

Fig. 24 Gestión y localización del suelo, según posición media de 110 barrios de vivienda social en la estructura urbana del Conurbano Bonaerense.

\begin{tabular}{|c|c|c|c|c|}
\hline \multicolumn{5}{|c|}{$\begin{array}{l}\text { Estructura urbana clasificada por deciles vs mecanismos de gestión de suelo para vivienda } \\
\text { social }\end{array}$} \\
\hline Decil & Modalidades de adquisición & Tipologías & Programa & \\
\hline 10 & & & & Mejor \\
\hline 9 & & & & \\
\hline 8 & & & & \\
\hline 7 & Prescripción administrativa & & & \\
\hline 6 & Cesiones urbanísticas & Instrumentos Urbanísticos & SPUVYA & \\
\hline 5 & $\begin{array}{l}\text { Tierra fiscal ocupada } \\
\text { Tierra fiscal ociosa }\end{array}$ & Estado Terrateniente & & \\
\hline 4 & Tierra de privados & $\begin{array}{l}\text { Instrumentos Jurídico } \\
\text { Tierra privada }\end{array}$ & & \\
\hline 3 & $\begin{array}{l}\text { Expropiación } \\
\text { Compra directa }\end{array}$ & & PFCV-Muni & \\
\hline 2 & $\begin{array}{l}\text { Donación de tierras de privados } \\
\text { Juicios por deuda } \\
\text { Aporte de tierra por empresas (TPU) }\end{array}$ & $\begin{array}{l}\text { Mecanismo de Mercado } \\
\text { Instrumentos Tributarios }\end{array}$ & $\begin{array}{l}\text { PFEH } \\
\text { PFCV-TPU }\end{array}$ & \\
\hline 1 & Dación en pago & & & Peor \\
\hline
\end{tabular}

Fuente: del Río y Duarte (2010) "Las modalidades de gestión del suelo y la localización de la vivienda social en el Conurbano Bonaerense 2003-2009", Taller Transformaciones Urbanas, Ambientales y Políticas Públicas. Área de Estudios Urbanos. IGG-FCS-UBA, Buenos Aires. 
Otra lectura posible la aporta la entrada por programa habitacional. En este caso, se puede ver que la ubicación de las soluciones habitacionales en áreas más consolidadas o mejor ubicadas (decil 6) se explica en gran medida por el SPUVyA, que actúa principalmente en villas o asentamientos históricos del primer cordón del Conurbano Bonaerense. En este caso, es importante aclarar que la adquisición "formal" del suelo es posterior al proceso de autourbanización por parte de los pobladores. Es decir, la localización no fue decidida por el Estado (aunque sí legitimada). Se trata de una decisión realizada con antelación por los pobladores ${ }^{124}$, quienes al momento de realizar la toma de tierra evaluaron determinado contexto de oportunidad y decidieron ubicarse allí. Si, además, consideramos que los barrios pertenecientes a los programas PFEH y PFCV, los cuales se construyen en las que se han definido como nuevas localizaciones, se registra una caída abrupta en la calidad de la ubicación hasta las áreas más devaluadas de la estructura urbana (decil 2-3).

Queda claro que la política habitacional se distribuye de modo diferencial en el espacio urbano. Allí donde se encuentran las mejores condiciones generales de calidad urbana, parece existir un territorio "prohibido" para la vivienda social. Frecuentemente se argumenta que la escasez de suelo y/o la densidad de ocupación del tejido urbano dificultan la construcción de vivienda social en áreas consolidadas. Sin embargo, estas objeciones técnicas y la posibilidad de realizar operaciones urbanas en áreas centrales o distribuir determinados efectos de centralidad parecen variar según el sector social. De hecho, el boom inmobiliario actual reafirma la presencia de importantes transformaciones en las principales centralidades metropolitanas.

Las dificultades de los barrios de vivienda social para emplazarse en entornos de mayor calidad urbana se agravan al considerar la relación entre el volumen de soluciones habitacionales y su ubicación en la jerarquía urbana (ver figura 25). Más del 60\% de las soluciones habitacionales se realizan en las áreas con menores condiciones de calidad urbana (decil 1 y 2). Si se agrupan los cinco deciles inferiores, ese porcentaje asciende a cerca del $80 \%$, mientras que en los cinco deciles superiores apenas supera el $20 \%$. Por otra parte, el peso de las soluciones habitacionales localizadas en los cuatro deciles superiores (decil 5 al 8) de la figura 25, se explican en gran medida por el SPUVyA, mientras que la soluciones que se ubican entre los deciles 1 y 4 se explican por el PFEH y PFCV.

\footnotetext{
${ }^{124}$ De hecho, la mejor posicionamiento en la estructura urbana se debe en gran medida a desfaje temporal entre la instancia y el proceso en el cual dichos barrios se constituyen como parte del espacio urbano y el momento en el cual son (re)urbanizados y regularizados como tal. En algunos casos se tratan de villas con más de 40 o 60 años de antigüedad.
} 
Fig. 25 Distribución de soluciones habitacionales según ubicación en la estructura urbana de los 24 partidos del AMBA.

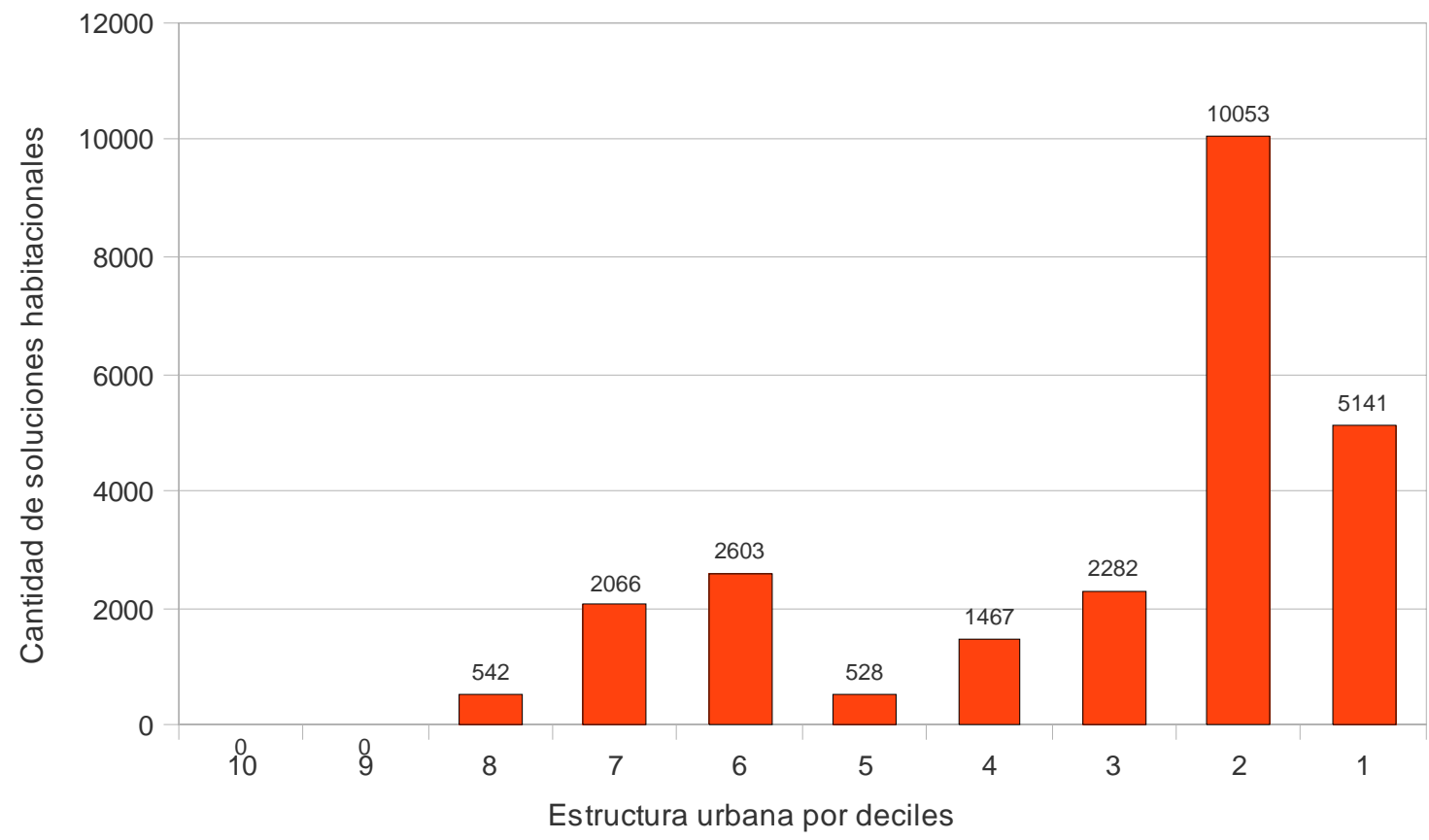

Fuente: del Río y Duarte (2010) "Las modalidades de gestión del suelo y la localización de la vivienda social en el Conurbano Bonaerense 2003-2009", Taller Transformaciones Urbanas, Ambientales y Políticas Públicas. Área de Estudios Urbanos. IGG-FCS-UBA, Buenos Aires.

Hemos visto que la regularización de tierras mediante el SPUVyA y el aporte de suelo por empresas constructoras o TPU (como la modalidad predominante de adquisición de suelo del PFCV) formaron parte de la estrategia del Estado al momento de hacerse del suelo necesario para la política de vivienda. Sin embargo, los resultados en términos de los atributos extrínsecos a la vivienda son marcadamente diferentes entre estos programas. Por otra parte, la tendencia identificada en a figura 25 no pude disociarse del comportamiento del mercado de suelo.

El principio del "mayor y mejor uso" parece ordenar el volumen de vivienda social en el mercado de localizaciones intra-urbanas de modo inverso a la pendiente imaginaria de la renta del suelo. Si bien en la matriz de la estructura urbana confeccionada a fines operativos no se incorporó la variable precio del suelo, a modo de ejemplo podríamos tomar la distancia promedio a la centralidad urbana ${ }^{125}$ para reconstruir una pendiente inversa a la cantidad de viviendas sociales representadas en la figura 25 . Este análisis muestra claramente que cuando la localización de la vivienda social queda librada a la lógica impuesta por la economía urbana, el mercado tiene reservado su lugar para este tipo residencial.

\footnotetext{
${ }^{125}$ Mientras que en el decil 10 la distancia media a la centralidad urbana es de 0,36 kilómetros, en el decil 10 la distancia promedio llega a 3,1 kilómetros con registros máximos hasta 30 kilómetros.
} 
Dentro del PFCV, la operatoria TPU merece un comentario especial. Como vimos, esta estrategia fue diseñada por el IVBA como respuesta a la carencia de tierra de disponibilidad pública. En este contexto, la provincia realizó un esfuerzo para aportar fondos adicionales para la compra del suelo y la adquisición de suelo se resolvió a través de la oferta realizada por las empresas constructoras. Sin embargo, los resultados aquí presentados, en términos de la localización de esta modalidad de adquisición de suelo, son elocuentes de una configuración de la demanda pública ajustada al orden impuesto por el mercado de suelo. La operatoria PFCV-TPU fue la modalidad de adquisición de suelo que tuvo la mayor escala y el peor desempeño en la absorción de externalidades urbanas.

\subsubsection{Algunas consideraciones al interior de las fronteras municipales}

En el apartado anterior hicimos referencia al lugar ocupado en la estructura urbana a nivel regional o metropolitano por los barrios construidos por la política habitacional. En este apartado, se mostrará el resultado de dicho análisis en función de la posición relativa de los barrios de vivienda social en la estructura urbana municipal ${ }^{126}$.

En la figura 24 se vio que las viviendas construidas en nuevas localizaciones (PFEHTyT y PFCV) quedaron ubicadas en zonas de menor jerarquía urbana. Por ello, aquí se realiza un análisis particularizado de estos programas en función de la realidad urbana de cada municipio. Es decir, se analiza la posición media de los barrios de vivienda social en la estructura urbana de los municipios, y no en el conjunto del Conurbano Bonaerense (24 PGBA). Las preguntas que están en juego son, básicamente: ¿Hasta qué punto varía el acceso a determinadas condiciones de calidad urbana si se modifica la escala de análisis o la unidad de medida de la matriz de la estructura urbana ${ }^{127}$ ?; y, ¿Lograron los municipios que manifiestan tener cierta preocupación por la gestión del suelo tener un mejor desempeño en términos de la localización de los barrios de vivienda social?.

\footnotetext{
${ }^{126}$ La metodología utilizada para la confección de la matriz de la estructura urbana es la misma que la utilizada a nivel regional (ver anexo metodológico A2) pero con una reclasificación de las variables por deciles a nivel jurisdiccional.

${ }^{127}$ Desde el punto de vista metodológico, es discutible si el análisis locacional de los programas habitacionales aquí evaluados, deben ceñirse sólo a una contrastación con las condiciones de calidad urbana al interior de los límites municipales o debe atender al conjunto del aglomerado (24PGBA). Cualquier de estas entidades son susceptibles de ser utilizada como espacio de referencia estadístico y parecieran existir argumento a favor y en contra de cualquiera de dichas entidades jurisdiccionales. En relación a evaluar la localización en función de la entidad municipal, puede argumentares que es una decisión de gestión urbana que recae en la órbita municipal. También se puede sostener que dado que el barrio de vivienda social atenderá la demanda habitacional a escala municipal, las evaluación de las alternativas de localización residencial de sus habitantes deberían reducirse al mismo municipio. De igual modo, la asignación de los cupos de inversión parecen respetar criterios jurisdiccionales, no tendría sentido entonces compara la localización de la vivienda social con el mercado de localizaciones de otros municipios, si dicha inversión a priori se encuentra anclada territorialmente. Por otro lado, se podría argumentar que el fenómeno metropolitano no parece respetar jurisdicciones, que los procesos de movilidad residencial de los habitantes del aglomerado suelen tener una escala de carácter regional (aunque a veces respete cuencas municipales en función de las redes de oportunidad), y que las externalidades que hemos analizado tampoco respectan límites administrativos. Finalmente, la política que es objeto de análisis (el PFCV-TPU) ha surgido en respuesta a un problema que alcanza al conjunto del AMBA y la decisión de donde emplazar la vivienda social en dicha área ha sido de carácter provincial.
} 
En las jurisdicciones para los cuales se dispone información ${ }^{128}$ se evidencia que, a nivel municipal, la posición relativa del PFEH y el PFCV mejora, ascendiendo un peldaño en la jerarquía urbana (o, al menos, se concentra en el decil 3). En cambio, en la lectura regional (figura 26) la posición de los barrios de vivienda social de dichos programas tenía mayor participación en un decil con menores condiciones urbanas (decil 2). El análisis particular a nivel municipal muestra, entonces, un desplazamiento ascendente. Sin embargo, esto no sucede en una lectura desagregada de la modalidad TPU.

Fig. 26 Posición media de los barrios de vivienda social en nuevas localizaciones en la estructura urbana municipal, según PFCV y PEFEH (dato agregado) y modalidad TPU (desagregado).

\begin{tabular}{|c|c|c|c|c|c|c|c|c|c|c|c|c|c|}
\hline Decil & BER & FVA & ABR & ECH & EZE & LMT & MER & MRE & HUR & MAL & JCP & SFE & $\begin{array}{c}\text { Total, 12 } \\
\text { distritos }\end{array}$ \\
\hline 10 & & & & & & & & & & & & & Mejor \\
\hline 9 & & & & & & & & & & & & & \\
\hline 8 & & & & & & & & & & & & & \\
\hline 7 & & & & & & & & & & & & & \\
\hline 6 & & & & & & & & & & & & & \\
\hline 5 & & & & & & & & & 0 & 0 & & & \\
\hline 4 & & 0 & & & 0 & & & 0 & & & & & \\
\hline 3
\end{tabular}

Fuente: del Río y Duarte (2011) "La gestión del suelo y la distribución de la ciudad" En: Cravino (org) Construyento barrios. UNGS (en Prensa).

Por tanto, la escala de análisis incide en dichos resultados sólo cuando se consideran el conjunto de los barrios construidos por el PFCV y el PFEH, pero no cuando se analiza los

\footnotetext{
${ }^{128}$ A los efectos de la comparación, cabe aclarar que en algunos municipios se dispone de varios registros o barrios, mientras que en otros casos, como por ejemplo en Berazategui y Almirante Brown, sólo se analiza la localización del único barrio.
} 
barrios del PFCV-TPU de manera independiente. Es decir, cuando el espacio de referencia estadístico en el cual se analiza el efecto de la localización deja de referirse a los 24 partidos y pasa a considerar sólo el municipio en el cual se construyó el o los barrios, los resultados o la absorción relativa de externalidades urbanas mejora para el conjunto de los barrios construidos en nuevas localizaciones, pero no para el subconjunto de los barrios TPU.

En este sentido, es necesario realizar al menos tres comentarios: i) la lectura regional de una política habitacional de expansión urbana -con mayor participación en la segunda corona metropolitana que en la primera- incide, aunque sea mínimamente, en una sobrerepresentación de la posición periférica de la vivienda social ${ }^{129}$; ii) una mirada municipio por municipio muestra diferencias en las condiciones urbanas del suelo movilizado y/o de la capacidad de gestión para disponibilizarlo a nivel público, pero en el total agregando de los 12 distritos donde se desarrollan los programa analizados, la ubicación de la vivienda social sigue estando devaluada. En todos los partidos permanece constante la configuración de lo que anteriormente denominamos "territorios prohibidos" al momento de concebir la política habitacional (deciles 6 al 10); y, iii) la posición de los barrios pertenecientes a la modalidad TPU muestra mayor rigidez frente al cambio de escala.

Una segunda interpretación también es posible. Los municipios de Berazategui, Almirante Brown, Esteban Echeverría, La Matanza, Merlo y San Fernando muestran una peor localización de la vivienda social que los municipios de Florencio Varela, Ezeiza, Moreno, Hurlingham y Malvinas Argentinas. Al menos tres de estos últimos cinco pueden catalogarse como municipios con política activas de suelo. Simultáneamente, hay que recordar que, al interior de las realidades municipales, una misma posición relativa supone realidades distintas y deben ser analizadas cautelosamente.

En el caso de Malvinas Argentinas, dos de los barrios construidos estuvieron destinados a sectores ingresos medios o medios-bajos, y las características del entorno barrial parecen responder a esta premisa. En Hurlingham, por otro lado, la cesión de tierras del INTA Castelar en una zona residencial en consolidación, sumado a la proximidad a un corredor de escala metropolitana, explican en gran medida el resultado hallado. Los municipios de Ezeiza y Moreno, en cambio, adaptaron los programas habitacionales a lotes individuales y dispersos en distintas áreas de sus territorios, una estrategia apoyada en una política de suelo previa a la existencia de los programas habitacionales. En el caso de Moreno, el contraste es claro: la articulación del PFEH en lotes dispersos logró una mejor performance en la estructura de distribución de las externalidades urbanas municipales (decil 4), que la operatoria del PFCVTPU a través de la provisión de tierras por parte de las empresas constructoras (decil 1).

Por otra parte, la posición relativa de los barrios de vivienda social al interior de Esteban Echeverría es más desfavorable que la ubicación de los barrios al interior de Ezeiza, pero esto

\footnotetext{
${ }^{129}$ En la figura 26 se advierte que 11 de las 12 jurisdicciones analizadas pertenecen a la segunda corona metropolitana (con excepción de Hurlingham). De este modo, no es lo mismo identificar la posición media de los barrios en función de la estructura urbana de cada uno de estos municipios, que en relación al conjunto de los 12 distritos o en relación al conjunto de los 24 distritos.
} 
puede variar con el cambio de escala. De hecho, algunos de los barrios del primer municipio se encuentran mejor ubicados a nivel regional que los barrios del segundo municipio. Al mismo tiempo, debe tenerse en cuenta que la centralidad de Monte Grande tiene alcance hasta la jurisdicción de Ezeiza. Si consideramos, por último, la matriz de la estructura urbana de los 24 partidos del aglomerado, los barrios de ambos municipios se encuentran en la misma posición en la jerarquía metropolitana (decil 2).

En determinados municipios, ciertos barrios se emplazaron en zona clasificadas por el código de zonificación como rurales, aunque la incidencia ese tipo ubicación "formal" adquiere impactos distintos en uno y otro municipio. Florencio Varela y La Matanza, por ejemplo, son dos distritos con varios casos de esta naturaleza, pero la posición relativa global de los barrios en el caso de Florencio Varela muestra mejores resultados.

Son muchas las posibles consideraciones que podrían realizarse acerca de las variaciones municipales, pero éstas exceden el alcance de nuestro trabajo. Un estudio sobre este tema debería investigar dichas variaciones en profundidad, a efectos de indagar con mayor rigurosidad sobre el abordaje realizado por la propia administración local al momento de implementar los programas habitacionales, en relación a la forma en la fue problematizada la cuestión del suelo y en función de sus mediaciones al interior del entramado de la gestión urbana a escala municipal.

\subsection{Techo sí, ciudad no. La inserción urbana de la vivienda social}

En este capítulo hemos intentado poner de relieve cuál ha sido el "desempeño urbano" de la operatoria PFCV-TPU, dado que la misma representó una estrategia del Estado provincial al momento de facilitar la ejecución de los cupos de vivienda y resolver en simultáneo el problema del acceso al suelo en el Conurbano Bonaerense. El surgimiento de la "política federal de viviendas" produce una suerte de paradoja histórica para el urbanismo local, un volumen de intervenciones habitacionales prácticamente sin precedente colisionaron con el agotamiento del stock de suelo urbano disponible.

La modalidad de adquisición de suelo a cargo de las empresas constructoras, por medio de la oferta de tierra sujeta a la evaluación del IVBA, quedó presa de una oferta restringida, frente a la cual la pasividad del Estado no pudo hacer más que garantizar aspectos formales. En términos urbanos, esto significó el desarrollo de una política de vivienda que asimila el orden urbano existente y naturaliza la dinámica del mercado como el medio eficiente de asignación del recurso suelo.

En este sentido, hemos visto que históricamente la perspectiva productivista de la política de vivienda tuvo dificultades para incorporar la cuestión del suelo al diseño de la política habitacional. La reconstrucción de la arquitectura institucional del circuito administrativo del IVBA da cuenta en buena medida de este problema. 
En relación a la caracterización de la modalidad TPU como un mecanismo de adquisición de suelo de mercado, algunas de las particularidades que hemos observado pueden relativizar la forma típica de una transacción mercantilizada. Sin embargo, la comparación con otras formas de gestión de suelo y su posición relativa en la matriz de la estructura urbana confirmaron nuestras conjeturas iniciales. La modalidad más importante en cuanto a la cantidad de suelo adquirido, vía la intermediación del sector privado, fue la que tuvo el peor desempeño en la localización urbana.

En este sentido, en el capítulo 2, dijimos que, desde el punto de vista constructivo, la política de vivienda actual puede ser caracterizada como una política neodesarollista, pero la evidencia aquí recopilada parece indicar que las continuidades son más importantes que los cambios en materia de suelo. Podría decirse, entonces, que el enfoque desarrollista no presenta ninguna variante en este plano, o bien, que en materia de suelo la política actual continua asumiendo un enfoque neoliberal. Vale recordar que la provisión de suelo a cargo del promotor era una de las principales recomendaciones hechas por el Banco Mundial para la política de vivienda.

Por último, varios de los antecedentes marcan que el debate sobre la regulación de los mercados de suelo y las políticas de planeación urbana activas (que incorporen el componente de la vivienda social como un elemento constitutivo de las mismas) se encuentran en el centro del desarrollo de la política habitacional. Sin embargo, cabe advertir que esta modalidad de provisión de suelo que hemos analizado (TPU), en gran medida asociada a la primera etapa de implementación del PFCV, se ha difundidos de la provincia a los municipios. Es decir, en la segunda etapa del PFCV (Plurianual) la ejecución de las obras de vivienda quedó a cargo directo de los municipios, y éstos asumieron en gran medida un esquema de provisión de suelo a cargo del contratista.

De este modo, se plantea un nuevo interrogante acerca del devenir de la etapa de ejecución actual. Ya que, si bien los municipios tienen mayor control sobre la gestión de territorio, la lógica estructural de la política habitacional no ha variado y la relación de fuerzas del nuevo entramado dependerá en gran medida de los recorridos previos de la gestión urbana de los propios municipios. Como hemos visto, son pocos los casos en los que exista una lectura que trascienda el horizonte de la obra pública.

En suma, la asimilación por parte de la política de vivienda de un paradigma asociado a la obra pública, para el cual la vivienda no es más que un módulo de inversión independiente de su lugar de emplazamiento, nos lleva a plantear que frente a la tesis de las "casas voladoras", el "aterrizaje urbano" es inevitablemente "forzoso". Si recuperamos aquí la visión de algunos de los gestores de la política y el juego de las escalas, parece que no alcanza con que a nivel local se produzca una especialización (para seguir con la metáfora) en el diseño de "pistas de aterrizaje", sino que también es necesario dejar de concebir a la vivienda como un producto sin raíces urbanas, una concepción fuertemente arraigada en la lógica del financiamiento nacional de la política actual. 
Capítulo 4 


\section{Capitulo 4. El habitar y los efectos de lugar}

\section{Entre las trayectorias residenciales y las percepciones de los habitantes}

En este capítulo, se retoma la noción de lugar reconstruido -a través de la experiencia urbana de los habitantes- para complementarla o confrontarla con el concepto de lugar asignado a la vivienda social, del cual hemos dado cuenta en el capítulo anterior. El interrogante que nos guía, es: ¿cómo el lugar "asignado" a la vivienda social en el mercado de localización residencial intra-urbana, es reconstruido a través de las propias trayectorias residenciales de los habitantes y desde la experiencia del habitar los nuevos barrios vivienda social?

En este punto nos interesa reconstruir, por un lado, cómo el acontecimiento de la política habitacional es leído desde las trayectorias de los sujetos de modo de comprender la complejidad del proceso de movilidad residencial, más allá de la "satisfacción" (o no) producida por la nueva vivienda. Por otra parte, buscamos identificar qué efectos de lugar trae aparejada la residencia en los nuevos barrios de vivienda social. Para ello recurrimos al registro de la experiencia del habitar que, como señala Duhau y Giglia (2008), sitúa a la percepción del sujeto en el centro de las coordenadas espacio-temporales (revisar sección 1.3).

En la primera sección a partir de una serie de entrevistas en profundidad (realizadas en los años 2009 y 2010) nos introducimos en las historias de los adjudicatarios de vivienda social. Vale aclarar que los testimonios han sido seleccionados de manera azarosa a partir de los recorridos de campo y en base a la disponibilidad o predisposición del entrevistado pertenecientes a los barrios Santa Rosa (partido de Florencio Varela) y Malvinas (partido de Esteban Echeverría). Por otra parte, a partir de la identificación del lugar de residencia previo de los adjudicatarios de estos barrios, y otros adjudicatarios pertenecientes al barrio Favaloro (partido de José C Paz), se analiza la posición residencial de los mismos en la estructura urbana a efectos de analizar la localización más allá de la percepción de los sujetos. Por último, se identifica -en el marco de los altos niveles de satisfacción que los adjudicatarios expresanun proceso de valoración decreciente desde la vivienda a la zona en la que se inserta el barrio.

En la segunda sección, se intenta indagar a qué se debe este tipo de comportamiento perceptivo (la diferencia entre la valoración de la vivienda, el barrio y la zona), para lo cual se realiza un recorrido por la evaluación que los propios habitantes realizan de la política habitacional. Para ello se analizan 400 encuestas realizadas en el marco de una experiencia de trabajo más amplia del Equipo Infohabitat (ICO-UNGS) en los tres barrios antes mencionados. Las encuestas se realizaron en el año 2009 y el único criterio de selección utilizado fue que se trataran de barrios adjudicados (con mínimo un año de entrega) al momento de iniciar el trabajo de campo $^{130}$. Complementariamente se analizan las entrevistas grupales e individuales. El

\footnotetext{
${ }^{130}$ Es importante aclarar que la encuesta estuvo dirigida a barrios asociados a construcción de viviendas nuevas en nuevas localizaciones y la planificación del trabajo de campo se realizó en el año 2008, momento en que se produjo una paralización de la mayoría de las obras. Esto restringió el universo de selección. De allí que los barrios
} 
objetivo general de la sección, una vez caracterizada la población adjudicataria, es identificar los problemas emergentes en los nuevos barrios e identificar sus vínculos con la forma que adquiere la acción pública en materia de vivienda.

\subsection{Las trayectorias residenciales de los habitantes}

En esta sección, se presenta un conjunto de trayectorias habitacionales elaboradas a partir de los relatos de los habitantes de los nuevos barrios de vivienda social. La reconstrucción aquí propuesta no pretende dar cuenta de la "trazabilidad" habitacional en función de determinadas características socio-demográficas, o dicho de otro modo, considerando cuál debería ser la "población objetivo" de la vivienda social. Nuestro objetivo, más bien, es dar cuenta de cómo las decisiones residenciales (en el contexto restrictivo del mercado de tierra y vivienda) se articulan con las trayectorias socio-ocupacionales, las estrategias de las unidades domésticas y los ciclos vitales o afectivos de las personas. Estos recorridos dan lugar a diversas geografías personales de uso y apropiación de la ciudad, trama en la cual los sujetos construyen un conjunto de significados, representaciones o imaginarios acerca de su posición residencial y el resto del espacio urbano, permitiendo así una lectura de su lugar en la ciudad.

Las descripciones de las trayectorias que en el apartado siguiente se desarrollan se organizan en base a los siguientes interrogantes: i) quiénes son los habitantes de los barrios de viviendas sociales; ii) qué posición ocupan en el mercado de trabajo; iii) cómo resolvían el acceso al suelo y a la vivienda antes de que la política habitacional los transformara en adjudicatarios; iv) de qué modo accedieron al plan de viviendas; v) qué percepción tienen los habitantes de la vivienda, el barrio o la zona; vi) qué problemas identifican a partir del cambio de residencia. La justificación de este análisis reside en considerar que la revisión de estas preguntas puede brindar algunos elementos de reflexión al momento de pensar la política habitacional, la dinámica urbana general y el modo en que se desenvuelven las lógicas residenciales de los sectores populares.

Antes de introducirnos con mayor profundidad en las historias de los adjudicatarios, a modo de ejemplo los testimonios de cinco mujeres permiten poner rápidamente de relieve la importancia de las trayectorias al momento de pensar la política habitacional.

Surgen aquí diferentes aspectos del proceso de movilidad residencial, el acontecimiento de la mudanza al barrio de vivienda social y las formas de habitar el nuevo barrio. Mientras que para Mirta la adjudicación de la vivienda social significó un desarreglo de su estrategia de organización familiar que por momentos se vuelve insalvable hasta el punto de pensar en

seleccionados fueron los únicos que se habían adjudicado al momento de realizar la encuesta. Mientras que el barrio Santa Rosa y Malvinas fueron construidos en el marco del Programa Federal de Construcción de Viviendas (PFCV a través de la modalidad TPU), el barrio Favaloro se realizó a través del Programa Federal de Emergencia Habitacional (PFEH). Si bien, los primeros fueron construidos por empresas constructoras y el otro fue construido por cooperativas de trabajo, la tipología de la vivienda y del barrio no difiere, tampoco varían sustancialmente los problemas identificados ex post, por lo cual se los analizará de manera agregada. Además de estos tres barrios se había seleccionado el barrio Nine (partido de Moreno), pero por razones de seguridad no se pudo completar el trabajo de campo. 
abandonar la vivienda, para Silvia la vivienda significa un cambio positivo y ha resuelto un esquema de organización doméstica compatible con su actividad laboral y las demandas del barrio. Por otra parte, en el registro de Rosa y Susana tiene un peso importante la situación habitacional previa, aunque con matices diferentes. Mientras que para una, el acceso a la vivienda y su percepción actual del barrio está atravesada por la historia personal y su discapacidad; para la otra, el acceso a la nueva vivienda y su situación actual está fuertemente marcada por la impronta del antiguo barrio y los efectos exteriores del vecindario. Por último, Elena contrapone la tranquilidad de la casa propia a las penurias de pagar el alquiler, más vinculada al mundo del centro comercial del municipio, pone atención a la zona en la que se encuentra el barrio y a la ubicación al interior del barrio.

Mirta [38 años, nacida en Lomas de Zamora, secundario incompleto, desocupada] "volvería al barrio anterior" porque la mudanza al nuevo barrio implicó la desestructuración del arreglo familiar o la red en la cual se basaba su estrategia de reproducción. Antes, ella vivía en el barrio La Carolina (partido de Florencio Varela) en la casa de sus padres, quienes contaban hace tiempo con un inmueble prestado. Mirta es separada y madre de 5 hijos, los cuales tienen entre 15 y 3 años de edad. El inicio del ciclo lectivo significa para ella elegir entre salir a buscar trabajo o cuidar a sus hijos y llevarlos a la escuela. Durante el verano su hija mayor cuida a sus hermanos y ella puede realizar esporádicamente algunas changas. Su madre algunos días se queda a dormir y ayuda con los niños, pero no puede ayudarla todos los días porque es mayor y vive lejos. Mirta recibe el Plan Familia y depende económicamente del dinero que cada tanto le pasa el padre de los hijos. Anteriormente, trabajaba en galpones de estampillado. En ese tiempo, vivía con sus padres y era su madre la que se encargaba de los niños, de darles de comer y llevarlos a la escuela, mientras que ella salía a trabajar. El acceso a la vivienda estuvo mediado por el "delegado" de la sociedad de fomento.

En contraposición a esta historia, Silvia [32 años, nacida en Lanús, secundario incompleto, auxiliar escolar] también separada, ha resuelto la organización doméstica con la ayuda de otra persona, de modo compatible con su trabajo. Ella es madre de dos niños, de 7 y 5 años de edad, y trabaja (doble turno) de maestranza en dos establecimientos educativos distintos a los que concurren sus hijos. El tío de Silvia ha puesto un kiosco en el domicilio, esto le permite generar algún ingreso y, a su vez, cuidar a los niños. Él es quien se encarga de llevar a los chicos a la escuela y de darles de comer. Cuando los niños están en la casa, el pequeño comercio es lo suficientemente flexible como para permitirle atender la dinámica doméstica y ofrecer a través de la ventana del comedor del hogar amenidades varias. Ella está muy contenta con la casa, antes vivía en la localidad de 9 de Abril (partido de Esteban Echeverría) alquilando un pequeño departamento y le hubiese sido imposible acceder a algo "propio".

La historia de Rosa en cambio se encuentra atravesada, no sólo por las dificultades habitacionales sino también por problemas de salud. Rosa [40 años, nacida en Tucumán, primaria incompleta, discapacitada] es madre de 5 hijos, los 4 menores viven con ella, el mayor 
también vive en el barrio pero con su propia familia. A ella le faltan ambos riñones y es sometida periódicamente a tratamiento de diálisis, por su condición tiene la movilidad limitada y pasa la mayor parte del tiempo en el hogar, donde vende algunos productos de limpieza. Rosa trabajó toda la vida en el rubro de la limpieza hasta que se le declaró su enfermedad. Su esposo trabaja hace varios años como operario de frigorífico. Ellos se conocieron en la villa del ingenio azucarero donde ella nació y su marido chaqueño, trabajaba en la cosecha de la caña. Luego inmigraron al Gran Buenos Aires, donde vivieron de prestado en la casa de su hermano que vivía en un asentamiento en Esteban Echeverría. De allí se fueron a vivir y cuidar, dentro del mismo asentamiento, la casa de la parroquia evangélica porque eran demasiados en una misma casa. Más tarde se mudarían al barrio Malvinas.

En el caso de Susana [48 años, nacida en Monte Grande, secundario completo, telefonista de remisería] la valoración altamente positiva del nuevo barrio en el que vive se apoya fuertemente en la contraposición con el lugar de residencia previo. Susana está casada, es madre de dos hijas veinteañeras y recientemente abuela. El hogar está compuesto por ella y su marido, su madre, sus dos hijas y su nieto. Ella divide sus actividades entre la casa y su trabajo como telefonista en una remisería. Su esposo trabaja como chofer de camión, distribuye mercadería por distintos lugares del Conurbano. El hecho de que sus hijas terminaron los estudios secundarios y concurran a la Universidad Nacional de Lomas de Zamora constituye un orgullo para Susana. Para ella, la vivienda significó todo, ya que antes de mudarse al barrio vivían en un local comercial adaptado como vivienda en las inmediaciones de la estación de ferrocarril de Monte Grande. El lugar de residencia anterior se presentaba como problemático dadas las condiciones de hacinamiento y su ubicación en una zona "heavy" (adjetivo que utilizó para señalar la presencia de delincuentes) que restringía los accesos y egresos de la familia a la vivienda.

Para Elena [36 años, nació en Florencio Varela, secundaria completa, ama de casa] en cambio la vivienda y barrio actual no tienen nada de especial. Ella vive en "el fondo" del barrio Santa Rosa considera que la ubicación del barrio es peor que la de su barrio anterior. Pero por lo menos tiene la "tranquilidad de la casa es propia", para ella nada es pero que estar alquilando y sentir que uno ya no puede pagar más el alquiler. Antes de mudarse al barrio el grupo familiar de Elena alquilaba una pequeña casa en la localidad de Zeballos (partido de Florencio Varela), a la cual se habían ido a vivir tras hacerse insostenible la residencia en la casa de la familia de su hermano. Desde que nacieron sus dos hijos ella se dedicó la casa, antes trabajó en distintos locales comerciales. Su marido es empleado de comercio y trabaja en el centro de Florencio Varela.

En la sección 1.3 hemos puesto de relieve la importancia de confrontar la idea del lugar asignado a la vivienda social con la idea de lugar reconstruido por los propios habitantes. También hemos dicho que para poder indagar en la percepción de la política por parte de los adjudicatarios de la vivienda es necesario considerar sus trayectorias e inscribir dichas 
representaciones en un proceso de movilidad residencial más amplio. Los ejemplos antes presentados pretenden advertir algunos de estos aspectos, no obstante, es necesario introducirnos con más detalles en las trayectorias residenciales de los adjudicatarios y en su imbricación con la trayectoria laboral, para desde allí, analizar algunas de las visiones o imaginarios que se ponen en juego en los nuevos barrios de vivienda social y que constituyen en palabras de Bourdieu (1999) determinados efectos de lugar.

\subsubsection{Historias de "adjudicatarios" de la vivienda social}

A continuación se presentan el análisis de una serie de trayectorias laborales y residenciales, a partir de las cuales se intenta dar cuenta del proceso de movilidad residencial, de la configuración de sentidos que se tejen en dicho movimiento y del acontecer de la política habitacional en estas historias ${ }^{131}$.

\section{Nunca antes había sido propietario.}

José [61 años, nacido en Lomas de Zamora, realizó la educación primaria completa, hoy changuea como chofer y vende verduras] vivía a tan sólo cinco cuadras en un departamento alquilado en el barrio vecino al nuevo barrio. Toda su vida fue chofer de colectivo. Los últimos 14 años se dedicó a changuear para distintos propietarios de colectivos escolares. En la actualidad, vende frutas y verduras en la puerta de su casa hasta que comiencen las clases, momento en el cual arranca la demanda de trabajo. Él es padre de tres hijos, los cuales ya han formado familia. Desde hace mucho tiempo vive sólo con su segunda mujer, quien trabajó como administrativa de un centro médico hasta que se enfermó y fue jubilada por discapacidad. Como la mayoría de los habitantes del nuevo barrio creía que la vivienda era algo lejano, pero entiende que la situación de su mujer los ha favorecido porque no es común ver gente mayor en el barrio, aunque reconoce que hay muchos discapacitados.

"Nunca antes había sido propietario. Laburaba y alquilaba" [José, Barrio Malvinas de Esteban Echeverría, marzo de 2009]. Antes de mudarse al barrio, José alquilaba con su señora un departamento en la calle Vernet por 400 pesos por mes en la localidad de Malvinas (partido de Esteban Echeverría) a 5 cuadras de donde vive hoy, pero el alquiler ya se volvía pesado para la economía doméstica. José recuerda que las condiciones edilicias no eran las mejores y el barrio aún estaba en proceso de consolidación. De hecho, se sorprende porque el nuevo barrio tiene agua corriente y cloacas. Previamente al departamento de la calle Vernet, alquilaban en el mismo barrio otro departamento, ya que por su trabajo necesitaban estar cerca de Monte Grande. Con anterioridad ellos vivieron durante mucho tiempo en José León Suarez (partido de San Martín), lugar de donde es su segunda mujer. Entre 1990 y 1994, residieron en la ciudad de Usuahia (provincia de Tierra del Fuego). La hermana de su señora vivía allí y los había

\footnotetext{
${ }^{131}$ Los nombres utilizados para referenciar a cada uno de los entrevistados son de fantasía.
} 
tentado a probar suerte. Por entonces, él trabajaba de taxista, podían sostener el alquiler y ahorrar algo. Pero, en el año 1994, su mujer se enfermó de una hernia de esófago y decidieron volverse porque creyeron que en Buenos Aires la iban poder operar, aunque no fue así.

José se reconoce como "nacido y criado" en Lomas de Zamora, luego de hacer la colimba a fines de la década del sesenta en el Regimiento $N^{\circ} 10$ de Infantería de Montaña de Covunco (provincia de Neuquén), en el año 1971, regresó al Conurbano donde comenzó a trabajar como chofer para distintas líneas de colectivos y se casó con su primer mujer. En Lomas de Zamora tuvo a los 23 años a su primer hijo y a los 25 años al segundo. Dos años después en La Plata nació su tercera hija, en ese momento él tenía gente conocida en la línea 518 que lo hizo entrar a trabajar en la empresa. Vivía en el barrio Aeropuerto cerca de uno de los ramales del colectivo, donde también alquilaba. Después de un tiempo regresaron a Lomas de Zamora, el cambio de residencia era frecuente de acuerdo a sus posibilidades de trabajo. A mediados de los ochenta, cuando los hijos habían crecido él se separó de su primera mujer y al juntarse con su segunda mujer se fue a vivir a José León Suárez, partido de San Martín.

Sus tres hijos han formado familia. Su hijo mayor (38 años), vive con su familia en Aldo Bonzi (partido de La Matanza), realiza changas vendiendo mercadería a comercios minoristas, es propietario de tres máquinas de estampado de tela, las cuales alquilaba (aunque ahora las tiene en venta) y ha montado una pequeña verdulería en la puerta de la casa de José. Su segundo hijo (36 años) vive en la ciudad de Córdoba, hasta hace poco trabajaba como supervisor de la empresa Megatone, recientemente compró un vehículo para trabajar de fletero con la indemnización de su despido. Su hija menor (36 años) vive en Banfield (partido de Lomas de Zamora), es ama de casa y está casada con un policía. El mayor de los hijos es el más compinche, le da una mando a José, ya que al problema que representa la enfermedad de su mujer, se le sumaron sus propios problemas de salud y de trabajo. Ella está jubilada por discapacidad, ha sufrido una hernia de esófago, tiene un problema en un pulmón, perdió la vista y en el momento de la entrevista estaba internada temporalmente por una nueva descompensación. Él tampoco anda muy bien de salud, hace dos años tuvo un coma diabético y estuvo internado 20 días en el hospital Gandulfo de Lomas de Zamora. En la actualidad, declara no atender su salud, toma la medicación de vez en cuando y no respeta la dieta.

En este contexto, su hijo mayor vende verduras en la puerta de su casa para darle una mano. Su hijo compra verduras en el mercado y las envía en un flete a la casa de José. En algunos horarios él mismo atiende la pequeña verdulería montada en la vereda de la casa y en otros horarios su hijo se hace cargo. De esta manera logran un pequeño ingreso y el hijo intenta ayudarlo mientras espera que comiencen las clases y lo vuelvan a llamar a José los propietarios de los colectivos escolares.

Toda su vida José trabajo frente al volante, fue chofer de distintas líneas de colectivos, taxista, remisero, chofer de escolares... "A mi no me mandés a poner un ladrillo, nada. Vos dame un vehículo y te lo manejo" [ídem]. Su carta de presentación se mezcla con el inicio de su oficio. José se remonta a la época de la colimba, cuando fue chofer del "Teniente Coronel Viola, ese 
que después fue presidente" [ídem]. Por entonces, José era un soldado con algunos privilegios, de vez en cuando comía en el casino de oficiales, le compraban cigarrillos, los fines de semana solían salir del regimiento para viajar a la ciudad de Zapala. Cuando terminó el servicio militar obligatorio, tuvo la oportunidad de trabajar en el ejército nacional como dragoniante, pero prefirió regresar al Gran Buenos Aires, donde comenzó a trabajar como chofer de colectivos. Ejerció este oficio primero en la zona de Lomas de Zamora, y luego en La Plata. Durante el primer año se desempeñó como "pescador", es decir haciendo reemplazos o cubrirendo demandas adicionales. Este puesto requería disponibilidad para que lo citaran cualquier día, a cualquier hora. Con posterioridad, sin embargo, comenzó a trabajar en relación de dependencia y con horario más regulares. En el presente, José recuerda esos trabajos con cierta añoranza.

Luego de trabajar para la línea 518 de La Plata, consiguió trabajo en la empresa TALP.SA, también conocida como "La Costera", que realiza el recorrido entre La Plata y San Isidro por Ruta Nacional $N^{0}$ 4. Trabajo más de 20 años en esta empresa, también en relación de dependencia, hasta que renunció por cansancio de las tareas de chofer. Recuerda que, de haberse quedado allí, a los 55 años se podría haberse jubilado, mientras que ahora debe esperar hasta los 65 años para hacerlo. "Me retiré sólo. Un día agarre, dije no voy más y chau, renuncie. Me canse, antes se laburaba 14 horas, ahora se labura 7 horas 40, eh!!! Ha cambiado mucho... A parte los coches no frenaban, estaban los colectivos Beresford, esos que tenían la trompita chata.... Después estaban los Mercedes convencionales los que venían con trompita larga, venían con freno a piolín, frenabas y por ahí seguía de largo y por ahí tenías que romper la caja de velocidad para poder pararlo con 40 o 50 personas arriba, en la hora de laburo le metías 70 personas arriba. Y bueno luchas, te subía un pelotudo y se la agarraba con el que estaba ahí arriba del colectivo! [...] Peleas siempre, arriba de los colectivos peleas siempre, me peleé con un vigilante una vez, no sabía que era vigilante, después me mandó a encanar 24 horas, un cagón, viste..." [ídem.]

Al mudarse a Usuahia, trabajó como empleado de taxi durante 4 años. El movimiento del turismo favorecía la actividad, se trabajaba bien y, a veces, se cobrara en dólares. Sin embargo, la enfermedad de su mujer los hizo regresar nuevamente al Gran Buenos Aires en 1994. En ésta época no era tan fácil conseguir empleo, por lo que comenzó a trabajar para una agencia de remis con su Renault 12 particular. Más tarde, los gastos de la enfermedad de su mujer lo llevaron a vender el auto y comenzó a hacer "changas" como chofer de colectivos escolares. Desde entonces, él trabaja para varios propietarios de colectivos de manera alternativa, según la demanda existente. Normalmente, en época de clases, tiene trabajo diario de manera continua, trabajando de 8 de la mañana a 5 de la tarde y cobrando 50 pesos el día (1000 pesos mensuales aproximadamente). Con los viajes a los campos de deporte de los colegios privados o las excursiones de fin de semana a Luján o San Miguel del Monte alcanza los 1500 o 1800 pesos. En el verano el trabajo es escaso, aunque algunos fines de semana hace viajes al balneario de Punta Lara y sus patrones le pagan 110 pesos el día. 
"Yo soy un tipo que no tengo nada, me dedico al colectivo escolar. Yo fui toda la vida chofer, ahora ando con los colectivos escolares. En este momento está un poco todo medio parado, hasta que no arranquen las clases, no te llaman. Yo changueo, cuando me llaman voy, cuando no me llaman no voy. Hace 14 años que estoy con los escolares. Tuve coche remis, todo! Pero bue... Ahora hace como 14 años que ando así: changueando. Hay un tipo que tiene 5 colectivos pero te pagan en negro. Acá es así, no? y no tendría que ser así. Tendríamos que estar todos en blanco. Antes fui chofer de colectivo de línea, ahí tenía todo en blanco. Lo que pasa es que yo me fui antes... yo me podría haber jubilado a los 55, pero todavía estaban las máquinas esas de cortar boletos y te volvían loco. Ahora el que se queja que anda arriba de un colectivo, tienen caja automática, toca y salen... Me retiré solo, yo no me jubile todavía. Tengo 61 años, me faltan 4 años, ahora tengo que esperar 4 años para jubilarme. Un día agarre dije no voy más y chau, renuncie" [ídem.]

La condición laboral actual de chofer-changuero no es solidaria con los problemas de salud que tiene José. Después de trabajar varios años con uno de los propietarios de colectivos, logró cierta continuidad de trabajo. Sin embargo, cuando se descubrió que sufría un problema de diabetes, el patrón comenzó a darle menos trabajo y descontinuar sus viajes. En ese momento estuvo a punto iniciar un juicio laboral, pero las complicaciones del gremio y el temor a que ningún otro patrón le diera trabajo lo llevaron a no buscar un abogado, prefiriendo la posibilidad de seguir haciendo "changas" para otros propietarios.

El acceso a la vivienda estuvo condicionado en gran medida por la situación de salud de su mujer. Según José, no es común ver mucha gente mayor en el barrio, pero sí le dieron vivienda a muchos discapacitados. Varios conocidos se anotaron en el plan de viviendas antes que ellos, y muchos aún esperan en el listado del municipio sin ser adjudicatarios. En el año 2006, la localidad de Malvinas ya se había visto revolucionada por el aluvión de trabajadores en bicicletas, que cada mañana se dirigían a trabajar en la obra del plan de viviendas. El tránsito de camiones y materiales también era incesante. En el barrio vecino, barrio popular saturado de necesidades habitacionales, el comienzo de la obra generó expectativas en muchos vecinos. A José se le había declarado la diabetes recientemente, por lo que tenía problemas de trabajo, a la vez que los gastos en los medicamentos necesarios para tratar de la enfermedad de su mujer le dificultaban afrontar el pago del alquiler. Frente a esta situación, una conocida le dijo que se anotase en el plan de viviendas.

Él se reconoce bastante "quedado" para manejarse en ese sentido. Sin embargo, concurrió a la municipalidad y se anotó en el listado municipal. Aunque remarca que no tenía ningún tipo de expectativa, dos años después lo llamaron de la Dirección de Tierra del municipio para comunicarle que era adjudicatario de la vivienda y que al día siguiente se tenía que presentar en la municipalidad para recibir la carpeta con la documentación correspondiente. Él no lo podía creer, la sorpresa fue muy grata y resolvía un problema que desde mediados de los años noventa se le había vuelto cuesta arriba, dada la situación doméstica particular y su dificultad para obtener ingresos en un mercado de trabajo en plena transformación. 
La mudanza fue rápida, el municipio los intimó a tomar posesión al día siguiente de la adjudicación, dados los intentos de usurpación. "Esta puerta, vez como está, fue barreteada antes de que nosotros llegáramos, [el barrio] fue intrusado, 75 familia había [...] El día jueves nos dieron la carpeta y el día viernes nos dijeron, ahí en la plaza, que había que tomar ocupación enseguida, porque sino... no sabés como andaban revoleando. Yo ya tenía todo embalado en mi casa, no tengo muchos muebles, boludeces... A las 10 de la mañana abrieron un portón y vos tenías que tener la carpeta en la mano, buscabas la numeración de la casa, venía un tipo guiándote. Vos te tenías que quedar parado en el frente de la casa, al rato vino un tipo con un manojo de llaves, abrió la casa. Te dice: 'verifique si esta todo bien' y te pide la carpeta. La vivienda es como cualquiera, no tiene un carajo. Yo no pude alambrar porque ahora ando mal de laburo, sino ya hubiera alambrado" [ídem.]

Al indagar por la calidad edilicia de las viviendas, como la mayoría de los entrevistados, José considera que las viviendas son de buena calidad. Manifiesta su sorpresa porque disponen de agua corriente, cloacas y tiene instalación de gas (que está prevista para la conexión futura a la red). Pero, en paralelo, expresa diversos problemas vinculados con la calidad constructiva. En su caso, los primeros 15 días estuvo sin luz, porque a la instalación eléctrica le faltaba el cableado y la llave térmica. Al pedir explicaciones, le dijeron que el percance se debió a que su casa había sido una vivienda piloto construida como prototipo para ser evaluada por técnicos de nación y provincia. Pasados los dos meses de la mudanza, le comenzó a brotar agua a través del bajo mesada y del baño. Para su sorpresa, cuando la empresa constructora se hizo presente con la retro-excavadora y abrió un pozo, encontraron que al desagüe cloacal le faltaban dos metros y medio de caño para conectarse con la red.

En su condición de vecino de los barrios de alrededor al plan de viviendas, José recuerda que el proyecto no generó problemas ni oposición por parte de los vecinos. Al contrario, la transformación del terreno baldío benefició, según su opinión, a los barrios del entorno. El predio en el que se construyó el nuevo barrio era un viejo campo en el que hace mucho tiempo funcionaba un tambo mecánico. Un típico borde urbano, considerado por muchos de los habitantes de los barrios preexistentes como "la zona de atrás" o "el fondo". José señala que la obra movilizaba diariamente más de 1000 trabajadores, y éste movimiento le permitía intuir que algo bueno sucedía allí. En la actualidad se hacen muchos comentarios, los vecinos creen que se van a construir 2000 viviendas más, avanzando sobre la parte del predio que linda con la playa de logística del Correo Argentino y sobre la avenida Fair. En cierto sentido, la obra (su celeridad y su escala) irrumpe en un ámbito urbano relegado por el Estado y opera activando en el imaginario de los vecinos cierta idea de progreso.

Barrio adentro, José prefiere el perfil bajo. Exalta cierta preocupación por la privacidad, delimita el ámbito privado del hogar y prioriza los vínculos familiares. Su lema es "hacer la suya" como una estrategia para eludir la sociabilidad que se genera entrono al chisme barrial. Para él, esa es la clave de la buena relación entre los vecinos del barrio. "Yo no me meto con nadie: 'Buen día, buenas tardes". Yo me hablo con este, con este y con este. No tengo 
problema con ninguno. Vos hacés la tuya, yo la mía. Cada uno anda en la suya, por eso andan bien, no? Cada uno hace la suya, viste? Si vos no te metés en la casa del vecino, el vecino no se mete en tu casa. Yo no soy de ir a tomar mate con ninguno. Tomo mate en mi casa, con mi hijo" [ídem.]

La población del barrio es heterogénea. José considera que hay mucha gente con necesidad, pero también hay "gente de plata". Uno de sus indicios son los vehículos (la presencia de vehículos $4 \times 4$ en el barrio), pero también observa el hecho de que varias personas hayan alquilado los departamentos o envíen a sus hijos a escuelas privadas de Monte Grande o Canning. Esta atmósfera híbrida la explica sentenciando: "Esto es mucha política también" [Ídem.]. En el espacio social de barrio, el trabajo opera como principal criterio de distinción. Él remarca el papel que juega la condición laboral como ordenador de quién es quién en el barrio.

"Hay gente que tiene un buen laburo, hay gente que no tiene un buen laburo, hay gente que vive de un plan... Otro que tiene un laburo y tiene un recibo de sueldo. Veo descargar material en muchos lados. Si vos no tenés la guita, no comprás" [ídem.].

La forma de acceso a la vivienda también juega un rol importante en la clasificación de los residentes. La lectura social del proceso de adjudicación reconoce merecedores por necesidad ("gente que la precisa"), situaciones difusas ("gente que la tiene por tenerla") e infiltrados ("gente de plata"). Cabe desatacar aquí que las tres categorías que representan la legitimidad de la posesión trascienden, para el entrevistado, las fases de la asignación política, o la dinámica de mercantilización informal posterior a la adjudicación (o incluso de la ocupación, aún cuando esta práctica sea concebida en sentido peyorativo). Es decir, habiendo mediado cualquiera de estos tres procesos puede reconocerse una suerte de legitimidad social en la posesión.

Los principales conflictos que surgen del relato de José están vinculados a los aspectos planteados en el párrafo anterior y a la disputa por el acceso a los cupos. El barrio Malvinas sufrió varios intentos de toma u ocupación. Inicialmente, durante el proceso de construcción de las primeras etapas del barrio, una organización social realizó un acampe masivo en las inmediaciones del predio exigiendo ingresar al plan de viviendas. Avanzadas las obras, entregadas 5 de las 8 etapas del barrio, las viviendas aún en construcción fueron objeto de una ocupación. En esa ocasión la resolución del conflicto no fue negociada y medió el desalojo. "Había familias usurpando. Sabés la cana como anduvo laburando, sacando a la gente. Vino gendarmería a las 5 de la mañana los sacó a todos cagando. Helicóptero, un quilombo bárbaro. Los negros venían con carretilla trayendo las pocas porquerías. Arrancaban las puertas de los otros departamentos para taparse los departamentos de ellos. Había coches que se llevaban cabriada de fierro. Vino gendarmería y los sacó. Acá a la vuelta habían usurpado una casa, sacaron la gente de adentro con un regimiento. La habían agarrado piqueteros" [Ídem].

La administración municipal encargada de la selección de los adjudicatarios también fue objeto de cuestionamientos. A partir de una investigación periodística, el barrio fue conocido a nivel 
nacional y algunos de los funcionarios de la Dirección de Tierras del municipios de Esteban Echeverría fueron removidos de sus cargos por el nuevo intendente. Ello se debió a que la secretaria del área vendía las viviendas o "aseguraba" (mediante el cobro de un canon) el ingreso del interesado al listado de adjudicación. Luego de la presencia de la prensa en el barrio y de que el episodio cobrara difusión pública, los vecinos del barrio se encargaron de condenar socialmente a la imputada, quien residía en el barrio, mediante pintadas en la pared de su casa. Si bien en este caso podría encontrarse una explicación para los procesos de compra-venta o alquiler de las viviendas vinculado a un hecho de corrupción municipal, el proceso es más complejo y trasciende este tipo de prácticas. José sostiene que aunque las casas no se pueden vender, es común que la gente las venda o las alquile. Él mismo recibió una oferta por su casa.

"Vine yo a vivir y un tipo conocido, vino y me quiso poner la guita, me ofreció 55 lucas. Vino un tipo que la quería para hacer un local de la san p.., para poner un supermercado. Hace poquito vino y paró. Me ofrecía un departamento en Vernet, la segunda avenida después de Malvinas. Me daba para que me comprara un auto. Un Renault 9, para que yo laburaba. cuánto estará 12 lucas? Y, 4.000 pesos. Hoy me paró por allá, yo iba a comprar pan. A mí me hubiera venido bien. Porque yo agarro el vehículo y me voy a laburar de remis. Pero no, no, no... Pero él la tiene clara. Vino cuatro veces a verme [...] Un día yo estaba laburando y viene a hablar con la vieja [se refiere a su mujer], la vieja le pidió 65. Pero mirá comencemos a hacer número: 20 lucas vale el terreno, allá en Malvinas tenés que hablar de 30 lucas, 20 lucas vale el terreno, no vale 40 la casa? A mí me ofreció el departamento. Cuánto vale un departamento? 30 lucas? Yo no lo fui a ver, ni lo pienso ir a ver. 14 el auto y 4 lucas. Ya está. Todavía el pibe mío me dice: ‘Hacelo papá. Por lo menos te salvás con el auto, vas a laburar' Yo siempre tuve auto, el último un Renault 12 modelo 82 impecable, hace 6 años me vino la malaria y tuve que venderlo. Ya ahora, nunca más" [ídem.]

\section{Alquilábamos precariedad.}

Diego [27 años, nacido en Salta, terciario completo, trabajo como preceptor suplente y realiza changas] Antes de mudarse al barrio, vivía en Luis Guillón (partido de Esteban Echeverría), donde alquilaba un departamento con su pareja y la madre de su pareja. Él normalmente trabaja realizando suplencias como preceptor en las escuelas del partido de San Miguel, donde viven sus padres. Actualmente no tiene trabajo como celador escolar y se encuentra realizando una changa por dos semanas en la ciudad de Buenos Aires, en una empresa que realiza la mudanza del mobiliario del Teatro Colón. Su suegra [60 años, nacida en Uruguay, primaria incompleta, telefonista] es quien brinda un sostén de ingresos estables al hogar, ya que ella trabaja en blanco en una agencia de remis, donde se desempeña como telefonista. Su pareja [29 años, nacida en Lanús, primaria completa, ama de casa] es quien se dedica a las tareas del hogar y al cuidado de los niños.

La unidad doméstica está compuesta por 8 miembros. Diego y su pareja tienen 6 hijos, el hijo más grande tiene 8 años y los menores son mellizos nacidos hace menos de un año. La casa 
ya quedaba chica cuando eran 6 , por lo que siendo actualmente 8 personas, le gustaría realizar una ampliación, aunque los ingresos familiares no lo permiten y no sabe cuándo podrá hacerla. Ellos viven en uno de los dúplex de 44 metros cuadrados del barrio Malvinas. Consideran que el cambio de vivienda los favoreció.

Hasta el momento, están contentos con el barrio, aunque se quejan respecto la calidad de la vivienda: terminaciones, rajaduras, aberturas, etc. Entre el año 2001 y el 2008, vivieron en un departamento alquilado en Luis Guillón. Era una casa que el dueño subdividió e hizo cuatro departamentos tipo $\mathrm{PH}$, p0ero las condiciones no eran las mejores. La construcción era muy vieja, tenía problemas de humedad y se llovía. Alquilaban por 250 pesos, a los cuales se sumaban 50 pesos por mejoras (que nunca se concretaron). La mejor opción era irse. Antes del 2001 Diego vivía con su familia en el barrio Cuartel Segundo partido de San Miguel, al quedar embarazada su novia se mudó de allí a Luis Guillón.

Sin embargo, los vínculos con su familia en San Miguel son claves como fuente de acceso al trabajo. En la actualidad, después de estar desocupado algunos meses, Diego se encuentra realizando una "changa" en la ciudad de Buenos Aires para una empresa de fletes y mudanza. Para llegar al Teatro Colón, donde realiza este trabajo temporal, se toma 3 medios de transporte (colectivo-tren-subte), demorando una hora y media.

En el año 2008 estuvo trabajando como preceptor suplente en escuelas medias de San Miguel. Su madre trabaja en el sistema educativo y suele avisarle de las oportunidades de empleo. Para viajar de Luis Guillón a San Miguel, las peripecias del viaje eran mayores: "Uhhh... colectivo cruce Lomas, la Costera hasta Hurlingham y de ahí, depende del tiempo, a veces me bajaba en Morón y me tomaba el 303 o me iba a Hurlingham y me tomaba el tren hasta San Miguel. Tardaba 2 horas" [Diego, Barrio Malvinas de Esteban Echeverría, marzo de 2009]. Diego recuerda con pesadumbre el viaje ida y vuelta a San Miguel, todos los días (excepto un mes en cual tuvo más de una suplencia, una de las cuales era en el turno noche). En ese tiempo, él se quedaba a dormir en la casa de sus padres en San Miguel durante los días hábiles, ya que no hacía a tiempo de regresar a su casa por la noche y luego volver por la mañana al trabajo.

Para Diego, los períodos de desempleo suelen ser frecuentes, y se intercalan con las oportunidades de empleo. Previamente a su trabajo como preceptor, trabajó en una empresa de seguridad durante seis meses, a principios del 2008. La empresa de seguridad trabajaba como subcontratista para la cadena de supermercados СОTO, por lo que el régimen de trabajo era rotativo (tanto en el horario a cubrir, como en los lugares que debían ser custodiados). Recuerda como "lo pasearon" por todos lados. En ciudad de Buenos Aires trabajó en las sucursales de Villa Urquiza, Belgrano, Las Cañitas, Palermo. En el último tiempo pasó a trabajar en CОтО Tempreley, en el Partido de Lomas de Zamora. "El contrato establecía que yo no debía estar a más de 35 kilómetros. Cuando estaba en Luis Guillón por suerte la estación la tenía a 8 o 9 cuadras y después combinación de subte, pero ahí tenía 2 horas, 2 horas y media. Nunca más te digo... ojalá nunca necesiten mis hijos tanto, como para tener que volver 
a hacer... No, te la regalo. No, pero aparte es un desastre, te cambian las horas... laburás 16 horas por día.... [su pareja interrumpe:] laburaba 16 horas, llegaba se acostaba y capas que lo llamaban y decían: 'te pido por favor que venga porque me faltó uno...' [Diego reafirma:] Si, la necesidad te digo, ojalá que nunca más" [Ídem.].

Antes de trabajar en el rubro de la seguridad privada estuvo un tiempo desocupado. Entre 2005 y 2007, trabajó realizando suplencias como preceptor en las escuelas medias de San Miguel y Gran Bourg. Con anterioridad no tenía empleo.

En el año 2001, cuando se enteró de que sería padre, decidió mudarse con su pareja, que vivía con su madre. En ese tiempo, los padres de Diego ayudaban económicamente a la pareja, y su suegra era quien mantenía el hogar. En la actualidad se reproduce un esquema semejante, ya que su suegra es el principal sostén del hogar. Ella está en proceso de jubilarse y tiene un trabajo permanente, y Diego complementa los ingresos con empleos temporarios. El ingreso total del hogar es alrededor de 2000 pesos. Desde el año 2002 su suegra trabaja como telefonista en Luis Guillón, primero en una remisería, luego en otra. Con anterioridad a esto, trabajó por más de 22 años como empleada de limpieza para diferentes empresas.

La forma en la que su pareja se enteró del plan de viviendas fue a través de la madre de una amiga, quien recibió a través de la factura de la luz una cartilla de información municipal en 2005. En ese momento, ella se dirigió a la municipalidad y la anotaron en un "cuadernito". El trámite en la municipalidad fue engorroso. Las asistentes sociales no fueron a todas las casas. Cuando iban al municipio, no estaban los papeles o el personal no se encontraba. Ella se sorprendió al constatar que, si bien las viviendas eran para gente de bajos recursos, les pedían un recibo de sueldo mínimo de 1000 pesos o una certificación de ingreso extendida por un Juez de Paz para el caso de quienes trabajaban en negro. Un año más tarde, la inscribieron "como se debía" y le extendieron un comprobante.

En agosto de 2008, al volver de una visita a la casa de los padres de Diego en San Miguel, él y su pareja se encontraron con la sorpresa: la notificación de la adjudicación de la vivienda. Al día siguiente fueron a firmar todos los papeles al municipio, les entregaron la llave y ese día se mudaron. Diego afirma: “...nosotros ya desde el primer día nos quedamos [...] a nosotros nos entregaron las viviendas en $\mathbf{2 4}$ horas porque se les estaban metiendo... [se refiere a la tomas de casas]" [ídem.]. Al promediar la quinta etapa de entrega de viviendas, el barrio Malvinas sufrió una toma de viviendas aún en construcción organizada. La toma duro tres días, hasta que por la noche la policía realizó el desalojo.

En relación a la vivienda, Diego expresa "no poder quejarse". Para él existe una diferencia importante entre tener que pagar el alquiler y tener algo que "es propio". Sin embargo, respecto de la calidad de la vivienda, él expresaba: "Yo la veo mal, no sé si tiraron hilo o no, acá lo podés observar [...] La puerta de arriba no encajaba la cerradura, al colocar la puerta no midieron bien los espacios... y, esa puerta de ahí, tuve que llegar yo y reventar la cerradura por el tema de que no me dieron la llave de atrás... Estuvimos dos semanas entrando y saliendo por la ventana [...] Decían supuestamente que iban a venir con piso pero... A mi me queda 
la duda, porque en las primeras etapas tuvimos conocidos que les han entregado con piso, con calefón, con bajo mesada... Y, supuestamente, se dice que la cerámica de acá está y la tenés que ir a pedir a la municipalidad, como obra del intendente y te las dan. O sea, es todo variable. De cierto no hay nada. [...] El único problema que teníamos es que se corta el agua arriba y tenemos que esperar uno días para que vuelva. El problema es de presión, supuestamente la gente que no le subía el agua fue a quejarse a la municipalidad. Y la municipalidad dijo que teníamos que juntar firmas porque pusieron una sola bomba para la primera etapa" [ídem.]. Y a la lista se agregan: rajaduras, azulejos mal puestos, el cielo raso mal colocado, etc. Aunque por el momento es imposible cualquier modificación del dúplex, las ampliaciones ya están planteadas. Ellos sueñan con ampliar para delante, una división de la cocina-comedor mediante una barra, el garage por si el día de mañana es posible un coche, un piso más arriba del garage y la terraza.

En relación al barrio, y de la relación con los barrios vecinos, también surge un cosmos ambiguo entre un "adentro" y un "afuera" que se recrea contradictoriamente entre la tranquilidad declarada y los estigmas proyectados, o entre los faltantes y los activos de un barrio devaluado. La pareja de Diego comenta: "cuando vas fuera del barrio me miran, así, porque digo: 'me dieron la casita en el barrio tanto...' Ellos te miran, como diciendo: 'en ese barrio'. Pero nosotros, desde que vinimos acá la verdad re-tranquilo [Diego, apunta:] Después tenés la opinión de los remiseros que son de afuera del barrio, que te dicen: 'acá es la mejor parte del barrio', no es porque viva yo, pero atrás suele haber problema el sábado a la noche. Acá no escuchas nada el sábado o domingo a la noche, no tenés problemas, los chicos juegan, parece un pueblo, tenés un aire pueblerino donde todos los vecinos se conocen y se cuidan. Las primeras etapas... esas son las que comentan los remiseros, yo para ese lado nunca fui" [ídem.].

Esta cartografía barrial interna (que se configura a partir de nueve etapas de obra consecutivas y grupos de habitantes de barrios de origen distinto que fueron adjudicatarios en distintos períodos) no le impide a Diego sostener que entre los vecinos haya una buena relación. Él recuerda que se formó una asociación o grupo de vecinos para reclamar por el ingreso del colectivo al barrio (recientemente el intendente firmó el convenio con la empresa). Se realizó una reunión con la policía, se hizo un concurso para ponerle nombre a las calles y al barrio. Mientras tanto, esperan la construcción de la escuela, el jardín y la salita de primeros auxilios que prometió el intendente en el acto de inauguración.

Pero en este barrio no sólo la sociabilidad está "en obra". La construcción del espacio público y el reconocimiento urbano aún tienen un largo camino por recorrer. Los equipamientos son una de las materias pendientes, luego de tres años de finalizadas las primeras etapas del barrio. Al mudarse al barrio, las vacantes en las escuelas fue uno de los grandes problemas. Otra preocupación para Diego, que marca diferencialmente al barrio, es la cobertura de determinadas empresas de servicios urbanos (las empresas de cable de televisión y las telefónicas no entran al barrio). 
Como contraparte, la tranquilidad del barrio parece ser uno de los atributos destacados por él: "esto para ser un barrio nuevo, es bastante tranquilo. Los chicos tienen mucho espacio, pueden jugar enfrente, van y vienen y no hay problema. Vos te vas y el vecino de al lado te mira la casa. Los espacios públicos para la cantidad de gente que hay están bien, pero también hace falta, pero no creo que se pueda más tampoco. Tenemos una, dos, tres... cuatro plazas para 2 mil familias. Va a faltar un espacio para un club, se charlará, se hablará, yo lo creo necesario. Todavía no hay nada, sociedad de fomento, asociación civil, nada" [Ídem.]. En el caso de Diego, la apuesta al barrio esta hecha, "aunque falta, por ahora no se puede pedir más", pero el barrio es joven.

\section{No logro acostumbrarme al barrio.}

Cecilia [29 años, nacida en Santa Fé, primaria incompleta, ama de casa] antes de mudarse al barrio vivía en el barrio La Carolina (partido de Florencio Varela) donde alquilaba una vivienda. Desde que se mudó a la nueva vivienda ella sufre por no adaptarse al barrio. Cecilia es madre de cuatro hijos, pero en la casa viven de manera permanente su hijo menor, ella y su pareja actual. Cecilia se dedica al cuidado la casa y los niños, mientras que su pareja [29 años, nacido en Quilmes, primaria completa, empleado de seguridad] trabaja en una empresa que se encarga de la custodia del barrio San Jorge, un barrio de vivienda de interés social aún en construcción.

Si bien Cecilia ha desarrollado algunas actividades laborales fuera del ámbito doméstico, ella se ha dedicado principalmente al cuidado de los niños. El contexto de crisis la forzó entre el 2000 y el 2002 a buscar alguna alternativa de ingreso, por entonces trabajaba en casa de familia de la zona de Villa Aurora cuidando niños y realizaba de manera discontinua tareas como empleada doméstica por hora. Normalmente en la división de tareas del hogar ella se encargaba de la atención de la casa y los niños y su pareja trabajaba fuera de la casa. Un tiempo después se convirtió en "beneficiaria" del Plan Jefes y Jefas de Hogar. En la actualidad Cecilia y su nueva pareja repiten un esquema de organización familiar semejante, ella es "ama de casa", mientras que él trabaja fuera del hogar. Desde hace dos años su pareja trabaja en la empresa de seguridad privada Cadeco, custodiando de manera alternada una fábrica en la zona de la Rotonda de Alpargatas y un barrio de vivienda social, aún en construcción, en la zona de San Jorge. Anteriormente, él trabajó como albañil, remisero y policía. El ingreso aproximado del hogar son 1400 pesos y aparte de este ingreso, Cecilia recibe el Plan Más Vida destinado a la compra de alimentos.

Ella está particularmente preocupada por el trabajo de su pareja, quien trabaja como seguridad en el barrio San Jorge, un barrio de vivienda social en obra que ya tuvo varios intentos de ocupación. Es decir, la empresa de seguridad para la que él trabaja brinda allí el servicio de custodia a la empresa constructora. En relación al caso del barrio San Jorge, Cecilia se pregunta: por qué las casas una vez que están construidas no se entregan. En su opinión, el hecho de que las casas estén para entregar y no se entreguen, es lo que hace que la gente se 
impaciente. "La otra vez se armó un quilombo, porque la gente se quería meter. Tuvo que venir la policía, todo, un re-quilombo. Encima a la noche se quieren meter y es un despelote. Son dos vigiladores y un sereno. Dos por tres están a los tiros" [Cecilia, Barrio Santa de Florencio Varela, enero de 2009]. En la actualidad la obra del barrio San Jorge continúa demorada y la presión social está latente.

Hasta el año 1994, Cecilia vivió con su familia en Monteverde (partido de Florencio Varela), al quedar embarazada se mudó con su pareja. De los 14 a los 23 años, vivió en la casa de sus suegros en Villa Aurora (partido de Florencio Varela), lugar donde nacieron su segundo y tercer hijo. Tras separarse de su primera pareja, regresó en el año 2003 a la casa de su madre donde vivió transitoriamente durante dos meses. "No aguante más y me fui...", la reciente separación y la relación conflictiva con su madre la llevaron rápidamente a buscar otro lugar donde vivir. De allí, se mudó a Barrio El Parque (partido de Florencio Varela) con su hermano y su cuñada, donde estuvo compartiendo durante cinco años (2003-2007) el techo con sus parientes. Con el tiempo la falta de espacio se hizo notar, la familia de su hermano estaba en crecimiento, y al establecer una nueva relación, Cecilia y su nueva pareja decidieron alquilar una pequeña vivienda en el Barrio La Carolina, donde vivieron hasta que ella fue adjudicataria del plan de vivienda.

En el 2005, su cuñada (la mujer de su hermano) le había comentado a Cecilia que en el municipio estaban conformando el listado para el plan de viviendas y que podían ser hasta cinco personas máximo por vivienda. Por entonces, Cecilia estaba separada, sin trabajo y cobrando el plan de empleo. Junto con su cuñada y la madre de su cuñada, fue a anotarse a la Municipalidad. Llevó las partidas de nacimiento, los documentos de sus tres hijos y el suyo. Dos años y medio después, cuando prácticamente se había olvidado de la vivienda, recibió una llamada del municipio y la asistente social concurrió a su domicilio para tener una entrevista con ella, observar su situación habitacional y familiar y completar el papeleo y la documentación.

La presencia de la asistente social era un indicador fuerte, "su carpeta" y su situación tenían prioridad en el listado oficial, de hecho la asistente social le confirmó a Cecilia que ya era preadjudicataria de la vivienda. Sin embargo, ella seguía desconfiando: "Yo me había olvidado, digo es todo chamullo, todo política... No creía que me la iban a dar. Y después cuando me llamaron y me dijeron que me la iban a entregar, yo no lo podía creer que me la iban a dar... Yo no vine [al acto de inauguración]. Porque era como decir, todo chamullo, todo para llevar gente. Yo dije hasta que no esté adentro de la casa no les creo. No, yo no voy a ir a estar en el rayo del sol por ellos, para llevar gente, no... cuando yo esté adentro de la casa ahí lo voy a creer" [Ídem].

Desde que se mudó al barrio, Cecilia siente cierta insatisfacción en la que se combinan no sólo ciertas características urbanas o barriales, sino también otros motivos de índole personal: "A mi me gusta la casa, pero debe ser porque nunca estuve sola" [ídem]. La separación implicó para ella una serie de cambios, entre ellos ver a sus hijos con menor frecuencia y el alejamiento de 
la red de vínculos con la que había pasado la mitad de su vida. Posteriormente, retomó la frecuencia de contacto con sus familiares directos y sus hermanos la ayudaron. Pero desde que se mudó al barrio los ve menos. Ellos viven todos "del otro lado", su hermana vive en Plátanos (partido de Berazategui), su hermano en Villa Argüello, su otro hermano en Monteverde, al igual que su madre. Su marido trabaja con horarios alternados durante el día y la noche según los horarios que le marca la empresa. Cecilia pasa gran parte del día sola con su hijo menor, durante la semana sus hijos mayores viven con su padre, la familia (sus hermanos) está lejos y en el barrio le ha costado establecer nuevas relaciones.

Los tres hijos mayores viven de lunes a viernes con el padre en la casa de su ex-suegra y los fines de semana viven con ella. Según Cecilia, los chicos prefieren seguir viviendo con el papá porque no les gusta el barrio, no quieren cambiar de escuela y la mayoría de los amigos los tienen en Villa Aurora. "A ellos no le gusta el barrio, están acostumbrados allá, tienen su amistades, su colegio... Tengo el nene de 15 años que no quiere saber nada con venir. Me viene a ver un ratito y ya. Ni hablar de venir a quedarse, cambiar de colegio. No hay caso. Cuando son chiquitos los manejás, pero cuando son grandes es muy difícil, muy difícil" [ídem]. Esta situación está atravesada por la complejidad de las relaciones familiares o doméstica y además, se le suman las dificultades materiales. Su hermana le recuerda que si tuviera que llevar a los chicos a la escuela desde este, el nuevo barrio (Santa Rosa), al otro barrio (Villa Aurora), tendría que levantarse a las cuatro de la mañana.

Por lo general, Cecilia no sale de la casa, excepto al patio para colgar la ropa o tomar mate con la chica de al lado. Sólo se relaciona con la vecina de la casa lindante, no se trata con nadie más. Si sale de la casa normalmente es para salir del barrio. "Ya van dos años y no me puedo adaptar... debe ser que no estoy acostumbrada a esta zona [...] a mi me gusta la casa, pero debe ser porque nunca estuve sola. Porque acá casi no me hablo con nadie. Estoy todo el tiempo acá. Yo no soy de salir [...] Las casas son relindas, pero la gente... no es que me las doy de ohhh! Ni nariz parada, ni nada, porque yo me he criado en barrios peores. Pero digamos: éste es como un rejuntadero de todos los barrios de Bosque, de Villa Aurora, de La Sirena, de Solano, de La Carolina, de Parque... es todo un rejuntadero, digamos. Tenés diferentes tipo de personas, desde trabajadores hasta..." [ídem].

Cecilia se anotó junto con su cuñada y la madre de su cuñada, quienes le informaron de la existencia del plan de viviendas. Ella fue la primera a quién le entregaron la casa, la madre de su cuñada ya es pre-adjudicataria, mientras que su cuñada, aún continúa en lista de espera. Para su familia, Cecilia es una "privilegiada", debería estar "feliz" porque tiene una casa propia. Su hermana vive con su esposo en una casita que se construyó en el mismo terreno que sus suegros, quienes viven en otro barrio de vivienda social en la zona de Plátanos. Ella recuerda que la casita de su suegra, a diferencia de la casa de Cecilia, "fue pelada" le faltaban las terminaciones: contrapiso, revoque grueso y fino, instalación eléctrica, etc. Otro de los hermanos de Cecilia vive con toda su familia (5 miembros) en una piecita. En esta 
configuración de realidades habitacionales se construye la idea de "privilegio" que los familiares proyectan sobre Cecilia.

La mudanza implicó varios cambios en múltiples aspectos de la vida urbana, tanto en lo referido a la movilidad, la salud, la educación, como el consumo, entre otros. Para realizar las compras diarias Cecilia prefiere ir al barrio vecino, a unas quince cuadras, porque los comercios de barrio son más caros. "Acá te arrancan la cabeza. El supermercadito que está acá, a cinco cuadras, te arranca la cabeza, te cobra el doble de lo que vale..." [ídem]. Con la escuela vecina y la salita también tuvieron problemas porque los "discriminaban". Ella dejó de ir a la salita cercana, luego de llevar a su hijo recién nacido a vacunar y que le contestaran que no los atenderían porque en la partida de nacimiento figuraba que su hijo había nacido en una clínica privada. En relación al servicio de transporte, Cecilia cuenta que no alcanzan los colectivos para la cantidad de gente que hay en el barrio: "Viajás peor que los camiones de hacienda. Ahora no es nada, pero cuando empiecen las clases es un caos" [Ídem]. Otro problema son los horarios, después de las 22, 23 horas, no hay más transporte, no se puede salir, ni entrar al barrio, un remis hasta el centro cuesta aproximadamente 25 pesos, un monto inaccesible para la gran mayoría de las familias que viven en el barrio.

Aunque no le gusta el barrio, ella está conforme con la casa. Valora la vivienda en función de la autonomía residencial que implicó para ella, cuando se le preguntó: qué opinión tenía de la vivienda en relación a su casa anterior. Ella respondió: "Es mejor, una: porque es mía. No estoy alquilando y no estoy en la casa de nadie" [ídem]. En relación a la calidad de la casa, las representaciones se encuentran mixturadas, existe una contención de aspiraciones o cierta austeridad en la pretensiones de lo que podría esperarse de una vivienda social y la observación de problemas recurrentes: “...al menos hasta ahora no se me cayó nada, ningún techo, ninguna pared. Tiene sus cositas, sus pequeñas cositas [...] el otro día me llovió. Depende de cómo llueva, porque por ahí no goteaba y me empezó a gotear el otro día que Ilovió. Las paredes están medias rajadas [...] lo único que no me gusta es, que de una casa a la otra, nos divide una pared, se escucha todo... con esa misma pared, hicieron la casa de al lado. Es lo único que no me gusta, porque se escucha todo. Si te estás matando con tu marido te escuchan todos los vecinos. Si los vecinos se están matando vos los escuchas, eso es lo feo" [ídem].

Cecilia no logra adaptarse al barrio, no se siente parte pero tampoco quiere "dárselas de nada". Sin embargo, a lo largo de toda la entrevista, se pone en juego una suerte "de afuera" que se vuelve lejano y "un adentro" que no termina de ser asimilado, es como si el barrio se transformara una región del espacio social en la que Cecilia se encuentra atrapada: "las casas son relindas, pero la gente...". De allí, esta estrategia de aislarse, pasar gran parte del día dentro de la casa y no relacionarse con sus vecinos. Sus gustos, la privacidad y las normas mínimas de comportamiento parecen ser atributos difíciles de compartir con el resto de los vecinos: “...la música que te ponen... que molestan a los que trabajan... te invaden, al no tener cerco, vos estás acá, y pasan, como si fuera pancho por su casa..." [ídem]. 
La dificultad para mimetizarse con el entorno se transforma en una constante, cuando volvimos a indagar por qué no le gustaba el barrio, Cecilia respondió: "No, ya va a hacer dos años y no..." [su hermana, interrumpe:] "yo vivía en Avellaneda, de Avellaneda me fui a Plátanos, el fin del mundo para mi... es hasta que te adaptás, nadie conocía la estación Plátanos... pero es hasta que te adaptás, entonces te adaptás y listo ya está, es como toda casa nueva. Te adaptás..." [Cecilia, insiste:] "debe ser que no estoy acostumbrada a esta zona..." [su hermana, sentencia:] "pero gente así hay en todos lados, ni en los barrios privados ahora están seguros" [Ídem]. A Cecilia su propia historia parece incomodarle, como si estuviera desencajada en un sitio atravesado contradictoriamente por la necesidad, el privilegio, el desarraigo y la inmovilidad.

\section{De villero a adjudicatario.}

Armando [30 años, nacido en Florencio Varela, primaria completa, desocupado, realiza venta ambulante de verduras] antes de vivir en el Santa Rosa vivía en la "villita" de Bosques Centro en Ricardo Rojas (partido de Florencio Varela) con sus suegros. El relato de Armando resulta interesante por la modalidad de acceso al plan de vivienda. Su hermana que vivía en un barrio de vivienda social con etapas en proceso de ejecución (o sin terminar), le comentó a él y a su cuñado que "había casas sin terminar, ahí hace tiempo...", entonces ellos decidieron "usurpar". Luego de una semana de ocupación, en el contexto del desalojo policial, el comisario se encargó de darles una solución habitacional gestionando su inclusión en la lista de beneficiarios del barrio Santa Rosa. "Vino el policía me habló bien, me dijo que él no era falso que me iba a conseguir una casita y yo le creí [...] fue todo por el comisario, gracias a dios yo confié en él, lo que pasa es que llegó un momento que estaba desesperado y yo no aguantaba más..." [Armando, Barrio Santa Rosa de Florencio Varela, enero de 2009].

En la actualidad, Armando vive en el barrio Santa Rosa con su mujer [29 años, nacida en la provincia de Chaco, primaria incompleta, ama de casa y cobra el $\mathrm{PJH}$ ] y sus 4 hijos, la mayor de 12 años y el menor de 1 año. En el comedor de la vivienda funciona una pequeña verdulería que contribuye al ingreso del hogar. Hace un mes y medio, desde que se quedó desocupado, Armando se levanta a las 4 de la mañana, se toma el micro y recorre varios kilómetros para ir a comprar verdura al Mercado de Frutas y Verduras de Florencio Varela. Luego regresa con un flete a su casa con la mercadería para reponer los faltantes y de allí realiza distintos circuitos como vendedor ambulante. Para ello, prepara un "linga" en la que carga 40 bolsitas de verdura de cada lado. Y se dirige en micro a la zona de Bosques, Claipole y Marmol donde recorre a pie los barrios para vender verdura. Otra zona que suele frecuentar para trabajar, sin necesidad de utilizar el transporte público, es el barrio San Jorge aledaño a su barrio actual.

Según su visión estratégica, como la gente del barrio es humilde, "verdura es lo que más consume". Cuando Armando está en el hogar trabaja la verdulería, mientras su mujer atiende a los niños. Si él no se encuentra presente, o sale a trabajar de manera ambulante, su mujer atiende la venta. Esto les permite una estrategia flexible de obtención de ingresos, donde la 
casa funciona, a la vez, como lugar de depósito y de expendio de mercadería. La inversión en la compra mayorista y el flete se amortiza por ambos canales de comercialización. En el barrio, la atención es mixta y en horario extendido, mientras que la venta ambulante es extra-barrial y de horario reducido. La frecuencia de abastecimiento depende de las ventas y lo perecedero de los productos, a su vez, la dieta de la familia también se ajusta a este último factor.

Desde que quedó desocupado Armando trabaja en la calle cómo vendedor ambulante o realizando "changas". Antes, había trabajado en negro durante 2 años (de los 28 a los 30 años) en una empresa de zanjeo que realizaba obras en los partidos de Lanús y Florencio Varela, allí se quedó sin trabajo por discutir con el capataz. De los 18 a los 27 años, tuvo un empleo "en blanco" en una empresa harinera en la ciudad de La Plata. Durante 9 años, viajó de Florencio Varela a La Plata para realizar las tareas de distribución, carga y descarga de harina por la zona sur del Conurbano (en los partidos de Berazategui, Florencio Varela, Quilmes, entre otros). En el año 2005 se enfermó y se ausentó del trabajo. Al momento de reincorporarse, lo dieron por despedido, desde entonces se encuentra en juicio laboral con la empresa Campodónico. En la etapa previa a este período (de los 7 a los 17 años), no tenía empleo o trabajaba en la calle rebuscándoselas de diferentes maneras.

Armando es oriundo de Florencio Varela, de Ricardo Rojas, lugar donde pasó toda su infancia. Hasta los 7 años vivió con su padre en una casa prestada. Luego por problemas familiares vivió "en la calle" hasta los 14 años cuando conoció a su mujer y se fue a vivir con ella a la villa. En un primer momento, armaron una casilla atrás de la casa de sus suegros. Tiempo después, Armando tuvo una pelea con el padre de su pareja y decidió abandonar el fondo de la casa de sus suegros. En ese momento ocupó un terreno fiscal dentro de la misma villa y junto con su mujer comenzaron a construir progresivamente su "casita". Luego de un tiempo, distintos episodios y situaciones de pareja hicieron que Armando se separara de su mujer y abandonara su casa para irse a vivir a la vivienda de su hermana. La historia residencial y familiar de Armando fue muy cambiante, a la separación le sigue una etapa en la cual él vuelve a juntarse con su mujer. Pero, por entonces, debieron alquilar temporalmente, ya que su mujer había vendido la "casita" de la villa por recomendación de su madre y se encontraba viviendo nuevamente con sus padres.

Éste es un punto de inflexión en la vida de Armando, ya que a la dificultades de empleo se le suma la pérdida de su único capital material. "Cuando vine, mi finada suegra le hizo vender la casa a ella, otra vez no teníamos nada. Así que volver a empezar... la casa ya la habían vendido. Así que arrancar de cero y ahí... que alquilar, que esto, que lo otro, que hacer una casita en la casa de mi cuñado, que en la casa de mi hermana. Pero no es lo mismo" [ídem]. En el año 2005, alquilaron por unos meses una casita, pero Armando se quedó sin trabajo y no podían afrontar el alquiler. Frente a este escenario, la desesperación y el restringido horizonte de opciones habitacionales, él decidió ocupar una vivienda en construcción en el barrio de vivienda social en el cual su hermana había sido adjudicataria. Es decir, uno de los barrios de la localidad de Zeballos que contaba con una parte de viviendas entregadas, donde residía su 
hermana, y otras en etapa de ejecución, donde había comenzado lentamente un proceso de ocupación.

Según Armando, la posibilidad de ocupar una vivienda surgió en una visita al barrio de su hermana y la información brindada por ella: “...un día la fuimos a visitar y nosotros no teníamos casa, estábamos alquilando una casita y la teníamos que dejar [...] mi hermana me dijo: esa casa está ahí hace 10 meses, vino la gente y no la quería... había como 30 casas desocupadas en ese barrio y se iba metiendo gente, iban usurpando. Y como estaba mi hermana ahí, agarre fui y me metí. Las casas estaban deshabitadas, no tenían puerta, no tenían ventana, nada. Lo único que tenían era las paredes, techo, luz no tenía, no tenía los cables, nada. Agarre fui y me metí, puse un par de frazadas en las ventanas, unas maderas en las puertas y me quedé ahí [...] ya había como 30 familias que habían usurpado" [ídem]. Al momento del desalojo, la negociación con la policía y especialmente la gestión del comisario al interior de ejecutivo municipal, les permitió acceder a la lista de beneficiarios de viviendas del municipio.

En septiembre de 2005, la esposa de Armando fue preadjudicataria del plan de viviendas y casi dos años después se mudaron al barrio. Mientas tanto, el cuñado de Armando les prestó una piecita en su casa, es decir, luego del desalojo se refugiaron en la casa de sus familiares. Durante dos meses la familia vivió en un piecita con baño externo. Luego lograron construir atrás de la casa de su cuñado, en el mismo terreno, una casilla de cartón y chapa donde vivieron hasta que se mudaron al nuevo barrio de vivienda social. El barrio Santa Rosa se inauguró el 12 de julio del 2007, Armando y su familia se mudaron al barrio en la primera tanda de la entrega, al día siguiente del acto de inauguración presidencial.

Inicialmente, el barrio estaba cercado y con custodia para garantizar la seguridad de las etapas de obra aún en ejecución, por lo cual los vecinos del barrio debían registrar los egresos e ingresos. "El barrio estaba todo alambrado, había policía, había guardia las 24 hs, en las puntas todo vigilancia. Digamos a lo primero parecía una cárcel, vos pasabas y te pedían nombre, apellido, manzana, número de casa y tenías que saber el nombre, el titular, todo. O si no, no te dejaban pasar. Y después cuando vos te ibas a trabajar te preguntaban a dónde ibas, a qué hora volvías. Parecía un "country", yo le decía: para gil vos quién sos! Qué te crees que estoy preso yo!" [ídem].

A un año y medio de llegado al barrio, más allá de los problemas de humedad, goteras o rajaduras, Armando manifiesta estar muy conforme con la vivienda. Ahora ellos tienen baño adentro y dos piezas, una para los niños y otra para el matrimonio. Incluso se puede inferir de sus palabras que en el barrio continúa dándose un proceso de movilidad residencial. Proceso que por otra parte no sólo está asociado a limitaciones de la adjudicación (es decir, entrega de viviendas a gente que no la necesita), sino también a algunas cualidades que adquieren las viviendas en el campo del hábitat popular que sobre ellas se proyecte cierta demanda. "Acá a la vuelta vendieron una [casa] en 15.000 pesos. O la alquilan y se van [...] pero acá la gente paga por tener una casa machimbrada, revocada, con baño. Vos fijate el tamaño 
del baño... con los problemas de viviendas que hay, vos pensá que hay terrenos con 40 5 casas y hay casas con 4 o 5 familias" [ídem].

En otro plano, el mismo Armando reconoce que el barrio no le gusta. En el barrio anterior lo conocían todos y tenía a dos cuadras la escuela, a tres cuadras la estación y a una cuadra el colectivo. Hoy los niños van a la escuela que se ubica sobre la ruta provincial № 53 (a treinta cuadras), porque cuando se mudaron las escuelas de la zona no tenían vacantes. Algo semejante les sucedió con el servicio de salud, como la salita que se encuentra a dos cuadras del barrio casi no los atiende, ellos concurren al centro de Florencio Varela o a la salita de Bosques (su barrio anterior). Por otra parte, los dos niños menores practican fútbol como actividad recreativa en un club del barrio las Coloradas, que se encuentra más distante que la escuela.

La relación entre los vecinos y los problemas del barrio, según Armando, son normales "como en todo barrio". A excepción de sus dos cuñados que viven en el Barrio Santa Rosa, sus familiares y amistades se encuentran en Bosques. En general, los desplazamientos de los miembros del hogar se restringen a las actividades antes mencionadas (trabajo ambulante, educación de los niños, deporte infantil, acceso al sistema público de salud y visita de familiares). Las compras diarias las realizan en la zona aledaña del barrio y a pie, con excepción de algunos consumos mayores que los realizan en el centro de Florencio Varela, o en la avenida Sarmiento para lo cual utilizan el transporte público.

\section{A través del cupo UOCRA.}

María [21 años, nacida en Lomas de Zamora, completó los estudios de la EGB y es ama de casa] se dedica al cuidado de los niños y de la casa. El hogar está compuesto por ella, que está embarazada, sus dos hijas y su marido. Él [24 años, nacido en Lomas de Zamora, educación primaria completa, obrero de la construcción] trabaja para una empresa constructora y se dedica a la colocación de planchas de yeso, el ingreso actual del hogar son 1800 pesos mensuales. Si bien ellos no residían en el municipio de Esteban Echeverría, el acceso al plan de viviendas fue posible a través de la UOCRA, sindicato al cual está afiliado su marido. Antes de mudarse al barrio, María y su pareja vivían en la casa de su suegra en Burzaco (partido de Almirante Brown), en cuyo lote había comenzado un proceso de auto-construcción para suplir sus necesidades habitacionales.

El hogar está compuesto por María y su "marido"132, son una pareja joven con dos niñas de 5 y 3 años y esperan a otra niña que viene en camino. Ella concluyó la educación general básica (EGB) hasta noveno grado pero no pudo continuar estudiando. En el 2003, a los 15 años, quedó embarazada y abandonó la escuela. Él tenía 18 años y por entonces ya trabajaba de auxiliar en una carpintería. Al nacer la beba, ambos se fueron a vivir a la casa de la familia de él (en Burzaco). En un primer momento, este nuevo núcleo familiar se anexaba al núcleo

\footnotetext{
${ }^{132}$ Aunque formalmente no han realizado los trámites de matrimonio ella se refiere a él de ese modo.
} 
familiar preexistente y compartían la vivienda. Los escasos ingresos les impedían afrontar cualquier otra solución habitacional.

Al cabo de un año, la situación se volvió insostenible. Ella recuerda que el hecho de compartir la vivienda con los hermanos de su pareja y su suegra se tornaba complicado. La falta de privacidad de la pareja, la condición de "prestados", el no disponer de su propio espacio hizo que la relación se tensara. Su madre, por otra parte, quería que ella retornara a su casa en Adrogué. Ella que "era muy joven y le costaba asumir la maternidad", decidió regresar. Al poco tiempo, su marido había conseguido un nuevo empleo y mejorado su salario. Él ingresó a trabajar en una empresa constructora "en blanco" y se fue formando en el nuevo oficio, hoy es "durcklero"133. La estabilidad de ingreso y el contacto con el gremio le permitió hacerse de los saberes básicos para afrontar una pequeña obra. Así surgió el proyecto de autoconstrucción de una pequeña vivienda en el fondo de la casa la suegra de María. Una vez que este proyecto se tornó medianamente habitable ella se mudo nuevamente con su pareja a Burzaco.

"Vivía en la casa de mi mamá y después a lo de mi suegra. Después volví a lo de mi mamá y después otra vez a lo de mi suegra. Así fue. Cuando me peleé volví a mi casa y después volví a lo de mi suegra y ahí fue cuando hice la casa atrás. Porque yo vivía adentro de la casa de mi suegra. $Y$ el problema era eso. Era muy feo vivir todos juntos. Me volví a mi casa, hasta que mi marido me hizo algo y volví. Mi suegra no era "hincha", tengo muchos cuñados y es feo... Mi nena y yo... Es incómodo. No daba..." [María, Barrio Malvinas de Esteban Echeverría, julio de 2009].

En el 2006, luego de un año de vivir con su madre y sus hermanos, cuando su pareja concluyó la obra, una pequeña construcción en el fondo de la casa de su suegra, ella regresó a vivir con él. El humilde monoambiente compuesto por una pieza, un baño y una pequeña cocinita integrada, le permitió a la pareja construir un espacio doméstico, íntimo, privado, y sobrellevar mejor la relación intra e interfamiliar. "En mi casa, yo tenía que vivir adentro de la casa de mi mamá..." [Ídem.] El hecho de disponer de un "lugar propio", surge como un acontecimiento que consolida la unidad doméstica y coincide con el momento en el que María asume el rol como gestora de hogar. Ella nunca trabajó fuera de la casa. Si bien, existía claramente una división de tareas en la pareja, María asume claramente su papel de ama de casa, una vez que logra ejercer soberanía sobre un espacio reconocido como autónomo (en el cual administra la forma de uso y el derecho de regular el ingreso de los otros).

Pero conquistada la privacidad asechaba el hacinamiento. Por eso de no mediar el plan de viviendas en este proceso, el proyecto de la pareja era en "un futuro" seguir ampliando su casita, la familia crecía -ya había nacido la segunda niña- y el espacio se volvía nuevamente escaso. En ese contexto su marido, que es afiliado a la Unión Obreros de la Construcción de la República Argentina (UOCRA) y que trabajaba (aún lo sigue haciendo) en la construcción del barrio en el que hoy viven, se anotó en la lista confeccionada por el sindicato para el sorteo de

\footnotetext{
${ }^{133}$ Denominación utilizada para nombrar a quién se dedica a la colocación de placas industriales de yeso, refiere al nombre comercial de una marca registrada.
} 
un cupo de viviendas que el gremio negoció con la empresa y el Estado a contra entrega de cada una de las etapas de la construcción del barrio. Tiempo después la suerte estuvo de su lado y los llamaron para comunicarle que salió elegido en el sorteo de los diez lugares. Ella tuvo que llevar el recibo de sueldo de él y la documentación de los niños al municipio para concluir el trámite.

En diciembre de 2008, se mudaron al barrio con gran expectativa. Aunque cree que la ubicación del barrio es buena, "allá estaba en una zona más céntrica". El efecto temporal de la mudanza aún está presente y todavía se está "acostumbrando" al nuevo lugar de residencia. Para hacer trámites debe concurrir a una nueva delegación municipal para ella desconocida, ya no puede llamar a la comisaría que llamaba antes por el cambio de jurisdicción, el jardín y el supermercado le queda más lejos, tiene que caminar algunas cuadras para tomar el colectivo que antes pasaba por la esquina y requiere prestar mayor atención acerca de que deja o no en el patio para no tentar a los rateros barriales.

El primer problema concreto al mudarse fue encontrar vacante en el jardín de infantes para su hija mayor. En los establecimientos estatales cercanos al barrio no encontró lugar, la niña se encontraba en el número 190 de la lista de espera. Esto obligó a María a recurrir a un "jardín pago" para que la hija no pierda el ciclo lectivo, ella intenta auto justificar su decisión sosteniendo que el próximo año la niña comenzará la educación primaria. Pero, por otro lado, muestra cierta preocupación por la erogación que ello significa, entre la cuota del jardín y el transporte para llevarla gasta 300 \$, 1/6 de ingreso familiar total. Para ella es un monto que no pueden permitirse.

Normalmente, María se encuentra en la casa cuidando a las niñas, sólo sale del barrio para llevar a su hija mayor al jardín de infantes. Su marido, en cambio, pasa todo el día trabajando fuera del hogar. Tiene un trabajo rotativo, según donde se encuentre la obra es donde tiene que trabajar. En la actualidad trabaja dentro del mismo barrio en una de las etapas aún en construcción. Antes tenía que tomar 2 colectivos y tardaba una hora. Hoy se encuentra a 10 minutos a pie del obrador. En relación al empleo del tiempo, la pareja no realiza ningún otro tipo de actividades salvo las de consumo, ni tiene vida social más allá de la familia o el trabajo. Las compras cotidianas las realizan dentro del barrio, para otro tipo de compras van al centro de Monte Grande, el cual se constituye en una salida en sí misma, y los fines de semana suelen visitar a su madre y a su suegra, dinámica que no se ha visto afectada a partir de la mudanza al nuevo barrio.

Con respecto a la relación entre los vecinos del barrio María considera que es escasa. Ella habla sólo con los 4 o 5 vecinos de alrededor de su casa, no más. Con ellos tiene algún tipo de conversación, de intercambio o de relación. Con el resto prima la distancia, o a lo sumo se saludan. En el barrio aún no se ha consolidado ningún tipo de organización entre los vecinos. Según su opinión, es porque la gente no logra ponerse de acuerdo en las cosas comunes. Ella y su marido pensaron -a nivel individual- en concurrir al municipio a hablar con alguien, ya que la ciudad seguirá creciendo, en el barrio restan entregar las últimas etapas de viviendas y, aún 
no hay novedades de la construcción del jardín de infantes y de la escuela en el barrio. Esta cuestión les preocupa particularmente.

"A mi marido le dijeron que iban a hacer 3000 viviendas acá. Pero que iban a ser todas casitas, no dúplex. Con terreno grande. Pero es para otro nivel, porque acá la cuota era 80 o 100 y allá como van a ser tres piezas y terreno grande, como una casa normal va a ser. Como 600 pesos escuché que iba a ser... Supuestamente es el municipio, la misma empresa va hacer las casitas... Y después dijo el intendente que el cementerio van a hacer. Yo quiero que hagan un jardín, un colegio..." [ídem.]

Uno de los límites del barrio está constituido por terrenos baldíos sin construir, que han sufrido una valorización producto de la extensión de los servicios urbanos generada por el barrio de vivienda social. En estos terrenos, aparentemente, se producirá una nueva expansión urbana y residencial acordada entre el municipio y la empresa constructora pero el destinatario sería de otro sector social. Más allá de estas especulaciones lo interesante del relato de María es como se cuela la idea de que lo normal pertenece a otro nivel social.

Surgen aquí algunos aspectos interesantes para destacar, el más evidente, es que las casas del plan de vivienda social no son consideradas "normales". Probablemente habría que discutir el concepto de normalidad y la valoración social del mismo, no obstante cabe preguntarse por qué la vivienda social tiene cierta distancia de dicho concepto. Un segundo punto que aparece, es el reconocimiento lineal entre el concepto de vivienda social y un determinado sector social. Esto es coherente con las manifestaciones que asume la acción pública en materia habitacional, es decir, el atributo "social" de la vivienda no es transversal a todo el campo socioeconómico. La tercera apreciación es que la calidad de la oferta responde a la capacidad de pago, lo que lleva implícito la aceptación de las reglas de mercado, aún cuando la oferta esté mediada por la acción pública o la política habitacional.

Otro de los aspectos que se pone en juego, con algún punto de contacto con el párrafo anterior, es la imagen del barrio en el contexto urbano más amplio. María observa claramente el contraste entre las representaciones atravesadas por la experiencia de habitar el barrio y aquellos que lo ven desde afuera. Entre la imagen positiva del progreso urbano asociado a la obra y la imagen negativa vinculada a la degradación social. Entre la disputa por ser un barrio más y la asignación de un estatus diferencial. En el testimonio que se presenta a continuación, ella expresa, recurriendo a la memoria de los chistes familiares, que se ofende cuando las ideas que la gente tiene del barrio no concuerdan con su registro cotidiano.

“Algunos hablan bien, otros mal: 'que acá vinieron a hacer villas'. Y los que hablan bien dicen que: 'está lindo, que en vez de campo hicieron por fin algo... hay gente, algo que no había... ' Pero los otros dicen que esto es: 'la favella', nos re dieron! Cómo van a decir algo así! No sé yo no lo veo así. 'Chorros, drogados en la esquina', en otros lugares nos ven así, capaz que voy a lo de mi suegra y te cargan así... Pero a vos te da bronca. Te hacen esas cargadas... A mí no me gusta que digan así del barrio... Porque yo no lo veo así!" [ídem.] 
Si bien ella prefiere situar estas miradas en el plano del humor, tan real es la existencia del molestar que le ocasionan, como el hecho de que no cualquier lugar del municipio es objeto del mismo chiste. La broma familiar expresa de algún modo un conjunto de significados que operan en la construcción de un sentido común con el que María (como habitante del barrio) no parece estar de acuerdo. Nos referimos al imaginario urbano que supone que el barrio de vivienda social es equivalente a "la favella", asumiendo por carácter transitivo un conjunto de atributos vinculados a ella, como por ejemplo: el hecho de ser pobre. Como se veía en los párrafos anteriores, se encuentra generalizada la idea de que la vivienda social es para pobres, por tanto quien allí viva será pobre e indigno. De allí la contradicción que surge entre la experiencia cotidiana y la proyección del estigma.

Para cerrar, retomemos el concepto de la unidad de la vivienda. A partir de la mudanza a la nueva casa el cambio para María fue radical. El acceso al plan de vivienda social es un acontecimiento que marca un antes y un después en la trayectoria residencial del núcleo familiar. Ella está conforme con la vivienda, con "lo que le dieron". Al comparar su situación actual con el precario proyecto de autoconstrucción que la pareja llevaba adelante en el terreno de su suegra, María afirma: "Si no salía este plan, ni a palos iba a hacer una casa así" [ídem.] Esto pone en evidencia que la solución habitacional ofrecida por el Estado resuelve un cuadro previo que mostraba mayor complejidad de la que es posible encontrar hoy en el caso de María.

Por otra parte, al momento de realizar una comparación intergeneracional entre la forma en que accedieron a la vivienda su madre y su suegra, casi veinticinco años después, ella se observa en franca desventaja. Mientras que su madre había logrado comprar un terreno y con el tiempo construir por encargo su vivienda, para ella era imposible acceder a un terreno. En la actualidad espera que puedan juntar algún dinero para comprar materiales y que su marido, que trabaja en el gremio de la construcción, amplíe el dúplex en el que viven en el barrio Malvinas.

\section{Lo único positivo es que no estamos en la calle.}

Lucia [30 años, nacida en Rafael Calzada, no completó la educación secundaria, hoy es ama de casa y recibe la $A U H]$. Su maternidad le impidió insertarse en el mercado de trabajo. Madre de 4 hijos, los dos mayores (8 y 5 años de edad) los tuvo con su primera pareja, mientras que el tercero y el cuarto (2 y 1 año de edad) son hijos de su pareja actual. Él [35 años, nacido en Santiago del Estero, educación primaria completa, albañil] trabaja como jornalero en la construcción para un patrón que lo llama frecuentemente. Su condición laboral hace que el ingreso del hogar sea variable, 1000-1200 pesos mensuales. A ello se suma la asignación universal por hijo (AUH). Antes de mudarse al barrio "vivían de casa en casa". Y en su caso, el acceso al plan de viviendas está íntimamente ligado a la historia de asistencia social. 
Hasta mudarse al nuevo barrio, Lucia vivía en un hogar de mujeres solteras. Ya que cuando se separó de su primera pareja, su familia le cerró las puertas. De muy joven, ella se fue de su casa de Rafael Calzada (partido de Almirante Brown) para vivir con su novio. Desde un principio su familia desaprobó la relación porque él era un hombre golpeador. A los 21 años, ella quedó embarazada y a los 22 tuvo a su primer hijo. Por entonces, convivía con él en Pico de Oro (partido de Florencio Varela) en la casa de quien, en ese momento, era su suegra. Las suposiciones de su familia ya se habían confirmado y ella vivía encerrada en el círculo de violencia doméstica. Su vida social era limitada, y al no trabajar, sus alternativas de salirse de ese cuadro eran restringidas. Ella intentaba aguantar, pero la relación se tornaba cada vez más difícil. Su segundo embarazo fue un punto de inflexión. A los 25 años, quedó literalmente "en la calle" con su hijo mayor (que por esa época tenía 3 años) y el bebé.

Ella ya había solicitado ayuda institucional, recurrió a Acción Social como víctima de violencia familiar y en el municipio se había inscripto como demandante de viviendas. Su segundo hijo nació con una enfermedad y requería ser operado. En este contexto ella decidió separarse, vivió un tiempo en la calle y al poco tiempo recibió la ayuda del Ministerio de Desarrollo Social de la Nación. Su situación fue tramitada con carácter de urgencia dado el cuadro de vulnerabilidad. El bebé sufría una afección intestinal por la cual debía ser operado de urgencia y requería un trasplante. La operación fue exitosa, pero el niño quedo ostomizado y hoy requiere cuidados especiales. Luego de la estadía hospitalaria, los asistentes sociales se encargaron de buscar un lugar para Lucia y sus hijos. Durante 3 años, ellos vivieron en un hogar para madres solteras en Temperley (partido de Lomas de Zamora) hasta que en diciembre de 2007, se mudaron al nuevo barrio, Santa Rosa.

"A mí me dieron vueltas, miles de vueltas, es impresionante. Hasta me tuvieron que firmar los médicos de Casa Cuna. Me tuve que ir hasta la Casa de Gobierno. Yo entregué una carta a Cristina [Fernández de Kirchner] para que me deje entrar a vivir acá [...] Yo con la gente de Nación no me puedo quejar. Es más, yo creo que la casa la tengo por ellos [se refiere al equipo del Ministerio de Desarrollo Social de la Nación]. ¿Sabés cómo se movieron cuando yo dije quién era la mujer que no me quería dar la casa? [...] Ellos me ayudaron porque yo no podía entrar, no me daba el tiempo que yo vivía acá. Y yo vivía acá pero no tenía hecho el cambio de domicilio" [Lucia, Barrio Santa Rosa de Florencio Varela, Febrero de 2010].

Si bien, Lucia se había inscripto en el plan de viviendas en el 2005, el acceso a la vivienda fue una lucha de 3 años hasta fines del 2007. Hasta último momento no la reconocían como potencial adjudicataria debido a que su domicilio formal figuraba en otra jurisdicción (Rafael Calzada, partido de Almirante Brown). Fue por medio de la intervención del Ministerio de Desarrollo Social de la Nación que se destrabó su proceso de adjudicación. Sus dos hijos acreditaron domicilio en el partido de Florencio Varela, supuestamente con este argumento, lograron convencer a los funcionarios locales quienes esgrimían como criterio que el adjudicatario tenía que demostrar 5 años de antigüedad de residencia en el municipio, criterio que afectaba a todas las personas en la lista de espera. 
En el marco del Plan Familias del Ministerio de Desarrollo Social de la Nación, Lucía no sólo recibía ayuda económica, sino también asistencia profesional y atención especializada por la discapacidad de su hijo. Luego de atravesar varios años muy traumáticos en su vida, ella logró estabilizarse nuevamente. Mientras vivía en el refugio de madres solteras conoció a quien sería luego su segunda pareja. Tiempo después se transformó en adjudicataria de la vivienda social y decidieron irse a vivir juntos.

Él había nacido en Santiago del Estero pero desde los 7 años vivía en Florencio Varela. Primero vivió en Pico de Oro con su abuela que lo crió. A los 13 años, cuando terminó la escuela primaria, comenzó a realizar "changas". Luego, consiguió trabajo en una cafetería en Capital Federal y decidió independizarse. Durante 6 años tuvo el mismo trabajo, se juntó por primera vez y alquilaban un pequeño departamento. Cuando se separó y se quedó en la calle, "vivía de lado en lado, de prestado o donde caía la noche". Al trabajo de la cafetería, le siguieron 2 años en una pizzería también en Capital. Pero con la crisis de fines del noventa, la rotación se hacía más frecuente. Intercalaba "changas" de albañilería o en obras de sereno donde podía dormir. Durante un tiempo se dedicó a "trabajar para un político", cocinaba en un comedor y vivía en una unidad básica. Más recientemente, con la reactivación de la industria de la construcción el trabajo de albañil se volvió más frecuente.

Desde hace ya algunos años él trabaja en la zona de La Plata como jornalero para un patrón u oficial de construcción. Su ingreso es variable, expuesto a las inclemencias climáticas o a las discontinuidades entre obras, ronda los 1000-1200 pesos mensuales. A ello se suma la AUH que cobra Lucia para sus dos hijos menores. Los dos hijos mayores los tenía a cargo su padre y cobraba la AUH por ser monotributista social a través de una cooperativa de trabajo. Pero su ex pareja dejó de trabajar y ya no le pasa el dinero. Por esta razón, Lucia realizó el trámite para cobrar el subsidio ella directamente. Como su segundo hijo es discapacitado, además le corresponde una asignación diferencial por hijo con discapacidad. El traspaso del Plan Familia a la AUH fue muy engorroso para ella y tuvo muchas peleas con la delegación del ANSES de Florencio Varela. Pero el mes entrante espera cobrar normalmente la AUH y en 90 días comenzará a cobrar los 720 pesos de la pensión por discapacidad.

Al situarnos en el microcosmos de la vivienda y el barrio e indagar los impactos que éstos tuvieron en la trayectoria residencial de Lucia, la afirmación fue contundente: "Lo único positivo es que no estamos en la calle" [ídem.]. La respuesta se encuentra asociada a un relato regulado por una historia de asistencia que, a su vez, emerge como rasgo identitario rechazado y se manifiesta como una suerte de malestar-demanda frente a la percepción de la política de vivienda. Al principio todo parecía estar bien, pero al poco tiempo todo cambió y los defectos que Lucia percibe en relación a la nueva vivienda son innumerables ${ }^{134}$ : le entra agua por el techo, se salieron las canillas, se rajaron las paredes; la edificación no está bien hecha, la casa

\footnotetext{
${ }^{134}$ No se pretende con lo dicho minimizar ni desvalorizar las representaciones que la entrevistada proyecta sobre la vivienda y el barrio, muchos de los defectos constructivos por otra parte coinciden con nuestro propio registro de campo, sino más bien comprender el énfasis de sus observaciones y la práctica de demanda que se trasluce en la estructura del relato.
} 
no tiene columnas, se apoya una con la otra; las paredes son de ladrillo hueco y se escucha al vecino; el tanque de agua no corta y se rebalsa; el equipamiento de la casa es nulo, supuestamente iban a tener rejas, termotanque y cocina; los caños de la pileta del lavadero están mal puestos; se llueve el calefón, etc. El manejo de este petitorio o repertorio de problemas se presenta legitimado por la identificación de cierta causalidad que opera detrás de la construcción de los planes de vivienda y explicaría en parte la presencia de los vicios constructivos. "Hacían como se les cantaba [se refiere a las empresas constructoras]. Claro, el tiempo es ganancia, hace rápido que ganás más. El que viene después tiene que hacer todo como corresponde" [ídem.].

Para Lucia el barrio tampoco parece cumplir con las expectativas previas: la primera complicación fue el colegio, no había vacantes y los chicos tuvieron que ir a las escuelas de Pico de Oro, San Jorge y Varela Centro. En las reuniones previas a la mudanza, les habían informado que el barrio iba a contar con salita de salud, escuela, jardín de infantes y comisaria. La salita fue acondicionada transitoriamente en una de las viviendas y no da abasto para la cantidad de gente. $Y$ en la escuela, aún en construcción, comenzaron por inscribir niños que no pertenecen al barrio. Las calles figuran como asfaltadas pero son de tierra, cuando llueve se llenan de barro volviéndose intransitables. Para ir al supermercado hay que caminar 20 cuadras ya que en el barrio todo sale más caro. Los robos son otro problema frecuente en el barrio al cual hay que estar atento. Los servicios no son como en el resto de la ciudad. Los vecinos no respetan los horarios de silencio. Hay mucha rebeldía juvenil. Y el listado continúa....

"A la noche no entra ni un remisero. Acá si te agarra fiebre empezá a correr al hospital. Acá no te entra la ambulancia y los remiseros que tenés te trabajan hasta 10.30, 11 de la noche. El último colectivo que entra de Varela a acá entra 11.30 de la noche. Pero que sale del barrio a la estación de Varela, el último es 10.30 [...] Llamás al patrullero, tardan 3 horas, ya te mataron. Llamás una ambulancia, después de las 10 de la noche no te entra. Encima acá no hay teléfono particular, Telefónica no te pone. Acá hay satelital, un día nublado como hoy, no hay señal. Pero tenés que buscarla, acá no hay señal. Un día nublado, un día de Iluvia, fuiste. Te tenés que comunicar con alguien y olvidate" [Ídem.].

Otro de los aspectos puestos en tela de juicio por Lucia es la condición socioeconómica de los mismos habitantes, no todos son "gente con necesidad". De este modo, interpela el proceso de adjudicación de la política de vivienda y recorre el entretejido conflictivo atravesado por: relaciones clientelares, procesos administrativos opacos y la dinámica de mercado informal floreciente. A partir de ello, Lucia crea una cartografía barrial donde distingue entre: quienes acceden de modo formal (tener los papeles de la adjudicación) o informal y entre quienes, la residencia en el barrio, asume el carácter de merecida (credencial de necesidad) o injusta.

"Acá hay gente que le dieron las casas teniendo casa propia. $Y$ hay mucha gente que está en la calle y no tiene casa propia. Alquilan su casa y viven acá. Eso yo lo veo mal porque si supuestamente fue un asistente social y figura que tenés un terreno por qué te la dan 
[...] Acá a 50 personas de la UOCRA le dieron casa pero porque era un plan que hicieron ellos. Claro la UOCRA exigió eso: 'nosotros metemos a la gente'. Y mucha gente vendió y se fue. Por problemas de cosas que no tenían cerca, los colectivos, porque no entraban, ahora sí pero antes llegaban a la rotonda San Jorge y quedaban ahí [...] Hay casas que están compradas

acá. Se la compraron a la coordinadora. Suponete voy yo y antes que me la adjudiquen, con la coordinadora que estaba a cargo de todas las casas y bueno yo quiero tal casa. Bueno cuánto es. Yo cuando me agarré con María Rosa... que está en el municipio, yo me agarré muy fuerte con ella. Era ella la que me pedía papeles y papeles y papeles [...] Si vos acá te ponés a hacer una encuesta, tomas los nombres de todos, vas a Tierras y Viviendas y sacás el nombre de todos, te vas a fijar que el $30 \%$ no está y el otro $30 \%$ tiene casa aparte de esto. Y el 40 que te queda, gente que no tenía nada" [ídem.].

Una vez concluido el proceso de adjudicación y el año de garantía que las empresas constructoras están condicionadas a prestar, muchos de los entrevistados perciben cierta "ausencia" de Estado en el barrio. Sin embargo, las observaciones de Lucia van en sentido contrario. En el barrio Santa Rosa funcionaba una "feria busca" (de cosas usadas) y el municipio la levantó justificando que es un barrio residencial y no pueden permitirse esos usos. En otra ocasión unos vecinos del barrio -que pertenecen a organizaciones piqueteras que trabajan en cooperativas- organizaron una copa de leche donde los niños tomaban un vaso de leche con torta frita y el municipio se hizo presente para desmontarlo. Según Lucia, para organizar un comedor hay que pedir "permiso" al Municipio, con conocimiento de causa reflexiona: "pero, sino estas metido en la municipalidad..."

A lo largo de toda la entrevista, se cuelan ciertos conocimientos adquiridos a fuerza de la necesidad de saber acerca de las redes y los mecanismos de funcionamiento de los circuitos de asistencia estatal, los cuales por exposición fueron consolidándose en una especie de capacidad de demanda especializada. Y, en un determinado momento, Lucia comenzó a movilizar este activo individual más allá de los horizontes personales. Ya no pensaba sólo en conseguir beneficios para su familia sino para el barrio entero. Pero sus intereses parecen haberse topado con el "aparato" municipal.

"Yo conocía a una señora de La Plata... [por sus contactos con el Ministerio de Desarrollo Social de la Nación] Y estaba en un programa de movilizaciones donde luchamos para que nos dieran la mercadería de navidad, el año pasado. Era una colaboración de 3 pesos por persona para el flete. Para que te bajen acá la caja navideña, bolsón de alimentos y los juguetes para los chicos. El camión venía. En ruta 2 lo cortaron, la gente de Pereyra [intendente de Florencio Varela] y lo llevaron al Municipio. Y repartieron ellos la caja navideña y los juguetes [el marido acota:] Y eso lo había hecho ella. Lo había encabezado ella. Había mucha gente que no tenía y yo ponía de mi bolsillo. Y una vez vinieron a acá a querer pegarle a ella, tres mujeres, pagada por otra [Lucia retoma] Yo quedé muy mal con la gente, ahora quién me va a dar bola" [ídem.].

Más allá de lo anecdótico, en este fragmento y en el que sigue a continuación, se pone en evidencia la regulación externa del orden barrial y la eficiencia del entramado de control 
territorial municipal para administrar lo que puede y no puede acontecer en el rincón más recóndito del barrio.

El marido de Lucia dice: "Pereyra quería que vaya a trabajar con él porque ella mueve. Pero Pereyra hizo las cosas mal, en vez de dejar que entre el camión y después decirle a ella que trabaje para él porque tenía muy buena movilización de gente, no. Hizo todo mal. Ella hubiese entrado a trabajar en la municipalidad todo bien, pero hubiese seguido trabajando para el barrio. Después había otra movida que ella había organizado para levantar qué necesidades tenían en las casas, estaba todo en una lista. Andá a preguntarle a la municipalidad cuántas camas tienen, todo por la movida que hacen los demás. Ellos saben siempre qué va a venir, porque tienen gente en todos lados, también acá en el barrio, ven que hay una movida y enseguida empiezan a averiguar. Enseguida se enteran allá. [Lucia afirma] Ellos sabían todo de mí. $Y$ después pagó a tres mujeres del barrio la Esmeralda para que me vengan a gritar que era una chanta. Me mandó un patrullero para llevarme presa. Le dije al patrullero que le diga Julio Pereyra que 'no estoy por ninguna asociación política. Estoy ayudando a la gente'. Era cerca de las votaciones. Todos piensan que estás haciendo política. Y nosotros aprovechamos ese momento que están haciendo política, antes de las elecciones porque vos sabés que ahí sale. Yo quería ayudar a la gente del barrio" [ídem.].

Para finalizar, vale rescatar que en gran medida la ausencia de organizaciones políticas y sociales cristalizadas en el nuevo barrio, no inhibe la presencia de un flujo activo que circula por redes donde se intercambian significados y se movilizan recursos varios. De lo contrario, es difícil de explicar el funcionamiento del sistema de respuesta rápida para desactivar cualquier tipo de "competencia" política. En el ámbito municipal, el barrio se transforma rápidamente en arena política y un espacio de disputa a ser apropiado. Por otro parte, suelen operar distinciones entre los orígenes de las acciones políticas que provienen de la Nación, de la Provincia o del Municipio y de tal o cual grupo político.

Aunque cada una de las historias que aquí se reconstruyen permiten extraer alguna conclusión, en la sección 5.3, recuperaremos algunas reflexiones generales en el marco de la conclusión del capítulo. A continuación, analizaremos otra forma de abordar las trayectorias residenciales que si bien no contempla la experiencia de los propios sujetos, entendemos que puede aportar elementos complementarios a la hora de pensar la relación entre movilidad residencial y capital locacional de los adjudicatarios.

\subsubsection{Política de relocalización pasiva, de dónde vienen y a dónde van}

En este apartado nos proponemos reconstruir desde una mirada completamente distinta la huella de la política habitacional en los sujetos de la política. A partir de la identificación del lugar de residencia previo de adjudicatarios encuestados, nos propusimos realizar una comparación entre la posición residencial previa y la posterior a la mudanza al barrio de vivienda social. Para ello recurrimos a la matriz de la estructura urbana confeccionada en el 
capítulo 3 y a la geografía del espacio-tiempo de Hagerstrad (1975), para la cual una de las fuentes de restricciones de la actividad humana proviene de la relación de los cuerpos y el ámbito físico. Al trasladar esta perspectiva a la lectura del proceso de movilidad residencial, es posible comparar de dónde vienen y a dónde van los adjudicatarios, teniendo en cuenta los efectos de localización "puertas afuera" de la vivienda social.

Si bien el concepto de "relocalización" en la historia de la política habitacional ha estado asociado al concepto de "erradicación" de las villas y asentamientos informales, como parte de una política represiva y activa de segregación de la población de bajos ingresos de los lugares merecedores de cierto prestigio urbano (Ozlak, 1991). Consideramos que es importante recuperar la noción de relocalización pasiva o consensuada, ya que en función de la evidencia que hemos recogido en el capítulo 3, es útil para analizar la mediación propuesta por el mercado de localizaciones residenciales intra-urbana en la trayectoria residencial de los adjudicatarios, asilando analíticamente el efecto de la "casa propia".

En la figura 27, se selecciona a modo de ejemplo los que podrían ser los hitos o amojonamientos de la trayectoria laboral y residencial de uno de los entrevistados, a efectos de reconocer la podríamos denominar la huella del sujeto en la ciudad. Los puntos oscuros representan los distintos lugares de trabajo a lo largo de la vida de la persona, mientras que los puntos más claros representan los lugares de residencia.

Fig. 27 Lugares de residencia y trabajo en la trayectoria de Armando (Florencio Varela)

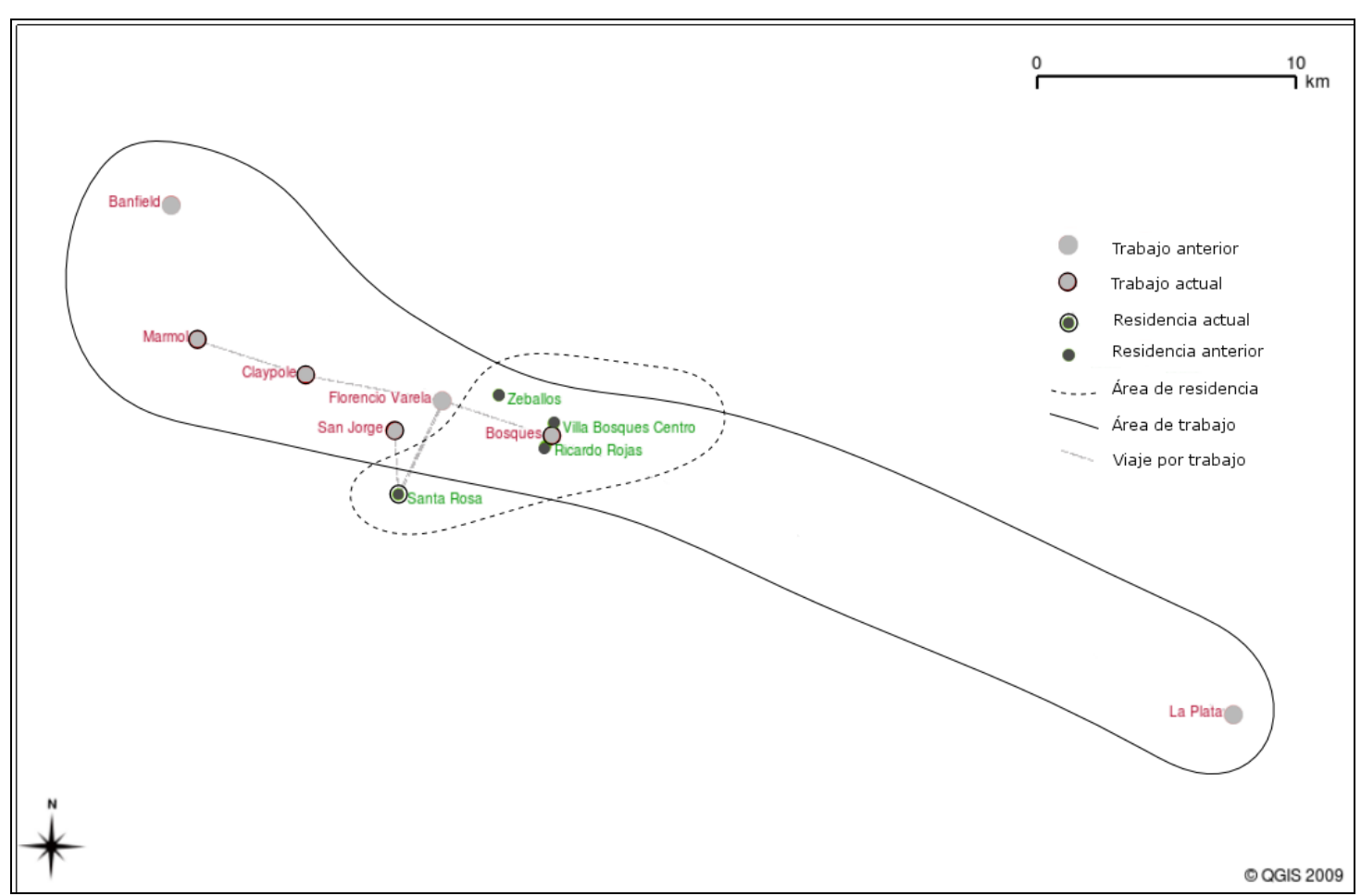

Fuente: elaboración propia en base a entrevista Armando [30 años, nacido en Florencio Varela, primaria completa, desocupado, realiza venta ambulante de verduras] 
Como resulta esperable, puede observarse que la extensión del área que se configura entorno a los lugares de trabajo es mayor que el área de residencia. Mientras que la escala de trabajo es metropolitana, la escala de residencia es municipal. Como vimos en el apartado anterior la historia de Armando [30 años, nacido en Florencio Varela, primaria completa, se define como desocupado y realiza venta ambulante de verduras] se compone de 4 tramos de empleo alternados con períodos de desocupación y 10 tramos de residencia ${ }^{135}$, en un recorrido de 30 años. La inestabilidad del ciclo residencial y la precariedad laboral constituyen sin duda un desafío que en parte excede a la política habitacional. En otros casos, la precariedad o inestabilidad laboral se traducen en ciclos de rotación residencial que no siempre encuentran lugar en los formatos de la política de vivienda. Más frecuentemente la mudanza al barrio de vivienda social trae aparejado una redención (o dislocamiento) de las redes sociales de proximidad que brindan sostén a las estrategias de vida de las unidades domésticas.

Por otro lado, uno de los aspectos que se pone en juego en el proceso de relocalización (en el cual la política habitacional tiene mucho aún para decir), tiene que ver con la inserción urbana de los conjuntos habitacionales. Para intentar dar cuenta de este aspecto al que venimos prestándole especial atención, en la figura 28 , hemos identificado los lugares de residencia previos de 382 adjudicatarios de vivienda social graficado los desplazamientos.

Fig. 28 Residencia origen vs. residencia destino de los adjudicatarios de vivienda social

Barrio Favaloro (José C. Paz)

Fuente: Elaboración propia, en base a encuesta a 400 hogares, Equipo Infohabitat (ICO-UNGS) 2009.

${ }^{135}$ En la gráfica no pueden observarse completamente debido a que una cambio de residencia se desarrolló en ocasiones el mismo barrio o localidad. En el caso de los lugares de trabajo se representan más lugares de trabajo que etapas debidos a un mismo trabajo o estrategia de obtención de ingresos puede tener más de un emplazamiento. 
Fig. 29 Residencia origen vs. residencia destino de los adjudicatarios de vivienda social en el Área Metropolitana de Buenos Aires (vista regional)

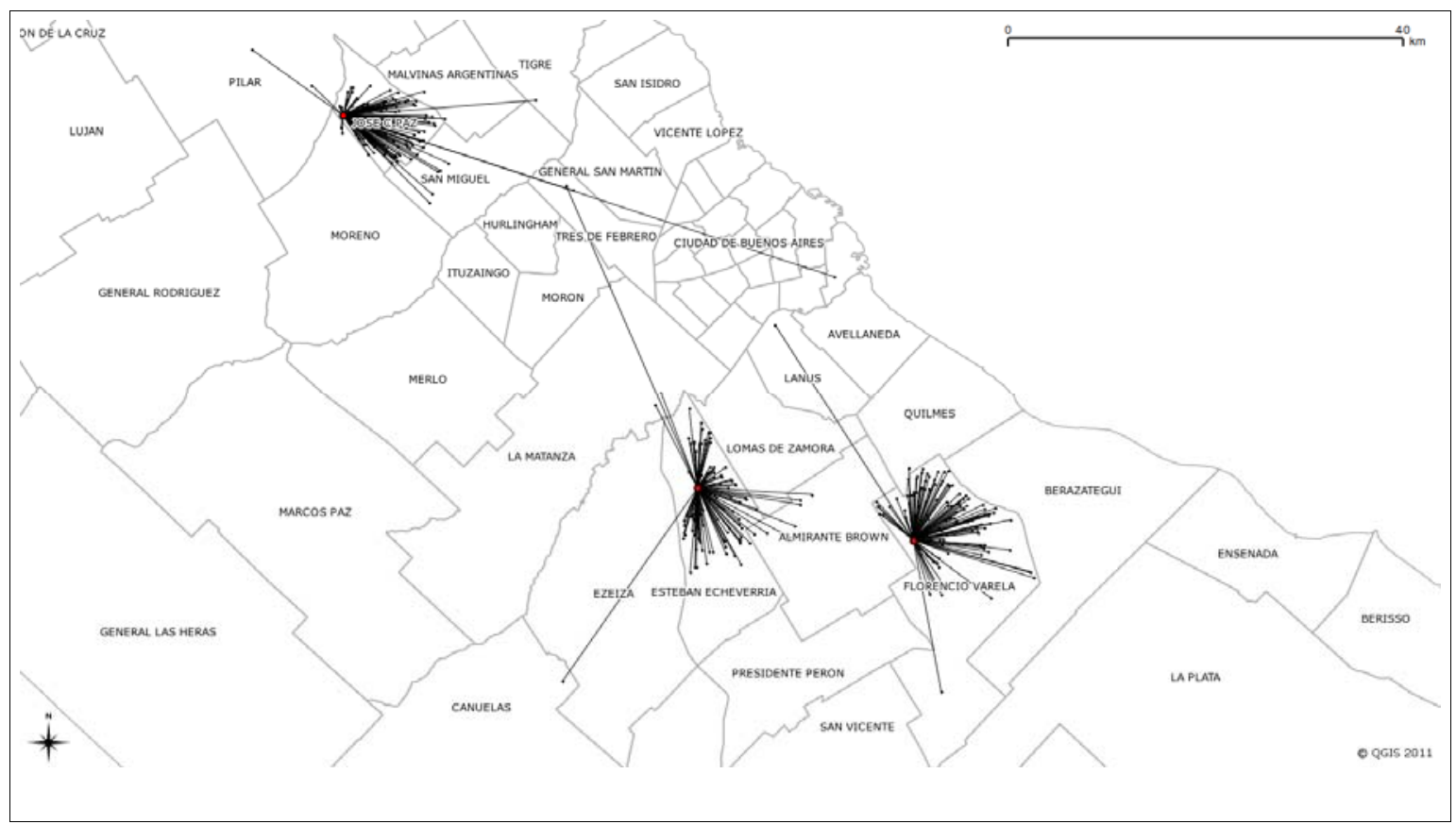

Fuente: Elaboración propia, en base a encuesta a 400 hogares, Equipo Infohabitat (ICO-UNGS) 2009.

El primer dato que surge es que la mudanza al barrio implica una migración en masa a nivel intra-municipal, que probablemente ( $y$ dependiendo de la escala del barrio) no encuentre antecedentes en la historia local. Una vez concluidas las distintas etapas de obra, algunos barrios llegan a tener 5 o 10 mil habitantes. En uno de los relatos de los funcionarios municipales entrevistados, indirectamente, se pone de este proceso y al mismo tiempo se caracteriza en parte la residencia de origen:

"La mayoría vivía en la casa de la madre o del padre o alquilaba un cuartito de alquiler... muy pocos eran los que alquilaban un departamento o una casa, a lo sumo alquilaban un cuartito. Pero la mayoría era eso, vivían dos o tres hijos con sus familias en la casa de los padres. Yo vivo acá a 15 cuadras y no sabés, quedaron los padres, no hay chicos.... en cuatro manzanas a la redonda de donde yo vivo se fueron 7 familias" (Entrevista Funcionario $N^{\circ} 4$ ).

Del cruce de la figura 28 y 29 con la matriz de la estructura urbana surge la figura 30 , en la cual se puede observar el cambio de la posición residencial mediado por el mercado de localizaciones intra-urbana. Por un lado, se representa la posición residencial previa de los adjudicatarios y, por otro, la localización en la estructura de deciles urbanos de la residencia de destino. De este modo, se puede verificar que no sólo hay una cambio de distribución dispersa a aglomerada, sino que al mismo tiempo la mudanza al barrio de vivienda social implica una devaluación de la localización, al menos en las posibilidades de absorción de externalidades urbanas o en términos de la composición del capital residencial de la familia que se define por el contexto urbano. 
Fig. 30 Posición residencial media antes de la mudanza (RPA) vs. posición media de de barrio de vivienda social, en la estructura urbana municipal y del los 24PGBA.

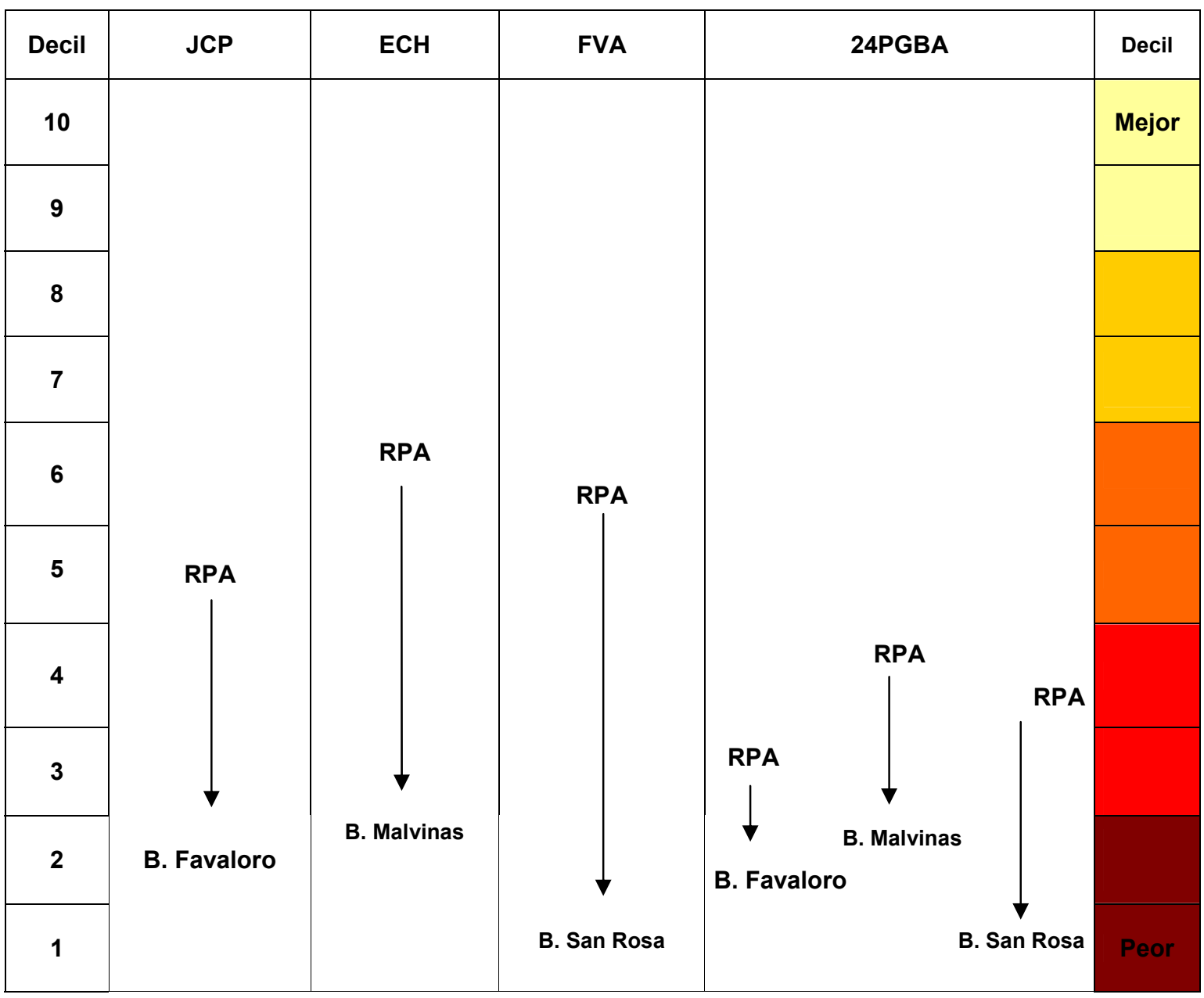

Fuente: elaboración propia en base a encuesta a 400 hogares, Equipo Infohábitat (ICO-UNGS) y fuentes de anexo A2.

Por último, por más que esta política de relocalización sea de carácter consensuado, ello no implica que la misma no pueda ser discutida. De hecho, la producción de vivienda nueva en nuevas localizaciones responde más a las necesidades del sector de la construcción que a las necesidades de la demanda (déficit cualitativo) y a su distribución geográfica. De allí que la gráfica propuesta proponga una especia de "analogía del tobogán", mientras que los adjudicatarios suben a la vivienda por escalera, a la ciudad lo hacen por el deslizadero.

\subsubsection{Vivienda "puertas afuera", los efectos de la zona}

Al analizar la valoración que los habitantes de los nuevos barrios realizan distinguiendo tres unidades espaciales discriminadas a priori (la casa, el barrio y la zona), la percepción de los mismos es coherente con los resultados hallados en el apartado anterior. No obstante, es importante aclarar que dichos resultados no inhiben -como veremos luego- los altos grados de 
satisfacción respecto a la política de vivienda en su conjunto, o incluso, el hecho de que en muchos casos opere un proceso de movilidad residencial ascendente.

Hecha esta aclaración, introduciremos una perspectiva inversa a la perspectiva sectorial que se ha caracterizado por concebir el producto de la política de vivienda a partir de la unidad edificio-lote. Algo que nos enseña el registro de la experiencia "del habitar" es, justamente, el modo en el cual el conjunto de dimensiones que hacen al hábitat se encuentran integradas en las trayectorias subjetivas (la unidad de la vivienda, el barrio y el entorno o la zona forma parte de la amalgama urbana). Si bien somos conscientes de la indivisibilidad de dichas entidades, a los efectos analíticos descentramos, momentáneamente, el recorte de la vivienda y el barrio, para comprender mejor el entorno o los efectos de proximidad que exceden la dimensión barrial y dan cuenta de las posiciones de los barrios de vivienda social en el conjunto urbano.

Un antecedente de las encuestas realizadas por el Área Social del Instituto de la Vivienda de la Provincia de Buenos Aires (IVBA, 2007: 172 casos) en el Barrio Malvinas (partido de Esteban Echeverría) y Santa Rosa (partido de Florencio Varela), seis meses después de entregadas las viviendas, refleja que entre el 92 y $73 \%$ de los encuestados se manifiesta conforme con la vivienda en los respectivos barrios, pero sólo entre el 46 y $21 \%$ de los encuestados considera que el barrio actual es mejor que el anterior (en relación al transporte, distancia al lugar de trabajo, normas de convivencia, seguridad, etc.). La misma fuente revela que el principal reclamo de los vecinos, una vez terminadas las obras, es lo que podríamos denominar la "demanda de ciudad". Al observar los datos de las necesidades de los vecinos, el inventario es el siguiente: transporte, asfalto, gas natural, teléfono público, centros educativos, centros de salud, seguridad, comercios, etc.

En este sentido, al momento de realizar las encuestas en los tres barrios estudiados decidimos indagar sobre la visión general que los vecinos tienen de la casa, el barrio y la zona y confrontarla con la situación habitacional previa. Los resultados pueden observarse en la figura 31. Los resultados de las encuestas corroboran la tensión entre la valorización positiva de la "casa" y una imagen positiva de la "zona", pero con un porcentaje bastante inferior al primero. Mientras que el $91 \%$ de los encuestados manifiestan una opinión satisfactoria en relación a la "casa", el nivel de satisfacción se reduce al $79 \%$ al indagar por el "barrio" y al $61 \%$ al preguntar por la "zona" en la que se encuentra el barrio. Vale aclarar que al comparar las tres categorías (casa, barrio, zona) con la escala ordinal (satisfactorio, intermedio e insatisfactorio) se observa que la disminución del nivel "satisfactorio" va acompañada de un aumento del nivel de satisfacción "intermedia" y no necesariamente de la "insatisfacción".

Sin embargo, al contrastar la situación actual con la situación anterior nuestro supuesto asociado a una valorización decreciente conforme a la escala de la unidad de análisis y el desplazamiento del espacio doméstico al espacio público- cobra más fuerza: para el 93\% de los hogares la "vivienda actual" es mejor que la "vivienda anterior", para el 68\% el "barrio actual" es mejor que el "barrio anterior", pero sólo para el 43\% la "localización del barrio actual" es mejor que la "localización del barrio anterior". Mientras que sólo para el 3\% la "vivienda 
actual" es peor que la vivienda anterior para el 33\% la "localización actual" es peor que la anterior. Si bien para el $43 \%$ la localización actual mejoró con respecto a la anterior y para el $24 \%$ es equivalente estos datos parecen ser más débiles que los cambios percibidos en el apartado 4.1.2, cabe notar la inversión del orden en la lectura de la figura 31.

Fig. 31 Valoración de la vivienda, el barrio y la zona

Situación actual (barrio de vivienda social)

\begin{tabular}{lc}
\hline ¿Qué opinión le merece la casa? & $90,7 \%$ Satisfactoria \\
& $7,6 \%$ Intermedia \\
¿Qué opinión le merece el barrio? & $1,8 \%$ Insatisfactoria \\
\hline \multirow{2}{*}{ ¿ué opinión le merece la zona? } & $79,3 \%$ Satisfactorio \\
& $15,8 \%$ Intermedio \\
& $4,8 \%$ Insatisfactorio \\
\hline \multirow{2}{*}{ ¿En relación a la vivienda anterior, esta es...? } & $61,4 \%$ Satisfactoria \\
\hline ¿Considerando el barrio anterior, este barrio es....? & $28,5 \%$ Intermedia \\
& $0,2 \%$ Insatisfactoria \\
\hline \multirow{2}{*}{ ¿En relación al barrio anterior la localización de este barrio...? } & \\
\hline
\end{tabular}

Fuente: Elaboración propia, en base a encuesta a 400 hogares, Equipo Infohabitat (ICO-UNGS) 2009.

En este sentido, y más allá de la intensidad queda claro una cuestión, operan realidades distintas "puertas afuera" y "puertas adentro" de la vivienda. La explicación de esto la buscaremos en la próxima sección al introducirnos en las representaciones de los habitantes y en las experiencias del habitar los nuevos barrios.

\subsection{Viviendas nuevas, barrios en construcción}

En esta sección se propone realizar un recorrido por la evaluación que los propios habitantes realizan acerca de la vivienda, el barrio y el entorno en el cual se emplaza sitúa el barrio. Se consideran, a tal efecto, las nuevas condiciones de habitabilidad generadas por la política habitacional, el impacto del acceso a la vivienda en la unidades domésticas, los cambios producidos a partir de la mudanza, los problemas emergentes y la configuración de nuevas 
demandas a nivel barrial, las particularidades que asume la dinámica de la sociabilidad barrial y los imaginarios en juego en relación al barrio y el entorno, entre otras dimensiones.

Para ello nos nutrimos, aparte de las entrevistas individuales y grupales realizadas a los propios vecinos, de 400 encuestas semi-estructuradas realizadas en los tres barrios ya mencionados (Santa Rosa, Malvinas y Favaloro) en el marco de un proyecto de trabajo más amplio del Equipo Infohabitat (ICO-UNGS). En dicha encuesta se barren una serie de ejes de análisis asociados a: i) la caracterización socio-demográfica de la jefa y el jefe del hogar, ii) la composición del hogar, iii) el perfil socio-ocupacional y habitacional, iv) los aspectos vinculados a la movilidad cotidiana de grupo familiar, v) la cuestión de la localización y el acceso a los equipamientos urbanos, vi) la evaluación de la vivienda, vii) las redes de intercambio y relaciones entre vecinos, viii) la forma de acceso a la vivienda, ix) y la percepción de los habitantes acerca de la casa, el barrio y la zona (ver formulario de la encuesta en el anexo A5). En las entrevistas se trabajaron, en general, los mismos ejes de análisis que en la encuesta, pero mientras que las entrevistas individuales permitieron reconstruir con mayor profundidad el registro comparativo hacia atrás (es decir, en función de las trayectorias laborales y residenciales), las entrevistas grupales dieron lugar a la identificación colectiva de las problemáticas de los barrios en tiempo presente.

Si bien cada uno de los barrios analizados tiene características específicas y merecería realizarse un estudio de caso particular de cada uno, a nivel metodológico nos hemos propuesto realizar una caracterización general de los barrios de vivienda social que son objeto de la "política federal de vivienda". En términos generales, las problemáticas emergentes no presentan mayores variaciones, por este motivo, los datos se presentan de manera agregada. No obstante, cuando sea necesario, o los datos agregados escondan alguna variabilidad significativa, introduciremos algunos comentarios particulares.

Por otra parte, más allá de las características materiales, algunas de las diferencias observadas entre los barrios responden, más a las características sociodemográficas del municipio, que al propio barrio. En este sentido, los niveles de pobreza de Florencio Varela y José C Paz difieren bastante de los de Esteban Echeverría. Por esta razón, las características de composición del hogar, el perfil socioeconómico u ocupacional y las condiciones de residencia previa, suponen que los barrios de los dos primeros municipios adquieran indicadores por debajo de la media general agregada al tomar en conjunto los tres barrios.

En el primer apartado de la sección y antes de introducirnos en el plano de la experiencia del habitar el barrio, realizamos una caracterización general de perfil socio-económico y ocupacional de los adjudicatarios, la composición de hogar y las condiciones residenciales previas con el objetivo de analizar los criterios de adjudicación que se han generalizado en los barrios analizados. En segundo término, proponemos una interpretación de la "satisfacción" habitacional que intenta dar cuenta del alto nivel de receptividad de la vivienda, en paralelo identificamos una serie de problemas o emergentes a nivel barrial (aquí recurrimos a reflexiones previas realizadas colectivamente, ver Cravino, del Río, Graham, Varela: 2011). En 
el tercer apartado, nos introducimos en la configuración del espacio barrial visto desde adentro y desde afuera (o en relación con los barrios del entorno y la ciudad), e identificamos una suerte de proceso de sociabilidad "en obra", a partir de la configuración instantánea y masiva de estos espacios urbanos. Por último, a modo de síntesis, buscamos reconstruir los mapas mentales de las representaciones colectivas que se generan en torno a la unidad de la vivienda, el barrio y la zona, con la intención de identificar los efectos que produce la política de vivienda "puertas adentro" y "puertas afuera" de la vivienda.

\subsubsection{Quiénes son los habitantes de los nuevos barrios}

Hemos visto que en el proceso de implementación de la política habitacional, la selección de la "población objetivo" y los criterios de asignación de la vivienda social suelen ser un tema controvertido. A nivel administrativo, no hay criterios objetivados uniformes entre las distintas jurisdicciones municipales que son las que finalmente canalizan la demanda. En este sentido, en este apartado nos preguntamos: ¿Qué relación existe entre el perfil socioeconómico de los destinatarios y sus necesidades habitacionales? Por otra parte, la inexistencia de prioridades uniformes es fértil a las representaciones o mecanismos opacos ${ }^{136}$ y aún cuando se identifica "cupos discrecionales", ello no implica necesariamente que no se generalicen criterios con asiento en la necesidad habitacional.

Si bien las decisiones de asignación de las viviendas son de carácter municipal y existen realidades territoriales heterogéneas en relación a la adjudicación, la provincia realiza a través del IVBA -con mayor o menor éxito- una suerte de "contralor" de los listados de "beneficiarios". Asimismo, a partir de las entrevistas a nivel municipal observamos que los municipios priorizaron a la población de familias jóvenes (y también mujeres solteras) con niños en edad escolar, con carencias habitacionales y bajo nivel socioeconómico. La demostración de una mínima capacidad de pago fue un requisito extendido en la mayoría de los municipios, esto se asocia a la necesidad de asegurar una tasa de recupero por parte del Estado. Aunque esto opera como un filtro a considerar, no ha sido criterio excluyente ya que se verifican adjudicaciones a población desocupada. A su vez, el requisito de un mínimo nivel de ingreso se hizo extensivo, tanto a trabajadores en empleos formales como informales (a través de declaración ante escribano público). Los adjudicatarios también reconocen que la idea de un umbral de ingresos operó como llave de entrada:

"Hay gente que puso 150 pesos que estaba cobrando del plan. No salieron. Gente que realmente necesitaba la casa y no salieron. Porque supuestamente te tiene que agarrar la del Instituto de Vivienda y cobrar. Entonces si vos no estás trabajando en

\footnotetext{
${ }^{136}$ El Conurbano Bonaerense aparece en los grandes medios como un espacio común, de corrupción, "cacicazgo" político y relaciones clientelares. Se proyecta así una idea de territorio homogéneo fundante de una institucionalidad que se asemeja al "lejano oeste". Dos de los barrios que fueron objeto de tratamiento periodístico por las modalidades de asignación de la vivienda social, en los municipios de Esteban Echeverría y José C. Paz, casualmente formaron parte del universo encuestado en este estudio. En uno de los barrios, se denunció a la funcionaria del Área de Tierras por la comercialización de las viviendas y el reaseguro del cupo. En el otro, la crítica se orientó a la distribución de un número de viviendas entre los concejales para que éstos las repartieran entre sus allegados.
} 
nada, no le dieron. Yo por suerte puse $\mathbf{\$ 6 0 0}$, por eso salí. Pero hay gente que necesitaba y no salió" (Entrevista Grupal Barrio Malvinas).

Por otra parte, se incluyó población mayor con problemas crónicos de salud, cupos por discapacidad y personas asistencializadas en otros programas sociales. También encontramos plazas destinadas a los empleados municipales ${ }^{137}$ y los denominados "cupos políticos". Sin embargo, ésta es una modalidad más en el conjunto de los mecanismos y según nuestro trabajo está lejos de ser una de las modalidades predominantes. $\mathrm{Y}$, paradójicamente, en algunos casos son actores, que si bien acceden por medio de la movilización de recursos que les otorgan las redes de afinidad política, a la vez, califican dentro de los requisitos de la definición de la "población objetivo". Esto, no obstante aparece fuertemente problematizado en las entrevistas grupales, aunque siempre filtrado por el criterio de la necesidad que determina cuándo los mecanismos de acceso son discrecionales y cuándo no.

Los resultados de las 400 encuestas realizadas a principios de 2009 nos permiten observar algunas características de la población adjudicataria. El promedio de ingreso mensual total del hogar en los barrios encuestados es $\$ 1.269$ (un poco más de U\$S 400), con extremos que van desde familias sin ingresos hasta registros máximos de hasta 5 mil pesos. Un ejercicio a partir del análisis de la estratificación económica que se realiza en el Informe de "Evolución de la Distribución del Ingreso" (INDEC, 2009) mediante información proveniente de la Encuesta Permanente de Hogares (EPH), permite constatar que los hogares encuestados se encuentran en el tercer decil de hogares de menores ingresos (si se considera la media del ingreso total familiar para el primer trimestre del 2009, momento en el cual se realizó la encuesta en los barrios estudiados). Dado que dicho informe ofrece los resultados de la EPH a nivel del conjunto de los aglomerados urbanos del país, una lectura a nivel del GBA con un nivel de ingreso levemente superior a la media nacional, hace descender el promedio del ingreso mensual total de los hogares encuestados al segundo decil de nivel de ingresos.

Fig. 32 Características socioeconómica de los hogares

\begin{tabular}{ll} 
Nivel socioeconómico & \\
\hline Nivel de educación de los jefes del hogar & $43,0 \%$ primaria completa \\
(selección de los cuatro primeros) & $24,9 \%$ secundaria incompleta \\
& $15,3 \%$ secundaria completa \\
& $10,7 \%$ primaria incompleta \\
\hline Ingreso mensual total del hogar & $\$ 1.269$ (algo más de U\$S 400) \\
\hline Personas que contribuyen al ingreso del hogar & 1,45 personas \\
\hline Hogares que reciben algún tipo de plan social & $60,7 \%$ planes "en general" \\
\end{tabular}

Fuente: Elaboración propia, en base a encuesta a 400 hogares, Equipo Infohabitat (ICO-UNGS) 2009.

\footnotetext{
${ }^{137}$ En el caso del municipio de José C. Paz, la encuesta muestra una mayor proporción en relación a los otros dos municipios. Recordemos que las encuestas se realizaron en 3 barrios de vivienda social en los municipios de Florencio Varela, Estaban Echeverría y José C Paz.
} 
De modo complementario, si se compara el ingreso promedio total del hogar de los barrios encuestados con el salario mínimo vital y móvil (SMVM) definido por el Consejo del Salario Mínimo, se registra que no existe prácticamente diferencia. Al momento de la encuesta el SMVM era de $\$ 1240$, por tanto la diferencia con el promedio de ingresos totales de los hogares (1269 \$) es apenas de \$29 Si bien se compara un promedio con una línea de corte ${ }^{138}$ y los datos de ingresos declarados en las encuestas suelen tener cierto subregistro, una comparación en términos generales no parece mostrar una gran distorsión de la asignación de los recursos.

Por otra parte, en la figura 33 puede observarse que una parte importante de los hogares recibe algún tipo de plan social. Cabría preguntarse si esto puede ser considerado una constatación de "necesidad" o, por el contrario, evidencia la cristalización de circuitos de acceso a los recursos estatales de determinados sectores de la población que deja por fuera a otros con igual o mayor grado de necesidad. Al mismo tiempo, en la misma figura el perfil socio-ocupacional nos muestra que el $64 \%$ de los jefes ocupados tienen una situación de estabilidad laboral, con un promedio de 6 años de antigüedad en el mismo empleo. Mientras que el $36 \%$ restante de los jefes con trabajo realizan ocupaciones intermitentes o esporádicas. Esto en parte puede asociarse al requisito de contar con un ingreso mínimo al momento de realizar el pago de la vivienda. Sin embargo, requería un estudio en mayor profundidad.

Fig. 33 Características socio-ocupacionales de los hogares

\begin{tabular}{lc} 
Perfil ocupacional & \\
\hline Jefas de hogar ocupadas fuera del hogar & $29,20 \%$ \\
\hline $\begin{array}{ll}\text { Puesto o tareas predominantes de la Jefa } \\
\text { (Ama de casa + Primeros 3) }\end{array}$ & $\begin{array}{c}6,4 \% \text { ama de casa } \\
9,6 \% \text { empleada doméstica } \\
4,9 \% \text { comerciante, }\end{array}$ \\
\hline Jefes de hogar ocupados fuera del hogar & $4,9 \%$ empleada estatal \\
\hline Puesto o tareas predominantes del Jefe & $80,20 \%$ \\
(Primeros 3) & $24,6 \%$ cuenta propia \\
\hline Ocupación esporádica del jefe & $20,9 \%$ operario \\
& $19,0 \%$ en la construcción \\
\hline Ocupación permanente del jefe & $36,0 \%$ \\
\hline Antigüedad, ocupación permanente del jefe & $64,0 \%$ \\
\hline
\end{tabular}

Fuente: Elaboración propia, en base a encuesta a 400 hogares, Equipo Infohabitat (ICO-UNGS) 2009.

\footnotetext{
${ }^{138}$ EI SMVM es la menor remuneración que debe percibir en efectivo el trabajador sin cargas de familia por su jornada laboral. No alcanza a al trabajo "en negro" (es decir, el no registrado formalmente).
} 
En paralelo, se destaca que el 19,8 \% de los jefes y el 70,8 \% de las jefas encuestadas no se encuentran ocupados. En este sentido, puede observarse una división de género en las estrategias de obtención del ingreso. En el universo de los ocupados la mayor parte de los jefes del hogar trabajan como "cuentapropistas", operarios industriales o en el sector de la construcción. Mientras que las jefas cuando trabajan fuera del hogar, lo hacen en mayor medida como empleadas domésticas. Pero en su mayoría se autodefinen como "amas de casa" que trabajan dentro del hogar.

En relación a la composición del hogar, se observa un tamaño promedio del hogar de 5 personas (en viviendas de $44 \mathrm{~m}^{2}$ ) y el tamaño de hogar máximo registrado fue de 13 miembros. Vale aclarar que las viviendas son diseñadas como vivienda evolutiva ${ }^{139}$, por este motivo suelen observarse situaciones donde el hacinamiento habitacional se reproduce el mismo día de la mudanza. Por otra parte, las encuestas confirman la presencia de jefes de hogar jóvenes y un porcentaje elevado de mujeres solas a cargo del hogar. La edad promedio de los jefes del hogar es de 35 años de edad, pero que varía entre los 18 y los 74 años. Esto da cuenta de un doble fenómeno: por un lado, la entrega de viviendas a personas mayores como se observaba en las entrevistas y, por otro, la conformación de hogares extendidos (jefe o núcleo familiar, más otros parientes).

Fig. 34 Características composición de los hogares

Composición del hogar

\begin{tabular}{lc}
\hline Tamaño promedio del hogar & 5,03 personas (min. 1/ máx. 13) \\
\hline Edad promedio de los jefes del hogar & 35 años (min. 18 / máx. 74) \\
\hline Hogares sin presencia de jefe hombre & $18,3 \%$ \\
\hline Comparte la vivienda con otros hogares & $2,00 \%$ \\
\hline
\end{tabular}

Fuente: Elaboración propia, en base a encuesta a 400 hogares, Equipo Infohabitat (ICO-UNGS) 2009.

En la figura 34 se observa que luego de la mudanza al nuevo barrio se registra un $2 \%$ de cohabitación, es decir, hogares que comparten la vivienda con otros hogares. Sin embargo, si se compara el índice de cohabitación con la situación anterior implica un impacto positivo relevante (antes de mudarse al nuevo barrio compartía la vivienda con otros hogares un $48 \%$ de los encuestados, luego de la mudanza sólo el $2 \%$ se encuentra en dicha situación). También se registra la presencia de hogares compuestos (jefe o núcleo familiar más otros no familiares) aunque ello no se represente en la figura. Estos datos expresan de algún modo los diversos

\footnotetext{
${ }^{139}$ Estos supone un diseño de vivienda mínima que cuente con posibilidades de crecimiento futuro.
} 
criterios de asignación y como las estrategias habitacionales o formas de habitar de los sectores populares se trasladan, coexisten y se reproducen en los nuevos barrios.

Finalmente, consideremos la condición habitacional previa como un indicador clave para evaluar los criterios de adjudicación. En la figura 35, surge un primer dato de relevancia acerca de la contracción de las oportunidades habitacionales en la instancia previa a la mudanza, la mitad de los hogares compartían la vivienda con parientes propios del encuestado o de su pareja. En general, los adjudicatarios son parejas jóvenes con dos o tres hijos que se han visto imposibilitadas de acceder a la vivienda a través del mercado y buscan refugio en la vivienda o en lotes de sus padres, intensificando las condiciones de hacinamiento o cohabitación, o desarrollando proceso de auto-construcción intra-lote.

Fig. 35 Condición habitacional previa de los hogares

\begin{tabular}{lr}
\hline ¿Con quien vivía? & $48,0 \%$ con parientes propios o de su pareja \\
$45,7 \%$ sólo con su familia \\
$6,3 \%$ otro
\end{tabular}

Fuente: Elaboración propia, en base a encuesta a 400 hogares, Equipo Infohabitat (ICO-UNGS) 2009.

Al cruzar esta situación con la condición de tenencia, se deduce que una porción menor "vive de prestado" o comparte la vivienda, pero no necesariamente con parientes, es decir, el préstamo no se explica por relaciones de parentesco, sino por otro tipo de redes o relaciones (por ejemplo: quienes viven temporalmente en una residencia a cambio del cuidado de la vivienda; también se registraron situaciones en las entrevistas de quienes compartían la vivienda, pero en forma de alquiler; o quienes eran allegados a la vivienda de algún pariente al interior de villas o asentamientos). Por tanto, aunque las encuestas no reflejen en su totalidad la diversidad de situaciones, las estrategias habitacionales previas son múltiples y dan cuenta de la dificultad de lograr la autonomía residencial de las familias.

Notemos que al $61 \%$ de los hogares encuestados le prestaban la casa o el lugar donde vivía antes de mudarse al barrio, un $20 \%$ de los hogares alquilaban la casa en la que vivían, un $8 \%$ se encontraba en otra situación, el $6 \%$ vivía en una casa de su propiedad y alrededor del $5 \%$ 
vivía en un asentamiento o villa ${ }^{140}$. El dato de propietarios llama la atención y concuerda con la preocupación registrada en las entrevistas en relación a la legitimidad del proceso de asignación de viviendas y los escenarios de venta o alquiler posterior. No obstante, es importante aclarar que la falla en el diseño de la encuesta hizo que las categorías de la encuesta no fueran excluyentes y, por lo tanto, tuvieran algunas limitaciones para captar la complejidad de los fenómenos observados en el campo. Por ejemplo: en el trayecto habitacional previo un hogar podía residir en un cuarto anexo a una vivienda de propiedad familiar o dicha situación podía desarrollarse en un asentamiento o una villa (pero no hemos podido capturar dichos fenómenos).

Más allá de estas últimas limitaciones procedimentales, los resultados obtenidos muestran que las viviendas fueron destinadas predominantemente a hogares con importantes necesidades habitacionales. Por otra parte, se evidencia que la vivienda social va dirigida a los sectores de menores ingresos, aunque no gravita estrictamente alrededor de los sectores más postergados de la estructura social.

\subsubsection{Interpretaciones acerca de la "satisfacción" habitacional}

Una mirada del producto de la política de vivienda nos enfrenta de inmediato a la dificultad del cómo y qué parámetros considerar para introducir la perspectiva de los habitantes. En este sentido, el problema de la "satisfacción" nos planteó una tensión entre la elevada valorización positiva que los habitantes tienen respecto de la vivienda y el extenso repertorio de problemas edilicios que plantean o los cuestionamientos a la calidad de la vivienda. Sin embargo, un recorrido por este terreno nos permitió indagar o analizar la brecha entre el umbral de necesidades que persisten (en relación a la vivienda recibida) y la constelación de sentidos e imaginarios que giran alrededor de la vivienda. Por ello al final del apartado hablamos de una suerte de efecto de patrimonialización asociada a la "casa propia".

El segundo problema, es la dificultad de disociar del hábitat como un todo (vivienda, barrio, zona y ciudad), la percepción que los habitantes tienen de la vivienda y viceversa. Ya que estos atributos extrínsecos definen también la calidad de la vivienda y aquí aparecen, para sumar complejidad al análisis, los efectos de vecindad del entorno, la sociabilidad barrial en proceso de consolidación y las representaciones del barrio en la jerarquía de lugares de la ciudad, etc. Si bien estos aspectos serán abordados en los apartados subsiguientes, interesa resaltar que son niveles de análisis diferentes pero realidades perceptivas interdependientes.

Un primer aspecto que se registra en campo, de manera bastante generalizada, son las bajas expectativas de los habitantes en la instancia previa a la adjudicación de la vivienda. Aún cuando medie la inscripción y la visita de la asistente social, sobre el proceso de adjudicación, parece siempre sobrevolar un suerte de fantasma. Esto de algún modo nos habla del

\footnotetext{
${ }^{140}$ No obstante estos promedios generales, cabe destacar que en el caso del Barrio Santa Rosa (Florencio Varela) el porcentaje de residentes en villas y asentamientos es mayor, mientras que en el Barrio Malvinas (Esteban Echeverría) se destaca la participación de los inquilinos.
} 
escepticismo de los habitantes acerca de la concreción de la acción pública y también modela la lectura posterior. Aquí un entrevistado manifiesta el descreimiento:

"Yo no creía, la verdad. Yo estaba alquilando hacía años. Y bueno no pensaba que me iban a dar la casa. Como sabía que estaban muchos acomodados, como se dice... No pensé nunca... y después cuando veo mi nombre... bueno en la lista... No lo podía creer, no lo podía creer" (Entrevista Grupal Barrio Malvinas).

Esta suerte de fantasma de la adjudicación suele reforzarse con los episodios de venta, alquiler y un conjunto de prácticas que se ponen de manifiesto entre los mismos vecinos y también alcanzan a los funcionarios públicos. Como se puede entrever en este testimonio:

- “¿Entonces hay gente que se anotó que todavía sigue esperando...?

- Y hay gente que...

- Lo que pasa es que hay gente acomodada

- Gente que las vendió, gente que las está alquilando

- Ponele, pasaba así. Si yo me la sacaba y no la necesitaba, capaz que la alquilo. Si pasó mucho así [...]

- Pero vos todo esto lo planteás allá en Casa de Tierra y no.

- ¿Y qué pasa? ¿Qué te dicen?

- Y nada, nada. Te dicen y bueno... Hay que esperar. Están en juicio, en desalojo. Y no, no es así [...]

- Y acá los principales son algunos, más los de la municipalidad

- Maru que vendió la casa y se comprobó

- A esa!!! La que trabajaba en Tierras

- Está viviendo en un dúplex y todos los parientes están viviendo alrededor de ella. ¿Cómo es el tema? Esa es la primera que tendrían que haber sacado" (Entrevista Grupal Barrio Malvinas, varios interlocutores).

En el caso del Barrio Santa Rosa, el cuestionamiento de la "selección" es también un emergente inevitable, aunque los datos de las encuestas nos obligan a relativizar la magnitud de algunas de las afirmaciones:

-"Lo que pasa es que esto era para gente que necesita realmente, lo que pasa es que acá no hay eso, hay de todo...

-Acá tenés cada gente que tiene cada $4 \times 4$, que vos te la quedás mirando como diciendo 'Vos necesitás una casa'...

-Sí, Okm. No se hizo bien, bien.. Una selección de la gente para saber quién es realmente el que tiene un terreno en otro lado. Acá se aseguró como que no estaba pagando impuestos. Lo averiguó la asistente social. Si vos no tenés nada a tu nombre, te asignan la casa si realmente la necesitás. Pero se encontraron con gente que está viviendo en otro lado y tiene la casa, prestada o alquilada que no la necesita.

- O la vendieron. Hay millones de casos acá.

-Lo mismo que hay miles de casas desocupadas. 
-Hubo casos. Acá en la esquina se metió gente y vino la titular y los sacó con la policía. Y después metió a otra gente a vivir.

-Realmente ella no necesitaba la casa porque tiene otra casa y le asignaron esta casa" (Entrevista Grupal Barrio Santa Rosa, varios interlocutores).

En otro sentido, una lectura de la evaluación de la vivienda rápidamente nos remite a la situación previa a la mudanza. Una clave para comprender las representaciones que los habitantes tienen de la vivienda se encuentra en su condición habitacional previa y en el perfil socioeconómico. Ambas, definen un horizonte de oportunidad, donde la adjudicación irrumpe trastocando un escenario que la mayoría de las veces negaba por tiempo indefinido el acceso a la vivienda de la familia nuclear. Entre los motivos de la mudanza vemos que el $76 \%$ de los hogares requería mudarse porque compartían la vivienda/lote o vivían en un lugar prestado. Debemos considerar que el $46 \%$ previamente vivía sólo con su familia y la adjudicación de la vivienda significó, como ya hemos dicho, un desmembramiento de los hogares extendidos o compuestos.

De allí que una alta proporción de los encuestados manifiesten que el cambio de la situación familiar fue "para mejor" y que se registre una reducción de la cantidad de miembros del hogar con la mudanza. En otros casos, vemos que en la nueva vivienda se reproducen situaciones de hacinamiento originales, aunque la magnitud de estos fenómenos es menor comparada con el primero. En un fragmento de la entrevista queda reflejada esta situación:

“...cuando acá abrieron las inscripciones para las casas, nos habían pedido que pongamos la cantidad de hijos varones que teníamos, la cantidad de hijas mujeres y el matrimonio, cuántos vivíamos en cada casa. Más o menos como para organizarte una casa donde vos puedas estar cómodo. Cuando llegamos acá. Hay dos dormitorios. O sea, yo tengo a mi mamá, a los tres varones y a mi hija en un solo dormitorio. La nena tiene 9 años. Decí que los 2 más grandes se me juntaron y se me fueron si no me estaría suicidando. Me quedaron los más chicos. Y aparte ya tengo 5 nietos. Pero acá también tengo en la manzana 9 a una señora, Correa Susana que tiene 15 chicos, no tiene 1. Y le dieron también 2 dormitorios" (Entrevista Grupal Barrio Santa Rosa).

En los barrios considerados en nuestro análisis, la tipología predominante es la vivienda unifamiliar de $44 \mathrm{~m}^{2}$ en planta baja y en lote individual de 150 a $200 \mathrm{~m}^{2}$, en general, la mayoría de las viviendas se encuentran apareadas. En uno de los barrios, esta tipología se combina con otra de duplex en terrenos de $100 \mathrm{~m}^{2}$, con lo cual se obtiene una mayor densidad de población y, por lo tanto, un mayor beneficio por parte de la constructora ${ }^{141}$. Las viviendas cuentan con servicio de agua corriente, cloacas e instalación eléctrica. En el caso del gas, los barrios cuentan con la instalación de la red pero no con los servicios. Por este motivo, los

\footnotetext{
${ }^{141}$ Si bien esto supone un mayor beneficio para las empresas constructoras en el ahorro del costo del suelo urbano, vale mencionar que en el Barrio Malvinas (Esteban Echeverría), la introducción de la tipología del duplex fue producto de la negociación del equipo del IVBA con la empresa, a efectos de modificar el proyecto urbano e introducir una serie de reservas para la introducción de espacios verdes, futuros equipamientos, etc.
} 
vecinos deben abastecerse por medio de gas envasado en garrafas (y las viviendas cuentan con una casilla para este fin).

Fig. 36 Problemas y percepción de la de la vivienda

\begin{tabular}{ll}
\hline Problemas de la vivienda & $37,1 \%$ Tiene grietas o rajaduras \\
& $24,6 \%$ Tiene Goteras \\
& $26,3 \%$ Otros problemas \\
\hline
\end{tabular}

Fuente: Elaboración propia, en base a encuesta a 400 hogares, Equipo Infohabitat (ICO-UNGS) 2009.

En el interior de la casa, los principales problemas identificados tienen que ver con grietas o rajaduras, goteras, problemas con las instalaciones o los desagües cloacales, la falta de equipamiento de la vivienda, la calidad de las terminaciones, el diseño de tipología, la presión de agua, etc.

A continuación presentamos algunos extractos de las entrevistas que dan cuenta de la variada gama de dificultades con las que se han encontrado los habitantes:

-"Vos querés saber realmente lo que eran las casas, ahí tenés un ejemplo de humedad, tres veces ya voy cambiando el flotador del tanque

-Igual se rompe por el tema de la presión de agua

-Sí, acá la presión de agua que hay a la noche es impresionante y se revienta. Y después en la cocina todo lo que es esta parte se me está hundiendo el mueble que tiene un año, se está hundiendo todo por dentro por la humedad. Y después el tema de la chimenea que dejaron para el "spar" que ahí es impresionante lo que filtra el agua cuando llueve. También es impresionante lo que entra el agua de allá. Las instalaciones eléctricas las hice verificar y está todo mal. El muchacho de al lado que es electricista matriculado que vive acá con la hermana, me hizo toda la instalación [...] -Acá la mayoría cuando fuimos a vivir al barrio, varias casas, tenían los caños del desagüe tapados con material porque la empresa que estaba contratada para hacer los trabajos, el contratista se comía la plata, no le pagaba a la gente, entonces qué hacía la gente? Llenaba de material los caños.

-La llave de paso de corte de gas, también tuvimos que cambiarla porque no servía [...]

-Impresionante lo que caía por esta pared, era una cascada. Y lo que era el baño, se solucionó el tema del baño y después me saltó la cocina, empecé a notar cuando enchufé la cocina que tenía un manchón de humedad. Y ahora no hay corriente, tenemos una pérdida" (Entrevista Grupal Barrio Santa Rosa, varios interlocutores).

La tipología de la vivienda es otro aspecto controvertido en un doble sentido, tanto desde el plano constructivo como social. 
"Además las divisiones, le hicieron una división en la cocina y entremedio de las dos piezas. Entendés? Está mal diseñada. Una pieza acá, una pieza allá y la cocina en el medio. Se podría haber hecho de otra manera. La cocina comedor, mirando para adelante una cosa así. Como tiene que ser, pero la cocina está en el medio!!! Las piezas tienen que estar cerca del baño. Pero no entremedio de la cocina las dos piezas" (Entrevista Grupal Barrio Malvinas).

En otro de los fragmentos se observa como la tipología afecta la vecindad, dada la ausencia de cercos o muros entre las viviendas e ingresos enfrentados entre las viviendas:

"El frente tendría que estar mirando para allá. Ponele que tengo un problema con mi vecina, tengo problemas porque es muy chismosa, y yo que no soy ninguna quedada, chocamos. Pero no me queda otra, porque voy a vivir un montón de años acá. Y me tengo que llevar lo más mejor posible. Entonces yo tengo que abrir la puerta y topármela todos los días. Si yo pudiera pongo una pared de dos metros" (Entrevista Grupal Barrio Malvinas).

Fig. 37 Calidad de los componentes de la vivienda

\begin{tabular}{lccccc}
\hline ¿Cómo considera la vivienda en relación a...? & MB & B & R & M \\
\hline Tamaño & $7,6 \%$ & $54,7 \%$ & $31,0 \%$ & $6,80 \%$ \\
Cantidad de cuartos & $2,8 \%$ & $50,4 \%$ & $39,1 \%$ & $7,5 \%$ \\
Espacio Libre & $10,1 \%$ & $83,2 \%$ & $5,0 \%$ & $1,8 \%$ \\
Posibilidades de ampliación & $11,6 \%$ & $78,8 \%$ & $7,6 \%$ & $2,0 \%$ \\
\hline & & & & \\
Calidad paredes & $3,5 \%$ & $57,6 \%$ & $27,3 \%$ & $11,5 \%$ \\
Calidad de aberturas & $5,5 \%$ & $65,3 \%$ & $19,6 \%$ & $9,5 \%$ \\
Calidad techo & $7,8 \%$ & $76,6 \%$ & $9,8 \%$ & $5,8 \%$ \\
Calidad piso & $6,3 \%$ & $62,0 \%$ & $22,4 \%$ & $9,3 \%$ \\
Calidad instalaciones & $4,8 \%$ & $72,3 \%$ & $14,4 \%$ & $8,60 \%$ \\
\hline
\end{tabular}

Fuente: Elaboración propia, en base a encuesta a 400 hogares, Equipo Infohabitat (ICO-UNGS) 2009.

Al considerar la calidad de los componentes de la vivienda en relación a la calidad de paredes, aberturas, techos, pisos e instalaciones. Podemos observar en una escala que se ordena para todos los componentes mencionados del siguiente modo: "buena", "regular", "mala" y "muy buena". Si bien, predominan las categorías intermedias y cierta "conformidad", ya hemos dicho que en las entrevistas grupales el énfasis puesto por los vecinos en los problemas constructivos se vuelve un tema recurrente. El testimonio a continuación muestra un indicio de cómo la lectura de la "satisfacción" se mezcla con la necesidad y los problemas:

"Y uno que lo necesitaba realmente era bueno, viste? $Y$ bueno, después los problemas... a mí también me rompieron todo el baño porque al abrir el agua principal, 
empezás a filtrar, filtrar y viene a ser un codo que está debajo de la canilla de la ducha" (Entrevista Grupal Barrio Santa Rosa).

En estas líneas otro de los vecinos sentenciaba:

“...no creo que se pueda para más tampoco...” (Vecino Barrio Malvinas).

Aquí, los entrevistados relatan con detalles los avatares de otras deficiencias vinculadas al problema de los desagües cloacales :

-"Debajo de eso hay otro cordón. Porque la calle quedó muy baja, un metro y medio baja. Le rellenaron más taparon todo el cordón que ya estaba todo terminado. Lo rellenaron con más toscas e hicieron otro cordón arriba y la cloaca quedó tapada, lo que es el caño de desagüe. No tiene salida a la calle [...]

-Sí tenemos cámaras pero bajo tierra, mirá como está ésta, con tres filas de ladrillos la tuvimos que levantar

-Y yo todavía no la encontré la cámara [...]

-El respiradero del baño que sale para afuera, ese caño, pasa por la cocina y por el baño, es la misma y el olor sale por la cocina, de la cloaca.

-Yo sentía un olor a podrido y decía 'de dónde sale". Y me dí cuenta que ese mismo caño que sale para afuera. Se ahorraron un respiradero

-Yo hecho lavandina y agua hervida todos los días" (Entrevista Grupal Barrio Santa Rosa, varios interlocutores).

En la figura 37 la "calidad" de las paredes es uno de los aspectos que recibe mayor cuestionamiento. No sólo por el grosor y la terminación, sino especialmente por el apareamiento de las viviendas ( $y$ el escaso aislamiento sonoro) cuestión que afecta la intimidad familiar. Esto se relaciona con el espacio de la privacidad y con la idea de que lo que ocurre dentro del hogar no debe trascender las paredes. El testimonio a continuación grafica algunos de estos aspectos:

-"Muy lindo los modelos pero no me gusta lo que es el tema pegado a la pared.

-Es que la casa en realidad es una sola.

-Claro es una sola, yo le hago una puerta ahí en el medio y ya estoy en la otra casa y ya somos parientes. Son ladrillos de 15 creo...

-No son de 8... Más el revoque que lleva deben ser $12 \mathrm{~cm}$, si llega...

¿¿Y eso le trae algún tipo de problemas?

-Y es que escuchás todo...

\section{-Lo que pasa es que tendría que haber sido separada}

-Si vos no querés escuchar a tu vecino, tenés que hacer otro muro

-Vos imagináte cuántas paredes se ahorraron

-Si querés llegar a edificar algo algún día arriba. A estas casas le tenés que hacer columnas, porque no tienen columnas" (Entrevista Grupal Barrio Santa Rosa, varios interlocutores). 
Fig. 38 Las modificaciones de la vivienda

\begin{tabular}{ll}
\hline ¿Hizo modificación o terminación a la vivienda? & $62,0 \%$ No \\
& $38,0 \% \mathrm{Si}$ \\
\hline \multirow{2}{}{ Cuál? } & $47,6 \%$ Rejas \\
& $20,7 \%$ Cerco \\
& $11,0 \%$ Piso cerámico \\
& $6,2 \%$ Cuarto \\
& $3,4 \%$ Pintura \\
& $2,1 \%$ Baño \\
& $2,1 \%$ local comercial \\
& $1,4 \%$ lavadero \\
& $1,4 \%$ garaje \\
& $1,4 \%$ galería \\
\hline
\end{tabular}

Fuente: Elaboración propia, en base a encuesta a 400 hogares, Equipo Infohabitat (ICO-UNGS) 2009.

Fig. 39 Los cambios en la vivienda a futuro

\begin{tabular}{ll}
\hline ¿Necesita ampliar/modificar vivienda? & $82,7 \% \mathrm{Si}$ \\
\hline ¿Cuál? & $17,3 \%$ No \\
& $75,5 \%$ Dormitorio \\
& $9,5 \%$ Medianera \\
& $4,0 \%$ Otros \\
& $2,8 \%$ Lavadero \\
& $0,9 \%$ Baño \\
& $0,6 \%$ Pintura \\
& $0,3 \%$ Local comercial \\
\hline
\end{tabular}

Fuente: Elaboración propia, en base a encuesta a 400 hogares, Equipo Infohabitat (ICO-UNGS) 2009.

Antes de indagar sobre las modificaciones que los habitantes han realizado a las viviendas. Vale aclarar que las unidades entregadas cuentan con dos dormitorios, baño, cocina integrada al comedor y una pileta de lavadero externa. En estas viviendas el 38\% de los encuestados hizo modificaciones o terminaciones. Entre estas modificaciones sobresale: la colocación de rejas, los cercos perimetrales y la colocación de piso cerámico. Por otra parte, el tamaño y la cantidad de cuatros es uno de los aspectos en la agenda de las familias que surge de una doble determinación: el formato de la política de vivienda mínima (o vivienda evolutiva) y la presión demográfica de las propias familias en crecimiento.

En relación a las necesidades de ampliación o modificación de la vivienda, el $83 \%$ de los encuestados manifestó que necesita ampliar o modificar la vivienda, la principal prioridad es añadir un dormitorio y la segunda con una distancia considerable es realizar un cerramiento perimetral. Si bien, el 93\% de quienes manifiestan necesitar otro dormitorio aún no han logrado construirlos, en general, la mayoría de encuestados observan en el lote posibilidades de 
crecimiento o ampliación ${ }^{142}$. Aunque la falta de recursos aparece en la mayoría de los casos como la principal restricción. En el corto plazo (un año y medio en promedio desde la adjudicación de las viviendas) 1 de cada 12 familias encuestadas ha podido afrontar la construcción de un nuevo dormitorio.

Fig. 40 Usos complementarios de la vivienda

\begin{tabular}{lc}
\hline ¿Algún espacio de la vivienda destinado a actividad no residencial? & $88,3 \% \mathrm{No}$ \\
& $11,8 \% \mathrm{Si}$ \\
\hline \multirow{2}{}{ ¿Cuál? } & $80,0 \%$ Comercio \\
& $8,9 \%$ Actividades comunitarias \\
& $4,4 \%$ Actividades religiosas \\
& $4,4 \%$ Otras \\
$2,2 \%$ Taller
\end{tabular}

Fuente: Elaboración propia, en base a encuesta a 400 hogares, Equipo Infohabitat (ICO-UNGS) 2009.

Otro aspecto controversial es la restricción de usos. En el convenio de adjudicación de las viviendas a los usuarios, al consultar por la existencia de espacios en la vivienda destinados a actividades no residenciales, el $12 \%$ de los hogares respondió que destina algún espacio de la vivienda a actividad no residencial. El comercio lideró el $80 \%$ de los casos, seguido de las actividades comunitarias, las actividades religiosas y los talleres. Complementariamente, resulta interesante destacar que el $48 \%$ de los vecinos realizan las compras diarias en el mismo barrio.

La situación antes mencionada muestra algo evidente que la política de vivienda normalmente niega. Por un lado, el espacio residencial funciona muchas veces como un espacio productivo (o el lugar donde funcionan actividades complementarias a los ingresos de los miembros del hogar, sobre todo, en los momentos de retracción del empleo) ${ }^{143}$. Por otra parte, muestra que la aglomeración de 2.500, 5.000 y 10.000 habitantes constituye una localidad urbana en sí misma que demanda una serie de funciones (comerciales o productivas).

Esto advierte al mismo tiempo, la escala que finalmente adquirieron muchos de los productos de la sumatoria de contratos de obras en un mismo espacio. $Y$ la realidad económica de las familias o el desarrollo de estrategias complementarias de obtención de ingresos, que paradójicamente en algunos casos, son actividades penalizadas por el municipio:

- "Te cobraron multa ¿por qué? ¿por un comercio?

\footnotetext{
${ }^{142}$ En el caso de algunas variantes tipológicas los entrevistados presentan dudas al respecto (por ejemplo en la tipología de viviendas en "tira", apareadas o dúplex).

${ }^{143}$ En los barrios se instalaron kioskos, pequeños almacenes, verdulerías, carnicerías, pizzerías, panaderías, talleres mecánicos, herrerías, entre otras actividades.
} 
-Sí, abrí la ventanita, como no tenía trabajo algo tengo que vender, estuve trabajando y esos $\$ 1000$ los invertí en el kioskito. Esto fue el mes pasado, tengo la multa ahí y el acta que le hicieron a mi señora" (Entrevista Grupal Barrio Santa Rosa).

Por último, al inicio del apartado hemos dicho que en el campo identificamos cierta tensión entre la valoración positiva declarada por los habitantes y el repertorio de problemas identificados. Un análisis general de los datos de las encuestas nos muestran que casi el $91 \%$ de los encuestados tiene una opinión satisfactoria de la vivienda y al menos del $2 \%$ se manifiesta insatisfecho (ver figura 40). Esto coexiste con la necesidad de los hogares de ampliar o modificar la vivienda y con las quejas por rajaduras o goteras, problemas con las instalaciones o los desagües cloacales, la falta de equipamiento de vivienda, el diseño de tipología que atentan contra la intimidad familiar, etc. En este sentido, el registro del "acceso a la casa propia" nos aporta un indicio importante que se traduce en una imagen de "comodidad" respecto a la situación habitacional previa.

En síntesis, podemos decir que resolver el salto de la barrera habitacional tácita existente para la mayoría de las familias, parece independiente de la forma o las condiciones en las cuales llevarlo a cabo. La comodidad de contar con un techo resultaría más significativa que las incomodidades generadas por (o percibidas en) la nueva residencia. Muchos declaran tener interés en pagar la vivienda, aún sin saber cuándo terminarán de hacerlo. A su vez, en un contexto de escasez de activos se cuela el legado inter-generacional o la idea de dejarle algo a los hijos. Este efecto de patrimonialización es, a nuestro juicio, el principal ordenador de las representaciones contradictorias que se tejen alrededor de la vivienda.

\subsubsection{El día después, espacio barrial y sociabilidad "en obra"}

A continuación se analizan algunos elementos que intentan dar cuenta de por qué los adjudicatarios tienen una valorización diferencial de la política de vivienda "puertas adentro" y "puertas afuera". Dos grandes cuestiones organizan, a nuestro modo de ver, las representaciones que aquí se ponen en juego. La primera, se asocia al modo particular que asume el proceso de sociabilidad barrial. La segunda, se vincula con la posición del barrio en la jerarquía urbana. En otras palabras, el día después de finalizada la obra y adjudicadas las viviendas comienza el proceso de construcción social de la espacialidad barrial. Allí entran a jugar los distanciamientos e intercambios entre los vecinos, el surgimiento de una larga lista de problemas, la organización alrededor de nuevas demandas, los efectos de vecindad del entorno, el estatus del barrio en los imaginarios urbanos, el problema del acceso a los equipamientos, entre otras dimensiones que a continuación intentamos caracterizar.

Un primer dato que se recoge en las entrevistas es la sensación de los vecinos de la desatención del barrio por parte del Estado, es decir, el día después de la adjudicación. A la intensidad del acto de entrega y la mudanza, le siguen las peripecias de los reclamos. Una vez 
pasado el año de garantía de obra ${ }^{144}$ la empresa constructora se retira de la escena. El ciclo de atención de los "vicios constructivos" se cierra y en este punto cambian los problemas, los interlocutores y los tiempos de respuesta en el ámbito municipal se aletargan. Aquí uno de los testimonios introduce el factor tiempo a la lectura de la política de vivienda:

"Y bueno cuando llegamos la verdad que uno está contento porque bueno recibimos la casa. Este... Estaba todo lindo, todo bien. Claro a medida que va pasando el tiempo uno se va dando cuenta..." (Entrevista Grupal Barrio Malvinas).

Sólo observemos un ejemplo de los tantos presentados por los vecinos, vinculados a los problemas del día después:

-“...cuando vino Edesur teníamos el problema de los medidores, claro, los medidores estaban bien puestos, pero la numeración de las casas no y a nosotros nos tocaba del otro lado.

-Vos vivías acá pero tu medidor estaba allá. Un lío tremendo, pagabas la luz del vecino" (Entrevista Grupal Barrio Santa Rosa, varios interlocutores).

Como éste varios testimonios dan cuenta de que, por un tiempo prolongado, el barrio seguirá en obra, ya sea por lo que aún falta para convertirse en un barrio más de la ciudad o ya sea por un conjunto de decisiones o acciones mal resueltas en la etapa previa. Para la mayoría de los vecinos, según los datos de la encuesta, no existe ninguna iniciativa o nuevos proyectos por parte del municipio para mejorar el barrio. Aunque como veremos las demandas son variadas y parecen inscribirse en gran medida en los que podríamos denominar aspectos intrínsecos de la dimensión urbano-habitacional.

\subsubsection{Desconfianza, integración e intercambios}

Otro de los aspectos que surge al introducirnos en el universo barrial es la desconfianza o distanciamientos entre los vecinos ${ }^{145}$. En este sentido, es importante recordar que el proceso de conformación barrial supone la reunión de cientos de familias de distintos lugares en un lapso muy breve de tiempo. Esta generación casi "instantánea” de los barrios de vivienda social asociada a una suerte de "migración" masiva sin redes de origen-destino, con escaso trabajo de acompañamiento previo ( $\mathrm{y}$ posterior) por parte de Estado y nula participación de los habitantes, contribuyen a explicar en algún punto esta desconfianza mutua. Un barrio convencional que suele caracterizarse por el devenir de mudanzas paulatinas o allegamientos familiares que se distribuyen temporalmente en largos períodos, es decir, esto supone que el recién llegado se inserta con algún tipo de vínculo al mundo social de los "establecidos". Pero los casos que aquí se analizan muestran una dinámica completamente diferente. Por este

\footnotetext{
${ }^{144}$ Período de tiempo en la cual la empresa constructora debe responder por las deficiencias constructivas.

${ }^{145}$ Esto sin embargo no inhibe una variada gama intercambios.
} 
motivo es necesario considerar los procesos de reconocimiento, hacia afuera y hacia adentro del barrio:

-“Llegamos a un lugar que no nos querían, nadie de los barrios de alrededor. No podías salir a comprar nada porque te discriminaban. Te atendían por la rejilla, no terminabas de decir quiero medio kilo de pan que te cerraban. Eso cuando llegamos, ahora ya está normal" (Entrevista Grupal Barrio Malvinas).

También se puede advertir el cambio en las relaciones al interior del barrio:

-"Porque antes al no conocernos, al no saber quién eras vos, vos. Teníamos miedo, por ahí nos metíamos a ayudar y vos nos sacabas carpiendo.

-Éramos bichos raros

-Nos mirábamos todos como con desconfianza

-Ahora no! Yo sé que él tiene un problema y voy a ir ahí y me voy a parar en el portón. Y seremos dos los del problema, o tres, como pasó acá en la esquina, como cuando les pasó a las pibas éramos un montón" (Entrevista Grupal Barrio Malvinas, varios interlocutores).

Fig. 41 Integración, intercambio y problemas entre vecinos

\begin{tabular}{|c|c|}
\hline Integración con los vecinos del barrio & $\begin{aligned} 56,4 \% & \text { Poca } \\
31,6 \% & \text { Mucha } \\
2,0 \% & \text { Nada }\end{aligned}$ \\
\hline Problemas con vecinos del barrio & $\begin{array}{ll}61,2 \% & \text { No } \\
38,8 \% & \text { Si }\end{array}$ \\
\hline Tipo de problemas entre vecinos & $\begin{array}{r}73,1 \% \text { discusiones vecinos (perros, basura, música) } \\
23,4 \% \text { inseguridad (drogas, delincuencia) } \\
3,4 \% \text { otros (violencia doméstica) }\end{array}$ \\
\hline ¿Tiene algún tipo de intercambio con los vecinos? & $\begin{array}{l}59,8 \% \text { Préstamo de herramientas } \\
55,8 \% \text { Intercambio de información } \\
32,3 \% \text { Préstamo de alimentos } \\
\text { 28,0\% Cuidado de niños } \\
\text { 16,5\% Préstamo de dinero } \\
\text { 13,8\% Trabajos en la vivienda }\end{array}$ \\
\hline Frecuencia de los intercambios & $\begin{array}{l}56,1 \% \text { Poca } \\
43,9 \% \text { Mucha }\end{array}$ \\
\hline
\end{tabular}

Fuente: Elaboración propia, en base a encuesta a 400 hogares, Equipo Infohabitat (ICO-UNGS) 2009.

Por otra parte, aunque la mayoría de las familias sostienen que la integración de los vecinos del barrio es poca, los problemas entre vecinos no parecen transcender los desencuentros de expectativas de sociabilidad, costumbre o hábitos distintos. La poca integración entre los vecinos y la presencia de algunos problemas, sin embargo no atenta contra un sinnúmero de intercambios que se verifican en la dinámica cotidiana del barrio entre los vecinos próximos ${ }^{146}$.

\footnotetext{
${ }^{146} \mathrm{En}$ las entrevistas se constata que cada hogar tiene algún vínculos más o menos estrechos con 2 o 3 hogares normalmente lindantes o cercanos a su vivienda, mientras que hay partes del barrio que directamente no las conocen o las evitan.
} 
Los préstamos de herramientas, el intercambio de información, el préstamo de alimentos, el cuidado de los niños suelen ser los más frecuentes, más raro es el préstamo de dinero o el hecho de trabajar en la vivienda de algún vecino (ver figura 41).

\subsubsection{Organización en torno a nuevas demandas}

Otra cuestión interesante de resaltar es que a pesar de que los vecinos no se encuentran organizados de manera estable (en términos de una organización consolidada), esto no impide la configuración de diversas demandas y la organización en base a intereses concretos no estables. En general los municipios buscaron promover la organización del barrio a partir de una estructura de delegados por manzana, con mayor o menor nivel de éxito. En algunos casos (o sectores del barrio) esto opera de manera solidaria con la pertenencia de los vecinos a redes municipales preexistentes, en otras, entran en franco conflicto. En este sentido, los nuevos barrios suelen estar atravesados por el desembarco de redes de mayor escala que buscan tener presencia (o control) a nivel barrial y vecinos que se organizan de diversas maneras frente a reclamos, demandas o actividades concretas. Existe desde ya, entre ambas dimensiones, diferentes modos de articulación o vasos comunicantes.

Fig. 43 Organización en torno a nuevas demandas

\begin{tabular}{lc}
\hline ¿Los vecinos se juntaron para hacer algún reclamo al municipio? & $64,3 \%$ No \\
& $35,7 \%$ Si \\
\hline ¿Los vecinos están organizados de alguna manera? & $80,9 \%$ No \\
& $19,1 \% \mathrm{Si}$ \\
\hline ¿Cuál? & $45,6 \%$ Los vecinos de la cuadra \\
& $38,2 \%$ Delegados \\
& $8,9 \%$ En torno a la seguridad \\
& $5,9 \%$ Manzanera \\
& $1,5 \%$ Petitorio \\
\hline \multirow{2}{}{ ¿Existen Nuevos proyectos del Municipio para mejorar barrio? } & $83,0 \%$ No \\
& $17,0 \%$ Si \\
\hline ¿Cuáles? & $74,2 \%$ Equipamiento \\
& $16,1 \%$ Transporte \\
$9,7 \%$ Otros
\end{tabular}

Fuente: Elaboración propia, en base a encuesta a 400 hogares, Equipo Infohabitat (ICO-UNGS) 2009.

Aunque la solidaridad o la "buena vecindad" no pareciera ser uno de los rasgos observados en las encuestas, numerosos relatos dan cuenta de relaciones fluidas y el conjunto de prácticas impulsadas por los habitantes en torno a la mejora del barrio. La gama de las accines organizadas por los habitantes es de lo más variada, se extiende desde la realización de concursos para definir el nombre del barrio o de las calles, mantener la plaza o los espacios públicos (inclusive colaborando con aportes monetarios), firmar un petitorio para demandar la escuela, el jardín o el ingreso del transporte hasta para reclamar por la inundación de determinado sector del barrio o la voladura de techos. 
Las reuniones con concejales, secretarios, diputados dentro y fuera del barrio para canalizar demandas también suelen ser frecuentes.

"Tedesco que pertenece a la municipalidad. Es como si fuera que a este barrio se lo tomó propio... ella es la dueña, ella decide, ella hace, deshace [...] Antes venía y hacía reuniones allá en el fondo, a la tercera, cuarta reunión que hizo fue que se agarró conmigo, porque yo le conté a todos los vecinos lo que pasaba en la reunión del Municipio. Yo venía y era boca de urna, me preguntaban y yo decía porque no tengo nada qué esconder, la que vive soy yo, ella no..." (Entrevista Grupal Barrio Santa Rosa).

A pesar de los fluidos contactos con la estructura política municipal, entre los vecinos suele aparecer una distinción entre el adentro y el afuera del barrio y/o entre "quién trabaja para..." y "quién trabaja por el barrio", en este otro testimonio vuelve a introducirse esa distinción:

"Antes de entrar, se dijo quién quería participar de la sociedad de fomento. Estábamos todo el grupo que supuestamente nos mudábamos en la primera tanda. Nos levantamos creo que como 30, quedamos 20. Después fuimos al Municipio delante de un abogado a hacer una votación. De los 20 se retiraron todos, quedaban solamente 3 [...] Pero, por qué. Porque vos no podés ir a los 4 meses de vivir acá, habiendo peleado para ya tener la escuela... y que te vaya el vicepresidente $y$ que te lleve a una vecina y a otro vecino y que te lleve allá y el vecino te diga no si en la escuela con buena voluntad 50 pibes te entran en un aula. Y la otra señora le llevó una carta de agradecimiento al intendente que no importaba que los chicos no tuvieran escuela, gracias por tener un techo" (Entrevista Grupal Barrio Santa Rosa).

Por otro lado, encontramos grupos de vecinos que se han organizado para arreglar las calles, colocas, cestos de basura, hasta para tramitar frente al IVBA la reasignación de las viviendas frente a situaciones de abandono o alquiler, e incluso para "desterrar" a quien realiza actividades ilícitas. En uno de los barrios, los vecinos se juntaron para hacer una pintada en la casa de quien siendo funcionaria vendió cupo en la lista de adjudicatarios. En otro barrio, un vecino perteneciente a una organización piquereta intentó armar un comedor y fue rápidamente desactivado por el aparato de control territorial del intendente, al igual que otras iniciativas llevadas adelante por otros vecinos, como solicitar mercadería a nivel provincial $u$ organizar ferias barriales.

Otro tipo de estrategias de los vecinos fue recurrir a los medios de comunicación como una forma ampliar el reclamo desatendido por el municipio:

-"Para tener escuela tuvimos que primero ir al diario de acá de Varela, ir caminando, llamar a los chicos de 'La Liga' y a 'Argentinos por su Nombre' -Irnos ahí con los chicos con guardapolvo todo, nosotros poner una mesa ahí, dos profesores se vinieron con sus guardapolvos. Acá, donde estaba la supuesta escuela virtual. Entonces dimos clases de apoyo escolar en el campo y ellos mostraban 
la escuela virtual y cómo los chicos estaban sentados estudiando en el piso. Y eso es lo que tuvimos que hacer, mirá a lo qué llegamos para que nos hagan la escuela. Encima la empresa que estaba contratada para la escuela es fantasma, nunca existió -Pero también le metieron pata porque se estaba pudriendo todo ya acá. Nosotros dábamos las clases en el campo y en la vereda de enfrente la teníamos a la mujer del intendente sentada en un auto de vidrios polarizados mirando lo que nosotros hacíamos. Se iba a armar semejante bardo..." (Entrevista Grupal Barrio Santa Rosa, varios interlocutores).

\subsubsection{Los problemas del barrio}

Entre el conjunto de dificultades que surgen, uno de los principales problemas deviene del desfasaje de la provisión de los equipamientos básicos de salud o educación. Encontrar "vacantes" en la escuela de los barrios de alrededor para muchos fue imposible, significó, en algunos casos, pérdidas del ciclo lectivo. La recurrencia de esta cuestión en todos los barrios muestra la desarticulación entre las distintas áreas y niveles de gobierno y el modo en el cual se concibe a los proyectos urbanos como sumatoria de viviendas.

En este punto es interesante señalar algunas de las estrategias que desarrollan las familias. No conseguir vacante en los barrios próximos, significó para muchas madres realizar grandes desplazamientos al barrio de origen y requerir utilizar uno, dos y hasta tres medios de transporte. En otros casos, el impacto del gasto de transporte en la economía del hogar implicó optar por el abandono del ciclo lectivo. En algunas situaciones, registramos fenómenos de doble residencia, es decir, los escolares permanecían en la zona en la que se encuentra la escuela (con algún pariente que aún vive en el barrio anterior) durante la semana o hasta finalizar ciclo lectivo.

"La más grande se queda en la casa de mi mamá, allá en La Carolina, no se quiso cambiar de escuela..." (Vecina del Barrio Santa Rosa).

También se identificaron casos de adolescentes que aún teniendo la posibilidad de asistir a un establecimiento próximo optaron por la escuelas de origen, debido a que sus vínculos sociales se encontraban consolidados en el barrio anterior e incluso, en algunos casos, temían ser estigmatizados en la nueva escuela por su pertenencia barrial.

Al indagar sobre qué problemas existen en el barrio, en primer lugar los hogares identifican la seguridad, seguido de los problemas entre vecinos y la falta de equipamientos (ver figura 44). En las entrevistas aparece cierta preocupación por los grupos de "adolescentes de la esquina", la presencia de la droga en la barrio o algún caso delictivo. Sin embargo, esta representación de la inseguridad debe ser contrapuesta a la opinión que los habitantes tienen del barrio. En este caso, el $44 \%$ de los hogares se inclinan por remarcar la "falta de equipamientos" como una de las principales falencias del barrio, el 38\% opina que el barrio es "tranquilo" y el $27 \%$ plantea que existe "falta de seguridad" (ver figura 38 ). 
Fig. 44 Principales problemas del barrio

\begin{tabular}{ll}
\hline ¿Existen problemas en el barrio? & $53,8 \%$ No \\
& $46,3 \% \mathrm{Si}$ \\
\hline ¿Cuáles? (Respuesta múltiple) & $58,3 \%$ Seguridad \\
& $16,0 \%$ Problemas con vecinos \\
$13,4 \%$ Falta de equipamiento \\
$12,8 \%$ Deficiencia de las viviendas \\
$5,3 \%$ Problemas mantenimiento del barrio \\
$0,5 \%$ Falta de Transporte \\
\hline
\end{tabular}

Fuente: Elaboración propia, en base a encuesta a 400 hogares, Equipo Infohabitat (ICO-UNGS) 2009.

Fig. 45 Opinión barrio (respuesta abierta reagrupada)

\begin{tabular}{ll}
\hline Percepción del barrio & $44,5 \%$ Falta de Equipamiento \\
¿Qué opina del barrio? (Respuesta & $38,0 \%$ Tranquilidad \\
múltiple) & $26,8 \%$ Falta seguridad / Droga / Delincuencia \\
& $13,3 \%$ Alejado del Centro / Falta de Transporte \\
& $11,5 \%$ Problemas mantenimiento / Limpieza de barrio \\
& $9,5 \%$ Chicos en la calle / Gente Molesta / Ruidos Molestos \\
& $7,3 \%$ Solidaridad / Buenos Vecinos \\
& $3,5 \%$ Espíritu de progreso de la gente / Vecinos mejoran
\end{tabular}

Fuente: Elaboración propia, en base a encuesta a 400 hogares, Equipo Infohabitat (ICO-UNGS) 2009.

A diferencia de los equipamientos comunitarios, la redefinición de las líneas de transporte (o el acceso de las mismas al barrio) fue un reclamo rápidamente atendido dada la flexibilidad del servicio. Aunque las demandas de los vecinos en este punto persisten, y se asocian a la calidad, la frecuencia y los horarios a partir del cual el barrio queda literalmente desconectado. Por otra parte, no se debe perder de vista que la escasez de recursos hace que el transporte público aparezca prácticamente como la única opción de movilidad:

“...lo que se te dificulta acá es salir" (Entrevista Grupal Barrio Santa Rosa).

Otro de los testimonios muestra varias complejidades asociadas al problema:

- $Y$ después otra cosa, con el tema transporte el intendente no deja que entre otra línea, porque quería entrar la 178, porque en la manzana 19 tenemos un delegado de esa línea, hicieron un supuesto arreglo

-Mucha gente para una sola línea de colectivo

- ¿Sabés qué pasa? la línea 500 le pertenece, la mitad al intendente y la otra mitad al dueño de la empresa

-Claro entonces otra línea no va a entrar. Lo que tenemos sí... Es un muchacho en el fondo que tiene un camión... un colectivo y lo hace pasar por trucho, a la mañana te saca... 
-Lo que tenemos que lograr ahora es que el 500 de acá al Materno [refiere al Hospital Materno-Infantil]" (Entrevista Grupal Barrio Santa Rosa).

Los problemas de conectividad y las dificultades de acceso al transporte público es una realidad extendida a otras áreas urbanas no consolidadas. Sin embargo, esto dificulta el acceso a los lugares centrales de la ciudad y, en un punto, refuerza la condición periférica de los nuevos barrios. Además deben considerarse el impacto de los desplazamientos en los tiempos de los habitantes y en la economía familiar. En los barrios encuestados, el gasto promedio del hogar en transporte representa el $14 \%$ de los ingresos totales y en promedio, la persona del hogar que más trabaja viaja ida y vuelta alrededor de 2 horas (116 minutos) ${ }^{147}$, con registros máximos de 8 horas.

Fig. 46 Cambio de residencia y acceso al transporte / empleo

\begin{tabular}{lc}
\hline Tiempo de viaje (ida-vuelta de la persona del hogar que más horas trabaja) al trabajo & 116 minutos \\
\hline Costo mensual aproximado de gasto en transporte del hogar & $\$ 179,0$ \\
\hline Relación costo-tiempo, de viaje antes de mudarse, era... & $49,9 \%$ mejor \\
& $37,2 \%$ igual \\
¿La ubicación de este barrio le da más oportunidades de empleo? & $12,9 \%$ peor \\
\hline
\end{tabular}

Fuente: Elaboración propia, en base a encuesta a 400 hogares, Equipo Infohabitat (ICO-UNGS) 2009.

Los mayores tiempos de viaje se explican normalmente por desplazamientos de tipo metropolitano que no se restringen al municipio o los distritos lindantes. Una de las vecinas entrevistadas que trabajaba en la urbanización de Nordelta, nos brinda un ejemplo al respecto:

"...yo estaba trabajando en Tigre y de Tigre a Varela tengo 3 horas y media, como viniendo rápido, te estoy diciendo..." (Vecina del Barrio Santa Rosa).

A pesar de que, ni el costo ni el tiempo de viaje llega a capturar completamente el problema, resulta interesante comparar la relación costo-tiempo antes de mudarse al barrio. En la figura 46 , se puede observar que para el $50 \%$ de los encuestados la relación costo-tiempo antes de mudarse era "mejor", para el $37 \%$ "igual" y sólo el $13 \%$ sostiene que antes su situación anterior era "peor". Esto también puede asociarse (al igual que en el caso de los escolares) a residencia o permanencia temporaria en otros lugares de la ciudad en el marco de las estrategias de

\footnotetext{
${ }^{147}$ En el caso del Barrio Malvinas (Florencio Varela) la media alcanza los 158 minutos. Esto coincide con la localización en la matriz de la estructura urbana trabajada en la sección anterior. También es coherente con la percepción del desmejoramiento de la conectividad de los habitantes de este barrio, para el 59\% de los encuestados la relación costotiempo de viaje antes de mudarse al barrio era mejor.
} 
obtención de ingreso, que en algunos casos siguen vinculadas a los lugares de residencia anterior y en otros no, pero la mudanza al nuevo barrio ha significado una restricción en términos de la accesibilidad-conectividad.

"Yo estuve trabajando en EDESUR y de bombero en Gerli. Ya vivíamos acá y mí mayor problema era salir de acá los domingos. Yo entraba a las 7 y tenía que quedarme en Bosque en la casa de un conocido o en la casa de mi padre para poder viajar al otro día" (Vecino del Barrio Santa Rosa).

En palabras de otro entrevistado se puede ver también como actúan la redes familiares:

“Estoy más allá que acá ¿Vos seguís yendo a dónde vivías antes? Sí a la casa de mi mamá, porque a veces me salen dos o tres cortes [de jardinería] y no llego, entonces me quedo por ahí" (Vecino del Barrio Santa Rosa).

\subsubsection{El estatus del barrio}

Otro emergente son las representaciones urbanas que se construyen entorno a los nuevos barrios de vivienda social. Las mismas dan cuenta del estatus contradictorio del barrio. Los estereotipos iniciales que tienen los vecinos de alrededor son por lo general de carácter peyorativo, la denominación de los "villeros" o los "delincuentes" suelen ser de carácter corriente. Sin embargo, otro modo en el cual los barrios contiguos clasifican a los nuevos vecinos, se asocia a la idea de los "privilegiados". En los registros de campo el privilegio entrecruza una doble imagen que puede ser sintetizada como "buenos barrios, malos vecinos". Es decir, desde un afuera, el barrio adquiere una imagen positiva (por la calidad relativa en relación al entorno) y, al mismo tiempo, sus habitantes son cuestionados en términos del merecimiento de la vivienda.

-“Este barrio no figura como complejo Santa Rosa como debería llamarse, figura, la 'Villa Vip'..." (Entrevista Grupal Barrio Santa Rosa).

La metáfora de la "villa vip" sintetiza la medida en que el barrio de vivienda social se distingue de la ciudad convencional, ya que desde el punto de vista urbanístico, los barrios normalmente contrastan con los barrios del entorno. Pero desde el punto de vista social, su estatus se asemeja al de una villa o asentamiento informal. Surge así una suerte de estigmatización de la necesidad que parece difícil de erradicar y que se reproduce tanto en el exterior como en el interior del barrio.

Algunos de los testimonios dan cuenta de cómo las denominaciones del barrio acusan este estatus devaluado y una identidad aún indefinida:

-"El barrio se llama Malvinas, pero como se dice... Tiene un significado de Plan Federal, no es Malvinas... Nosotros le pusimos Malvinas, nosotros, porque vivimos acá. Pero no sé bien cómo se llama el barrio. Unos Malvinas, Barrio Nuevo, Plan Federal, Las Casitas... De todo un poquito" (Entrevista Grupal Barrio Malvinas). 
Aquí otro de los entrevistados ensaya una explicación de la diferenciación del barrio dando cuenta de la influencia del contexto de origen, rasgo que parece perdurar en la dinámica posterior:

-"Esto es más fácil si yo agarro un camión y lo lleno de vacas y los tiro en el campo a pastar y digo... 'La más fuerte va a sobrevivir'. Eso fue lo que hicieron con nosotros

-Están muy ocupados [refiere a los funcionarios], no tienen tiempo para el barrio y la gente" (Entrevista Grupal Barrio Santa Rosa, varios interlocutores).

El hecho de no figurar en el mapa es otro de los rasgos que interpela la propia identidad de los vecinos, barrios con nombres difusos, calles sin nombre, números de casa y manzana que no se encuentran, son indicios de estar en un lugar que aún no ha terminado de realizarse. La auto-denominación que realiza uno de los entrevistados en el siguiente extracto es contundente:

-"Si vos vas hoy a decirle queremos el teléfono. Te dicen, 'No, si ahí no vive nadie. Si eso es campo'. Todos fantasmitas hay acá.

-Sí... Yo me estoy peleando con Telefónica para que entre el cableado [...]

-Pero esto es campo, nosotros acá somos fantasmas" (Entrevista Grupal Barrio Santa Rosa, varios interlocutores).

\subsubsection{Las relaciones de vecindad}

En otros tantos ejemplos se observa cómo los propios vecinos del barrio construyen al interior de la geografía barrial el criterio de diferenciación. Las fronteras y límites internos, en algunos casos, se asocia a las etapas de adjudicación del barrio que imprimen diferencias, dependiendo de la composición social o el origen de la población. La ubicación adentro del barrio es valorada de modo diferente en relación al lugar reservado para los equipamientos o la calle por donde circula el transporte. Quienes se encuentran próximos al borde que conecta el barrio con el resto de la ciudad, suelen diferenciarse de los que se encuentran en el "fondo". También se observan diferencias entre quienes mantienen y mejoran la casa y quienes no lo hacen, determinadas cuadras son presentadas como ejemplos de "buenas costumbres", en contraposición a las áreas abandonadas de los vecinos que no tienen iniciativa. Los propios vecinos construyen una sectorización del barrio y hablan de lugares que prefieren evitar.

No obstante, en relación a los barrios vecinos vale aclarar que, pese a la distancia que se observa, el tiempo o el reconocimiento mutuo suele transformar las imágenes iniciales y el nivel de conflictividad real parece ser menor que el declarado. Al momento de realizar las encuestas, por ejemplo, sólo el $10 \%$ de los encuestados manifiesta registrar algún problema con los barrios cercanos. Los casos identificados en la entrevistas se tratan de problemas de discriminación, inseguridad u otros desencuentros menores. 
Fig. 47 Barrios cercanos y percepción del entorno

\begin{tabular}{lr}
\hline ¿Se registran problemas con los vecinos de otros barrios? & $\begin{array}{l}64,2 \% \text { Ninguno } \\
29,1 \% \text { Poco } \\
6,7 \% \text { Mucho }\end{array}$ \\
\hline ¿Los barrios cercanos son... que el suyo? & $\begin{array}{l}52,0 \% \text { Iguales } \\
41,5 \% \text { Peores } \\
6,5 \% \text { Mejores }\end{array}$ \\
\hline ¿El nivel socioeconómico de los barrios cercanos es... que el suyo? & $\begin{array}{l}77,1 \% \text { Igual } \\
17,1 \% \text { Menor } \\
5,8 \% \text { Mayor }\end{array}$ \\
\hline ¿Cuál es la opinión en los barrios cercanos de su barrio? (respuesta & $\begin{array}{l}60,5 \% \text { somos todos iguales } \\
13,4 \% \text { mala imagen } \\
\text { abierta reagrupada) }\end{array}$ \\
$\begin{array}{ll}13,0 \% \text { están contentos } \\
11,8 \% \text { es mejor que el de ellos }\end{array}$ \\
\hline ¿Se registra algún problema con los barrios cercanos?
\end{tabular}

Fuente: Elaboración propia, en base a encuesta a 400 hogares, Equipo Infohabitat (ICO-UNGS) 2009.

Por otra parte, es lógico que barrios de las escalas antes mencionadas introduzcan ciertos impactos en el tejido social y urbano en el cual se insertan. Sin embargo, la dinámica urbana que el barrio genera en la zona, suele ser internalizada posteriormente de manera positiva por barrios vecinos. Es decir, la mayor circulación de transporte, el movimiento de gente, la dinámica comercial, extensión de los servicios que suele generar el nuevo barrio, produce un impacto positivo en la zona. Aquí uno de los entrevistados da cuenta de ello:

"...yo converso con un vecino de afuera del barrio que tiene pollería, que él está contento porque la gente no es mala, es toda gente laburante gracias a dios la que tocó en este sector y bueno... a él también lo beneficio en ese sentido" (Vecino del Barrio Malvinas).

En relación al impacto otra entrevistada, introduce la idea de progreso que el barrio contagia en los alrededores:

"He notado que la gente de alrededor ha tratado de mejorar sus viviendas... los que son dueños, propietarios, y la tenían así nomas, pasás y notás que la están levantando mejor, mejorando la fachada..." (Vecina del Barrio Malvinas).

Si bien la encuesta muestra que en términos generales los vecinos perciben cierta homogeneidad socioeconómica y urbana entre su barrio y los barrios de alrededor, ess interesante notar que la calidad de los barrios de alrededor disminuye en comparación al nivel socioeconómico (ver figura 47) ${ }^{148}$. Esto da cuenta indirectamente del contexto urbano en el cual se insertan los barrios y, a su vez, sirve para interpretar en términos urbanísticos las diferencias

\footnotetext{
${ }^{148}$ Es decir, para el $41,5 \%$ de los encuestados los barrios cercanos son peores que el suyo (en términos de calidad), pero sólo el $17 \%$ opina que el nivel socioeconómico de los barrios cercanos es menor.
} 
(más allá del cuestionamiento del merecimiento o no de la vivienda). El relato de uno de los funcionarios grafica este contraste:

"[Refiere a la relación entre el barrio nuevo y el existente]...la dicotomía de la gente, la bronca porque el tipo de enfrente qué hizo la casa, se compró el terrenito, no tiene agua, ni cloacas. $Y$ al tipo de enfrente le dan la casa, le dan todo... 'No puede ser, ¿yo por qué nada y él por qué todo?' Esa era la bronca entre la gente que vive acá y la gente que vive enfrente... Volvíamos el lunes y nos encontramos con todos los vidrios apedreados" (Entrevista Funcionario Municipal № 5 ).

En el tejido urbano los barrios de vivienda social adquieren un efecto de "insularidad" urbana (en relación a la calidad del barrio en general) ${ }^{149}$ que es acompañado por una relativa homogeneidad en el mapa social. En general, esto parece ser coherente con las características de las áreas de adquisición de suelo para vivienda social que hemos observado en el Capítulo 3. En este sentido, la inserción urbana de los nuevos barrios se produce en zonas de bajo valor inmobiliario ocupadas por familias de bajos ingresos, normalmente, se trata de intersticio en barrios semi-consolidados (o en proceso de expansión con escasos servicios urbanos) o parcelas rurales anexadas al borde urbano La descripción de un entrevistado da cuenta de ello:

"Esto era todo campo, como es todo campo ahí atrás, ahí creo que era un tambo mecánico, no sé si seguirá estando..." (Vecino del Barrio Malvinas).

\subsubsection{El futuro del barrio}

Otra cuestión clave al momento de analizar el impacto de la política de vivienda es la pregunta por el deseo de mudarse y la percepción de proyección a futuro del barrio. El 81,5\% de los encuestados respondió que no se mudaría de barrio, mientras que el 16,5\% desearía mudarse de barrio y otro tanto tiene dudas. Si bien las interpretaciones de esta respuesta pueden ser múltiples. En términos generales, podría decirse que confirma una valorización positiva del impacto de la política. No obstante, no podemos dejar de señalar, que como hemos visto en el análisis de las trayectorias residenciales, para la mayoría de los adjudicatarios la respuesta estatal constituye la única opción, es decir, en gran medida se trata de una demanda "cautiva".

Por otra parte, entre las principales razones para sostener la segunda opinión (desearía mudarse de barrio) se encuentran el no estar a gusto con la zona, con el barrio o con los nuevos vecinos. También aparecen respuestas asociadas a la inseguridad o la necesidad de estar más cerca de la familia. O porque simplemente no logran acostumbrarse al ambiente. Es interesante observar que en ninguno de estos casos la esfera de la vivienda aparece cuestionada, más bien son los efectos de lugar los que explican dichas motivaciones. Uno de los entrevistados en Florencio Varela sostenía:

\footnotetext{
${ }^{149} \mathrm{La}$ terminación de las viviendas o la disponibilidad de agua corriente y red de cloaca suelen ser atributos que contrastan con el tejido urbano de los alrededores.
} 
"...yo siempre dije que es un barrio de m... No tenés transporte, yo allá en Bosque tenía lo que era el tren a cuatro cuadras, la Ruta 2 a cinco o seis, podía llegar a la hora que quisiera a la noche... y bueno ya eso me molestaba bastante y acá sigue igual, no hay nada. Y mi señora me dice aguanta, ya va a mejorar, va a mejorar [...] yo me mudaría otra vez para allá [...] ahí tenía todo, a una cuadra el mercado, la carnicería. Me conocían, tenía conocidos, lo que sea, a mi viejo a media cuadra" (Vecino del Barrio Santa Rosa).

Fig. 48 Deseo de mudarse y vínculo con el barrio anterior

\begin{tabular}{ll}
\hline ¿Desea mudarse de barrio? & $81,5 \% \mathrm{No}$ \\
& $16,5 \% \mathrm{Si}$ \\
\hline ¿Dónde viven los familiares que más frecuenta? & $52,0 \% \mathrm{NS}$ \\
& $20,5 \%$ En otro lugar del municipio \\
& $11,9 \%$ Fuera el municipio \\
& $10,6 \%$ En el barrio \\
& $4,6 \%$ No tiene familiares \\
\hline ¿Mantiene el vínculo con su barrio anterior? & $75,6 \% \mathrm{Si}$ \\
& $24,4 \% \mathrm{No}$ \\
\hline
\end{tabular}

Fuente: Elaboración propia, en base a encuesta a 400 hogares, Equipo Infohabitat (ICO-UNGS) 2009.

La comparación con el barrio anterior da cuenta del cambio de posición en la estructura de externalidades urbanas. Otro de los testimonios contrapone esta situación con el reconocimiento de la posesión de la vivienda y el deseo de irse del barrio:

"Yo me quiero ir para allá. Sí, es mi casa, todo lo que vos quieras. Pero... no, yo cuando me voy para allá... me quiero ir para allá" (Vecina del Barrio Malvinas)

En este otro registro reaparece nuevamente la dimensión de la centralidad urbana y deja entrever cómo es percibida la localización del barrio:

"...yo no me mudaría, ahora el resto de mi familia sí... tenían colectivos para Constitución, para Pompeya, para el Cruce Varela, para el lado de Berazategui, estaban acostumbrados a otro ritmo de vida, estaban los mercados, estaban la panadería, tenía todo, entendés? Venir acá, al medio de la nada..." (Vecina del Barrio Santa Rosa).

Otro entrevistada sostenía:

“...y extraño un poco... no es la comodidad, pero... no me gusta el ambiente, no me gusta [...] me cuesta. Me acostumbro más vale, porque ya te digo, tengo mi casa. Pero si me tengo que ir para allá, me voy [...] extraño la comodidad, que vos tenés los colectivos, no tener que andar pisando el barro..." (Vecina del Barrio Malvinas). 
Los testimonios no sólo dan cuenta del deseo de mudarse producto de las "amenidades" del barrio anterior o de la proximidad de las redes sociales, sino también como una cuestión intrínseca a la sociabilidad barrial:

- "Al principio si me gustaba, pero viste después ya cuando empezás a ver muchas cosas...

- ¿Y la casa te gusta?

- La casa sí. Me gusta porque estoy tranquila. Pero ya viste tenés algunas cosas alrededor que no te gusta. A veces me agarra el ataque y me quiero ir, me quiero ir" (Entrevista Grupal Barrio Malvinas).

La proyección a futuro del barrio es otro de los aspectos que pone en evidencia que el barrio aún se encuentra "en obra". La idea de un barrio joven dependiente del devenir de la acción pública y de la capacidad de organización de los propios vecinos es recurrente, pero la sensación de incertidumbre aparece también como una realidad que contiene las expectativas.

"Mirá yo pienso que el barrio va a mejorar ahora cuando terminen el colegio, el jardín, la salita, que entre otra línea de colectivo, va a ser otra cosa... Ya vas a ver la gente que se fue, que renunció, que alquiló, va a venir, va a volver. A la escuela le falta poco ya..." (Entrevista Grupal Barrio San Rosa).

"Uno se imagina un futuro para mejor... Uno se imagina que sí pero uno puede decir, pero de acá... Por ahí querés mejorar el barrio pero por ahí se te dá vuelta todo" (Entrevista Grupal Barrio Malvinas).

En este punto también las visiones de los vecinos son contrapuestas, mientras que algunos vecinos están convencidos que el barrio mejorará, otros en cambio no ven futuro posible:

-“...creo que va a ir decayendo un poco más de lo que está ahora

-Si acá darían más oportunidad, mejores condiciones a la gente, creo que esto puede mejorar, puede salir adelante.

-Pasa que también hay mucha gente que tiene voluntad, hay mucha que te tira en contra..." (Entrevista Grupal San Rosa, varios interlocutores).

Hasta aquí hemos realizado una descripción de los temas emergentes en el plano barrial, si bien este barrido está lejos de ser sistemático y exahustivo, de algún modo deja al descubierto la complejidad y la persistencia de los efectos que produce la propia política el día después de terminadas y adjudicadas las viviendas. Probablemente, algunos de los aspectos aquí considerados excedan el plano estricto de la política habitacional, pero muchos otros merecen ser revisados a la luz de la problematización del diseño de políticas de hábitat de carácter integral. A partir de las observaciones aquí expuestas en el apartado que se presenta a continuación y en la sección 4.3 planeamos algunas ideas de carácter más concluyente.

\subsubsection{La cartografía de la vivienda, el barrio y el entorno}


A partir de los problemáticas analizadas anteriormente en este apartado nos proponemos realizar una síntesis de la lectura de los distintos registros de campo, con el objetivo de identificar las nociones centrales que se aglutinan en torno a la entidad de la vivienda, el barrio y la zona. Por otra parte, nos interesa recuperar la metáfora de la valoración decreciente de la política (habitacional) "puertas afuera" de la vivienda vista en el apartado 4.1.3, ya que a nuestro juicio tiene un vínculo estructural con la cartografía aquí propuesta.

En la figura 49, se presenta un esquema preliminar fruto de la exploración y el análisis de los datos. Aunque se parte del supuesto que existe una intersección e interdependencia entre los universos perceptuales, se buscó identificar diferentes significados para cada una de las entidades analizadas (vivienda-barrio-zona). En otras palabras, aún cuando es imposible aislarse completamente de la percepción que los habitantes tienen del hábitat los subuniversos de la vivienda, del barrio o de la zona (de la ciudad en la que se encuentra el barrio), por recurrencia o saturación de los registros para cada uno de estos niveles de análisis, es posible identificar ciertas ideas fuerza.

En este punto, dentro del conjunto de sentidos que se vinculan a la vivienda, notamos que se condensa un significado fuertemente asociado a la patrimonizalización doméstica o efecto la "casa propia". Como ya hemos visto, esto nos permite explicar la tensión entre el elevado nivel de aceptación que ofrece la política (habitacional) en relación a la vivienda y el sinnúmero de problemas, falencias o deficiencias identificadas por los mismos habitantes.

En cambio, las representaciones dominantes de la dimensión barrial responden a una genética diferente profundamente mediada por la acción pública. El estatus del plan de viviendas, barrio estatal o de barrio de vivienda social supone un proceso particular de conformación que se presenta dispuesto a marcar la trayectoria urbana del barrio. La constitución misma de la identidad del adjudicatario unida a la necesidad. La mudanza masiva y rápida al nuevo barrio de vivienda social que es simultáneamente demandado y rechazado, y la reunión de cientos o miles de familias que se desconocen entre sí y que, al mismo tiempo, tienen por delante la ardua tarea de consolidar el barrio, da lugar un proceso de sociabilidad que tiene rasgos distintos al de otros barrios de la ciudad. De allí que los registros ligados a la entidad barrio se configuran en relación a una "sociabilidad en obra" que da cuenta del inicio de un proceso prolongado e incierto, en parte, determinado por un "final de obra" que normalmente no contempla el día después y mucho menos la participación de los sujetos destinatarios de la política.

El análisis del entorno del barrio o la zona, permitió una mirada de las condiciones de localización extrínsecas al barrio, que de un modo u otro terminan por definir el estatus o la posición del barrio en la jerarquía urbana. Interesa notar que los emergentes que giran en relación a la zona, dan cuenta de la baja cualificación urbana de los entornos (servicios, equipamientos, transporte) y los estereotipos que los barrios de alrededor proyectan sobre los nuevos vecinos. En esta instancia, la ausencia de la lectura de la ciudad como espacio público y colectivo por parte de la política de vivienda o la ubicación marginal en la estructura urbana, 
ordena las representaciones emergentes inscriptas en las perspectivas de los propios habitantes.

Fig. 49 Esquema perceptivo casa-barrio-zona en los barrios de vivienda social

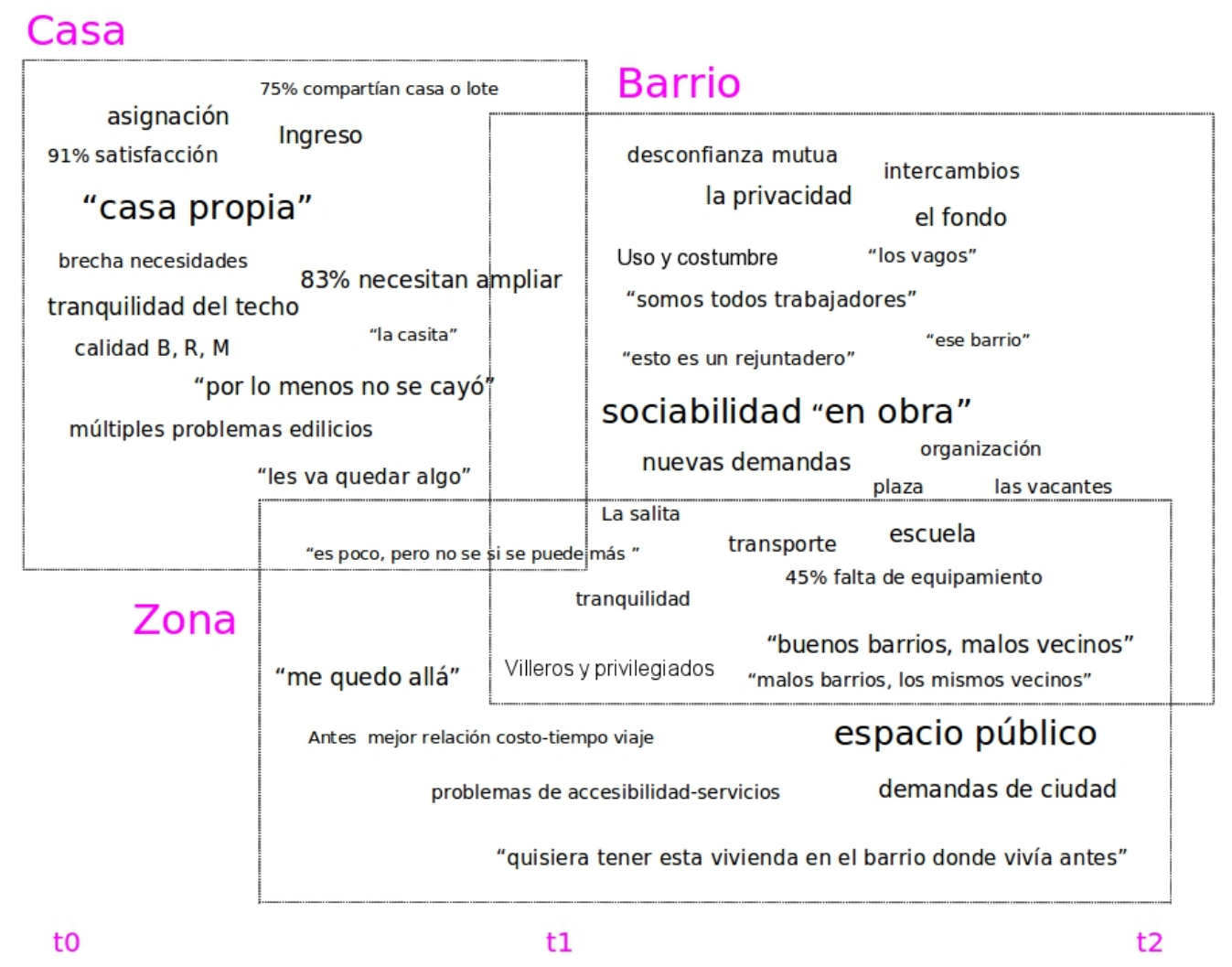

Fuente: elaboración propia.

A modo de síntesis, este recorrido exploratorio permitió reconocer subuniversos perceptivos diferentes y contradictorios entre las unidades espaciales en las cuales interviene la política habitacional. Con el esquema de la figura 50, buscamos representar la tensión existente entre la lógica del metro cuadrado y el acceso a la ciudad en el campo propio de la política habitacional.

En el ámbito de la casa, la política de vivienda es profundamente eficaz. En este sentido, el dispositivo de la industria de la construcción regulado por la máxima productivista, concibe como unidad de intervención la vivienda-lote, entidad que en nuestro análisis se manifiesta solidaria con la tranquilidad familiar de contar con un techo. Sin embargo, la dimensión colectiva del espacio urbano supone otro tipo de complejidades que se presentan opuestas a la racionalidad viviendista. El análisis del barrio, de la zona o el entorno barrial permitió visualizar (desde la integralidad de la mirada de los habitantes y, aunque más no sea, de modo indirecto) otras dimensiones en torno al hábitat, que en general colacionan con la concepción sectorial, para la cual el barrio es una simple sumatoria de viviendas. 
Fig. 50 Esquema síntesis entidades casa-barrio-zona

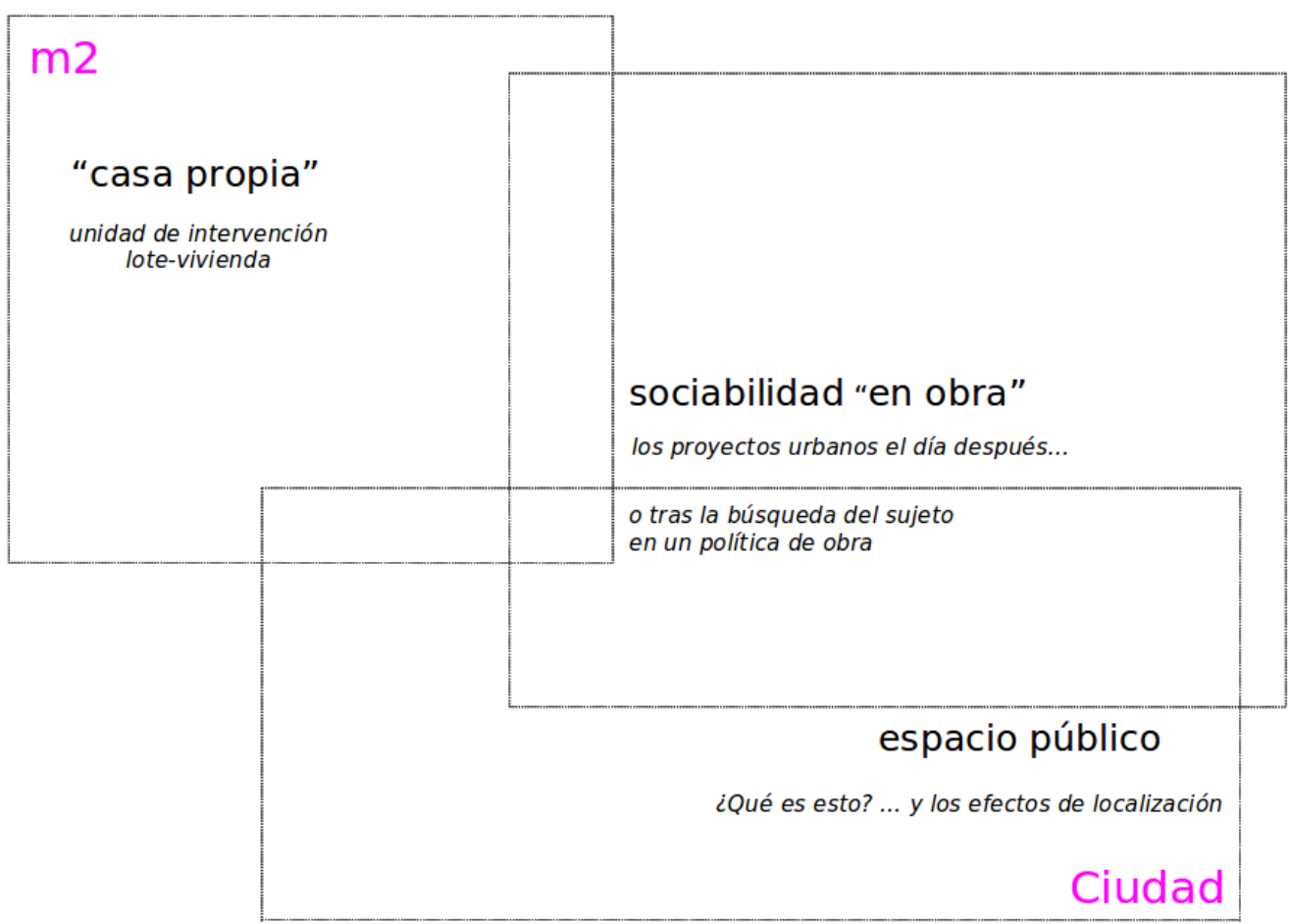

Fuente: elaboración propia.

En este punto, la ciudad -en tanto ámbito de sociabilidad, de espacio colectivo y matriz de distribución de centralidad- apareció como una materia pendiente. La mirada de cómo la política (habitacional) concibe a los sujetos de su acción y la dinámica del habitar, junto al locus propio de las viviendas sociales, da cuenta de las limitaciones del diseño y la implementación de una política de construcción de vivienda nueva. Política que continúa teniendo, por un lado, un desbalance en su relación con el espacio privado de la ciudad frente al espacio púbicocolectivo; por otro lado, la prioridad de concebir "adjudicatarios" de vivienda y no sujetos urbanos con múltiples necesidades de uso del espacio urbano.

\subsection{Quisiera tener esta casa en el barrio donde vivía antes...}

En esta sección se presenta una mirada de la política de viviendas desde la experiencia de los habitantes, a modo de cierre del capítulo 4. En la sección 4.1 reconstruimos las trayectorias residenciales de los adjudicatarios con la intención de leer el acontecimiento de la política de vivienda en el recorrido trasversal de sujetos, partimos del supuesto de que este enfoque nos permitiría restablecer la relación del sujeto con el problema del hábitat de manera más integral. En la sección 4.2, una vez identificado el perfil socioeconómico de los adjudicatarios, se 
caracterizaron los principales problemas emergentes en los nuevos barrios de vivienda social, con el objetivo de identificar los efectos de lugar generados por la política.

A partir del análisis de las trayectorias residenciales pudo observarse que existe una relación intrínseca entre: i) los cambios de residencia, ii) la dinámica de los ciclos de vida, iii) la forma y la disponibilidad de recursos de las redes en las que participan los sujetos entrevistados y iv) las propias restricciones estructurales del contexto en el que se insertan dichas unidades domésticas.

A pesar de la generalización de una estructura de opciones restringida, hemos visto que previo a convertirse en adjudicatarias de viviendas sociales, las familias pusieron en práctica diversas modalidades de resolución de acceso al hábitat. De igual modo, aunque los habitantes de los nuevos barrios comparten una posición residencial evaluada por el resto de la sociedad y autopercibida (en mayor o menor medida) como diferente, la residencia en un mismo barrio da lugar a distintas formas de habitar.

El hito de la mudanza al barrio también adquirió múltiples significados entre las familias, esto se enlaza con las características de los recorridos residenciales previos y con las expectativas sociales de los proyectos individuales o familiares y, a su vez, supone lecturas diferentes según la escala de análisis. Por ejemplo, suelen aparecer demarcadas un conjunto de distinciones entre la casa y el barrio o su inserción en la ciudad.

La reconstrucción de los relatos permitió adentrarnos, indirectamente, en el mundo del hábitat popular más allá de los barrios de vivienda social. En este sentido, se ha visto que este subuniverso del espacio residencial está atravesado por un sinnúmero de necesidades e incertidumbres. La saturación de las intensidades de uso de las viviendas de familiares y la imposibilidad de acceder al mercado formal suelen derivar en un mercado de alquiler (donde priman relaciones precarias e inestables) y, también, en modalidades de ocupación informal en el mercado inmobiliario mediadas por proceso de auto-construcción.

Por otra parte, la esfera doméstica del hábitat popular registra múltiples dinámicas. La escasez de ingresos o la discontinuidad de los mismos, dadas las características de la inserción en el mercado de trabajo, se combinan con el allegamiento y la estructuración de hogares compuestos o extendidos. En algunos casos, esto es acompañado por la intensificación del hacinamiento o la densificación progresiva intra-lote o el desarrollo de otras prácticas de adaptación habitacional acordes a: las necesidades de las familias, la dinámica de ingresos intermitentes y los ciclos de vida del hogar. El emergente del arrendamiento suele ser más frecuente avanzado el proceso de consolidación del barrio y como estrategia de ingreso complementario. En este sentido hemos visto que algunos de los entrevistados han sido inquilinos de pequeñas viviendas o departamentos con condiciones materiales deficitarias y con relaciones contractuales altamente precarias. Además, se encontraron varias situaciones en las que la vivienda a préstamo" o el compartir el espacio con otros suele ser frecuente. Para las nuevas generaciones el estar "de prestado" en el lote o en la casa de los familiares es una práctica corriente. 
La consolidación de la vivienda surge, en la mayoría de los casos, como un activo intergeneracional, en el cual se invierten recursos y esfuerzos de auto-explotación del trabajo. Esta es una brecha que en el caso de los adjudicatarios la política de vivienda parece acortar. Dicho de otra forma, aquella cuestión que parecía inalcanzable para una generación diez años atrás, mal o bien, parece haber experimentado una redefinición.

Aquí la temporalidad juega un papel importante, el acortamiento del tiempo referido a la tranquilidad de acceder a la "casa propia", está acompañado de ondas más largas en términos del reconocimiento del barrio o en el proceso de consolidación urbana más amplio. Las condiciones urbanas de los entornos barriales suelen expresar eso (lo hemos visto en los problemas de equipamiento básico de educación o salud al interior del barrio, de su conectividad con el resto de la ciudad o la cobertura diferencial de ciertos servicios urbanos).

En este escenario, las múltiples formas de hábitat popular establecen relaciones específicas con el conjunto de los tipos residenciales y las vecindades socio-urbanas. Más allá del cambio de posición residencial, los recorridos residenciales de adjudicatarios parecen encontrarse en una determinada región de la estructura urbana. En los nuevos barrios, por ejemplo, los habitantes expresan el malestar de estereotipos urbanos proyectados sobre ellos, critican la ubicación del barrio o manifiestan desarreglos de las redes domésticas a partir de la mudanza. Para algunos, el barrio es joven y constituye una apuesta a futuro. Para otros, es difícil que el escenario cambie. En algunos casos incluso la vivienda social es un dispositivo que fija al habitante al barrio, en tanto cristaliza una relación institucional de adjudicatarios a ese lugar, y ello opera como un obstáculo para la movilidad residencial. En otras palabras, salirse del barrio no está contemplado.

La capacidad de pago es una lógica que parece ordenar el universo de posibilidades, esto se traduce en la asimilación de condiciones de precariedad del mercado de alquiler, frente a la condición "de prestado" en la familia y se traslada a las viviendas sociales. El "no me puedo quejar", "no creo que se pueda más tampoco", "por lo menos no se cae a pedazos" son ejemplos de ello. Por otra parte, desde el punto de vista de la movilidad residencial, el acceso al plan de viviendas se presenta como una elección de los habitantes con un sentido progresivo. Dicho de otro modo, en el marco de posibilidades de la trayectoria es la mejor opción posible. Entonces, los problemas edilicios recurrentes son minimizados por la austeridad de expectativas respecto a la calidad del producto de la política. Se cristaliza así la imagen de que lo normal pertenece a otro nivel social.

En el plano de la relación con el Estado, el contexto de oportunidad debe ser aprovechado sea por su fugacidad como por necesidad. La aparición de los planes de vivienda tienen una escala espacial e histórica insólita en el Conurbano Bonaerense en comparación a las últimas tres décadas. $\mathrm{Y}$ esto es percibido en la misma historia habitacional de los adjudicatarios o, de manera indirecta, a través de sus redes sociales. De hecho, aún cuando habían sido confirmados como adjudicatarios de vivienda, muchos se mostraban desconfiados o se presentaron incrédulos frente al devenir del proceso: "yo hasta que no esté adentro, no les 
creo" o "me anoté pero me había olvidado". En los relatos aparecen entremezcladas, la idea del "progreso" de la acción pública en territorios relegados, con la escasa previsibilidad que tiene la implementación misma de la política y el proceso de adjudicación.

Las proyecciones externas sobre el barrio dieron cuenta de clasificaciones que varían entre la idea de "los privilegiados" y "los sospechosos de siempre". Aquí aparecen condensados diferentes aspectos: la configuración de activos y faltantes al comparar el barrio con su entrono o con las posiciones residenciales previas, el valor que tiene la resolución de acceso a la vivienda y resolver una cuestión que aparece como una problemática generacional, el cuestionamiento de la modalidad de acceso al programa y la asociación mecánica de un determinado tipo residencial a la pobreza y el delito.

Por otro lado, el registro de la experiencia al interior del barrio introdujo otros matices. En cuanto a las formas de acceso a la vivienda, se distingue entre los merecedores e "infiltrados" . Estas categorías son transversales a los casilleros de adjudicatario formal o la posesión de hecho. El otro gran organizador del barrio es el trabajo, tener trabajo o no marca quién es quién en el barrio. A su vez, las condiciones particulares de inserción de cada una de las unidades domésticas en el mercado de trabajo están estrechamente ligadas a la posición residencial previa a la mudanza al barrio.

En el juego de sociabilidad barrial encontramos que la desconfianza entre los vecinos se origina en parte, por las condiciones particulares del proceso de conformación barrial (masivo, de ocupación instantánea y fuera del contexto de las redes sociales). Sin embargo, también hemos visto que la presencia de distanciamientos sociales no anuló múltiples intercambios y procesos de organización en torno a demandas concretas para la mejora del barrio. Asimismo, debe considerarse que la dificultad en la apropiación del espacio por parte de los habitantes y de construcción de redes sociales, se ha visto agravada por la falta de espacios de participación antes, durante y después de la ejecución de las obras. Por otra parte, el seguimiento de la política ex post ha sido escaso una vez finalizado el año de garantía de obra y las nuevas demandas han estado vinculadas a la capacidad organizativa de los vecinos. Esto obliga a repensar, no sólo la instancia previa a la obra, sino lo que acontece el "día después" tanto en el plano material como simbólico.

Los resultados de las encuestas confirmaron que la adjudicación de la vivienda tiene un impacto positivo en la mayoría de los hogares, esto tiene un vínculo estrecho con las condiciones originales de acceso a la vivienda y los escasos horizontes de oportunidad para mejorarlas. Sin embargo, la capitalización económica que implica el acceso a la "casa propia", no concuerda con los niveles de capitalización de las condiciones de calidad urbana que brinda la zona en la que se encuentra el barrio. Más aún, en algunos casos, las entrevistas permiten afirmar que las unidades domésticas han sufrido una "descapitalización" de la posición intraurbana a partir de la mudanza al barrio. Hemos observado una creciente valorización de la acción pública "puertas adentro" y una valorización decreciente en relación al entorno o la zona 
donde se encuentra ubicado el barrio. De allí que la constitución de los nuevos reclamos se encontraran orientados a un conjunto de elementos que convergen en la "demanda de ciudad". Por otra parte los criterios de asignación de la vivienda han sido heterogéneos y no siempre explícitos. Sin embargo, el análisis del perfil demográfico y socioeconómico de la población adjudicataria mostró que se han objetivado mecanismos de asignación coherentes con las necesidades habitaciones de los destinatarios. En este sentido, podemos decir que para la mayoría de las familias la política ha permitido un salto de las barreras habitacionales tácitas. Esto explica en gran medida la valoración positiva del impacto de la política de vivienda en los barrios analizados, aunque no inhibe la persistencia de múltiples problemas.

La evaluación que los habitantes hacen de la acción pública en materia habitacional mostró que la "satisfacción" habitacional adquiere un vector decreciente del espacio doméstico al espacio público. Si bien esto se encuentra en gran medida determinado por el efecto de patrimonialización o "tranquilidad de la casa propia". No menos cierto es que la acción pública concibe el binomio vivienda-lote como unidad de intervención y se despreocupa por la relación entre el barrio, el espacio público y la ciudad como una matriz compleja de distribución de las oportunidades de reproducción social.

Por lo tanto, la relocalización pasiva inducida por la política de vivienda trajo aparejado una devaluación de la posición residencial de los adjudicatarios en la estructura de externalidades urbanas. En otras palabras, "puertas afuera" del barrio de vivienda social se produjo una "descapitalización" de los hogares en el mercado de localización residencial intra-urbana. La frase de uno de entrevistados es elocuente y, al mismo tiempo, marca el problema del lugar como uno de los principales aspectos críticos de la política habitacional: "quisiera tener esta casa en el barrio donde vivía antes". 


\section{Conclusiones}




\section{Conclusiones}

En las páginas anteriores hemos procurado trabajar la relación existente entre el lugar asignado a la vivienda social y el lugar (re)construido por los propios sujetos destinatarios de las viviendas. Para lograr este objetivo, uno de los ejes que ha estructurado la investigación ha sido la identificación de las mediaciones producidas por la política habitacional entre los lugares y los sujetos, por un lado, y la estructura urbana, por el otro. En otras palabras, el trabajo intenta poner en evidencia la amplia gama de determinaciones que se ponen en juego en el espacio urbano. El resultado de este recorrido da cuenta de las características particulares que asumió la inserción urbana de "política federal de viviendas" (2003-2010) en el Conurbano Bonaerense.

1. Uno de los primeros puntos sobre los que vale la pena hacer hincapié para iniciar las conclusiones generales a este trabajo es el hecho de que la magnitud de la inversión pública anunciada para la construcción de viviendas sociales en el Conurbano Bonaerense dentro del marco del Plan Federal de Viviendas resultó altamente sorpresiva para todos los actores involucrados. En el período de análisis, los compromisos asumidos por el gobierno nacional para la construcción de viviendas en éste aglomerado urbano se asemejan, en términos de la cantidad de unidades habitacionales a construir, al crecimiento registrado durante la totalidad del último período intercensal. Es más, a pesar de que los tiempos de ejecución real estuvieron lejos de los originalmente anunciados y que aún queda por ver si todas las unidades anunciadas podrán serán efectivamente ejecutadas (para lo cual se requieren nuevas asignaciones presupuestarias), la importancia que la política de vivienda actual adquiere en el área metropolitana es fácilmente perceptible. Independientemente de los motivos que llevaron al gobierno nacional a planificar y ejecutar una política pública de esta magnitud, la huella dejada por la "política federal de viviendas" en la configuración del espacio residencial del área estudiada es insoslayable. En otras palabras, lo que se intenta destacar es el hecho de que el financiamiento público intentó ajustarse a los indicadores existentes sobre el déficit habitacional en el Conurbano Bonaerense (en lugar de depender de las cuotas de coparticipación del Sistema Federal de Vivienda).

Además, cabe señalar que la impronta de esta política pública adquiere una significación adicional, asociada a la renovada intervención directa del Estado en materia habitacional en el Conurbano Bonaerense, tras tres décadas de relativo repliegue. No debe olvidarse que, durante la década de los noventa, la política habitacional en el área metropolitana se había centrado en la atención del problema de la tierra (como sostienen Cravino, Fernández y Varela, 2002), pero desde una perspectiva ex post de regularización dominial. Es decir, en el período anterior al estudiado aquí se implementó una estrategia que "corrió detrás" del problema habitacional, siendo los sectores populares los actores que protagonizaban la resolución del 
acceso al hábitat a través de los procesos de auto-construcción y auto-urbanización del ciudad. El planteo de la problemática habitacional en estos términos es coherente con la restauración de principio de responsabilidad individual en el acceso al suelo y a la vivienda, dejando como resultados el franco crecimiento de la informalidad urbana y un espacio urbano más excluyente debido a la influencia del proyecto neoliberal. Frente todo esto, resulta evidente que la aparición de la "política federal de viviendas" muestra un contraste importante.

2. En el año 2003 se inauguró un nuevo capítulo de la política habitacional argentina. Tras el desfinanciamiento del FONAVI, el sistema de viviendas había quedado paralizado e incapaz de dar respuesta a una demanda habitacional largamente postergada y recrudecida por la crisis. La profundización de las políticas de ajuste de fines de los noventa y la intensificación del ciclo recesivo rápidamente dispararon los niveles de desempleo y pobreza. Esto restringió aún más los horizontes de posibilidad habitacional de los sectores populares, que en el contexto de crisis asumieron una estrategia defensiva y orientada a la satisfacción de necesidades aún más básicas que las habitacionales.

Con posterioridad a la crisis político-económica de 2001, la salida de la convertibilidad, el reposicionamiento del Estado y la asimilación de un nuevo esquema económico generaron condiciones propicias para que se comenzara a registrar un proceso de crecimiento de la economía. En este contexto, se redefinió la orientación del gasto público, transformando a la inversión en materia de vivienda en una prioridad. El gobierno nacional transfirió una masa significativa de recursos no reembolsables a las provincias para activar el sistema de provisión pública de vivienda. Paradójicamente, esto se hizo por fuera del circuito preestablecido en el marco del Sistema Federal de Vivienda. De este modo, el gobierno nacional logró retomar control sobre el sistema de vivienda, retrotrayéndose así a la etapa previa a la descentralización del FONAVI (pero sin verse atado al marco normativo del mismo y contando con el amplio margen de maniobra conferido por la Ley de Emergencia Económica).

En este marco, se estableció como modalidad de ejecución una "política por convenio". El Estado nacional retomó la potestad de definir el "cuánto", el "cómo" y el "a quién" de la política habitacional. Sin embargo, más allá de los convenios marco, el financiamiento de cada proyecto de obra quedó supeditado a la firma de un "convenio particular" entre la Nación y los correspondientes subejecutores. De este modo, mientras que la definición de los programas y la provisión de los recursos volvieron a ser controlados de forma centralizada, la ejecución de las obras continuó siendo descentralizada. De allí que coincidamos con varios autores (Rodulfo, 2007; Rodríguez y Di Virgilio, 2008; Fernández Wagner, 2008) en observar que en el período actual se verifica un proceso de recentralización de la política de vivienda.

Esta última tendencia se confirma en los registros de los funcionarios de los distintos niveles de gobierno, vistos en el capítulo 2. Tanto a nivel municipal como provincial se observó una imposibilidad de control sobre las variables críticas (entre ellas, el control y la previsibilidad de los recursos), lo cual resulta congruente con la concepción macroeconómica que adquirió la política de vivienda actual. Además de buscar resolver el déficit habitacional, la construcción de 
viviendas sociales fue concebida por el gobierno nacional como una herramienta estratégica para el apalancamiento de la producción y la generación de empleo.

3. Uno de los elementos que mayor peso tuvo para impulsar la reintroducción de la cuestión de la vivienda en la agenda pública se relaciona a la capacidad del sector de empujar el crecimiento del PBI. En tal sentido, el PFCV (el programa más importante a nivel nacional, provincial y del AMBA por el volumen de recursos asignados y por la cantidad de viviendas construidas) fue el programa emblema del "poder de los ladrillos" como medio para generar un despegue económico. Desde esta matriz, se apuntó a generar una estrecha relación entre inversión, producción, trabajo y consumo.

La inversión pública comenzó a ser vista como la dinamizadora de la industria de la construcción y sus sectores afines, siendo su estructura atomizada y la visibilidad social de su impacto rasgos diferenciales de este tipo de obra pública. Por la gran demanda de fuerza de trabajo asociada a esta actividad, la construcción pasó a constituir una eficaz herramienta de política pública destinada a facilitar el acceso al mercado de trabajo para miles de asalariados y jornaleros. A su vez, dicho incremento en las tasas de empleo redundarían en un importante aumento en el incide en el consumo de vastos sectores de la población.

Desde una lectura económica, la inversión en vivienda adquirió un doble componente distributivo: en primer lugar, por la vía del trabajo o el ingreso; y, en segundo lugar, a través de la adjudicación de la vivienda a hogares con privaciones habitacionales. Por otra parte, el componente de la inversión en capital fijo, el pulso de los tiempos de financiamiento y el direccionamiento hacia una industria con arraigo local o regional definieron el armado territorial de la política habitacional.

De este modo, la visión productivista se presentó profundamente asociada a la necesidad de reconstruir el tejido productivo y generar empleo luego de la crisis socioeconómica y política más trascendente de la Argentina de las últimas décadas. Es más, la historia de la política habitacional muestra que existe una recurrencia de esta visión en los períodos post crisis, vinculándose tanto a la capacidad intrínseca del sector como a los intereses a él relacionados. Sin embargo, como hemos visto en el capítulo 2, esta lógica no necesariamente opera de manera solidaria con los abordajes territoriales que introducen una lectura del hábitat más integral (como la propuesta por los enfoque de los programas habitacionales conocidos como "alternativos"). Por otro lado, aunque este tipo de enfoque adquirió difusión en los noventa, continúa siendo secundario en la actualidad. Aunque se debe reconocer que se produjo dentro de la "política federal de viviendas" un crecimiento del financiamiento destinados la diversificación de otras acciones como los programas: PFEH, PFMV y SPUVYA. Y, en el año 2007, se lanzó una nueva etapa del PROMEBA II, programa de referencia de los enfoques alternativos.

En el caso de Brasil, frente al impacto de la crisis internacional, Rolnik y Kazou (2009) advierten acerca de los riesgos de adoptar una visión productivista en el marco de la política habitacional. Para ellos, la "trampa" se observaba en el hecho de estimular la producción de 
viviendas y mantener el crecimiento de la industria de la construcción radica en confundir una política de creación de puestos de trabajo en la industria de la construcción con una estrategia de política de vivienda urbana. Más allá de que la construcción de viviendas puede actuar como una solución keynesiana clásica en tiempos de crisis (basada en la movilización de inversiones públicas hacia sectores intensivos en el uso de mano de obra y de rápido despliegue), los efectos de esta política son completamente distintos a los de una política habitacional. En el plano de la política pública urbana, estos autores alertan sobre la necesidad de crear métodos de financiación que no se limiten a la construcción de viviendas nuevas en terrenos vacíos, pensando para ello en estrategias de intervención en las zonas urbanas consolidadas. Y dicen: "No caigamos en la trampa seductora de los números: un millón de hogares? Sí, pero dónde, cómo y para quién?" (Rolnik y Kazou, 2009: 5). Esta advertencia es sugerente para pensar qué sucede en el AMBA, e incluso en otros lugares de la Argentina.

En el caso del PFCV ejecutado por el IVBA, las respuestas a estos interrogantes las encontramos en los registros emergentes en el transcurso del proceso de implementación y en "el día después" del final de obra. Esta última dimensión surgió como una preocupación recurrente en los municipios analizados, los cuales asumen finalmente (juntos con los habitantes) los conflictos que surgen a nivel territorial. Pero, pese a la dependencia que comparten respecto del financiamiento central y de un conjunto de decisiones que se toman a otras escalas jurisdiccionales, los municipios analizados muestran significativas diferencias en cuanto a la reflexión que producen sobre las problemáticas emergentes en el transcurso de la implementación de la política, el modo de encausarlas y la introducción de variantes en la realización de la acción pública.

Esto se encuentra determinado, en gran medida, por: las trayectorias o experiencias de gestión urbana; la existencia, en algunos casos, de un proyecto de urbano municipal explícito que piense desde otro lugar la relación con la vivienda social o el hábitat popular; el impacto previo generado en algunos municipios por los programas habitacionales "alternativos", incidiendo en el reprocesamiento de la cuestión en gestión a nivel local; $y$, las variaciones que introducen las condiciones sociales, técnica y políticas a nivel distrital. De allí que, en período analizado, el contraste entre los municipios de Florencia Varela o Moreno sean significativos respecto a los municipios de Esteban Echeverría o José C. Paz.

Mientras que, en algunos casos, observamos que los municipios problematizan, negocian o evalúan la localización de las viviendas, su integración urbana y la forma en las que se constituye el vinculo con los "adjudicatarios"; en otros, se evidencia una posición más pasiva frente al acontecimiento urbano de la localización de la vivienda social, como da cuenta la metáfora del "plato volador" (aún cuando el municipio haya extendido un certificados de aptitud urbanística). En otros casos, los destinatarios son incluso considerados clientes (nos referimos a los episodios de la comercialización de las viviendas por los propios funcionarios públicos). Junto a las interesantes experiencias de articulación en la forma en la cual algunos municipios sintetizan o digieren estos programas estandarzados, coexiste una racionalidad (a nuestro 
juicio, dominante) que instituye una lógica sectorial. Esta racionalidad tensiona profundamente lo que acontece en el entramado de la política habitacional, e incluso choca con la lógica de planificación integral del territorio. Priman allí los conceptos del producto de obra pública, unidad de inversión y "polígono" de intervención. Pero, en paralelo, se produce un aprendizaje de durante el proceso de la misma práctica de gestión territorial.

Desde el punto de vista temporal, a la instancia posterior a la intensidad de la obra le suceden las complicaciones del día después. Estos "efectos colaterales" expresan la dimensión territorial de estos programas y son afrontados de manera diferida según las posibilidades materiales, técnicas e institucionales de los municipios. El origen de nuevas demandas por parte de la población, responde tanto a una aplicación de expectativas como también a limitaciones del alcance de esta visión productivista. De allí que una lectura de la gestión del hábitat que introduzca la cuestión de la localización y los sujetos, o del "sitio de vida" (como señaló uno de los funcionarios entrevistados), sea vista como una complicación, "retardando" la respuesta efectiva ante una demanda que es grande y no puede esperar.

4. Frente a esto último, es importante recordar los dichos de uno de los adjudicatarios: "quisiera tener esta casa en el barrio donde vivía antes...". La satisfacción de este deseo podría ser interpretada como algo que entorpece el desarrollo de la política, pero también podría ser vista como una idea que evidencia una contradicción subyacente entre la vivienda y los efectos de lugar, al tiempo que nos informa de nuevas posibilidades a explorar al momento de pensar nuevas líneas de acción pública. De este modo, la lectura de la experiencia del hábitat y la reconstrucción de las trayectorias residenciales de los "adjudicatarios" (realizada en el capítulo 4) permitieron observar de modo trasversal la relación entre el hábitat, los sujetos y el acontecimiento de adjudicación de la vivienda en sus vidas.

Esto nos permitió ver que, a pesar de la restringida cartera de opciones a su disposición, las unidades domésticas pusieron en práctica diversas modalidades de resolución de acceso al hábitat antes de convertirse en adjudicatarias de vivienda social. De igual modo, aunque los habitantes de los nuevos barrios comparten una posición residencial percibida (tanto por la sociedad como por ellos mismos) como "diferente", la residencia en un mismo barrio da lugar a distintas formas de habitar y a diversas representaciones acerca de: la valoración del producto de la política habitacional (la vivienda, el barrio y las condiciones de localización); la percepción de los efectos de vecindad; la auto-evaluación de su propia trayectoria residencial; etc. En otras palabras, el acontecimiento de la mudanza al barrio también adquirió múltiples significados entre las familias. Esto se enlaza con las características de los recorridos residenciales previos y con las expectativas sociales de los proyectos individuales o familiares, a la vez que supone lecturas diferentes según la escala de análisis. Esto permite afirmar que la elevada heterogeneidad de las trayectorias cuestiona la respuesta habitacional homogénea y única.

En este sentido, aún cuando la vivienda social implicó una mejora generalizada en las condiciones de vida de los adjudicatarios, la relación entre vivienda social y movilidad residencial no mostró una tendencia única (es decir, se identificaron trayectorias ascendentes, 
estables y descendentes). Esto es especialmente significativo al evaluar de modo diferenciado la unidad de la vivienda, el barrio y la zona o el entorno. Por esta razón, consideramos que los efectos del mercado de localización residencial intra-urbana pueden verse reflejados en las trayectorias analizadas.

En los barrios del PFCV observamos que la vida en los nuevos barrios supone un proceso de sociabilidad complejo, dados los efectos "normales" de la mudanza, los desajustes observados a nivel doméstico, la repentina redefinición de las redes sociales y los imaginarios urbanos que en estos procesos se ponen en juego. Por otra parte, la geografía barrial asociada a este proceso de sociabilidad "en obra" también responde a las condiciones generadas por la política en el plano de la habitabilidad urbana "puertas afuera" de la vivienda y a lo que hemos denominado "política de relocalización pasiva" o consensuada. Se han observado expresiones de ello en un sinnúmero de emergentes, donde se destaca particularmente la organización social en torno a nuevas demandas de lo que podemos llamar "demandas de ciudad".

Los resultados de las encuestas confirmaron que la adjudicación de la vivienda tiene un impacto positivo en la mayoría de los hogares. Esto tiene un vínculo estrecho con las condiciones originales de acceso a la vivienda y los escasos horizontes de oportunidad para mejorarlas. Sin embargo, la capitalización económica asociada a los efectos de patrimonialización de la "casa propia" se desliza hacia abajo al analizar la posición global en el mercado de localizaciones residenciales intra-urbanas y el acceso a las externalidades urbanas asociadas a él, se puede afirmar que la vivienda social adquiere un comportamiento diferencial según el componente de la movilidad residencial que se analice. Es decir, el análisis de la posición residencial en la estructura de las externalidades urbanas a partir de la identificación de las zonas en la que se encuentra cada uno de los barrios (origen-destino), mostró que en general las unidades domésticas sufrieron una "descapitalización" residencial "puertas afuera" de la vivienda.

5. La mirada de ciudad que se pone en juego en el marco de la política habitacional difiere sustantivamente del esquema planteado en el párrafo anterior. Más que pensar en términos del espacio urbano como una matriz en la que se distribuyen condiciones de habitabilidad, la política del espacio inscripta en la política de vivienda del PFCV supone más bien un proceso de estructuración a partir del prototipo de la vivienda. La intervención pública no actúa emplazando viviendas en función de su capacidad de brindar servicios habitacionales (lo cual depende tanto de las condiciones intrínsecas de la vivienda y el barrio, como de las condiciones extrínsecas de los mismos), ni tiene en consideración la forma en la cual las mismas se procesan al interior de la gestión urbana. En su lugar, podríamos decir que el barrio es producto de la suma de viviendas estandarizadas, que garantizan la producción industrializada y el proyecto urbano un arreglo de la disposición de los lotes acorde al mayor aprovechamiento del suelo, el cual a su vez fue considerado un mero insumo.

El cuadro urbano termina por completarse en función de la conexión del barrio a las redes de infraestructura a través de obras de nexo y mediante las reservas de tierra destinadas para la 
construcción (diferida) de los equipamientos comunitarios básicos y los espacios verdes. Surge aquí algo interesante, "lo urbano" se expresa de diversas maneras: como parte de un componente de obra de nexo (la infraestructura); en términos del trazado interno del barrio (el proyecto urbano); como algo sujeto a la formalidad de la normativa urbanística (el cumplimiento de la legislación); y, donde la localización (componente suelo) es considerado un mero insumo para la ejecución de la obra de viviendas. La relación con la ciudad existente (extrínseca) surge, en el mejor de los casos, como la ubicación de las viviendas dentro del perímetro urbano (aunque hemos visto que esta no es necesariamente un criterio excluyente).

En contraposición a ello, la emergencia del problema habitacional como un problema urbano, en tanto ámbito por excelencia de la reproducción de la fuerza de trabajo (pero donde la vivienda deja de ser considerada un componente del salario ${ }^{150}$ ), nos remite a otro aspecto subyacente de la cuestión. La derivación de esta contradicción intrínseca del ámbito de la producción permite identificar el núcleo de la tensión en otro plano. Nos referimos al problema de la apropiación privada de la renta urbana generada por la propia acción del Estado y del colectivo social. Probablemente, esta debería ser la cuestión central de una política habitacional leída en clave urbana, ya que a nuestro juicio allí reside la tensión central de la exclusión o la inclusión urbana-habitacional.

6. Uno de los problemas emergente a la hora de implementar la "política federal de viviendas" fue el acceso y la disponibilidad de suelo, situación particularmente agravada en el Conurbano Bonaerense producto del agotamiento del stock de suelo urbano disponible y junto con el significativo cupo de viviendas asignadas en el marco del PFCV. Frente ello, el IVBA diseñó una innovación en el esquema de licitación de obra pública denominada TPU, que en la provincia de Buenos Aires constituyó una variante del PFCV. Su principal características fue que las empresas constructoras presentaron la construcción de viviendas en una única oferta con el desarrollo de la infraestructura básica asociada, el diseño del proyecto urbano y la tierra (siendo ésta de su propiedad o encontrándose en asociación con el propietario).

Esta operatoria no sólo fue la más significativa en términos del volumen de suelo adquirido en el contexto de la "política federal de viviendas", sino que además fue la modalidad de adquisición de suelo con peor desempeño en el acceso a la estructura de externalidades urbanas. De este modo, más allá del precio pagado por el suelo y su correlación (o no) con las características de la localización del mismo, lo cierto es que la comparación de los mecanismos de mercado con otros mecanismos de adquisición de suelo para vivienda social mostró un peor desempeño en el primer caso y un claro contraste respecto su localización en la ciudad.

Además de las características que diferencian a la adquisición de suelo para la construcción de planes de vivienda social respecto a la adquisición destinada otros usos residenciales (vistas

150 Otras variantes que complejizan aún más el panorama, son: la restricción de ingresos corrientes, una proporción de la población que continúa excluida del mercado de trabajo y, otra parte, que se encuentra atrapada en relaciones de precariedad laboral, etc. todas estas variantes visibles en el mercado de trabajo forman parte de un conjunto de restricciones más amplias del modelo de acumulación vigente, que no hacen más que contribuir a profundizar el problema analizado. 
en apartado 3.1.3), la "tercerización" de esta responsabilidad a favor de las empresas constructoras empeoró aún más las condiciones de inserción urbana. Las razones de ello se encuentran en que la operatoria PFCV-TPU sujeta a la evaluación del IVBA quedó presa de una oferta restringida $y$, frente a la presión por licitar (a riesgo de perder el cupo), la administración provincial sólo garantizó los aspectos urbanísticos formales y tuvo muy poca capacidad de negociación respecto a la localización de los nuevos barrios. En términos urbanos, esto significó la asimilación del orden impuesto por el mercado de localizaciones residenciales intra-urbanas. En otras palabras, el lugar asignado a la vivienda social en la ciudad reconoció al mercado como el medio "eficiente" de asignación del recurso suelo.

El problema de la localización de la vivienda social nos remitió inmediatamente a la tensión de la producción del espacio urbano, como valor de uso o valor de cambio. Aún cuando estas no sean categorías conceptuales opuestas, su diferenciación es clave en materia de política urbana-habitacional, ya que el Estado dispone de un sin número de mecanismos para seleccionar localizaciones urbanas con elevado valor de uso y minimizar los costos de acceso o adquisición de dicho suelo. Lo contrario significó, como hemos visto, asimilar desde el sector público la lógica del desarrollador privado. Esto es, minimizar la calidad de la localización de la vivienda social dada la escasa capacidad de pago de los destinatarios del producto final.

Siendo el Estado un actor protagónico en la generación de plusvalías urbanas, resulta necesario comprender los intereses que hicieron que el mismo concurra al mercado asumiéndose como un demandante más de suelo urbano. Dicho de otro modo, es importante comprende por qué el Estado externalizó la demanda de suelo para uso público o social del proceso urbanización (del cual él no sólo participa, sino que lo habilita, posibilita y modela a través de la regulación del espacio público). Internalizar esta cuestión y sus costos a cuenta del proceso general de urbanización permitiría, no sólo garantizar la disponibilidad de suelo para los proyectos públicos o mixtos de urbanización, sino que también posibilitaría financiar toda la política habitacional. Además, esto generaría una oferta heterogénea de suelo, acorde a las necesidades de la demanda (que, a pesar de su capacidad de pago limitada, tiene necesidades variadas),

La forma observada en la cual la política habitacional digiere el vínculo entre suelo y vivienda nos permite afirmar que, si bien la adjudicación de la vivienda a sectores de bajos ingresos debe ser reconocida como una acción progresiva desde el punto de vista socioeconómico, ésta adquiere rasgos regresivos en relación al acceso a las externalidades urbanas en la zona en la que se insertan los barrios de vivienda social. Esto se confirmó tanto en el análisis de posición residencial previa de los adjudicatarios, como en el registro de sus percepciones. Es decir, las miradas del suelo y la localización, combinadas con las trayectorias residenciales, nos aportaron una lectura que amplía las dimensiones que se ponen en juego en la lectura de la problemática habitacional. 
En este sentido, el análisis de las trayectorias muestra que frente a una heterogeneidad de realidades y los múltiples déficits, la política habitacional continúa teniendo una respuesta de un producto homogéneo. La localización no es un aspecto explícitamente problematizado por los habitantes de vivienda social, sin embargo, variados indicios mostraron que esta es una cuestión que cruza transversalmente la percepción de los habitantes. Por un lado, la operación de desdoblamiento que en las entrevistas éstos realizan de modo recurrente entre la vivienda y el barrio, pone en evidencia una distinción: una parte de la "insatisfacción" de la vivienda social remite a su carga de significado y otra parte a una dimensión barrial (la sumatoria de viviendas agrupadas) que reúnen y evidencian a necesidad. Al mismo tiempo, la política de relocalización y una forma de constitución barrial que difiere de la forma "normal", son registros que afectan la forma de sociabilidad.

Por otra parte, otros rasgos de los efectos de localización pueden verse reflejados en los atributos extrínsecos vinculados a los barrios. La proximidad a los equipamientos comunitarios de salud y educación, se tratan de un componente particularmente sensible en la vida cotidiana de las familias de bajos ingreso. De igual modo, el acceso al transporte público y los grandes desplazamientos para buscar trabajo o preservar el empleo fueron cuestiones que se manifestaron problemáticas. Estos significa en muchos caso una prolongación de las jornada de trabajo y el deteriora las condiciones de vida. Complementariamente la movilidad diaria de las familias supone salir del barrio (casi exclusivamente por trabajo y educación), las prácticas de consumo se realizan en general dentro de los mismos barrios o alrededores próximo y la recreación tienden a concentrarse en el barrio. Resulta paradójico que estas dimensiones no sean entonces contempladas en el diseño de la política, tanto en términos de estrategias de producción de condiciones de habitabilidad complementarias, como a través de la innovación de las formas de adquisición de suelo que priorices nuevas lógicas de localización de la vivienda social.

Recuperando la experiencia del PFCV-TPU podríamos concluir que el enfoque desarrollista no presenta ninguna variante en este plano respecto del enfoque neoliberal, o bien, que en materia de suelo la política actual simplemente continua asumiendo dicha perspectiva. ${ }^{151}$ Existen distintos motivos posibles que convierten a la cuestión del suelo en un obstáculo importante para la política habitacional. Entre ellos, algunos de los más importantes podrían ser: el modo en el cual la política actual de vivienda se enraíza en el entramado de intereses preexistentes (condicionando el desarrollo de la acción pública); la forma en la cual las posibilidades y/o intereses de los agentes de la administración tamizan el problema; y, la utilización de una racionalidad que excede a todos estos actores.

7. Por otro lado, resulta inevitable hacer mención a las características que asume el desarrollo inmobiliario del AMBA en la actualidad. Luego de la crisis del régimen de convertibilidad, la economía experimentó una fuerte recuperación económica (con tasas de crecimiento que

${ }^{151}$ Como señala Cuenya (1997), en los años noventa las recomendaciones de política habitacional del Banco Mundial referidas al suelo, fueron asimilar un esquema de provisión de suelo a cargo del promotor mediante la compra directa en el mercado. 
variaron entre el $7 \%$ y el $9 \%$ en el quinquenio entre 2003 y 2008), retomando esta tendencia a partir de 2010. La recuperación del PBI se apoyó en la reconfiguración de un nuevo perfil agroexportador, combinado con la difusión de una (re)industrialización sustitutiva y con una impronta neokeynesiana en términos de inversión y políticas públicas. Este proceso permitió un aumento considerable del empleo y la disminución de los niveles de pobreza (persistiendo un núcleo de precariedad e informalidad laboral en el orden de un tercio de la estructura del mercado de trabajo). En este marco, la industria de la construcción es el sector que ha liderado el crecimiento económico a nivel país: en el período 2003-2008, la construcción creció al 19,3\% anual, mientras que la industria manufacturera lo hizo al 9,4\% y el sector de la agricultura, la ganadería y la silvicultura al 4,5\% (valores anualizados; DNPM, 2010). No debe perderse de vista que la mitad de la facturación del sector de la construcción se explica por la inversión residencial (CAC, 2008).

En tal sentido, el hecho de que el sector de la construcción haya sido el más dinámico de la economía se explica tanto por la expansión del mercado inmobiliario (que canaliza la liquidez de los sectores beneficiado por el nuevo tipo de cambio y los saldos exportables), como por el cambio en la matriz de inversión pública (que supone un nuevo protagonismo del Estado en grandes obras de infraestructura, construcciones viales, equipamientos y viviendas). Además, una correcta interpretación del boom inmobiliario requiere analizar, complementariamente, a la cultura patrimonialista, a las estrategias asociadas al "ahorro en ladrillos", al impacto producido por el derrumbe del sistema financiero argentino en el 2001 y la desconfianza que ello proyectó sobre los depósitos bancarios de allí en adelante. Por esto apelamos al concepto de ciudadbanco para entender el sentido que adquiere el suelo urbano como capital ficticio (o financiero). Este concepto permite visualizar que allí se depositan, no sólo una parte de los excedentes generados por el modelo de acumulación actual, sino también una proporción de aquellos que se originaron en la década precedente y que tras el "corralito" encontraron refugio en el suelo urbano.

Estas notas pueden parecer disruptivas dado que refieren a un conjunto de actores y a una porción del espacio urbano limitada. Sin embargo, es importante advertir (como hemos visto en el capítulo 1) que aún cuando esta lógica de funcionamiento del mercado de suelo urbano no se materialice en el conjunto de la ciudad, sí se extiende a su totalidad en términos de orden urbano. Como resultado de esto, buena parte de la normativa urbanística se orienta a preservar las expectativas de valorización futura de dicho espacio.

Por otro lado, el aumento de la conflictividad urbana ${ }^{152}$ que se observa en la actualidad no puede disociarse de la lógica que prima en la etapa actual del desarrollo urbano. El mercado inmobiliario se ha transformado en un destino privilegiado de inversión financiera, induciendo (como muestra Baer, 2011) un proceso de apreciación diferencial del suelo urbano en relación a otros bienes, e incluso al poder adquisitivo del salario medio. Esto supone una tensión al

\footnotetext{
152 Nos referimos al crecimiento de los asentamientos precarios, los conflictos por el acceso al suelo, las tomas masivas de tierras y la intensificación de los desalojos, entre otras manifestaciones.
} 
interior del propio Estado que, por un lado, ve en el desarrollo inmobiliario privado un proceso de crecimiento de la producción (asociado a la industria y al empleo) y, por otro, busca ampliar la oferta de vivienda pública asimilando una lógica semejante en base un supuesto de complementariedad o solidaridad entre dichos universos. Sin embargo, en la puja por la distribución del espacio urbano, la creciente valorización del mismo como mercancía significa mayores restricciones en el acceso a la ciudad, especialmente cuando ello no es acompañado por una mejora equivalente en términos del ingreso de los sectores populares.

8. En este punto, es indudable que, en el espacio metropolitano, la "política federal de viviendas" alteró la ecuación entre ciudad y acción pública en materia habitacional, posibilitando el acceso a la vivienda a miles de familias que hasta entonces habían visto obturada cualquier posibilidad de resolver su problema habitacional. De allí la efectividad de esta política y la profundización del rumbo que la misma adquirió.

Sin embargo, en las páginas anteriores vimos que la inserción intra-urbana de la vivienda social es una deuda histórica y actual ${ }^{153}$ de la política habitacional. En este plano, es necesario revisar el alcance de la política de vivienda como una política social y asistencial, para inscribirla en una discusión más amplia alrededor del derecho a la ciudad. Ello implicaría buscar formas de articulación más complejas entre una política que persigue restituir derechos a través de la producción, el trabajo y la vivienda, con otra que introduzca el papel que juega el espacio urbano en la distribución del producto social y en las condiciones de reproducción social de las mayorías. Al mismo tiempo, un proyecto de esta naturaleza requiere interpelar las condiciones de exclusión generadas por la propia matriz urbana.

Esto lleva a pensar a la ciudad a partir de nuevos principios de articulación. El principal de éstos seguramente sea redefinir la relación material y simbólica entre el espacio públicocolectivo de la ciudad y los inmuebles urbanos como valor de cambio. En clave de la política pública que aquí hemos analizado, esto tal vez pueda traducirse del siguiente modo: para restablecer un concepto "social" de la vivienda es inevitable que el conjunto de las viviendas (o, más precisamente, de los inmuebles urbanos, el espacio y las relaciones que los conectan) sean consideradas "sociales".

\footnotetext{
${ }^{153}$ Situación que hemos visto particularmente agravada en el caso de la provisión de suelo a cargo de las empresas constructoras, innovación en la forma de adquisición de suelo para vivienda social que estudiamos en el capítulo 4 bajo la modalidad del PFCV-TPU.
} 


\section{Bibliografía}




\section{Bibliografía}

Aboy Rosa (2003) "La vivienda social en Buenos Aires en la segunda guerra (1946-1955)" en Scripta Nova, Vol. VII, núm. 146 (031), Barcelona.

Acuña, Carlos y Repetto, Fabián (2001) "Marco de Análisis de las políticas sociales" Mimeo, CEDI, Buenos Aires.

Abramo, Pedro (2003) "A teoría económica da favela: quatro notas preliminares sobre a localizacao residencial dos pobres e o mercado imobiliario informal". En: Abramo (org.) $A$ cidade da informalidade. Sette Letras-Faperj-Lincoln Institute. Río de Janeiro.

Abramo, Pedro (2006) La ciudad caleidoscópica. Ed. Cartoné. A Coruña. España

Armus, Diego (1990) (comp.) Mundo urbano y cultura popular: Estudios de historia social argentina, Editorial Sudamericana, Buenos Aires.

Arrossi, Silvina, Clichevsky, Nora y Perelman, Pablo (1991) "El acceso a la tierra en el Conurbano Bonaerense: Nuevas soluciones para un viejo problema" en Revista Medio Ambiente y Urbanización № 34, IIED América Latina, Buenos Aires.

Azuela, Antonio. (1989) La ciudad, propiedad privada y el derecho. El Colegio de México, México.

Azuela, Antonio (1995): "Vivienda y propiedad privada" en Revista Mexicana de Sociología, vol. LVII, No 1. México.

Azuela, A. y T. François (1997) El acceso de los pobres al suelo urbano. Centro de Estudios Mexicanos y Centroamericanos. UNAM. Instituto de Investigaciones sociales. Programa Universitario de Estudios sobre la Ciudad.

Baer, Luis (2011) El mercado de suelo formal de la Ciudad de Buenos Aires en su contexto metropolitano. Tesis de Doctorado. FFyL - UBA.

Ballent, Anahí (2005) Las huellas de la política: vivienda, ciudad, peronismo en Buenos Aires, 1943-1955. Universidad Nacional de Quilmes. Bernal.

Bettiol, Gloria Virginia y Baccaro, Maria Teresa (2008) "Evaluación de Programa Federal de Construcción de Viviendas. Caso testigo 1990 viviendas Esteban Echeverría" Trabajo final del Programa de Actualización y Posgrado Hábitat y Pobreza en América Latina. FADU-UBA.

Biglia, Marisa; Marsili, Inés y Vallina, Liliana (2008) "Metodología de intervención del Área Social del Instituto de la Vivienda de la Provincia de Buenos Aires (IVBA). Plan Federal de Vivienda. Programa Construcción de Vivienda, operatoria llave en mano". Trabajo final del Programa de Actualización y Posgrado Hábitat y Pobreza en América Latina. FADU-UBA. 
Boils Morales, G. (2008) "Segregación y modelo habitacional en grandes conjuntos de vivienda en México" en: Cordera, Rolando et al. Pobreza, desigualdad y exclusión social en la ciudad del siglo XXI. Siglo XXI Editores, México.

Bolivar, Teolinda (1996) "La Autourbanización y la Autoconstrucción en la Producción de las Ciudades Latinoamericanas: Piezas para armar una crítica " en Reflexiones sobre la autocosntrucción del hábitat popular en América Latina. Programa CYTED, Red XIV.B. Santiago, Chile.

Bourdieu, Pierre. (1999) La miseria del mundo. Fondo de Cultura Económica, México.

Bourdieu, Pierre. (2001) Las estructuras sociales de la economía. Editorial Manantial. Buenos Aires.

Brubaker, R. y Cooper, F. (2001) "Más allá de "identidad"'. En: Apuntes de Investigación No 7. CECYP. Buenos Aires.

Brain, Isabel y Sabatini, Francisco (2006) "Los precios del suelo en alza carcomen el subsidio habitacional, contribuyendo al deterioro en la calidad y localización de la vivienda social". Revista Prourbana No 4. PUC. Santiago, Chile.

Burgwal, G. (1999) "Prácticas cotidianas de resistencia" En: Kingman y Salman (1999) Antigua modernidad y memoria del presente. FLACSO, Ecuador.

Camagni (2005) Economía urbana. Antoni Bosh Editor.

Cancilini García, Nestor. (1997) Imaginarios urbanos. Edudeba, Buenos Aires.

Carman, María. (2006) Las trampas de la cultura. Los "intrusos" y los nuevos usos del barrio de Gardel. Espacios del saber, Buenos Aires.

Carrión, Fernado (1991) "La investigación urbana América Latina" en: Revista Nueva Sociedad n114.

Carpon, Guénola y González Arellano, Salomón (2006) "Las escala de la segregación y de la fragmentación urbana" Revista Trace. N49, CEMCA, México.

Casaussu, Cecilia. M. (1998) "El uso del método biográfico en el estudio de trayectorias sociales precarias" en: Lulle, T et al (Coords) Los usos de la historia de vida en las ciencias sociales. Antrhopos Editorial-Rubi. Barcelona.

Castells, Manuel. (1974) La cuestión urbana. Siglo XXI Editores. México.

Catenazzi, Andrea y Di Virgilio, Mercedes (2005) "La ciudad como objeto de política social" en Andrenacci, L (comp) (2005) Problemas de política social e la Argentina contemporánea. UNGS Prometeo.- 
Clichevsky, Nora (1975) El mercado de tierras en el área de expansión de Buenos Aires y su incidencia sobre los sectores populares (1943-1973). Centro de Estudios Urbanos y Regionales - CEUR, Instituto Torcuato Di Tella-ITDT, Buenos Aires.

Clichevsky, Nora (2000) "Informalidad y segregación urbana en América Latina" Serie Medio Ambiente y Desarrollo. № 28. Cepal. Santiago de Chile.

Clichevsky, Nora (2003) "Pobreza y acceso al suelo urbano. Algunos interrogantes sobre la regularización en América Latina" Serie Medio Ambiente y Desarrollo. № 75. Cepal. Santiago de Chile.

Coulomb, René y Schtingart Marta (Coord) (2006) Entre el Estado y el mercado. La vivienda en el México de hoy. UAM Azcapotzalco y Miguel Angel Porrua Editores. México.

Cowes, Victoria y López Clide (2007) "Indicadores y aplicación de a información sobre la vivienda en la Argentina". Convenio SSDUyV-UNQ.

Cravino, María Cristina; Fernández Wagner, R. y O. Varela. (2002) "Notas sobre la política habitacional en el AMBA en los años '90". Instituto del Conurbano, UNGS. Buenos Aires.

Cravino, María Cristina (2007) Vivir en la villa. Relatos, trayectorias y estrategias habitacionales. Tesis doctoral. Tomo 3. Facultad de Filosofía y Letras - UBA.

Cravino, María Cristina (2008) Los mil barrios informales en el AMBA, UNGS, Los Polvorines.

Cravino, María Cristina; del Río, Juan Pablo; Duarte, Juna Ignacio (2008) "Un acercamiento a la dimensión cuantitativa de los asentamientos y villas Área Metropolitana de Buenos Aires" En: Cravino (org.) Los mil barrios (in)formales del AMBA. Aportes para la construcción de un observatorio del hábitat popular. UNGS. Los Polvorines.

Cravino, Ana (2008) "Del conventillo a las Casas Baratas, la casa chorizo y el cottage" Seminario Ciudad y Programas de Hábitat. UNGS, Los Polvorines.

Cuenya Beatriz. y Falú A. (Comp.) (1997) Reestructuración del Estado y Política de vivienda en Argentina. UBA-Centro de Estudios Avanzados, Oficina de Publicaciones del CBC.

Cuenya, Beatriz (1998) "Cambios en el contexto urbano y socioeconómico y su impacto en las condiciones habitacionales de la población argentina". Revista Interamericana de Planificación, Volumen XXX - Números 119 y 120, Ecuador.

Cuenya, Beatriz (2000) "Globalización y políticas urbanas. Transformaciones de las políticas urbanas en la ciudad de Buenos Aires". Revista Sociológica. Balance y nuevas problemáticas de los estudios urbanos. Revista del Departamento de Sociología, Universidad Autónoma Metropolitana, México.

Cuenya, Beatriz; Fidel, C. y Herzer, H. (Coords.) (2004). Fragmentos Sociales. Problemas urbanos de la Argentina. Primera Ed. Buenos Aires: Siglo XXI editores Argentina. 
Cuenya, Beatriz (2005) "Cambios, logros y conflictos en la política de vivienda en la Argentina hacia fines del siglo XX" Boletín CF+S Ciudades para un Futuro más Sostenible. №29-30. Instituto Juan de Herrera. Madrid.

Danani, Claudia; Chiara, Magdalena y Filc Judith (1997) El Fondo de Reparación Histórica del Conurbano Bonarense. Una aproximación macroinstitucional" Colección de investigación. Serie informe de Investigación N² 2. ICO-UNGS.

Delaunay, D y Dureau, F (2004) "Componentes sociales y espaciales de la movilidad residencial en Bogotá" Revista de Estudios Demográficos y Urbanos. El Colegio de México, México.

Delgado Mahecha, Olividio (2003) Debates sobre el espacio en la geografía contemporánea. Universidad Nacional de Colombia. RET. Bogotá

Del Río, Juan Pablo y Duarte, Juan Ignacio (2011) "Las modalidades de gestión del suelo y la localización de la vivienda social en el marco de los Programas Federales de Vivienda 20032009 en el Conurbano Bonaerense" En: Di Virgilio, Herzer, Merlinsky y Rodríguez (comp) La cuestión urbana interrogada. Editorial Café de las Ciudades. Buenos Aires.

Del Río, Juan Pablo y Duarte, Juan Ignacio (2011) "La gestión del suelo y la distribución de la ciudad" En: Cravino (org) Construyento barrios. UNGS (en Prensa).

De Soto, Hernando (2000) El misterio del capital: por qué el capitalismo triunfa en occidente y fracasa en el resto del mundo. Empresa Editora El Comercio, Lima.

Di Virgilio, Mercedes. (2007) Trayectorias residenciales y estrategias habitacionales en sectores populares y medios en Buenos Aires. Tesis doctoral. FCS-UBA.

Duarte, Juan Ignacio (2010) "Adquisición de suelo (por el Estado) para las políticas de vivienda y regularización dominial. El caso del Conurbano Bonaerense 2003/2008" Informe de Investigación. Lincoln Institue of Land Policy.

Duhau, Emilio (1998) Hábitat popular y política urbana. México, Universidad Autónoma Metropolitana, Unidad Azcapotzalco.

Duhau, Emilio y Gilia, A (2008) Las reglas del desorden. Habitar la metrópoli. Siglo XXI Ed. México.

Duhau, Emilio y Rodríguez, M. S. (2006) "Suelo para Vivienda" en Coulomb, René y Schtingart Marta (Coord) (2006) Entre el Estado y el mercado. La vivienda en el México de hoy. UAM Azcapotzalco y Miguel Angel Porrua Editores. México.

Escolar, Marcelo (1998) "Lugar, acontecimiento y realismo filosófico, el problema de la teoría del espacio y del tiempo". Doc. Anàl. Geogr. 32. 
Engels, F (1873) Contribuciones al problema de la vivienda www.marxists.org/espanol/me/1870s/vivienda/index.htm

Echeverría, A. (2006) "Ningún barrio es descartable" Representaciones sociales y asentamientos en el Gran Buenos Aires. Ponencia publicada en el Seminario Latinoamericano Teoría y política sobre Asentamientos Informales, UNGS.

Fernandes, Edesio (2002) "La influencia del Misterio del Capital de Hernando de Soto" en Land Lines, v14, n1. USA, Cambridge.

Fernández Palacín, Fernando (1992) "Algunas ideas sobre análisis locacional" Revista Cuadernos de Geografía, n3. Universidad de Cadiz, Andalucia.

Fernández Wagner, Raúl (2007) "Elementos para una revisión crítica de las políticas habitacionales en América Latina" Inédito.

Fernández Wagner, Raúl (2008) Democracia y Ciudad. Procesos y políticas urbanas en las ciudades argentinas (1983-2008). Colección 25 años 25 libros. Biblioteca Nacional y UNGS.

Fernández Wagner, Raúl (2008b) "los asentamientos informales como cuestión. Revisión de algunos debates" En: Cravino (org.) Los mil barrios (in)formales del AMBA. Aportes para la construcción de un observatorio del hábitat popular. UNGS. Los Polvorines.

Gaggero, Horacio y Garro, Alicia (1996) Del trabajo a casa Política de vivienda del gobierno peronista. Editorial Biblios. Buenos Aires.

Gaja i Diaz, Fernando (2003) "El suelo como excusa: el desarrollismo rampante" Papeles de la FIM - Revista de Investigación Marxista, n20. Madrid.

García-Montalvo, José (2000) "El precio del suelo: la polémica interminable" en García-Milà. (Editor) II Jornada sobre Nuevas Fronteras de la Política Económica, Centre de Recerca en Economía Internacional (CREI), Barcelona.

Gerscovich, Alicia; Lagües, Oscar; Maidana Legal, Andrés; y Tellechea, Jorge. (s/f) "Vivienda de interés social ¿Casas para la gente?" en: Borthagaray, Juan Manuel (Comp) Habitar Buenos Aires: Las manzanas, los lotes y las casas. FADU-UBA.

Gilbert, A. (2001) “¿Una casa es para siempre? Movilidad residencial propiedad de la vivienda en los asentamientos autoproducidos" Rev. Territorios №6. UAndes. Bogotá.

Girola, María Florencia (2007) "Procesos de apropiación del espacio y sociabilidad vecinal en el gran conjunto urbano situado en la ciudad de Buenos Aires." En: Antropológica Año XXV No 36.

Grafmeyer, Y. et Danseau, F (1998) (Comp) Trajetories familiales et espaces de vie en milieu urbain. Presses Universitaires de Lyon. 
Suárez, Ana Lourdes y otros (2009) "Segregación Residencial en Argentina" Aportes para el Desarrollo Humano en Argentina. PNUD. Buenos Aires.

Hall, Peter (1996) Ciudades del mañana. Historia del urbanismo en el siglo XX. Ediciones del Serbal, Colección La Estrella Polar, Barcelona.

Hardoy, Jorge E. y Satterthwaite David (1987) Las Ciudades del Tercer Mundo y el Medio Ambiente de la Pobreza. Grupo Editor Latinoamericano, IIED-América Latina, Buenos Aires.

Hagestrand, T. (1975) "Space, time and human conditions", en Karlguist (dir) Dynamic allocation of urban space, Farnborough, Saxon-House.

Haggett, Peter (1976) Análisis locacional en la geografía humana. Editorial Gustavo Gilli. Barcelona.-

Harvey, David. (1973) Urbanismo y desigualdad social. Editorial Siglo XXI de España.

Harvey, David. (1982) Los límites del capitalismo y la teoría marxista. Ed Fondo de Cultura Económica. México.

Harvey, David (2011) "The urban roots of financial crises: reclaiming the city for anti-capitalist struggle" In: Socialist Register 2012: The Crisis and the Left. Vol 48.

Hidalgo Dattwyler, R. (2007) "¿Se acabo el suelo en la gran ciudad? Las nuevas periferias metropolitanas de la vivienda social en Santiago de Chile" en Revista Eure v. 33 n 98. Santiago.

Iracheta Cenecorta, Alfonso X. (2005) "Mercado de suelo para la vivienda de interés social en ciudades seleccionadas: indicadores y orientaciones básicas", Proyecto Fondo Sectorial CONAFOVI-CONACYT, 8392. México.

Jaramillo, Samuel (1990), "El Desenvolvimiento de la discusión sobre la urbanización latinoamericana: ¿Hacia un nuevo paradigma de interpretación?”, en La investigación urbana en América Latina (vol. 2) Ed. CIUDAD, Quito.

Jaramillo, Samuel. (2003) "Los fundamentos económicos de la participación en plusvalías" CIDE. Universidad de los Andes y Lincoln Institute of Land Policy.

Jaramillo, Samuel (2008) "Reflexiones sobre la "informalidad" fundiaria como peculiaridad de los mercados de suelo en la ciudades de América Latina" Revista Territorios n18-19. Universidad de Rosario-ACIUR. Bogotá.

Jaramillo, Samuel (2009) Hacia una teoría de la renta del suelo. Universidad de los Andes

Kowarik, Lucio (1979) A Espoliacao Urbana. Rio de janeiro: Paz e Terra.

Kuwarick, Lúcio (1996) "Expoliación urbana, luchas sociales y ciudadanía: retazos de nuestra historia reciente". En: Estudios Sociológicos del Colegio de México. México. 
Kowarick, Luicio (1982) Explotación y reproducción de la fuerza de trabajo y la vivienda en Brasil, en Prdiclla (Comp.) Ensayo sobre el problema de la vivienda en América Latina. Colección Ensayos Universidad Autónoma Metropolitana Xochimilco, México.

Kleiman, M. (2002) "Permanencia e mudanca na padrao de alocacao socioespacial das redes de infra-estructura urbana no Rio de Janeiro - 1938-2001". En: VVAA (2002) Planejamento e território. Ensaios sobre a desigualdade. Cuadrenos IPURR-UFRJ. DP\&A Editora. Río de Janeiro.

Lago, L. C. (2002) "A lógica segregadora na metrópole brasileira: novas teses sobre antigos processos". En: VVAA (2002) Planejamento e território. Ensaios sobre a desigualdade. Cuadrenos IPURR-UFRJ. DP\&A Editora. Río de Janeiro.

Lago, L. C. (2002) "A lógica segregadora na metrópole brasileira: novas teses sobre antigos processos". En: VVAA (2002) Planejamento e território. Ensaios sobre a desigualdade. Cuadrenos IPURR-UFRJ. DP\&A Editora. Río de Janeiro.

Lefebvre, Henry. (1976) La revolución urbana. Alianza Editorial, Madrid.

Lefebvre, Henry. (1978) El derecho a la ciudad. Editorial Península, Barcelona.

Levy (1998) "Habitat et hbitants: position et mobilite dans l'espace résidentiele" En: Grafmeyer, Y. et Danseau, F (1998) (Comp) Trajetories familiales et espaces de vie en milieu urbain. Presses Universitaires de Lyon.

Lewis, Dan. A y Sinha, V. (2007) "Movin up and moving out? Economic and residential mobility of low-incom chicago families" in Urban Affairs Review. V. 43 N.2 Sage Publications.

Lindón, Alicia (2007). Los imaginarios urbanos y el constructivismo geográfico: los hologramas espaciales. En Eure, XXXIII No 99. Santiago de Chile

Lomnitz, Larissa (1975) Como sobreviven los marginados. Siglo XXI, México

López Clide y Cowes Vicky (2008) "Indicadores de Déficit Habitacional" en Seminario Ciudad y Programas de Hábitat. UNGS. Los Polvorines.

Lungo, Mario y Oporto José Francisco (1995) "Vivienda y acceso a la tierra urbana" Boletín $C F+S$. Ciudades Para el Futuro más Sostenible n29/30. Madrid.

Lungo, Mario (1996) "La Autoconstrucción del Hábitat Popular: Perspectivas frente a los cambios estructurales de la Economía y la Sociedad" Programa CYTED, Red XIV.B. Santiago,Chile.

Martínez de Jiménez, L. M. (2001) Políticas Habitacionales. La situación habitacional y la política de vivienda desarrollada en la Argentina en las dos últimas décadas. Módulo 11. De: Maestría en Hábitat y Vivienda 2001. Universidad Nacional de Mar del Plata y Universidad Nacional de Rosario. Argentina, UNR Editora. 
Martínez Hinojal, Fernando (2004) "Mentiras sobre suelo y vivienda. Diez típicas falacias sobre el suelo y la vivienda protegida" Boletín CF+S. Ciudades Para el Futuro más Sostenible n29/30. Madrid.

Marcuse, Peter (2002) "Enclaves sí, guetos no: la segregación y el Estado", en Revista de Estudios Regionales y Urbanos. Espacios y Debates № 45. San Pablo.

Martínez de Jiménez, Lydia Mabel (2007) "La políticas federal de viviendas en la Argentina" en: Peyloubet Ciencia y tecnología para el hábitat popular. Editorial Nobuko. Buenos Aires.

Massey, Doreen (2005) "La filosofía y la política de la espacialidad" en Artuch, Leonor Pensar este tiempo: espacios, efectos, pertenencias. Paidós Buenos Aires.

Merklen, Denis (1997) "Organización comunitaria y práctica política. Las ocupaciones de tierras en el conurbano de Buenos Aires". En: Nueva Sociedad No 149, mayo-junio. Venezuela.

Merklen, Denis (2005) Pobres ciudadanos. Las clases populares en la era democrática (Argentina, 1983-2003). Editorial Gorla, Buenos Aires.

Mesa Sánchez, Nora Elena (1985) "Interpretación de la urbanización en América Latina" Ponencia presentada en el Talleres Latinoamericanos del Programa de Estudios de Vivienda para América Latina, PEVAL. Universidad nacional de Colombia, Medellin.

Moliner, Fernando Ramón (2005) "El suelo urbano" Ruislip, Inglaterra, 1974. Reeditado por el Boletín CF+S 29/30, 2005. Madrid.

Monreal, Pilar (1996) Antropología y pobreza urbana. Los libros de la catarata. Madrid.

Montes, Carlos (2000) "A 20 años de la liberalización de los mercados de suelo" Revista Eure. v.26 n.77 Santiago de Chile.

Morales Schechinger, Carlos (2005) "Algunas reflexiones sobre el mercado de suelo urbano" Curso de Especialización en Mercado y Políticas de Suelo. LILP. Bogotá, 2008.

Nuñez, Jorge A. (2010) "El catolicismo social frente al problema de la vivienda obrera" en Historia Actual On Line N ${ }^{\circ} 21$. España.

Oslender, U. (2002) "Espacio, lugar y movimientos sociales: hacia una especialidad de la resistencia" Scripta Nova, vol. VI, núm. 115. Universidad de Barcelona.

Ostuni, Fernando (2008) “"

Oszlak, Oscar y O'Donnell, uillerno. (1976). "Estado y políticas estatales en América Latina: hacia una estrategia de investigación" CEDES. Buenos Aires.

Oszlak, Oscar (1991) Merecer la ciudad: los pobres y el derecho al espacio urbano. Centro de Estudios del Estado y Sociedad. Buenos Aires 
Pelli, Victor Saúl (1996) "Autoconstrucción, el camino hacia la Gestión Participativa y Concertada del hábitat" Programa CYTED, Red XIV.B. Santiago,Chile.

Pérez, Alejandra y Sagredo, María Paz (2011) Localización de Viviendas Sociales de acuerdo al Subsidio Habitacional. Un techo para Chile.

Peyloubet, Paula (2007) Ciencia y tecnología para el hábitat popular: construcción y participación del conocimiento. I Seminario Iberoamericano de Ciencia y Tecnología. Editorial Nobuko. Buenos Aires.

Peyloubet, De Salvo y Ortecho (Comp) (2010) Ciencia y tecnología para el hábitat popular. Fortalecimiento del espacio desciplinar en los Sistemas de CyT. IV Seminario Iberoamericano de Ciencia y Tecnología para el hábitat popular. Editorial Nobuko. Buenos Aires.

Poléses, Mario (2005) Economía urbana y regional. Introducción a la relación entre territorio y desarrollo. LUR. Costa Rica.

Préteceille, Edmond (2002) "La construcción social de la segregación urbana". En Revista de Estudios Regionales y Urbanos. Espacios y Debates № 45. San Pablo.

Pradilla, Emilio (Comp) (1982) Ensayo sobre el problema de la vivienda en América Latina. Colección Ensayos Universidad Autónoma Metropolitana Xochimilco, México.

Prévôt Schapira, M. F. (2001) "Fragmentación espacial y social: Conceptos y realidades" en Perfiles Latinoamericanos n19. Flacso Mexico.

Puebla, C (2002) Del Intervensionismo estatal a las estrategias facilitadora. Los cambios en la política de vivienda en México, 1972-1994. El colegio de México. CEDDU, México.

Pugliese, Luciano (2004) "Programa de gestión del suelo urbano" UGEIF Ministerio de Economía de la Provincia de Buenos Aires.

Relli, M. (2007) Producción de hábitat popular. Estado y actores comunitarios en el barrio Las Malvinas de La Plata, provincia de Buenos Aires, 1990. Tesis de Maestría en Hábitat y Vivienda, Universidad de Mar del Plata. Facultad de Arquitectura, Urbanismo y Diseño.

Remy, J. (1998) "Les sociabilites urbanies: effetc de milieu et trajectoires sociales" en: Yves Grafmeyer et Francine Danseau (Comp) Trajetories familiales et espaces de vie en milieu urbain. Presses Universitaires de Lyon.

Rey, María Laura (2011) "Hacia una política de inclusión" Revista Voces en el Pan Fenix, nº 5. FCE-UBA. Buenos Aires.

Ribeiro Queiroz, L. C. (2002) "Segregação y acumulação urbana e poder: classes e disegualdades na metropole de Rio de janeiro". En: VVAA (2002) Planejamento e território. Ensaios sobre a desigualdade. Cuadrenos IPURR-UFRJ. DP\&A Editora. Río de Janeiro. 
Ricoeur, Paul (2004) La memoria, la historia y el olvido. Fondo de Cultura Económica, Buenos Aires.

Riofrio, Gustavo (1981) "Problema y política de tierra urbana" Revista Interamerica de Planificación. Vol XV, n60. Caracas.

Ramirez Franco, Luz Dary (2008) "Revisión teórica de a estructura espacial y la identificación de subcentros de empleo" en Ensayos de Economía, n33. UNC, Medellín.

Robles Claudio, Goméz Juan Carlos y Corvalán Nicolás (1996) "Impacto social de la política de vivienda: una evaluación desde los pobladores, 1990-1993" Revista Proposiciones n27. Santiago de Chile.

Roch, Fernando (2002) "Agentes sociales y tendencias urbanísticas: hegemonía inmobiliaria y pérdida de urbanidad" Ciclo de conferencias Ciudades del siglo XXI, Barcelona.

Roch, Fernando (2003) "A propósito del precio de la vivienda" Reedición 2005 Boletín CF+S. Ciudades Para el Futuro más Sostenible n29/30. Madrid.

Rolnik, Raquel, Cymbalista Renato e Nakano Kazuo (2008) "Solo urbano e habitação de interesse social: a questão fundiária na política habitacional e urbana do país" http://raquelrolnik.wordpress. com/2008/06/29

Rolnik, Raquel; Klintowitz; Reis y Bischof (2009) "Como produzir moradia bem localizada como os recursos do programa minha casa minha vida" SNPU-Ministerio das Cidades. Governo Federal de Brasil.

Rolnik, Raquel e Nakano, Kazuo (2009) "As armodilhas do pacote habitacional" en: Le Monde.

Rodríguez, Alfredo y Sugranyes Ana (Editores) (2005) Los con techo: un desafío para la política de vivienda social. Ediciones SUR. Santiago de Chile.

Rodríguez, Maria Carla, Di Virgilio, María Mercedes et al (2007) Políticas del hábitat, desigualad y segregación socioespacial en el área metropolitana de Buenos Aires. AEU-IIGG I FSOC-UBA.

Rodríguez, Maria Carla y Di Virgilio, María Mercedes (2008) "Principales tendencias en la política habitacional argentina (1976-2006)" en Seminario Ciudad y Programas de Hábitat. ICOUNGS.

Rodríguez, Marcela y Taborda, Alberto (2009) Análisis de políticas públicas. Formación, estilos de gestión y desempeño : políticas de vivienda, Córdoba 1991-2007. Editorial Brujas. Córdoba.

Rodríguez J, María José (2000) Modelos socio-demográficos. Tesis doctoral. Universidad de Alicante.

Rodríguez Jorge y ArriagadaC (2004) "Segregación residencial en la ciudad latinoamericana" En Revista Eure. n89. Santiago de Chile 
Rodríguez (2001) "Segregación residencial socioeconómica: ¿qué es?, ¿cómo se mide? Que está pasando, ¿importa?" Serie población y desarrollo nº 16 .Cepal. Santiago de Chile.

Rodulfo, María Beatriz (2003) "La situación habitacional u las políticas públicas” Mimeo.

Rodulfo, María Beatriz (2007) "Políticas habitacionales. Alternativas de intervención y gestión" en: Peyloubet (Comp) Ciencia y tecnología para el hábitat popular. Editorial Nobuko. Buenos Aires.

Rodulfo, María Beatriz (2010) "Política habitacional. La lógica de los actores y la dinámica de los programas post crisis" en: Peyloubet, De Salvo y Ortecho (Comp) Ciencia y tecnología para el hábitat popular. Fortalecimiento del espacio desciplinar en los Sistemas de CyT. Editorial Nobuko. Buenos Aires.

Romero, Gustavo (1996) "Las alternativas y opciones de la Autoconstrucción de vivienda en América Latina " Programa CYTED, Red XIV.B. Santiago,Chile.

Rosenbaum, J. et al (2002) "How Do Places Matter? The Geography of Opportunity, Selfefcacy and a Look Inside the Black Box of Residential Mobility" Housing Studies, Vol. 17, No. 1.

Sabatini, Francisco; Cáceres, Gonález y Cerda, Jorge (2001) "Segregación residencial en las principales ciudades chilenas: Tendencias de las tres últimas décadas y posibles cursos de acción" en Revista Eure, n82. Santiago de Chile.

Sabatini, Francisco (2001) "Reforma de los mercados de suelo en Santiago, Chile: efectos sobre los precios de la tierra y la segregación residencial" en Revista Eure, n77. Santiago de Chile.

Sánchez Hernández, José Luis (2003) Naturaleza, localización y sociedad: tres enfoques para la geografía económica. Ediciones Universidad de Salamanca. Salamanca.

Santos, Milton (1990) Por una geografía nueva. Espasa-Calpe. Madrid.

Santos, Milton (2000) La naturaleza del espacio. Técnica y tiempo. Razón y emoción. Barcelona. Editorial Ariel.

Santos, Milton. (2007) O Espaco del cidadao. Editora USP. Sao Paulo.

Sautu, R (2004) "Estilos y prácticas de la investigación biográfica" en Sautu, R (Comp.). El método biográfico. Ediciones Lumiere.

Schteingart, M. (2001) "La división social del espacio en las ciudades" Perfiles Latinoamericanos n19. FLASO Mexico

Sepúlveda Ocampo, R. (2001) Políticas Habitacionales. Revisión crítica de la política habitacional chilena. Módulo 12. De: Maestría en Hábitat y Vivienda 2001. Universidad Nacional de Mar del Plata y Universidad Nacional de Rosario. Argentina, UNR Editora. 
Singer (1971) "Urbanización dependencia y marginalidad" En: Castells y Vellz Imperialismo y Urbanizacion en América Latina.

Signorelli, Amalia (1999) Antropología urbana. Editorial Antrophos, Barcelona.

Smolka, Martin. (2003). "Precios elevados (e inaccesibles) de la tierra habilitada/ urbanizada" Curso de Especialización en Mercados y Política de Suelo en América Latina. Bogotá.

Soja, Edward W. (2010) "The city and spatial justice" Spatial Justice Journal

Sousa, Natalia Batista (2008) Estructura urbana y su relación con el proceso de segregación espaical. Tesis de Maestría en Gestión y Valoración Urbana. Universidad Politécnica de Cataluña.

Torres, H. (1993) Mapa social de Buenos Aires (1940-1990). Buenos Aires. Serie Difusión 3. Ed. Dirección de Investigaciones. Secretaría de Investigación y posgrado.

Topalov, Christian (1979) La urbanización capitalista. Editorial Edicol. México.

Topalov, Christian (2004) "De la "cuestión social" a los "problemas urbanos": los reformadores y la población de las metrópolis a principios del siglo XX". En: Política Social y Economía Social: debates fundamentales. UNGS/Editorial Altamira/Fundación OSDE. Buenos Aires.

Trivelli, Pablo (1982) "La accesibilidad al suelo urbano y la vivienda por parte de los sectores de menos ingresos en América Latina" Revista Eure, n26. Santiago de Chile.

Trivelli, Pablo (2006) "Sobre el debate acerca de la política de suelo y la formación de los precios de la tierra urbana en el Gran Santiago, antecedentes teóricos y empíricos" Centro de Políticas Públicas de la Póntificia Universidad Católica de Chile.

Turner, John F. C. (1976) Houssing by people. Towards autonomy in building environmments. Marion Boyyards. London.

Valladares, Licia y Coelho, Madga Partes (1995) "La Investigación Urbana en América Latina. Tendencias Actuales y Recomendaciones" Seire Gestión de las Transformaciones Sociales MOST. Documentos de debate, $n^{\circ} 4$. UNESCO. Paris.

Vio, Marcela (2008) "Programas Públicos de Hábitat y producción de la Ciudad Metropolitana. Análisis del Programa Federal de Construcción de Vivienda en la Región Metropolitana de Buenos Aires, 2004-2008" en Seminario Ciudad y Programas de Hábitat. UNGS. Los Polvorines.

Winograd, Marcos (1988) Intercambios. Espacio editora. Buenos Aires.

Wacquant, Loïs (2007) Los condenados de la ciudad. Gueto, periferias y Estado. Siglo XXI, Buenos Aires.

Wacquant, Loïs (2011) "El diseño de la seclusión urbana en el siglo XXI" En Herramientas. Revista de debate y crítica marxista. Ediciones Herramienta, Buenos Aires. 
Yujnosvky, Oscar (1974) "Revisión histórica de la política de vivienda en la Argentina desde 1880" en Summa № 72, febrero de 1974.

Yujnosvky, Oscar (1984) Claves políticas del problema habitacional argentino 1955-1981. Grupo Editor Latinoamericano. Buenos Aires. 


\section{Fuentes documentales}

- ABBA, A. (2005) Centralidades Metropolitanas En: "Diagnóstico para la Formulación de Lineamientos Estratégicos para el Territorio Metropolitano de Buenos Aires" DPOUTSSUyV.

- BOzZANO, H. (2002-2004) "Atlas Metropolitano. Patrones territoriales y códigos de ordenamiento territorial y usos del suelo, Región Metropolitana de Buenos Aires" UNLP-CONICET-CIC.Consulta de Información Cartográfica.

- CONAVI (2011) Revista de Comisión Nacional de Vivienda № 33.

- COHRE (2005) "El derecho a la vivienda en la Argentina" Informe de Misión. Centro de misión de investigación, 2004. Centro de Derecho a la Vivienda y Contra los Desalojos.

- DGCyE-UNLP (2003) Información Cartográfica Sistema de transporte público de pasajeros. Convenio Dirección general de Cultura y Educación-Universidad Nacional de La Plata.

- DGSIG (2005) "Distribución Territorial del Precio de Oferta de Terrenos en la Región Metropolitana" Informe de la Dirección General de Sistemas de Información Geográfica del Gobiernos de la Ciudad de Buenos Aires.

- INDEC (1991, 2001, 2010) Censo Nacional de Población Hogares y Vivienda. Instituto Nacional de Estadística y Censos.

- IVBA (2005) Contrato de obra PFCV-TPU. Instituto de la Vivienda de la provincia de Buenos Aires.

- IVBA (2005b) Pliegos de Contrato de Licitación PFCV-TPU. Instituto de la Vivienda de la provincia de Buenos Aires.

- IVBA $(2007,2008,2009,2001)$ Base de dato gerencial. Instituto de la Vivienda de la provincia de Buenos Aires

- IVBA (2006) "Instituto de la Vivienda de la Provincia de Buenos Aires, 50 años (19562006)". Instituto de la Vivienda, Ministerio de Infraestructura, Vivienda y Servicios Públicos. Gobierno de la Provincia de Buenos Aires.

- IVBA (2007) Encuestas de Satisfacción Habitacional, realizada por el Área Social de Instituto de la Vivienda de la provincia de Buenos Aires, en barrios Santa Rosa del partido de Florencio Varea y en barrio Malvinas de Esteban Echeverría. 
- IVBA (2009) Informe de Gestión, Instituto de la Vivienda de la provincia de Buenos Aires.

- IVBA (2010) Informe de Gestión, Instituto de la Vivienda de la provincia de Buenos Aires.

- ONU (2011) "Vivienda adecuada como elemento integrante del derecho a un nivel de vida adecuado y sobre el derecho a la no discriminación en este contexto" Informe Relatoría Especial de Naciones Unidas Visita oficial a la República Argentina. Abril, 2011.

- SDUV (2004) Presentación del Programa Federal del Fortalecimiento y Optimización del Recupero de Cuota de las Viviendas FONAVI. Subsecretaría de Desarrollo Urbano y Vivienda. Ministerio de Planificación Federal, Inversión Pública y Servicios.

- SDUV (2004b) "Programa Federal de Construcción de Viviendas". Primer Convenio Nación-Provincias. Subsecretaría de Desarrollo Urbano y Vivienda. Ministerio de Planificación Federal, Inversió

- SDUV (2005) "Programa Federal de Construcción de Viviendas Purianual". Segundo Convenio Nación-Provincias. Subsecretaría de Desarrollo Urbano y Vivienda. Ministerio de Planificación Federal, Inversión Pública y Servicios.

- SDUV (2008) "La política federal de vivienda. Balance de 4 años de Gestión" Subsecretaría de Desarrollo Urbano y Vivienda. Ministerio de Planificación Federal, Inversión Pública y Servicios.

- SDUV (2009) "Reglamento Particular Programa Federal de Construcción de Viviendas Techo Digno". Subsecretaría de Desarrollo Urbano y Vivienda. Ministerio de Planificación Federal, Inversión Pública y Servicios.

- SDUV (2009b) "Informe de Auditoría FONAVI-Programas Federales". Subsecretaría de Desarrollo Urbano y Vivienda. Ministerio de Planificación Federal, Inversión Pública y Servicios.

- $\operatorname{SDUV}(\mathrm{s} / \mathrm{f})$ Presentación de la Programa Federal de Fortalecimiento y Optimización del Recupero de Cuotas FONAVI. Subsecretaría de Desarrollo Urbano y Vivienda. Ministerio de Planificación Federal, Inversión Pública y Servicios.

- SDUV-UNGS (2007) "Análisis Georreferenciado para el Seguimiento de Nuevas Intervenciones Públicas en Hábitat en el Área Metropolitana". Convenio Subsecretaría de Desarrollo Urbano y Vivienda de la Nación y Universidad Nacional de General Sarmiento. 
- SIOUT (2006) Sistema de Ordenamiento Urbano y Territorial. Secretaría de Asuntos Municipales de la provincia de Buenos Aires. Información Cartográfica, actualizada al año 2006.

\section{Páginas web consultadas}

- www.boletinoficial.gov.ar: Boletín Oficial de la República Argentina

- $\quad$ www.gob.gba.ar/html/gobierno/diebo/indez boletin.php: Boletín Oficial de la Provincia de Buenos Aires

- http://dpct.ec.gba.gov.ar : Catastro Interactivo, Dirección Provincial de Catastro Territorial

- www.cnvivienda.org.ar: Consejo Nacional de la Vivienda

- www.ec.gba.gov.ar/Estadistica/indez.php : Dirección Provincial de Estadística

- www.indec.gov.ar: Instituto Nacional de Estadística y Censos

- $\quad$ www.vivienda.mosp.gba.gov.ar: Instituto de la Vivienda de la Provincia de Buenos Aires

- www.mecon.gov.ar/onp: Oficina Nacional de Presupuesto

- www.vivienda.gov.ar: Subsecretaría de Desarrollo Urbano y Vivienda de la Nación

\section{Periódicos}

- www.clarín.com : Diario Clarín

- www.lanacion.com.ar : Diario La Nación

- www.pagina12.com.ar: Diario Página 12

- www.tiempoinfonews.com: Diario Tiempo Argentino 


\section{Índice de abreviaturas}

AMBA: Área Metropolitana de Buenos Aires

AUH: Asignación universal por hijo

BHN: Banco Hipotecario Nacional

BID: Banco Interamericano de Desarrollo

CAC: Cámara Argentina de la Construcción

CAPRICO: Comisión Central de Asociaciones Privadas para la Reactivación de la Industria de la Construcción

CGE: Confederación General Económica

CGT: Confederación General de Trabajo

CNCB: Comisión Nacional de Casas Baratas

CONADE: Consejo Nacional de Desarrollo

CONAVI: Consejo Nacional de Vivienda

DGA: Dirección General de Administración

DGIS: Dirección General de Inmobiliario Social

DGO: Dirección General de Obras

EPH: Encuesta Permanente de Hogares

FONAVI: Fondo Nacional de Vivienda

FOPAR: Fondo Participativo de Inversión Social

FOPROVI: Fondo Provincial de la Vivienda

FRHCB: Fondo de Reparación Histórica de Conurbano Bonaerense

INDEC: Instituto nacional de Estadística y Censos

IPV: Instituto Provinciales de Vivienda 
IVBA: Instituto de la Vivienda de la Provincia de Buenos Aires

MBS: Ministerio de Bienestar Social

MPFIPS: Ministerio de Planificación Federal, Inversión Pública y Servicios

NBI: Necesidades básicas insatisfechas

PEVE: Plan de Erradicación de Villas de Emergencia

PFCV: Programa Federal de Construcción de Viviendas

PFCV-TF: Programa Federal de Construcción de Viviendas modalidad Tierra Fiscal

PFCV-TPU: Programa Federal de Construcción de Viviendas modalidad Tierra y Proyecto urbano

PFEH: Programa Federal de Emergencia Habitacional "Techo y Trabajo"

PFMV: Programa Mejoramiento de Vivienda "Mejor Vivir"

PFRFONAVI: Programas Federales de Reactivación Fonavi I y II

PFSH: Programa Federal de Solidaridad Habitacional

24PGBA: 24 Partidos del Gran Buenos Aires

PNUD: Programa de Naciones Unidades para el Desarrollo

PROMEBA: Programa de Mejoramiento de Barrios

PROMHIB: Programa Mejoramiento Habitacional e Infraestructura Básica

PROPASA: Provisión de agua potable, ayuda social y saneamiento básico

PROSOFA: Programa Social en Áreas de Frontera Grupos Vulnerables

PVEA: Plan de Viviendas Económicas Argentinas

RMBA: Región Metropolitana de Buenos Aires

SDUV: Secretaría de Desarrollo Urbano y Vivienda

SEV: Secretaria de Estado de la Vivienda

SMHU: Subprograma Federal de Mejoramiento del Hábitat Urbano, Infraestructura y Obras Complementarias 
SMVM: salario mínimo vital y móvil

SPUVyA: Subprograma Federal de Urbanización de Villas y Asentamientos Precarios UOCRA: Unión Obreros de la Construcción de la República Argentina 


\section{Índice de figuras}

Fig. 1 Esquema de retroalimentación entre especulación inmobiliaria, gestión e informalidad p.41

Fig. 2 Cantidad de viviendas terminadas por el FONAVI, total país 1979-2002

p.90

Fig. 3 Política de vivienda de primera generación vs. de segunda generación

p.96

Fig. 4 Cantidad de viviendas terminadas IVBA, total provincia 1978-2002

p.98

Fig. 5 Cantidad de soluciones habitacionales según programa, total provincia 1992-2003

Fig. 6 Cantidad de viviendas terminadas (FONAVI + P. Federales) total país 1979-2009

Fig. 7 Programas habitacionales nacionales dependientes de la SDUV, 2010

Fig. 8 Cantidad de soluciones habitacionales terminadas 2003-2010 total país según programas federales y otros programas nacionales i en ejecución al 2010

Fig. 9 Cantidad de vivienda y mejoramientos terminados, en ejecución y a iniciar según programas federales en ejecución 2003-2010, total país

Fig. 10 Producción habitacional según viviendas y soluciones habitacionales por ejercicio Fonavi y Programas Federales, total país 1993-2009

Fig. 11 Cantidad de viviendas terminadas IVBA, total provincia 1978-2010

Fig. 12 Distribución de los programas federales según porcentaje de soluciones habitacionales en ejecución 2003-2010, Conurbano Bonaerense vs. Total país

Fig. 13 Temas emergentes en la relación entre niveles de gobierno, PFCV (2003-2010)

Fig. 14 Viviendas nuevas y mejoramientos en ejecución o terminados según programas federales en Conurbano Bonaerense, 2003-2009

Fig. 15 Identificación de actores involucrados en la operatoria PFCV-TPU

Fig. 16 Lógicas en la adquisición de suelo en el mercado de localización residencial

Fig. 17 Dimensiones de análisis y variables para la clasificación de la estructura urbana

Fig. 18 Posición de la operatoria TPU según distribución de condiciones de calidad urbana, nivel socioeconómico y distancia al borde urbano en los 24PGBA

Fig. 19 Inversión total por barrios del PFCV-TPU

Fig. 20 infraestructura de nexo (en \%) sobre inversión total, barrios del PFCV-TPU ordenados (de izquierda a derecha) según calidad de localización

Fig. 21 Incidencia suelo (en \%) sobre inversión de obra de vivienda, barrios del PFCV-TPU ordenados (de izquierda a derecha) según calidad de localización 
Fig. 22 Precio del suelo $\left(\$ / \mathrm{m}^{2}\right)$ de los barrios del PFCV-TPU vs índice de calidad de la localización (IEU)

Fig. 23 Precio del suelo $\left(\$ / \mathrm{m}^{2}\right)$ de los barrios del PFCV-TPUvs valuación fiscal $\left(\$ / \mathrm{m}^{2}\right)$ ARBA

Fig. 24 Gestión y localización del suelo, según posición media de 110 barrios de vivienda social en la estructura urbana del Conurbano Bonaerense

Fig. 25 Distribución de soluciones habitacionales según ubicación en la estructura urbana de los 24 partidos del AMBA

Fig. 26 Posición media de los barrios de vivienda social en nuevas localizaciones en la estructura urbana municipal, según PFCV y PEFEH (dato agregado) y modalidad TPU (desagregado)

Fig. 27 Lugares de residencia y trabajo en la trayectoria de Armando (Florencio Varela)

Fig. 28 Residencia origen vs. residencia destino de los adjudicatarios de vivienda social

Fig. 29 Residencia origen vs. residencia destino de los adjudicatarios de vivienda social en el Área Metropolitana de Buenos Aires (vista regional)

Fig. 30 Posición residencial media antes de la mudanza (RPA) vs. posición media de de

Fig. 31 Valoración de la vivienda, el barrio y la zona

Fig. 32 Características socioeconómica de los hogares

Fig. 33 Características socio-ocupacionales de los hogares

Fig. 34 Características composición de los hogares

Fig. 35 Condición habitacional previa de los hogares

Fig. 36 Problemas y percepción de la de la vivienda

Fig. 37 Calidad de los componentes de la vivienda

Fig. 38 Las modificaciones de la vivienda

Fig. 39 Los cambios en la vivienda a futuro

Fig. 40 Usos complementarios de la vivienda

Fig. 41 Integración, intercambio y problemas entre vecinos

Fig. 43 Organización en torno a nuevas demandas

Fig. 44 Principales problemas del barrio

Fig. 45 Opinión barrio (respuesta abierta reagrupada)

Fig. 46 Cambio de residencia y acceso al transporte / empleo 
Fig. 47 Barrios cercanos y percepción del entorno

Fig. 48 Deseo de mudarse y vínculo con el barrio anterior

Fig. 49 Esquema perceptivo casa-barrio-zona en los barrios de vivienda social

Fig. 50 Esquema síntesis entidades casa-barrio-zona

p.266 
Anexo 
A1 Guión de entrevistas a funcionarios (municipales, provinciales y nacionales). Las primeras entrevistas exploratorias se realizaron en el año 2008 y las últimas entrevistas a funcionarios se realizaron en el año 2011, durante este período se produjeron distintos cambios en los guiones de entrevistas. Aquí, se adjuntan los principales ejes indagados, los cuales a su vez sufrieron algunas según los niveles de gobierno.

Características y objetivos de la "política federal de viviendas"

- ¿En qué consiste la política de vivienda hoy? ¿Cuáles son las principales características del Plan Federal de Viviendas? ¿Cuáles son las principales diferencias entre los programas?

- ¿Qué diferencia hay con la política de vivienda anterior (años noventa y etapa de institucionalización del FONAVI)?

Articulación institucional

- ¿Cuál es el rol del Municipio, la Provincia y la Nación en la política? ¿Cómo son articulaciones institucionales?

- ¿Cuál es el margen de maniobra que tiene ustedes? ¿Qué tipo de decisiones toman?

- ¿Qué modificaciones han introducido en el proceso de implementación respecto del diseño original? ¿Por qué?

- ¿Qué áreas del participan en la política de vivienda? ¿Cómo es la relación entre las áreas?

Niveles de ejecución y dificultades en el proceso de implementación

- ¿Qué nivel de ejecución (proyectos, licitación, avance de obra, entrega, etc.) tiene actualmente cada uno de los programas y subprogramas en el AMBA / Municipio?

- ¿Qué tipo de problemas surgieron en la implementación? ¿Qué cuestiones son las que demoran los plazos previstos? ¿Por qué no se pudieron ejecutar las viviendas que fueron anunciada?

- ¿Es posible realizar una evaluación diferenciada por programa? ¿EI PFCV remite alguna particularidad?

\section{Política y adquisición de suelo}

- ¿Cuáles es el origen de la tierra que se destina a los planes de vivienda social? ¿Quién y cómo lo financia?

- ¿Cuál ha sido la modalidad mayoritaria de adquisición de suelo en el AMBA?

- ¿La Provincia/Municipio tiene algún tipo de estrategia definida al respecto? ¿Se evalúa de algún modo la tierra que se destina a este uso? 
- ¿Cómo funciona el proceso de adquisición de suelo vía la modalidad TPU del PFCV? ¿Qué características específicas tiene esta modalidad? ¿Cómo y por qué surgió?

- ¿Cuáles son los requisitos puestos a la empresa y los criterios de selección implementados desde el Estado? ¿Cómo se concibe el pago del suelo? ¿Cuál es la incidencia del suelo en el costo total del proyecto?

- ¿Hay diferencia en a calidad del suelo entre el TPU y otros programas o subprogramas?

\section{Condiciones urbanas}

- ¿En qué consiste la instancia de supervisión del Estado para darle factibilidad o aprobación a los TPU? ¿La Provincia/Municipio rechazó o modificó algún proyecto?

- ¿Qué criterios urbanísticos son evaluados en términos del emplazamiento de los nuevos barrios?

- ¿Qué relación existe entre la política de vivienda con la estrategia urbana del municipio? (Sólo en el caso de los municipios)

\section{Calidad y demandas}

- ¿Cómo considera los resultados en términos de la calidad de localización?

- ¿Qué tipo de vínculo tiene hoy con los nuevos barrios? ¿Se está realizando alguna otra acción complementaria? ¿Qué nuevas demandas surgen en los barrios?

- ¿Cómo evalúa usted lo desempeños en términos de la calidad constructiva? ¿Se hace algún control de calidad? ¿Cómo?

- ¿Tuvieron muchas demandas al respecto? ¿De qué tipo? ¿Se están aplicando las garantías de construcción?

\section{Adjudicación, entrega y recupero escrituración}

- ¿Cómo se trabajan la demanda habitacional? ¿Cuáles fueron los requisitos y criterios utilizados para confeccionar la lista de "destinatarios"? ¿Qué tipos de vínculos tienen con las organizaciones sociales u otras entidades?

- ¿Cuántas (y cuáles) viviendas ya se entregaron? ¿Realizan algún tipo de trabajo con la genta antes (durante y después) de entregar? ¿Cuál?

- ¿Cómo está planteado el tema del recupero? ¿Qué componentes son considerados para su cálculo? ¿Ya se está cobrando?

- ¿Cuáles son paso para llegar a la escritura definitiva en el caso de aquellos que reciben vivienda?

\section{$\underline{\text { Recapitulación }}$}

- ¿Cuáles son los principales características y obstáculos de la política actual de vivienda? 


\section{A2 Notas metodológicas sobre la construcción de la matriz de estructura urbana}

La matriz de análisis preliminar de la estructura urbana es el resultado de la integración de un conjunto de variables las cuales se detallan a continuación. Su confección es de carácter exploratorio y responde a la necesidad de evaluar la localización de los barrios de vivienda social a partir de una caracterización de sus entornos inmediatos.

La unidad de análisis espacial de referencia para dicho análisis fueron los radios censales urbanos de los 24 partidos del AMBA (7.924 registros) los cuales fueron procesados mediante un sistema de información geográfica a efectos de realizar un lectura de carácter regional del mercado de localizaciones intra-urbanas.

Los entornos de los barrios de vivienda social se definieron a partir de las selección de los radios censales con los cuales se intersecta espacialmente el barrio y a partir de los radios contiguos. Cuando las variables analizadas no pertenecen a la fuente del Censo Nacional de Poblaciones Hogares y Viviendas, por ejemplo: el estudio de Centralidades Metropolitanas (Abba, 2005), el dato fue embebido en el registro del radio censal a partir de la medida de la distancia de los radios urbanos a dichas centralidades.

La construcción del dato atiende fundamentalmente al reparto de las externalidades urbanas, es decir, a la necesidad de analizar la localización de la vivienda social no en términos absolutos o en base a umbrales de calidad, sino en clave distributiva. Por ello, se utilizó como criterio de clasificación de las variables el decil.

La pregunta que opera detrás de la metodología propuesta no es cuán buena o cuán mal son las externalidades urbanas a las que accede la vivienda social, más bien nos preguntamos independientemente de que las condiciones urbana metropolitanas tengan tal o cual umbral, cómo se distribuyen éstas desde una mirada situada en la vivienda social o, dicho de otro modo, cuál es la posición relativa de la vivienda social en la estructura de distribución existente. 
Fig. 51 Selección de variables para la clasificación de la estructura urbana

\begin{tabular}{|c|c|c|}
\hline Dimensiones & Variables y ponderación & Tratamiento del dato \\
\hline $\begin{array}{l}\text { Centralidad } \\
\text { urbana }\end{array}$ & $\begin{array}{l}\text { Centralidades comerciales }(25 \%)^{\star}(\text { ii)**, centralidades según } \\
\text { número de empleados y compacidad bancaria }(50 \%) \text { (i), } \\
\text { centralidades normativas primarias y secundarias definida por la } \\
\text { zonificación de usos del suelo y áreas habilitadas para uso } \\
\text { residencial de alta densidad según zonificación }(12,5 \%) \text { (iii) y } \\
\text { casco histórico según mancha urbana Censo } 1947(12,5 \%)(\mathrm{v})\end{array}$ & $\begin{array}{l}\text { Unidad de medida: distancia en } \\
\text { metros. Integración a través de } \\
\text { media ponderada según calidad } \\
\text { de la fuente y jerarquización de } \\
\text { centros atractores de flujos. } \\
\text { Posterior clasificación en deciles. }\end{array}$ \\
\hline $\begin{array}{l}\text { Accesibilidad- } \\
\text { conectividad }\end{array}$ & $\begin{array}{l}\text { Red de transporte público automotor (25\%) (iv), área de } \\
\text { influencia de las estaciones de ferrocarril, corredores con más } \\
\text { de tres líneas de transporte y corredores según códigos de } \\
\text { zonificación }(37,5 \%) \text { (iv y v), existencia de transporte público a } \\
\text { menos de } 300 \text { metros a nivel de segmento censal }(6,2 \%) \text { (vi) y } \\
\text { existencia de al menos una cuadra pavimento a nivel de } \\
\text { segmento censal }(31,2 \%)(\text { vi). }\end{array}$ & $\begin{array}{l}\text { Unidad de medida: distancia en } \\
\text { metros. Integración a través de } \\
\text { media ponderada según calidad } \\
\text { de la fuente y jeraquización de } \\
\text { redes y corredores. Posterior } \\
\text { clasificación en deciles. }\end{array}$ \\
\hline $\begin{array}{l}\text { Consolidación } \\
\text { urbana }\end{array}$ & $\begin{array}{l}\text { Servicios en la vía pública según segmento censal: existencia } \\
\text { de al menos una cuadra pavimentada, existencia de alumbrado } \\
\text { público, existencia de teléfono público a menos de } 300 \text { metros, } \\
\text { existencia de transporte público a menos de } 300 \text { metros y } \\
\text { servicio regular de recolección de residuos al menos } 2 \text { veces } \\
\text { por semana (vi). }\end{array}$ & $\begin{array}{l}\text { Unidad de medida: porcentaje } \\
\text { agregado por radio censal. } \\
\text { Clasificación por deciles y } \\
\text { posterior cálculo de promedio. }\end{array}$ \\
\hline $\begin{array}{l}\text { Conexión a } \\
\text { servicios } \\
\text { sanitarios } \\
\text { básicos }\end{array}$ & $\begin{array}{l}\text { Según López y Cowes (2008) procedencia de agua en la } \\
\text { vivienda por red pública (agua corriente) y el servicio sanitario } \\
\text { (hogares con inodoro con descarga y desagüe a red pública) } \\
\text { (vi). }\end{array}$ & $\begin{array}{l}\text { Unidad de medida: porcentaje por } \\
\text { radio censal. Clasificación por } \\
\text { deciles y posterior cálculo de } \\
\text { promedio. }\end{array}$ \\
\hline $\begin{array}{l}\text { Calidad de } \\
\text { ocupación de } \\
\text { la vivienda }\end{array}$ & $\begin{array}{l}\text { Según López y Cowes (2008) hogares con hacinamiento crítico } \\
\text { (más de } 3 \text { personas por cuarto), baño de usos exclusivo y } \\
\text { servicio sanitario (ídem anterior) (vi). }\end{array}$ & $\begin{array}{l}\text { Unidad de medida: porcentaje por } \\
\text { radio censal. Clasificación por } \\
\text { deciles y posterior cálculo de } \\
\text { promedio. }\end{array}$ \\
\hline $\begin{array}{l}\text { Calidad } \\
\text { constructiva }\end{array}$ & $\begin{array}{l}\text { Calidad material de los materiales de la vivienda (Calmat I o no } \\
\text { deficitario) y la cañería de distribución de agua dentro de la } \\
\text { vivienda, baño con inodoro con descarga de agua y cocina con } \\
\text { pileta con instalación de agua (vi). }\end{array}$ & $\begin{array}{l}\text { Unidad de medida: porcentaje por } \\
\text { radio censal. Clasificación por } \\
\text { deciles y posterior cálculo de } \\
\text { promedio. }\end{array}$ \\
\hline $\begin{array}{l}\text { Nivel socio- } \\
\text { económico }\end{array}$ & $\begin{array}{l}\text { Nivel de equipamiento del hogar: tenencia de computadora y } \\
\text { conexión a Internet, tenencia de heladera o freezer, tenencia de } \\
\text { horno microondas, tenencia de lavarropas, tenencia de teléfono, } \\
\text { tenencia de televisión por cable y tenencia de videocasetera- } \\
\text { reproductor (vi). }\end{array}$ & $\begin{array}{l}\text { Unidad de medida: porcentaje por } \\
\text { radio censal. Clasificación por } \\
\text { deciles y posterior cálculo de } \\
\text { promedio. }\end{array}$ \\
\hline $\begin{array}{l}\text { Distancia } \\
\text { borde } \\
\text { periurbano }\end{array}$ & $\begin{array}{l}\text { Radios censales según proporción de población urbana, rural } \\
\text { agrupada y rural dispersa (25\%) (vi), radios urbanos ajustados a } \\
\text { tejido urbano real -en ocasiones el límite de los radios censales } \\
\text { no se ajusta a la mancha urbana, es decir, un mismo polígono } \\
\text { integra áreas urbanas y rurales- (25\%) (v), área del código de } \\
\text { zonificación de usos rural intensivo o extensivo (iv) y áreas de } \\
\text { uso real del suelo asociado a usos periurbanos y rurales (50\%) } \\
\text { (ii). }\end{array}$ & $\begin{array}{l}\text { Unidad de medida: distancia en } \\
\text { metros. Integración a través de } \\
\text { media ponderada según calidad } \\
\text { de la fuente y jerarquización del } \\
\text { zonificación de uso del suelo. } \\
\text { Posterior clasificación en deciles. }\end{array}$ \\
\hline
\end{tabular}

Nota: * El porcentaje indica la ponderación utilizada para integrar las variables. ** El número romano entre indica la fuente. Fuente: elaboración propia en base a: i) Abba, A. (2005) Centralidades Metropolitanas En: "Diagnóstico para la Formulación de Lineamientos Estratégicos para el Territorio Metropolitano de Buenos Aires" DPOUT-SSUyV ; ii) Atlas Metropolitano de Buenos Aires (2002-2004) "Atlas Metropolitano. Patrones territoriales y códigos de ordenamiento territorial y usos del suelo, Región Metropolitana de Buenos Aires". UNLP-CONICET-CIC; iii) Sistema de Ordenamiento Urbano y Territorial. Secretaría de Asuntos Municipales de la provincia de Buenos Aires. Año: consulta al 2006; iv) Sistema de transporte público de pasajeros (2003) Convenio DGCyE - UNLP; v) Sistema de Información Territorial de la Dirección Provincial de Ordenamiento Urbano y Territorial. Año: consulta al 2007; vi) INDEC (2001) Censo Nacional de Población Hogares y Vivienda.

En la figura 51 se representan en la primera columna las dimensiones de análisis. En la segunda columna, se detallan las variables seleccionadas para cada una de las dimensiones 
de análisis, entre paréntesis se registra la ponderación (en caso en que se haya utilizado) y la fuente de donde proviene el dato. En la tercer columna, se detalla la unidad de medida del dato (por ejemplo: porcentaje de hogares por radio censal o distancia en metros del centro del radio censal a la red de transporte público), el criterio de agregación de la variables (en algunos casos, se clasifican las variables por deciles y luego se los promedia y recalcula, en otros casos, se realiza un promedio ponderado y luego se clasifican por deciles).

Si bien, estas metodología fue pensada para hacer un análisis de la localización de tipo matricial, es decir, analizar a cada uno de los barrios de vivienda en función de cada una de la dimensiones (por ejemplo: un barrio puede encontrarse en un área rural o de borde urbano y, sin embargo, tener muy buena conectividad al transporte), también se utilizan todas las dimensiones agregadas en un único índice sintético producto de la sumatoria de las dimensiones de análisis y su clasificación en deciles (IEU = IC + AC + CSU + CSS + CCV + COV + NSE + RR). Por otra parte, la lectura aquí propuesta se realiza para el conjunto del espacio urbano de los 24 partidos del GBA, pero complementariamente se ha realizado un tratamiento o una reclasificación de los datos a nivel municipal a efectos de destacar particularidades partido por partido.

No obstante el detalle del cuadro síntesis, repasemos los criterios de definición de cada una de las dimensiones de análisis que componen la matriz.

Centralidad urbana (IC). El análisis de centralidad se realizó a partir de un concepto amplio, refiere al concepto de centralidad como producto de la atracción de flujos, espacios de consumo, concentración de actividades comerciales y financieras, pero también se lo asocia al proceso de verticalización urbana y la antigüedad del tejido urbano. Para ello se integraron al SIG distintas fuentes, de esta forma se obtuvo una malla de: centralidades comerciales, centralidades financiera a distintas escalas (según cantidad y compacidad bancaria), centralidades normativas primarias y secundarias, áreas habilitadas para uso residencial de alta densidad y áreas asociadas al casco histórico (considerando la mancha urbana de mediados del siglo XX, Censo 1947). De este modo se obtuvo una configuración espacial ponderada ${ }^{154}$ de centralidad a partir de la cual se clasificó en deciles la totalidad de las unidades de análisis y la posición relativa de los barrios de vivienda social (proceso que se repite sucesivamente con el resto de las dimensiones de análisis).

Accesibilidad-conectividad (AC). La matriz de accesibilidad y conectividad se definió en base a la existencia de infraestructura que permite determinado calidad de circulación en transporte automotor particular y la disponibilidad de transporte público. En este caso se integraron las

154 Dado que por lo general se observa una complementariedad entre categorías y fuentes de información, lo que se buscó a través de la ponderación es jerarquizar algunas variables más significativas conceptualmente en la definición de cada una de dimensiones analizadas (por ejemplo, el dato de la normativa de usos del suelo a la hora de definir la centralidad se le dio poco peso, porque fueron datos complementarios a los de las centralidades comerciales y financieras que otros estudios identificaron empíricamente) y, a la vez, priorizar la calidad y precisión de las fuentes de información (por ejemplo, a la información de red de líneas de colectivos se le otorga más peso que a la identificación de la existencias de transporte público a nivel segmento censal y agregada en el radio censal, ya que la primera es más ajustada que la segunda). 
siguientes variables: red de transporte público automotor, estaciones de ferrocarril, corredores con tres líneas o más de transporte, corredores normativos, existencia de transporte público y existencia de pavimento en el segmento al que pertenece el radio censal.

Consolidación urbana (CSU). Los niveles de consolidación urbana se definen generalmente por la presencia de infraestructura y servicios urbanos. En este caso, se ha decidido separar los servicios domiciliarios básicos, y se sumaron las variables a nivel de radio censal que hacen referencia a la cobertura de servicios en la vía pública, nos referimos a: existencia de calle pavimentada, existencia de alumbrado público, existencia de teléfono público, existencia de transporte público y servicio regular de recolección de residuos.

Conexión a servicios sanitarios básicos (CSS). Dada las particularidades del proceso de producción del espacio del Conurbano Bonaerense y la criticidad en materia sanitaria, se decidió observar los niveles de consolidación en base a la cobertura de agua y cloacas de manera separada del resto de los servicios, entendiendo que se trata de la dimensión más "dura" del proceso de consolidación urbana. Las variables procesadas por radio censal, fueron: la procedencia de agua en la vivienda por red pública (agua corriente) y el servicio sanitario (hogares con inodoro con descarga y desagüe a red pública).

Calidad de ocupación de la vivienda (COV). Recuperando algunas líneas de trabajo innovadoras en la concepción del déficit habitacional (López y Cowes, 2008) y considerando que la calidad de la vivienda se vincula al menos en parte con las condiciones de calidad urbana externas a la vivienda, se recupero en base al trabajo de estas autoras la calidad de ocupación de la vivienda definida por el nivel de hacinamiento (relación persona/cuartos) y modalidad de uso del baño. Las variables censales consideradas en este caso fueron: hacinamiento crítico (más de 3 personas por cuarto), baño de uso exclusivo y servicio sanitario.

Calidad constructiva (CCV). En la misma línea se trabajó con la calidad constructiva de la vivienda (López y Cowes, 2008) como la relación entre los materiales constructivos (de las paredes, techos y pisos) y las instalaciones internas. La variables censales procesadas fueron: la calidad material de los materiales de la vivienda (Calmat I o no deficitario) y la cañería de distribución de agua dentro de la vivienda, baño con inodoro con descarga de agua y cocina con pileta con instalación de agua.

Bordes Urbanos (RR). Se identificaron las áreas asociados al límite entre el espacio urbano y los ámbitos periurbanos o rurales. En esta interfase entre lo urbano y lo rural es donde los operadores inmobiliarios encuentran áreas de fertilidad a partir de los procesos de transmutación rentística. En este caso, el interés radica en identificar las configuraciones donde el espacio urbano tiene baja densidad, se vuelve más desarticulado y, por lo general, los niveles de consolidación del tejido urbano son escasos. Esto permite verificar si los barrios de vivienda social se encuentra por fuera del área urbana o en el límite de la misma.

Las variables seleccionadas para abordar esta dimensión fueron: los radios censales según tipo (en base a la proporción de población urbana, rural agrupada y rural dispersa), radios 
urbanos ajustados a tejido urbano real (en ocasiones el límite de los radios censales no se ajusta a la mancha urbana, es decir, un mismo polígono integra áreas urbanas y rurales), área del código de zonificación de usos rural intensivo o extensivo y áreas de uso real del suelo asociado a usos periurbanos y rurales.

Nivel socioeconómico (NSE). A parte de la dimensiones de análisis constitutivas de las condiciones de calidad urbana y debido a la inexistencia de la variable ingresos a nivel censal y falta de una categorización socio-ocupacional acabada en el CNPHyV, se trabajo en una aproximación al nivel socioeconómico, a partir de ordenamiento por deciles y la sumatoria de un conjunto de variables que intentan dar cuenta de esta dimensión.

A partir de los datos primarios del censo se construyeron una serie de variables a nivel de radio censal, asociadas a la capacidad de generar ingresos por nivel educativo y tasa de dependencia económica (NSE2): proporción de receptores de ingresos, proporción de población inactiva y coeficiente años de escolaridad aprobados (a partir de la relación entre la cantidad de población con más de 12 años de educación escolarizada y la cantidad de población con menos de 7 años de educación escolarizada). Por otro lado, se identificaron una serie de variables que dan cuenta del nivel de equipamiento del hogar (NSE3): tenencia de computadora y conexión a Internet, tenencia de heladera o freezer, tenencia de horno microondas, tenencia de lavarropas, tenencia de teléfono, tenencia de televisión por cable y tenencia de videocasetera-reproductor.

Más allá de las variantes en la naturaleza conceptual de estos dos indicadores, en el tipo de análisis propuesto y al nivel de agregación de los datos no representan diferencias en la posición media de los entornos de los barrios de vivienda social, y al momento de integrar dicho indicador en un índice sintético (IEU) se opto por NSE3. 


\section{A3 Guión entrevista, trayectorias residenciales de "adjudicatarios" de vivienda.}

Entrevistas realizadas en el barrio Santa Rosa (Florencio Varela) y Malvinas (Esteban Echeverría) durante el año 2009 y 2010, aquí se adjunta guión de los principales ejes abordados, nos obstante durante el transcurso de las entrevistas surgieron nuevos temas que derivaron en nuevas preguntas e indagaciones.

\section{Datos del entrevistado}

- Nombre, contacto nuevo encuentro, dirección (casa, barrio, partido), fecha en la que se mudo al barrio, fecha de habilitación barrio, organización social, política o comunitaria (en caso de que corresponda).

\section{Características de la unidad doméstica}

- Cuadro composición del hogar (miembros y relaciones de parentesco, edades y sexo, ocupación, lugar de trabajo y tipo de tarea, nivel de instrucción, lugar de nacimiento, y relación de parentesco). Nivel de ingreso.

$\underline{\text { Reconstrucción trayectoria residencial }}$

- $\quad$ Antes que fueras adjudicataria/o de esta vivienda: ¿Dónde vivían y cómo? (Describir condiciones de acceso a la vivienda) ¿Por qué? ¿De qué forma acceden/accedieron sus padres a la vivienda?

- ¿Qué alternativas habitacionales se les presentaban o analizaban antes de que apareciera la opción del plan de vivienda? ¿Esto fue cambiando con el tiempo? ¿Por qué? ¿Ya se habían presentado al municipio a solicitar vivienda?

- Cuadro lugares de residencia anterior (ambos jefes) según: nº de mudanzas, dirección, forma de acceso (alquiler, compra, préstamo, otro), tenencia (formal /informal), motivos de la mudanza, etapa del ciclo doméstico, duración y trabajo.

- Cuadro trabajos anteriores (ambos jefes) según: $n^{\circ}$ de ocupación, lugar de trabajo, tipo de tarea o actividad, seguridad social, duración, motivo del cambio, percepción de movilidad.

- ¿Qué cosas evaluaron o tuvieron en cuenta en cada una de esa mudanza? ¿Por qué se mudaron a ese lugar y no a otro?

- ¿Cuál de esos lugares consideran que fue acorde a las necesidades de la familia? ¿Por qué? ¿Qué características tenía?

A partir de la adjudicación de la vivienda social

- ¿ ¿Cómo se enteraron del plan de viviendas? ¿A través de quién? Descripción de pasos desde la recepción de la información y la inscripción hasta la mudanza.

- ¿QQué significó para ustedes acceder a esta vivienda? ¿Por qué?

- ¿ ¿Cuáles fueron los principales cambios que resaltaría desde que la familia se mudo al barrio?

- ¿Qué opinan de las características de la vivienda / el barrio / la zona? ¿Cómo era la vivienda / barrio / zona donde vivía antes? ¿Qué características tenía?

- Una vez que se mudaron al barrio ¿Surgió algún tipo de problema? ¿De qué tipo? Desarrollar

- ¿Los vecinos hicieron algún tipo de reclamo? ¿Se organizaron de alguna manera? ¿Qué reclamaban? ¿A quién?

- ¿ ¿Cómo ve el barrio a futuro? ¿Por qué? ¿Si pudieran se mudarían? 
A4 Guión de entrevistas grupales a los vecinos de los barrios de vivienda social. Entrevistas realizadas en el barrio Santa Rosa (Florencio Varela) y Malvinas (Esteban Echeverría), año 2010, se adjunta guión de los disparadores a partir de los cuales se trabajaron con grupos de 5-6 vecinos varias cuestiones complementarias con .

Nota: entrevistas realizada en el barrio Santa Rosa (Florencio Varela) y Malvinas (Esteban Echeverría) en febrero de 2010.

- Presentación...

- ¿Cuándo llegaron al barrio? ¿Cómo fue la experiencia de la mudanza?

- ¿Y a partir de ese momento cómo es el día a día en el barrio?

- ¿Cómo es la relación entre los vecinos?

- ¿Fue cambiando? ¿Cómo? ¿Y por qué?

- ¿Tuvieron algún problema con la casa? ¿Cuál?

- ¿Qué tipo de problemas surgieron en relación al barrio?

- ¿Los vecinos se organizaron de alguna manera? ¿Cómo? ¿Y para qué?

- ¿Cómo es la relación del barrio con el Municipio? ¿Por qué?

- ¿Qué tipos de reclamos hicieron? ¿A quién? ¿De qué forma?

- ¿Cómo es la relación con los vecinos de los barrios de alrededor?

- ¿Qué es lo que más y menos les gusta de la casa / barrio / zona?

- ¿Comparado al lugar donde vivían antes cómo evalúan (en los 3 casos) el cambio?

- ¿Cómo ve el barrio a futuro? ¿Por qué? ¿Si pudieran se mudarían? 
A5 Formularios encuesta hogares adjudicatarios barrios de Santa Rosa (Florencio Varela), Malvinas (Esteban Echeverría), Favaloro (José C. Paz), Nine (Moreno) desarrollada de manera colectiva por el Equipo Infohábitat (ICO- UNGS, 2009).

ENCUESTA PLAN FEDERAL DE CONSTRUCCIÓN DE VIVIENDAS (Infohábitat - UNGS)

Los datos de esta encuesta son totalmente anónimos y sólo serán utilizados a fin de conocer la situación habitacional del Gran Buenos Aires

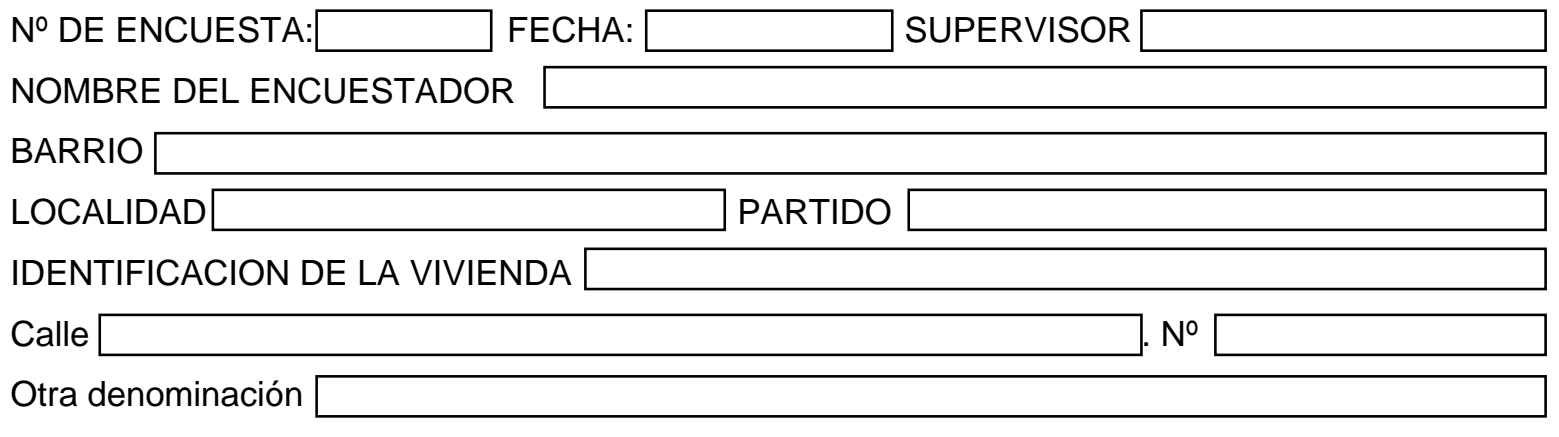

Croquis (si no tiene número croquis de la manzana y ubicación de la vivienda)

Ecuestado: Jefe del hogar mujer Jefe del hogar varón Otro Si es otro, especificar la relación de parentesco con el jefe

\section{JEFES QUE COMPONEN EL HOGAR}

1. CUANTOS JEFES HAY: 1. MUJER

2. HOMBRE

2. ¿Comparten la vivienda/cuarto con otros hogares? SI $\mathrm{NO}$

3. ¿Cuántos hogares habitan la vivienda?

B. JEFA DEL HOGAR MUJER

4. EDAD $\square$. AÑOS

5. ESTADO CIVIL: 1. Soltero/a

2. Casado/a

3. Unión de hecho 
4. Divorciado/a-separado/a

5. Viudo/a $\square$

6. LUGAR DE NACIMIENTO: País

Provincia/departamento

Ciudad/localidad

7. NIVEL DE EDUCACION

1. ninguna (analfabeto)

2. primaria incompleta

3. primaria completa

4. secundaria incompleta

5. secundaria completa

6. terciario incompleto

7. terciario completo

8. universitario incompleto

9. universitario completo

8. OCUPACION Si son más de dos, registrar la cantidad de ocupaciones y elegir la ocupación que da más ingresos (excluyente)

1. ocupado

2. desocupadd

3. jubilado pensionado

4. plan de empleo

5. ama de casa

9. Está ocupado...

1. De forma permanente

2. De forma esporádica (changas)

Tiene más de una ocupación: SI - NO. Si es si cuantas

10. PUESTO o TAREA que realiza (describir brevemente)

11. LUGAR de trabajo (empresa o institución)

En la casa

12. Ubicación geográfica de donde desarrolla el trabajo

Calle $\longrightarrow$ No

Ciudad o partido

Localidad o barrio

Rotativo

13. Tiene PLAN DE EMPLEO? SI

NO

Cuál?

14. INGRESOS. Monto total aproximado que percibe $\$$ 
15. EDAD AÑOS

16. ESTADO CIVIL:
1. Soltero/a $\square$
2. Casado/a
3. Unión de hecho
4. Divorciado/a-separado/a $\square$
5. Viudo/a $\square$

17. LUGAR DE NACIMIENTO: País

Provincia/departamento
Ciudad/localidad

18. NIVEL DE EDUCACION

1. ninguna (analfabeto)

2. primaria incompleta

3. primaria completa

4. secundaria incompleta

5. secundaria completa

6. terciario incompleto

7. terciario completo

8. universitario incompleto

9. universitario completo

19. OCUPACION. Si son más de dos, registrar la cantidad de ocupaciones y elegir la ocupación que da más ingresos (excluyente)

1. ocupado $\square$

2. desocupado

3. jubilado pensionado

4. plan de empleo

5. a cargo de la casa

20. Está ocupado ...

1. De forma permanente

2. De forma esporádica (changas)

3. Tiene más de una ocupación SI NO $\square$ Cantidad de ocupaciones

21. PUESTO o TAREA que realiza (describir brevemente)

22. LUGAR de trabajo (empresa o institución) En la casa

23. Ubicación geográfica de donde desarrolla el trabajo

Calle

Ciudad o partido

Localidad o barrio Rotativo 
24. Tiene PLAN DE EMPLEO? SI

$\mathrm{NO}$

Cuál?

25. INGRESOS. Monto total aproximado que percibe $\$$

\section{HOGAR}

26. QUIENES COMPONEN EL HOGAR

1. Cuantas personas componen el hogar:

2. Cuantos menores de 18 años

3. Cuantos mayores o igual de 18 años

27. INGRESOS DEL HOGAR

1. Cuántas personas contribuyen al ingreso del hogar?

2. Cuánto es el monto aproximado del ingreso mensual total del hoge

$\underline{\mathrm{n} / \mathrm{r}}$

3. Recibe algún miembro del hogar planes sociales? NO . SI $\square$ Cuáles?

Plan familia

Plan de empleo

Plan Más vida

Becas

Otro, Cual?

\section{TRAYECTORIA HABITACIONAL}

28. FECHA DE MUDANZA AL BARRIO

29. RESIDENCIA PREVIA. Antes de vivir aquí ¿Dónde vivía?:

Barrio

Localidad $\longrightarrow$ Partido

Calle

Entre 1

Entre 2

Con quien vivía:

1. compartía la vivienda con parientes propios o parientes de su pareja

2. vivía solo con su familia $\square$

3. otro: $\square$ Cuál?

Condición de tenencia:

4. le prestaban la casa o un lugar dentro la casa en que vivía

5. vivía en un asentamiento/villa $\square$

6. alquilaba

7. estaba en una casa de su propiedad $\square$

8. otro: $\square$ Cual?

MOTIVO. ¿Por qué motivo se mudó? 
30. Al mudarse al barrio ¿hubo situaciones familiares que se modificaron? SI

NO $\square$

31. Cómo?

32. Considera que el cambio (de situación familiar) fue? Malo . Regular . Bueno Muy bueno

33. ¿Cambio la cantidad de miembros del hogar producto de la mudanza? SI $\square$ NO

¿Cuántos miembros eran antes?

ULTIMAS 3 MUDANZAS, sin contar la última que ya explicó, desde las más recientes hasta las más lejos en el tiempo (si fueran menos de 3 mudanza registre las que correspondan)

34. RESIDENCIA 1. Desde $\square$ mes $\square$ año. Hasta $\square$ mes $\square$ año.

Barrio
Localidad $\square$ Partido $\square$
Provincia/ Departamento $\square$ País $\square$

Con quien vivía:

1. compartía la vivienda con parientes propios o parientes de su pareja $\square$

2. vivía solo con su familia

3. otro $\square$ Cuál?

Condición de tenencia:

4. le prestaban la casa o un lugar dentro la casa en que vivía

5. vivía en un asentamiento/villa $\square$

6. alquilaba

7. estaba en una casa de su propiedad

8. otro $\square$ Cual?

MOTIVO. ¿Por qué motivo se mudó?

35. RESIDENCIA 2. Desde $\square$ mes $\square$ año. Hasta $\square$ mes $\square$ año.

Barrio

Localidad $\longrightarrow$ Partido $\square$

Con quien vivía:

1. compartía la vivienda con parientes propios o parientes de su pareja $\square$

2. vivía solo con su familia $\square$

3. otro $\square$ Cuál?

Condición de tenencia: 
4. le prestaban la casa o un lugar dentro la casa en que vivía

5. vivía en un asentamiento/villa $\square$

6. alquilaba

7. estaba en una casa de su propiedad $\square$

8. otro: $\square$ Cual?

MOTIVO. ¿Por qué motivo se mudó?

36. RESIDENCIA 3. Desde $\square$ mes $\square$ año. Hasta $\square$ mes $\square$ año.

Barrio

Localidad Partido

Provincia/ Departamento País

Con quien vivía:

1. compartía la vivienda con parientes propios o parientes de su pareja $\square$

2. vivía solo con su familia

3. otro: $\square$ Cuál?

Condición de tenencia:

4. le prestaban la casa o un lugar dentro la casa en que vivía

5. vivía en un asentamiento/villa

6. alquilaba $\square$

7. estaba en una casa de su propiedad $\square$

8. otro: $\square$ Cual?

MOTIVO. ¿Por qué motivo se mudó?

\section{E. TRAYECTORIA LABORAL}

ULTIMOS 3 TRABAJOS JEFA MUJER, sin contar el actual hacia atrás

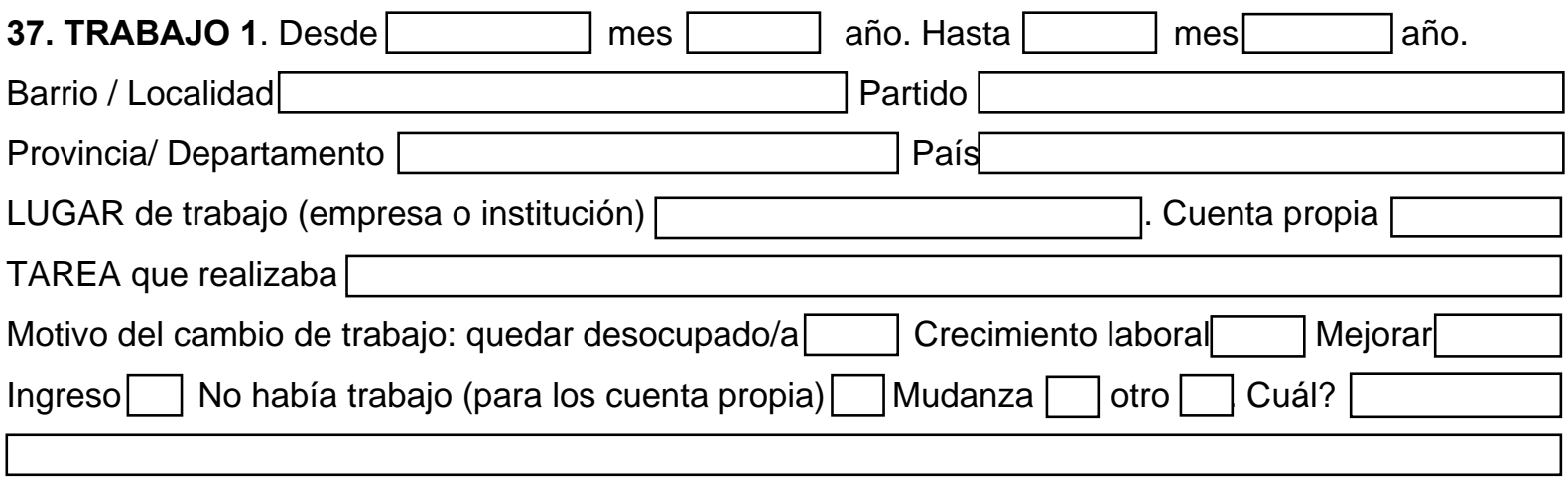
38. TRABAJO 2. Desde
$\operatorname{mes}$ año. Hasta ไaño. 
Provincia/ Departamento

País

LUGAR de trabajo (empresa o institución)

Cuenta propia

TAREA que realizaba

Motivo del cambio de trabajo: quedar desocupado/a

Crecimiento laboral

Mejorar

Ingreso $\square$ No había trabajo (para los cuenta propia) $\square$ Mudanza $\square$ otro $\square$ Cuál?

39. TRABAJo 3. Desde $\square$ mes $\square$ año. Hasta $\square$ mes $\square$ año.

Barrio / Localidad Partido

Provincia/ Departamento País

LUGAR de trabajo (empresa o institución) . Cuenta propia $\square$

TAREA que realizaba

Motivo del cambio de trabajo: quedar desocupado/a $\square$ Crecimiento laboral $\square$ Mejorar $\square$ Ingreso $\square$ No había trabajo (para los cuenta propia) $\square$ Mudanza $\square$ otro $\square$ Cuál?

40. ¿Cuál fue su mejor trabajo?

Por qué?

ULTIMOS 3 TRABAJOS JEFE VARON, desde el último hacia atrás (excluyendo el actual)

41. TRABAJO 1. Desde $\square$ mes $\square$ año. Hasta $\square$ mes $\square$ año.

Barrio / Localidad $\square$
Provincia/ Departamento
LUGAR de trabajo (empresa o institución) $\square$ País $\square$ Cuenta propia $\square$
TAREA que realizaba
Motivo del cambio de trabajo: quedar desocupado/a $\square$ Crecimiento laboral $\square$ Mejorar $\square$ Mudanza $\square$ otro $\square$ Cuál?
Ingreso $\square$ No había trabajo (para los cuenta propia) $\square$ Mudal

Ingreso $\square$ No había trabajo (para los cuenta propia) $\square$ Mudanza $\square$ otro $\square$ Cuál?

42. TRABAJO 2. Desde $\square$ mes $\square$ año. Hasta $\square$ mes $\square$ año.

\begin{tabular}{l} 
Barrio / Localidad $\longrightarrow$ Partido \\
Provincia/ Departamento $\square$ País \\
\hline
\end{tabular}

LUGAR de trabajo (empresa o institución) . Cuenta propia

TAREA que realizaba

Motivo del cambio de trabajo: quedar desocupado/a $\square$ Crecimiento laboral $\square$ Mejorar $\square$ Ingreso $\square$ No había trabajo (para los cuenta propia) $\square$ Mudanza $\square$ otro $\square$ Cuál?

43. TRABAJO 3. Desde

mes año. Hasta mes año. 


\begin{tabular}{|c|c|}
\hline Barrio / Localidad [ & Partido \\
\hline Provincia/ Departamento & País \\
\hline LUGAR de trabajo (empresa o institución)[ & . Cuenta propia [ \\
\hline TAREA que realizaba & \\
\hline Motivo del cambio de trabajo: quedar desocupado/a & Crecimiento laboral [ \\
\hline No había trabajo (para los cuenta propia) [ & Mudanza $\square$ otro $\square$ Cuál? \\
\hline
\end{tabular}

¿Cuál fue su mejor trabajo? $\square$ Por qué?

\section{F. MOVILIDAD COTIDIANA}

44. TRASLADO AL TRABAJO de los miembros del hogar que trabajan. Cuáles de los siguientes medios de transporte utiliza para ir al trabajo? (si utiliza más de un medio de transporte, márquelos).

1. No sale del barrio

2. A pie

3. Bicicleta

4. Colectivo $\square$ Marcar la cantidad (en caso de más de uno)

5. Tren $\square$ Marcar la cantidad (en caso de más de uno)

6. Vehículo particular

7, Vehículo del trabajo

8. Caballo con carro

9. Moto $\square$

10. Subte $\square$ Marcar la cantidad (en caso de más de uno)

11. Colectivo informal Marcar la cantidad (en caso de más de uno)

12. Remisse trucho

13. Otro $\square$ Cual?

45. TIEMPO. Tiempo de viaje aproximado (ida y vuelta) de la persona del hogar que más horas trabaja $\square$ horas $\square$ minutos

46. COSTO mensual aproximado de gasto en transporte de TODA la familia: \$

47. Antes de mudarse al barrio, considera que la relación costo o tiempo de traslado a su lugar de trabajo era: mejor $\square$ igual $\square$ o peor $\square$ Por qué?

48. La ubicación de este barrio le permite conseguir trabajo? SI

NO No sabe

Por qué?

49. En dónde hace sus COMPRAS DIARIAS (pan, verduras, leche, bebidas, cigarrillos, etc.) 
1. En el barrio

2. En los alrededores del barrio

3. En otro lugar del municipio $\square$ En qué localidad

4. Fuera del municipio $\square$ En que Municipio

5. No realiza compras

50. Y las COMPRAS más GRANDES (ropa, electrodomésticos, muebles, alimentos del mes..)?

1 En el barrio

2. En los alrededores del barrio

3. En otro lugar del municipio $\square$ En qué localidad

4. Fuera del municipio $\square$ En que Municipio

5. No realiza compras

51. Dónde compra los MATERIALES DE CONSTRUCCION?

1. En el barrio

2. En los alrededores del barrio

3. En otro lugar del municipio $\square$ En qué localidad

4. Fuera del municipio En que Municipio

5. No realiza compras

52. Las personas que ESTUDIAN en el hogar, lo hacen en... (marcar más de una opción en caso de que varias personas estudien en distintos lugares)

1. 1. En el barrio

2. En los alrededores del barrio

3. En otro lugar del municipio $\square$ En qué localidad

4. Fuera del municipio $\square$ En que Municipio

5. No estudian

53. Dónde vive sus AMIGOS que más frecuenta?

1. En el barrio

2. En los alrededores del barrio

3. En otro lugar del municipio $\square$ En qué localidad

4. Fuera del municipio $\square$ En que Municipio

5. No tiene amigos

54. Tiene familiares en el barrio? SI $\square$ NO $\square$ Cuáles?

55. Practica alguna RELIGION? SI NO $\square$ Cuál?

Dónde práctica sus actividades religiosas?

1. En el barrio 
2. En los alrededores del barrio

3. En otro lugar del municipio $\square$ En qué localidad

4. Fuera del municipio $\square$ En que Municipio

56. Usted o algún miembro del hogar participa de alguna ORGANIZACION barrial / comunitaria /de base/ o política? SI $\square$ NO $\square$ Cuál?

En donde se reúnen

1. 1. En el barrio

2. En los alrededores del barrio

3. En otro lugar del municipio $\square$ En qué localidad

4. Fuera del municipio $\square$ En que Municipio

\section{F. EQUIPAMIENTOS URBANOS Y LOCALIZACION}

57. INTEGRACIÓN BARRIO-CIUDAD. ¿Es fácil trasladarse del barrio a otros lugares del municipio o a los lugares que la familia necesitar ir frecuentemente?

$\mathrm{SI} \square$ NO $\square$ Por qué?

58. LOCALIZACIÓN. Teniendo en cuenta la localización del barrio y su anterior lugar de residencia, cree que la localización: empeoró $\square$ es igual $\square$ o mejoró

59. Los centros EDUCATIVOS que utiliza la familia?

\section{Jardín Maternal:}

1. No utiliza

2. En el barrio

3. En los alrededores del barrio

4. En otro lugar del municipio $\square$ En qué localidad

5. Fuera del municipio $\square$ En que Municipio

\section{Educación básica.}

1. No utiliza

2. En el barrio

3. En los alrededores del barrio

4. En otro lugar del municipio $\square$ En qué localidad

5. Fuera del municipio $\square$ En que Municipio

4. Otro. Cual?

1. No utiliza

2. En el barrio

3. En los alrededores del barrio

4. En otro lugar del municipio $\square$ En qué localidad

5. Fuera del municipio $\square$ En que Municipio 
60. Las instituciones de SERVICIOS DE SALUD que utilizan donde se ubican?

1. Salita / Unidad sanitaria:

1. No utiliza

2. En el barrio

3. En los alrededores del barrio

4. En otro lugar del municipio $\square$ En qué localidad

5. Fuera del municipio $\square$ En que Municipio

2. Hospital público:

1. No utiliza

2. En el barrio

3. En los alrededores del barrio

4. En otro lugar del municipio $\square$ En qué localidad

5. Fuera del municipio $\square$ En que Municipio

3. Clínicas privadas.

1. No utiliza

2. En el barrio

3. En los alrededores del barrio

4. En otro lugar del municipio $\square$ En qué localidad

5. Fuera del municipio $\square$ En que Municipio

4. Otro. Cual?

1. No utiliza

2. En el barrio

3. En los alrededores del barrio

4. En otro lugar del municipio $\square$ En qué localidad

5. Fuera del municipio $\square$ En que Municipio

5. Identifican problemas en los servicios educativos? SI $\square$ NO $\square$ Cuáles?

61. De lo siguiente, qué utiliza?

1. Plaza / Parque:

1. No utiliza

2. En el barrio

3. En los alrededores del barrio

4. En otro lugar del municipio $\square$ En qué localidad

5. Fuera del municipio $\square$ En que Municipio

2. Centros culturales:

1. No utiliza $\square$

2. En el barrio 
3. En los alrededores del barrio $\square$

4. En otro lugar del municipio $\square$ En qué localidad

5. Fuera del municipio $\square$ En que Municipio

3. Biblioteca popular / pública.

1. No utiliza $\square$

2. En el barrio

3. En los alrededores del barrio $\square$

4. En otro lugar del municipio $\square$ En qué localidad

5. Fuera del municipio $\square$ En que Municipio

\section{Sociedad de fomento:}

1. No utiliza $\square$

2. En el barrio

3. En los alrededores del barrio

4. En otro lugar del municipio En qué localidad

5. Fuera del municipio $\square$ En que Municipio

5. Clubes deportivos/canchitas:

1. No utiliza $\square$

2. En el barrio

3. En los alrededores del barrio

4. En otro lugar del municipio $\square$ En qué localidad

5. Fuera del municipio $\square$ En que Municipio

6. Comedor comunitario.

1. No utiliza $\square$

2. En el barrio

3. En los alrededores del barrio

4. En otro lugar del municipio $\square$ En qué localidad

5. Fuera del municipio $\square$ En que Municipio

7. Otro. Cual?

1. No utiliza $\square$

2. En el barrio

3. En los alrededores del barrio

4. En otro lugar del municipio $\square$ En qué localidad

5. Fuera del municipio $\square$ En que Municipio

62. ¿En qué lugar se encuentran los vecinos? . No se encuentran

63. ¿Qué opina de la calidad de...?

1. calles:

mala $\square$ regular $\square$ buena $\square$ muy buena

2. transporte público:

3. alumbrado público: malo $\square$ regular $\square$, bueno $\square$ muy bueno malo $\square$ regular $\square$ bueno $\square$ muy bueno 
4. veredas:

5. recolección de residuos:

mala $\square$ regular $\square$ buena $\square$ muy buena

6. espacio público:

malos regulares buena $\square$ muy buena

64. Teniendo la calidad del espacio público de su anterior lugar de residencia, el del barrio es: peor $\square$ igual $\square$ o mejor $\square$

65. PERCEPCIÓN DEL BARRIO ¿Qué es lo más lindo del barrio?

¿Qué es lo más feo?

¿Qué le agregaría a su barrio?

¿Qué le quitaría a su barrio?

\section{G. CARACTERÍSTICAS DE VIVIENDA}

66 ¿Qué le parece la nueva vivienda en relación a la vivienda anterior en la que vivía?

Peor igual o mejor

67. DESCRIPCIÓN DE LA VIVIENDA CUANDO FUE ENTREGADA (Marcar con una cruz o con números para piezas de acuerdo a lo que corresponda)

Dormitorios $\square$ cantidad $\square$

Baño $\square$ cantidad $\square$ 
Cocina $\square$ unida al living $\square$ independiente $\square$

Comedor/living $\square$

Lavadero $\square$

Otro ¿Cuál?

68. ¿Le hizo alguna modificación o terminación a la vivienda? SI $\square$ No $\square$

¿Cuál?

69. ¿Necesita ampliar o modificar a la vivienda? SI $\square$ NO $\square$ ¿Cuál es la modificación necesaria?

70. ¿Algún espacio del inmueble está destinado a una actividad no residencial (económica, religiosa, cultural, social, comunitaria, etc.? SI $\square$ No $\square$ ¿Cuál?

71. ¿La nueva vivienda le demanda nuevos gastos? SI $\square$ NO $\square$ ¿Cuál/es?

72. ¿Paga algún SERVICIO? SI $\square$ NO $\square$ ¿Cuál?

Si es no pasa a la pregunta....

73.Actualmente tiene algún servicio: 1 impago $\square$ 2. impago y cortado $\square$

74. La casa tiene alguno de los siguientes PROBLEMAS:

4. goteras: $\mathrm{SI} \square \mathrm{NO} \square$

5. grietas o rajaduras: $\mathrm{SI} \square \mathrm{NO}$

6. otro: SI $\square$ NO $\square$ ¿Cuál?

75. Como considera a la vivienda en relación a:

1. Tamaño:

malo $\square$ regular $\square$ bueno $\square$ muy bueno

2. Cantidad de cuartos: malo $\square$ regular $\square$ bueno $\square$ muy bueno $\square$

3. Calidad de las paredes: malo $\square$ regular $\square$ bueno $\square$ muy bueno $\square$

4. Calidad de las aberturas: malo $\square$ regular $\square$ bueno $\square$ muy bueno $\square$

5. Calidad del techo:

6. Calidad del piso: malo $\square$ regular $\square$ bueno $\square$ muy bueno

7. Calidad de las instalaciones: malo $\square$ regular $\square$ bueno $\square$ muy bueno $\square$

8. Espacio libre (patio, jardín): malo $\square$ regular $\square$ bueno $\square$ muy bueno $\square$

9. Posibilidades de ampliación: malo $\square$ regular $\square$ bueno $\square$ muy bueno $\square$ malo $\square$ regular $\square$ bueno $\square$ muy bueno $\square$

76. PERCEPCIÓN DE LA VIVIENDA ¿Qué es lo más lindo de la vivienda?.. 
Qué es lo más feo de la vivienda?

¿Qué le agregaría a su vivienda?

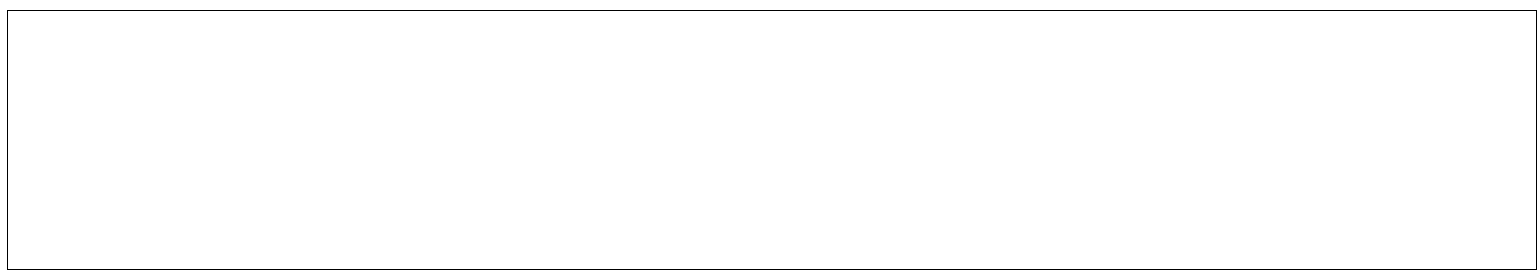

¿Qué le quitaría a su vivienda?

\section{H. REDES DE INTERCAMBIO Y RELACIONES ENTRE VECINOS}

77. Ante una necesidad u emergencia ¿puede contar cuenta con algún vecino del barrio?<smiles></smiles>

78. ¿Algún miembro del hogar mantiene alguno de los siguientes tipos de INTERCAMBIO con los vecinos que viven en el barrio?

0 . No tiene intercambios de ningún tipo (pasar a pregunta)

1. Cuidado de los niños

2. Pequeños trabajos en la vivienda (reparación, construcción, luz, agua, cloaca...)

3. Préstamos de herramientas

4. Préstamo de alimentos

5. Prestamos de dinero

6. Información

7 Otro $\square$ Cuál?

79. ¿Con qué regularidad?: 1 poca 2 mucha

80. Califique la integración / unidad / buena relación de los VECINOS DEL BARRIO: 
1. nada $\square 2$ poca $\square 3$ mucha $\square$

81. Califique la de integración / unidad /buena relación de los vecinos del barrio con los BARRIOS CERCANOS? 1. nada $\square 2$ poca $\square$ 3 mucha $\square$

82 Usted considera que los barrios cercanos, son...... que el suyo.

1. peores $\square 2$ igual $\square 3$ mejores $\square$

83 Usted considera que el nivel socioeconómico de los barrios cercanos, es...

1. menor $\square 2$ igual $\square 3$ mayor $\square$

84. ¿ Qué cree que OPINAN los BARRIOS CERCANOS de su barrio?.

85. ¿Se ha registrado algún PROBLEMA entre los vecinos del barrio? SI NO ¿Cual/es?

86. ¿Se ha registrado algún problema con los barrios cercanos? SI NO ¿Cual/es?

\section{ACCESO A LA VIVIENDA}

87. ¿Cómo accedió a su casa? 
88. ¿Qué trámites hizo para llegar a la vivienda? ¿Con quién? ¿Se anotó o lo anotaron? ¿Cuántas veces hizo trámite? ¿Se anotó en una oficina municipal o en otro lugar? ¿Cuál?

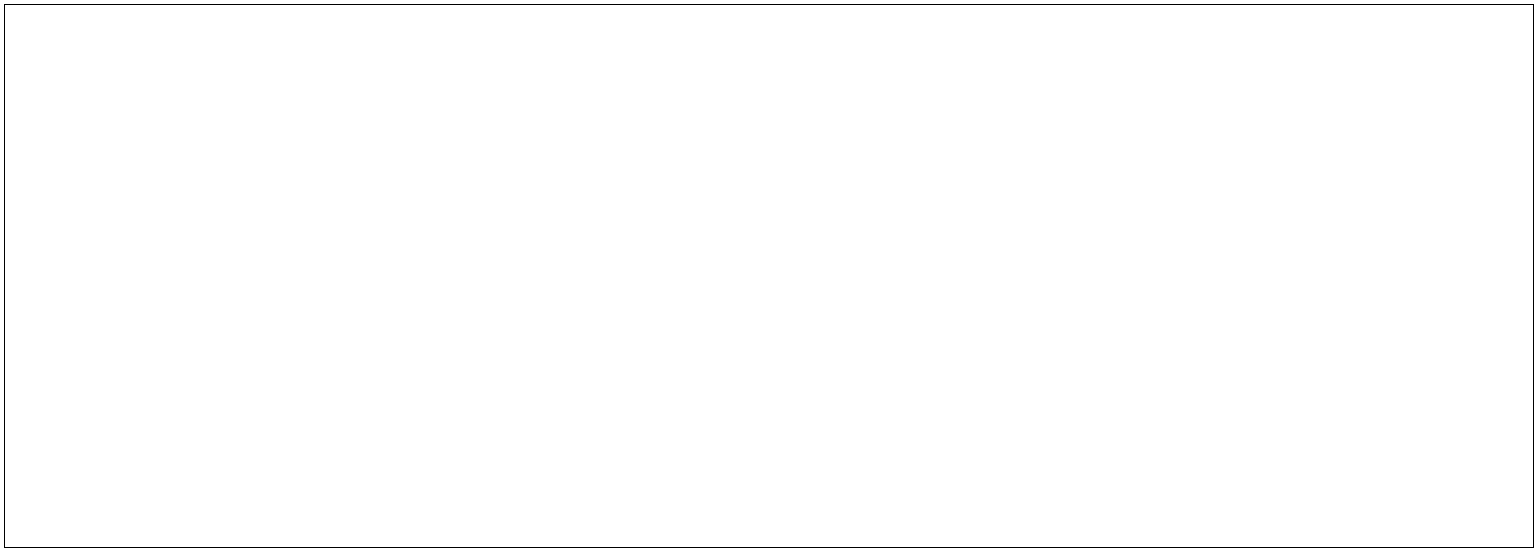

89. ¿Cuándo inició el trámite?

90. ¿Qué papeles presentó o le pidieron?

91¿Qué requisitos le exigían?

92. ¿Eligió la vivienda o la cantidad de ambientes? SI No

93. ¿Le dieron algún tipo de participación? SI NO ¿Cómo?

94. ¿Hicieron reuniones informativas? SI- NO ¿De qué tipo?.

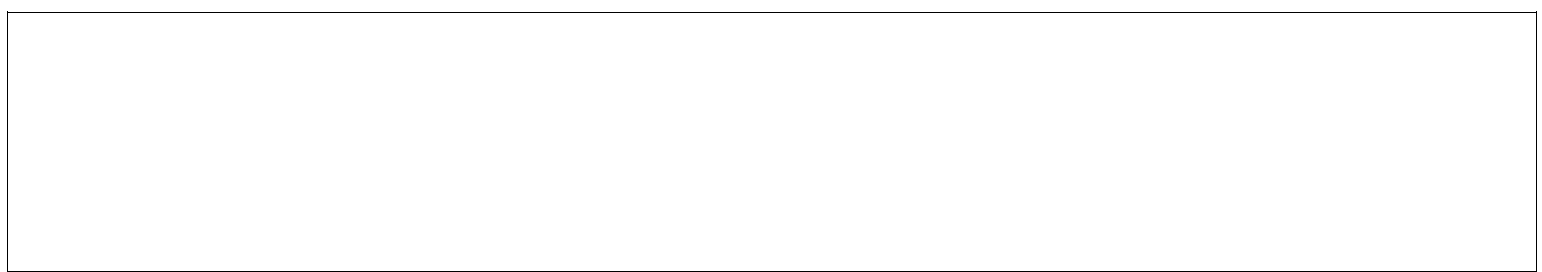

95. PAGO. ¿Ya empezó a pagar? S Si es si: Cuanto paga? \$ No Se encuentra al día SI NO Si es no ¿Por qué? 
Si es no ¿Cuánto cree que pagaría o le dijeron que tiene que pagar? \$ No sabe

Si es no: ¿Usted considera que podrá pagar esa cuota? SI $\square$ NO $\square$

96. PAPELES-TENENCIA. ¿Tiene algún papel de la casa? SI NO ¿Cuál/es?

\section{J. OPINIÓN SINTESIS}

97. ¿Qué opinión le merece la CASA?

98. ¿Qué opinión le merece el BARRIO?

99. ¿Qué opinión le merece la ZONA donde está ubicado el barrio?

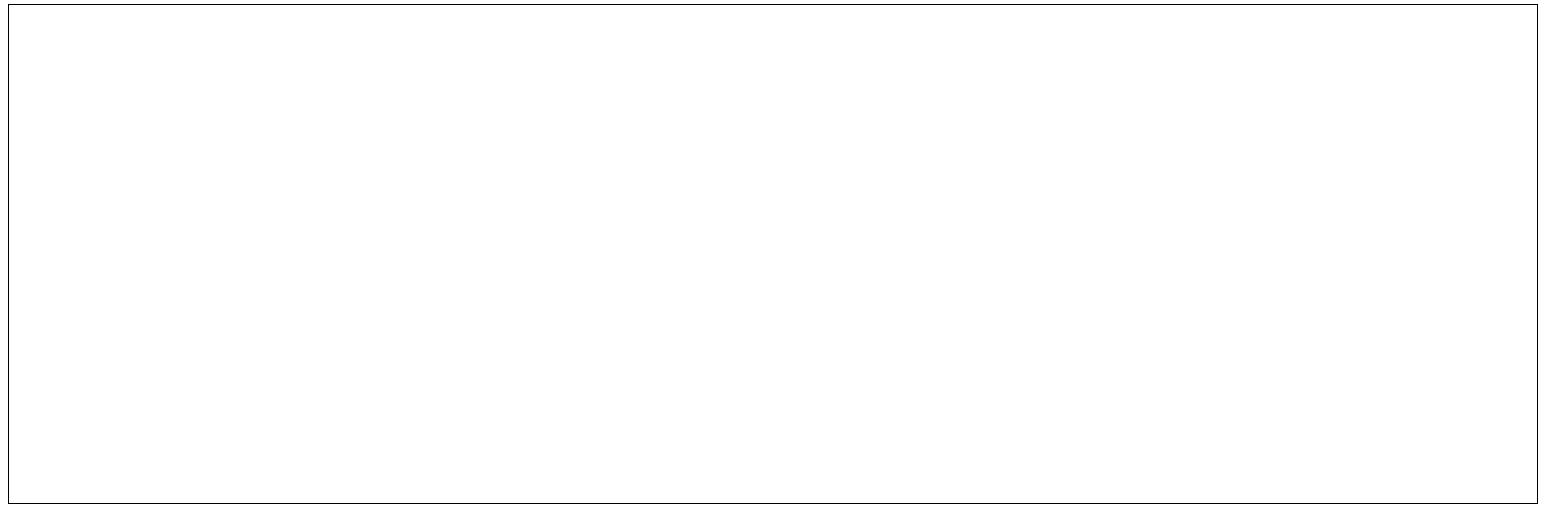

100. ¿Desea mudarse de barrio? SI $\square$ NO $\square$ NS $\square$ ¿Por qué? 